\title{
Recovery Of Rare Earth Elements (Rees) From Coal Mine Drainage Sludge Leachate
}

\author{
Panpan Ren \\ West Virginia University, pr0003@mix.wvu.edu
}

Follow this and additional works at: https://researchrepository.wvu.edu/etd

Part of the Metallurgy Commons

\section{Recommended Citation}

Ren, Panpan, "Recovery Of Rare Earth Elements (Rees) From Coal Mine Drainage Sludge Leachate" (2019). Graduate Theses, Dissertations, and Problem Reports. 7454.

https://researchrepository.wvu.edu/etd/7454

This Dissertation is protected by copyright and/or related rights. It has been brought to you by the The Research Repository @ WVU with permission from the rights-holder(s). You are free to use this Dissertation in any way that is permitted by the copyright and related rights legislation that applies to your use. For other uses you must obtain permission from the rights-holder(s) directly, unless additional rights are indicated by a Creative Commons license in the record and/ or on the work itself. This Dissertation has been accepted for inclusion in WVU Graduate Theses, Dissertations, and Problem Reports collection by an authorized administrator of The Research Repository @ WVU.

For more information, please contact researchrepository@mail.wvu.edu. 


\title{
RECOVERY OF RARE EARTH ELEMENTS (REES) FROM COAL MINE DRAINAGE SLUDGE LEACHATE
}

\author{
Panpan Ren \\ Dissertation submitted to the Benjamin M. Statler College of Engineering and Mineral \\ Resources \\ at West Virginia University \\ in partial fulfillment of the requirements \\ for the degree of \\ Doctor of Philosophy \\ in \\ Mechanical Engineering
}

\author{
Xingbo Liu, Ph.D., Committee Chairperson \\ Paul Ziemkiewicz, Ph.D. \\ Aaron Noble, Ph.D. \\ Konstantinos Sierros, Ph.D. \\ Edward M. Sabolsky, Ph.D. \\ Department of Mechanical and Aerospace Engineering \\ Morgantown, West Virginia \\ 2019
}

Keywords: REE recovery, solvent extraction, scrub, stripping

Copyright 2019 Panpan Ren 


\title{
Abstract \\ RECOVERY OF RARE EARTH ELEMENTS (REES) FROM COAL MINE DRAINAGE SLUDGE LEACHATE
}

\author{
Panpan Ren
}

Acid mine drainage (AMD) is the primary cause of aquatic habitat loss in the Appalachian Coal Basin and many other mining districts across the U.S. and the world. The objective of this work is to develop a cost-effective and environmentally benign process to treat and recover Rare Earth Elements (REEs) from AMD. Solvent extraction (SX) is one effective way to turn AMD into a commercially viable feedstock for rare earth production.

In this work, SX experiments were conducted on Y-Ca-Mg-Al-HDEHP-n-heptane- $\mathrm{HNO}_{3}-\mathrm{H}_{2} \mathrm{O}$ system to simulate AMD treatment for Yttrium recovery by changing four parameters: $\mathrm{pH}$ values, concentration ratio of Yttrium $(\mathrm{Y})$ over total major metal ions ( $\mathrm{Ca}, \mathrm{Mg}$ and $\mathrm{Al}$ ) (Y:CMA ratio), extractant HDEHP concentration in organic solvent $n$-heptane $(\mathrm{C}(\mathrm{HDEHP}))$, volume ratio of organic phase to aqueous phase (O:A ratio). Extraction efficiencies of major metal ions and $\mathrm{Y}$ were compared under different conditions. Separation factors of $Y$ over total major metal ions were also analyzed. The most desirable SX conditions for this system were found by numerical optimization. Using waste water with low REE concentrations as feedstock, the separation factor can reach about 3000 under the following conditions: 1) solution $\mathrm{pH} 2.4$,2) extracting with HDEHP at a concentration of $15 \mathrm{~g} / \mathrm{L}$ in 3) in $\mathrm{n}$-heptane solvent at 4) O:A ratio of 1.5 .

Besides work on synthetic solution, bench-scale REEs recovery from different kinds of sludge leachate with different $\mathrm{pH}$ values, mid-scale and multi-step SX experiments were performed. The whole process mainly includes solvent extraction, scrub and stripping steps. The estimated TREE percentage in solid phase obtained in one mid-scale experiment $(1.25 \mathrm{~kg}$ wet sludge from DLM site; solvent extraction: $20 \mathrm{~L}$ filtered leachate $(\mathrm{pH} 3.2)$ with $30 \mathrm{~L}$ organic solution; obtained $2.5 \mathrm{~g}$ concentrate solid sample) increased from initial $0.77 \%$ in leachate to final $4.63 \%$ in the solid.

To determine how many steps required for sufficient recovery of REEs and high selectivity of REEs over major metal ions, bench-scale exploratory tests of solvent extraction, scrub and stripping process were conducted to provide a purposeful starting point for the scale-up lab SX system testing. Results of this program were provided as McCabe Thiele diagrams. Optimum parameters and steps needed were obtained for different kinds of leachate in this work. Continuous work following whole flowsheet with optimum parameters was conducted on RS leachate for REEs recovery and separation of heavy and light REEs. 


\section{ACKNOWLEDGMENTS}

The author wishes to acknowledge the funding provided by U.S. Department of Energy National Energy Technology Laboratory and West Virginia University Research Corporation (Project FE0026927). I would like to thank technology manager Dr. Mary Anne Alvin and project manager Dr. Jessica Mullen.

I would like to express my deepest appreciation to my committee chair, Dr. Xingbo Liu, who has been supportive of my research and scholarship. He continually conveyed the attitude and spirit of curiosity and seriousness in regard to research. Without his guidance and persistent help this dissertation would not have been possible.

Each of the members of my dissertation committee has provided me extensive personal and professional guidance and taught me a great deal about scientific research. I would especially like to thank Dr. Paul Ziemkiewicz and Dr. Aaron Noble for their advice for the related research. I really appreciate Dr. Edward M. Sabolsky and Dr. Konstantinos Sierros being my committee members and providing help for this dissertation. I am grateful to all of those with whom I have had the pleasure to work during this project, especially Bo Guan, Dr. Greg Collins and Dr. Chris Vass. I would also thank NRCCE Analytical Laboratory and Virginia Tech team partner for most ICP analysis.

Nobody has been more important to me in the pursuit of the degree than the members of my family. I would also like to thank my friends for their help in both work and life. 


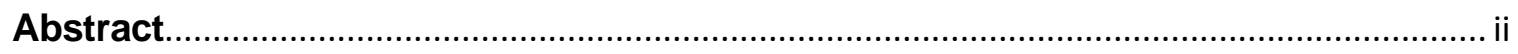

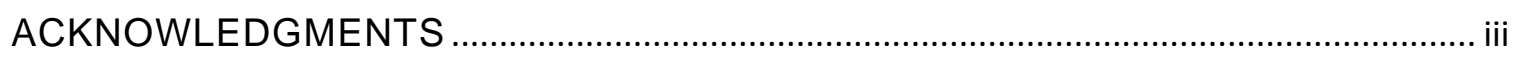

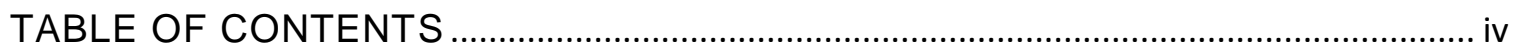

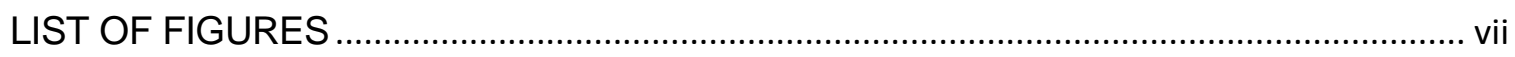

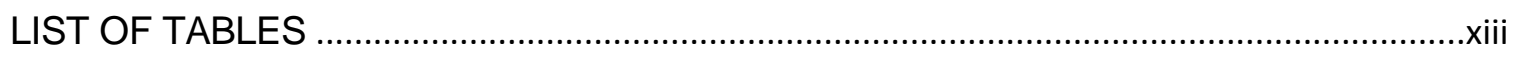

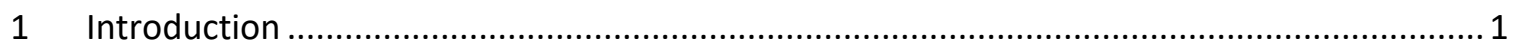

1.1 Rare earth elements and their application in industry ........................................... 1

1.2 Resource and production of rare earth elements ................................................. 1

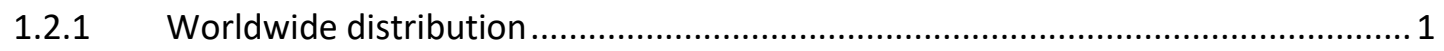

1.2.2 Technologies for REEs separation .............................................................. 2

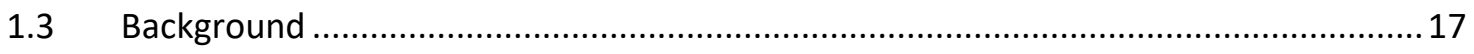

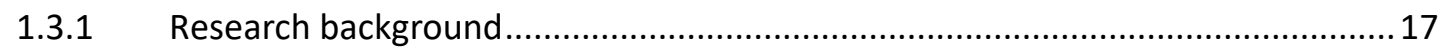

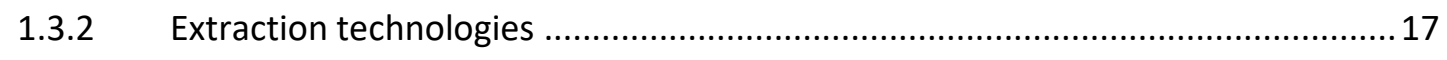

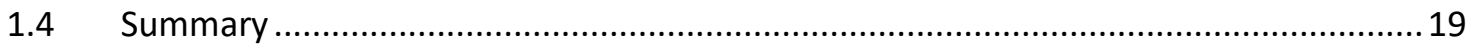

2 Solvent extraction of metal elements in acidic nitrate solution by Di-(2-ethylhexyl)

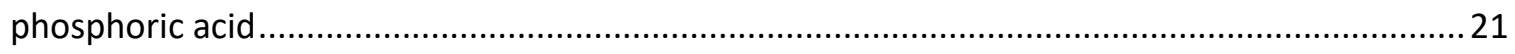

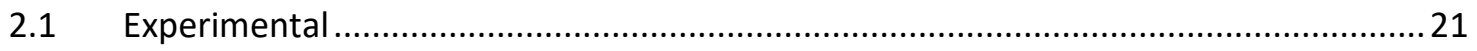

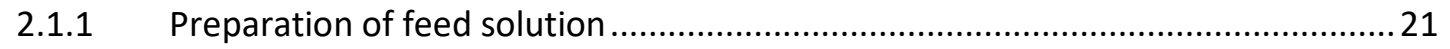

2.1.2 Equilibration of aqueous and organic phases................................................ 21

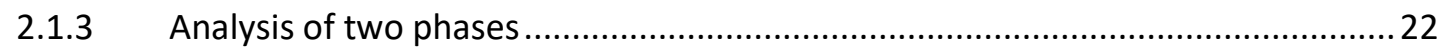

2.1.4 Extraction Percentages and Separation factor studies ......................................23

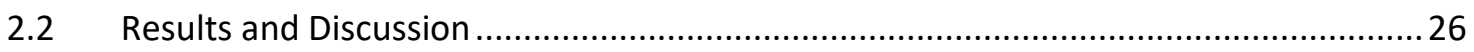

iv 
2.2.1 Extraction efficiencies of major metal ions and REEs .......................................26

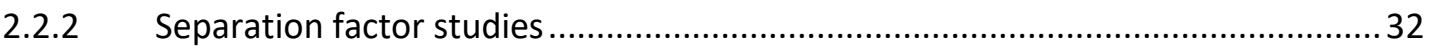

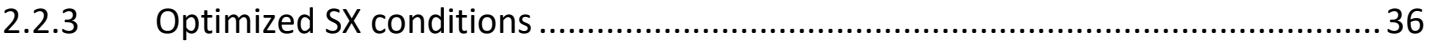

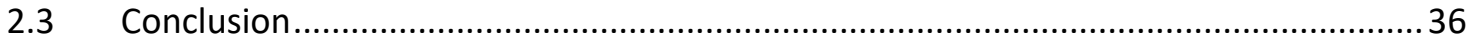

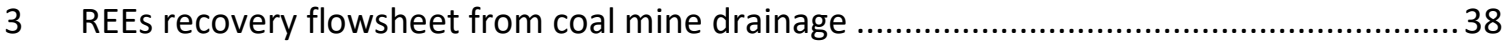

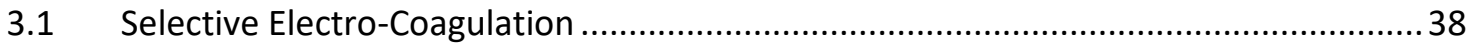

3.1.1 Preliminary work by electrochemical methods ................................................... 38

3.1.2 Selective Electro-Coagulation ....................................................................... 41

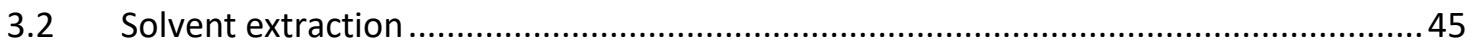

3.2.1 Preliminary work on solvent extraction....................................................... 46

3.2.2 REEs recovery from sludge with high Iron composition ....................................51

3.2.3 REEs recovery from sludge with low Iron composition ......................................57

3.3 Mid-scale ALSX experiment for REEs recovery ….................................................. 73

3.3.1 Mid-scale SX on DLM pH 3.2 leaching solution................................................ 73

3.3.2 Mid-scale SX on DLM pH 2.6 leaching solution................................................ 75

3.3.3 Mid-scale SX on DLM pH 2.6 leaching solution followed by evaporating .............77

3.3.4 Mid-scale SX experiments on McV leaching solution ....................................... 79

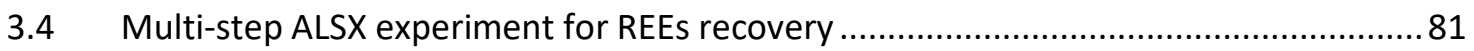

3.4.1 Multi-step ALSX experiment on pH 1.4 leaching solution ................................... 81

3.4.2 Multi-step ALSX experiment on $\mathrm{pH}$ 4.2 leaching solution ....................................... 84

3.4.3 Multi-step ALSX experiment on $\mathrm{pH} 3$ leaching solution ........................................ 88

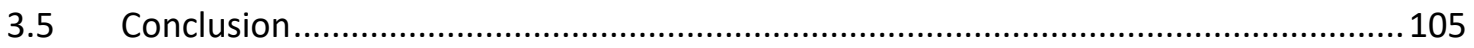

$4 \quad$ REEs recovery exploratory tests from coal mine drainage to support scale-up system .....107

4.1 Bench-Scale Solvent Extraction Support....................................................... 108

4.1.1 SX McCabe-Thiele Exploratory Test-OM-PLS 1.1 .......................................... 108 
4.1.2 SX McCabe-Thiele Exploratory Test-OM-PLS 2.7 ..........................................117

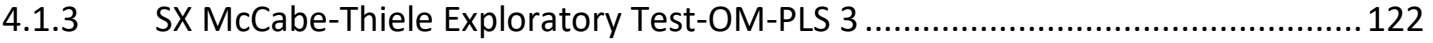

4.1.4 SX McCabe-Thiele Exploratory Test-DLM-PLS 2.5 ...........................................130

4.1.5 SX McCabe-Thiele Exploratory Test-DLM-PLS 3.1...........................................

4.1.6 SX McCabe-Thiele Exploratory Test-RS-PLS 3 …............................................. 146

4.1.7 Bench-Scale Solvent Extraction Support Summary ...........................................154

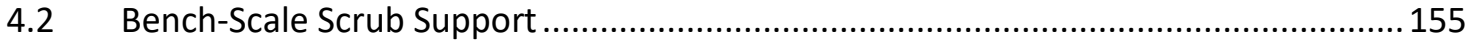

4.2.1 Scrub McCabe-Thiele Exploratory Test-OM........................................................ 155

4.2.2 Scrub McCabe-Thiele Exploratory Test-DLM …................................................. 160

4.2.3 Scrub McCabe-Thiele Exploratory Test-RS......................................................... 164

4.3 Bench-Scale Stripping Support - McCabe-Thiele Exploratory Test-RS ....................... 165

4.4 Summary of exploratory tests on RS leachate and bench-scale REE recovery on it ...173

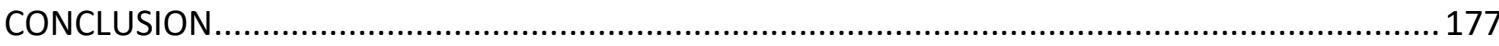

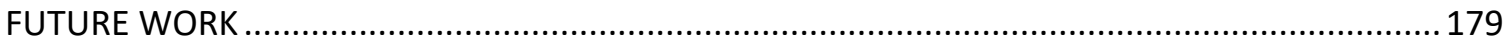

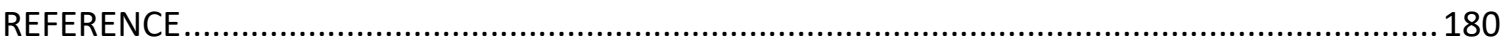




\section{LIST OF FIGURES}

Figure 1.1 A pilot test separating $\mathrm{Gd}$ and Tb in a HEH(EHP)-Cl system. ................................... 4

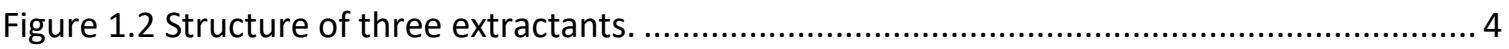

Figure 1.3 Flowsheet for recovery of REEs from apatite. …................................................... 5

Figure 1.4 Schematic of a hollow fiber membrane module for membrane solvent extraction (left); Elemental concentration of NdFeB magnets in the (a) feed and (b) strip solutions, and (c) the ratio of REEs in the strip to the feed and (d) REE extraction rate (right) .......................................... 6

Figure 1.5 Schematic of rare earths and nickel separation by solvent extraction with two mutually immiscible ionic liquids.

Figure 1.6 Flowsheet for hydrometallurgical treatment of monazite and considered Metal(Ligand)-H2O systems for recovery of RE metals and Th.

Figure $1.7 \mathrm{Eh}-\mathrm{pH}$ diagrams for $\mathrm{M}-\mathrm{H}_{2} \mathrm{O}$ systems at $25^{\circ} \mathrm{C}$ : (a) $[\mathrm{Th}]=10^{-3} \mathrm{M}$, (b) $[\mathrm{Nd}]=10^{-3} \mathrm{M},(\mathrm{c})$ $[\mathrm{Ce}]=10^{-3} \mathrm{M},(\mathrm{d})[\mathrm{La}]=10^{-3} \mathrm{M}$.

Figure 1.8 Effect of oxalic acid dosage $\mathrm{pH}$ on the recovery and purity of RE oxalate precipitates. ( $Y X, Y A, N H$-- Different kinds of RE minerals)......

Figure 1.9 Speciation of rare earths (REE) at $\mathrm{pH} 6$ in synthetic solutions used in scavenging experiments (left); Graph of $\mathrm{Nd}_{\text {scav }}$ and $\mathrm{Y}_{\text {scav }} \mathrm{vs.} \mathrm{pH}$, as determined from experiments performed with Fe-bearing and with Fe-free solutions, respectively (right) 10

Figure 1.10 A bacterial extracellular matrix (ECM) for selective and differential abstraction of REEs.

Figure 1.11 Electrochemical technologies for wastewater treatment and resource reclamation.

Figure 1.12 The standard electrode potentials $\left(\mathrm{E}_{\mathrm{RE}}{ }^{3+} / \mathrm{RE}=-2.2\right.$ to $\left.-2.4 \mathrm{~V} \mathrm{VS} \mathrm{SHE}\right)$ of the rare earth elements are very close owing to their similar chemical nature. 12

Figure 1.13 Simple schematic of the proposed electrochemical method for REE recovery. ........ 13

Figure 1.14 Separation and recovery process of RE metals from scraps using molten salt and alloy diaphragm, which maintains a high separation ability of Dy in a continuous operation. 14

Figure 1.15 Schematic diagram of a lab-scale two-electrode electrocoagulation cell.................. 15

Figure 1.16 Standard Potentials in Aqueous Solution. 16 
Figure 2.1 O:A ratio effect on extraction efficiencies of major metal ions and rare earth ions from Y0.5CMA solution

Figure 2.2 O:A ratio effect on extraction efficiencies of major metal ions and rare earth ions from YCMA solution.

Figure 2.3 O:A ratio effect on extraction efficiencies of major metal ions and rare earth ions from Y2CMA solution. 29

Figure 2.4 Extractant concentration effect on extraction efficiencies of major metal ions and rare earth ions from Y0.5CMA solution. 30

Figure 2.5 Extractant concentration effect on extraction efficiencies of major metal ions and rare earth ions from YCMA solution. 31

Figure 2.6 Extractant concentration effect on extraction efficiencies of major metal ions and rare earth ions from Y2CMA solution 32

Figure 2.7 Analysis of separation factors of $Y$ over total major metal ions under different significant model terms (O:A ratio, $\mathrm{pH}$ and $\mathrm{Y}: \mathrm{CMA}$ ratio interaction, and $\mathrm{Y}: \mathrm{CMA}$ ratio and HDEHP concentration interaction). ${ }^{\ddagger}$.

Figure 2.8 Optimized SX solution for the system with minimized extraction efficiency of major metal ions, maximized extraction efficiency of $\mathrm{Y}$ and maximized separation factor of $\mathrm{Y}$ over major metal ions. ${ }^{\ddagger}$

Figure 3.1 Removal efficiency of $\mathrm{Zn}$ and $\mathrm{Y}$ from solution with different concentration ratio under the same operating conditions

Figure 3.2 Removal efficiency of $\mathrm{Zn}$ and $\mathrm{Y}$ from solution with different $\mathrm{pH}$ values under the same operating conditions. (Red lines: $\mathrm{pH}=3$; Blue lines: $\mathrm{pH}=5$ )

Figure 3.3 Removal efficiency of $\mathrm{Zn}$ and $\mathrm{Y}$ with different current density under same operating conditions.

Figure 3.4 Removal efficiency of $\mathrm{Y}$ and $\mathrm{Zn}$ for $\mathrm{pH} 7.0$ synthetic solution. 45

Figure 3.5 Removal efficiency of major ions from solution of major ions and $\mathrm{Y}$ ions. .45

Figure 3.6 Incorporation of solvent extraction to achieve metal separation and concentration in a hydrometallurgical circuit which involves recycling of all reagents. 47 Figure 3.7 Initial results of separating REE ions from major ions in leaching solution by solvent extraction. .48

Figure 3.8 Extraction rate of major ions from solution with $\mathrm{Cl}^{-}$under different conditions...... 49 viii 
Figure 3.9 Extraction rate of major ions from solution without $\mathrm{Cl}^{-}$(75 mL solution: $37.5 \mathrm{~mL}$ solvent: 0.63 gm HDEHP) 50

Figure 3.10 Metal ions data of sulfuric acid leaching solution of McVille sludge under pH of 2.0.

Figure 3.11 Metal ions data of sulfuric acid leaching solution of McVille sludge under pH of 3.5.

Figure 3.12 Metal ions data of nitric acid leaching solution of McVille sludge under $\mathrm{pH}$ of $2.0 \ldots 53$

Figure 3.13 Metal ions data of nitric acid leaching solution of McVille sludge under $\mathrm{pH}$ of $3.5 \ldots 53$

Figure 3.14 Metal ions data of nitric acid leaching solution from McVille site under $\mathrm{pH}$ 4.0 ......54

Figure 3.15 Metal ions and REE results from McV sludge leaching and SX data $\mathrm{pH} 1.1$.............57

Figure 3.16 Metal ions data of nitric acid leaching solution from DLM site under $\mathrm{pH}$ 4.0...........58

Figure 3.17 Metal ions data of nitric acid leaching solution from DLM site under pH 3.2 ...........59

Figure 3.18 Metal ions data of nitric acid leaching solution from DLM site under $\mathrm{pH} 3.6 \ldots \ldots . . . . .59$

Figure 3.19 Metal ions and REE from DLM sludge (pH 1.4), n-heptane solvent. .........................60

Figure 3.20 Metal ions and REE from DLM sludge $(\mathrm{pH} 1.4)$, kerosene solvent. ........................... 61

Figure 3.21 Metal ions and REE from DLM sludge (pH 3.2), kerosene solvent. ...........................62

Figure 3.22 Metal ions data of sludge leaching, solvent extraction and precipitation experiments. 63

Figure 3.23 Effect of extractant to solvent ratio on ALSX efficiency, leaching $\mathrm{pH} 3.2 \ldots \ldots \ldots \ldots \ldots . . . . . .65$

Figure 3.24 Metal ions and REE results from DLM sludge leaching and SX data ( $\mathrm{pH} 1.4)$ by increasing solvent volume and strip using $\mathrm{H} 2 \mathrm{SO} 4$ solution.

Figure 3.25 Metal ions and REE results of DLM sludge leaching and SX data (pH1.4) by increasing

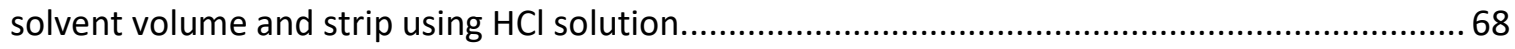

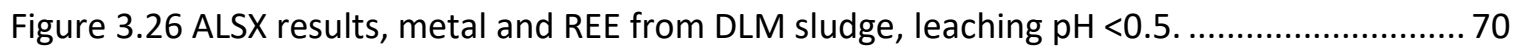

Figure 3.27 Metal ions and REEs results from DLM sludge leaching and SX data $\mathrm{pH} 1.4 \ldots \ldots \ldots \ldots . . .73$

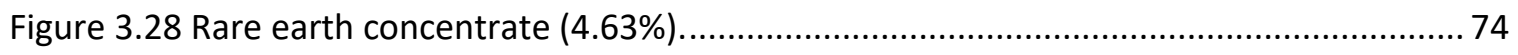

Figure 3.29 Metal ions and REES data of DLM sludge leaching solution ( $\mathrm{pH} 2.6)$ using kerosene as solvent...... .76

Figure 3.30 Metal ions data of DLM sludge leaching solution pH 2.6 using n-heptane as solvent.

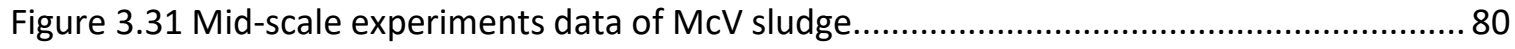


Figure 3.32 Effect of extraction stages on solvent extraction efficiency of pH 1.4 DLM sludge leaching solution.

Figure 3.33 Metal ions distribution data in different step solution (Two-step SX - high extractant ratio)

Figure 3.34 Metal ions distribution data in different step solution (Two-step SX - low extractant ratio) 87

Figure 3.35 Acid resistant filtering instrument (left); partly acid resistant filtering instrument (right). 89

Figure 3.36 Flowsheet of six-step treatment for REE recovery. 90

Figure 3.37 Critical REE, heavy REE and light REE distribution in whole process (Table A, B and C).

Figure 3.38 Critical REE, heavy REE and light REE distribution in whole process (Table D and E). 95

Figure 3.39 Flowsheet of seven-step treatment for REE recovery. 97

Figure 3.40 Critical REE, heavy REE and light REE distribution in whole process (Table F). 98

Figure 3.41 Flowsheet of twelve-step treatment for REE recovery. 99

Figure 3.42 Critical REE, heavy REE and light REE distribution in whole process (Table I, J and K). 103

Figure 3.43 TREE purity for 1st SX run with different extractant concentration (Table F, I, J and K). 104

Figure 3.44 TREE purity for 2 nd SX run with different extractant concentration (Table F, I, J and K). 104

Figure 3.45 TREE purity for 3rd SX run with different extractant concentration (Table F, I, J and K). 105

Figure 3.46 Extractant concentration effect on SX for TREE recovery from DLM PLS 2.4......... 106

Figure 4.1 Extraction efficiency of TMM, TREE, CREE, HREE and LREE- OM PLS 1.1................. 110

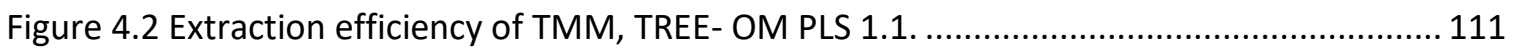

Figure 4.3 Critical REE, heavy REE and light REE distribution- OM PLS 1.1............................. 112

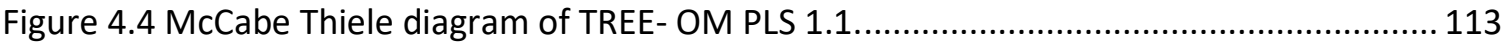

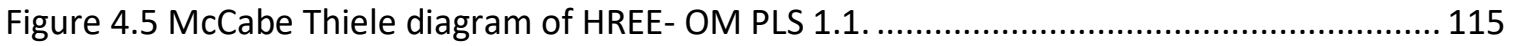

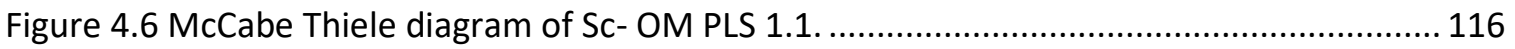

Figure $4.7 \mathrm{H}+$ concentration change determined by ICP and PH- OM PLS 1.1......................... 117 $x$ 
Figure 4.8 Filtering equipment and effect on OM PLS. 118

Figure 4.9 Filtering effect on OM PLS content. 118

Figure 4.10 SX results on original leaching solution of OM sludge and filtered OM PLS 2.7...... 119

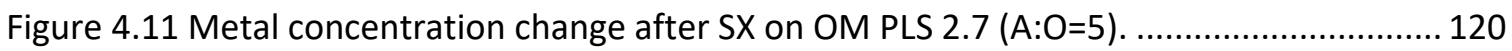

Figure 4.12 Extraction efficiency of TMM, TREE, CREE, HREE and LREE- OM PLS 2.7 ................ 121

Figure 4.13 Critical REE, heavy REE and light REE distribution- OM PLS 2.7 ............................. 121

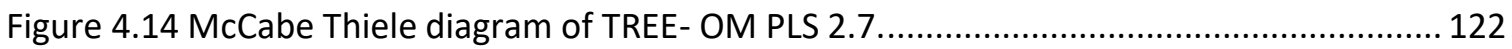

Figure 4.15 Concentration and mass change in OM PLS making process. ................................ 123

Figure 4.16 Extraction efficiency of TMM, TREE, HREE and LREE- OM PLS 3 ........................... 124

Figure 4.17 Extraction efficiency of individual elements- OM PLS 3 ...................................... 125

Figure 4.18 Heavy REE and light REE distribution- OM PLS 3 .............................................. 126

Figure 4.19 McCabe Thiele diagrams of TREE, HREE and LREE- OM PLS 3- 0.05 M.................... 127

Figure 4.20 McCabe Thiele diagrams of TREE, HREE and LREE- OM PLS 3- 0.3 M..................... 128

Figure 4.21 McCabe Thiele diagrams of TREE, HREE and LREE- OM PLS 3- 1.0 M...................... 130

Figure 4.22 Extraction efficiency of CREE, HREE and LREE- DLM PLS 2.5 ............................... 132

Figure 4.23 Critical REE, heavy REE and light REE distribution- DLM PLS 2.5 .......................... 133

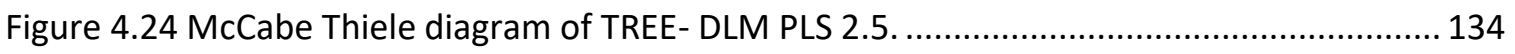

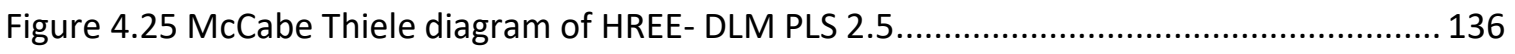

Figure 4.26 Concentration and mass change after $\mathrm{pH}$ adjustment to optimize DLM PLS........... 137

Figure 4.27 Extraction efficiency of TMM, TREE, CREE, HREE and LREE- DLM PLS 3.1............... 138

Figure 4.28 Critical REE, heavy REE and light REE distribution- DLM PLS 3.1 ............................ 139

Figure 4.29 McCabe Thiele diagram of TREE- DLM PLS 3.1.................................................... 140

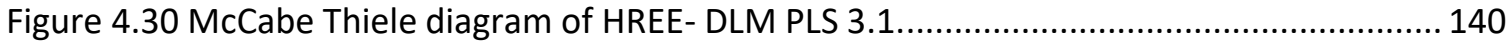

Figure 4.31 Extraction efficiency of TMM, TREE, CREE, HREE and LREE- DLM PLS 3 .................. 142

Figure 4.32 Critical REE, heavy REE and light REE distribution- DLM PLS 3 ............................. 143

Figure 4.33 McCabe Thiele diagrams of TREE, HREE and CREE- DLM PLS 3- 0.3 M.................... 144

Figure 4.34 McCabe Thiele diagrams of TREE, HREE and CREE- DLM PLS 3- 1.0 M................... 146

Figure 4.35 Pictures of solution in the RS PLS optimized process. ......................................... 146

Figure 4.36 Concentration and mass change in RS PLS making process. ................................. 147

Figure 4.37 Extraction efficiency of TMM, TREE, HREE and LREE- RS PLS 3 .............................. 149

Figure 4.38 Heavy REE and light REE distribution- RS PLS 3 ............................................... 150 
Figure 4.39 McCabe Thiele diagrams of TREE, HREE and LREE- RS PLS 3- 0.05 M..................... 151

Figure 4.40 McCabe Thiele diagrams of TREE, HREE and LREE- RS PLS 3- 0.3 M........................ 152

Figure 4.41 McCabe Thiele diagrams of TREE, HREE and LREE- RS PLS 3- 1.0 M........................ 154

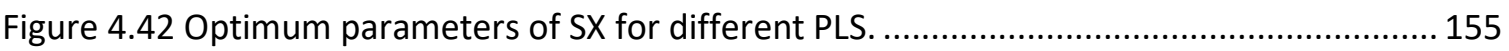

Figure 4.43 Pictures of water scrub process after equilibrium............................................... 156

Figure 4.44 Water scrub efficiency of individual and total elements for OM loaded organic. ... 157

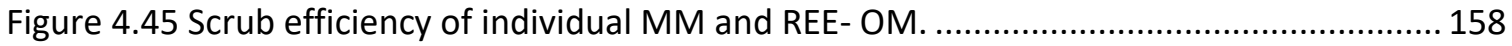

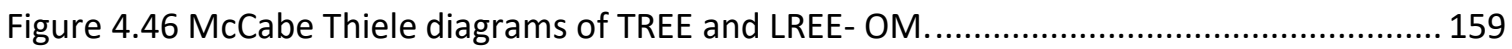

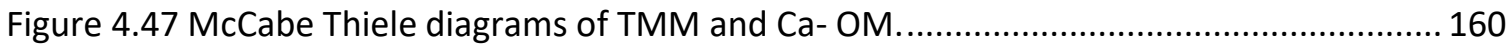

Figure 4.48 Pictures of $\mathrm{HCl}$ scrub process after equilibrium-DLM.......................................... 162

Figure 4.49 Pictures of water scrub process after equilibrium............................................... 162

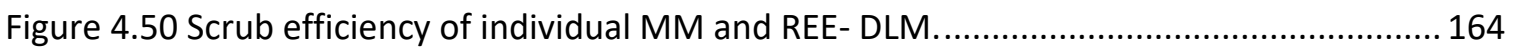

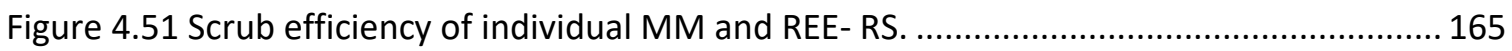

Figure 4.52 McCabe Thiele diagrams of TREE and TMM scrub process- RS. .............................. 165

Figure 4.53 Pictures of the $\mathrm{HNO}_{3}$ stripping process after equilibrium - RS. .............................. 166

Figure 4.54 Pictures of the $\mathrm{HCl}$ stripping process after equilibrium - RS................................. 167

Figure 4.55 Stripping efficiency of individual MM and REE- RS............................................. 169

Figure 4.56 McCabe Thiele diagrams of TREE stripping process- RS...................................... 170

Figure 4.57 McCabe Thiele diagrams of LREE stripping process- RS. ....................................... 171

Figure 4.58 McCabe Thiele diagrams of HREE stripping process- RS....................................... 172

Figure 4.59 McCabe Thiele diagrams of TMM stripping process- RS. .................................... 173

Figure 4.60 Whole flowsheet with optimum parameters from exploratory tests for RS REE

recovery. … 


\section{LIST OF TABLES}

Table 1-1 Recovery of REEs spiked in demineralized water, synthetic seawater, and seawater.... 3

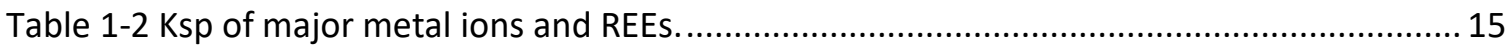

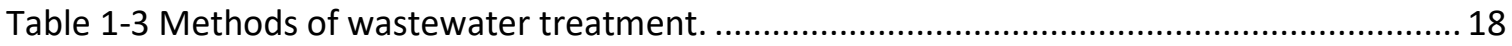

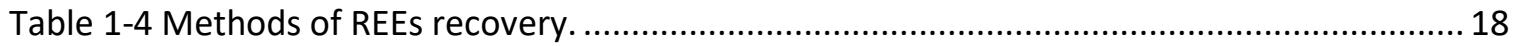

Table 2-1 Solvent extraction parameters on synthetic solution................................................ 25

Table 2-2 ANOVA analysis results of four factorial model on response of average separation

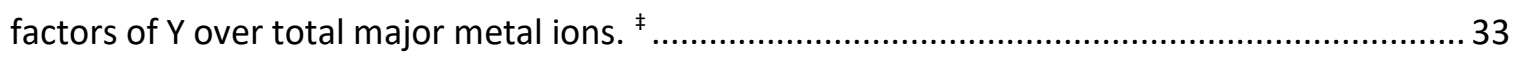

Table 3-1 Initial results of removing Zn ions from wastewater by EC. ........................................ 38

Table 3-2 Initial results of separating $\mathrm{Y}$ ions from zinc $(\mathrm{Zn})$ ions by EC and ED ......................... 41

Table 3-3 Recovery efficiency and purity of $Y$ with different current density under same operating

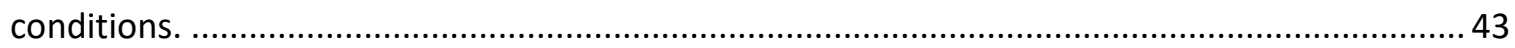

Table 3-4 Initial results of separating $\mathrm{Y}$ ions from $\mathrm{Zn} / \mathrm{Ca}$ ions by SX......................................... 47

Table 3-5 Results of pH adjustment and SX experiment. ........................................................ 50

Table 3-6 Results of solvent extraction experiment for McVille sludge under different $\mathrm{pH}$ values.

Table 3-7 Results of solvent extraction experiment for McVille sludge under initial pH 4.0....... 54 Table 3-8 Phase volume ratio effect results of solvent extraction experiment for McV sludge

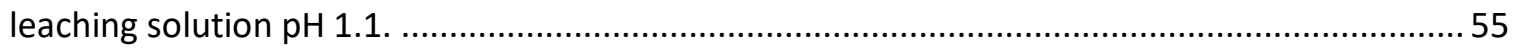

Table 3-9 Results of solvent extraction experiment for DLM sludge under $\mathrm{pH}$ 4.0......................58

Table 3-10 Results of solvent extraction experiment for DLM sludge under different $\mathrm{pH}$ values. 59 Table 3-11 Results of ALSX experiment using DLM leaching solution of $\mathrm{pH} 1.4$ and two different solvents. 60

Table 3-12 Results of ALSX experiment for DLM leaching solution of $\mathrm{pH} 3.2$ using solvent kerosene.

Table 3-13 Results of solvent extraction and precipitation experiments on DLM leachate.......... 63

Table 3-14 Effect of extractant to solvent ratio for DLM sludge, leaching $\mathrm{pH}$ 3.2. ......................65

Table 3-15 Results of DLM sludge leaching and SX data ( $\mathrm{pH}$ 1.4) by increasing solvent volume and strip using $\mathrm{H}_{2} \mathrm{SO}_{4}$ solution. .66 
Table 3-16 Results of DLM sludge leaching and SX experiments (pH 1.4) by increasing solvent volume and strip using $\mathrm{HCl}$ solution. .67

Table 3-17 Experimental results, ALSX experiment, DLM sludge, leaching $\mathrm{pH}<0.5$. .70

Table 3-18 Results of solvent extraction experiment for DLM sludge leaching solution $\mathrm{pH} 1.4 \ldots 71$

Table 3-19 Results of the large scale ALSX trial using DLM sludge, leaching pH 3.2. .74

Table 3-20 Results of solvent extraction experiment for DLM sludge leaching solution pH 2.6 using kerosene as the solvent. 76

Table 3-21 Results of solvent extraction experiment for DLM leachate $\mathrm{pH} 2.6$ using $\mathrm{n}$-heptane as solvent. .78

Table 3-22 Results of mid-scale experiments of McV sludge. 81 Table 3-23 Results of effect of extraction stages for pH 1.4 DLM sludge leaching solution solvent extraction experiments.

Table 3-24 Results of solvent extraction experiment for DLM sludge under different SX conditions (high extractant ratio).

Table 3-25 Results of solvent extraction experiment for DLM sludge under different SX conditions (low extractant ratio). .85

Table 3-26SX results of leaching solution with different acid type and different filtering instrument.

Table 3-27 SX results of leaching solution with different filtration effect. 93

Table 3-28 SX results of leaching solution with and without water scrub step. 96

Table 3-29 SX results of leaching solution with different extractant concentration in organic phase by using new flowsheet. 99

Table 3-30 Appropriate parameters range for TREE recovery from different leachates. ........... 105

Table 4-1 Parameters and $\mathrm{pH}$ results of solvent extraction exploratory test of OM PLS 1.1..... 108

Table 4-2 Parameters and $\mathrm{pH}$ results of solvent extraction exploratory test of OM PLS 2.7 ..... 117

Table 4-3 Parameters of solvent extraction exploratory test of OM PLS 3. 123

Table 4-4 Parameters and $\mathrm{pH}$ results of solvent extraction exploratory test of DLM PLS $2.5 \ldots 130$

Table 4-5 Parameters and $\mathrm{pH}$ results of solvent extraction exploratory test of DLM PLS 3.1. ... 137

Table 4-6 Parameters of solvent extraction exploratory test of DLM PLS 3. 141

Table 4-7 Parameters and pH results of solvent extraction exploratory test of RS PLS 3. 147

Table 4-8 Parameters of DI water scrub exploratory test on OM loaded organic. 155 xiv 
Table 4-9 Parameters of scrub exploratory test of OM loaded organic.

Table 4-10 McT charts results summary of REE for OM scrub tests........................................ 159

Table 4-11 McT charts results summary of MM for OM scrub tests........................................ 160

Table 4-12 Parameters and $\mathrm{pH}$ results of diluted $\mathrm{HCl}$ scrub exploratory test of DLM. ............... 161

Table 4-13 Parameters and pH results of water scrub exploratory test of DLM........................ 162

Table 4-14 Parameters of $0.01 \mathrm{M} \mathrm{HCl}$ scrub exploratory test of DLM loaded organic................. 163

Table 4-15 Parameters of water scrub exploratory test of RS loaded organic............................ 164

Table 4-16 Parameters of $\mathrm{HNO}_{3}$ stripping exploratory tests of RS scrubbed loaded organic. .... 166

Table 4-17 Parameters of $\mathrm{HCl}$ stripping exploratory tests of RS scrubbed loaded organic......... 166

Table 4-18 McT charts results summary of TREE for RS stripping tests. .................................. 170

Table 4-19 McT charts results summary of LREE for RS stripping tests.................................... 171

Table 4-20 McT charts results summary of HREE for RS stripping tests.................................. 172

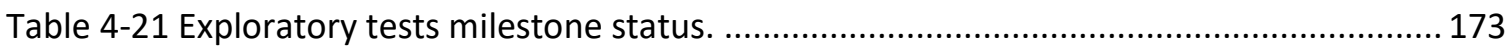

Table 4-22 Parameters used for REE recovery from RS leachate. ........................................... 174

Table 4-23 Results of REE recovery from RS leachate following whole flowsheet...................... 175 


\section{RECOVERY OF RARE EARTH ELEMENTS FROM COAL MINE DRAINAGE SLUDGE LEACHATE}

\section{Introduction}

\subsection{Rare earth elements and their application in industry}

Rare earth elements (REEs) are a group of seventeen chemical elements in the periodic table, specifically the fifteen lanthanides plus scandium and yttrium.(Separation Hydrometallurgy of Rare Earth Elements / Jack Zhang ( Springer, 2016) These elements have many similar properties, and that often causes them to be found together in same ore deposits. ("REE - Rare Earth Elements - Metals, Minerals, Mining, Uses," 2018) While named rare earths, they are in fact not that rare and are relatively abundant in the Earth's crust. However, these metals are very difficult to mine because it is unusual to find them in concentrations high enough for economical extraction.

Rare earth elements have wide applications due to their special physical and chemical properties. They are usually used in alloys(Yan et al., 2017), glass and ceramics(Arnold, 2015), phosphors(Xie, Hirosaki, Li, \& Takeda, 2010), magnets(Goto, Kimura, Lawes, Ramirez, \& Tokura, 2004), and batteries(W. Li et al., 2016). Rare earth metals and alloys that contain them are used in many devices that people use every day such as rechargeable batteries, fluorescent lighting, catalytic converters, precision-guided weapons and much more. They really benefit our life.

\subsection{Resource and production of rare earth elements}

\subsubsection{Worldwide distribution}

Rare earth elements are not as rare as their name indicates; however, not many REE deposits are mineable. Most of the mineable deposits have been found in China, America, India, Middle Asian nations, South Africa, Australia, and Canada. From 2006 to 2011, China produces over 90 \% of REOs worldwide and REOs consumed in the United States are import-reliant.(Separation Hydrometallurgy of Rare Earth Elements / Jack Zhang ( Springer, 2016)

According to USGS 2017 report, the United States continues to rely on foreign sources 100 percent for 21 mineral commodities including rare earths, manganese, niobium and vanadium.(Survey, 2018) The suspension of U.S. rare-earth mining in late 2015 continued throughout 2017. In Nebraska, one company 
commissioned an operation that produced separated rare earth oxides from recycled fluorescent light bulbs. The company planned to ramp up production to 18 tons per month using a proprietary technology.(Survey, 2018) Lynas Corp (largest producer of REE materials outside of China) has signed a memorandum of understanding in 2019 with Texas-based Blue Line Corp (US-based processor of REE products) to set up a REE separation facility in the United States. The joint venture aims to fill main gap in the US supply chain and would be the only large-scale producer of separated medium and heavy REE products in the world, outside of China.(Reporter, 2019)

\subsubsection{Technologies for REEs separation}

REEs are usually used as individual element in industry application. Prior to individual REE separation, the rare earth ore will go through a series of physical separation and hydrometallurgical processing. To concentrate the rare earth minerals, the commonly used ore beneficiation technologies include gravity separation, flotation, and magnetic separation. Different with the physical beneficiation, hydrometallurgical processing of REE mineral concentrate is chemical processing, which converts the rare earth mineral concentrate to a rare earth compound. The compound is either a final product or an intermediate product for the succeeding production of individual REEs or other compounds.

The processes for rare earth extraction include the decomposition of rare earth mineral concentrate, and the concurrent or subsequent leaching of the rare earth elements from the decomposed minerals. Ore beneficiation concentrate can be decomposed by, for example, acid roasting, caustic cracking, and chlorination. The rare earth elements can be selectively extracted using solvent extraction, ion-exchange, or chemical precipitation to produce either mixed rare earth oxides or individual rare earth oxides.

Rare earth elements are very useful and only rare earth mineral supply is not enough. Recovery of REEs from waste materials effectively is not only a significant good way for valuable REEs production but also a pollutant treatment method. A literature review on REE recovery/separation from nature water and waste materials is studied. Mostly, solubilized REE are recovered/separated as high purity end-products either by solvent extraction or selectively precipitated with oxalic acid to form oxalates. There are also some electrochemical processes for REE recovery.

\subsubsection{Solvent extraction}

Researchers conducted the recovery of REEs spiked in demineralized water, synthetic seawater, and seawater by loading $50 \mathrm{mg}$ of complexing agents onto C18. (B., 1990) The high distribution coefficients of REEs in the mixture of HDEHP (65\%) and $\mathrm{H}_{2}$ MEHP (35\%) make them very strong complexing agents over 
the dissolved REEs present in natural waters. And they can be used in acidic solutions. As can be seen from Table 1-1 (B., 1990), no loss of REEs recovery was shown for demineralized water, but in cases of synthetic seawater and seawater approximately the same percent loss was found for La. HDEHP-lanthanide complexes were characterized by other researchers. (Marie, Hiscox, \& Nash, 2011) From the research results, for preconcentration and determination of REEs in samples which don't have Ca or have a very low Ca concentration (e.g. freshwater, ground water, etc.), $50 \mathrm{mg}$ of complexing agents is enough for quantitative recovery of about 6 micrograms REEs. Adsorption of the mixture onto $\mathrm{C}_{18}$ cartridges provides a rapid, reliable, and simple technique for the concentration of trace REEs in seawater.

\begin{tabular}{|c|c|c|c|}
\hline \multirow[b]{2}{*}{ element } & \multicolumn{3}{|c|}{$\%$ recovery $^{a}$} \\
\hline & $\begin{array}{l}\text { demineralized } \\
\text { water }\end{array}$ & $\begin{array}{l}\text { synthetic } \\
\text { seawater }\end{array}$ & seawater \\
\hline $\mathrm{La}$ & 99.6 & 89.7 & 88.8 \\
\hline $\mathrm{Ce}$ & 99.2 & 99.1 & 98.7 \\
\hline $\operatorname{Pr}$ & 99.9 & 99.1 & 99.0 \\
\hline $\mathrm{Nd}$ & 99.1 & 99.0 & 98.9 \\
\hline $\mathrm{Sm}$ & 99.7 & 99.3 & 99.2 \\
\hline $\mathrm{Eu}$ & 98.6 & 99.5 & 99.4 \\
\hline $\mathrm{Cd}$ & 99.7 & 100.0 & 99.8 \\
\hline $\mathrm{Tb}$ & 99.1 & 99.1 & 99.3 \\
\hline Dy & 98.6 & 99.7 & 99.4 \\
\hline Ho & 98.3 & 99.1 & 99.7 \\
\hline $\mathrm{Er}$ & 99.3 & 99.7 & 99.5 \\
\hline $\mathrm{Tm}$ & 98.1 & 99.3 & 99.6 \\
\hline $\mathrm{Yb}$ & 98.2 & 99.9 & 99.8 \\
\hline $\mathrm{Lu}$ & 98.1 & 99.3 & 99.5 \\
\hline
\end{tabular}

${ }^{a}$ The $\mathrm{pH}$ of the all samples was adjusted to 3.5 before preconcentration.

Table 1-1 Recovery of REEs spiked in demineralized water, synthetic seawater, and seawater.

$\mathrm{HEH}(\mathrm{EHP})$ is an extractant with similar structure with HDEHP. The development of a new environmentally friendly approach for rare earth separation in a HEH(EHP)-Cl system was investigated. (L. Wang et al., 2013) They first studied on a $\mathrm{HEH}(\mathrm{EHP})-\mathrm{Cl}$ system to simulate a model of the proposed equilibrium acidity control technology to determine the extraction equilibrium and mass balances for a counter current extraction system. A pilot test separating $\mathrm{Gd}$ and $\mathrm{Tb}$ in a $\mathrm{HEH}(\mathrm{EHP})-\mathrm{Cl}$ system is performed using the proposed equilibrium acidity control technology (Figure 1.1). The method is used in an industrial separation process with ammonia-free emissions. 


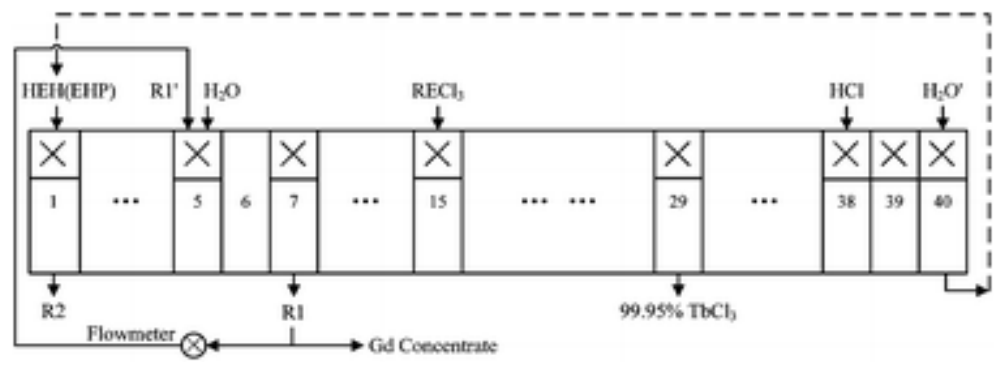

Figure 1.1 A pilot test separating Gd and Tb in a HEH(EHP)-Cl system.

In industry, three of the best known commercially available extractants are tri-n-butyl phosphate (TBP), di-n-butyl n-butylphosphonate (DBBP) and P350. (Preston, 1996) Their structures are shown in Figure 1.2.

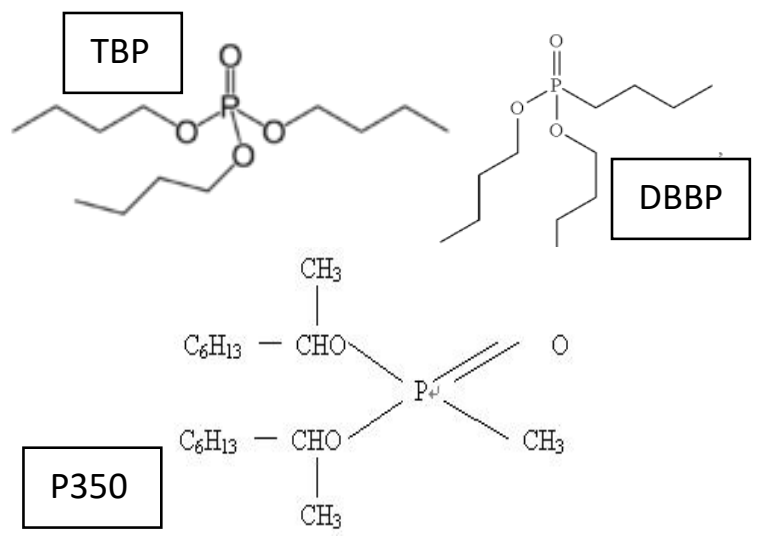

Figure 1.2 Structure of three extractants.

Because $\mathrm{Ca}^{2+}$ can be extracted by TBP, it is difficult to separate rare earths from $\mathrm{Ca}^{2+}$ effectively with it. Researchers show a new hydrometallurgical process for extracting rare earths from apatite using solvent extraction with P350. (H. Li, Guo, Zhang, Li, \& Wang, 2006) The main component of nitric acid leaching liquor of apatite is $\mathrm{Ca}$ (most), Fe, Mg and REEs. Figure 1.3 (H. Li et al., 2006) shows the general flowsheet for recovery of REEs from apatite leachate with extractant P350. First: dissolve apatite with nitric acid, after filtration, add ammonium nitrate $\left(\mathrm{NH}_{4} \mathrm{NO}_{3}\right)$ to adjust acidity. Then rare earths were extracted with P350. The impurity loaded in organic phase can be removed by scrubbing with nitric acid solution, while the scrubbing process will cause loss of REEs loaded in organic phase. $\mathrm{HNO}_{3}$ was chosen to strip $\mathrm{RE}^{3+}$ from loaded organic phase. The stripping solution was subjected to precipitation of rare earths with $10 \% \mathrm{H}_{2} \mathrm{C}_{2} \mathrm{O}_{4}$ solution and the precipitate was then ignited at $700-800 \circ \mathrm{C}$ to obtain an oxide concentrate. The results show that rare earths can be separated with P350 from Ca, P, Fe and other impurities. The purity of mixed rare earth oxides (REO) is more than $95 \%$ and the yield obtained can be over $98 \%$. 


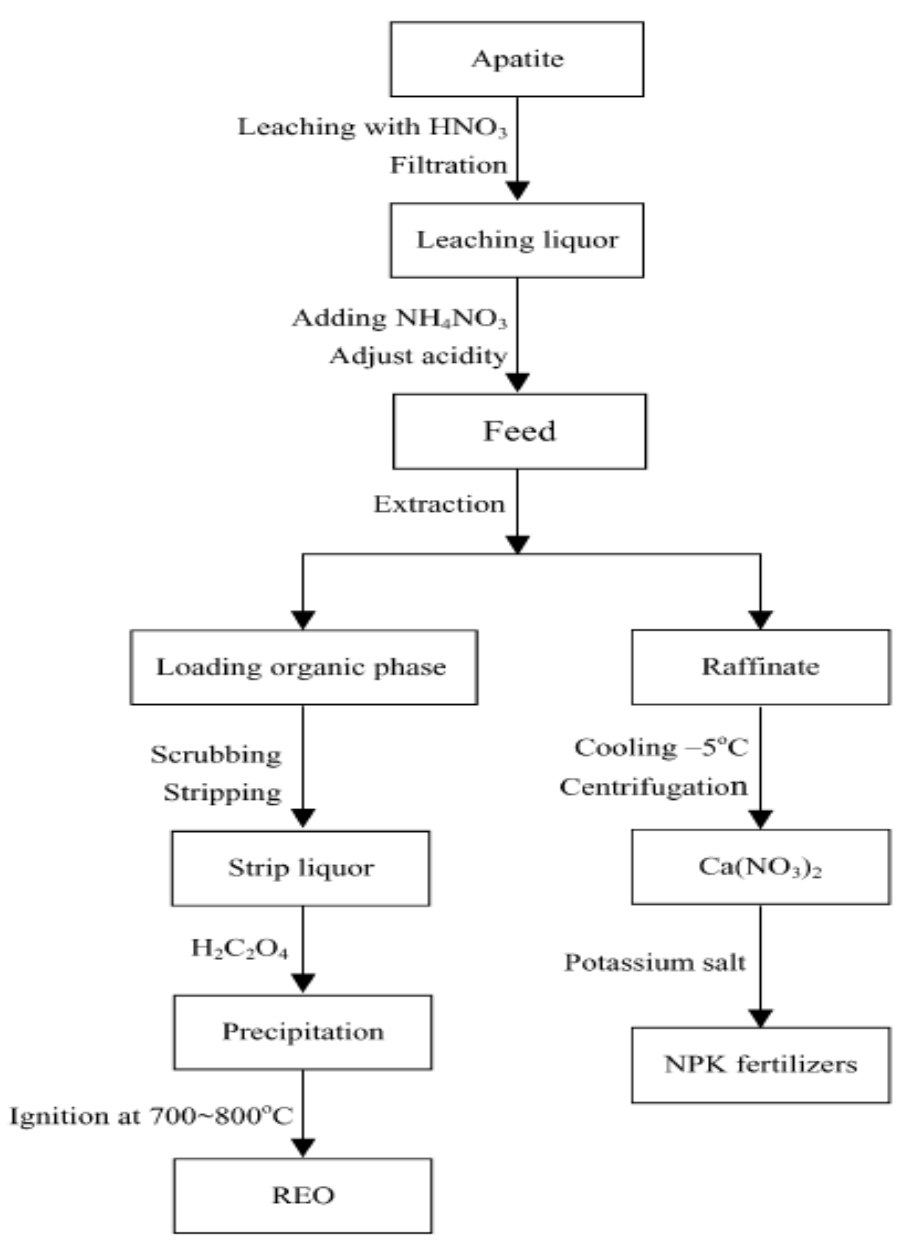

Figure 1.3 Flowsheet for recovery of REEs from apatite.

$\mathrm{NdFeB}$ permanent magnet scrap is a sufficient waste material for $\mathrm{Nd}$ recovery for recycling use. (Dupont \& Binnemans, 2015; Gergoric, Ekberg, Foreman, Steenari, \& Retegan, 2017; Riaño \& Binnemans, 2015) The rare earth elements (REEs) were successfully recovered from industrial scrap magnets via membrane assisted solvent extraction (MSX). As shown in Figure 1.4 (left) (D. Kim et al., 2015), in the MSX system, an organic phase consisting of extractant and organic solvent is immobilized in the pores of hollow fiber membranes, and the aqueous feed solution flows through the lumen side and strip solution through the shell side of hollow fiber modules. The membrane modules in the MSX system provides high contact surface area to achieve a high REE extraction efficiency. The system showed high selectivity for REE ions with no coextraction of non-REEs. This high selectivity of REEs over non-REEs may be caused by the nonequilibrium separation process of MSX. Coextraction of non-REEs will occur when the process approaches equilibrium. In the feed solution, REEs ratio is very high (Figure 1.4, right), which makes it different from REEs extraction in natural water. 

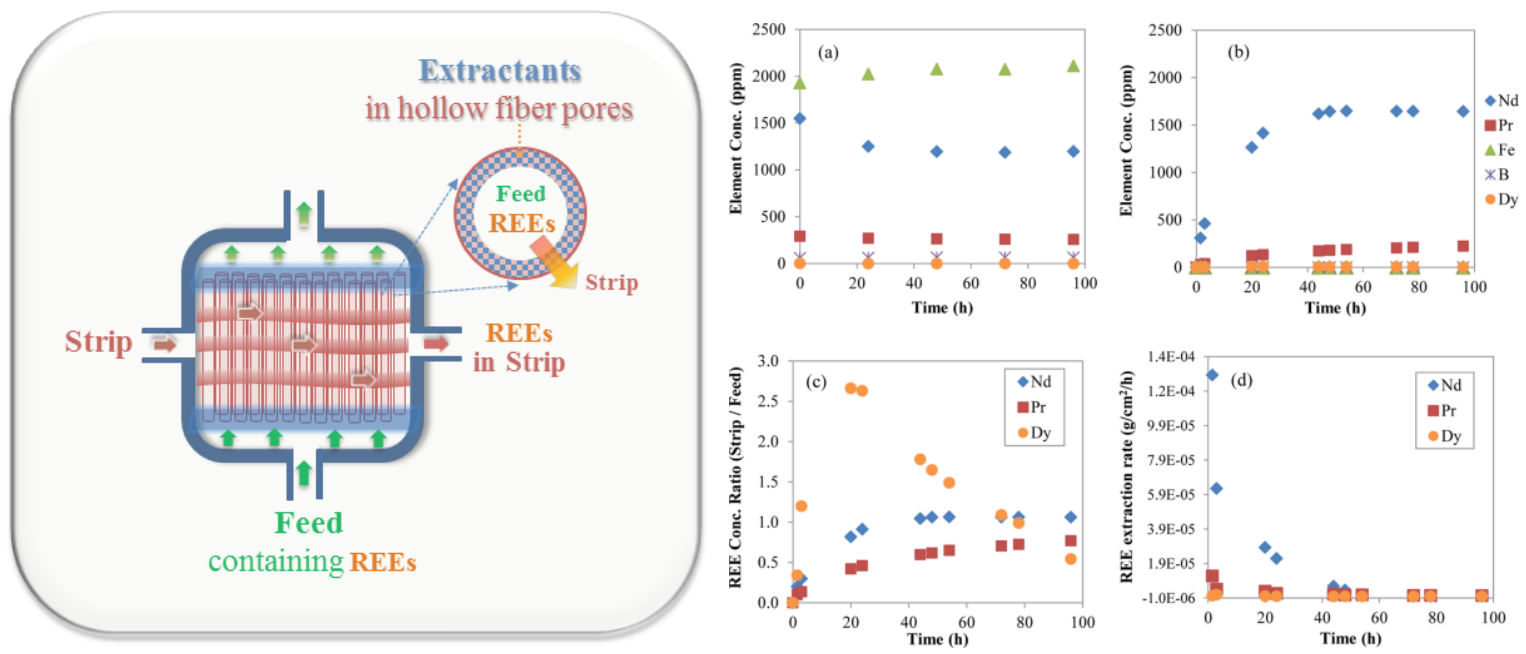

Figure 1.4 Schematic of a hollow fiber membrane module for membrane solvent extraction (left); Elemental concentration of NdFeB magnets in the (a) feed and (b) strip solutions, and (c) the ratio of REEs in the strip to the feed and (d) REE extraction rate (right).

Ionic liquids are also used in research about solvent extraction of REEs. (Hoogerstraete, Wellens, Verachtert, \& Binnemans, 2013; Larsson \& Binnemans, 2014; Riaño \& Binnemans, 2015; Alok Rout \& Binnemans, 2013; A. Rout \& Binnemans, 2014; Alok Rout, Kotlarska, Dehaen, \& Binnemans, 2013; Alok Rout, Wellens, \& Binnemans, 2013; K. Wang et al., 2017) Two immiscible ionic liquids were used for rare earths separation from nickel, Figure 1.5 (Alok Rout, Wellens, et al., 2013). They are with properties allowing the transfer of the rare earths from one ionic liquid phase to another. Such a separation process is valid for the recycling of REEs from nickel metal hydride (NiMH) batteries. Direct dissolution of rareearth oxides in 1-ethyl-3-methylimidazolium chloride, which is formed by adding a small amount of concentrated hydrochloric acid to one of the used ionic liquids, was possible.

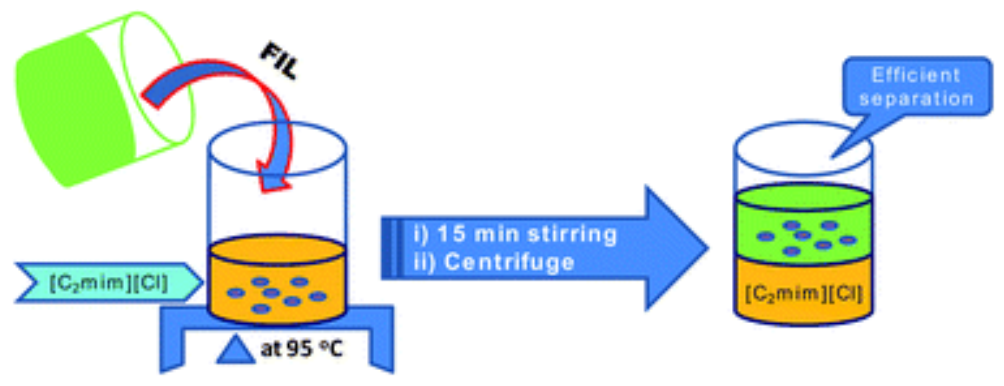

Figure 1.5 Schematic of rare earths and nickel separation by solvent extraction with two mutually immiscible ionic liquids. 


\subsubsection{Selective- precipitation}

By using concentrated alkali to precipitate REEs minerals is a conventional way to recover REEs. The mineral monazite $\left((\mathrm{RE}, \mathrm{Th}) \mathrm{PO}_{4}\right)$ is one of the key sources of REEs in nature. Well established hydrometallurgical methods for leaching of monazite and the related metal recovery processes are described in literatures. (Jordens, Cheng, \& Waters, 2013; E. Kim \& Osseo-Asare, 2012) After physical beneficiation, the chemical processing of monazite follows two main routes, i.e., acid treatment by sulfuric acid and alkaline decomposition by $\mathrm{NaOH}$, as shown in Figure 1.6. In neutralization and precipitation process, reagents such as ammonium hydroxide, sodium sulfate, oxalic acid, and hydrofluoric acid, are normally be used. Separation and purification processes often include solvent extraction.

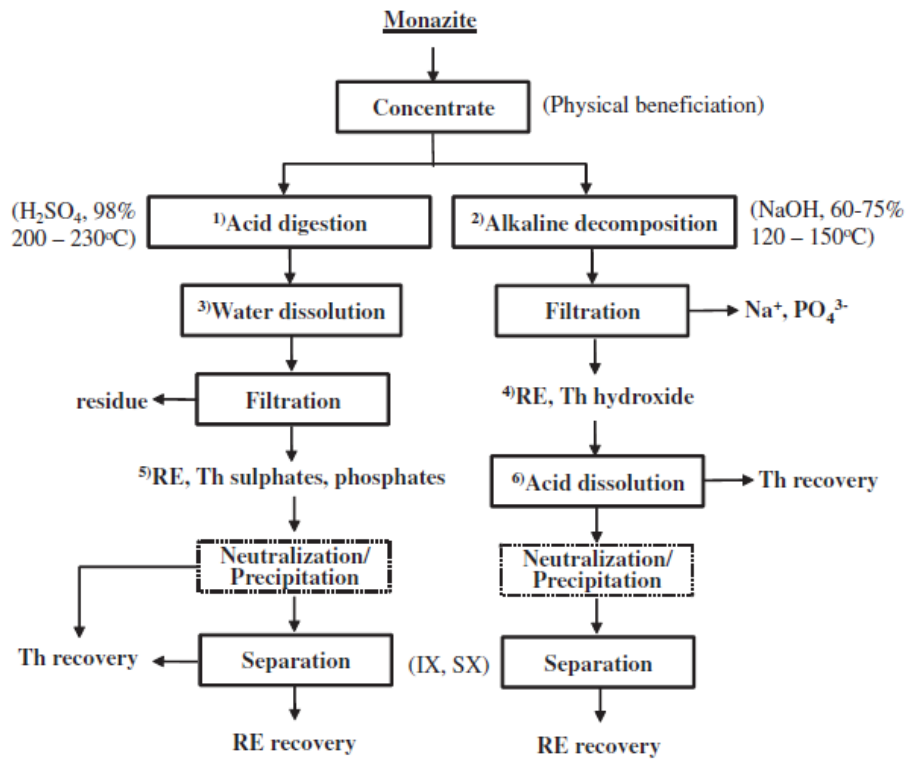

\begin{tabular}{|c|c|c|}
\hline System & Application & Processes \\
\hline \multirow[t]{3}{*}{$\mathrm{M}-\mathrm{H}_{2} \mathrm{O}$} & $\begin{array}{l}\text { - Dissolution of metal oxides resulting from } \\
\text { alkaline treatment of monazite }\end{array}$ & -Step 2, 4 \\
\hline & $\begin{array}{l}\text { - Th/RE separation via precipitation after } \\
\text { water dissolution }\end{array}$ & -Step 3 \\
\hline & $\begin{array}{l}\text { - Th/RE selective dissolution after alkaline } \\
\text { treatment }\end{array}$ & -Step 6 \\
\hline $\mathrm{M}-\mathrm{SO}_{4}-\mathrm{H}_{2} \mathrm{O}$ & $\begin{array}{l}\text { - Dissolution of metal sulfates resulting from } \\
\text { sulfuric acid digestion of monazite } \\
\text { - Dissolution and separation of RE metal scrap } \\
\text { e.g. Nd-Fe-B magnet }\end{array}$ & -Step 1,3 \\
\hline $\mathrm{M}-\mathrm{PO}_{4}-\mathrm{H}_{2} \mathrm{O}$ & - Acid and alkaline decomposition of monazite & -Step 1,2 \\
\hline $\mathrm{M}-\mathrm{PO}_{4}-\mathrm{SO}_{4}-\mathrm{H}_{2} \mathrm{O}$ & - Acid decomposition of monazite & -Step 1,5 \\
\hline
\end{tabular}

(M: La, Nd, Ce, Th)

Figure 1.6 Flowsheet for hydrometallurgical treatment of monazite and considered Metal-(Ligand)-H2O systems for recovery of RE metals and Th. 
The followed equations indicate the alkali decomposition process of rare earth phosphates with hot, concentrated alkali $(50-75 \% \mathrm{NaOH})$.

$$
\begin{aligned}
& \mathrm{RE}\left(\mathrm{PO}_{4}\right)_{(\mathrm{s})}+3 \mathrm{NaOH} \rightarrow \mathrm{RE}(\mathrm{OH})_{3(\mathrm{~s})}+3 \mathrm{Na}^{+}+\mathrm{PO}_{4}{ }^{3-} \\
& \mathrm{Th}_{3}\left(\mathrm{PO}_{4}\right)_{4(\mathrm{~s})}+12 \mathrm{NaOH} \rightarrow 3 \mathrm{Th}(\mathrm{OH})_{4(\mathrm{~s})}+12 \mathrm{Na}^{+}+4 \mathrm{PO}_{4}{ }^{3-}
\end{aligned}
$$

For all the processing steps, the Eh-pH diagrams can be used to predict reaction conditions, which favor dissolution or precipitation of RE metal oxides as well as the corresponding complexes with phosphate and sulfate ions. Thus, appropriate separation flowsheet can be selected. The considered Metal-(Ligand)$\mathrm{H}_{2} \mathrm{O}$ systems and their relevance to monazite hydrometallurgy are listed in table in Figure 1.6.

As the Figure 1.7 (E. Kim \& Osseo-Asare, 2012) shows, rare earth hydroxides form under relatively alkaline conditions $(\mathrm{pH}>7.5)$, while $\mathrm{ThO}_{2}$ is stable even at relatively low $\mathrm{pH}$ (down to $\mathrm{pH}^{\sim 1}$ ). This indicates that mixed RE-Th (hydr)oxides may be separated by selective dissolution. Thus, the $\mathrm{Nd}-$, $\mathrm{Ce}-$, and Lahydroxides resulting from alkaline decomposition of monazite can readily dissolve as $\mathrm{RE}(\mathrm{III})$ species in acidic to neutral $\mathrm{pH}$ solutions, leaving $\mathrm{Th}$ in a stable solid phase as $\mathrm{ThO}_{2}$ even under relatively acidic conditions ( $\mathrm{pH} \sim 1$ ). Conversely, Th and RE metals, initially present as dissolved species in acidic solution, may be separated by $\mathrm{pH}$ adjustment; as $\mathrm{pH}$ is raised, $\mathrm{ThO}_{2}$ is expected to form first.
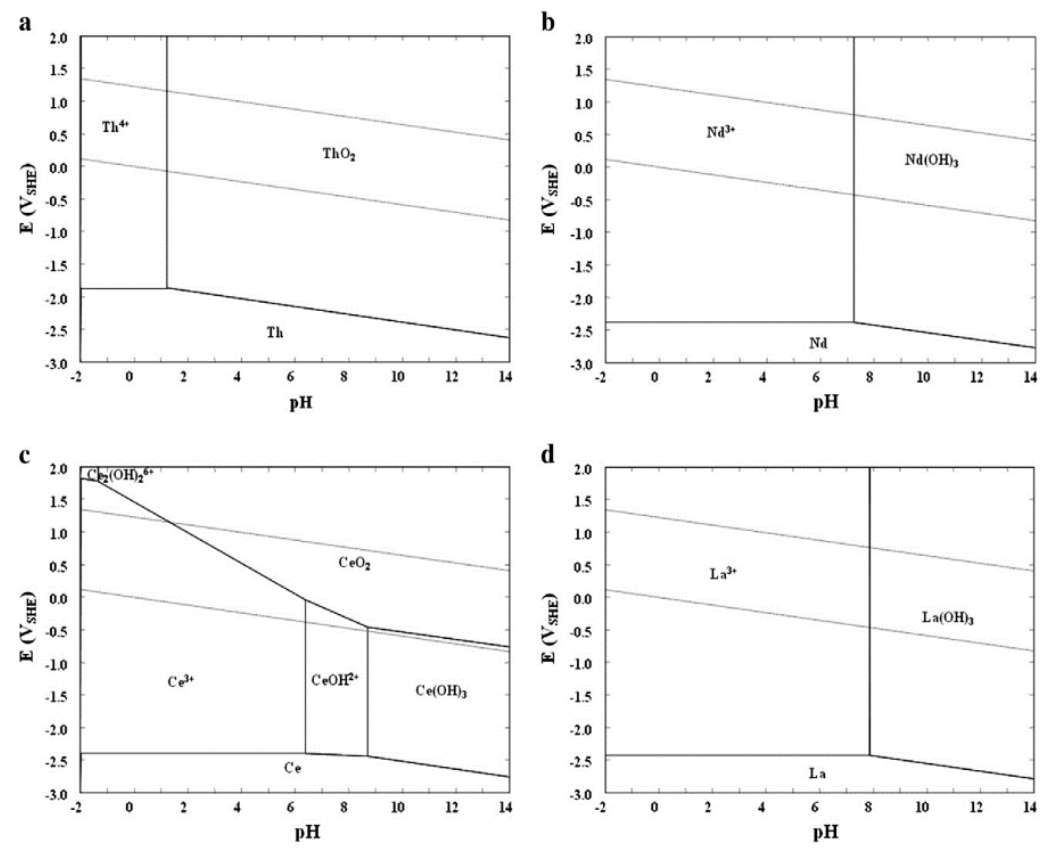
Figure 1.7 Eh-pH diagrams for $\mathrm{M}-\mathrm{H}_{2} \mathrm{O}$ systems at $25^{\circ} \mathrm{C}$ : (a) $[\mathrm{Th}]=10^{-3} \mathrm{M},(\mathrm{b})[\mathrm{Nd}]=10^{-3} \mathrm{M},(\mathrm{c})[\mathrm{Ce}]=10^{-3} \mathrm{M}$,

$$
\text { (d) }[\mathrm{La}]=10^{-3} \mathrm{M} \text {. }
$$

Oxalic acid is often used for REEs selective precipitation to increase REEs purity. (Hoogerstraete, Blanpain, Gerven, \& Binnemans, 2014; R. Chi, 1999) A solution chemistry approach is developed to study oxalic acid efficiency in recovering REEs from the leachates of weathered clays. In Figure 1.8 (R. Chi, 1999), for all three leachates examined, when increasing the mole ratio, RE recovery increases. RE recovery efficiency stabilizes at a mole ratio of approximately 2.5 to 3 , which is higher than the corresponding stoichiometric requirement (1.5). Excess oxalic acid was consumed by precipitating and complexing non-REEs. The optimal pH for precipitation to obtain the highest REEs recovery with the highest purity was approximately 2. It is identified experimentally and confirmed by solution chemistry calculations.
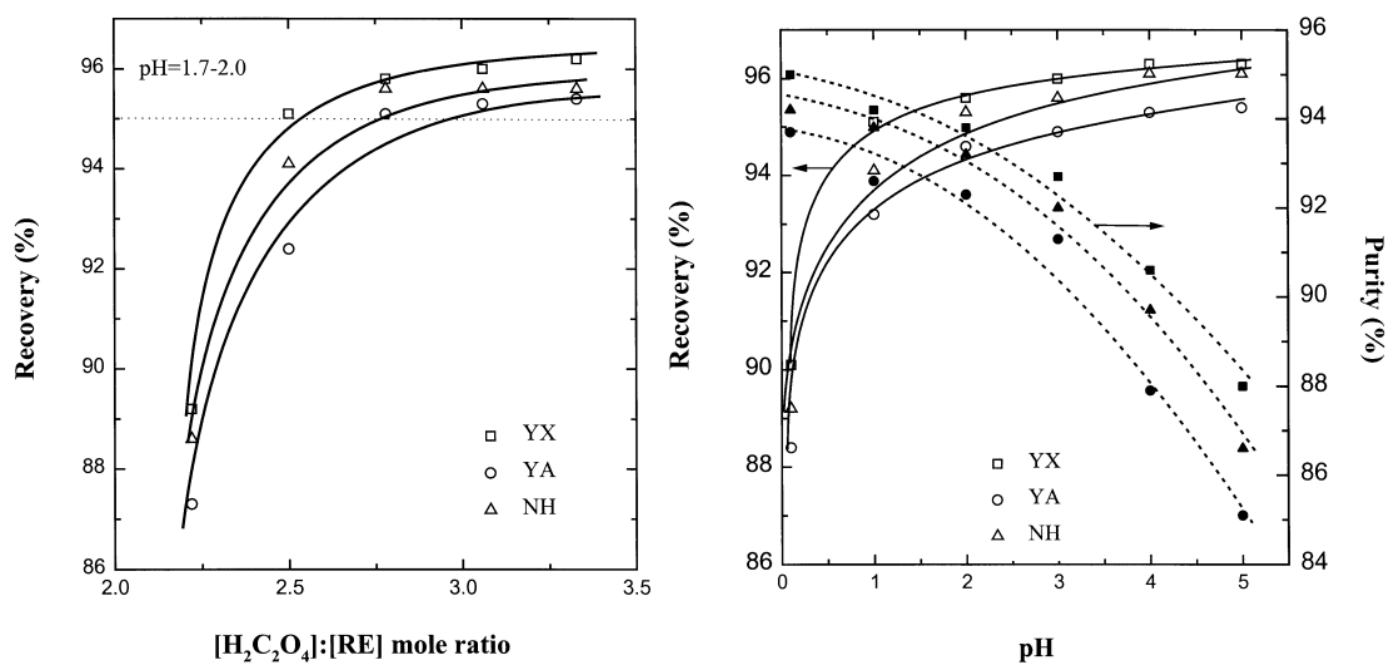

Figure 1.8 Effect of oxalic acid dosage pH on the recovery and purity of RE oxalate precipitates. (YX, YA, NH -- Different kinds of RE minerals)

With the aim to study the fractionation that results from the interaction of dissolved REE with precipitating Fe oxyhydroxide, scavenging experiments were performed at different $\mathrm{pH}$ with synthetic solutions containing dissolved Fe ( 7 mg/L), Rare Earths ( $2 \mathrm{REE}: ~ 61 \mu \mathrm{g} / \mathrm{L})$ in a matrix of $(0.01 \mathrm{M}) \mathrm{HCl}$. (Bau, 1999)

From published thermodynamic data, REE speciation in the synthetic solution at $\mathrm{pH} 6$ is plotted in Figure 1.9 (Bau, 1999) (left). At pH 6, the free metal ions take more than $95 \%$ of the total REE content of the synthetic solutions, while chloride, nitrate, and hydroxide complexes are less than $2 \%$ respectively. There is no significant difference of speciation along the REE series. The results of the experiments conducted a variable $\mathrm{pH}$ show that scavenging of REE is highly $\mathrm{pH}$-dependent. $\mathrm{REE}_{\text {scav }}$ ( $\mathrm{Nd}$ and $\mathrm{Y}$ as indicators of REE, 
after $180 \mathrm{~min}$ ) increases from less than $10 \%$ at $\mathrm{pH}$ less than 4.6 to more than $90 \%$ at $\mathrm{pH}$ larger than 6 , Figure 1.9 (Bau, 1999) (right). This is in significant contrast to the behavior of the REE when no Fe oxyhydroxides are present; in which case $\mathrm{REE}_{\text {scav }}$ (after $180 \mathrm{~min}$ ) increases linearly with $\mathrm{pH}$ from $1 \%$ at $\mathrm{pH}$ 4 to less than $5 \%$ at $\mathrm{pH} 6.2$.
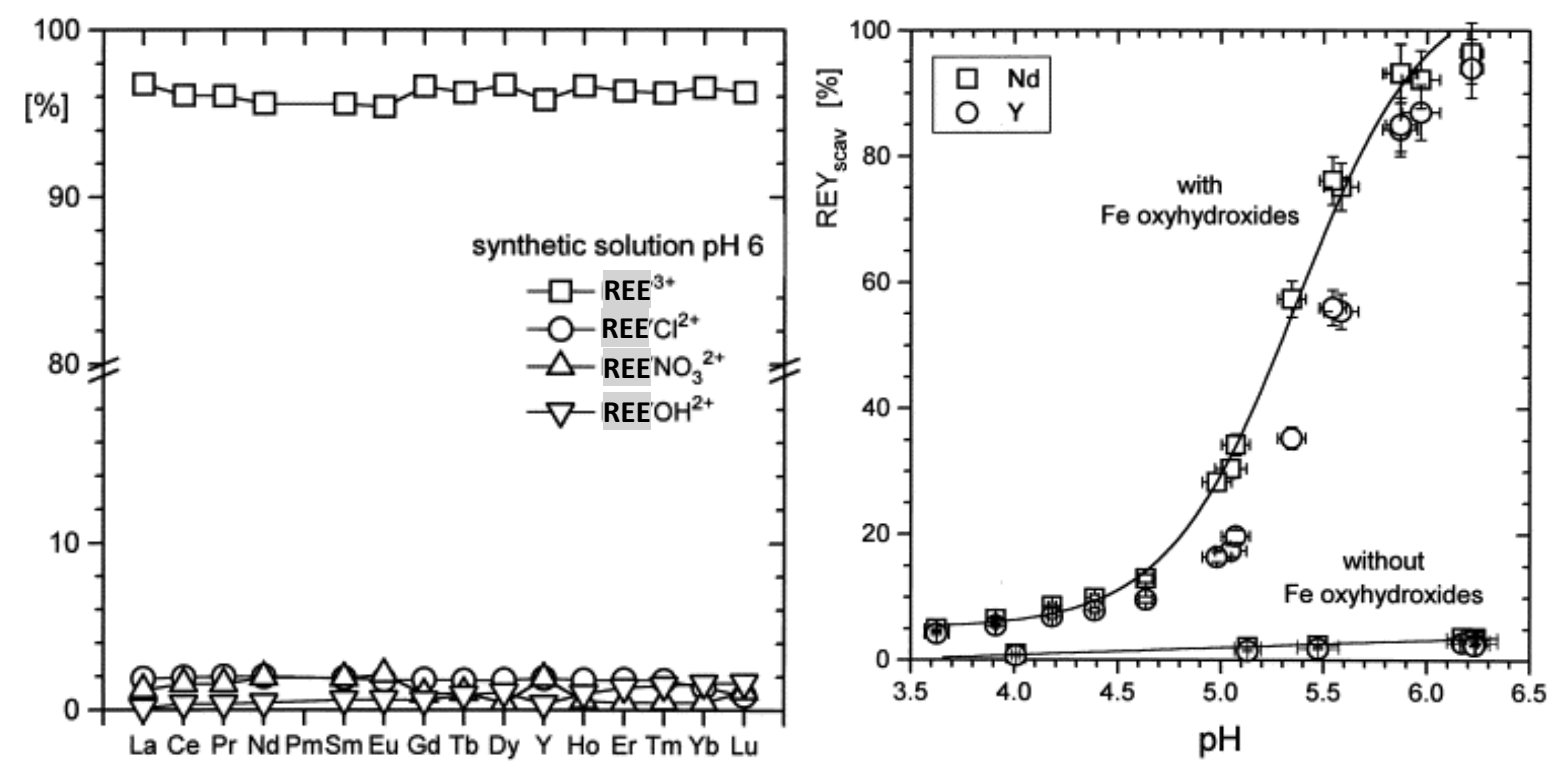

Figure 1.9 Speciation of rare earths (REE) at pH 6 in synthetic solutions used in scavenging experiments (left); Graph of $\mathrm{Nd}_{\text {scav }}$ and $\mathrm{Y}_{\text {scav }} \mathrm{vs.} \mathrm{pH}$, as determined from experiments performed with Fe-bearing and with Fe-free solutions, respectively (right).

\subsubsection{Bacterial extracellular matrix binding REES}

Researchers repurposed a bacterial extracellular matrix (ECM) for selective and differential abstraction of REEs, Figure 1.10. (Tay, Manjula-Basavanna, \& Joshi, 2018) Herein, the curli amyloid fibers in E. coli biofilms are genetically modified to display lanthanide binding tags (LBTs). The curli-LBT filters showed lanthanide specificity in the presence of other metal ions and they can be used to preferably bind several heavy REEs. Bound lanthanides can be recovered using diluted acid stripping, and the filters can be reused for multiple cycles of sorption and desorption almost without loss of efficiency. 


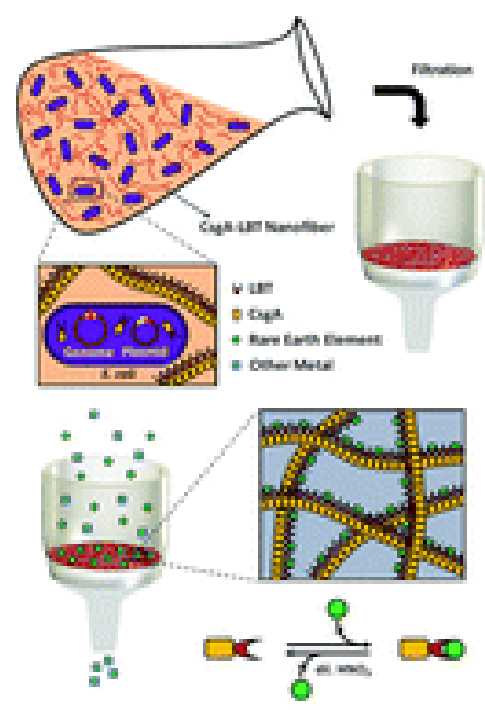

Figure 1.10 A bacterial extracellular matrix (ECM) for selective and differential abstraction of REEs.

\subsubsection{Electrochemical methods}

Electrochemical technologies for wastewater treatment and resource reclamation are reviewed, to achieve research needs and improvements for commercial application of these electrochemical processes.(Feng, Yang, Liu, \& Logan, 2016) Most environmental pollutants can be successfully eliminated or converted to non- hazardous materials by one or more processes, including electrochemical oxidation, electrochemical reduction, electrocoagulation and flotation, electrodialysis, and electrochemical advanced oxidation processes, Figure 1.11.

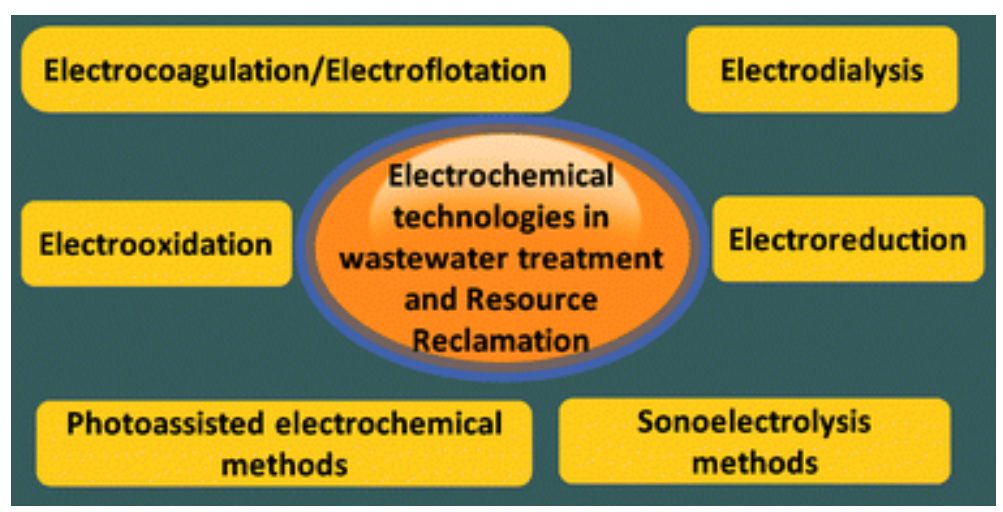

Figure 1.11 Electrochemical technologies for wastewater treatment and resource reclamation.

\section{By electrodeposition}

A theoretical analysis on electrochemical recovery of REEs from magnet scrap was proposed by PRAKASH. (PRAKASH, 2014) They provide theoretical framework for using electrochemistry to selectively extract 
REEs of magnet scraps into aqueous solution. Thermodynamic and electrochemical behavior of different components in the alloy are theoretically predicted and correlated with available data from the literature, Figure 1.12 (Bard, Parsons, \& Jordan, 1985).

\begin{tabular}{|c|c|}
\hline $\left.\mathrm{E}^{0}{ }_{(\mathrm{Cu}}^{2+} / \mathrm{Cu}\right)=0.09$ & $\mathrm{Cu}^{2+}+2 \mathrm{e}^{-} \Leftrightarrow \mathrm{Cu}$ \\
\hline $\mathrm{E}_{\left({ }^{0} \mathrm{Co}^{2+} / \mathrm{Co}\right)}=-0.54$ & $\mathrm{Co}^{2+}+2 \mathrm{e}^{-} \Leftrightarrow \mathrm{Co}$ \\
\hline $\mathrm{E}_{\left(\mathrm{Ni}^{0} / \mathrm{Ni}\right)}^{2+}=-0.5$ & $\mathrm{Ni}^{2+}+2 \mathrm{e}^{-} \Leftrightarrow \mathrm{Ni}$ \\
\hline $\left.\mathrm{E}_{(\mathrm{Fe}}^{0+} / \mathrm{Fe}\right)=-0.65$ & $\mathrm{Fe}^{2+}+2 \mathrm{e}^{-} \Leftrightarrow \mathrm{Fe}$ \\
\hline $\mathrm{E}_{(\mathrm{B}(\mathrm{OH}) 3 / \mathrm{B})}^{0}=-1.14$ & $\mathrm{H}_{3} \mathrm{BO}_{3}+3 \mathrm{H}^{+}+3 \mathrm{e}^{-} \Leftrightarrow \mathrm{B}+3 \mathrm{H}_{2} \mathrm{O}$ \\
\hline$E_{\left(\operatorname{RE}^{3+} / \mathrm{RE}\right)}^{0}=-2.44$ & $\mathrm{RE}^{3+}+3 \mathrm{e}^{-} \Leftrightarrow \mathrm{RE}$ \\
\hline
\end{tabular}

Figure 1.12 The standard electrode potentials $\left(\mathrm{E}_{\mathrm{RE}}{ }^{3+} / \mathrm{RE}=-2.2\right.$ to $-2.4 \mathrm{~V}$ vs SHE$)$ of the rare earth elements are very close owing to their similar chemical nature.

A simple schematic is illustrated in Figure 1.13 (PRAKASH, 2014) for the conceptual framework of the electrochemical cell described in the paper. First, the scrap magnets can be placed as anodes in a simple 2-electrode electrochemical cell. Then an in-progress dissolution is shown in plot b). Although only rare earth ions selectively dissolution is preferred, co-dissolution of non-REEs will occur due to chemical dissolution and the complex microstructure of the alloy. These co-dissolved non-REEs can be further deposited back on the cathode in plot c). Thus, a partially purified solution enriched in REEs is suitable for further elemental recovery. By projecting thermodynamic predictions for different REEs, it can be noted that enhanced selective recovery of REEs is not only possible, it is also a naturally favored process, to an extent. 

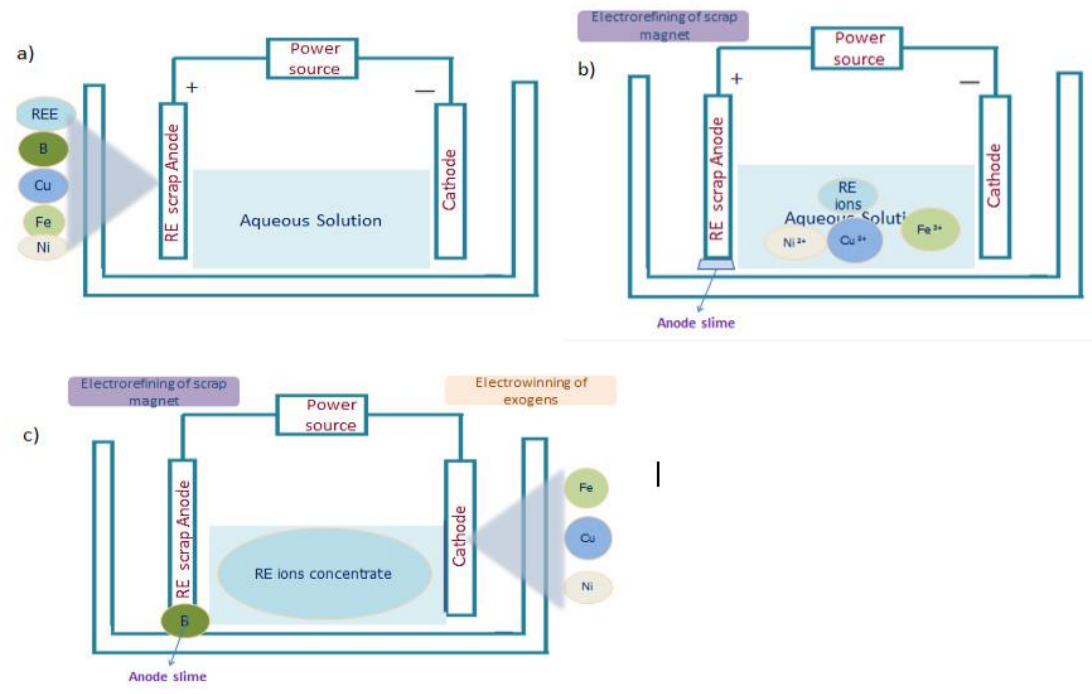

Figure 1.13 Simple schematic of the proposed electrochemical method for REE recovery.

\section{By molten salt electrochemistry}

A new separation and recovery process for REEs from magnet scraps using molten salt electrochemistry utilizing an alloy diaphragm was proposed. (Yasuda, 2016) In the proposed process, two molten salt electrolytes are separated by a RE-iron group (IG) alloy diaphragm. RE magnets scraps are used as an anode to dissolve REEs into the molten salt in the anode chamber, and then, $\mathrm{Pr}, \mathrm{Nd}$, and Dysprosium (Dy) are separated using the differences of both the formation potentials and formation rates of the RE-IG alloys. The RE metals are separately recovered through electrodeposition onto the cathode, Figure 1.14 (Yasuda, 2016). Here, the Pr-Nd alloy and Dy metal are separately recovered at the cathode in the anode chamber and the cathode in the cathode chamber, respectively.

Alloy samples were prepared by potentiostatic electrolysis using Ni plate electrodes at various potentials in molten salt. In this case, high separation factors $[x D y /(x P r+x N d)]_{a l l o y}$ is required. High separation factors of 9.9 and 22.9 for $[x D y /(x P r+x N d)]_{\text {alloy }}$ were obtained at $0.42 \mathrm{~V}$ and $0.45 \mathrm{~V}(\mathrm{vs}$. $\mathrm{Na}+/ \mathrm{Na})$, respectively. This indicated the possibility of effective separation and recovery of REEs from the used magnet scraps. 


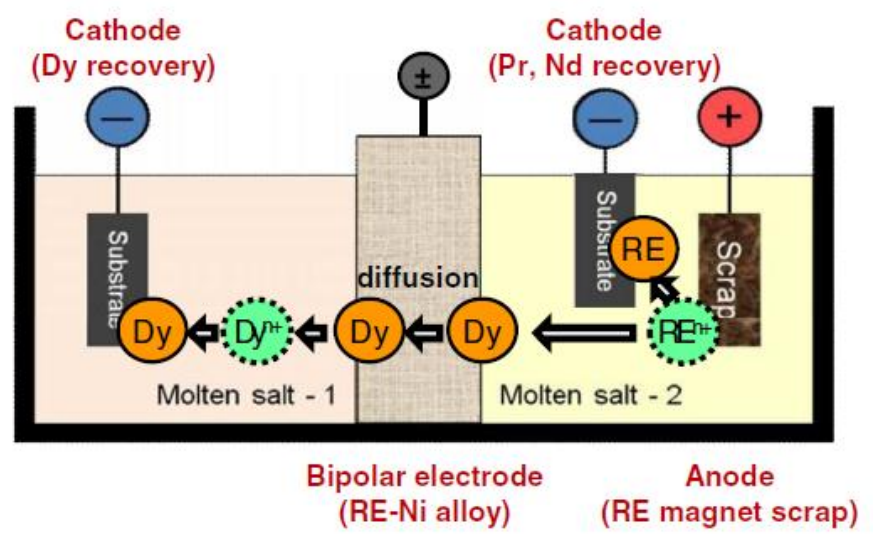

Figure 1.14 Separation and recovery process of RE metals from scraps using molten salt and alloy diaphragm, which maintains a high separation ability of Dy in a continuous operation.

Considering the actual operation of Dy recovery by the proposed alloy diaphragm method, although the enrichment of Dy is with high separation factor in the initial stage of the process, the separation factor decreases in the long-term operation due to the decreased Dy concentration in the anode chamber. Therefore, for continuous recovery of Dy with high separation factor, the molar ratio of $[x D y /(x P r+x N d)]$ in molten salt in the anode chamber should not turn into too low. As illustrated in Figure 1.14, simultaneous or intermittent electrolytic removal of $\mathrm{Pr}$ and $\mathrm{Nd}$ from the anode chamber is a possible way to solve this problem.

\section{By electro-coagulation}

The theory of electro-coagulation (EC) has been discussed in many research papers. (Chen, Ren, Li, Trembly, \& Liu, 2018; Mollah, 2001; Nepo, 2016) It is generally accepted that the EC process involves three continuous stages: (a) formation of coagulants by electrolytic oxidation of the sacrificial electrode; (b) destabilization of the contaminants, particulate suspension, and breaking of emulsions; (c) aggregation of the destabilized phases to form flocs, Figure 1.15. Details of these steps require further study. 


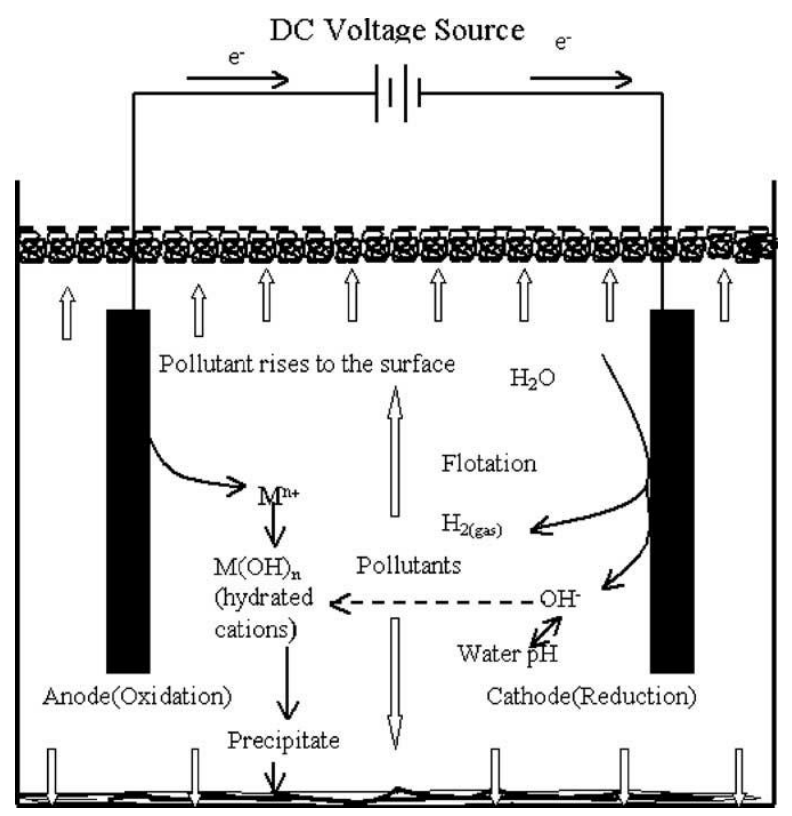

Figure 1.15 Schematic diagram of a lab-scale two-electrode electrocoagulation cell.

There is no literature recovering REEs by EC until now to my best knowledge. If electrochemical stripping effectiveness and selectivity of REEs over major metal ions is observed, EC may be an effective way to separate REEs from major metal ions.

Factors affecting EC process are: Initial $\mathrm{pH}$; Initial conductivity; current density; distance between electrodes; Experiment time; others.

- The initial $\mathrm{pH}$ affects the formation of coagulant.

- The $\mathrm{pH}$ changes with time and it should be suitable for the formation of hydroxides in the whole process. High $\mathrm{K}_{\mathrm{sp}}$ difference of major metal ions and REEs will make the separation feasible, Table $1-2$.

Table 1-2 Ksp of major metal ions and REEs.

\begin{tabular}{ccc}
\hline Metal & Molecular formula & Ksp \\
\hline Sacrificial electrode & $\mathrm{Al}(\mathrm{OH})_{3}$ & $1.9 \times 10^{-33}$ \\
& $\mathrm{Fe}(\mathrm{OH})_{3}$ & $1.1 \times 10^{-36}$ \\
\hline \multirow{3}{*}{ Normal heavy metal } & $\mathrm{Cu}(\mathrm{OH})_{2}$ & $6 \times 10^{-20}$ \\
& $\mathrm{Mn}(\mathrm{OH})_{2}$ & $4 \times 10^{-14}$ \\
& $\mathrm{Zn}(\mathrm{OH})_{2}$ & $1.8 \times 10^{-14}$ \\
\hline
\end{tabular}




\begin{tabular}{ccc}
\hline & $\mathrm{Y}(\mathrm{OH})_{3}$ & $8.0 \times 10^{-23}$ \\
REES & $\mathrm{Yb}(\mathrm{OH})_{3}$ & $3.0 \times 10^{-24}$ \\
& $\mathrm{Er}(\mathrm{OH})_{3}$ & $4.1 \times 10^{-24}$ \\
\hline
\end{tabular}

- Under same condition, increasing the initial conductivity will decrease the applied voltage and IRdrop, thereby minimizing the energy cost.

- The voltage affects the reactions occurring at both anodes and cathodes. Obvious difference of reduction potential of major metal ions and REES will also facilitate the separation process by EC, Figure 1.16.

\begin{tabular}{|c|c|c|c|c|c|}
\hline $\begin{array}{l}\mathrm{O}_{2}(g)+4 \mathrm{H}^{+}(a q)+4 \mathrm{e}^{-} \\
\mathrm{Br}_{2}(l)+2 \mathrm{e}^{-}\end{array}$ & $\begin{array}{l}\longrightarrow 2 \mathrm{H}_{2} \mathrm{O}(l) \\
\longrightarrow 2 \mathrm{Br}^{-}(a q)\end{array}$ & $\begin{array}{l}1.23 \\
1.09\end{array}$ & \multirow[t]{5}{*}{$\left.\mathrm{E}_{(\mathrm{Cu}}^{0} / \mathrm{Cu}\right)=0.09$} & \multicolumn{2}{|l|}{$\mathrm{Cu}^{2+}+2 \mathrm{e}^{-} \Leftrightarrow \mathrm{Cu}$} \\
\hline $\operatorname{Ag}^{+}(a q)+\mathrm{e}^{-}$ & $\longrightarrow \mathrm{Ag}(\mathrm{s})$ & 0.80 & & & \\
\hline $\mathrm{Fe}^{3+}(a q)+\mathrm{e}^{-}$ & $\longrightarrow \mathrm{Fe}^{2+}(a q)$ & 0.77 & & & \\
\hline $\mathrm{O}_{2}(g)+2 \mathrm{H}^{+}(a q)+2 \mathrm{e}^{-}$ & $\longrightarrow \mathrm{H}_{2} \mathrm{O}_{2}(a q)$ & 0.70 & & & Standard \\
\hline $\mathrm{I}_{2}(s)+2 \mathrm{e}^{-}$ & $\longrightarrow 2 \mathrm{I}^{-}(a q)$ & 0.54 & & & reduction \\
\hline $\begin{array}{l}\mathrm{O}_{2}(g)+2 \mathrm{H}_{2} \mathrm{O}(l)+4 \mathrm{e}^{-} \\
\mathrm{Cu}^{2+}(a q)+2 \mathrm{e}^{-}\end{array}$ & $\begin{array}{l}\longrightarrow 4 \mathrm{OH}^{-}(a q) \\
\longrightarrow \mathrm{Cu}(\mathrm{s})\end{array}$ & $\begin{array}{l}0.40 \\
0.34\end{array}$ & $\mathrm{E}^{0}\left(\mathrm{CO}^{2+} / \mathrm{CO}^{\circ}\right)=-0.54$ & $\mathrm{Co}^{2+}+2 \mathrm{e}^{-} \Leftrightarrow \mathrm{Co}$ & \multirow{4}{*}{$\begin{array}{l}\text { (V } \mathrm{Ag} / \mathrm{AgCl}) \text { of } \\
\text { different } \\
\text { elements }\end{array}$} \\
\hline $\mathrm{Sn}^{4+}(a q)+2 \mathrm{e}^{-}$ & $\longrightarrow \mathrm{Sn}^{2+}(a q)$ & 0.15 & \multirow{3}{*}{$\begin{array}{l}\mathrm{E}_{\left(\mathrm{Ni}^{0} / \mathrm{Ni}\right)}^{2+}=-0.5 \\
\left.\mathrm{E}_{(\mathrm{Fe}}^{0}{ }^{2+} / \mathrm{Fe}\right)=-0.65\end{array}$} & $\mathrm{Ni}^{2+}+2 \mathrm{e}^{-} \Leftrightarrow \mathrm{Ni}$ & \\
\hline $2 \mathrm{H}^{+}(a q)+2 \mathrm{e}^{-}$ & $\longrightarrow \mathrm{H}_{2}(\mathrm{~g})$ & 0 & & & \\
\hline $\mathrm{Pb}^{2+}(a q)+2 \mathrm{e}^{-}$ & $\longrightarrow \mathrm{Pb}(\mathrm{s})$ & -0.13 & & $\mathrm{Fe}^{2+}+2 \mathrm{e}^{-} \Leftrightarrow \mathrm{Fe}$ & \\
\hline $\mathrm{Ni}^{2+}(a q)+2 \mathrm{e}^{-}$ & $\longrightarrow \mathrm{Ni}(s)$ & -0.26 & & & \\
\hline $\mathrm{Cd}^{2+}(a q)+2 \mathrm{e}^{-}$ & $\longrightarrow \mathrm{Cd}(\mathrm{s})$ & -0.40 & \multirow{3}{*}{$E_{(\mathrm{B}(\mathrm{OH}) 3 / \mathrm{B})}^{0}=-1.14$} & & \\
\hline $\mathrm{Fe}^{2+}(a q)+2 \mathrm{e}^{-}$ & $\longrightarrow \mathrm{Fe}(s)$ & -0.45 & & \multicolumn{2}{|c|}{$\mathrm{H}_{3} \mathrm{BO}_{3}+3 \mathrm{H}^{+}+3 \mathrm{e}^{-} \Leftrightarrow \mathrm{B}+3 \mathrm{H}_{2} \mathrm{O}$} \\
\hline $\mathrm{Zn}^{2+}(a q)+2 \mathrm{e}^{-}$ & $\longrightarrow \mathrm{Zn}(s)$ & -0.76 & & \multirow{4}{*}{\multicolumn{2}{|c|}{$\mathrm{RE}^{3+}+3 \mathrm{e}^{-} \Leftrightarrow \mathrm{RE}$}} \\
\hline $2 \mathrm{H}_{2} \mathrm{O}(l)+2 \mathrm{e}^{-}$ & $\longrightarrow \mathrm{H}_{2}(g)+2 \mathrm{OH}^{-}(a q)$ & -0.83 & \multirow{3}{*}{$\left.\mathrm{E}^{0}{ }_{(\mathrm{RE}}^{3+} / \mathrm{RE}\right)=-2.44$} & & \\
\hline $\mathrm{Al}^{3+}(a q)+3 \mathrm{e}^{-}$ & $\longrightarrow \mathrm{Al}(\mathrm{s})$ & -1.66 & & & \\
\hline $\mathrm{Mg}^{2+}(a q)+2 \mathrm{e}^{-}$ & $\longrightarrow \mathrm{Mg}(\mathrm{s})$ & -2.37 & & & \\
\hline
\end{tabular}

Figure 1.16 Standard Potentials in Aqueous Solution.

- The current density affects the removal effectiveness and current efficiency directly.

- The distance between the two electrodes affects the IR-drop. Decreasing the distance between the electrodes will decrease the IR-drop, thereby increasing the current efficiency. The distance between the two electrodes also affects the electric field which influences mass transfer between electrodes and the formation of precipitation and floc.

- The removal effectiveness is also affected by treatment time.

If difference of removal efficiency of REEs and major metal ions can reach high enough, EC may be a feasible method to separate REEs from major metal ions. 


\subsection{Background}

\subsubsection{Research background}

Rare earth elements are very useful and only rare earth mineral supply is not enough. Recovery of REEs from waste materials effectively is not only a significant good way for valuable REEs production but also a pollutant treatment method.

AMD is the largest, by volume, industrial pollutant in the Northern Appalachian Basin. Coal companies and state agencies routinely treat vast volumes of this waste stream as an environmental liability for decades after coal mine closure. (Skousen et al., 2017) During the generation and migration of AMD, liberated sulfuric acid mobilizes several metal ions, mainly $\mathrm{Ca}, \mathrm{Al}, \mathrm{Fe}, \mathrm{Mg}, \mathrm{Mn}, \mathrm{Si}$, including REEs. Treatment of AMD usually consists of neutralization, oxidation, and metal hydroxide precipitation using either hydrated lime or caustic soda as the treatment agent. Multiple precipitate (AMD sludge) samples were taken at several sites. The sampling sites represented a range of AMD treatment systems. In the sampled sites evaluated by the cooperators of this project, the REE concentrations of the generated precipitates varied from 29 to 1286 ppm. (Vass, Noble, \& Ziemkiewicz, 2019a, 2019b) These precipitates are used as feedstock for this project. REE recovery is a new concept and until now, AMD treatment has not been optimized toward mineral recovery. Research are conducted on how to recover REE economically.

At first, AMD sludges are dissolved to leachate, then extraction technology is applied to further concentrate REEs. Our objective is to develop an optimized/combined process to recovery valuable metal elements and separate REEs form major metal elements. After optimized process flowsheet is obtained, scale-up research will be conducted to recover REEs economically.

\subsubsection{Extraction technologies}

Herein, different extraction technologies were compared. A wide range of wastewater treatment techniques are known which includes electrochemical processes, biological processes, as well as a range of physico-chemical processes that require chemical additions, Table 1-3. (Mollah, 2001) During wastewater treatment, one or more of these processes can occur. Biological processes are usually time consuming and low efficient. Chemical precipitation is one method people usually use, but it's costly and there is secondary pollution due to the adding of precipitating agent. It takes large energy input for electrochemical process. In order to increase the efficiency and decrease the cost, there is an urgent need to develop innovative, more effective and inexpensive techniques for treatment of wastewater. 
Table 1-3 Methods of wastewater treatment.

\begin{tabular}{|c|c|c|}
\hline Biological processes & Physico-chemical processes & Electrochemical processes \\
\hline Nitrification & Filtration & Electrocoagulation (EC) \\
\hline Denitrification & Carbon adsorption & Electroflotation \\
\hline Phosphorous removal, and & Chemical precipitation, and & Electrodecantation, and \\
\hline others & others & others \\
\hline
\end{tabular}

Even though commercial REE recycling is presently very limited, the REEs from wastewater can be recovered through several processing technologies such as solvent extraction, precipitation and electrochemical process, Table 1-4. Solvent extraction is a traditional method for REE separation from REE minerals in industry and is effective. Precipitation is a simple way to recover rare earth elements from aqueous solution. Electrochemical process is environment friendly. However, there are many problems in these processes. Precipitation requires high chemical usage and suffers from generation of large amounts of chemical waste and low selectivity due to co-precipitation of non-REEs. Solvent extraction requires a large number of stages to produce highly pure REEs suitable for reuse. The significant possibility for solvent and extractant losses due to their solubility in highly acidic solutions may also hinder its application for REE recycling and reuse. Electrochemical process requires large energy input and it's difficult to be used for industry scale system.

It is very important to develop a method combining different kinds of technology to achieve both high selectivity and efficiency for REE recovery. Based on literature review, promising techniques for REES recovery for AMD leachate include electro-coagulation and solvent extraction. Solvent extraction method is mainly researched in this project due to its potential for commercial use.

Table 1-4 Methods of REEs recovery.

\begin{tabular}{cccc}
\hline Methods & Solvent extraction & Precipitation & Electrochemical process \\
\hline Disadvantages & many stages & high chemical usage & large energy input \\
& &
\end{tabular}




\begin{tabular}{cccc} 
& $\begin{array}{c}\text { solvent and extractant } \\
\text { losses } \\
\text { solvent pollution }\end{array}$ & $\begin{array}{c}\text { large amounts of chemical } \\
\text { waste } \\
\text { low selectivity }\end{array}$ & \\
\hline Advantages & effective & simple & environment-friendly \\
\hline
\end{tabular}

\subsection{Summary}

Based on previous literature review, most REE recovery work were conducted on REE concentrated minerals and REE based waste materials. Few work was researched on waste water with extremely low rare earth elements composition, for example AMD. In this project, AMD sludge is used as feedstock for REE recovery. Economic methods with potential commercial use in industry need to be proposed for REE recovery with high yield and purity.

Research objectives: to develop a cost-effective and environmentally benign process to treat and recover REEs from sludges generated during treatment of acidic coal mine drainage (AMD).

1. Process development:

a. Conducting a study on synthetic solution developing effective REE extraction technology (Chapter 2); Extraction efficiency of $Y$ element should be more than $90 \%$ for successful process.

b. Conducting a study on real sludge leachates to demonstrate the feasibility of REE recovery from AMD sludge (Chapter 3); Except for high extraction efficiency of REEs, the enrichment factor for TREE from initial leachates to final product should be at least 10 to be considered as successful process.

2. Process troubleshooting/continuous improvement:

a. Integration and optimization of REE recovery and extraction processes from AMD sludge leachates (Chapter 3); To find more appropriate parameters and treatment flowsheet to increase the enrichment factor.

b. Conducting exploratory tests to determine appropriate parameters and how many steps required for sufficient recovery of REEs and high selectivity of REEs over major metal ions to support scale up system (Chapter 4).

In preliminary work, electro-coagulation and solvent extraction are performed to recover REEs and compared. Solvent extraction on synthetic solution with similar REEs over major metal ions concentration ratio of AMD leachate are conducted systematically. Finally, solvent extraction is chosen as main REEs 
recovery method. REEs recovery from coal mine drainage and separation from major metal ions are achieved by using solvent extraction and operational flowsheets with detailed parameters are developed to concentrate REEs from AMD sludges with different compositions. 


\section{Solvent extraction of metal elements in acidic nitrate solution by Di-(2- ethylhexyl) phosphoric acid}

\subsection{Experimental}

\subsubsection{Preparation of feed solution}

In one of the researched AMD sludge leachates, $Y$ takes about $40 \%$ of REEs and it is representative of the heavy REE group, which is more valuable than light REE group. Thus, in the synthetic solution, $\mathrm{Y}$ was chosen as indicator of REEs and Ca, Mg and Al were selected as major metal ions. Stock solutions of Y(III), $\mathrm{Ca}(\mathrm{II}), \mathrm{Mg}(\mathrm{II})$ and $\mathrm{Al}(\mathrm{III})$ were prepared by dissolving the respective metal nitrate: $\mathrm{Y}_{(}\left(\mathrm{NO}_{3}\right)_{3} \cdot 6 \mathrm{H}_{2} \mathrm{O}$, $\mathrm{Ca}\left(\mathrm{NO}_{3}\right)_{2} \cdot 4 \mathrm{H}_{2} \mathrm{O}, \mathrm{Mg}\left(\mathrm{NO}_{3}\right)_{2} \cdot 6 \mathrm{H}_{2} \mathrm{O}, \mathrm{Al}\left(\mathrm{NO}_{3}\right)_{3} \cdot 9 \mathrm{H}_{2} \mathrm{O},(>98 \%)$ provided by Sigma-Aldrich, in deionized water. The $\mathrm{pH}$ of the aqueous solution was adjusted to several values by adding dilute nitric acid solution.

The extractants di-(2-ethylhexyl) phosphoric acid (D2EHPA, CAS No. 298-07-7, 97 wt.\%) were supplied by Sigma-Aldrich. Extractants were used as received without further purification. The extractants was dissolved in $\mathrm{n}$-heptane $(95 \%$, by Alfa Aesar) to the desired concentration.

All experiments were repeated three times to ensure valuable results for future REE recovery research. All data in figures included standard error bar.

\subsubsection{Equilibration of aqueous and organic phases}

Feed solution ( $\mathrm{Y}, \mathrm{Ca}, \mathrm{Mg}, \mathrm{Al}, \mathrm{NO}_{3}$ ) were synthesized for $\mathrm{SX}$ experiments. The $\mathrm{pH}$ of the aqueous solution was adjusted to the several value by adding dilute nitric acid solution. Solvent extraction experiments were carried out in a separation funnel. For each experiment, $10 \mathrm{~mL}$ of aqueous phase with known $\mathrm{pH}$ value was mixed with various volumes of the extractant mixture at room temperature and mixed for 2 min. After standing still for $\mathbf{2 0} \mathrm{min}$ for equilibration, the phases could separate. After complete phase separation, the concentrations of major metal ions and rare earth ions in the aqueous solutions were determined by ICP-OES and ICP-MS analysis and the concentrations of metal ions in the organic phase were calculated by a mass balance. The final volumes of aqueous and organic solutions after the complete separation of phases were measured and no obvious changes in volumes were detected during the extraction. All the experiments were performed at room temperature.

The extraction reaction can be expressed as Equation 2.1: 


$$
M_{(a)}^{n+}+n H L_{(o)}=M L_{n(o)}+n H_{(a)}^{+}
$$

Equation 2.1

In the reaction, $M_{(a)}^{n+}$ indicates the metal ions with valence of $\mathrm{n}+$ in aqueous solution and $H L_{(o)}$ indicates extractant in organic solvent. $M L_{n(o)}$ indicated the metal-extractant complex in organic phase after extraction and hydrogen ions are released in aqueous solution.

If a system contains various solute species, the distribution ratio is defined as Equation 2.2:

$$
\boldsymbol{D}=\frac{\sum\left[\boldsymbol{M}_{(\boldsymbol{o})}\right]}{\sum\left[\boldsymbol{M}_{(\boldsymbol{a})}\right]}
$$

Equation 2.2

$$
\boldsymbol{\beta}_{M_{1} / M_{2}}=\frac{D_{M_{1}}}{D_{M_{2}}}
$$

Equation 2.3

Under the same solvent extraction conditions, $\beta_{M_{1} / M_{2}}$ is the separation factor of solute $M_{1}$ and $M_{2}, D_{M_{1}}$ and $D_{M_{2}}$ are the distribution ratios of solute $\mathrm{M}_{1}$ and $\mathrm{M}_{2}$, Equation 2.3. The higher the separation factor is, the easier the separation of $M_{1}$ from $M_{2}$.

$$
E \%=\frac{\text { Solute } M 1 \text { in organic phase }}{\text { Total solute M1 in organic and aqueous phases }}=\frac{D}{1+D} \times 100
$$

Equation 2.4

In practice, extraction percentage is often used for designing separation schemes. It is the percentage of the valuable solute extracted into the organic phase out of the total valuable solute in the system. Its relationship with distribution ratio is shown in Equation 2.4. The extraction percentage curve as a function of a system variable can be constructed by experiment measurements.

\subsubsection{Analysis of two phases}

After complete phase separation, the concentrations of major metal ions and rare earth ions in the aqueous solutions were determined by ICP-AES and ICP-MS analysis. Inductively coupled plasma atomic emission spectroscopy (ICP-AES), also referred to as inductively coupled plasma optical emission 
spectrometry (ICP-OES), is an analytical technique used for the detection of chemical elements. It is a type of emission spectroscopy that uses the inductively coupled plasma to produce excited atoms and ions that emit electromagnetic radiation at wavelengths characteristic of a particular element. (Wikipedia, 2018a) The intensity of this emission is indicative of the concentration of the element within the sample. Inductively coupled plasma mass spectrometry (ICP-MS) is a type of mass spectrometry which is capable of detecting metals and several non-metals at concentrations as low as one part in $10^{15}$ on non-interfered low-background isotopes. (Wikipedia, 2018b) This is achieved by ionizing the sample with inductively coupled plasma and then using a mass spectrometer to separate and quantify those ions. Compared to atomic absorption spectroscopy, ICP-MS has greater speed, precision, and sensitivity.

For ICP methods, the analytical lab runs EPA Method 200.7. Method 200.7 requires what are called Instrument Performance Checks. They are known concentrations of standards compared back to the 5point calibration. They are required to be within $10 \%$ of true value. That means the percent recovery of the standard must be within $90-110 \%$ of true value. Laboratory Control Spike (LCS), also known as a Laboratory Fortified Blank, refers to a separate preparation of a known concentration standard that goes through the same treatment as the samples. The recovery for an LCS must be between $85-115 \%$ of true value. Two LCSs with my samples were run because there is not enough sample volume to run Matrix Spikes or Duplicates, which is a requirement of method 200.7.

Methods with lower measurement uncertainty were not found. Typical measurement uncertainties for these schemes will approach 5-15\% relative as the sample concentration range approaches the method upper limit. As results approach the detection limit in concentration, the associated measurement uncertainty will increase exponentially. Some of the extraction efficiency results are less than $0 \%$ due to the analysis error.

There are no obvious changes in volumes of aqueous and organic solutions before and after the complete separation of phases. The concentrations of metal ions in the organic phase were calculated by a mass balance.

\subsubsection{Extraction Percentages and Separation factor studies}

Solvent extraction (SX) is one effective way to recover REEs from aqueous samples. After pretreatment of waste materials, SX can be used to separate REEs from other metal ions in aqueous solution. Since ratio of REEs to other metal ions in pretreatment solution from waste materials is very low, a library of SX parameters on separation effectiveness of REEs from major metal ions is necessary. 
Here, solvent extraction experiments were conducted on Y-Ca-Mg-Al-HDEHP-n-heptane- $\mathrm{HNO}_{3}-\mathrm{H}_{2} \mathrm{O}$ system by changing $\mathrm{pH}, \mathrm{HDEHP}$ concentration in organic phase, volume ratio of organic phase to aqueous phase (Table 2-1). Since pH > 3.0 will cause precipitation of synthesized feed solution, pH values of 1.0, 1.6, 2.4, and 3.0 were chosen. Distribution ratios, separation factors and extraction percentages were obtained to study SX parameters effect on recovery of REEs from wastewater. 
Table 2-1 Solvent extraction parameters on synthetic solution.
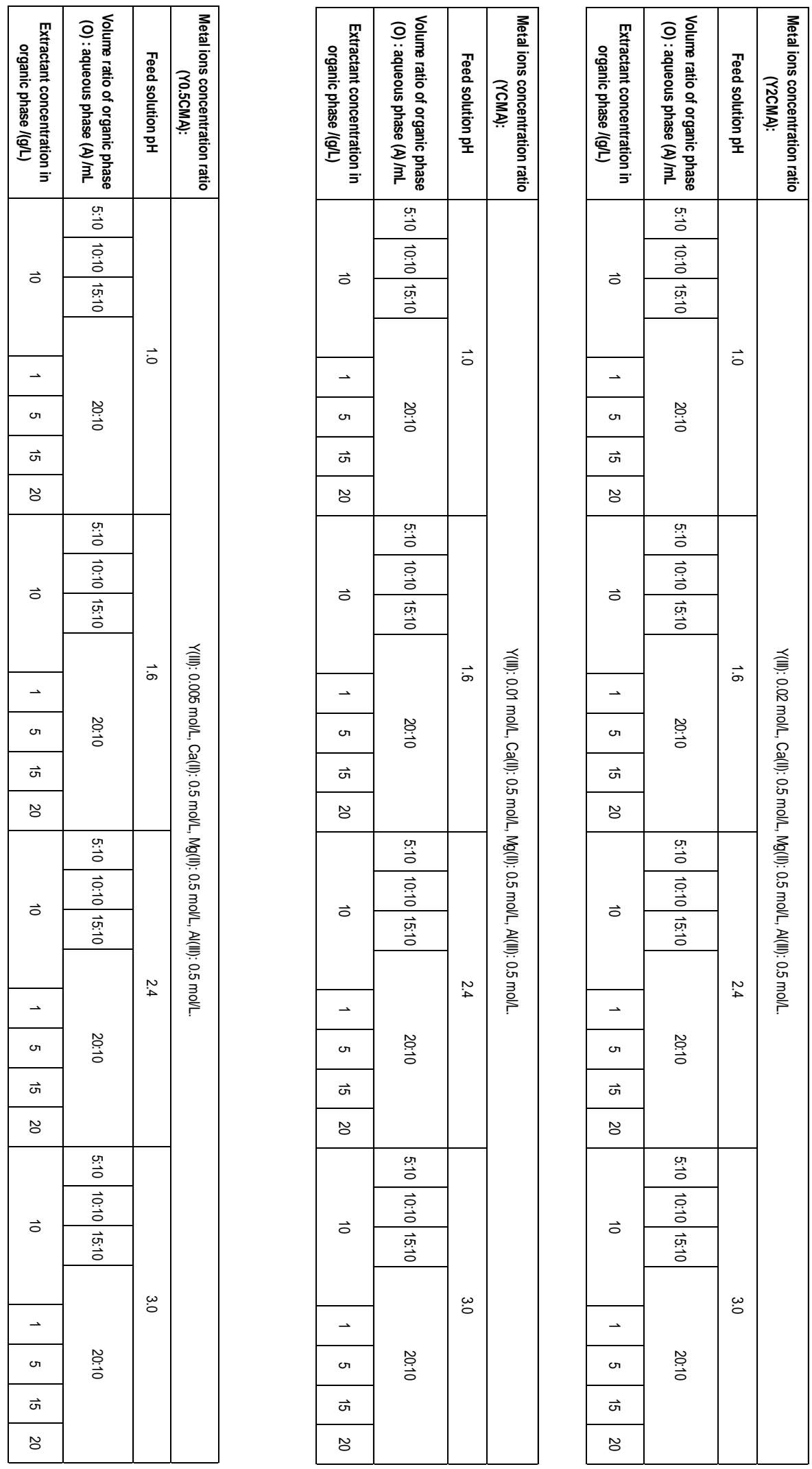


\subsection{Results and Discussion}

\subsubsection{Extraction efficiencies of major metal ions and REEs}

\subsubsection{Phase volume ratio effect}

Extraction efficiencies of major metal ions and rare earth ions from Y0.5CMA solution were plotted vs. $\mathrm{O}: \mathrm{A}$ ratio in Figure 2.1. The extractant concentration was $10 \mathrm{~g} / \mathrm{L}$. Extraction efficiencies of major metal ions were very low under low $\mathrm{pH}$ values. Extraction efficiencies of $\mathrm{Y}$ were all high and they decreased at $\mathrm{pH} 3$ due to competitive extraction of major metal ions. This was because that rare earth ion $\mathrm{Y}$ was easier to react with extractant HDEHP in this system. Less hydrogen ions (high $\mathrm{pH}$ ) in aqueous phase facilitated reaction of metal ions and extractant, Equation 2.1. Some extraction efficiencies were calculated as negative due to measurement error by ICP methods.

The extraction efficiencies of $Y$ under different conditions were also compared. Increasing O:A ratio increased extraction efficiency of $\mathrm{Y}$ at all $\mathrm{pH}$ values. This was caused by more metal-extractant complex (Y(DEHP)3) dissolved in the organic phase when increasing organic phase volume. Extraction efficiency of $\mathrm{Y}$ was highest at highest O:A ratio. At high O:A ratio ( $>1.5)$ and low pH $(<2.4), 10 \mathrm{~g} / \mathrm{L}$ extractant was enough for $\mathrm{Y}$ extraction (>95\%). At same O:A ratio for solution with different $\mathrm{pH}$, extraction efficiencies of $\mathrm{Y}$ were highest at $\mathrm{pH}$ of 2.4 . 
Y0.5CMA; pH 1.0; C(HDEHP) $10 \mathrm{~g} / \mathrm{L}$.

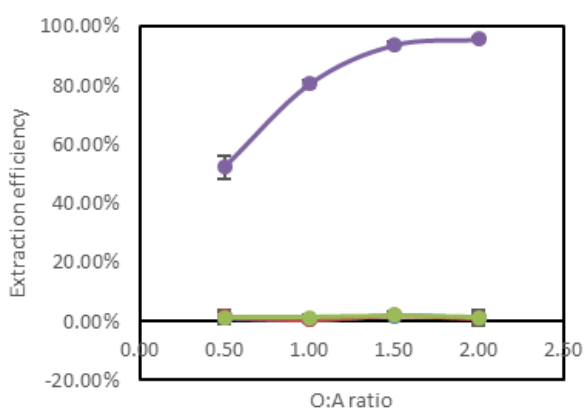

Y0.5CMA; pH 2.4; C(HDEHP) $10 \mathrm{~g} / \mathrm{L}$.

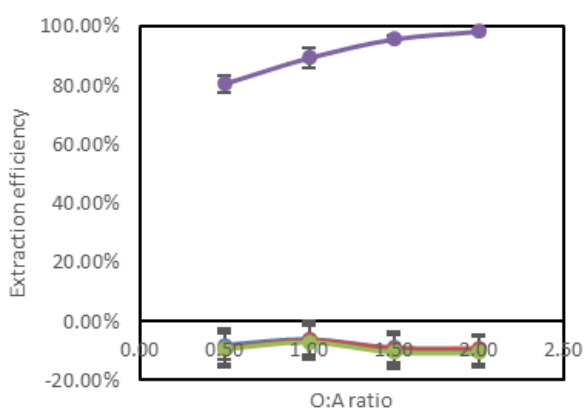

Y0.5CMA; pH 1.6; C(HDEHP) $10 \mathrm{~g} / \mathrm{L}$.

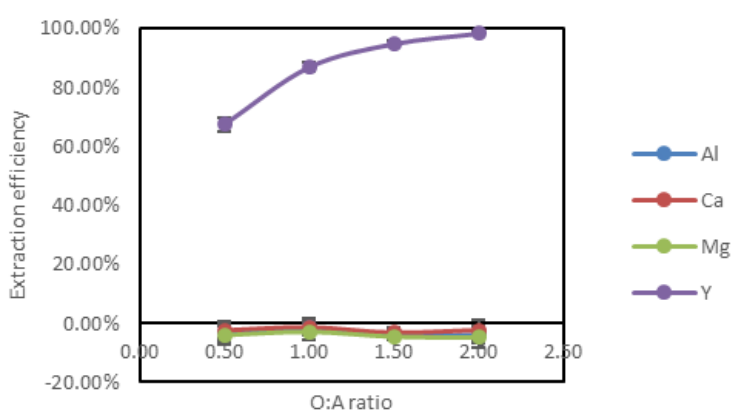

Y0.5CMA; pH 3.0; C(HDEHP) $10 \mathrm{~g} / \mathrm{L}$.

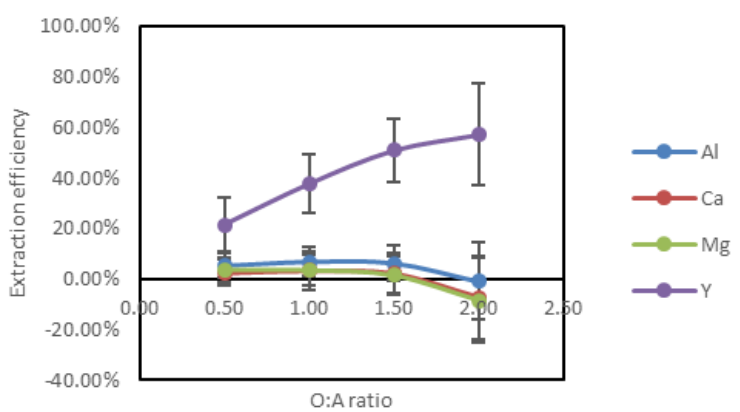

Figure 2.1 O:A ratio effect on extraction efficiencies of major metal ions and rare earth ions from Y0.5CMA solution.

Extraction efficiencies of major metal ions and rare earth ions from YCMA solution are shown in Figure 2.2. The extractant concentration remained as $10 \mathrm{~g} / \mathrm{L}$. Extraction efficiencies of major metal ions were still very low under low $\mathrm{pH}$ values. Extraction efficiencies of $\mathrm{Y}$ were lower than results of Y0.5CMA solution. At $\mathrm{pH}$ 3, competitive extraction occurred, and extraction efficiencies of $\mathrm{Y}$ were much lower. But due to higher concentration ratio of $\mathrm{Y}, 10 \mathrm{~g} / \mathrm{LX}$ was not enough for $\mathrm{Y}$ extraction and less than $90 \%$ of $\mathrm{Y}$ were extracted at high O:A ratios and low $\mathrm{pH}$ values. At same O:A ratio, extraction efficiencies of $\mathrm{Y}$ were high at $\mathrm{pH} 1.6$ and 2.4. Effect of O:A ratio on extraction efficiency of $\mathrm{Y}$ was same for different solution. 
YCMA; pH 1.0; C(HDEHP) $10 \mathrm{~g} / \mathrm{L}$.

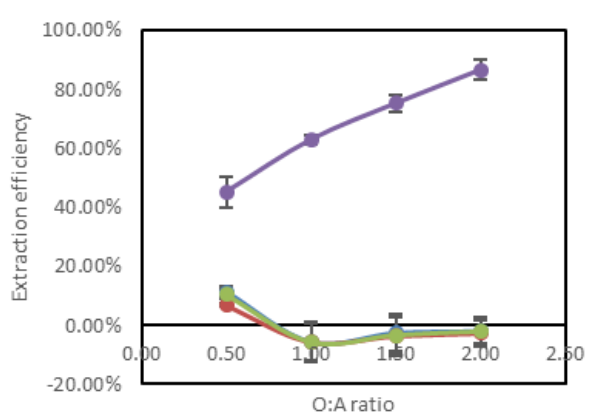

YCMA; $\mathrm{pH} 2.4 ; \mathrm{C}(\mathrm{HDEHP}) 10 \mathrm{~g} / \mathrm{L}$.

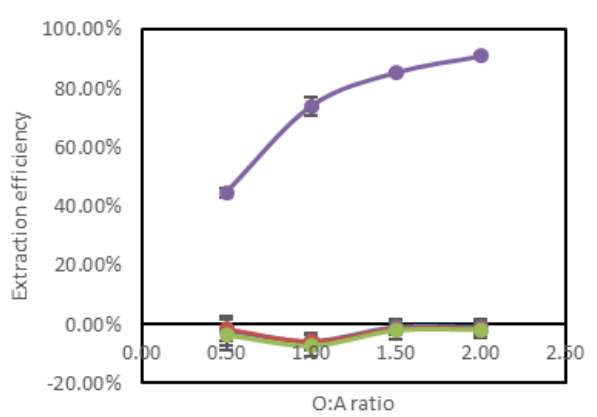

YCMA; $\mathrm{pH} 1.6 ; \mathrm{C}(\mathrm{HDEHP}) 10 \mathrm{~g} / \mathrm{L}$.
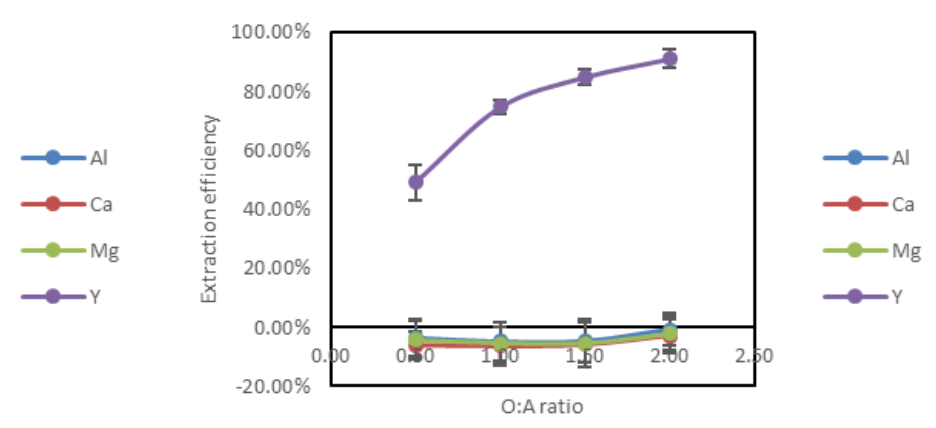

YCMA; pH 3.0; C(HDEHP) $10 \mathrm{~g} / \mathrm{L}$.

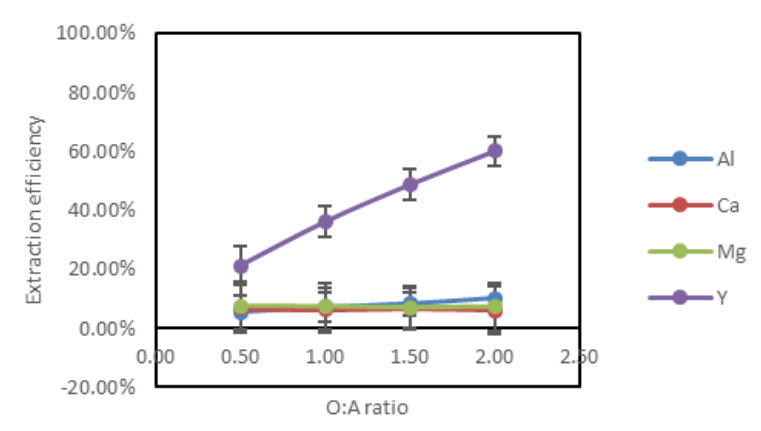

Figure 2.2 O:A ratio effect on extraction efficiencies of major metal ions and rare earth ions from YCMA solution.

Extraction efficiencies of major metal ions and rare earth ions from Y2CMA solution are shown in Figure 2.3. The extractant concentration was still $10 \mathrm{~g} / \mathrm{L}$. Extraction efficiencies of major metal ions were higher than those of the other two solutions. Competitive extraction was obvious at all $\mathrm{pH}$ values and extraction efficiencies of $Y$ were all lower than those two series. $10 \mathrm{~g} / \mathrm{L}$ extractant was not enough for $\mathrm{Y}$ extraction and only less than $70 \%$ of $Y$ was extracted. Effect of O:A ratio on extraction efficiency of $Y$ remained same for different solution. Raising O:A ratio increased extraction efficiency of $\mathrm{Y}$. 
Y2CMA; pH 1.0; C(HDEHP) $10 \mathrm{~g} / \mathrm{L}$.

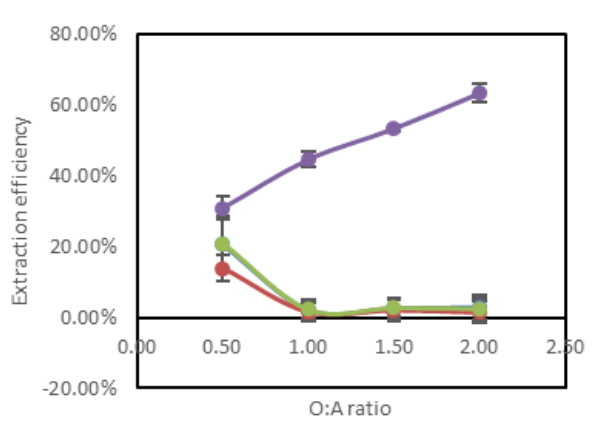

Y2CMA; pH 2.4; C(HDEHP) $10 \mathrm{~g} / \mathrm{L}$.

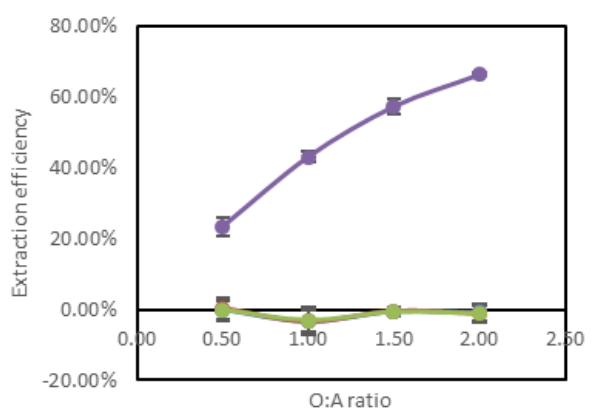

Y2CMA; pH 1.6; C(HDEHP) $10 \mathrm{~g} / \mathrm{L}$.

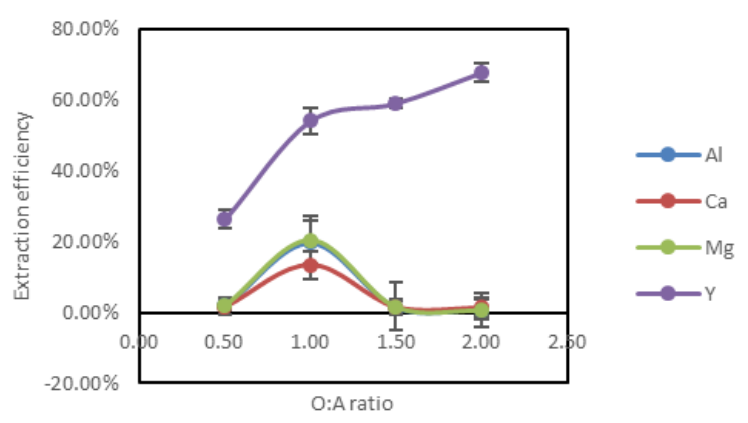

Y2CMA; pH 3.0; C(HDEHP) $10 \mathrm{~g} / \mathrm{L}$.

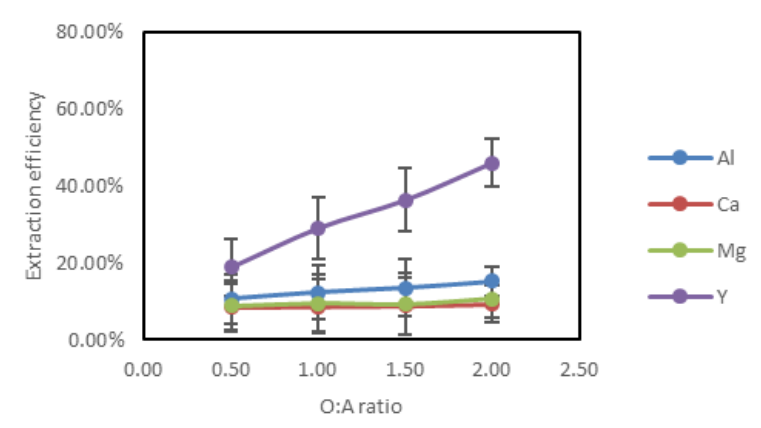

Figure 2.3 O:A ratio effect on extraction efficiencies of major metal ions and rare earth ions from Y2CMA solution.

\subsubsection{Extractant concentration effect}

Extraction efficiencies of major metal ions and rare earth ions from Y0.5CMA solution were plotted in Figure 2.4 at different extractant concentration. The volume ratio of O:A was 2 and the extractant concentration changed from $1 \mathrm{~g} / \mathrm{L}$ to $20 \mathrm{~g} / \mathrm{L}$. Extraction efficiencies of major metal ions were very low under low $\mathrm{pH}$ values. Some extraction efficiencies were calculated as negative due to measurement error by ICP methods.

The extraction efficiencies of Yttrium (Y) under different conditions were also compared. Increasing extractant concentration increased extraction efficiency of $\mathrm{Y}$ at all $\mathrm{pH}$ values. As Equation 2.1 shows, more extractant in organic phase will facilitate reaction of metal ions and extractant. At $\mathrm{pH} \mathrm{3}$, extraction efficiencies of $Y$ decreased due to competitive extraction of major metal ions. There was no obvious difference between extractant concentration of 15 and $20 \mathrm{~g} / \mathrm{L}$. At high O:A ratio of 2 and low pH values $(<2.4), 15 \mathrm{~g} / \mathrm{L}$ extractant was enough for $Y$ extraction ( 100\%). 
Y0.5CMA; $\mathrm{pH} 1.0 ; \mathrm{O}: \mathrm{A}=2$.

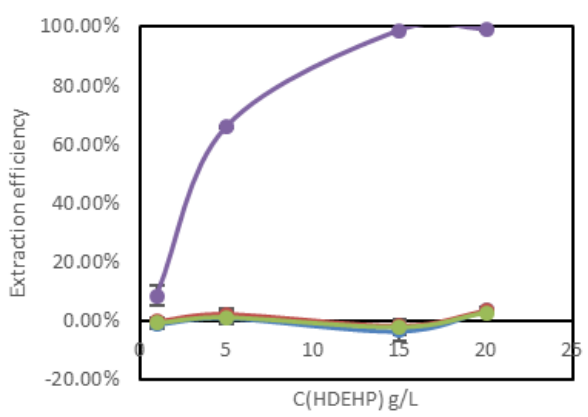

Y0.5CMA; $\mathrm{pH} 2.4 ; \mathrm{O}: \mathrm{A}=2$.

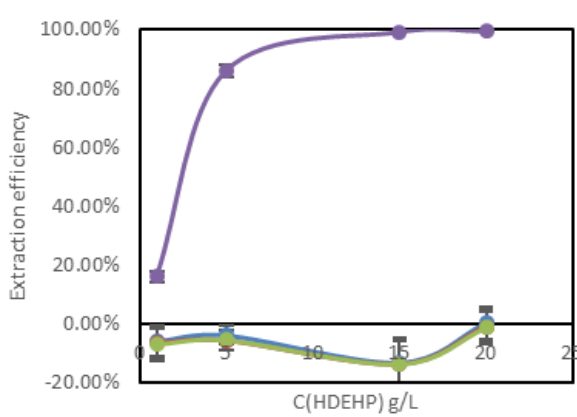

$\longrightarrow$ A

$\longrightarrow \mathrm{Ca}$

$\longrightarrow \mathrm{Mg}$

$\longrightarrow Y$

$\longrightarrow$ Al

$\longrightarrow \mathrm{Ca}$

$\longrightarrow \mathrm{Mg}$

$\longrightarrow Y$
Y0.5CMA; $\mathrm{pH} 1.6 ; \mathrm{O}: \mathrm{A}=2$

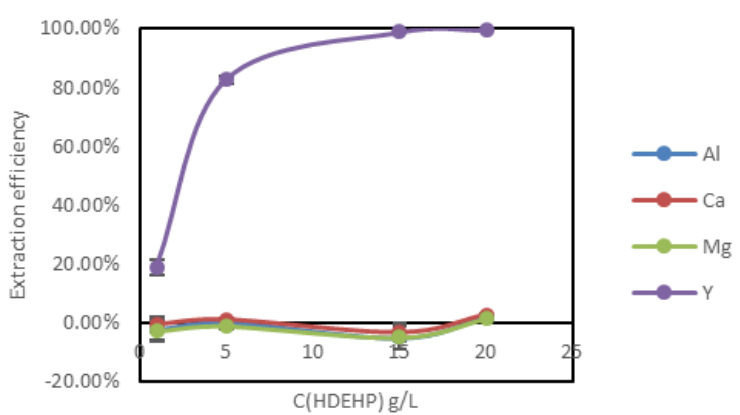

Y0.5CMA; $\mathrm{pH} 3.0 ; \mathrm{O}: \mathrm{A}=2$.

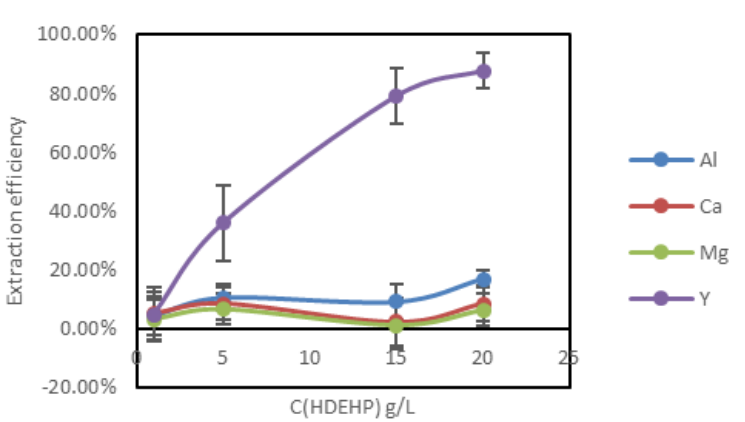

Figure 2.4 Extractant concentration effect on extraction efficiencies of major metal ions and rare earth ions from Y0.5CMA solution.

Extraction efficiencies of major metal ions and rare earth ions from YCMA solution are shown in Figure 2.5 by changing extractant concentration. The volume ratio of O:A remained as 2 and the extractant concentration changed from $1 \mathrm{~g} / \mathrm{L}$ to $20 \mathrm{~g} / \mathrm{L}$. Extraction efficiencies of major metal ions were still very low under low pH values. At pH 3, competitive extraction occurred, and extraction efficiency of $\mathrm{Y}$ were lower than those under other $\mathrm{pH}$ values. Although concentration ratio of $Y$ was higher than that of $\mathrm{Y} 0.5 \mathrm{CMA}$ solution, $15 \mathrm{~g} / \mathrm{L}$ extractant was still enough for $\mathrm{Y}$ extraction and almost $100 \%$ of $\mathrm{Y}$ were extracted at high $\mathrm{O}: \mathrm{A}$ ratio and low $\mathrm{pH}$ values. Effect of extractant concentration on extraction efficiency of $\mathrm{Y}$ was same for different solution. 
YCMA; $\mathrm{pH} 1.0 ; \mathrm{O}: \mathrm{A}=2$.

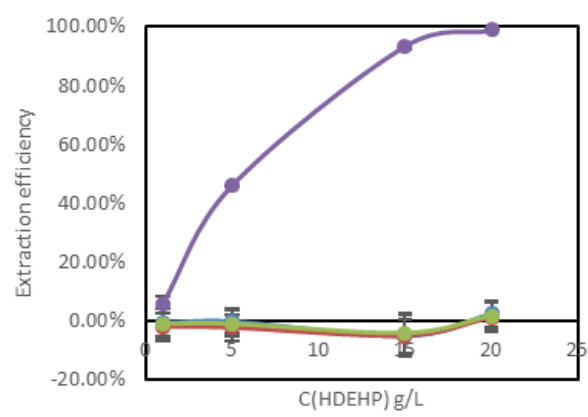

YCMA; $\mathrm{pH} 2.4 ; \mathrm{O}: \mathrm{A}=2$.

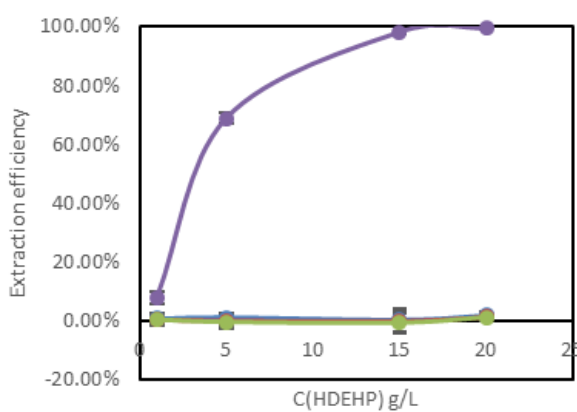

$\longrightarrow$ Al

$\longrightarrow \mathrm{Ca}$

$\longrightarrow \mathrm{Mg}$

$\longrightarrow Y$

$\longrightarrow \mathrm{Ca}$

$\longrightarrow \mathrm{Mg}$

$\rightarrow r$
YCMA; pH 1.6; O:A=2.

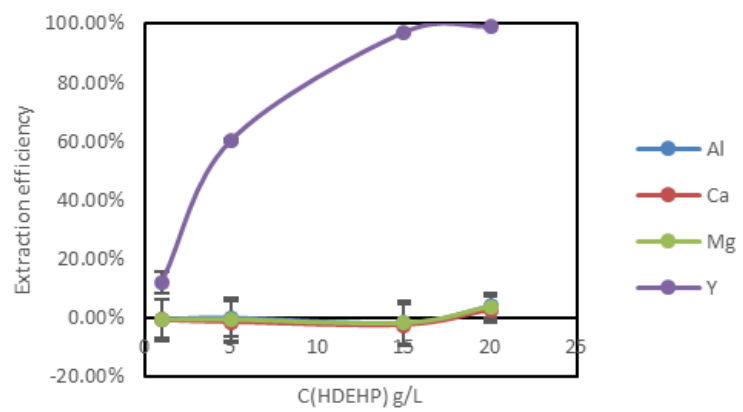

YCMA; $\mathrm{pH} 3.0 ; \mathrm{O}: \mathrm{A}=2$.

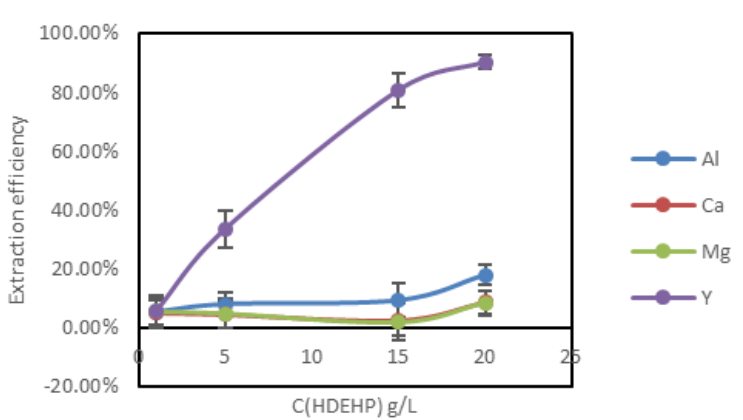

Figure 2.5 Extractant concentration effect on extraction efficiencies of major metal ions and rare earth ions from YCMA solution.

Extraction efficiencies of major metal ions and rare earth ions from Y2CMA solution are shown in Figure 2.6 at different extractant concentration. The volume ratio of O:A was kept as 2 and the extractant concentration changed from $1 \mathrm{~g} / \mathrm{L}$ to $20 \mathrm{~g} / \mathrm{L}$. Extraction efficiencies of major metal ions were higher than those of the other two solutions. Competitive extraction was obvious at all $\mathrm{pH}$ values and extraction efficiencies of $Y$ were all lower than those two series. $20 \mathrm{~g} / \mathrm{L}$ extractant was not enough for $\mathrm{Y}$ extraction and less than $90 \%$ of $Y$ were extracted. Raising extractant concentration increased extraction efficiency of $\mathrm{Y}$ at all $\mathrm{pH}$ values. 
Y2CMA; $\mathrm{pH} 1.0 ; \mathrm{O}: \mathrm{A}=2$

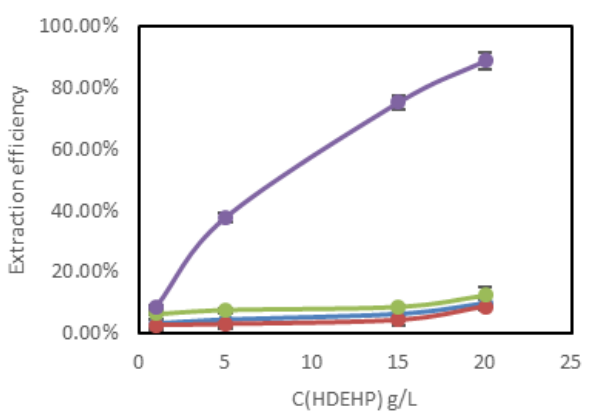

Y2CMA; $\mathrm{pH} 2.4 ; \mathrm{O}: \mathrm{A}=2$.

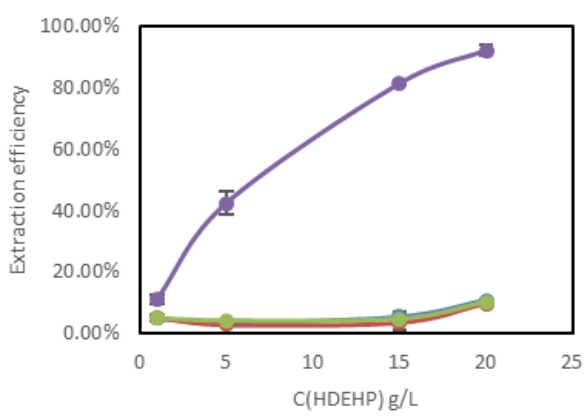

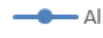

$\longrightarrow \mathrm{Ca}$

$\longrightarrow \mathrm{Mg}$

$\longrightarrow Y$

$\longrightarrow \mathrm{Ca}$

$\longrightarrow \mathrm{Mg}$

$\longrightarrow Y$
Y2CMA; $\mathrm{pH} 1.6 ; \mathrm{O}: \mathrm{A}=2$.

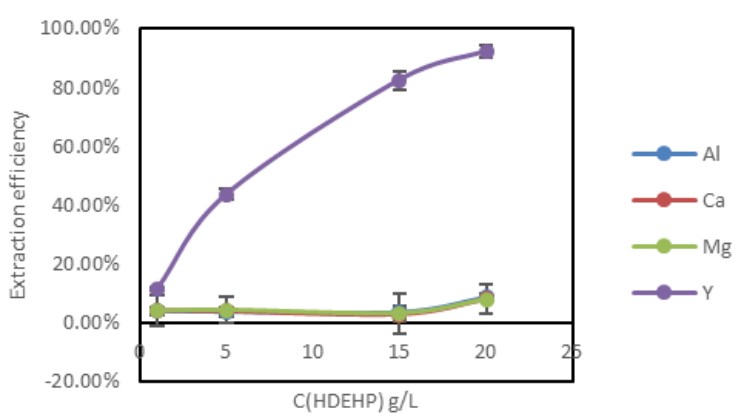

Y2CMA; $\mathrm{pH}$ 3.0; O:A=2.

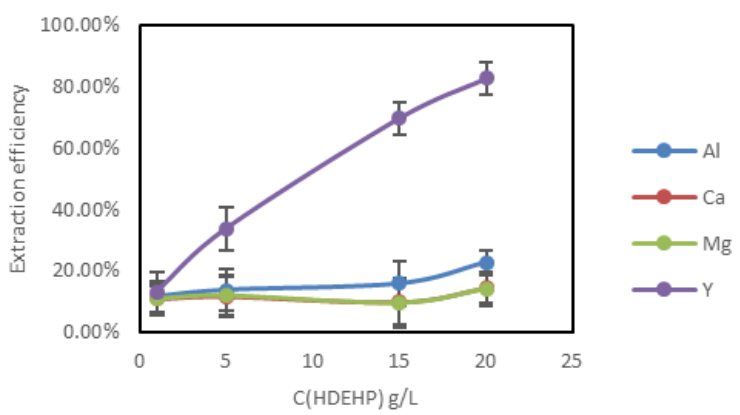

Figure 2.6 Extractant concentration effect on extraction efficiencies of major metal ions and rare earth ions

\section{from Y2CMA solution.}

\subsubsection{Separation factor studies}

ANOVA analysis. Analysis of variance (ANOVA) is a collection of statistical models and their associated estimation procedures used to analyze the differences among group means in a sample. The sources of the variation in the sample were identified and the sum of squares (SS) of the deviations of the values from the mean of those values were calculated. Mean of the squares (MS) equaled to SS over the degrees of freedom (df). The F test statistic (F-value) for each source was the MS for that row divided by the MS of the error (residual row). Since the F-statistic followed an F-distribution with df of factors and df of error, p-value of a factor was also calculated.

Extraction efficiencies analysis based on experiments of 96 runs are hereinbefore discussed. These data are analyzed by Design-Expert software and data of total 240 runs (4: $\mathrm{pH} * 3: \mathrm{Y}: \mathrm{CMA}$ ratio *5: C(HDEHP) *4: O:A ratio) experiments were predicted based on significant model with reasonable error. ANOVA analysis results of all four parameters effect on average separation factors of Y over total major metal ions 
are shown in Table 2-2. The Model F-value of 56.71 implied the model was significant. There was only a $0.01 \%$ chance that an F-value this large could occur due to random error.

P-values less than 0.0500 indicated model terms were significant. In this system, $\mathrm{pH}, \mathrm{Y:CMA}$ ratio, HDEHP concentration, $\mathrm{O}: \mathrm{A}$ ratio, $\mathrm{pH}$ and $\mathrm{Y}: \mathrm{CMA}$ ratio interaction, $\mathrm{Y}: \mathrm{CMA}$ ratio and HDEHP concentration interaction were significant model terms.

Table 2-2 ANOVA analysis results of four factorial model on response of average separation factors of $\mathrm{Y}$ over total major metal ions. *

\begin{tabular}{lcccccc}
\hline Source & Sum of Squares & df & Mean Square & F-value & p-value & \\
\hline Model & 486.60 & 26 & 18.72 & 56.71 & $<0.0001$ & significant \\
A-pH & 93.07 & 3 & 31.02 & 94.00 & $<0.0001$ & \\
B-Y:CMA ratio & 83.26 & 2 & 41.63 & 126.13 & $<0.0001$ & \\
C-C(HDEHP) & 253.84 & 4 & 63.46 & 192.28 & $<0.0001$ & \\
D-O:A ratio & 38.88 & 3 & 12.96 & 39.27 & $<0.0001$ & \\
AB & 8.24 & 6 & 1.37 & 4.16 & 0.0013 \\
BC & 15.01 & 8 & 1.88 & 5.69 & $<0.0001$ \\
Residual & 22.77 & 69 & 0.3300 & & & \\
Cor Total & 509.38 & 95 & & & & \\
\hline
\end{tabular}

Due to minor measurement error by ICP methods, the error of separation factor after several steps' calculation (Equation 2.2 and Equation 2.3) becomes significant. Correction term (0.9 1.1) was applied to raw experiment data to avoid negative separation factor. The figures of predicted separation factors of $Y$ over total major metal ions are shown in Figure 2.7, including one factor graph (D: O:A ratio) and interaction graphs $(\mathrm{AB}$ : $\mathrm{pH}$ and $\mathrm{Y}: \mathrm{CMA}$ ratio interaction, $\mathrm{BC}: \mathrm{Y}: \mathrm{CMA}$ ratio and HDEHP concentration interaction). The round dots (Design Points) in graphs show calculation results from raw experiment data with correction term. The graphs contain least significant difference (LSD) bars around the predicted means based on the model. Most predication results were in reasonable agreement with experiment results. There was a significant difference in the predictions for one point. It indicates that there was a 
notable measurement error for the separation factor result of experiment parameters: Y0.5CMA, pH value of 2.4, O:A ratio of $2, \mathrm{C}(\mathrm{HDEHP})$ of $20 \mathrm{~g} / \mathrm{L}$.

O:A ratio effect. In O:A ratio range from 0.5 to 2, the higher the O:A ratio, the higher the separation factors. Under $\mathrm{pH}$ value of 2.4 and extractant concentration of $10 \mathrm{~g} / \mathrm{L}$, highest separation factors for Y2CMA feed solution was 112.02 .

pH and Y:CMA ratio interaction effect. The separation factors of $Y$ over total major metal ions were highest for $\mathrm{Y0.5CMA}$ with lowest $\mathrm{Y}$ concentration ratio. 2.4 was the best $\mathrm{pH}$ value for $\mathrm{Y}$ separation from other metal ions in these feed solutions. Highest separation factor for Y0.5CMA solution at extractant concentration of $20 \mathrm{~g} / \mathrm{L}$ and O:A ratio of 2 was 7526.3. Separation factors for YCMA solution were much lower than those of Y0.5CMA. Separation factor was 1941.28 for YCMA feed solution under same conditions and 236.24 for Y2CMA feed solution. Though separation factors for Y2CMA solution were much lower than those of the other two solution, it was still high enough for $\mathrm{Y}$ separation and recovery.

Y:CMA ratio and HDEHP concentration interaction effect. The separation factors of $Y$ over total major metal ions were highest for Y0.5CMA. In extractant concentration range from $1 \mathrm{~g} / \mathrm{L}$ to $20 \mathrm{~g} / \mathrm{L}$, the higher the extractant concentration, the higher the separation factors. 

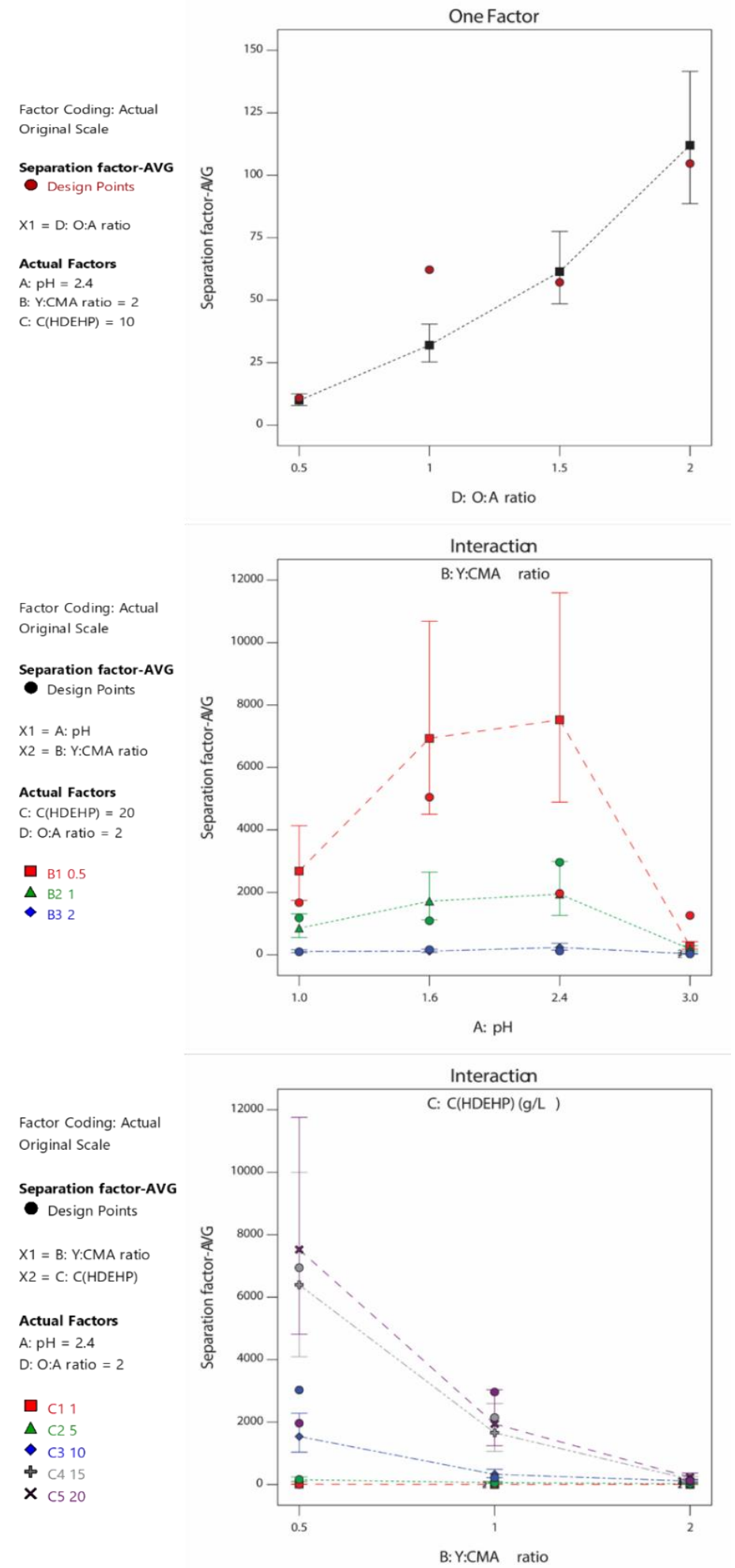

Figure 2.7 Analysis of separation factors of $Y$ over total major metal ions under different significant model terms (O:A ratio, $\mathrm{pH}$ and $\mathrm{Y}$ :CMA ratio interaction, and Y:CMA ratio and HDEHP concentration interaction). * 


\subsubsection{Optimized SX conditions}

The optimized SX conditions for the system with minimized extraction efficiency of major metal ions, maximized extraction efficiency of $Y$ and maximized separation factor of $Y$ over total major metal ions are shown in Figure 2.8. After numerical optimization, the treatment condition is the optimized one over 100 and the desirability to reach our goal is almost 1 (0.957). Desirability is an objective function that ranges from zero outside of the limits to one at the goal. The numerical optimization finds a point that maximizes the desirability function. To recover REEs from wastewater with very low REEs concentration, adjusting solution $\mathrm{pH}$ to 2.4 and using extractant HDEHP with concentration of $15 \mathrm{~g} / \mathrm{L}$ in solvent $\mathrm{n}$-heptane at O:A ratio of 1.5, the separation factor can approach 3007.3.
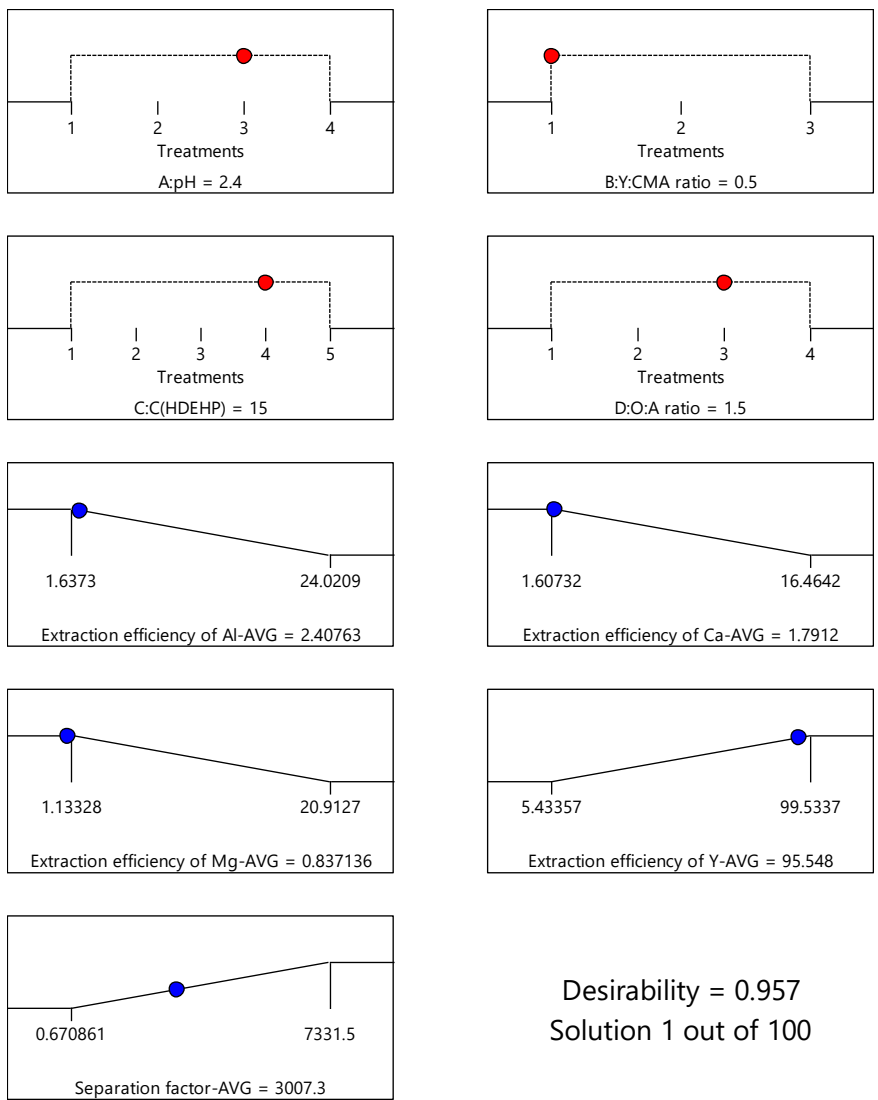

Desirability $=0.957$

Solution 1 out of 100

Figure 2.8 Optimized SX solution for the system with minimized extraction efficiency of major metal ions, maximized extraction efficiency of $Y$ and maximized separation factor of $Y$ over major metal ions. *

\subsection{Conclusion}

Solvent extraction (SX) is one effective way to recover REEs from aqueous solution. Here, solvent extraction experiments were conducted on $\mathrm{Y}-\mathrm{Ca}-\mathrm{Mg}$-Al-HDEHP-n-heptane- $\mathrm{HNO}_{3}-\mathrm{H}_{2} \mathrm{O}$ system by changing 
$\mathrm{pH}, \mathrm{HDEHP}$ concentration in organic phase, volume ratio of organic phase to aqueous phase. Three different low ratios of REEs to major metal ions were used for SX feed solution.

The higher the extractant concentration, the more extracted $Y$ in the organic phase. But to concentrate REEs from wastewater with very low REE content, lower extractant concentration should be used to reduce competitive extraction. The lower the A:O ratio, the easier to recover $\mathrm{Y}$ from aqueous solution. $\mathrm{pH}$ 2.0 is appropriate for $Y$ separation in these solutions. For this solvent extraction system, the lower the concentration ratio of $\mathrm{Y}$ to other metal ions, the easier to separate $\mathrm{Y}$ from them. The appropriate condition to separate and recover REE in similar system and parameters range is using extractant concentration 15 $\mathrm{g} / \mathrm{L}$ at O:A ratio of 1.5. This work provides a basis for rare earth production from wastewater. 


\section{REEs recovery flowsheet from coal mine drainage}

AMD is the largest, by volume, industrial pollutant in the Northern Appalachian Basin. Coal companies and state agencies routinely treat vast volumes of this waste stream, which often persists as an environmental liability, for decades after coal mine closure. Precipitated solids generated during routine AMD treatment contains significant concentrations of REEs. The objective is to develop a cost-effective and environmentally benign process to treat and recover Rare Earth Elements (REEs) from acid mine drainage (AMD), which has been considered a serious long-term environmental problem associated with coal mining.

\subsection{Selective Electro-Coagulation}

\subsubsection{Preliminary work by electrochemical methods}

An extensive literature review on REE recovery methods indicated solubilized REEs are currently recovered/separated as high purity end-products either by solvent extraction or selectively precipitated with oxalic acid to form oxalates. There are also some electrochemical processes available for REE recovery. The advantages and disadvantages of these electrochemical methods were investigated.

Electrocoagulation (EC) is a complicated process involving many chemical and physical phenomena that uses consumable electrodes to supply ions into the wastewater stream. In an EC process, the coagulating ions are produced in situ. EC theory and influencing factors (e.g., initial pH, conductivity, current density, distance between two electrodes, treatment time) that affect the efficiency of EC process are already discussed in literature review in Chapter 1.

As proof-of-concept, some preliminary work was conducted by removing zinc $(\mathrm{Zn})$ from wastewater. Results of these preliminary tests are presented in Table 3-1. Inductively coupled plasma-optical emission spectrometry (ICP-OES) is used to test concentrations of metals in solution after the EC process. Based on these tests, EC is effective to remove heavy metal ions from solution.

Table 3-1 Initial results of removing $\mathrm{Zn}$ ions from wastewater by EC.

\begin{tabular}{clllllll}
\hline Sample \# & $\mathbf{1}$ & $\mathbf{2}$ & $\mathbf{3}$ & $\mathbf{4}$ & $\mathbf{5}$ & $\mathbf{6}$ & $\mathbf{7}$ \\
\hline Electrode material & $\mathrm{Al}$ & $\mathrm{Al}$ & $\mathrm{Al}$ & $\mathrm{Al}$ & $\mathrm{Al}$ & $\mathrm{Al}$ & $\mathrm{Fe}$ \\
\hline
\end{tabular}




\begin{tabular}{|c|c|c|c|c|c|c|c|}
\hline $\begin{array}{l}\text { Initial concentration of } \mathrm{Zn} \\
(\mathrm{mg} / \mathrm{l})\end{array}$ & 500 & 500 & 500 & 500 & 500 & 500 & 500 \\
\hline Current density $\left(\mathrm{mA} / \mathrm{cm}^{-2}\right)$ & 4.1 & 4.1 & 4.1 & 4.1 & 4.1 & 4.1 & 4.1 \\
\hline Electrodes distance (mm) & 10 & 10 & 10 & 10 & 20 & 10 & 10 \\
\hline EC time (min) & 30 & 15 & 30 & 60 & 30 & 30 & 30 \\
\hline Concentration of $\mathrm{NaCl}(\mathrm{mol} / \mathrm{l})$ & 0 & 0.1 & 0.1 & 0.1 & 0.1 & 0.1 & 0.1 \\
\hline Initial pH & 5.24 & 4.53 & 4.66 & 4.53 & 4.53 & 3.2 & 4.53 \\
\hline Final pH & 3.77 & 4.47 & 4.54 & 255.16 & 4.47 & 4.26 & 4.52 \\
\hline $\begin{array}{l}\text { Residual concentration of } \mathrm{Zn} \\
(\mathrm{mg} / \mathrm{l})\end{array}$ & 355.54 & 363.29 & 349.27 & 255.16 & 334.71 & 310.93 & 294.58 \\
\hline Removal (\%) & 29 & 27 & 31 & 49 & 33 & 38 & 41 \\
\hline $\begin{array}{l}\text { Residual concentration of } \\
\mathrm{Al} / \mathrm{Fe}(\mathrm{mg} / \mathrm{l})\end{array}$ & 24.43 & 6.74 & 5.36 & 2.22 & 5.46 & 43.39 & 106.54 \\
\hline
\end{tabular}

The lab scale EC reactor is equipped with two parallel plates (aluminum and iron) of rectangular shape, used as anode and cathode, respectively. Certain environmental benign salt, such as $\mathrm{NaCl}$ (Sodium chloride) was added to adjust the initial conductivity of the waste water, and a minor addition of $\mathrm{HCl}$ (hydrochloric acid) or $\mathrm{NaOH}$ (Sodium hydroxide) solutions will be used to adjust the initial $\mathrm{pH}$, which was varied between 3-7.

At the anode:

$\mathrm{M}(\mathrm{s}) \rightarrow \mathrm{M}(\mathrm{aq})^{\mathrm{n}+}+\mathrm{ne}^{-}$

$2 \mathrm{H}_{2} \mathrm{O}(\mathrm{I}) \rightarrow 4 \mathrm{H}^{+}(\mathrm{aq})+\mathrm{O}^{2}(\mathrm{~g})+4 \mathrm{e}^{-}$

At the cathode:

$\mathrm{M}(\mathrm{aq})^{\mathrm{n}+}+\mathrm{ne}-\rightarrow \mathrm{M}(\mathrm{s})$

$2 \mathrm{H}_{2} \mathrm{O}(\mathrm{I})+2 \mathrm{e}-\rightarrow \mathrm{H}_{2}(\mathrm{~g})+2 \mathrm{OH}^{-}$

If iron or aluminum electrodes are used, the generated $\mathrm{Fe}(\mathrm{aq})^{3+}$ or $\mathrm{Al}(\mathrm{aq})^{3+}$ ions will immediately be subjected to further spontaneous reactions to produce corresponding hydroxides and/or polyhydroxides. These hydroxides/ polyhydroxides/ polyhydroxymetallic compounds have strong affinity for dispersed 
particles to cause coagulation. The gas evolved at the electrodes can cause flotation of the coagulated materials.

Removal efficiency: $f_{R E}=\left(C_{B, R E}-C_{A, R E}\right) / C_{B, R E} ; f_{M M}=\left(C_{B, M M}-C_{A, M M}\right) / C_{B, M M}$

Where $C_{B}$ and $C_{A}$ are the average concentrations of heavy metal ions (REEs, major metals) before electrolysis and after an electrolysis time $t$, respectively.

Objective: The $f_{R E}$ is as large as possible and the difference between $f_{R E}$ and $f_{M M}$ is as large as possible.

Some preliminary work for REE separation was conducted using electro-coagulation (EC) and electrodeposition (ED). Results of these tests are presented in Table 3-2. The reactor of ED is similar to that of EC. The anode material of ED is carbon while anode of EC is iron or aluminum. When using electrochemical methods, chemical $\mathrm{NaCl}$ needs to be added into the solution to increase the conductivity in order to decrease the energy cost.

Samples \#1 and \#2 are to determine the effect of different electro-coagulation times on the removal efficiency of $\mathrm{Zn}$ and $\mathrm{Y}$. From the results, we can see the removal efficiencies of $\mathrm{Zn}$ and $\mathrm{Y}$ increase with increasing time. The removal efficiency of $\mathrm{Y}$ after 15 minutes is much higher than that of $\mathrm{Zn}$. The recovery efficiency of Yttrium (Y) was approximately 100\% while the purity of $Y$ was only about $20 \%$ (sample \#1 and \#2). It indicates REEs like $Y$ can be separated from normal metals like $\mathrm{Zn}$ if we choose appropriate operation parameters. However, the absolute removal values of $\mathrm{Zn}$ and $\mathrm{Y}$ are similar. If the difference of concentrations of $\mathrm{Y}$ and $\mathrm{Zn}$ in the solution is very small, EC cannot separate them effectively.

Researchers also tried ED for the separation based on the literature. (PRAKASH, 2014) Samples \#3 and \#4 are to determine the effect of different $\mathrm{pH}$ on the removal efficiency of $\mathrm{Zn}$ and $\mathrm{Y}$ by applying the same potential during electro-deposition. The effect of $\mathrm{pH}$ on the removal efficiency is small. The standard reduction potential of $\mathrm{Y}$ is much more negative than $\mathrm{Zn}$. Thus, $\mathrm{Zn}$ should be deposited on the cathode prior to $Y$. The absolute loss of $Y$ is much less than that of $Z n$; but, the percent of $Y$ loss in the process is somehow high.

Samples \#4 and \#5 are to determine the effect of different potentials on the removal efficiency of $\mathrm{Zn}$. The higher removal efficiency of $\mathrm{Zn}$ in sample \#5 compared to sample \#4 is due to the production of $\mathrm{OH}^{-}$, which also will lead to a higher removal efficiency of $\mathrm{Y}$. Therefore, different voltages below $3 \mathrm{~V}$ need to be chosen to find an optimum voltage for separation between REEs and Zn. 
Experiments were conducted combining ED with solvent extraction, (i.e., using a solution containing extractant HDEHP), sample \#6, in the electro-deposition experiment. The density of HDEHP is very similar to that of water. HDEHP is mixed with an aqueous solution almost uniformly during stirring. This caused the conductivity of the solution to be very low and the removal efficiency of $\mathrm{Zn}$ was 0 .

Table 3-2 Initial results of separating Y ions from zinc (Zn) ions by EC and ED.

\begin{tabular}{|c|c|c|c|c|c|c|c|c|}
\hline Method & $\begin{array}{c}\text { Solution } \\
\text { (mg/L) }\end{array}$ & $\begin{array}{c}\text { Sample } \\
\#\end{array}$ & $\begin{array}{c}\text { Initial } \\
\text { pH }\end{array}$ & $t / \min$ & $\begin{array}{l}\text { Constant } \\
\text { U or j }\end{array}$ & $\mathrm{d} / \mathrm{cm}$ & $\begin{array}{l}\text { Removal } \\
\text { efficiency } \\
\text { of } \mathrm{Zn}(\%)\end{array}$ & $\begin{array}{c}\text { Removal } \\
\text { efficiency } \\
\text { of Y (\%) }\end{array}$ \\
\hline \multirow{4}{*}{$\begin{array}{c}\text { Electro- } \\
\text { coagulation }\end{array}$} & & 1 & & 15 & & & 24.02 & 55.15 \\
\hline & $C\left(Z n^{2+}\right)=100$ & 2 & 3 & 60 & $2 \mathrm{~mA} / \mathrm{cm}^{2}$ & 2 & 75.40 & 93.9 \\
\hline & $C\left(Y^{3+}\right)=20$ & 3 & 3 & 30 & $2 \mathrm{~V}$ & & 29.17 & 29.0 \\
\hline & $\mathrm{C}(\mathrm{NaCl})=2958$ & 4 & 5 & 9 & $2 \mathrm{~V}$ & & 28.61 & 26.5 \\
\hline \multirow[t]{2}{*}{$\begin{array}{c}\text { Electro- } \\
\text { deposition }\end{array}$} & & 5 & 5 & 15 & $3 \mathrm{~V}$ & 3 & 38.68 & - \\
\hline & $\begin{array}{c}\text { Same solution } \\
\text { as above + } \\
\text { HDEHP }\end{array}$ & 6 & 5 & 30 & $2 \mathrm{~V}$ & & 0 & - \\
\hline
\end{tabular}

\subsubsection{Selective Electro-Coagulation}

Since concentrations of REE in AMD sludge are much less than those of normal metals, EC was chosen as an appropriate method to separate REE for other metals. Systematic studies are conducted on the effect of electro-coagulation parameters (e.g., electrode material, current, $\mathrm{pH}$, other chemical concentrations) on the efficiency and selectivity of extracting REEs.

Figure 3.1 shows the effect of concentration ratio of REE to major ions on the selectivity of electrocoagulation. The differences of removal efficiency between $\mathrm{Y}$ and $\mathrm{Zn}$ under same conditions are 
not obvious. The lowest ratio of yttrium $(Y)$ to zinc $(Z n)$ here is only one-tenth $(1 / 10)$. When the ratio decreases to one-hundredth $(1 / 100)$ or less, the difference may be obvious.

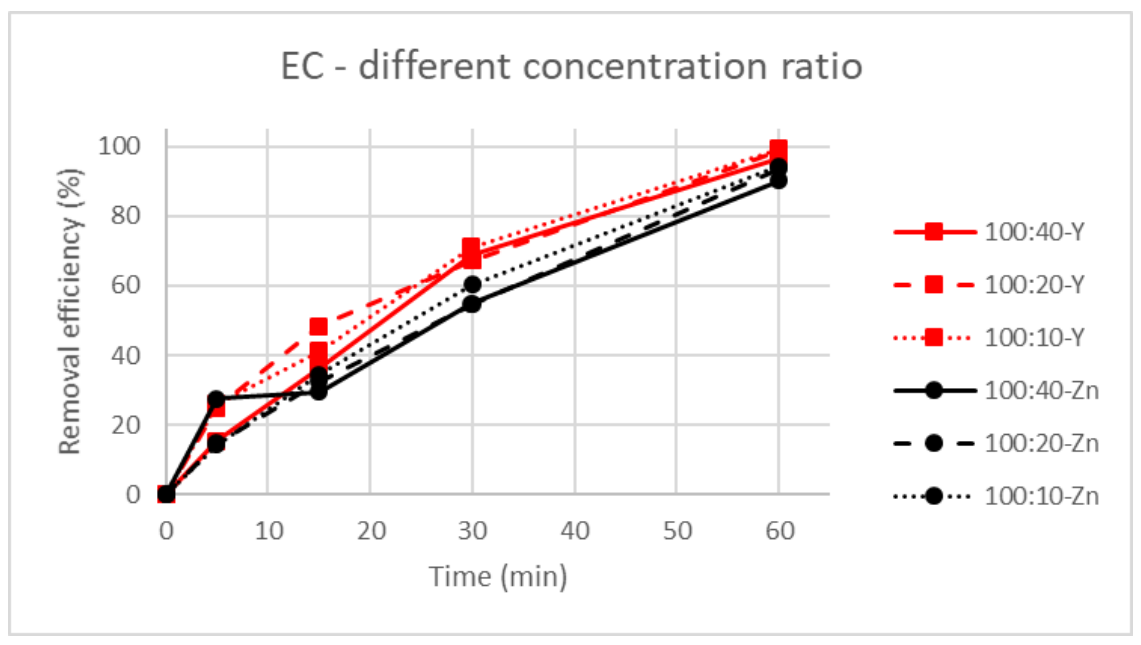

Figure 3.1 Removal efficiency of $\mathrm{Zn}$ and $\mathrm{Y}$ from solution with different concentration ratio under the same operating conditions.

Figure 3.2 shows the effect of $\mathrm{pH}$ on the selectivity of EC. The removal efficiency of $\mathrm{Y}$ after 15 minutes of treatment is much higher than that of $\mathrm{Zn}$ under $\mathrm{pH}=3$. However, for $\mathrm{pH}=5$, the difference was not as obvious indicating REEs, such as $\mathrm{Y}$, can be separated from major metals, such as $\mathrm{Zn}$, as long as we choose appropriate operation parameters. In fact, the $\mathrm{pH}$ of leaching solution is low, which is beneficial to recovery of REEs using electrocoagulation.

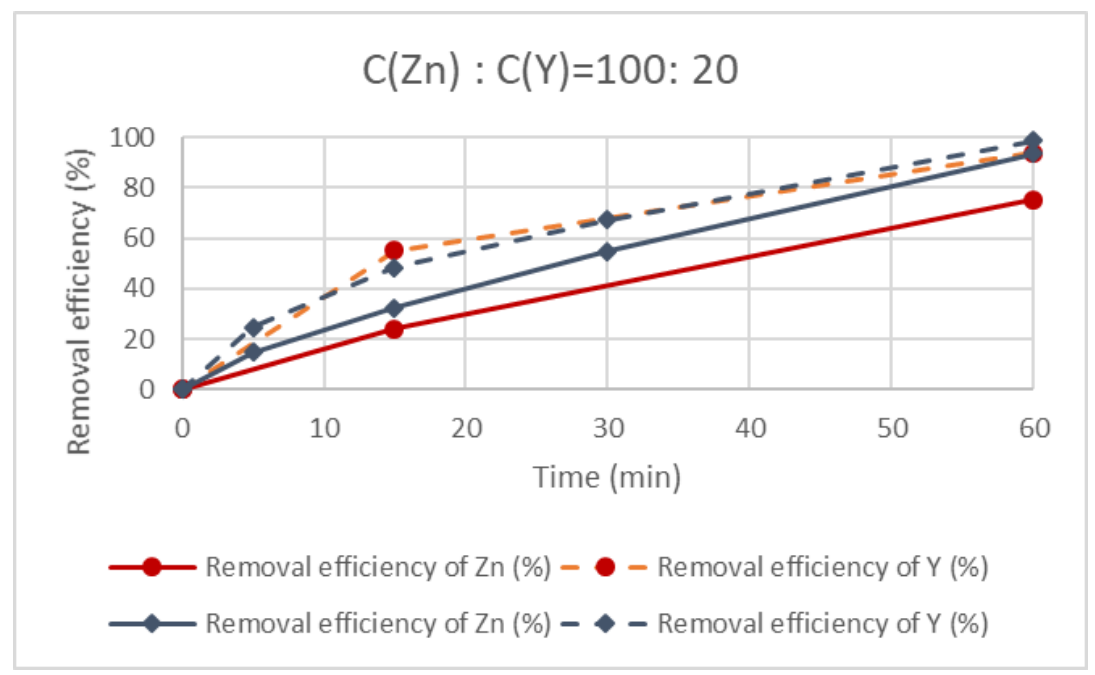

Figure 3.2 Removal efficiency of $\mathrm{Zn}$ and $\mathrm{Y}$ from solution with different $\mathrm{pH}$ values under the same operating conditions. (Red lines: $\mathbf{p H}=3$; Blue lines: $\mathbf{p H}=5$ ). 
Current density is a main parameter for the electrocoagulation process. Figure 3.3 shows the effect of current density on the removal efficiency of $\mathrm{Zn}$ and $\mathrm{Y}$. The experiments were done on a solution containing $100 \mathrm{mg} / \mathrm{L} \mathrm{Zn}^{2+}$ and $10 \mathrm{mg} / \mathrm{L} \mathrm{Y}^{3+}$ at a pH of 5.0 and under different current densities. Difference of removal efficiency between $\mathrm{Y}$ and $\mathrm{Zn}$ was most obvious at a treatment time of five minutes under a current density of $2 \mathrm{~mA} / \mathrm{cm}^{2}$. The purity of $Y$ was increased from $9.1 \%$ in the initial solution to $15.4 \%$ in the flocs while the recovery efficiency of $Y$ was only $25.9 \%$, see Table $3-3$. When the recovery efficiency of $Y$ was $100 \%$ at a treatment time of 60 minutes under a current density of $4 \mathrm{~mA} / \mathrm{cm}^{2}$, the purity of $Y$ didn't increase due to the same high removal efficiency of $\mathrm{Zn}$. Based on previous results, lower $\mathrm{pH}$ and lower ratio of REEs to major ions of leaching solution are beneficial to recovery of REEs under similar operating conditions. If appropriate current density is chosen, higher purity and recovery efficiency of REEs from leaching solution may be obtained.

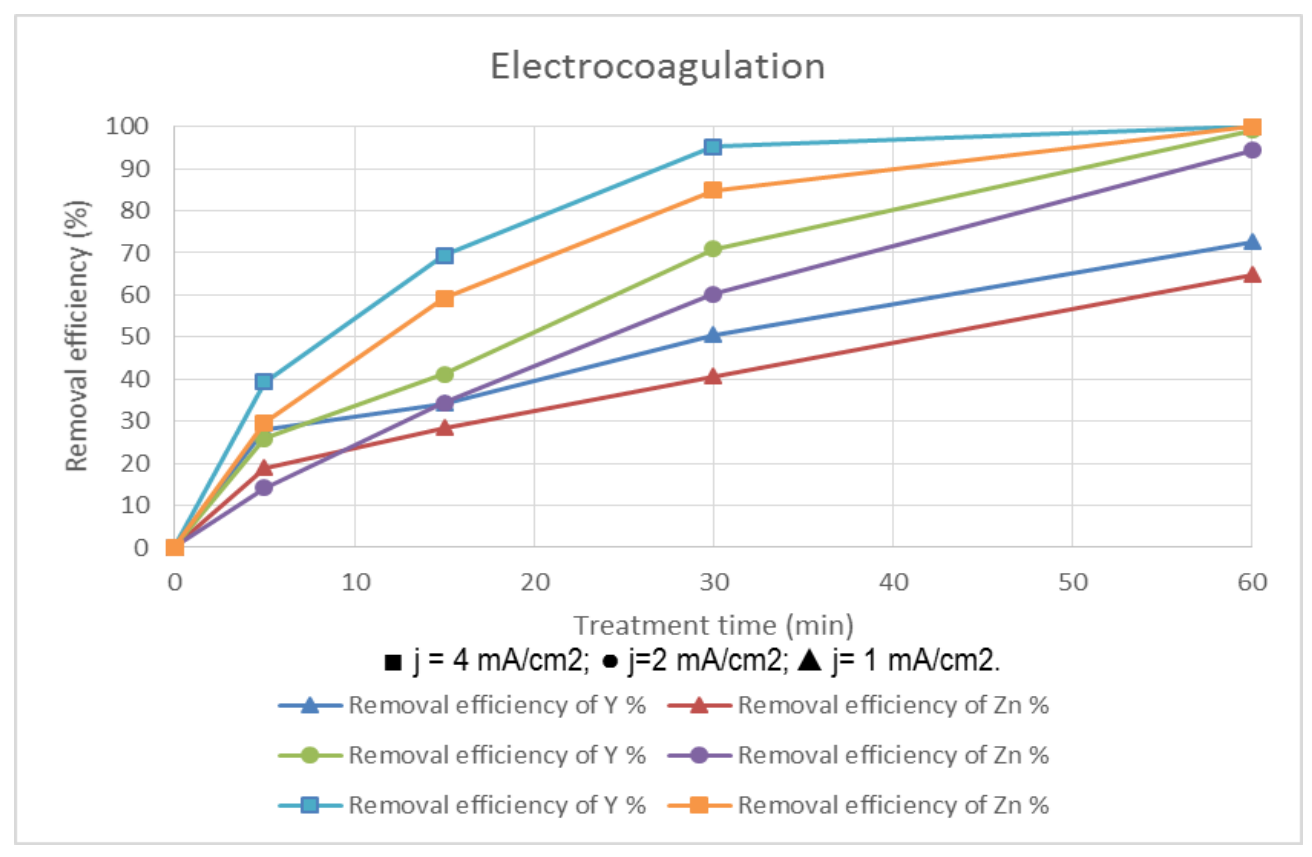

Figure 3.3 Removal efficiency of $\mathrm{Zn}$ and $\mathrm{Y}$ with different current density under same operating conditions.

Table 3-3 Recovery efficiency and purity of $Y$ with different current density under same operating conditions.

\begin{tabular}{cccc}
\hline Description & Time (minutes) & Recovery efficiency of $\mathbf{Y}(\%)$ & Purity of $\mathbf{Y}(\%)$ \\
\hline \multirow{3}{*}{$=1 \mathrm{~mA} / \mathrm{cm}^{2}$} & 0 & 0 & 9.1 \\
& 5 & 28 & 12.86 \\
& 15 & 34.3 & 10.73 \\
\hline
\end{tabular}




\begin{tabular}{cccc}
\hline 30 & 50.5 & 11.05 \\
60 & 72.7 & 10.09 \\
$\mathrm{j}=2 \mathrm{~mA} / \mathrm{cm}^{2}$ & 5 & 0 & 9.10 \\
& 15 & 25.9 & 15.43 \\
& 30 & 41.2 & 41.20 \\
$\mathrm{j}=4 \mathrm{~mA} / \mathrm{cm}^{2}$ & 60 & 70.9 & 10.68 \\
& 0 & 99.2 & 10.52 \\
& 5 & 0 & 9.10 \\
& 15 & 39.4 & 11.75 \\
& 30 & 69.4 & 10.48 \\
& 60 & 95.2 & 10.09 \\
\hline Remark: & 100 & $>9.08$ \\
\hline
\end{tabular}

Remark: initial solution $100 \mathrm{mg} / \mathrm{L} \mathrm{Zn}^{2+} ; 10 \mathrm{mg} / \mathrm{L} \mathrm{Y}^{3+}$.

Solution $\mathrm{pH}$ is one of the main parameters for electrocoagulation process. Prior experiments were conducted on $\mathrm{pH}=5.0$ synthetic solution under different current densities. The difference of removal efficiency between $\mathrm{Y}$ and $\mathrm{Zn}$ was most obvious at a treatment time of five minutes under a current density

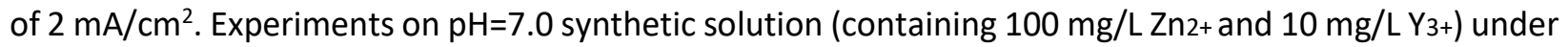
current density of $2 \mathrm{~mA} / \mathrm{cm} 2$ were conducted. Figure 3.4 shows the removal efficiency of $\mathrm{Zn}$ and $\mathrm{Y}$ for a $\mathrm{pH} 7.0$ solution. The difference between removal efficiency of $\mathrm{Y}$ and $\mathrm{Zn}$ was most obvious at a treatment time of 5 minutes under a current density of $2 \mathrm{~mA} / \mathrm{cm} 2$. The purity of $Y$ was increased from $9.1 \%$ in the initial solution to $15.2 \%$ in the flocs while the recovery efficiency of $Y$ was $100 \%$.

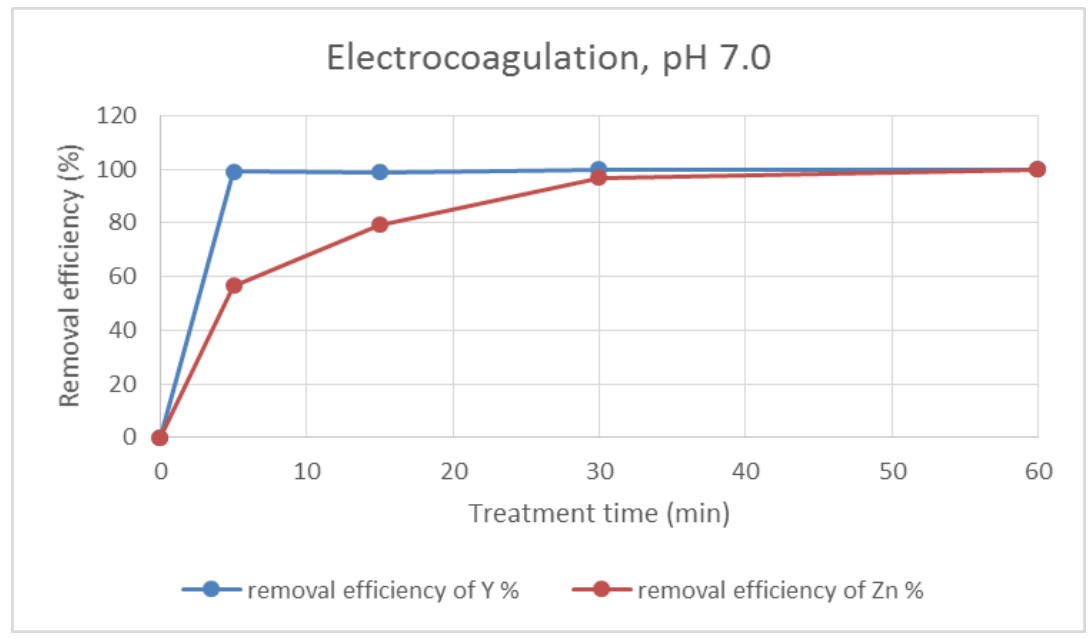


Figure 3.4 Removal efficiency of $\mathrm{Y}$ and $\mathrm{Zn}$ for $\mathrm{pH}$ 7.0 synthetic solution.

Further experiments on lower ratio synthetic solution were conducted. Figure 3.5 shows EC treatment data for different major metal ions and $Y$ ions in a synthetic solution (Ca: $752.9 \mathrm{mg} / \mathrm{L}$, Fe: $215.98 \mathrm{mg} / \mathrm{L}$, Mg: $262.8 \mathrm{mg} / \mathrm{L}, \mathrm{Y}: 0.63 \mathrm{mg} / \mathrm{L}$, nitrate solution). The decreased removal efficiencies observed for Fe and $\mathrm{Mg}$ at a treatment time of 60 minutes were due to experimental and test error. Fe ions are much easier to remove than $\mathrm{Mg}$ and $\mathrm{Ca}$ ions. Fe ions can't be removed under low current density $\left(\mathrm{j}=0.5 \mathrm{~mA} / \mathrm{cm}_{2}\right)$ because the $\mathrm{K}_{\mathrm{sp}}$ of $\mathrm{Fe}(1.1 \times 10-36)$ is very low and similar to that of aluminum $1.9 \times 10-33$. Therefore, iron electrodes are also used for the EC process. But, it's not beneficial to our process. We need to remove iron ions by adjusting $\mathrm{pH}$ or using other methods prior to recovering $\mathrm{Y}$ by electrocoagulation.

Since the removal efficiency of Fe was about $40 \%$ and the initial concentration of Fe was much higher than $Y$, the purity of $Y$ can only be increased from $0.05 \%$ (initial ratio) to $0.72 \%$ even if all $Y$ was recovered. The real purity of $\mathrm{Y}$ must be lower than $0.72 \%$.

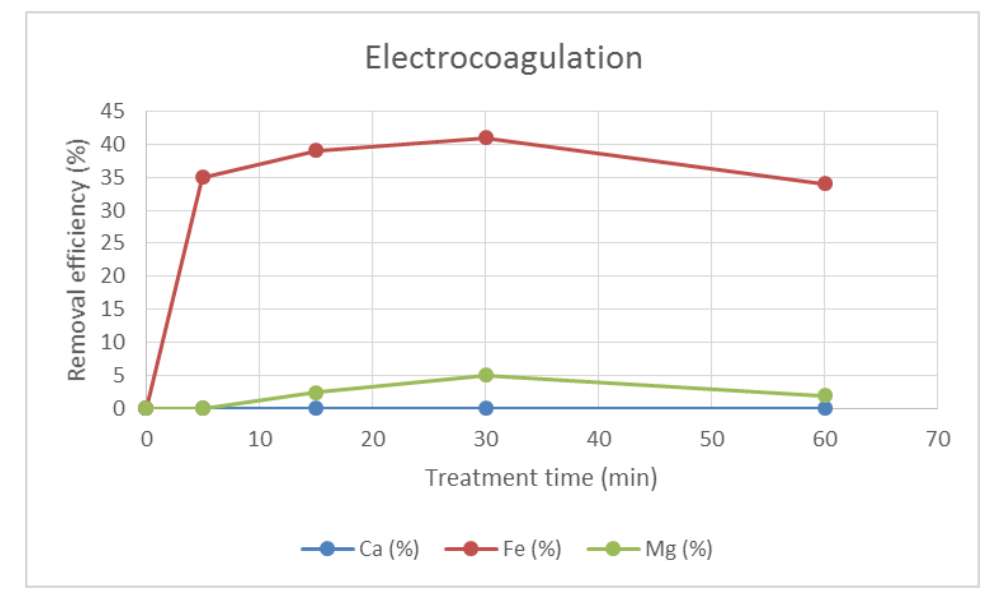

Figure 3.5 Removal efficiency of major ions from solution of major ions and $\mathrm{Y}$ ions.

\subsection{Solvent extraction}

Solvent extraction (SX) is transferring one (or more) solute(s) contained in a feed solution to another immiscible liquid (solvent). It is a method to separate compounds based on their relative solubilities in two different immiscible liquids, usually water and an organic solvent. The process is commonly performed after a chemical reaction between metal ions and extractants. 
The solubility of metal ions in water is much higher than in an organic solvent. But solubility of complexes of high valence metal ions (such as REE ions) with extractants in an organic solvent is much higher than in water. Thus, rare earth elements can be enriched by this method.

The parameters affecting solvent extraction efficiency are:

1. Extractant properties: It should react with REEs much easier than with other metal ions. HDEHP is widely used for REE extraction.

2. Solvent properties: The solubility of REE-extractant complex in a solvent should be as high as possible.

3. $\mathrm{pH}$ : The $\mathrm{pH}$ should be beneficial for a reaction between REE-extractant and solubility of compounds in organic solvent.

4. Ratio of extractant to solvent; volume ratio of two phase; concentration ratio of REE ions to major metal ions in feed solution. They are also to be beneficial for solubility of REE compounds in organic solvent.

5. Anions in feed solution, temperature, et al. They should be beneficial for a reaction between REEextractant.

\subsubsection{Preliminary work on solvent extraction}

The incorporation of solvent extraction to achieve metal separation and concentration in a hydrometallurgical circuit is shown in Figure 3.6. First, leach the valuable contents in waste into solution; then use SX to extract mixed REEs into organic phase; third, strip mixed REEs in organic phase to aqueous phase; finally, use reducing agent and precipitating agent to recover REEs as valuable product.

Solvent extraction is one critical process of the whole circuit. It's transferring one (or more) solute(s) contained in a feed solution to another immiscible liquid (solvent). The solutes here are metal ionextractant complexes, including major metal ion-HDEHP (extractant) complexes and REE-HDEHP (extractant) complexes. The solubility of metal ions in water is much higher than in an organic solvent. But solubility of complexes of high valence metal ions (such as REE ions) with extractant in an organic solvent is much higher than in water. Thus, REEs can be enriched by this method. REEs will be selectively removed from the aqueous stream by HDEHP during solvent extraction and concentrate in the organic phase. Acid stripping step will then be used to strip REEs from the organic phase. 


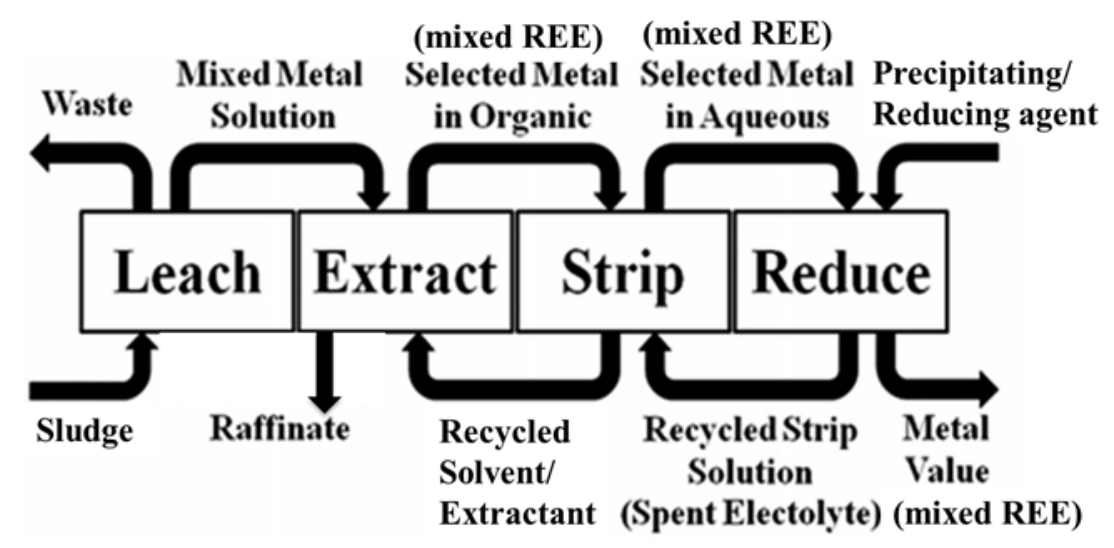

Figure 3.6 Incorporation of solvent extraction to achieve metal separation and concentration in a hydrometallurgical circuit which involves recycling of all reagents.

Di-(2-ethylhexyl) phosphoric acid (HDEHP) is a commonly used phosphoric acid extractant in rare earth separation. The high distribution coefficients of REEs in HDEHP and its ability to be used in acidic solutions make it a very strong complexing agent over the dissolved REEs. (B., 1990) HDEHP forms stable complexes by hydrogen bonds with metal ions, especially heavy rare earths. However, it is difficult to strip the stable complexes from the organic solution.

Some preliminary work was conducted to check SX effectiveness for REEs recovery and the test results are listed in Table 3-4. HDEHP was chosen as extractant for $\mathrm{Y}$. The remaining concentrations of $\mathrm{Zn}$ and $\mathrm{Ca}$ in the aqueous phase were tested using ICP-OES. The ratio of aqueous phase to organic phase is 2:1. The effect of HDEHP mass on the extracting efficiency of normal metals was investigated.

The extracting efficiency of $\mathrm{Zn}$ into an organic phase is very high (sample \#1), which will hinder the separation of $\mathrm{Y}$ from $\mathrm{Zn}$. The extracting efficiency of $\mathrm{Ca}$ into an organic phase is relatively low (sample \#2). The reason for the difference may be: 1) Zn is easier to be extracted using HDEHP than Ca; 2) the existence of $\mathrm{Cl}^{-}$makes co-extracting of normal metals easier. Further experiments need to be done to prove it.

The extracting efficiency of Ca decreases with decreasing the mass of HDEHP. In order to separate REE from normal metals, extracting efficiency of $\mathrm{Zn}$ and Ca should be as low as possible.

Table 3-4 Initial results of separating $\mathrm{Y}$ ions from $\mathrm{Zn} / \mathrm{Ca}$ ions by $\mathrm{SX}$.

\begin{tabular}{cccccc}
\hline $\begin{array}{c}\text { Solution } \\
(\mathrm{mg} / \mathrm{L})\end{array}$ & $\begin{array}{c}\text { Sample } \\
\#\end{array}$ & $\begin{array}{c}\text { Solution } \\
(\mathrm{mL})\end{array}$ & $\begin{array}{c}\text { Heptane } \\
(\mathrm{mL})\end{array}$ & $\begin{array}{c}\text { HDEHP } \\
(\mathrm{g})\end{array}$ & $\begin{array}{c}\text { Extracting efficiency } \\
\text { of } \mathrm{Zn} / \mathrm{Ca}(\%)\end{array}$ \\
\hline
\end{tabular}




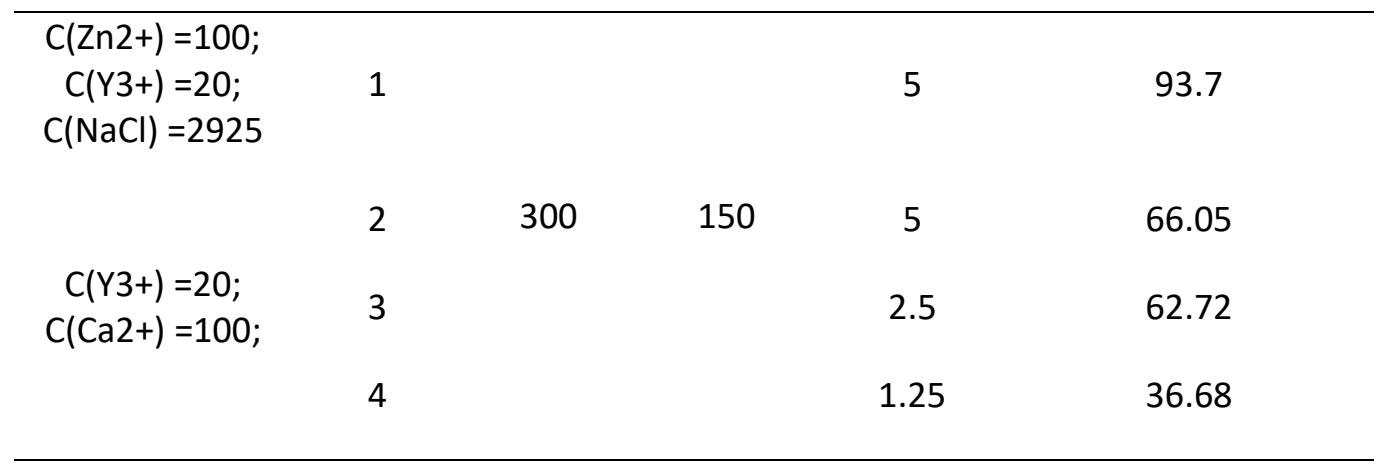

Figure 3.7 shows extraction results of both major ions and REEs using solvent extraction from sludge leaching solution from an AMD site. Extraction rates of REEs are high. For some major ions, barium (Ba) and iron (Fe), the extraction rates are also high. However, the initial concentration of Ba is very low (0.109 $\mathrm{mg} / \mathrm{L}$ ), absolute extraction amount of $\mathrm{Ba}$ is much less than other major ions. Thus, only Fe ions can be a problem. The ratio of REEs to major ions in leaching solution was about $0.3 \%$. The recovery efficiency of TREEs was approximately $50 \%$ while the purity of REEs increased to about $1 \%$. Therefore, a prior step is needed to remove Fe ions to increase purity of recovered REEs.

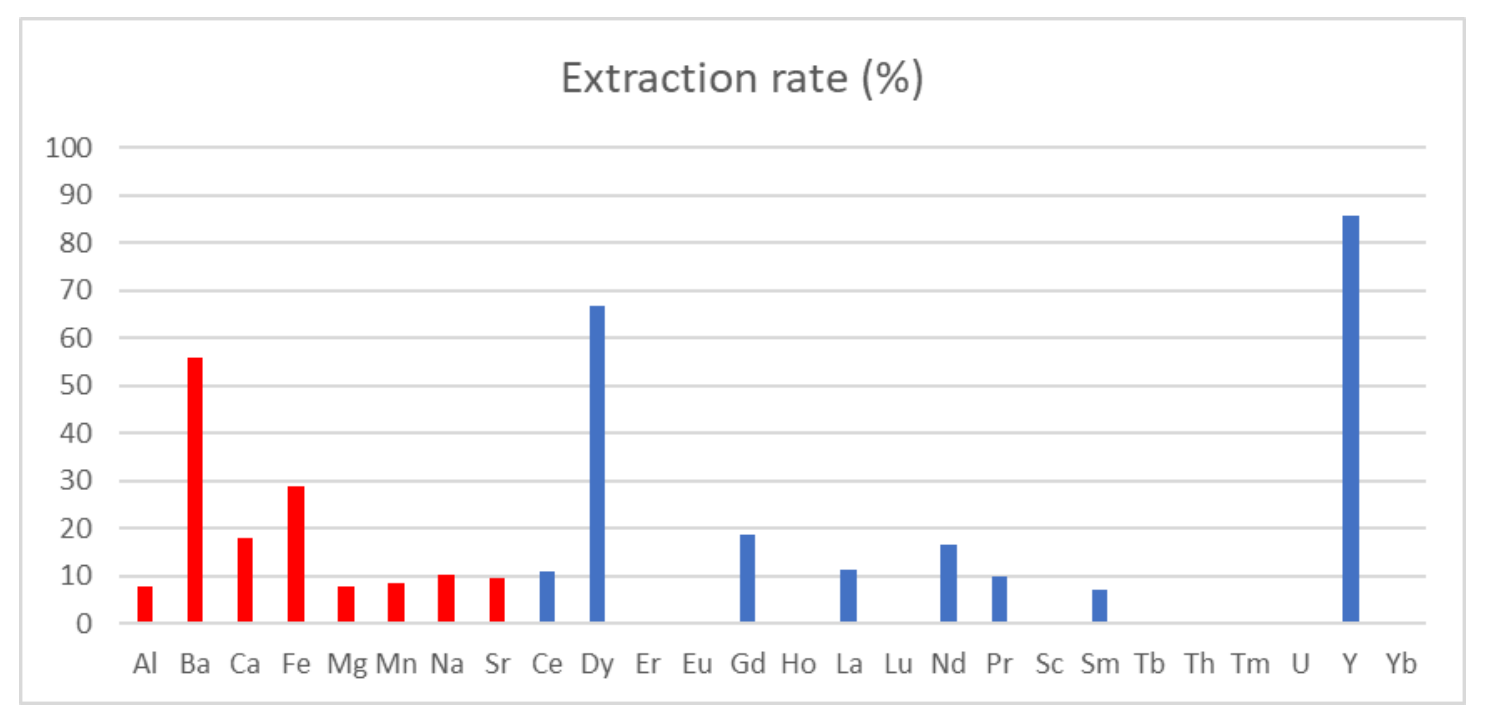

Figure 3.7 Initial results of separating REE ions from major ions in leaching solution by solvent extraction.

The effect of HDEHP percentage on the extracting efficiency of major metal ions was investigated using synthetic solution (Ca: $752.9 \mathrm{mg} / \mathrm{L}$, Fe: $215.98 \mathrm{mg} / \mathrm{L}, \mathrm{Mg}: 262.8 \mathrm{mg} / \mathrm{L}, \mathrm{Y}: 0.63 \mathrm{mg} / \mathrm{L}$ ). The extracting efficiency decreased with decreasing the percentage of HDEHP; however, the difference was not obvious. 
In order to separate REE from major metal ions, extracting efficiency of major metal ions should be as low as possible.

Solvent extraction results of major ions from two different synthetic solutions with the same concentrations of metal ions, with and without chloride ions are shown, Figure 3.8 and Figure 3.9 show that removal efficiency of Fe is much higher than $\mathrm{Ca}$ and $\mathrm{Mg}$. The existence of Fe ions is not good to the selectivity of the process. It will decrease the purity of REEs in the organic phase.

Prior research results have discussed this problem before. The co-extraction of Fe could be attributed to the formation of tetrachloroanions of Fe in the presence of chloride ions. (D. Kim et al., 2015)

$$
\begin{aligned}
& 2 \mathrm{Fe}+6 \mathrm{HCl} \rightarrow 2 \mathrm{FeCl}_{3}+3 \mathrm{H}_{2} \\
& \overline{\text { TODGA }}+\mathrm{FeCl}_{3}+\mathrm{HCl} \leftrightarrow \overline{\text { TODGA} \cdot \mathrm{H}^{+} \cdot \mathrm{FeCl}_{4}^{-}} \\
& \overline{3 \mathrm{TODGA} \cdot \mathrm{H}^{+} \cdot \mathrm{FeCl}_{4}^{-}}+\mathrm{Nd}^{3+}+3 \mathrm{Cl}^{-} \\
& \leftrightarrow \overline{\left[(\mathrm{TODGA})_{3} \mathrm{Nd}\right]^{3+}\left(\mathrm{FeCl}_{4}^{-}\right)_{3}}+3 \mathrm{HCl}
\end{aligned}
$$

Figure 3.8 and Figure 3.9 also show extraction rates of major ions are lower when the solution did not contain chloride ions. However, the extraction rate of Fe is still high. Removal of iron ions by adjusting $\mathrm{pH}$ or using other methods is necessary prior to recovering $\mathrm{Y}$ by solvent extraction.

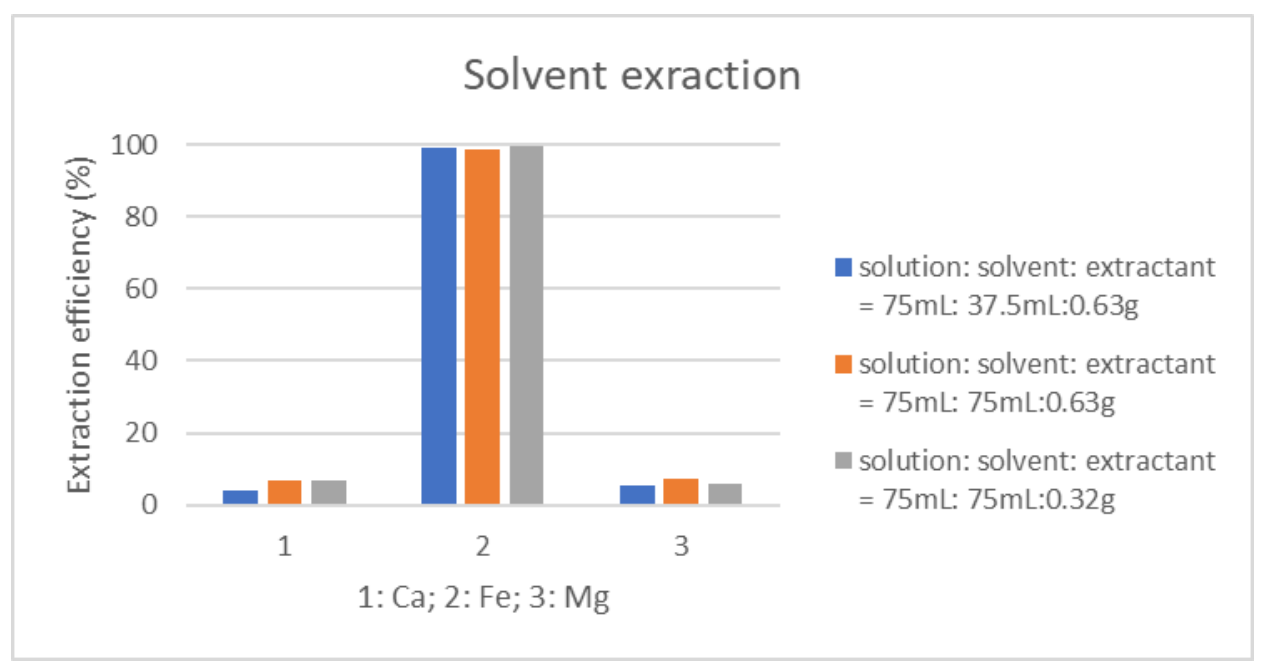

Figure 3.8 Extraction rate of major ions from solution with $\mathrm{Cl}^{-}$under different conditions. 


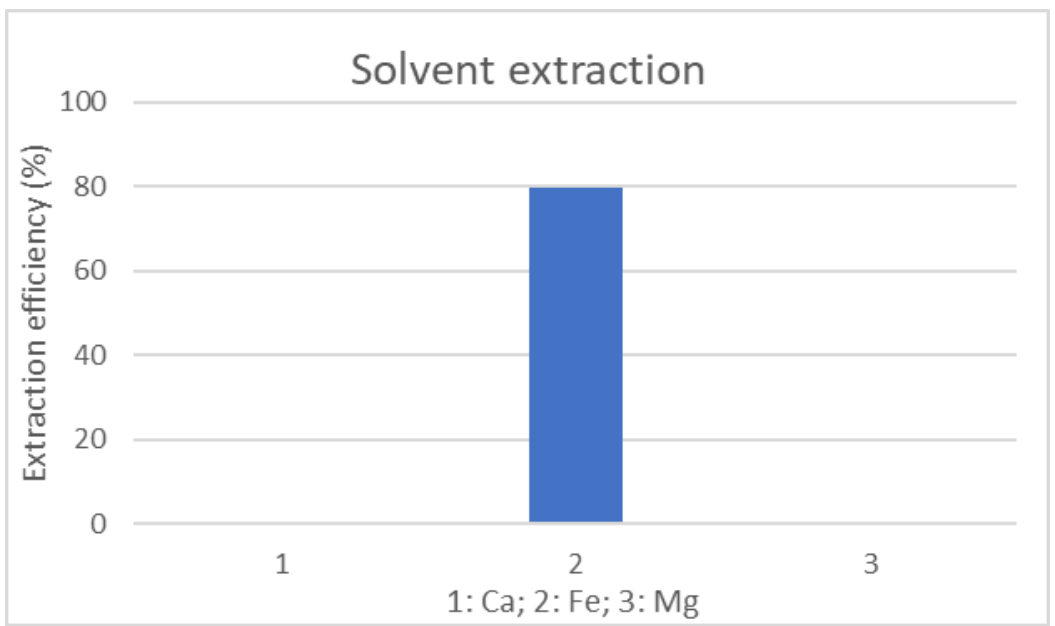

Figure 3.9 Extraction rate of major ions from solution without $\mathrm{Cl}^{-}(75 \mathrm{~mL}$ solution: $37.5 \mathrm{~mL}$ solvent: $0.63 \mathrm{gm}$ HDEHP).

Based on prior results, about 0.5\% HDEHP should be enough to extract $Y$ ions under this experimental condition. To reduce the co-extraction efficiency of Fe, which could be attributed to the formation of tetrachloroanions of Fe in the presence of chloride ions, a solution without chloride ions was used.

SX experiments were conducted using a synthetic solution (Ca: 752.9 mg/L, Fe: 215.98 mg/L, Mg: 262.8 $\mathrm{mg} / \mathrm{L}, \mathrm{Y}: 0.63 \mathrm{mg} / \mathrm{L}$, nitrate solution). The initial ratio of $Y$ to major ions in the synthetic solution was about $0.05 \%$. Concentrations of $Y$, see Table $3-5$, remaining in aqueous solution were measured by ICP-MS. After $\mathrm{pH}$ adjustment to remove Fe ions in the initial solution and before the SX step, the recovered $\mathrm{Y}$ in organic phase after solvent extraction was increased to $1.03 \%$. The recovery efficiency of $Y$ in the whole process was about $69 \%$ and the loss of $Y$ was mainly due to $\mathrm{pH}$ adjustment. During the SX step, the co-extraction efficiency of Fe was $98 \%$ while $\mathrm{Ca}$ and $\mathrm{Mg}$ were not co-extracted. Iron ions need to be removed by adjusting the $\mathrm{pH}$ prior to recovering $\mathrm{Y}$ by $\mathrm{SX}$. The recovery efficiency of the $\mathrm{Y}$ here was approximately $70 \%$, and the purity of $Y$ was increased from $0.05 \%$ to about $1 \%$.

Table 3-5 Results of pH adjustment and SX experiment.

\begin{tabular}{lllll}
\hline Solution & Description & $\mathbf{Y}(\mathbf{m g} / \mathrm{L})$ & $\begin{array}{l}\text { Extraction } \\
\text { efficiency of } \mathbf{Y}(\%)\end{array}$ & Remarks \\
\hline $752.9 \mathrm{mg} / \mathrm{L} \mathrm{Ca}^{2+} ;$ & $\begin{array}{l}\text { measured initial } \\
\text { concentration }\end{array}$ & 0.61 & - & $\begin{array}{l}\text { experimental } \\
\text { error (synthetic } \\
\text { solution) }\end{array}$ \\
$215.98 \mathrm{mg} / \mathrm{L} \mathrm{Fe}^{3+} ;$ & & & & sol
\end{tabular}




\begin{tabular}{lllll}
\hline $262.8 \mathrm{mg} / \mathrm{L} \mathrm{Mg}^{2+} ;$ & $\begin{array}{l}\text { after } \mathrm{pH} \text { adjustment }(2.27 \\
\text { to } 3.60) \text { to remove Fe ions }\end{array}$ & 0.42 & 31.15 & $\begin{array}{l}\text { objective: as low } \\
\text { as possible }\end{array}$ \\
$\begin{array}{llll}0.63 \mathrm{mg} / \mathrm{L} \mathrm{Y}^{3+} \mathrm{w} / \mathrm{o} \\
\text { Chloride }\end{array}$ & after solvent extraction & $<0.01$ & $>97.62$ & $\begin{array}{l}\text { objective: as high } \\
\text { as possible }\end{array}$
\end{tabular}

\subsubsection{REEs recovery from sludge with high Iron composition}

\subsubsection{Leach acid and $\mathrm{pH}$ effect}

Leaching, solvent extraction experiments for sludge from the McV site to recover REEs have been conducted and the effect of $\mathrm{pH}$ on solvent extraction efficiency has been studied. Nitric acid and sulfuric acid solutions were used for leaching process under different $\mathrm{pH}$ values. For leaching, the solution $\mathrm{pH}$ can't be lower than 2.0 in order to reduce competitive extraction nor can it be higher than 4.0 in order to reduce REE loss.

When using sulfuric acid solution for the leaching process, most metal ions were dissolved under a pH of 2. While under a pH of 3.5, most REEs were dissolved while only part major metal ions were dissolved. Especially for iron (Fe), almost no Fe ions were dissolved, Figure 3.10 and Figure 3.11. Due to the competitive extraction between Fe and REEs, feed solution with a pH of 3.5 is more beneficial to enrich REEs than a pH of 2.0. The extraction efficiency of REEs was $95.38 \%$ while the extraction efficiency of MM (major metal ions) was $30.35 \%$ for the $\mathrm{pH} 3.5$ feed solution, Table 3-6.

Leaching experiments on $\mathrm{McV}$ sludge were also done using $\mathrm{HNO}_{3}$ under $\mathrm{pH}$ of 2.0 and 3.5, Figure 3.12 and Figure 3.13. Leaching sludge to $\mathrm{pH}$ of about 3.5 is very useful to remove iron ions. Also, $\mathrm{H}_{2} \mathrm{SO}_{4}$ was better at leaching Iron and Magnesium ions than $\mathrm{HNO}_{3}$. But $\mathrm{HNO}_{3}$ was better at leaching Calcium ions. To reduce major metal ions leaching, $\mathrm{HNO}_{3}$ was better for feed solution preparation. Solvent extraction experiments to recover REEs have been conducted using feed solution from the leaching process. The ratio of solution to solvent to extractant was $100 \mathrm{~mL}: 100 \mathrm{~mL}: 0.84 \mathrm{~g}$. Concentrations of REEs remaining in solution after solvent extraction are very low indicating most are extracted in the organic phase. However, concentrations of major metal ions remaining in solution after solvent extraction are very high, Figure 3.13. Major metal ions are almost not extracted to organic phase (1.84\%) while most of REEs are extracted (96.25\%), Table 3-6.

When the anions in the feed solution are nitrate ions, the extraction efficiency of REEs was very high. When the anions in the feed solution are sulfate ions, the extraction rate of REEs was relatively low, 
especially when the $\mathrm{pH}$ is very low. Based on these results, the $\mathrm{pH}$ of the feed solution can't be too low in order to reduce competitive extraction. $\mathrm{HNO}_{3}$ is more beneficial for extraction of $\mathrm{REEs}$ than $\mathrm{H}_{2} \mathrm{SO}_{4}$.

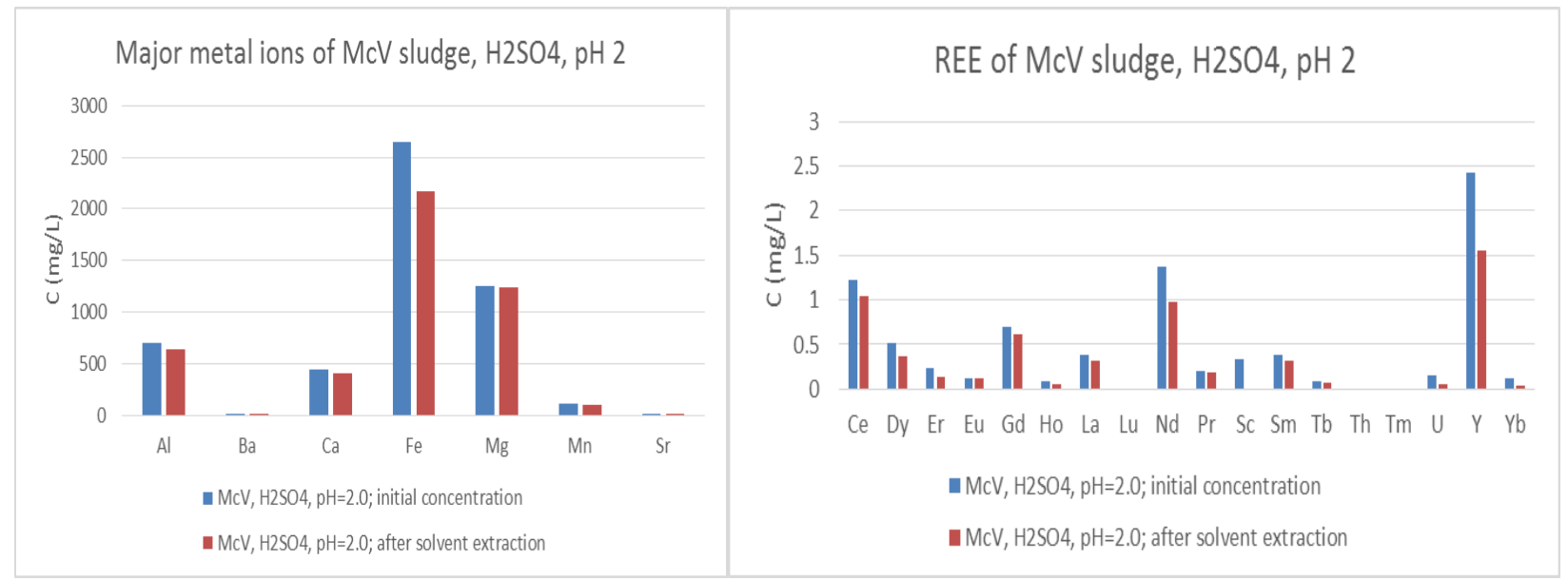

Figure 3.10 Metal ions data of sulfuric acid leaching solution of McVille sludge under pH of 2.0.

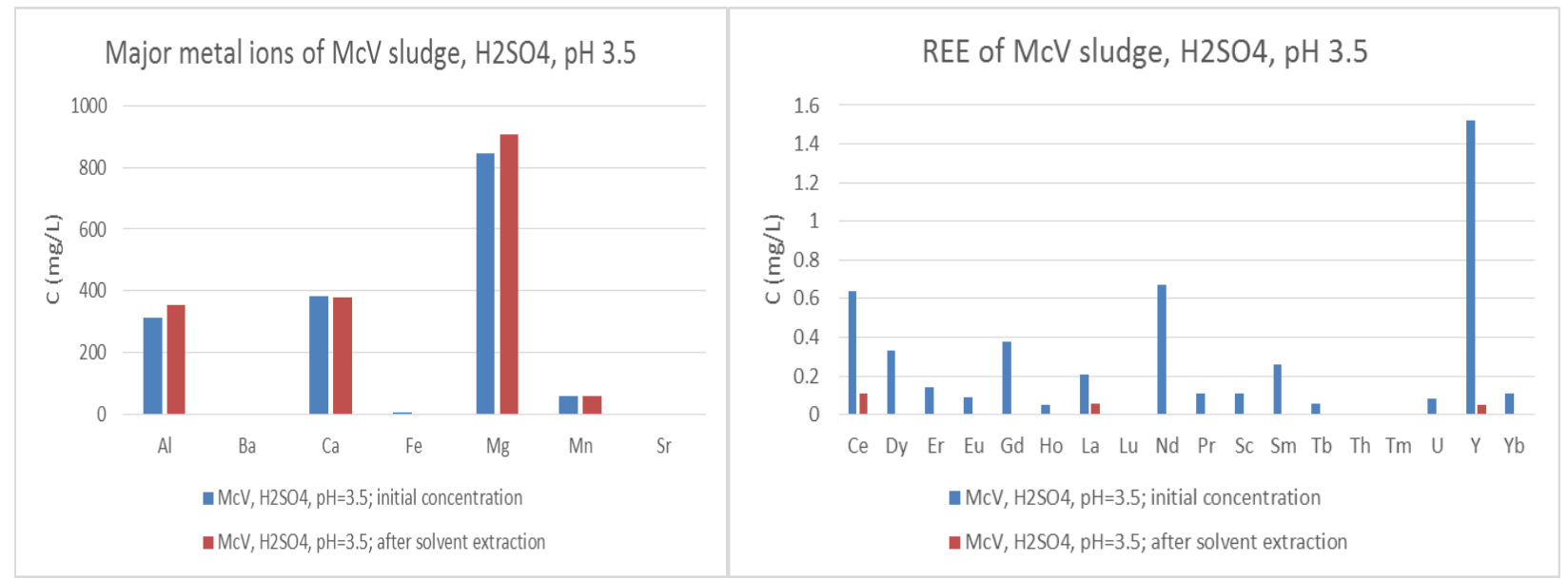

Figure 3.11 Metal ions data of sulfuric acid leaching solution of McVille sludge under pH of 3.5. 


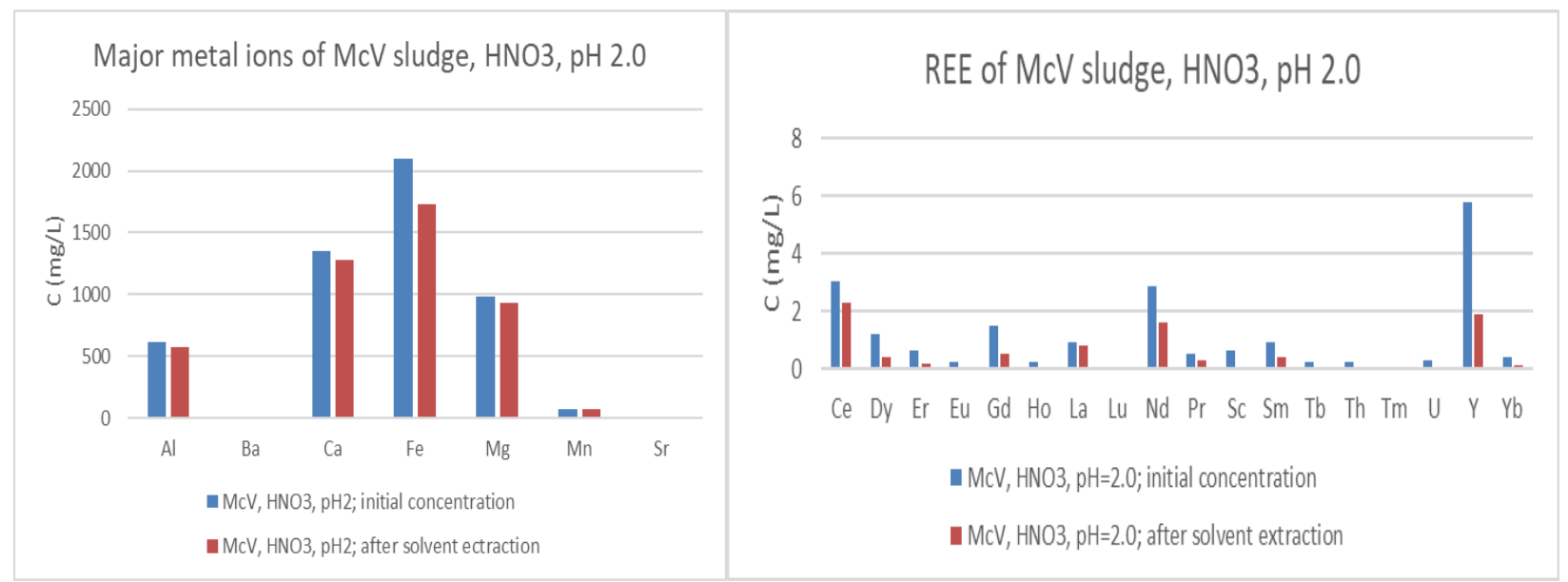

Figure 3.12 Metal ions data of nitric acid leaching solution of McVille sludge under pH of 2.0.

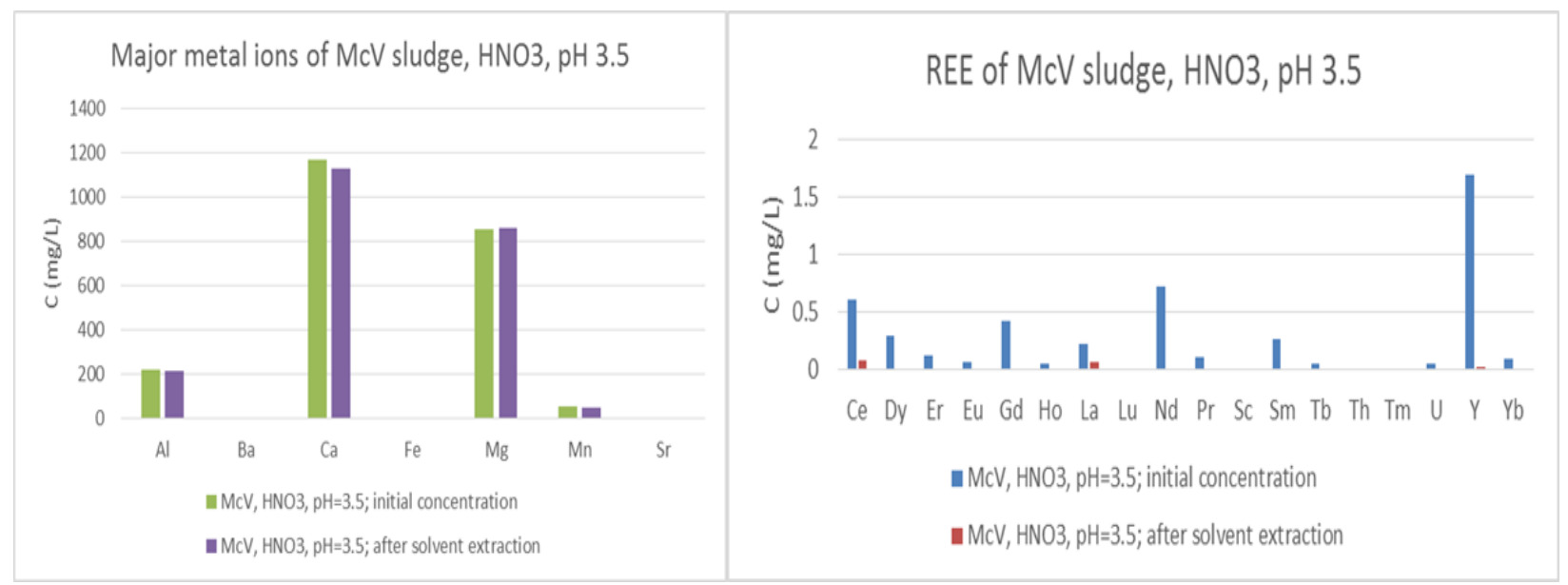

Figure 3.13 Metal ions data of nitric acid leaching solution of McVille sludge under pH of 3.5.

Table 3-6 Results of solvent extraction experiment for McVille sludge under different pH values.

\begin{tabular}{|c|c|c|c|c|c|c|c|c|}
\hline \multirow{2}{*}{ acid } & \multirow{2}{*}{$\mathrm{pH}$} & \multirow{2}{*}{ Treatment } & \multicolumn{2}{|c|}{ TMM } & \multicolumn{2}{|c|}{ TREE } & \multirow{2}{*}{$\begin{array}{l}\text { ^TREE } \\
\text { solid }\end{array}$} & \multirow{2}{*}{$\begin{array}{l}\text { Enrich } \\
\text { factor }\end{array}$} \\
\hline & & & $\mathrm{mg} / \mathrm{L}$ & \% extr. & $\mathrm{mg} / \mathrm{L}$ & \% extr. & & \\
\hline $\mathrm{HNO}_{3}$ & 2.0 & Initial & 5112.14 & & 19.77 & & $0.39 \%$ & \\
\hline $\mathrm{HNO}_{3}$ & 2.0 & After SX & 4585.06 & $10.31 \%$ & 8.98 & $54.58 \%$ & $2.01 \%$ & 5.2 \\
\hline $\mathrm{HNO}_{3}$ & 3.5 & Initial & 2304.77 & & 4.80 & & $0.21 \%$ & \\
\hline $\mathrm{HNO}_{3}$ & 3.5 & After SX & 2262.39 & $1.84 \%$ & 0.18 & $96.25 \%$ & $9.83 \%$ & 47.3 \\
\hline $\mathrm{H}_{2} \mathrm{SO}_{4}$ & 2.0 & Initial & 5164.02 & & 8.37 & & $0.16 \%$ & \\
\hline $\mathrm{H}_{2} \mathrm{SO}_{4}$ & 2.0 & After SX & 4545.07 & $11.99 \%$ & 5.83 & $30.35 \%$ & $0.41 \%$ & 2.5 \\
\hline $\mathrm{H}_{2} \mathrm{SO}_{4}$ & 3.5 & Initial & 1615.73 & & 4.76 & & $0.29 \%$ & \\
\hline
\end{tabular}




$\begin{array}{lllllllll}\mathrm{H}_{2} \mathrm{SO}_{4} & 3.5 & \text { After SX } & 1708.35 & -5.73 \% & 0.22 & 95.38 \% & -5.15 \% & -\end{array}$

Remarks: Est. TREE in solid phase is calculated as total mass (concentration of cations times solution volume) of rare earth cations over total mass of rare earth cations and major metal cations.

Leaching and solvent extraction, and acid stripping experiments for sludge from the McV site to recover REEs have been conducted under a pH of 4.0. For major ions under $\mathrm{pH} 4.0$, only part of calcium (Ca) and magnesium (Mg) compounds were dissolved, Figure 3.14. For REE compounds, most of them were not dissolved. Therefore, a pH of 4.0 can't be used for the leaching process in order to reduce the REE loss.

During the solvent extraction step, the ratio of solution to solvent to extractant was $100 \mathrm{~mL}: 150 \mathrm{~mL}: 0.84$ g. The extraction rates of REEs were almost $100 \%$. But estimated TREE in solid phase were only $0.571 \%$ for McV sludge due to low TREE concentration in the leaching solution. After solvent extraction, acid stripping experiments of REEs back into aqueous phase were conducted. $30 \mathrm{~mL} 7.0 \% \mathrm{HNO}_{3}$ solution was used for the acid stripping process; but, concentrations of REEs were very low in the stripping solution. Stripping efficiency of TREE using diluted nitric acid solution was also very low, less than $21.0 \%$, Table 3-7.

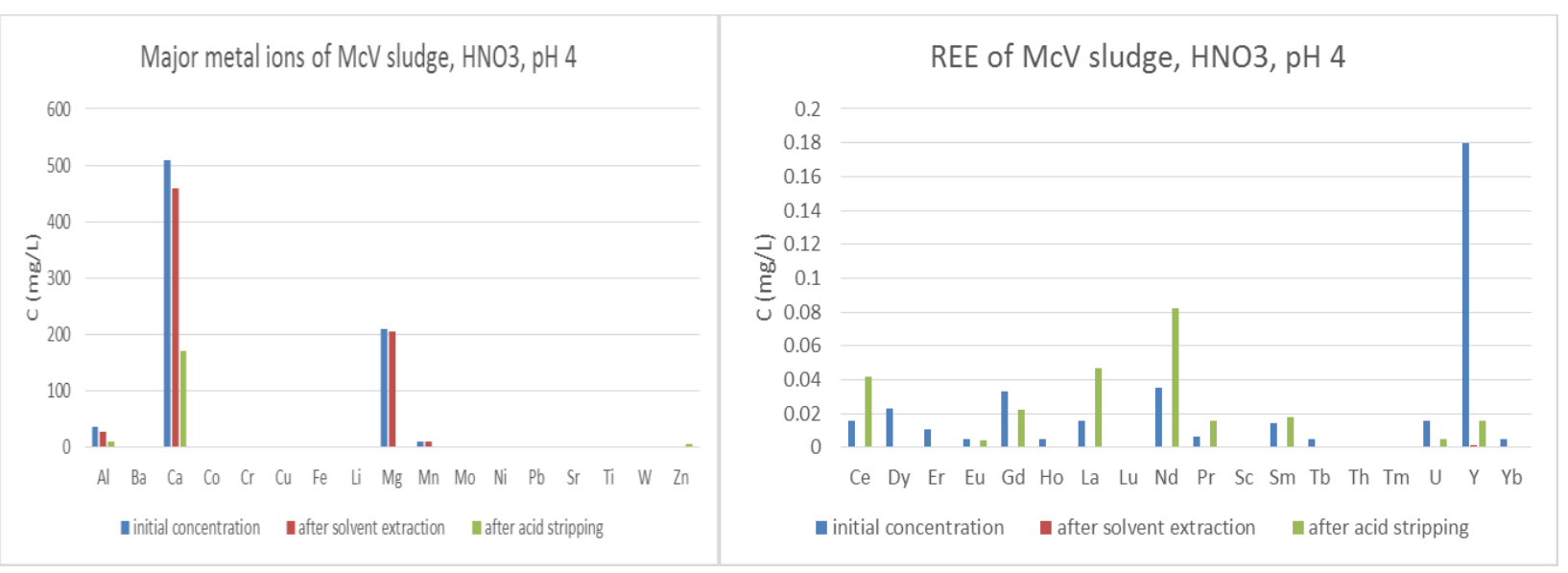

Figure 3.14 Metal ions data of nitric acid leaching solution from McVille site under pH 4.0.

Table 3-7 Results of solvent extraction experiment for McVille sludge under initial pH 4.0.

\begin{tabular}{ccccccc}
\hline \multirow{2}{*}{ Treatment } & \multicolumn{2}{c}{ TMM } & \multicolumn{2}{c}{ TREE } & ^TREE & Enrich. \\
& $\mathrm{mg} / \mathrm{L}$ & $\%$ extr. & $\mathrm{mg} / \mathrm{L}$ & $\%$ extr. & solid & factor \\
\hline PLS & 771.69 & & 0.37 & & $0.05 \%$ & \\
RA & 707.41 & $8.33 \%$ & 0.001 & $\mathbf{9 9 . 7 3 \%}$ & $0.57 \%$ & 11.9 \\
AST & 190.115 & $88.73 \%$ & 0.252 & $20.49 \%$ & $0.13 \%$ & 2.8 \\
\hline
\end{tabular}

$\mathrm{PLS}=$ pregnant leach solution $\left(5 \mathrm{~g}\right.$ wet sludge $+100 \mathrm{~mL}$ diluted $\mathrm{HNO}_{3}$ ) 
RA=raffinate after $S X$

AST=acid strip

\subsubsection{Phase volume ratio effect}

Leaching, solvent extraction, and acid stripping experiments for sludge from the McV site were conducted. Nitric acid ( $\mathrm{HNO}_{3}$ ) was used for the leaching process and the feed solution used for solvent extraction was $\mathrm{pH}$ 1.1, clear solution. Extractant HDEHP was used for all solvent extraction processes.

For solvent extraction experiments, three ratios of solution to solvent to extractant were used: (b) $100 \mathrm{~mL}$ solution + $100 \mathrm{~mL}$-heptane + $0.56 \mathrm{~g}$ HDEHP; (c) $100 \mathrm{~mL}$ solution + $150 \mathrm{~mL}$-heptane + $0.84 \mathrm{~g}$ HDEHP; and (d) $100 \mathrm{~mL}$ solution $+200 \mathrm{~mL}$-heptane $+1.12 \mathrm{~g}$ HDEHP. The volume of solvent and extractant mixer changed: $b<c<d$.

Extraction efficiencies of REEs were all lower than $30 \%, 25.0 \%$ (b) $<26.6 \%$ (c) $<29.8 \%$ (d), Table $3-8$, due to the very low $\mathrm{pH}$ of feed solution. The recovered REEs in organic phase after SX was mainly from yttrium (Y) and dysprosium (Dy). However, extraction efficiency of major metal ions increased rapidly, 5.3\% (b) < $7.3 \%$ (c) < $12.6 \%$ (d), Table 3-8. Extraction of major metal ions was mainly from iron (Fe), as shown in Figure 3.15. Thus, the estimated TREE in solid phase was calculated as $0.74 \%$ (b) $<0.57 \%$ (c) $<0.37 \%$ (d), indicating under low pH conditions, increasing organic phase volume ratio did not help enrich REEs.

The same acid stripping parameters were used for organic phase after three solvent extraction experiments. $100 \mathrm{~mL} \mathrm{9 \%} \mathrm{HCl}$ acid solution at room temperature $26^{\circ} \mathrm{C}$ was used for acid stripping. Acid stripping efficiency of REEs was about $80 \%$ while that of major metal ions was $100 \%$, Table $3-8$. The estimated TREE in solid phase was calculated as $0.41 \%$. The enrichment factor was only 2.6. Pretreatment, like $\mathrm{pH}$ adjustment, of feed solution is therefore necessary for SX.

Table 3-8 Phase volume ratio effect results of solvent extraction experiment for McV sludge leaching solution pH 1.1.

\begin{tabular}{|c|c|c|c|c|c|c|c|c|}
\hline \multirow{2}{*}{ Treatment } & \multicolumn{3}{|c|}{ TMM } & \multicolumn{3}{|c|}{ TREE } & \multirow{2}{*}{$\begin{array}{l}\wedge T R E E \\
\text { solid \% }\end{array}$} & \multirow{2}{*}{$\begin{array}{l}\text { Enrich. } \\
\text { factor }\end{array}$} \\
\hline & $\mathrm{mg} / \mathrm{L}$ & $\mathrm{mg}$ & $\%$ extr. & $\mathrm{mg} / \mathrm{L}$ & $\mathrm{mg}$ & $\%$ extr. & & \\
\hline $\mathrm{PLS}^{\mathrm{a}}$ & 785.3 & & & 1.24 & & & $0.16 \%$ & \\
\hline $\mathrm{RA}^{\mathrm{b}}$ & 743.6 & 4.17 & $5.30 \%$ & 0.93 & 0.031 & $25.00 \%$ & $0.74 \%$ & 4.68 \\
\hline $\mathrm{RA}^{\mathrm{c}}$ & 728.2 & 5.71 & $7.30 \%$ & 0.91 & 0.033 & $26.60 \%$ & $0.57 \%$ & 3.64 \\
\hline $\mathrm{RA}^{\mathrm{d}}$ & 686.7 & 9.86 & $12.60 \%$ & 0.87 & 0.037 & $29.80 \%$ & $0.37 \%$ & 2.37 \\
\hline
\end{tabular}




\begin{tabular}{|c|c|c|c|c|c|c|c|c|}
\hline AST e & 65.29 & 6.53 & $156.60 \%$ & 0.27 & 0.027 & $87.10 \%$ & $0.41 \%$ & 2.61 \\
\hline AST $^{f}$ & 43.98 & 6.6 & $115.50 \%$ & 0.16 & 0.024 & $72.70 \%$ & $0.36 \%$ & 2.3 \\
\hline AST $^{g}$ & 58.13 & 11.63 & $117.90 \%$ & 0.15 & 0.03 & $81.10 \%$ & $0.26 \%$ & 1.63 \\
\hline \multicolumn{9}{|c|}{ a $300 \mathrm{~mL}$ solution from ( $25 \mathrm{~L}$ water $+375 \mathrm{~mL} 70 \% \mathrm{HNO}+1.25 \mathrm{~kg}$ wet McV sludge) } \\
\hline \multicolumn{6}{|c|}{ b $100 \mathrm{~mL}$ solution + $100 \mathrm{~mL}$ n-heptane $+0.56 \mathrm{~g}$ HDEHP } & \multicolumn{3}{|l|}{ Code: } \\
\hline \multicolumn{6}{|c|}{ c $100 \mathrm{~mL}$ solution $+150 \mathrm{~mL}$-heptane $+0.84 \mathrm{~g}$ HDEHP } & \multicolumn{3}{|c|}{ PLS=pregnant leach solution } \\
\hline \multicolumn{6}{|c|}{ d $100 \mathrm{~mL}$ solution $+200 \mathrm{~mL}$-heptane $+1.12 \mathrm{~g}$ HDEHP } & \multicolumn{3}{|c|}{$\mathrm{RA}=$ raffinate after $\mathrm{SX}$} \\
\hline \multicolumn{6}{|c|}{ e $100 \mathrm{~mL}$ acid solution $+100 \mathrm{~mL}$ organic phase from $\mathrm{b}(9 \% \mathrm{HCl}$ at $\mathrm{RT})$} & \multirow{2}{*}{\multicolumn{3}{|c|}{ AST=acid strip }} \\
\hline \multicolumn{6}{|c|}{${ }^{f} 150 \mathrm{~mL}$ acid solution $+150 \mathrm{~mL}$ organic phase from c $(9 \% \mathrm{HCl}$ at RT) } & & & \\
\hline \multicolumn{9}{|c|}{ g $200 \mathrm{~mL}$ acid solution $+200 \mathrm{~mL}$ organic phase from d (9\% HCl at RT) } \\
\hline
\end{tabular}

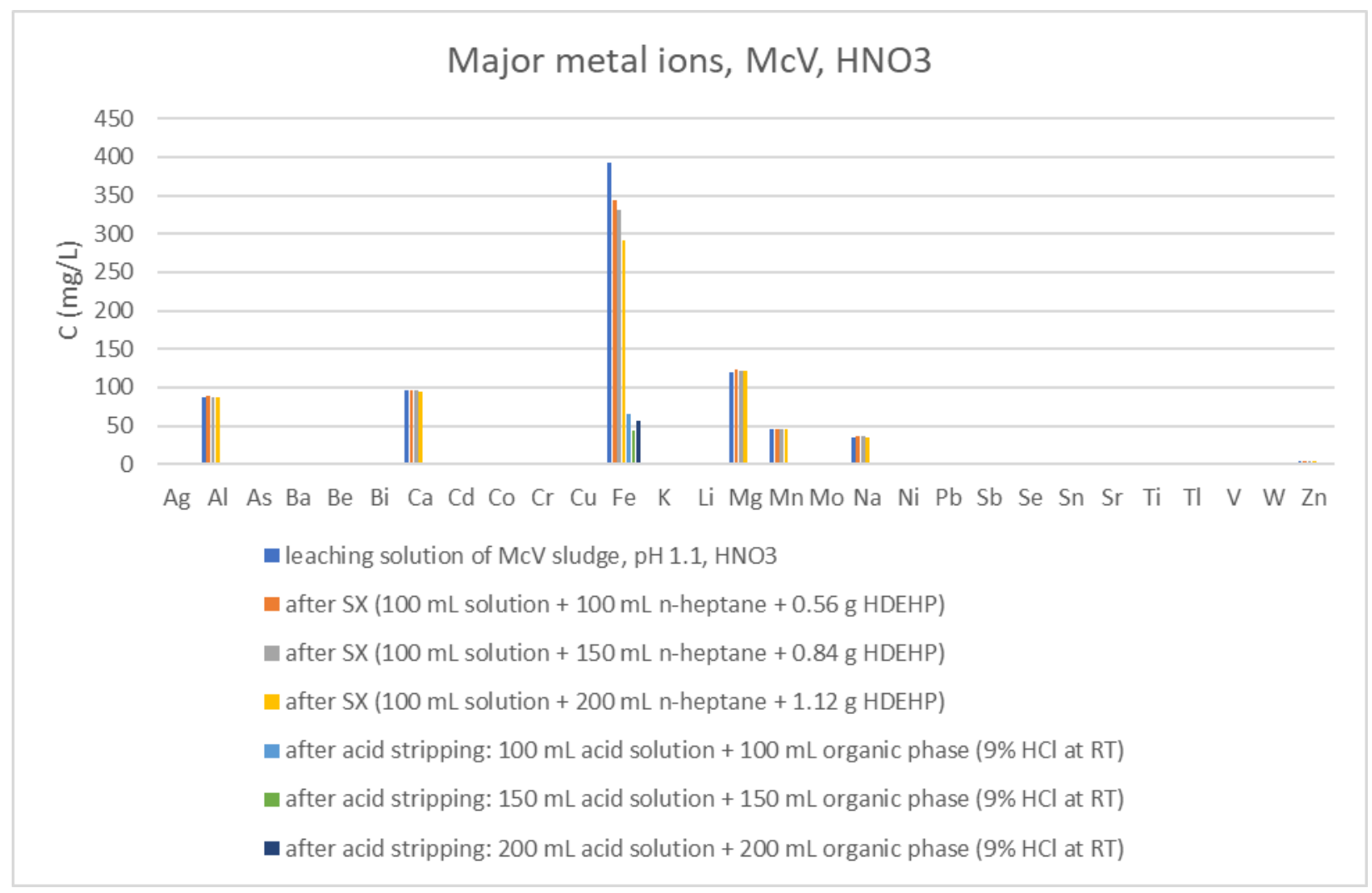




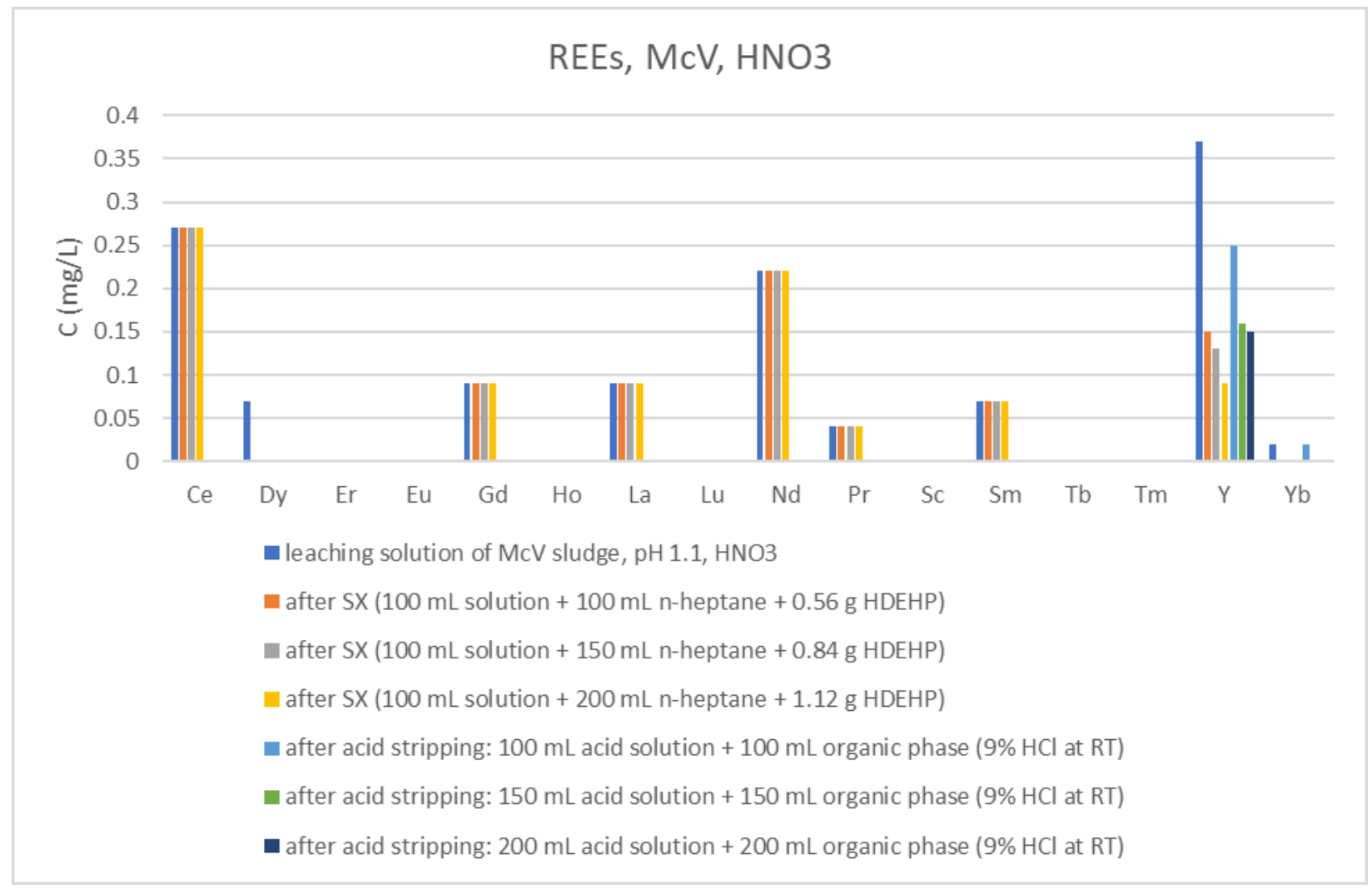

Figure 3.15 Metal ions and REE results from McV sludge leaching and SX data pH 1.1.

\subsubsection{REEs recovery from sludge with low Iron composition}

\subsubsection{1 $\mathrm{pH}$ effect}

Leaching and solvent extraction experiments for sludge from DLM site to recover REEs have been conducted under a $\mathrm{pH}$ of 4.0, Figure 3.16. For leaching solution of sludge from the DLM site, the total REE ratios are much higher than those from the $\mathrm{McV}$ site. $\mathrm{HNO}_{3}$ was found to be of greater benefit for the extraction of REEs than $\mathrm{H}_{2} \mathrm{SO}_{4}$. Thus, nitric acid was used for following leaching process.

During the solvent extraction step, the ratio of solution to solvent to extractant was $100 \mathrm{~mL}: 150 \mathrm{~mL}: 0.84$ g. The extraction rates of REEs were almost $100 \%$. But estimated TREE in solid phase was $2.67 \%$ for DLM sludge. After solvent extraction, acid stripping experiments of REEs back into aqueous phase were conducted. $30 \mathrm{~mL} 7.0 \% \mathrm{HNO}_{3}$ solution was used for the acid stripping process; but, concentrations of REEs were very low in the stripping solution. Stripping efficiency of TREE using nitric acid solution was also very low, less than $12 \%$, Table 3-9. 


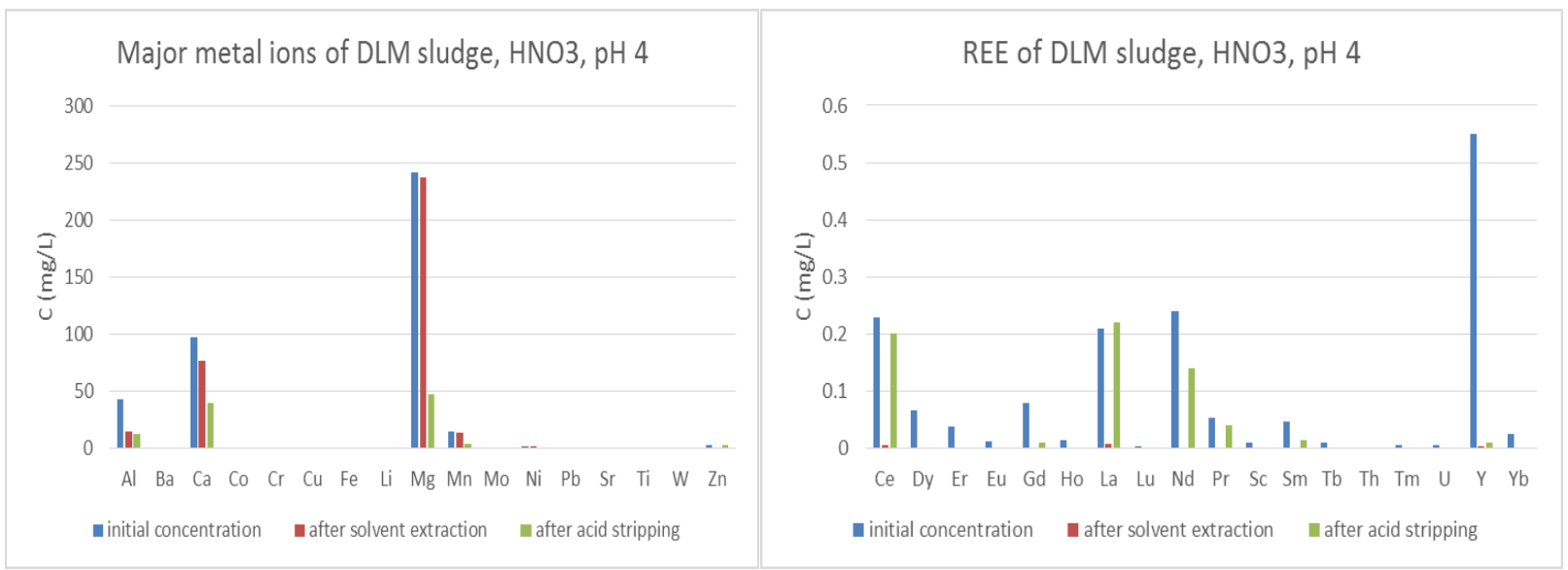

Figure 3.16 Metal ions data of nitric acid leaching solution from DLM site under pH 4.0.

Table 3-9 Results of solvent extraction experiment for DLM sludge under pH 4.0.

\begin{tabular}{ccccccc}
\hline \multirow{2}{*}{ Treatment } & \multicolumn{2}{c}{ TMM } & \multicolumn{2}{c}{ TREE } & ^TREE & Enrich. \\
& $\mathrm{mg} / \mathrm{L}$ & $\%$ extr. & $\mathrm{mg} / \mathrm{L}$ & $\%$ extr. & solid & factor \\
\hline PLS & 403.11 & & 1.608 & & $0.40 \%$ & \\
RA & 345.01 & $14.40 \%$ & 0.017 & $98.94 \%$ & $2.67 \%$ & 6.7 \\
AST & 106.443 & $55.00 \%$ & 0.635 & $11.97 \%$ & $0.59 \%$ & 1.5 \\
\hline PLS=pregnant leach solution $\left(5\right.$ g wet sludge $+100 \mathrm{~mL}$ diluted $\left.\mathrm{HNO}_{3}\right)$ & \\
RA=raffinate after SX \\
AST=acid strip
\end{tabular}

Leaching and solvent extraction experiments for sludge from the DLM site to recover REE were conducted under $\mathrm{pH}$ 3.2. For major ions, most aluminum compounds were dissolved except for calcium and magnesium compounds comparing to results under $\mathrm{pH}$ 4. More REEs were dissolved under $\mathrm{pH} 3.2$ than under $\mathrm{pH}$ 4. During the solvent extraction step, the ratio of solution to solvent to extractant was $100 \mathrm{~mL}$ : $150 \mathrm{~mL}: 0.84 \mathrm{~g}$. The estimated REEs in solid phase increased from $0.63 \%$ to $5.85 \%$ after solvent extraction. The enrichment factor for the solvent extraction step is 9.2. After solvent extraction, acid stripping of REEs back into the aqueous phase was also conducted. $\mathrm{HNO}_{3}$ is beneficial for extraction while $\mathrm{H}_{2} \mathrm{SO}_{4}$ is not. Thus $50 \mathrm{~mL} 9.8 \% \mathrm{H}_{2} \mathrm{SO}_{4}$ solution was used to strip REEs, which is the reverse reaction of extraction. But concentrations of REEs were still very low in the stripping solution. Stripping efficiency of REEs using sulfate acid solution was very low, less than $20.0 \%$, see Table $3-10$. However, the acid stripping step reconcentrated the REEs and the estimated TREEs in the solid phase increased to $8.63 \%$. 
After adjusting leaching solution of $\mathrm{pH} 3.2$ to $\mathrm{pH} 3.6$, concentrations of metal ions didn't change much, but concentration of Fe decreased obviously, Figure 3.17 and Figure 3.18; however, they were much higher than under $\mathrm{pH} 4$, see Figure 3.16. During the solvent extraction step, the ratio of solution to solvent to extractant was $100 \mathrm{~mL}: 150 \mathrm{~mL}: 0.84 \mathrm{~g}$. The enrichment factor for the solvent extraction step is 12.6 , higher than $\mathrm{pH}$ 3.2. After solvent extraction, acid stripping of REEs back into the aqueous phase was also conducted. $50 \mathrm{~mL}$ 9.8\% $\mathrm{H}_{2} \mathrm{SO}_{4}$ solution was used to strip REEs. Stripping efficiency of REEs was also very low, see Table 3-10. Based on results presented in Table 3-9 and Table 3-10, pH 3.2 is better than 3.6 to enrich REEs and is much better than $\mathrm{pH} 4$; but, the stripping efficiency of REE using $\mathrm{H}_{2} \mathrm{SO}_{4}$ solution was still low.

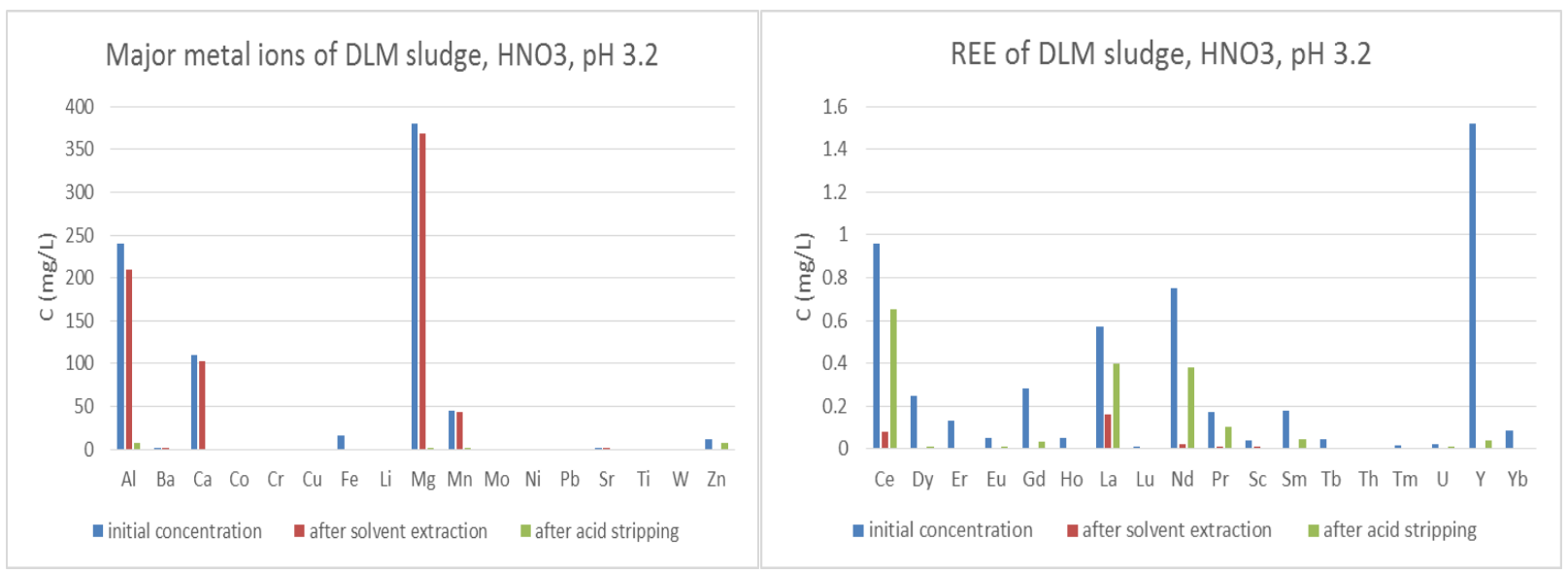

Figure 3.17 Metal ions data of nitric acid leaching solution from DLM site under pH 3.2.

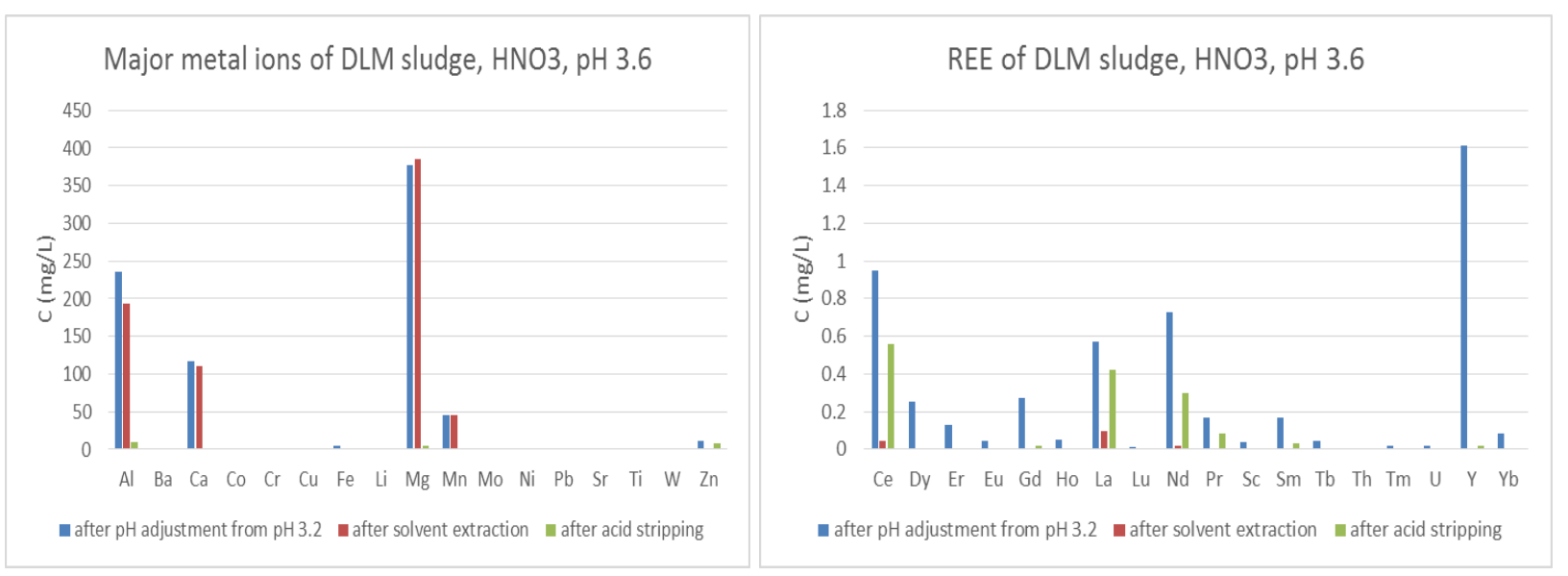

Figure 3.18 Metal ions data of nitric acid leaching solution from DLM site under pH 3.6.

Table 3-10 Results of solvent extraction experiment for DLM sludge under different pH values. 


\begin{tabular}{|c|c|c|c|c|c|c|c|}
\hline \multirow{2}{*}{$\mathrm{pH}$} & \multirow{2}{*}{ Treatment } & \multicolumn{2}{|c|}{ TMM } & \multicolumn{2}{|r|}{ TREE } & \multirow{2}{*}{$\begin{array}{l}\text { ^TREE } \\
\text { solid }\end{array}$} & \multirow{2}{*}{$\begin{array}{l}\text { Enrich } \\
\text { factor }\end{array}$} \\
\hline & & $\mathrm{mg} / \mathrm{L}$ & $\%$ extr. & $\mathrm{mg} / \mathrm{L}$ & $\%$ extr. & & \\
\hline \multirow[t]{3}{*}{3.2} & PLS & 803.25 & & 5.131 & & $0.63 \%$ & \\
\hline & RA & 725.25 & $9.71 \%$ & 0.281 & $94.52 \%$ & $5.85 \%$ & 9.2 \\
\hline & AST & 17.7 & $11.35 \%$ & 1.672 & $17.24 \%$ & $8.63 \%$ & 13.6 \\
\hline \multirow[t]{3}{*}{3.6} & PLS & 791.5 & & 5.162 & & $0.65 \%$ & \\
\hline & RA & 735.6 & $7.06 \%$ & 0.174 & $96.63 \%$ & $8.19 \%$ & 12.6 \\
\hline & AST & 22.7 & $20.30 \%$ & 1.451 & $14.54 \%$ & $6.01 \%$ & 9.3 \\
\hline \multicolumn{4}{|c|}{ SX (100 mL solution:150 mL n-heptane:0.84 g HDEHP) } & Code: & \multicolumn{3}{|c|}{ PLS=pregnant leach solution } \\
\hline \multicolumn{4}{|c|}{ Acid stripping $\left(50 \mathrm{~mL} 9.8 \% \mathrm{H}_{2} \mathrm{SO}_{4}\right)$} & & \multicolumn{3}{|c|}{$\mathrm{RA}=$ raffinate after $\mathrm{SX}$} \\
\hline
\end{tabular}

Leaching and solvent extraction experiments for sludge from the DLM site to recover REE were conducted under $\mathrm{pH}$ 1.4. REE concentrations in the initial solution were almost twice than under $\mathrm{pH}$ 3.2. While of the major metal ions, only aluminum and magnesium increased substantially at the lower pH, see Figure 3.19. For the $\mathrm{pH} 1.4$ solution, solvent extraction efficiency for both major metal ions and REE were less than $50 \%$ for both solvents (Table 3-11). The higher hydrogen ion concentration is working against the desired direction of the SX reaction.

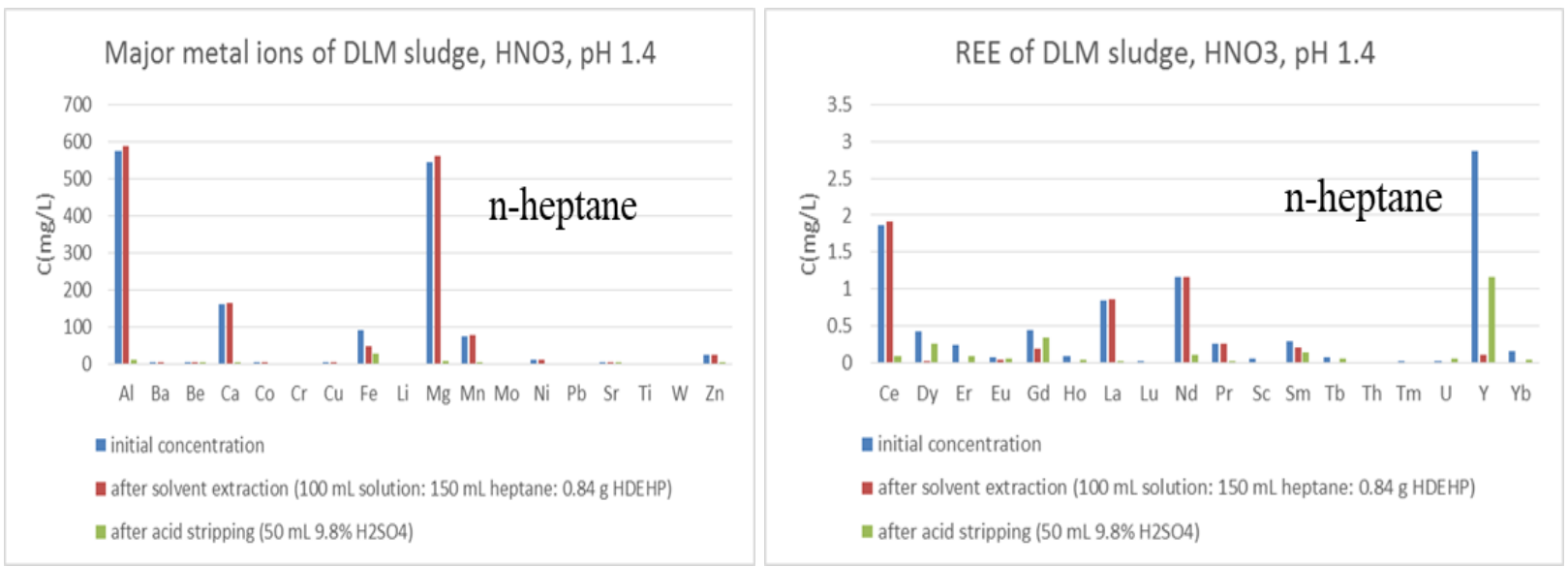

Figure 3.19 Metal ions and REE from DLM sludge (pH 1.4), n-heptane solvent.

Table 3-11 Results of ALSX experiment using DLM leaching solution of pH 1.4 and two different solvents.

\begin{tabular}{ccccccccc}
\hline & \multicolumn{3}{c}{ TMM } & \multicolumn{3}{c}{ TREE } & \multirow{2}{\wedge}{ TREE } & Enrich. \\
\cline { 2 - 6 } Treatment & $\mathrm{mg} / \mathrm{L}$ & $\mathrm{mg}$ & $\%$ extr. & $\mathrm{mg} / \mathrm{L}$ & $\mathrm{mg}$ & $\%$ extr. & solid \% & factor \\
\hline PLS & 1487.74 & & & 8.97 & & & $0.60 \%$ & \\
RA $^{\mathrm{a}}$ & $1406.52^{\#}$ & 8.12 & $5.46 \%$ & 4.85 & 0.41 & $45.98 \%$ & $4.83 \%$ & 8.06
\end{tabular}




\begin{tabular}{|c|c|c|c|c|c|c|c|c|}
\hline $\mathrm{AST}^{\mathrm{b}}$ & 52.42 & 2.62 & $32.27 \%$ & 2.55 & 0.13 & $30.90 \%$ & $4.63 \%$ & 7.73 \\
\hline PLS & 1487.74 & & & 8.97 & & & $0.60 \%$ & \\
\hline $\mathrm{RA}^{\mathrm{c}}$ & 1423.83 & 6.39 & $4.30 \%$ & 4.58 & 0.44 & $49.01 \%$ & $6.44 \%$ & 10.74 \\
\hline AST & 65.99 & 3.3 & $51.60 \%$ & 2.46 & 0.12 & $27.90 \%$ & $3.59 \%$ & 5.99 \\
\hline \multicolumn{7}{|c|}{${ }^{\mathrm{a}} 100 \mathrm{~mL}$ solution: $150 \mathrm{~mL}$-heptane: $0.84 \mathrm{~g}$ HDEHP } & \multicolumn{2}{|l|}{ Code: } \\
\hline \multicolumn{7}{|c|}{${ }^{\mathrm{b}} 50 \mathrm{~mL} 9.8 \% \mathrm{H}_{2} \mathrm{SO}_{4}$} & \multicolumn{2}{|c|}{ PLS=pregnant leach solution } \\
\hline \multicolumn{7}{|c|}{ c $100 \mathrm{~mL}$ solution: $150 \mathrm{~mL}$ kerosene: $0.84 \mathrm{~g}$ HDEHP } & \multicolumn{2}{|c|}{$\mathrm{RA}=$ raffinate after $\mathrm{SX}$} \\
\hline \multicolumn{7}{|c|}{ \# correction term of 0.95 was applied } & \multicolumn{2}{|c|}{ AST=acid strip } \\
\hline
\end{tabular}

\subsubsection{Solvent effect}

Leaching, solvent extraction, and acid stripping experiments for sludge from the DLM site have been conducted and the effect of solvent on solvent extraction efficiency has been studied. Nitric acid was used for all leaching process and the extractant HDEHP was used for all solvent extraction process. The ratio of solution to solvent to extractant for solvent extraction experiments was $100 \mathrm{~mL}: 150 \mathrm{~mL}: 0.84 \mathrm{~g}$.

For $\mathrm{pH} 1.4$ solution, when using $\mathrm{n}$-heptane as the solvent, major metal ion concentrations were indicated as increasing by about $5 \%$ after SX. This caused the estimated TREE concentration to reach $36 \%$. This was likely an analytical artifact. When the major metal concentration was corrected to reflect the generally $5 \%$ decrease seen in the other experiments the results were much more realistic (4.63\%), Table 3-11. Solvent extraction efficiencies are low for both solvents for $\mathrm{pH} 1.4$ solution, Figure 3.20.

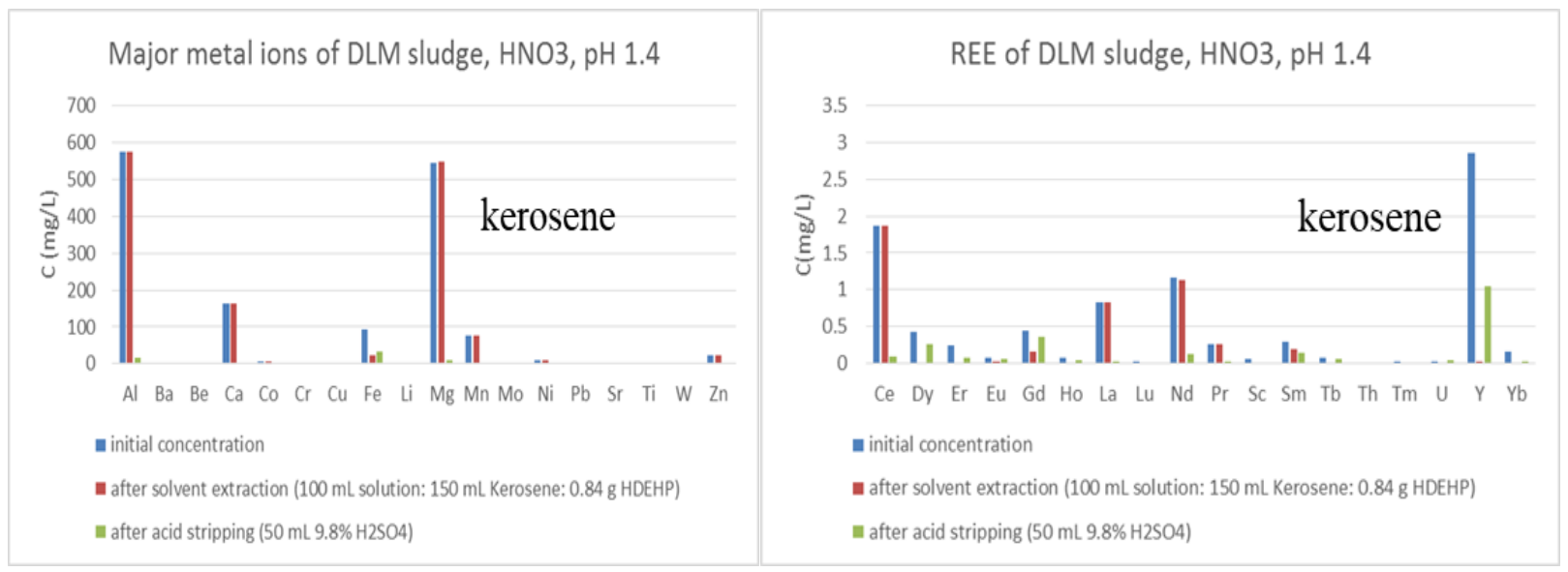

Figure 3.20 Metal ions and REE from DLM sludge (pH 1.4), kerosene solvent.

Under a pH 3.2, the solvent extraction efficiency of REEs was similar using different solvents while the solvent extraction efficiency of major metal ions was slightly higher using $n$-heptane as the solvent (9.71\%) 
than using kerosene as solvent (7.10\%), see Table 3-10 and Table 3-12. The difference may be due to magnesium extraction. After acid stripping from the two solvents, concentrations of REE in solution were lower from n-heptane than from kerosene, see Figure 3.17 and Figure 3.21. Under the same acid stripping conditions ( $50 \mathrm{~mL} 9.8 \% \mathrm{H}_{2} \mathrm{SO}_{4}$ ), acid stripping efficiency of both major metal ions and REE was higher when $\mathrm{n}$-heptane was used as the solvent. This indicates metal ion-HDEHP complexes are more stable in $\mathrm{n}$ heptane than in kerosene.

Overall, the acid stripping efficiency for pH 3.2 initial solution was lower than for the pH 1.4 initial solution. The lower leaching $\mathrm{pH}$ appears to be beneficial to the acid stripping process.

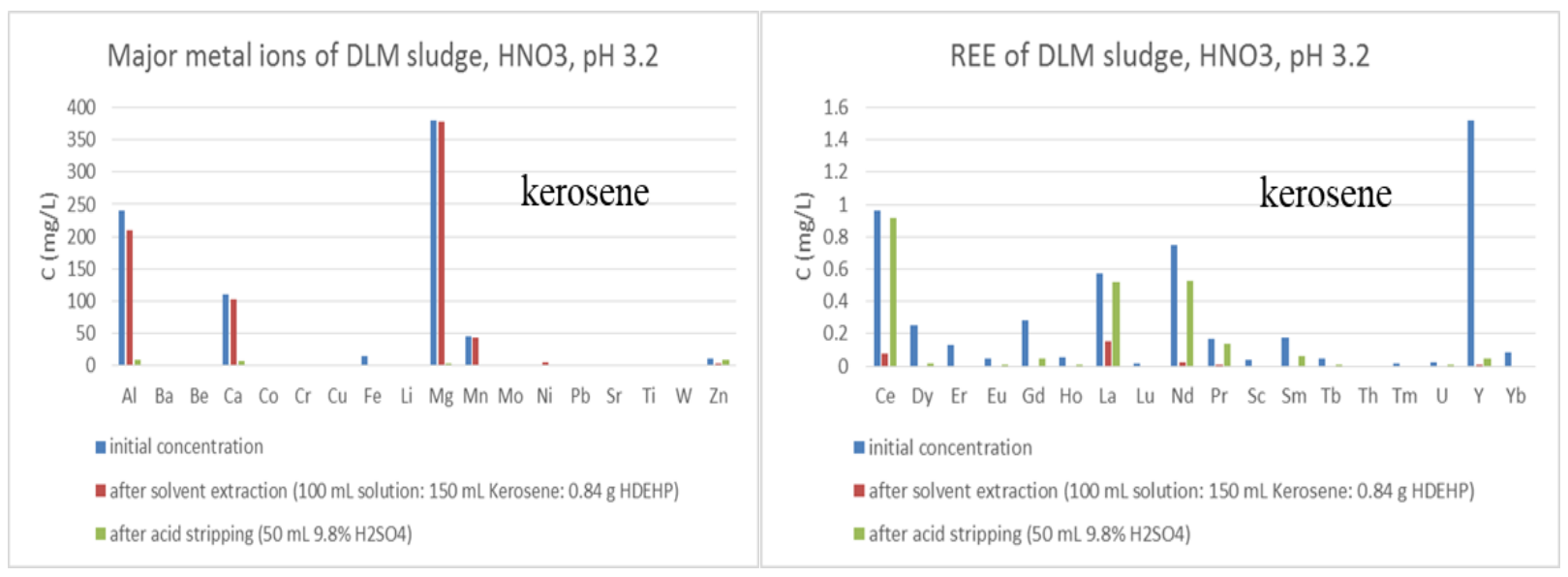

Figure 3.21 Metal ions and REE from DLM sludge (pH 3.2), kerosene solvent.

Table 3-12 Results of ALSX experiment for DLM leaching solution of pH 3.2 using solvent kerosene.

\begin{tabular}{|c|c|c|c|c|c|c|c|c|}
\hline \multirow[b]{2}{*}{ Treatment } & \multicolumn{3}{|c|}{ TMM } & \multicolumn{3}{|c|}{ TREE } & \multirow{2}{*}{$\begin{array}{c}\text { ^TREE } \\
\text { solid \% }\end{array}$} & \multirow{2}{*}{$\begin{array}{l}\text { Enrich. } \\
\text { factor }\end{array}$} \\
\hline & $\mathrm{mg} / \mathrm{L}$ & $\mathrm{mg}$ & $\%$ extr. & $\mathrm{mg} / \mathrm{L}$ & $\mathrm{mg}$ & $\%$ extr. & & \\
\hline PLS & 803.45 & & & 5.13 & & & $0.63 \%$ & \\
\hline $\mathrm{RA}^{\mathrm{a}}$ & 746.37 & 5.71 & $7.10 \%$ & 0.27 & 0.49 & $94.70 \%$ & $7.84 \%$ & 12.36 \\
\hline $\mathrm{AST}^{\mathrm{b}}$ & 31.03 & 1.55 & $27.20 \%$ & 2.31 & 0.12 & $23.80 \%$ & $6.93 \%$ & 10.92 \\
\hline \multicolumn{7}{|c|}{ a100 mL solution: $150 \mathrm{~mL}$ kerosene: $0.84 \mathrm{~g}$ HDEHP } & \multicolumn{2}{|l|}{ Code: } \\
\hline \multirow{3}{*}{\multicolumn{7}{|c|}{${ }^{b} 50 \mathrm{~mL} 9.8 \% \mathrm{H}_{2} \mathrm{SO}_{4}$}} & \multicolumn{2}{|c|}{ PLS=pregnant leach solution } \\
\hline & & & & & & & \multicolumn{2}{|c|}{$\mathrm{RA}=$ raffinate after $\mathrm{SX}$} \\
\hline & & & & & & & \multicolumn{2}{|c|}{ AST=acid strip } \\
\hline
\end{tabular}




\subsubsection{Extractant concentration effect}

Leaching, solvent extraction, acid stripping and precipitation experiments for sludge from DLM site have been conducted. Leaching experiments were conducted on sludge from DLM site using nitric acid to obtain $\mathrm{pH} 3.2$ initial solution. For solvent extraction, the ratio of solution to solvent to extractant for solvent extraction experiments was $100 \mathrm{~mL}: 150 \mathrm{~mL}$ kerosene: $1.68 \mathrm{~g}$. After solvent extraction, $100 \mathrm{~mL}$ $0.38 \% \mathrm{HCl}$ was used for acid stripping. Major ions' and REEs' responses are summarized in Figure 3.22. Acid stripping efficiency of REEs was more than $40 \%$ (Table 3-13). The estimated TREE in solid phase calculated after acid stripping step was $8.46 \%$.

After acid stripping, precipitation experiments were conducted by adding $\mathrm{NaOH}$ to solution. The final $\mathrm{pH}$ was greater than 13. Concentrations of dissolved REEs after precipitation are essentially zero. These acid stripping and precipitation results indicate if properly configured, very high (13.2\%) initial REE concentrations can be achieved. Throughout, it is important to note these results are the result of a single solvent extraction mixer/settlement cell where future work will focus on multiple mixer/settlers working in series. Much higher purities would be expected under those conditions.
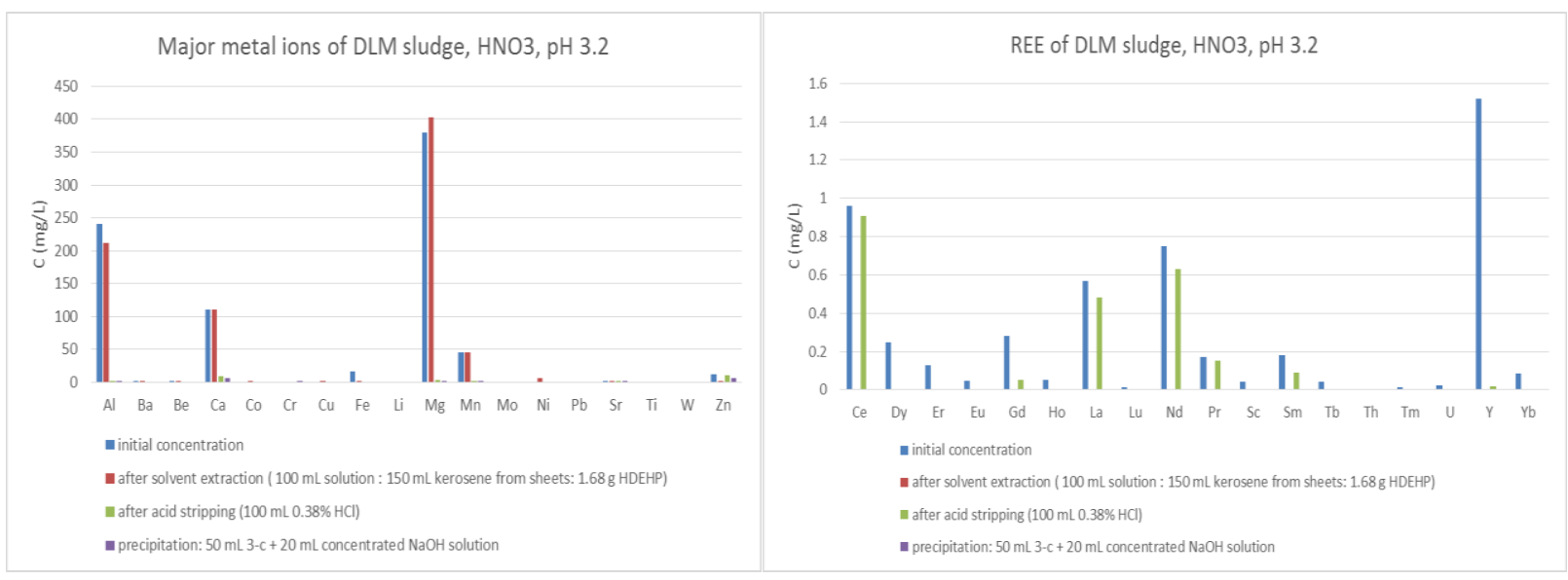

Figure 3.22 Metal ions data of sludge leaching, solvent extraction and precipitation experiments.

Table 3-13 Results of solvent extraction and precipitation experiments on DLM leachate.

\begin{tabular}{|c|c|c|c|c|c|c|c|c|c|}
\hline \multirow{2}{*}{$\mathrm{pH}$} & \multirow[b]{2}{*}{ Treatment } & \multicolumn{3}{|c|}{ TMM } & \multicolumn{3}{|c|}{ TREE } & \multirow{2}{*}{$\begin{array}{l}\text { ^TREE } \\
\text { solid \% }\end{array}$} & \multirow{2}{*}{$\begin{array}{l}\text { Enrich. } \\
\text { factor }\end{array}$} \\
\hline & & $\mathrm{mg} / \mathrm{L}$ & $\mathrm{mg}$ & $\%$ extr. & $\mathrm{mg} / \mathrm{L}$ & $\mathrm{mg}$ & $\%$ extr. & & \\
\hline \multirow[t]{2}{*}{3.2} & PLS ${ }^{a}$ & 803.45 & $\begin{array}{r}80.3 \\
5\end{array}$ & & 5.13 & 0.51 & & $0.63 \%$ & \\
\hline & $\mathrm{RA}^{\mathrm{b}}$ & 783.16 & $\begin{array}{r}78.3 \\
2\end{array}$ & $2.50 \%$ & 0 & 0 & $100.0 \%$ & $20.18 \%$ & 31.81 \\
\hline
\end{tabular}




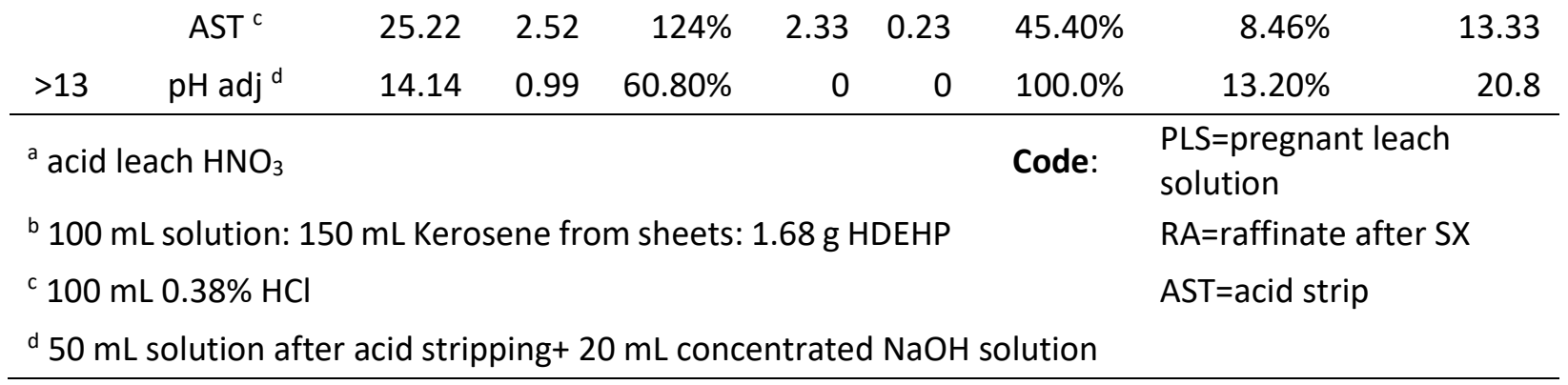

\subsubsection{Phase volume ratio effect}

A series of acid leaching/solvent extraction (ALSX) runs for sludge from the DLM site to recover REE were performed under $\mathrm{pH} 3.2$ to refine operating conditions, Figure 3.23.

For the first solvent extraction run, the ratio of solution to solvent to extractant for solvent extraction experiments was $100 \mathrm{~mL}: 150 \mathrm{~mL}: 1.68 \mathrm{~g}$. The ratio of extractant was twice that of the experiment reported in Table 3-10. The estimated TREE in solid phase was 6.32\% (Table 3-14), which is similar to 5.85\% (Table 3-10). It indicated that 0.84g HDEHP in $150 \mathrm{~mL} n$-heptane was enough for extraction and increasing the ratio of extractant didn't have significant effect.

After the initial solvent extraction, $100 \mathrm{~mL} 1.96 \% \mathrm{H}_{2} \mathrm{SO}_{4}$ was used for acid stripping from the organic phase. The estimated TREE in solid phase was 7.57\% (Table 3-14, $100 \mathrm{~mL} 1.96 \% \mathrm{H}_{2} \mathrm{SO}$ ), slightly lower than $8.63 \%$ (Table 3-10, $50 \mathrm{~mL}$ 9.8\% $\mathrm{H}_{2} \mathrm{SO}_{4}$ ). However, acid stripping efficiency of both major metal ions and REE was more than $40 \%$. Although higher hydrogen ion concentration can facilitate retard solvent extraction, higher volumes of more dilute acid solution was better than lower volume concentrated acid solution for acid stripping process. If using acid solution with the same hydrogen ion concentration, stripping efficiency of REEs using $\mathrm{HCl}$ solution would be slightly higher than that of $\mathrm{H}_{2} \mathrm{SO}_{4}$, Table 3-13 and Table 3-14.

After adding more solvent to recover dissolved REE from the aqueous phase after the first solvent extraction, concentrations of both major metal ions and REE were higher than previous concentrations. Again, this shows the sensitivity of the mass balance approach to analytical error. Also, the second acid stripping step can remobilize some major metal ions. This indicated that HDEHP may affect metal ion concentration measurement. Thus, while the major ion concentration results post solvent extraction were, in some cases, prone to error, the estimated TREE in solid phase calculated after acid stripping step was reliable. 


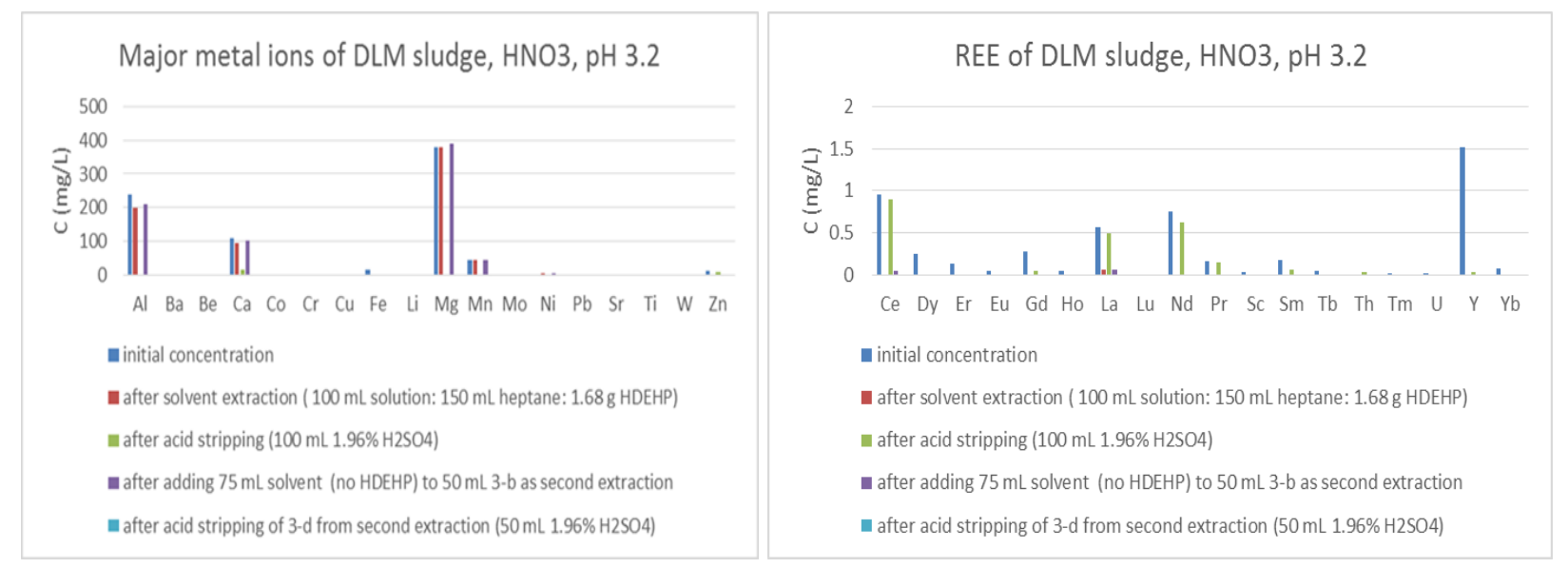

Figure 3.23 Effect of extractant to solvent ratio on ALSX efficiency, leaching pH 3.2.

Table 3-14 Effect of extractant to solvent ratio for DLM sludge, leaching pH 3.2.

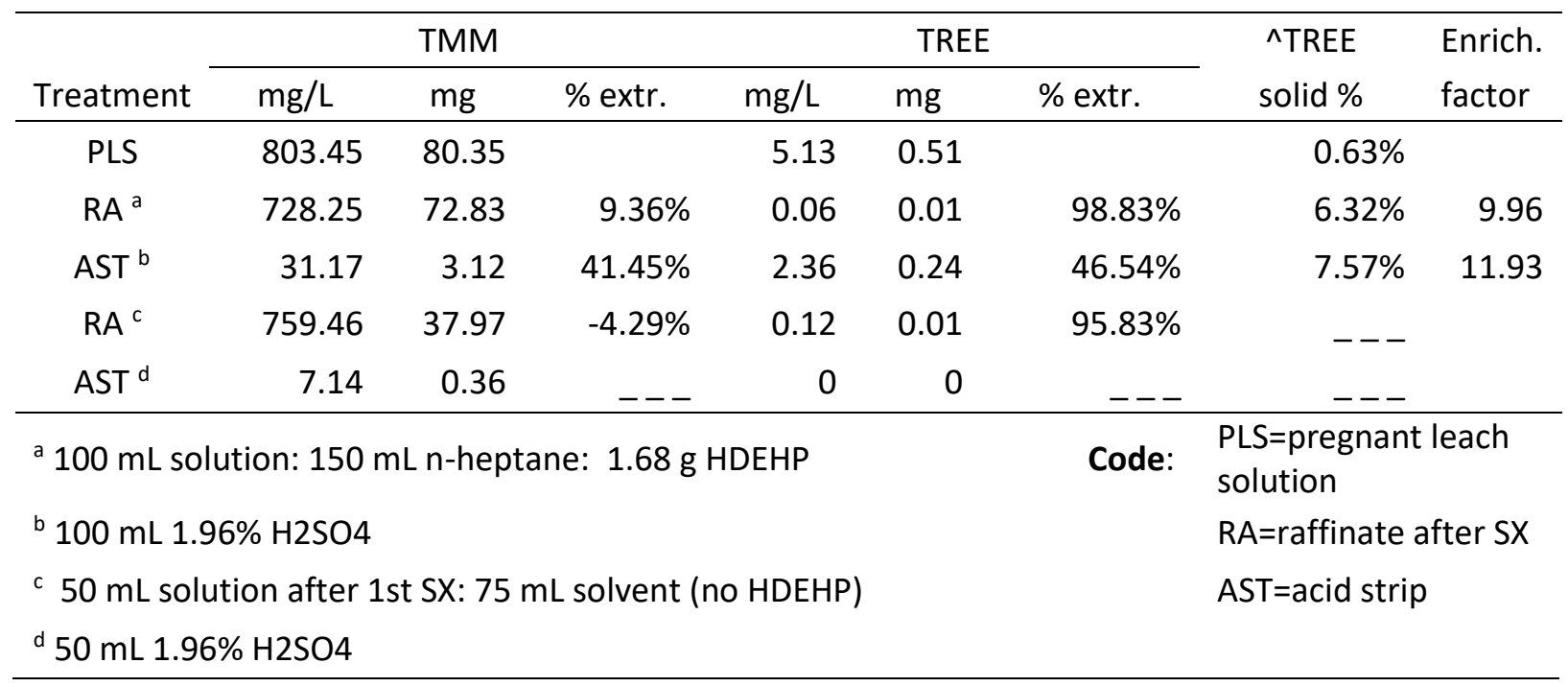

Leaching, solvent extraction, and acid stripping experiments for sludge from the DLM site have been conducted. Feed solution used for solvent extraction was $\mathrm{pH}$ 1.4. The ratio of solution to solvent to extractant for SX experiments was $100 \mathrm{~mL}: 300 \mathrm{~mL}: 1.68 \mathrm{~g}$, increasing solvent and extractant mix volume ratio in comparison with previous experiments. Results were obtained in test runs using our laboratory bench SX unit, which consists of a single mixer-settler. It is important to note, SX uses multiple mixersettlers to achieve significant REE purities. Our phase 2 SX unit will include 100 mixer-settlers. Solvent extraction efficiency of REEs was 54\% (Table 3-15 and Table 3-16, Figure 3.24 and Figure 3.25), like previous results of REEs extraction efficiency of about $50 \%$. 
Solvent extraction efficiency of major metal ions was only 5\%, Table 3-15 and Table 3-16. During the acid stripping process, a 1:1 volume ratio of $9.8 \%$ sulfuric acid $\left(\mathrm{H}_{2} \mathrm{SO}_{4}\right)$ solution to organic phase was used. Acid stripping efficiency of major metal ions was higher than that of REEs. It indicates that REE-HDEHP complexes are more stable in solvent than major metal-HDEHP complexes. Acid stripping efficiency of major metal ions and REEs were $100 \%$ and $76 \%$, Table 3-15, both much higher than previous results using a highly diluted acid solution. For the acid stripping process, concentrated hydrochloric acid $(\mathrm{HCl}, 18 \%)$ was also used. The volume ratio of acid solution to organic phase was 1:3. Acid stripping efficiency of major metal ions was also higher than that of REEs. Acid stripping efficiency of major metal ions and REEs were $100 \%$ and $65 \%$, Table $3-16$, both much higher than previous results using highly diluted $\mathrm{HCl}$ solution and like the results of $\mathrm{H}_{2} \mathrm{SO}_{4}$, Table 3-15. Under this condition, one-third acid solution over organic phase was enough for stripping with higher hydrogen ion concentration.

Table 3-15 Results of DLM sludge leaching and SX data (pH 1.4) by increasing solvent volume and strip using $\mathrm{H}_{2} \mathrm{SO}_{4}$ solution.

\begin{tabular}{|c|c|c|c|c|c|c|c|c|}
\hline \multirow[b]{2}{*}{ Treatment } & \multicolumn{3}{|c|}{ TMM } & \multicolumn{3}{|c|}{ TREE } & \multirow{2}{*}{$\begin{array}{l}\text { ^TREE } \\
\text { solid \% }\end{array}$} & \multirow{2}{*}{$\begin{array}{l}\text { Enrich. } \\
\text { factor }\end{array}$} \\
\hline & $\mathrm{mg} / \mathrm{L}$ & $\mathrm{mg}$ & $\%$ extr. & $\mathrm{mg} / \mathrm{L}$ & $\mathrm{mg}$ & $\%$ extr. & & \\
\hline PLS ${ }^{a}$ & 1549.38 & 77.47 & & 9.22 & 0.46 & & $0.59 \%$ & \\
\hline $\mathrm{RA}^{\mathrm{b}}$ & 1473.77 & 73.69 & $4.90 \%$ & 4.26 & 0.21 & $53.80 \%$ & $6.16 \%$ & 10.41 \\
\hline $\mathrm{AST}^{\mathrm{c}}$ & 25.79 & 3.87 & $102.30 \%$ & 1.25 & 0.19 & $75.60 \%$ & $4.62 \%$ & \\
\hline \multicolumn{6}{|c|}{ a leaching solution, DLM, pH 1.4, $50 \mathrm{~mL}$} & Code: & \multicolumn{2}{|c|}{$\begin{array}{l}\text { PLS=pregnant leach } \\
\text { solution }\end{array}$} \\
\hline \multicolumn{7}{|c|}{ b after SX (50 mL solution:150 mL n-heptane:0.84g HDEHP) } & \multicolumn{2}{|c|}{$\mathrm{RA}=$ raffinate after $\mathrm{SX}$} \\
\hline \multicolumn{7}{|c|}{ c after acid stripping (150 mL 9.8\% H2SO4) } & \multicolumn{2}{|c|}{ AST=acid strip } \\
\hline
\end{tabular}



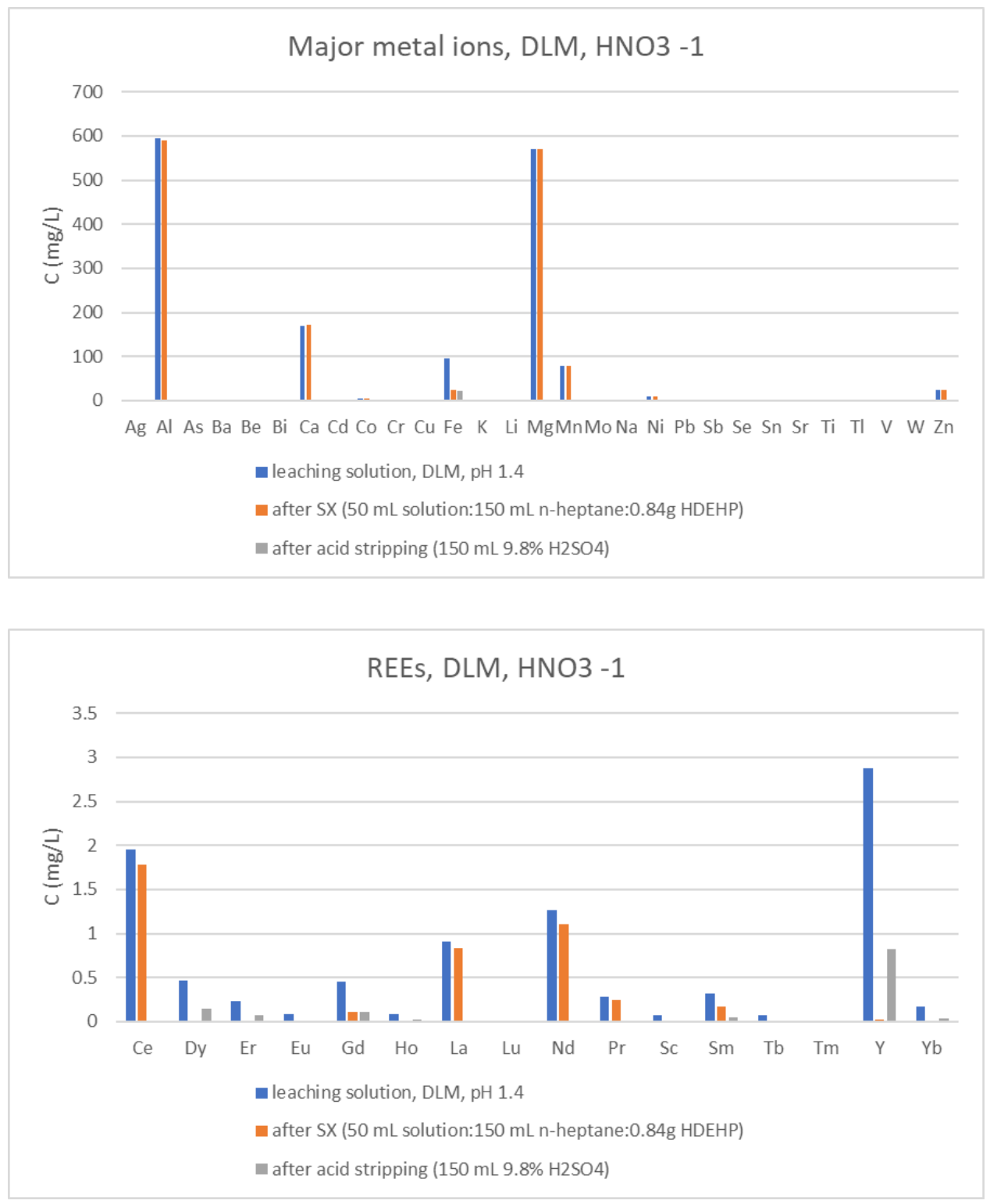

Figure 3.24 Metal ions and REE results from DLM sludge leaching and SX data (pH 1.4) by increasing solvent volume and strip using $\mathrm{H} 2 \mathrm{SO} 4$ solution.

Table 3-16 Results of DLM sludge leaching and SX experiments (pH 1.4) by increasing solvent volume and strip using $\mathrm{HCl}$ solution.

\begin{tabular}{|c|c|c|c|c|c|c|c|c|}
\hline \multirow[b]{2}{*}{ Treatment } & \multicolumn{3}{|c|}{ TMM } & \multicolumn{3}{|c|}{ TREE } & \multirow{2}{*}{$\begin{array}{l}\text { ^TREE } \\
\text { solid \% }\end{array}$} & \multirow{2}{*}{$\begin{array}{l}\text { Enrich. } \\
\text { factor }\end{array}$} \\
\hline & $\mathrm{mg} / \mathrm{L}$ & $\mathrm{mg}$ & $\%$ extr. & $\mathrm{mg} / \mathrm{L}$ & $\mathrm{mg}$ & $\%$ extr. & & \\
\hline PLS ${ }^{a}$ & 1549.38 & 154.94 & & 9.22 & 0.92 & & $0.59 \%$ & \\
\hline $\mathrm{RA}^{\mathrm{b}}$ & 1469.57 & 146.96 & $5.20 \%$ & 4.24 & 0.42 & $54.01 \%$ & $5.87 \%$ & 9.93 \\
\hline
\end{tabular}




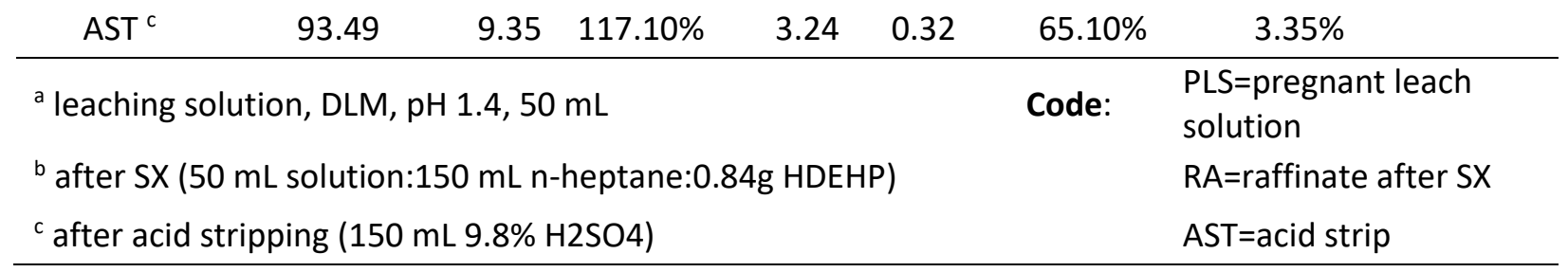
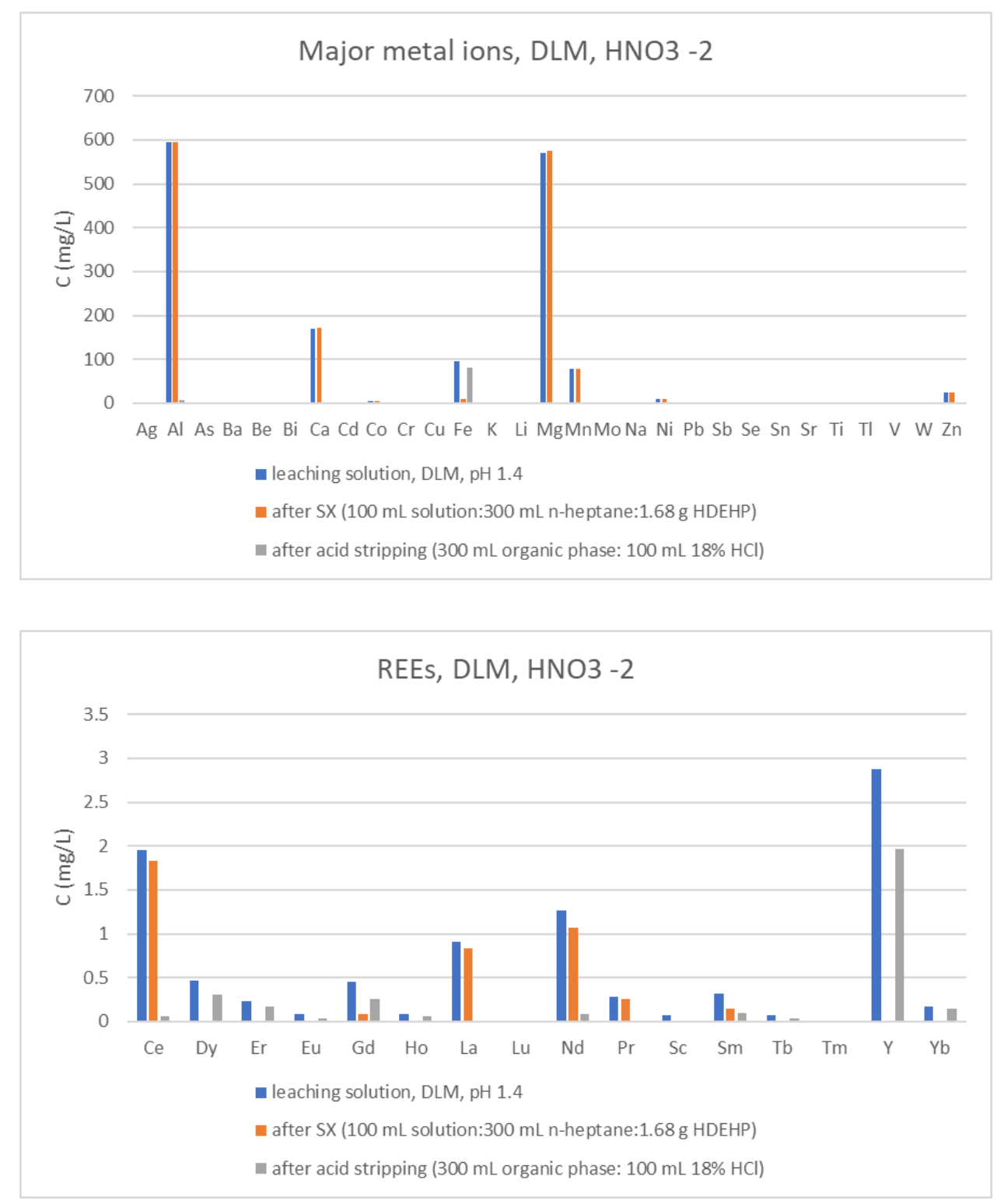

Figure 3.25 Metal ions and REE results of DLM sludge leaching and SX data (pH1.4) by increasing solvent volume and strip using $\mathrm{HCl}$ solution. 


\subsubsection{Acid stripping parameters}

Leaching, solvent extraction, and acid stripping experiments for sludge from DLM site were conducted and the effect of acid stripping step on stripping efficiency was studied. Leaching experiments were conducted on sludge from DLM site using nitric acid to obtain a $\mathrm{pH}<0.5$ initial solution (Figure $3.26,1 \mathrm{~g}$ wet sludge). Both dissolved major metal ions and REEs are much more than $\mathrm{pH} 3.2$ (Figure 3.17, $5 \mathrm{~g}$ wet sludge). The estimated TREE in solid phase was $0.63 \%$ (Table 3-17), same as the pH 3.2 initial solution (Table 3-10). Low pH did get much more REEs in initial solution; but it did not help on increasing REE purity.

The $\mathrm{pH}$ adjustment step had little effect on either major metal ions or REEs. For solvent extraction, the ratio of solution to solvent to extractant for solvent extraction experiments was $100 \mathrm{~mL}: 150 \mathrm{~mL}: 1.68 \mathrm{~g}$. After solvent extraction, multi-step acid stripping was conducted. $100 \mathrm{~mL} 0.98 \% \mathrm{H}_{2} \mathrm{SO}_{4}$ was used for first acid stripping and the estimated TREE in solid phase was 3.16\%, lower than at $\mathrm{pH} 1.4$ and much lower than at $\mathrm{pH}$ 3.2. The second acid stripping step using the same acid solution to strip the organic phase again did not increase REEs amount or purity. For the third acid stripping step, $100 \mathrm{~mL} 0.70 \% \mathrm{HNO}_{3}$ was used and more REEs was obtained. This indicated that $0.70 \% \mathrm{HNO}_{3}$ was better than $0.98 \% \mathrm{H}_{2} \mathrm{SO}_{4}$ to strip metal ions. Besides, first acid stripping efficiency of both major metal ions and REE for $\mathrm{pH} 3.2$ solution are much higher than that of $\mathrm{pH}<0.5$ solution. Thus, for very low $\mathrm{pH}$ initial solution, concentrated acid solution may be better to strip metal ions. Also, due to the rapidity of the stripping reaction, multi-stage stripping offered no additional benefit.

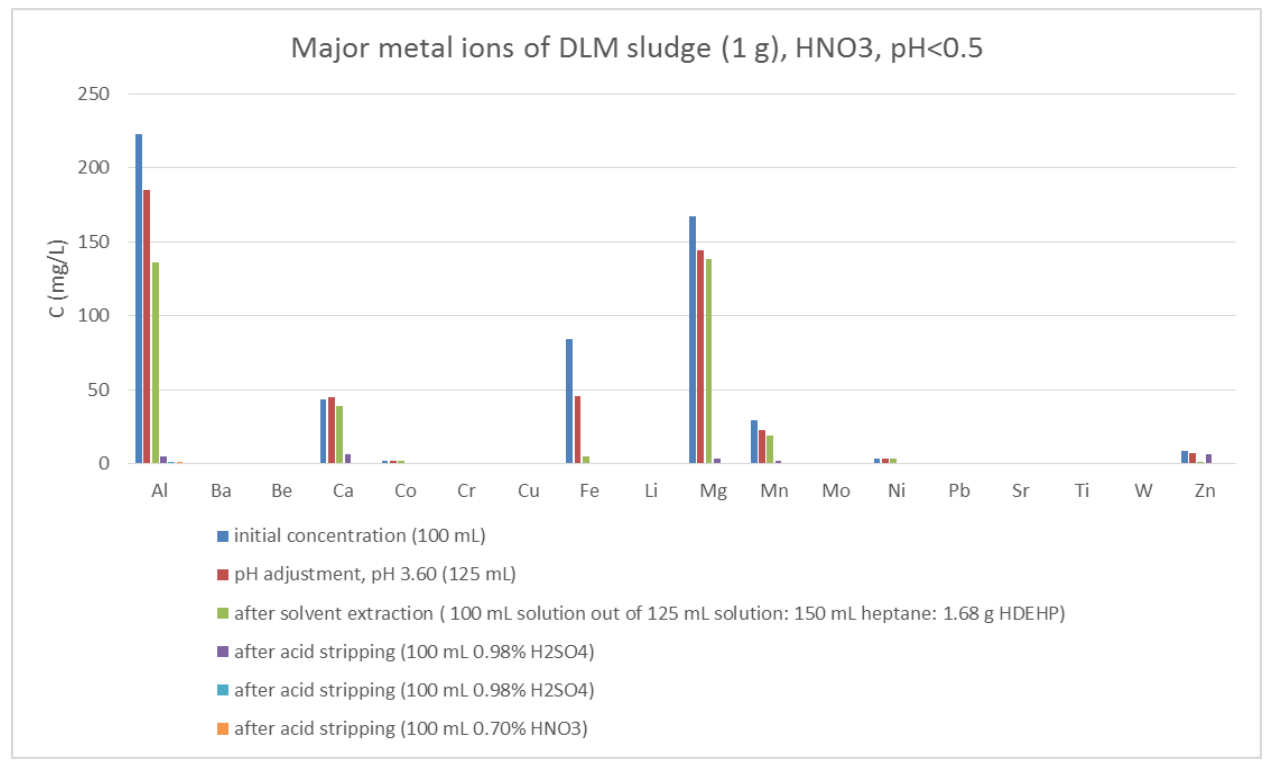




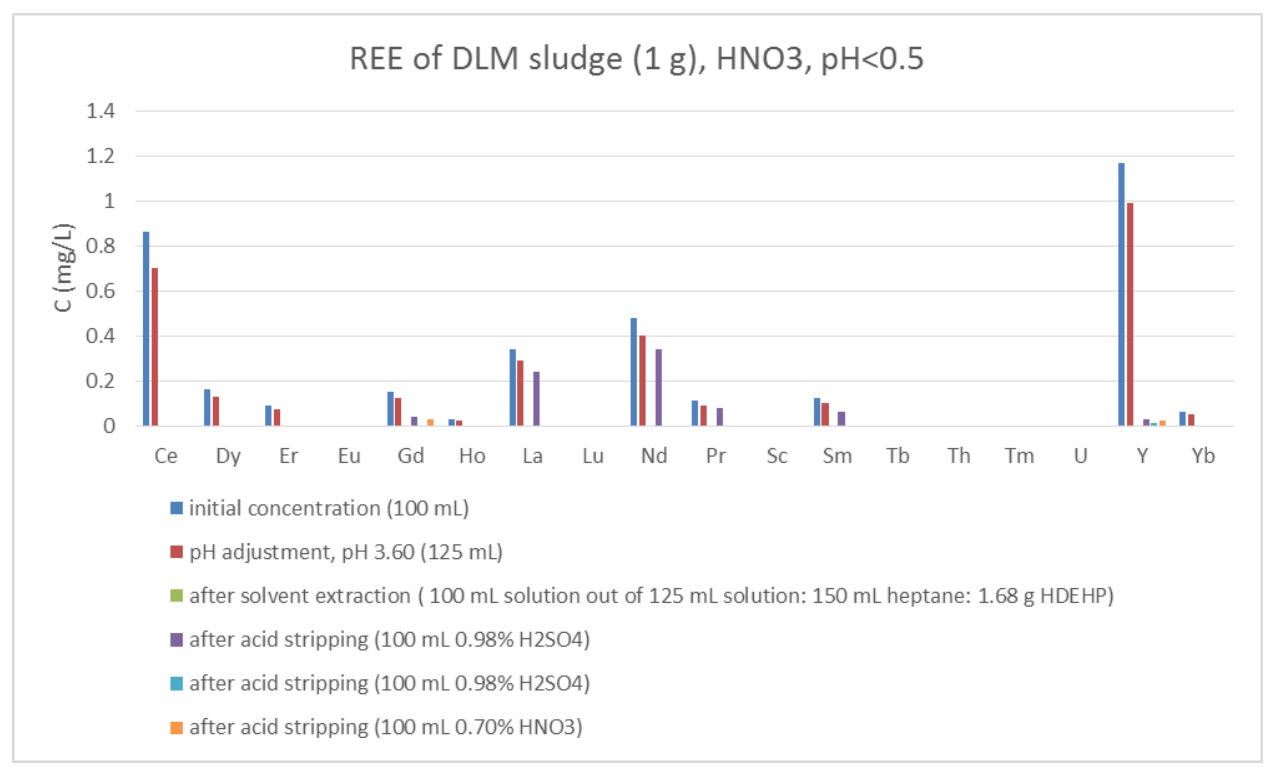

Figure 3.26 ALSX results, metal and REE from DLM sludge, leaching $\mathrm{pH}<0.5$.

Table 3-17 Experimental results, ALSX experiment, DLM sludge, leaching $\mathrm{pH}<0.5$.

\begin{tabular}{|c|c|c|c|c|c|c|c|c|c|}
\hline \multirow[b]{2}{*}{$\mathrm{pH}$} & \multirow[b]{2}{*}{ Treatment } & \multicolumn{3}{|c|}{ TMM } & \multicolumn{3}{|c|}{ TREE } & \multirow{2}{*}{$\begin{array}{l}\text { ^TREE } \\
\text { solid \% }\end{array}$} & \multirow{2}{*}{$\begin{array}{l}\text { Enrich. } \\
\text { factor }\end{array}$} \\
\hline & & $\mathrm{mg} / \mathrm{L}$ & $\mathrm{mg}$ & $\%$ extr. & $\mathrm{mg} / \mathrm{L}$ & $\mathrm{mg}$ & $\%$ extr. & & \\
\hline$<0.5$ & PLS & 563 & 56.3 & & 3.57 & 0.36 & & $0.63 \%$ & \\
\hline \multirow[t]{9}{*}{3.6} & $\mathrm{pH}$ adj & 455.68 & 56.96 & & 2.96 & 0.37 & & $0.65 \%$ & 1.02 \\
\hline & $\mathrm{RA}^{\mathrm{a}}$ & 344.62 & 34.46 & $24.37 \%$ & 0 & 0 & $100.0 \%$ & $3.22 \%$ & 5.12 \\
\hline & $\mathrm{AST}^{\mathrm{b}}$ & 24.19 & 2.42 & 0.0531 & 0.79 & 0.08 & $26.69 \%$ & $3.16 \%$ & 5.02 \\
\hline & $\mathrm{AST}^{\mathrm{c}}$ & 1.58 & 0.16 & $0.37 \%$ & 0.01 & 0 & $0.46 \%$ & $0.63 \%$ & 1 \\
\hline & $A S T^{d}$ & 1.28 & 0.13 & $0.30 \%$ & 0.05 & 0.01 & $2.31 \%$ & $3.76 \%$ & 5.97 \\
\hline & $\begin{array}{l}\text { a } 100 \mathrm{~mL} \mathrm{so} \\
1.68 \mathrm{~g} \mathrm{HDEH}\end{array}$ & tion out & $125 \mathrm{~m}$ & olution: & $\mathrm{OmLh}$ & tane: & Code: & \multicolumn{2}{|c|}{$\begin{array}{l}\text { PLS=pregnant leach } \\
\text { solution }\end{array}$} \\
\hline & b $100 \mathrm{~mL} 0.9$ & $\% \mathrm{H} 2 \mathrm{SO} 4$ & & & & & & \multicolumn{2}{|c|}{$R A=$ raffinate after $S X$} \\
\hline & c $100 \mathrm{~mL} 0.9$ & $\% \mathrm{H} 2 \mathrm{SO} 4$ & & & & & & \multicolumn{2}{|c|}{ AST=acid strip } \\
\hline & d $100 \mathrm{~mL} 0.7$ & $\% \mathrm{HNO}$ & & & & & & & \\
\hline
\end{tabular}

Leaching, solvent extraction, and acid stripping experiments for sludge from the DLM site were conducted. Feed solution used for solvent extraction was $\mathrm{pH}$ 1.4. The ratio of solution to solvent to extractant for solvent extraction experiments was $100 \mathrm{~mL}: 150 \mathrm{~mL}: 0.84 \mathrm{~g}$. Solvent extraction efficiency of REE was $48.6 \%$, while extraction efficiency of major metal ions was only $6.6 \%$, Table $3-18$. The recovered REEs in 
organic phase after SX were mainly from yttrium $(Y)$, Figure 3.27. Four different acid stripping experiments were conducted.

Major metal ion concentrations increased by about $5 \%$ after SX. This caused the acid stripping efficiency of major metal ions to reach as high as $264 \%$. This was likely an analytical artifact. When the major metal concentration was corrected to reflect the generally $5 \%$ decrease, the results were much more realistic.

$100 \mathrm{~mL} 9 \% \mathrm{HCl}$ acid solution at $78^{\circ} \mathrm{C}$ was used for acid stripping with volume ratio of 1:1.5 to organic phase. Acid stripping efficiency of REEs was almost $100 \%$ while that of major metal ions was about $60 \%$, Table 3-18. The estimated TREE in solid phase was calculated as $6.84 \%$. When $100 \mathrm{~mL} 9 \% \mathrm{HCl}$ acid solution at room temperature $26^{\circ} \mathrm{C}$ was used for acid stripping with same volume ratio, acid stripping efficiency of REEs was about $60 \%$ while that of major metal ions was about $70 \%$, Table 3-18. The estimated TREE in solid phase was calculated as $3.91 \%$, indicating higher temperature facilitates the acid stripping process, especially for REEs. $100 \mathrm{~mL} \mathrm{4.5 \%} \mathrm{HCl}$ acid solution at $78^{\circ} \mathrm{C}$ was also used for acid stripping with the same volume ratio. Acid stripping efficiencies of REEs and major metal ions were both like those of $9 \% \mathrm{HCl}$ solution at $78{ }^{\circ} \mathrm{C}$. The estimated TREE in solid phase was calculated as $6.80 \%$, indicating $4.5 \% \mathrm{HCl}$ solution was enough for stripping of REEs at relatively high temperature and $9 \%$ is not necessary.

$100 \mathrm{~mL} \mathrm{4.5 \%} \mathrm{HCl} \mathrm{acid} \mathrm{solution} \mathrm{at} \mathrm{room} \mathrm{temperature} \mathrm{was} \mathrm{also} \mathrm{used} \mathrm{for} \mathrm{acid} \mathrm{stripping} \mathrm{with} \mathrm{same} \mathrm{volume}$ ratio. Acid stripping efficiency of REEs was like that of $9 \% \mathrm{HCl}$ solution at same temperature. However, acid stripping efficiencies of major metal ions was less than that of $9 \% \mathrm{HCl}$ solution. The estimated TREE in solid phase was calculated as $6.00 \%$, larger than $3.91 \%$, Table $3-18$. It indicates that, at room temperature, $4.5 \% \mathrm{HCl}$ solution was better than $9 \% \mathrm{HCl}$ solution to enrich REEs.

Table 3-18 Results of solvent extraction experiment for DLM sludge leaching solution pH 1.4.

\begin{tabular}{|c|c|c|c|c|c|c|c|c|}
\hline \multirow[b]{2}{*}{ Treatment } & \multicolumn{3}{|c|}{ TMM } & \multicolumn{3}{|c|}{ TREE } & \multirow{2}{*}{$\begin{array}{c}\text { ^TREE } \\
\text { solid \% }\end{array}$} & \multirow{2}{*}{$\begin{array}{l}\text { Enrich } \\
\text { factor }\end{array}$} \\
\hline & $\mathrm{mg} / \mathrm{L}$ & $\mathrm{mg}$ & $\%$ extr. & $\mathrm{mg} / \mathrm{L}$ & $\mathrm{mg}$ & $\%$ extr. & & \\
\hline PLS & 1549.38 & & & 9.22 & & & $0.59 \%$ & \\
\hline $\mathrm{RA}^{\mathrm{a}}$ & $1446.95^{\#}$ & 40.97 & $6.61 \%$ & 4.74 & 1.79 & $48.59 \%$ & $4.19 \%$ & 7.08 \\
\hline $\mathrm{AST}^{\mathrm{b}}$ & 57.9 & 5.79 & $56.50 \%$ & 4.25 & 0.43 & $94.90 \%$ & $6.84 \%$ & 11.56 \\
\hline $\mathrm{AST}^{\mathrm{c}}$ & 69.36 & 6.94 & 0.677 & 2.82 & 0.28 & $62.90 \%$ & $3.91 \%$ & 6.6 \\
\hline$A S T^{d}$ & 62.5 & 6.25 & $61.00 \%$ & 4.56 & 0.46 & $101.80 \%$ & $6.80 \%$ & 11.49 \\
\hline $\mathrm{AST}^{\mathrm{e}}$ & 40.6 & 4.06 & $39.60 \%$ & 2.59 & 0.26 & $57.80 \%$ & $6.00 \%$ & 10.14 \\
\hline
\end{tabular}

a $400 \mathrm{~mL}$ solution: $600 \mathrm{~mL}$-heptane: $3.36 \mathrm{~g}$ HDEHP

Code: 
b $100 \mathrm{~mL}$ acid solution $\left(9 \% \mathrm{HCl}\right.$ at $\left.78^{\circ} \mathrm{C}\right)+150 \mathrm{~mL}$ organic phase

PLS=pregnant leach solution

c $100 \mathrm{~mL}$ acid solution $\left(9 \% \mathrm{HCl}\right.$ at $\left.\mathrm{RT} 26^{\circ} \mathrm{C}\right)+150 \mathrm{~mL}$ organic phase

RA=raffinate after $S X$

d $100 \mathrm{~mL}$ acid solution $\left(4.5 \% \mathrm{HCl}\right.$ at $\left.78^{\circ} \mathrm{C}\right)+150 \mathrm{~mL}$ organic phase AST=acid strip

e $100 \mathrm{~mL}$ acid solution $\left(4.5 \% \mathrm{HCl}\right.$ at RT $\left.26^{\circ} \mathrm{C}\right)+150 \mathrm{~mL}$ organic phase

\# test correction term 0.95

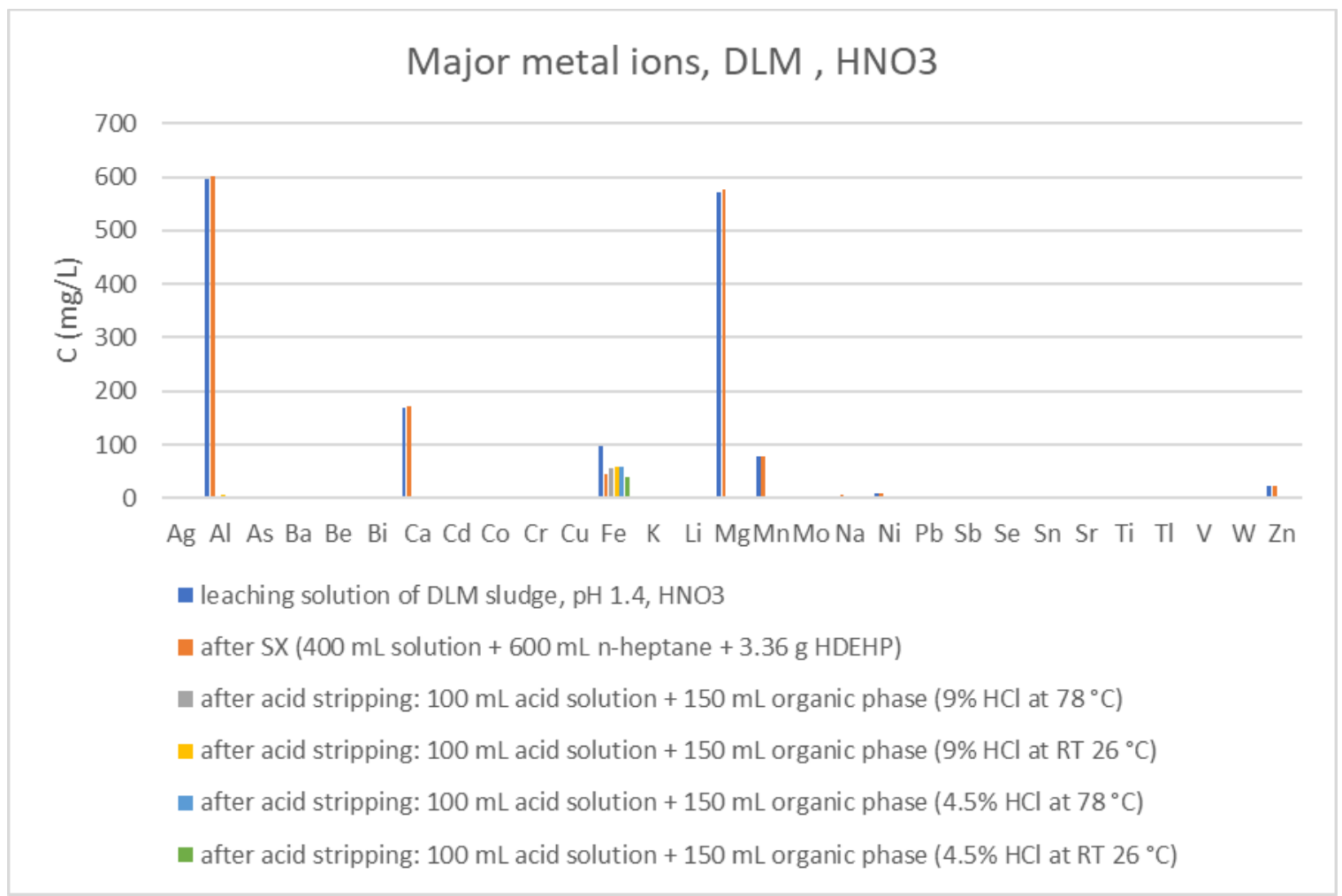




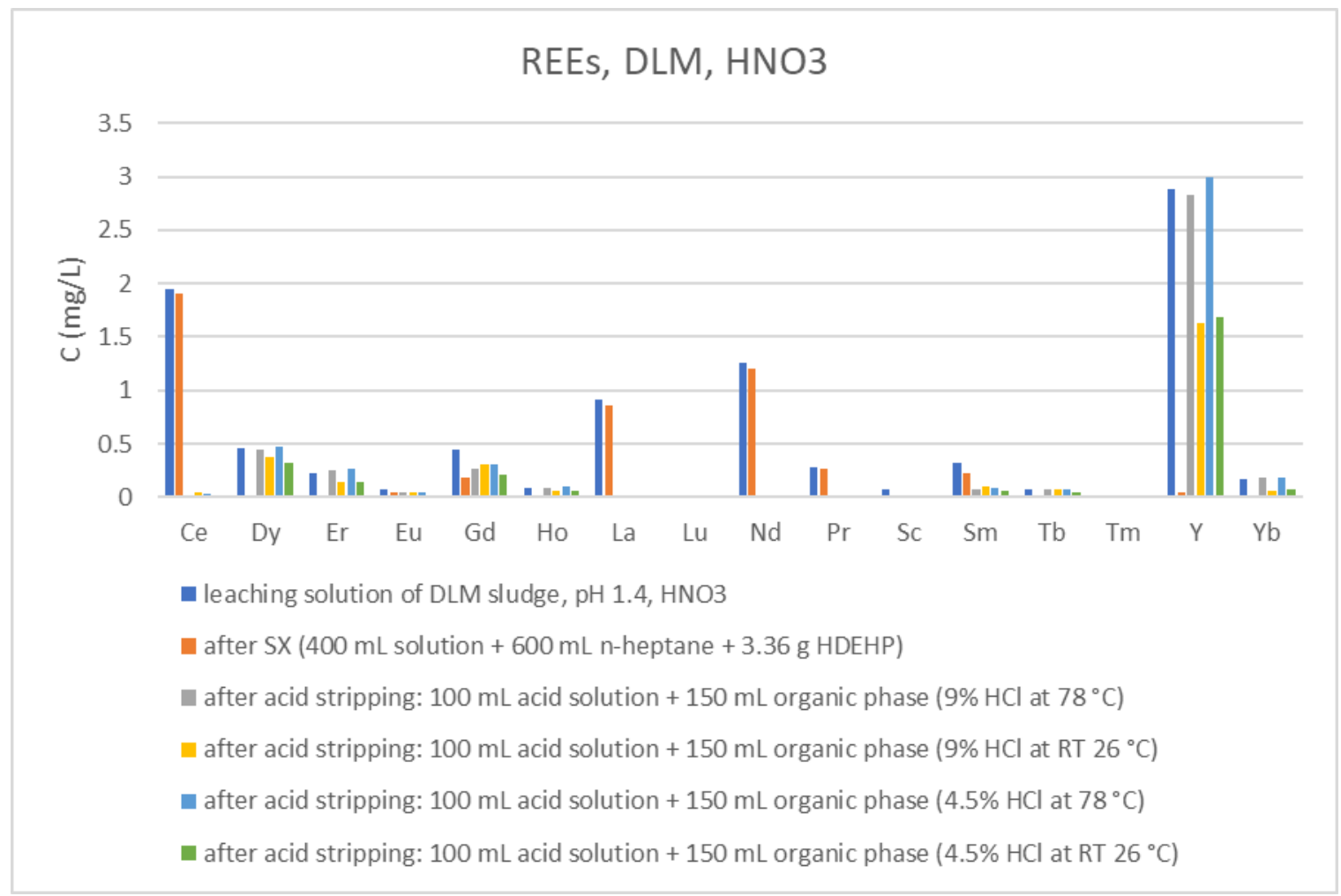

Figure 3.27 Metal ions and REEs results from DLM sludge leaching and SX data pH 1.4.

\subsection{Mid-scale ALSX experiment for REEs recovery}

\subsubsection{Mid-scale SX on DLM pH 3.2 leaching solution}

A mid-scale leaching experiment was conducted on $1.25 \mathrm{~kg}$ wet sludge from DLM site. After leaching under $50 \mathrm{rpm}$ for 1 hour, the solution was filtered through three continuous e.g. 50, 5, $1 \mu \mathrm{M}$ filters. Solvent extraction was conducted on a $20 \mathrm{~L}$ filtered solution ( $\mathrm{pH}$ 3.2) with $30 \mathrm{~L}$ kerosene (solvent) and $336 \mathrm{~g}$ HDEHP (extractant) for 30 minutes. The solution was then mixed with $20 \mathrm{~L}$ of water containing $600 \mathrm{~mL} 38 \% \mathrm{HCl}$ with the organic phase for 30 minutes to simulate the acid stripping step. Precipitation of REEs was then accomplished by adding $320 \mathrm{~g} \mathrm{NaOH}$ (flake, 98\%) to the solution and mixed until all $\mathrm{NaOH}$ dissolved resulting in a $\mathrm{pH}$ of 12 . Wet precipitate was obtained after filtering. The precipitates were then dried in an oven for 5 days to obtain $2.5 \mathrm{~g}$ of concentrate sample (Figure 3.28) with a total REE concentration of 4.63\%. This result and all others in this document are reported on the elemental, dry weight basis. This result was consistent with the mass balance models used to refine our acid leaching/solvent extraction (ALSX) process at a small-scale demonstration in the laboratory. 
Solution samples and $0.257 \mathrm{~g}$ solid sample were sent for chemical analysis, in the solid sample. Solvent extraction efficiency of REEs was $96.44 \%$; but, acid stripping efficiency of REEs was only $14.46 \%$. The precipitation step recovered all dissolved REEs. Calculating as before, estimated TREE in solid phase was calculated as $4.51 \%$ from solution sample results and calculated as $4.63 \%$ based on TREE/total cation ions (Table 3-19).

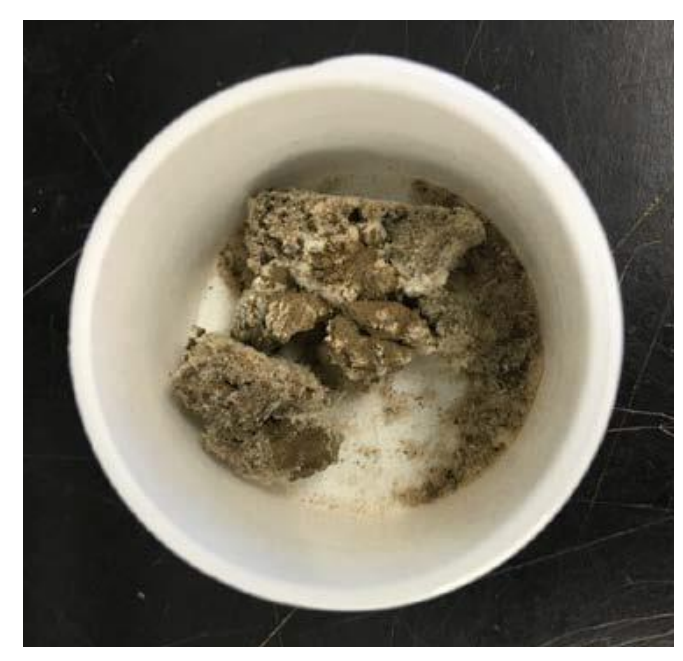

Figure 3.28 Rare earth concentrate $(4.63 \%)$.

Table 3-19 Results of the large scale ALSX trial using DLM sludge, leaching pH 3.2.

\begin{tabular}{|c|c|c|c|c|c|c|c|c|c|}
\hline \multirow[b]{2}{*}{$\mathrm{pH}$} & \multirow[b]{2}{*}{ Treatment } & \multicolumn{3}{|c|}{ TMM } & \multicolumn{3}{|c|}{ TREE } & \multirow{2}{*}{$\begin{array}{l}\text { ^TREE } \\
\text { solid \% }\end{array}$} & \multirow{2}{*}{$\begin{array}{l}\text { Enrich. } \\
\text { factor }\end{array}$} \\
\hline & & $\mathrm{mg} / \mathrm{L}$ & $\mathrm{mg}$ & $\%$ extr. & $\mathrm{mg} / \mathrm{L}$ & $\mathrm{mg}$ & $\%$ extr. & & \\
\hline \multirow[t]{3}{*}{3.2} & PLS & 2133.19 & & & 16.56 & & & $0.77 \%$ & \\
\hline & $\mathrm{RA}^{\mathrm{a}}$ & 2058.45 & 1494.8 & $3.50 \%$ & 0.59 & 319.4 & $96.44 \%$ & $17.61 \%$ & 22.85 \\
\hline & $\mathrm{AST}^{\mathrm{b}}$ & 92.88 & 1857.52 & $124 \%$ & 2.31 & 46.2 & $14.50 \%$ & $2.43 \%$ & 3.15 \\
\hline \multirow[t]{5}{*}{12} & $\mathrm{pH} \operatorname{adj}^{\mathrm{c}}$ & 43.96 & 879.14 & $52.70 \%$ & 0 & 0 & $100.00 \%$ & $4.51 \%$ & 5.85 \\
\hline & a $100 \mathrm{~mL}$ so & ution:150 & $\mathrm{nL}$ kerose & e: $1.68 \mathrm{~g}$ & HDEHP & & & Measured $^{d}$ & \\
\hline & b 20 L wate & containin & $600 \mathrm{~mL} 3$ & $\% \mathrm{HCl}$ & & & & $4.63 \%$ & \\
\hline & c $320 \mathrm{~g} \mathrm{NaO}$ & H (flake 98 & & & & & & & \\
\hline & ${ }^{d}$ based on & hemical aı & alysis of $p$ & ecipitates & & & & & \\
\hline
\end{tabular}




\subsubsection{Mid-scale SX on DLM pH 2.6 leaching solution}

Mid-scale leaching, solvent extraction, and acid stripping experiments for sludge from the DLM site were conducted on $\mathrm{pH} 2.6$ leaching solution. Under pH 2.6, most REEs were dissolved while only part major metal ions were dissolved, as shown in Figure 3.29. The ratio of solution to solvent to extractant for solvent extraction experiments was $100 \mathrm{~mL}: 150 \mathrm{~mL}$ : $1.68 \mathrm{~g}$. Solvent extraction efficiency of REE was $88.53 \%$ while solvent extraction efficiencies of major metal ions were only 8.8\%, Table 3-20 and Figure 3.29.

Major metal ion concentrations were indicated as increasing by about $5 \%$ after SX. This caused the acid stripping efficiency of major metal ions to reach $342.68 \%$. This was likely an analytical artifact. When the major metal concentration was corrected to reflect the generally $5 \%$ decrease, the results were much more realistic.

Under the same acid stripping conditions $(1.1 \% \mathrm{HCl})$, the acid stripping efficiency of major metal ions was much higher than that of REEs. It indicates that REE-HDEHP complexes are more stable in kerosene than major metal-HDEHP complexes. Since acid stripping is the reverse reaction of solvent extraction, higher extraction efficiency results in lower acid stripping efficiency due to more stable complexes in solvent. We conclude acid stripping needs to be undertaken using higher acid concentrations.

After acid stripping, precipitation experiments were conducted by adding $\mathrm{NaOH}$ to solution. The final $\mathrm{pH}$ was 8.2. Concentrations of dissolved REEs after precipitation were almost zero. Precipitation can recover all REE and increase REE purity. Calculating as before, estimated TREE in solid phase was calculated as $1.17 \%$ from solution sample results and calculated as $1.28 \%$ based on TREE/total cation ions (Table 3-20). The results were not as good as the first-time mid-scale experiments. The main reason was during this experiment, the feed solution for solvent extraction after leaching was turbid. Many large particles existed

in suspension even after filtering and an intermediate phase existed other than organic phase and aqueous phase during solvent extraction, resulting in REE-HDEHP complexes which were not recovered to the organic phase. 

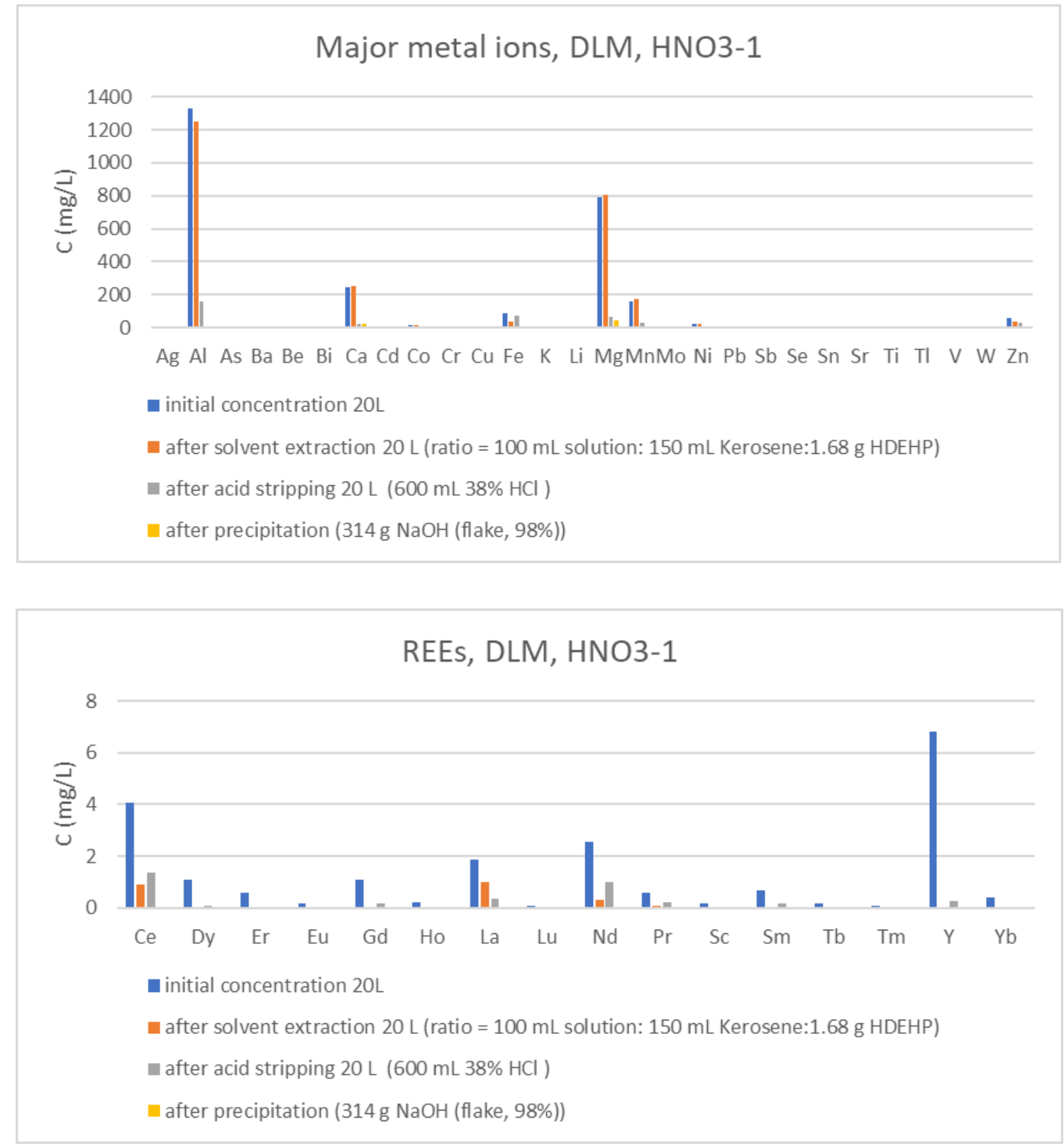

Figure 3.29 Metal ions and REES data of DLM sludge leaching solution (pH 2.6) using kerosene as solvent.

Table 3-20 Results of solvent extraction experiment for DLM sludge leaching solution pH 2.6 using kerosene as the solvent.

\begin{tabular}{|c|c|c|c|c|c|c|c|c|c|}
\hline \multirow[b]{2}{*}{$\mathrm{pH}$} & \multirow[b]{2}{*}{ Treatment } & \multicolumn{3}{|c|}{ TMM } & \multicolumn{3}{|c|}{ TREE } & \multirow{2}{*}{$\begin{array}{l}\text { ^TREE } \\
\text { solid \% }\end{array}$} & \multirow{2}{*}{$\begin{array}{l}\text { Enrich. } \\
\text { factor }\end{array}$} \\
\hline & & $\mathrm{mg} / \mathrm{L}$ & $\mathrm{mg}$ & $\%$ extr. & $\mathrm{mg} / \mathrm{L}$ & $\mathrm{mg}$ & $\%$ extr. & & \\
\hline \multirow[t]{3}{*}{2.6} & PLS & 2702.33 & & & 20.58 & & & $0.76 \%$ & \\
\hline & $\mathrm{RA}^{\mathrm{a}}$ & 2463.99 & 4766.87 & $8.80 \%$ & 2.36 & 364.4 & $88.53 \%$ & $7.10 \%$ & 9.4 \\
\hline & $\mathrm{AST}^{\mathrm{b}}$ & 372.36 & 7447.2 & $156 \%$ & 3.62 & 72.4 & $19.90 \%$ & $0.96 \%$ & 1.27 \\
\hline
\end{tabular}




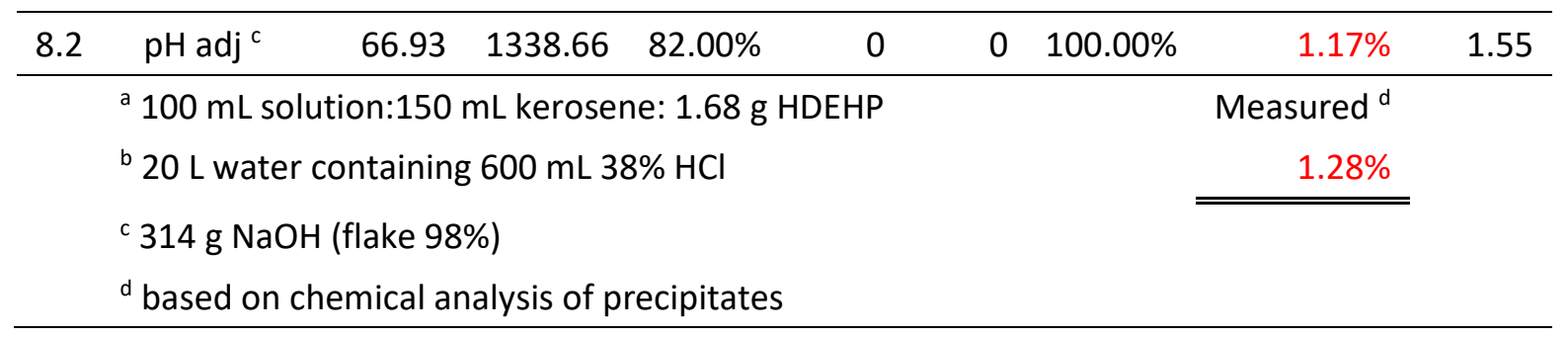

\subsubsection{Mid-scale SX on DLM pH 2.6 leaching solution followed by evaporating}

Mid-scale leaching, solvent extraction experiments for sludge from DLM site have been conducted. Feed solution used for solvent extraction was also $\mathrm{pH}$ 2.6. The ratio of solution to solvent to extractant for solvent extraction experiments was $100 \mathrm{~mL}: 150 \mathrm{~mL}: 1.68 \mathrm{~g}$. The extraction efficiency of REEs was very high, as shown in Figure 3.30; however, only 0.5\% TREE were detected in the final solid. This indicates most of the extracted REEs were in the intermediate phase. Effective filtration to achieve a clear solution is necessary for effective recovery.

Since acid stripping efficiency of REEs was too low by using a diluted acid solution and using a concentrated acid solution was of high cost, another treatment method was tried. After solvent extraction, an evaporating-cooling experiment on the organic phase was conducted to separate solvent and metalHDEHP complexes. The solvent $n$-heptane can be totally recycled. After-treatment on complexes was done to obtain solid REEs concentrate. These included combustion of the liquid metal-extractant complex under $700{ }^{\circ} \mathrm{C}$ for 5 hours to eliminate residual solvent and obtain a solid. The solid was very acidic and hard. After adding $100 \mathrm{~mL} \mathrm{40g/L} \mathrm{NaOH}$ solution to it, filtering and drying, a REE concentrated solid should be obtained.

Calculating as before, estimated TREE in solid phase was calculated as 4.92\% from solution sample results and calculated as $5.81 \%$ based on TREE/total cation ions (Table 3-21). The composition of phosphorus element was larger than $25 \%$ in the final solid, the phosphorous apparently being the post combustion HDEHP residue. 


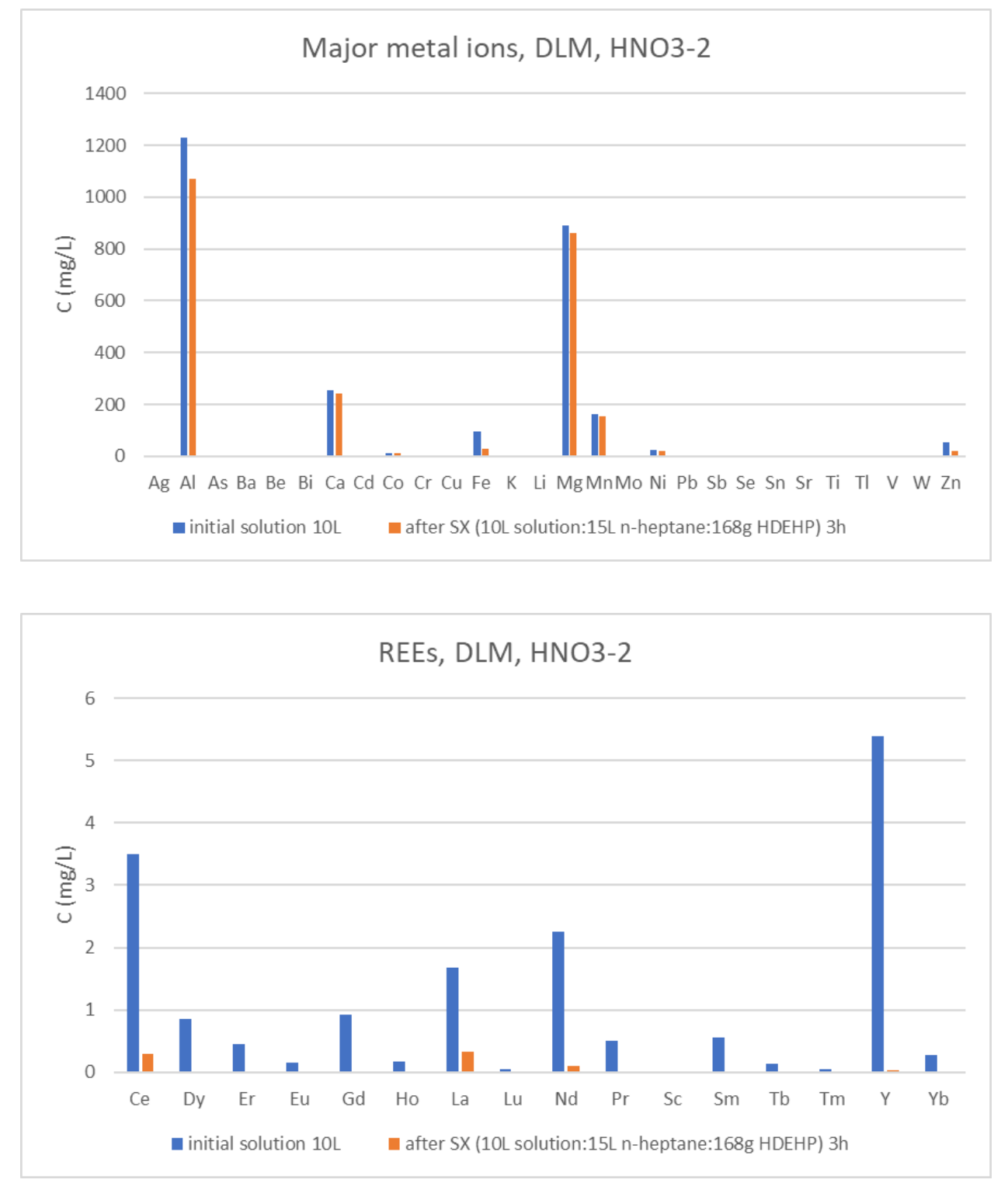

Figure 3.30 Metal ions data of DLM sludge leaching solution pH 2.6 using n-heptane as solvent.

Table 3-21 Results of solvent extraction experiment for DLM leachate pH 2.6 using n-heptane as solvent.

\begin{tabular}{|c|c|c|c|c|c|c|c|c|c|}
\hline \multirow[b]{2}{*}{$\mathrm{pH}$} & \multirow[b]{2}{*}{ Treatment } & \multicolumn{3}{|c|}{ TMM } & \multicolumn{3}{|c|}{ TREE } & \multirow{2}{*}{$\begin{array}{l}\text { ^TREE } \\
\text { solid \% }\end{array}$} & \multirow{2}{*}{$\begin{array}{l}\text { Enrich. } \\
\text { factor }\end{array}$} \\
\hline & & $\mathrm{mg} / \mathrm{L}$ & $\mathrm{mg}$ & $\%$ extr. & $\mathrm{mg} / \mathrm{L}$ & mg & $\%$ extr. & & \\
\hline \multirow{2}{*}{2.6} & $\mathrm{PLS}^{\mathrm{a}}$ & 2722.19 & & & 16.93 & & & $0.62 \%$ & \\
\hline & $\mathrm{RA}^{\mathrm{b}}$ & 2409.25 & 3129.4 & $11.50 \%$ & 0.75 & 161.8 & $95.57 \%$ & $4.92 \%$ & 7.95 \\
\hline & \multicolumn{7}{|c|}{${ }^{\mathrm{a}}$ acid leach $\mathrm{HNO}_{3}$ (0.5 kg AMDp, $10 \mathrm{~L}$ solution) } & \multicolumn{2}{|c|}{ Measured $^{\mathrm{c}}$} \\
\hline & \multicolumn{7}{|c|}{ b $100 \mathrm{~mL}$ solution:150 mL n-heptane: $1.68 \mathrm{~g}$ HDEHP } & \multicolumn{2}{|l|}{$5.81 \%$} \\
\hline & \multicolumn{9}{|c|}{${ }^{\mathrm{C}}$ based on chemical analysis of after-treatment solid } \\
\hline
\end{tabular}




\subsubsection{Mid-scale SX experiments on McV leaching solution}

Mid-scale leaching, solvent extraction experiments for sludge from McV site have been conducted. Nitric acid was used for leaching processes and HDEHP was used for solvent extraction processes. The pH of feed solution used for solvent extraction was less than 1 . The ratio of solution to solvent to extractant for solvent extraction experiments was 10 L solution: 15 L n-heptane: 84 g HDEHP.

The extraction efficiency of REEs was only $14.95 \%$, Table 3-22, due to low pH of feed solution. As shown in Figure 3.31, the purple line indicates concentrations after $2^{\text {nd }}$ acid stripping, they were very high due to solution volume change from $10 \mathrm{~L}$ to $300 \mathrm{~mL}$, especially for element Iron and Yttrium. They are two main extraction elements.

Since acid stripping efficiency of REEs was too low by using a diluted acid solution and using a concentrated acid solution was of high cost, another treatment method was tried. After solvent extraction, an evaporating-cooling experiment on the organic phase was conducted to separate solvent and metalHDEHP complexes. The solvent n-heptane can be totally recycled. After evaporating, acid stripping and precipitation were conducted to obtain REE concentrated solid.

Because oxalic acid reacts with REEs to form precipitate much easier than major metal ions, $10 \%$ oxalic acid was used for $1^{\text {st }}$ acid stripping. But it turned out that stripping efficiency of REEs was very low while that of major metal ions was high. The reason may be that the concentration of hydrogen ions in the organic phase from SX process was too high, after extraction occurred, much hydrogen ions will be in the aqueous phase to inhibit REE oxalates formation. The estimated TREE in solid phase was calculated as only $0.06 \%$. Thus, oxalic acid cannot be used for low pH SX.

$300 \mathrm{~mL} 18 \% \mathrm{HCl}$ solution was used for second acid stripping process. The stripping efficiencies of both major metal ions and REEs were both very high. After acid stripping, precipitation experiments were conducted by adding $\mathrm{NaOH}$ to solution. The final $\mathrm{pH}$ was larger than 14 . Concentrations of dissolved REEs after precipitation were zero. Precipitation can recover all REE and increase REE purity. Calculating as before, estimated TREE in solid phase was calculated as $0.48 \%$ from solution sample results and calculated as $0.44 \%$ based on TREE/total cation ions (Table 3-22). Pretreatment, like $\mathrm{pH}$ adjustment, of feed solution is necessary for SX. 

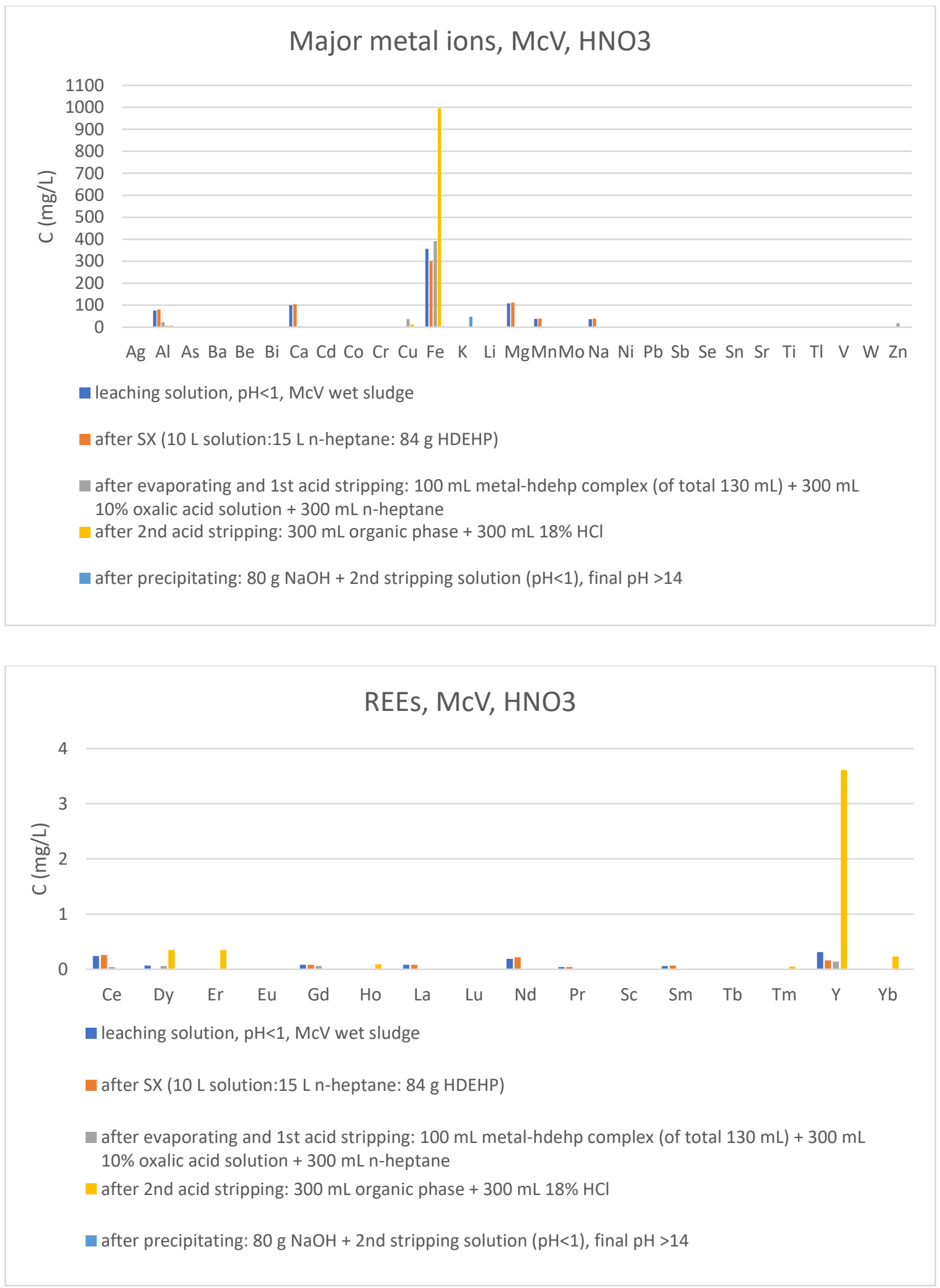

Figure 3.31 Mid-scale experiments data of McV sludge. 
Table 3-22 Results of mid-scale experiments of McV sludge.

\begin{tabular}{|c|c|c|c|c|c|c|c|c|c|}
\hline \multirow[b]{2}{*}{$\mathrm{pH}$} & \multirow[b]{2}{*}{ Treatment } & \multicolumn{3}{|c|}{ TMM } & \multicolumn{3}{|c|}{ TREE } & \multirow{2}{*}{$\begin{array}{l}\text { ^TREE } \\
\text { solid \% }\end{array}$} & \multirow{2}{*}{$\begin{array}{l}\text { Enrich. } \\
\text { factor }\end{array}$} \\
\hline & & $\mathrm{mg} / \mathrm{L}$ & $\mathrm{mg}$ & $\%$ extr. & $\mathrm{mg} / \mathrm{L}$ & $\mathrm{mg}$ & $\%$ extr. & & \\
\hline \multirow[t]{4}{*}{$<1$} & PLS ${ }^{a}$ & 722.51 & 7225.1 & & 1.07 & 10.7 & & $0.15 \%$ & \\
\hline & $\mathrm{RA}^{\mathrm{b}}$ & 683.74 & 6837.4 & $5.40 \%$ & 0.91 & 9.1 & $14.95 \%$ & $0.41 \%$ & 2.78 \\
\hline & $\mathrm{AST}^{\mathrm{c}}$ & 479.77 & 187.11 & $48.30 \%$ & 0.3 & 0.12 & $7.30 \%$ & $0.06 \%$ & \\
\hline & $\mathrm{AST}^{\mathrm{d}}$ & 1020.42 & 397.96 & $198 \%$ & 4.68 & 1.83 & $123.10 \%$ & $0.46 \%$ & 3.09 \\
\hline$>14$ & $\mathrm{pH} \operatorname{adj}^{\mathrm{e}}$ & 57.8 & 22.54 & $94.30 \%$ & 0 & 0 & $100.00 \%$ & $0.48 \%$ & 3.27 \\
\hline \multicolumn{10}{|c|}{ b 10 L solution:15 L n-heptane: 84 g HDEHP } \\
\hline \multicolumn{10}{|c|}{$\begin{array}{l}{ }^{\circ} \text { after evaporating and then acid stripping: } 100 \mathrm{~mL} \text { metal-HDEHP complex (of total } 130 \mathrm{~mL} \text { ) }+300 \mathrm{~mL} \\
10 \% \text { oxalic acid solution }+300 \mathrm{~mL} \text {-heptane }\end{array}$} \\
\hline \multicolumn{10}{|c|}{ d after $2 \mathrm{nd}$ acid stripping: $300 \mathrm{~mL}$ organic phase $+300 \mathrm{~mL} 18 \% \mathrm{HCl}$} \\
\hline \multicolumn{10}{|c|}{$\begin{array}{l}\text { e after precipitating: } 80 \mathrm{~g} \mathrm{NaOH}+\text { solution after } 2^{\text {nd }} \text { acid stripping }(\mathrm{pH}<1) \text {, final } \mathrm{pH}>14 \\
{ }^{f} \text { measured from solid sample data (data of } \mathrm{Fe} \text { and } \mathrm{Y} \text { element were estimated from solution sample test } \\
\text { results due to exceeding detection limit) }\end{array}$} \\
\hline
\end{tabular}

\subsection{Multi-step ALSX experiment for REEs recovery}

\subsubsection{Multi-step ALSX experiment on $\mathrm{pH} 1.4$ leaching solution}

Leaching, multi-step solvent extraction, and multi-step acid stripping experiments for sludge from the DLM site have been conducted. Feed solution used for solvent extraction was $\mathrm{pH} 1.4$, clear solution. The ratio of solution to solvent to extractant for solvent extraction experiments was $100 \mathrm{~mL}: 150 \mathrm{~mL}: 0.84 \mathrm{~g}$.

For the first solvent extraction, extraction efficiency of REEs was only about $50 \%$ due to low $\mathrm{pH}$ of feed solution. The recovered REEs in organic phase after SX was mainly from element yttrium (Y). The extraction efficiencies of element cerium (Ce), lanthanum (La), and neodymium ( $\mathrm{Nd}$ ) were low, as shown in Figure 3.32. Increasing ratio of extractant will help to increase extraction efficiency. The ratio of extractant is half of that as previous experiments. The estimated TREE in solid phase was 5.74\% (Table $3-23)$.

After first solvent extraction, $100 \mathrm{~mL} 0.38 \% \mathrm{HCl}$ was used for acid stripping from the organic phase. The estimated TREE in solid phase was $12.46 \%$ (Table 3-23). However, acid stripping efficiency of both major metal ions and REEs were lower than $10 \%$. Higher hydrogen ion concentration and higher volume of acid solution can facilitate acid stripping process. 
For the second solvent extraction, $75 \mathrm{~mL}$ solution after the first solvent extraction was used for feed solution. The extraction efficiency of REEs was only about $10 \%$, much lower than the first solvent extraction. The estimated TREE in solid phase was about 1.1\%.

After the second solvent extraction, $75 \mathrm{~mL} 0.38 \% \mathrm{HCl}$ was used for acid stripping from the organic phase. The estimated TREE in solid phase was 6.48\% (Table 3-23). The acid stripping efficiency of both major metal ions and REEs were larger than $10 \%$, because the metal ion loading in the organic phase was already very low and the diluted acid was nearly enough for stripping.

For the third solvent extraction, $50 \mathrm{~mL}$ solution from the second solvent extraction was used as the feed solution. The extraction efficiency of REEs was similar to that of second solvent extraction. The estimated TREE in solid phase was about $0.6 \%$. Major metal ion concentrations after the third SX were higher than the feed solution after the second SX. This was likely an analytical artifact. Thus $5 \%$ reduction was applied for analysis. When the major metal concentration was corrected to reflect the generally $5 \%$ decrease, the results were much more realistic.

After the third solvent extraction, $50 \mathrm{~mL}$ of $0.38 \% \mathrm{HCl}$ were used for acid stripping from the organic phase. The estimated TREE in the solid phase was $3.24 \%$. The acid stripping efficiency of both major metal ions and REE were also similar to that of second acid stripping.

Multi-step SX runs on solution after SX can help recover more REE from waste sludge. To increase purity, multi-step SX runs on solution after each acid stripping step will be required. More concentrated HDEHP and acid will be needed for the process. 

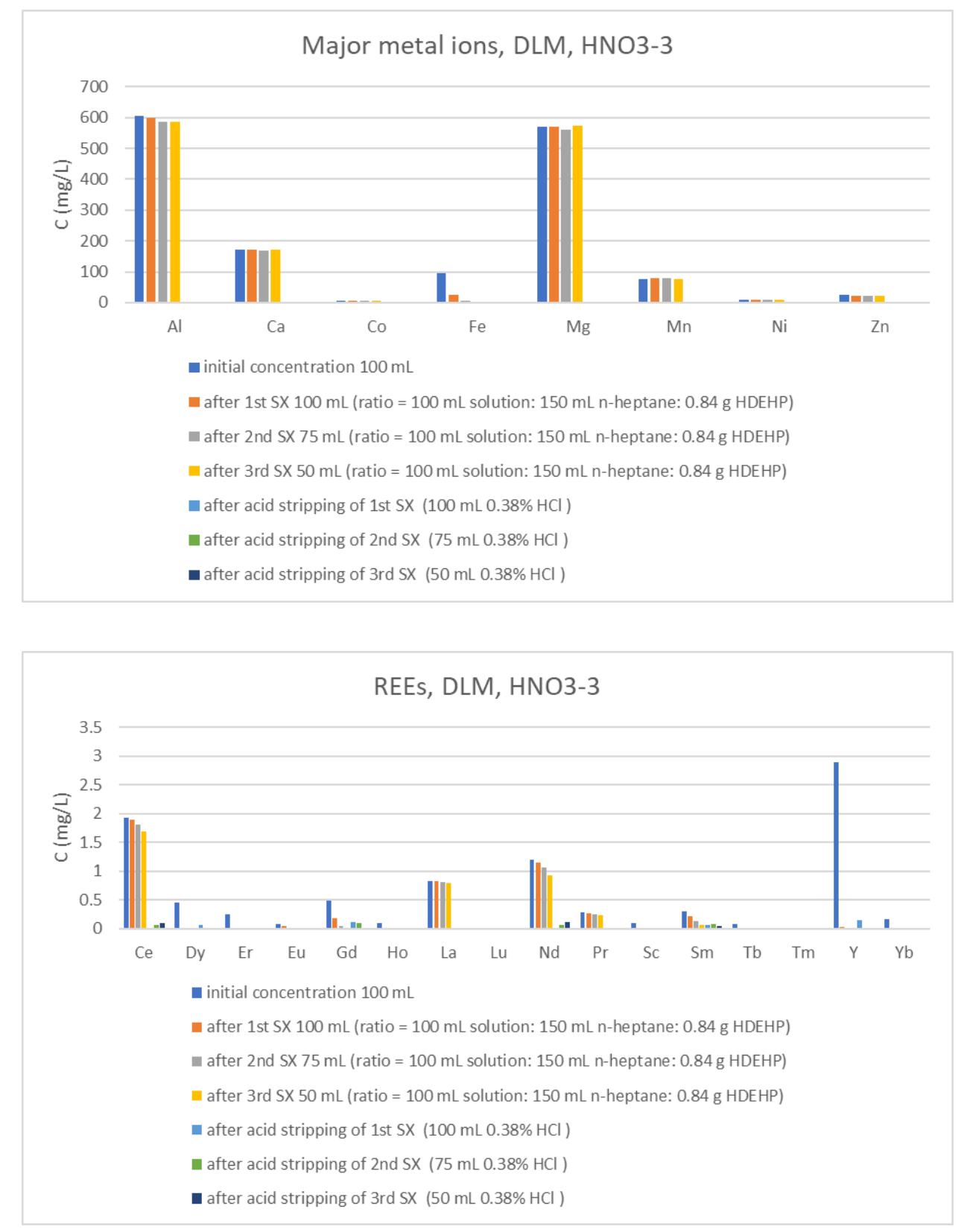

Figure 3.32 Effect of extraction stages on solvent extraction efficiency of pH 1.4 DLM sludge leaching solution.

Table 3-23 Results of effect of extraction stages for pH 1.4 DLM sludge leaching solution solvent extraction experiments.

\begin{tabular}{ccccrcrrrr}
\hline & \multicolumn{3}{c}{ TMM } & \multicolumn{3}{c}{ TREE } & ^TREE & Enrich. \\
\cline { 2 - 6 } Treatment & $\mathrm{mg} / \mathrm{L}$ & $\mathrm{mg}$ & $\%$ extr. & $\mathrm{mg} / \mathrm{L}$ & $\mathrm{mg}$ & $\%$ extr. & solid \% & factor \\
\hline PLS & 1560.68 & & & 9.14 & & & $0.58 \%$ & \\
RA $^{\text {a }}$ & 1486.19 & 7.45 & $4.77 \%$ & 4.6 & 0.45 & $49.67 \%$ & $5.74 \%$ & 9.87
\end{tabular}




\begin{tabular}{rrrrrrrrr} 
RA $^{\text {a }}$ & 1441.57 & 3.35 & $3.00 \%$ & 4.11 & 0.04 & $10.65 \%$ & $1.09 \%$ & 1.87 \\
RA $^{\text {a }}$ & 1373.53 & 3.4 & $4.72 \%$ & 3.7 & 0.02 & $9.98 \%$ & $0.60 \%$ & 1.03 \\
AST $^{\mathrm{b}}$ & 2.67 & 0.27 & $3.58 \%$ & 0.38 & 0.04 & $8.37 \%$ & $12.46 \%$ & 21.4 \\
AST $^{\mathrm{b}}$ & 4.47 & 0.34 & $10.02 \%$ & 0.31 & 0.02 & $63.27 \%$ & $6.48 \%$ & 11.13 \\
AST $^{\mathrm{b}}$ & 7.47 & 0.37 & $10.98 \%$ & 0.25 & 0.01 & $60.98 \%$ & $3.24 \%$ & 5.56 \\
\hline
\end{tabular}

a $100 \mathrm{~mL}$ solution: $150 \mathrm{~mL} \mathrm{n}$-heptane: $0.84 \mathrm{~g}$ HDEHP

${ }^{\mathrm{b}} 0.38 \% \mathrm{HCl}$

\subsubsection{Multi-step ALSX experiment on pH 4.2 leaching solution}

Leaching and solvent extraction experiments for sludge from DLM sites to recover REEs have been conducted under a $\mathrm{pH}$ of 4.2 . For this leaching solution, the initial TREE percentage is $1.04 \%$, much higher than previous leaching results $0.40 \%$ (DLM, HNO3, $\mathrm{pH} 4.0$ ). This may be due to non-uniform distribution of REE in DLM sludge. Metal ions distribution in different step solution were shown in Figure 3.33 and Figure 3.34. After two-step SX runs, the estimated TREE in solid phase was about $51 \%$.

During the $1^{\text {st }}$ solvent extraction step, the ratio of solution to solvent to extractant was $100 \mathrm{~mL}: 150 \mathrm{~mL}$ : $0.84 \mathrm{~g}$. The extraction rates of REEs were $100 \%$. The estimated TREE in solid phase was about $9 \%$. After solvent extraction, acid stripping experiments of REEs back into aqueous phase were conducted. $100 \mathrm{~mL}$ $\mathrm{HCl}$ solution $\left(9 \%, 60^{\circ} \mathrm{C}\right)$ was used for the acid stripping process; but stripping efficiencies of metal ions were different, about 95\% in Table 3-24 and about 70\% in Table 3-25, in the two stripping processes under same conditions. It indicates that repeatability of the stripping process was not that good.

After acid stripping, $\mathrm{pH}$ adjustment on stripping solution was conducted. After $\mathrm{pH}$ was adjusted to 2.4, loss of TREE was a little higher than major metal ions. Thus, the estimated TREE in solid phase after this step decreased. During the $2^{\text {nd }}$ solvent extraction step, the ratio of solution to solvent to extractant was $100 \mathrm{~mL}: 150 \mathrm{~mL}: 0.84 \mathrm{~g}$ in Table 3-24. The extraction rates of REEs were 100\%. After solvent extraction, acid stripping experiments of REEs back into aqueous phase were conducted. $100 \mathrm{~mL} \mathrm{HCl}$ solution (9\%, $60^{\circ} \mathrm{C}$ ) was used for the acid stripping process. The estimated TREE in solid phase were about $51 \%$. In Table $3-25$, the ratio of solution to solvent to extractant was $100 \mathrm{~mL}: 150 \mathrm{~mL}: 0.42 \mathrm{~g}$ during the $2^{\text {nd }}$ solvent extraction step. The extraction rates for both major metal ions and REEs were lower than that in Table 3-24. After acid stripping, the estimated TREE in solid phase were about $46 \%$. Since concentrations of both major metal ions and REEs in filtered solution after $\mathrm{pH}$ adjustment were very low, lower ratio of extractant 
in organic phase for SX was required. It can be concluded from the difference of estimated TREE in solid phase after this step. $44.88 \%$ (Table 3-25) was much higher than $32.20 \%$ (Table 3-24).

Table 3-24 Results of solvent extraction experiment for DLM sludge under different SX conditions (high extractant ratio).

\begin{tabular}{|c|c|c|c|c|c|c|c|c|c|}
\hline \multirow[b]{2}{*}{$\mathrm{pH}$} & \multirow[b]{2}{*}{ Treatment } & \multicolumn{3}{|c|}{ TMM } & \multicolumn{3}{|c|}{ TREE } & \multirow{2}{*}{$\begin{array}{c}\wedge \text { TREE } \\
\text { solid \% }\end{array}$} & \multirow{2}{*}{$\begin{array}{l}\text { Enrich. } \\
\text { factor }\end{array}$} \\
\hline & & $\mathrm{mg} / \mathrm{L}$ & $\mathrm{mg}$ & $\%$ extr. & $\mathrm{mg} / \mathrm{L}$ & $\mathrm{mg}$ & $\%$ extr. & & \\
\hline \multirow[t]{3}{*}{4.2} & $\mathrm{PLS}^{\mathrm{a}}$ & 575.87 & 57.59 & & 6.05 & 0.61 & & $1.04 \%$ & \\
\hline & $\mathrm{RA}^{\mathrm{b}}$ & 514.5 & 51.45 & $10.70 \%$ & 0 & 0 & $100.0 \%$ & $8.97 \%$ & 8.63 \\
\hline & $\mathrm{AST}^{\mathrm{c}}$ & 61.05 & 6.1 & $99.50 \%$ & 5.84 & 0.58 & $96.5 \%$ & $8.73 \%$ & \\
\hline \multirow[t]{3}{*}{2.4} & $\mathrm{pH} \operatorname{adj}^{\mathrm{d}}$ & 47.75 & 5.01 & $17.90 \%$ & 3.4 & 0.36 & $38.9 \%$ & $6.65 \%$ & \\
\hline & $\mathrm{RA}^{\mathrm{b}}$ & 40.59 & 4.06 & $15.00 \%$ & 0 & 0 & $100.0 \%$ & $32.20 \%$ & 30.97 \\
\hline & $\mathrm{AST}^{\mathrm{c}}$ & 3.09 & 0.31 & $43.20 \%$ & 3.22 & 0.32 & $94.7 \%$ & $51.01 \%$ & 49.07 \\
\hline
\end{tabular}

a leaching solution, DLM, pH 4.2, $100 \mathrm{~mL}$

${ }^{b}$ after SX (100 mL solution:150 mL n-heptane:0.84 g HDEHP)

${ }^{c}$ after acid stripping $\left(150 \mathrm{~mL}\right.$ organic phase: $100 \mathrm{~mL} \mathrm{HCl}$ solution $\left(9 \%, 60^{\circ} \mathrm{C}\right)$ )

${ }^{\mathrm{d}} \mathrm{pH}$ adjustment on stripping solution and then filtering

Table 3-25 Results of solvent extraction experiment for DLM sludge under different SX conditions (low extractant ratio).

\begin{tabular}{|c|c|c|c|c|c|c|c|c|c|}
\hline \multirow[b]{2}{*}{$\mathrm{pH}$} & \multirow[b]{2}{*}{ Treatment } & \multicolumn{3}{|c|}{ TMM } & \multicolumn{3}{|c|}{ TREE } & \multirow{2}{*}{$\begin{array}{l}\text { ^TREE } \\
\text { solid \% }\end{array}$} & \multirow{2}{*}{$\begin{array}{l}\text { Enrich } \\
\text { factor }\end{array}$} \\
\hline & & $\mathrm{mg} / \mathrm{L}$ & $\mathrm{mg}$ & $\%$ extr. & $\mathrm{mg} / \mathrm{L}$ & $\mathrm{mg}$ & $\%$ extr. & & \\
\hline \multirow[t]{3}{*}{4.2} & $\mathrm{PLS}^{\mathrm{a}}$ & 575.87 & 57.59 & & 6.05 & 0.61 & & $1.04 \%$ & \\
\hline & $\mathrm{RA}^{\mathrm{b}}$ & 514.3 & 51.43 & $10.70 \%$ & 0 & 0 & $100.00 \%$ & $8.95 \%$ & 8.61 \\
\hline & $\mathrm{AST}^{\mathrm{c}}$ & 53.21 & 5.32 & $86.40 \%$ & 4.08 & 0.41 & $67.40 \%$ & $7.12 \%$ & \\
\hline \multirow[t]{3}{*}{2.4} & $\mathrm{pH}$ adj ${ }^{\mathrm{d}}$ & 47.75 & 5.01 & $5.80 \%$ & 3.4 & 0.36 & $12.50 \%$ & $6.65 \%$ & \\
\hline & $\mathrm{RA}^{\mathrm{e}}$ & 43.68 & 4.37 & $8.50 \%$ & 0.09 & 0.01 & $97.40 \%$ & $44.88 \%$ & 43.17 \\
\hline & $\mathrm{AST}^{\mathrm{c}}$ & 3.24 & 0.32 & $79.80 \%$ & 2.82 & 0.28 & $85.20 \%$ & $46.52 \%$ & 44.74 \\
\hline
\end{tabular}

${ }^{a}$ leaching solution, DLM, pH 4.2, $100 \mathrm{~mL}$

${ }^{b}$ after SX (100 mL solution:150 mL n-heptane:0.84 g HDEHP)

${ }^{c}$ after acid stripping $\left(150 \mathrm{~mL}\right.$ organic phase: $100 \mathrm{~mL} \mathrm{HCl}$ solution $\left(9 \%, 60^{\circ} \mathrm{C}\right)$ )

${ }^{\mathrm{d}} \mathrm{pH}$ adjustment on stripping solution and then filtering

e after SX (100 mL solution:150 mL n-heptane:0.42 g HDEHP) 

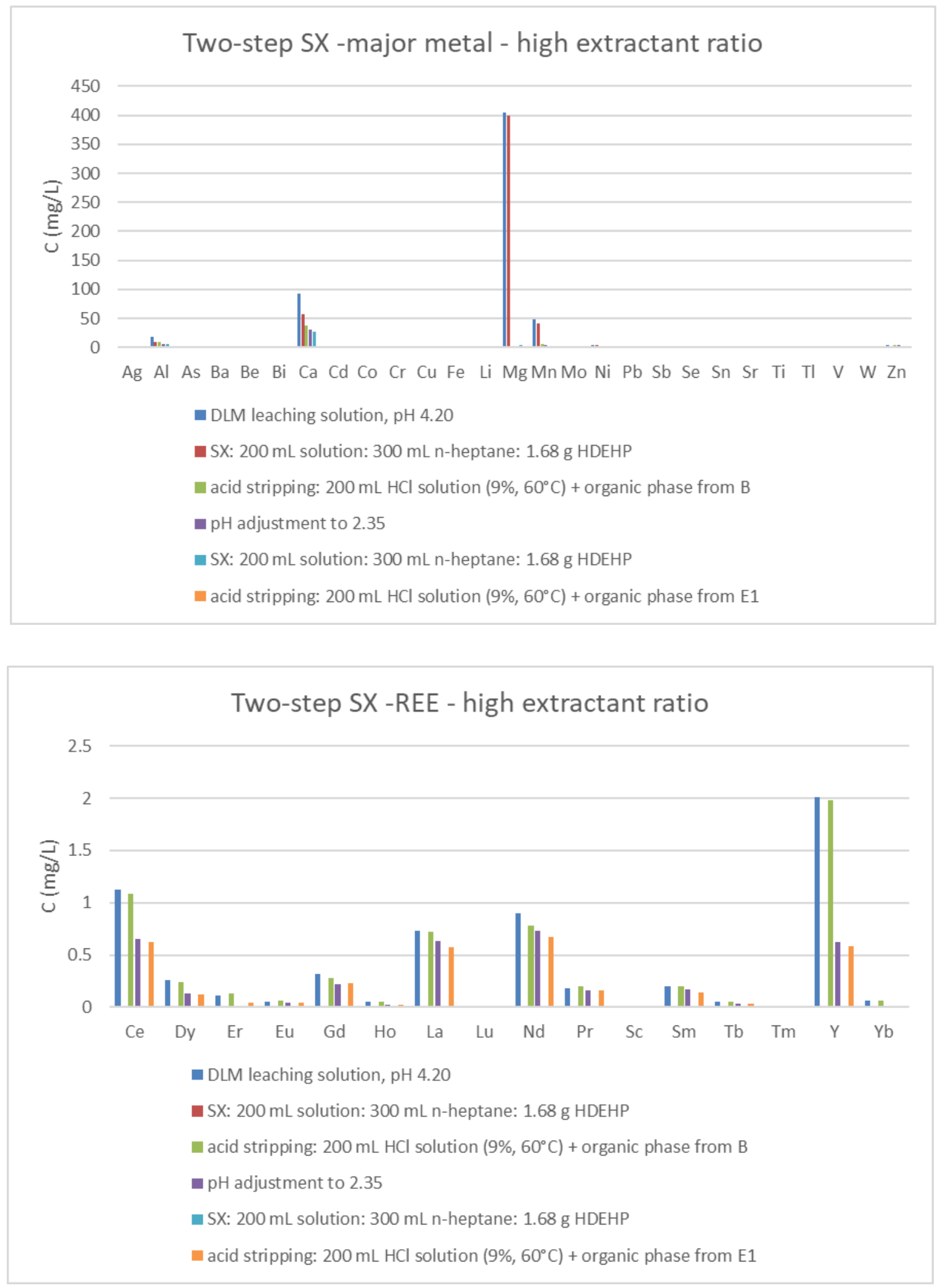

Figure 3.33 Metal ions distribution data in different step solution (Two-step SX - high extractant ratio). 

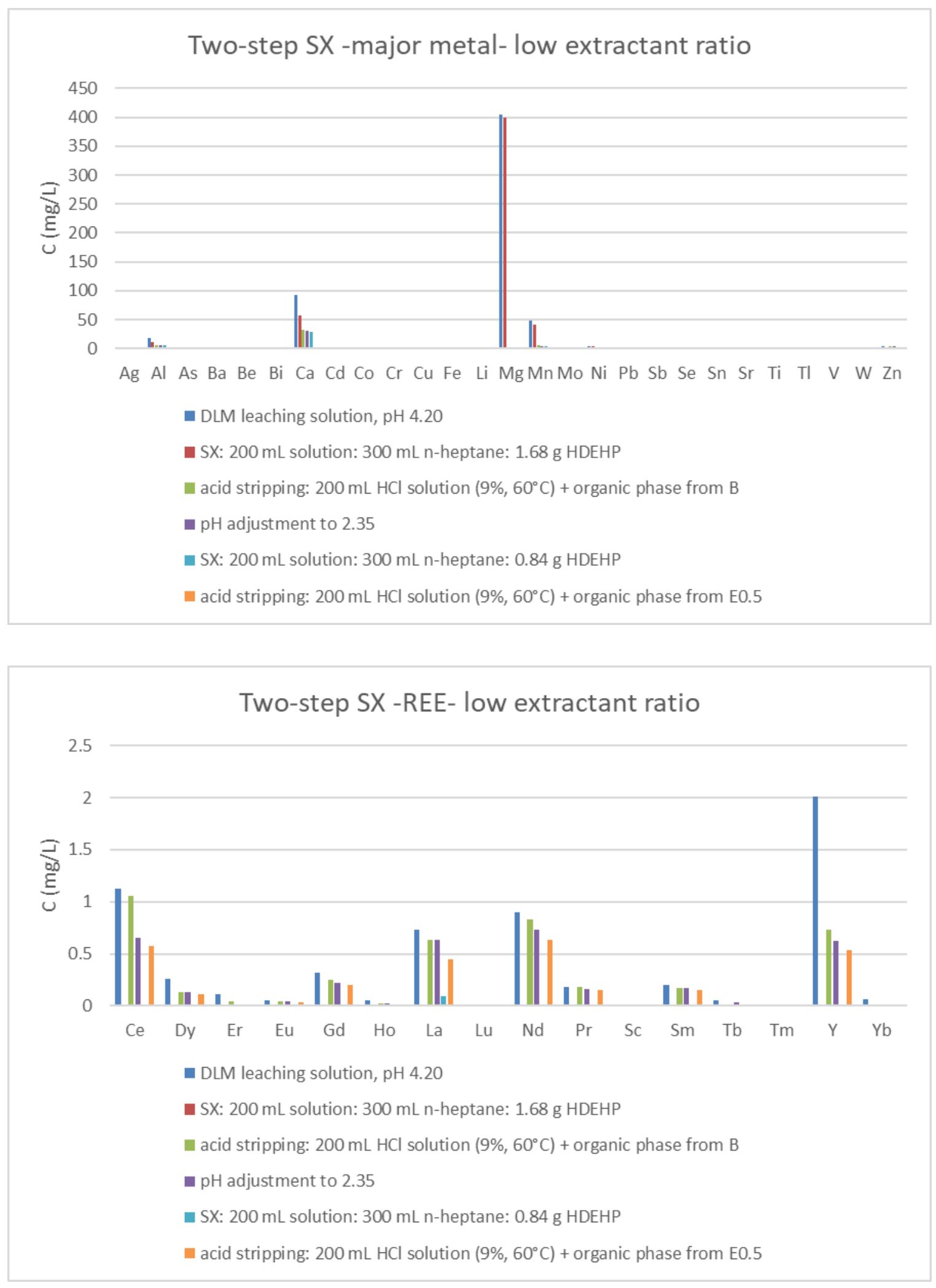

Figure 3.34 Metal ions distribution data in different step solution (Two-step SX - low extractant ratio). 


\subsubsection{Multi-step ALSX experiment on pH 3 leaching solution}

A select number of laboratory-scale exploratory tests to identify novel processing routes were conducted on DLM leaching solution of $\mathrm{pH}$ 3. They included the following three parts.

1) Filtering effect on solvent extraction (SX) feed solution: a) acid resistant filtering equipment; b) clear feed solution for SX.

2) Novel flowsheet configurations: addition of water scrub circuit; multi-step solvent extraction runs.

3) Novel reagent mixtures for solvent extraction: extractant concentration change.

The estimated TREE in solid phase (\%) in all tables and figures are calculated based on cation elements data. All leaching solution were obtained from sludge of DLM site.

\section{1) Filtering effect on solvent extraction $(S X)$ feed solution}

Leaching solution influences a lot on SX efficiency. There are two issues that we encountered and need to pay attention to in order to obtain fine feed solution.

a) Filtering equipment should be acid resistant.

Anywhere that leaching solution will flow through must be acid resistant. Figure 3.35 shows acid resistant filtering instrument (left) and partly acid resistant filtering instrument (right). Left vacuum filter that we used includes ceramic funnel and glass container. The chamber of the large vacuum filter (right) is rubberized, but the pipe below the chamber is not coated steel. When low pH leaching solution flows through it, iron concentration will increase. Table 3-26 shows SX results of leaching solution with different acid type and different filtering instrument. It concludes results of Table A, B and C. These three tables show results of six step treatment for REE recovery. The flowsheet is shown in Figure 3.36. The main difference of major ion concentration for these three tables' initial leaching solution is Iron element concentration. Iron competitive extraction will lead to low TREE in final product. The estimated TREE in solid phase based on cation measurement data was $42 \%$ (Table A) by using acid resistant filtering instrument. However, the estimated TREE in solid phase were only $7 \%$ (Table B) and $10 \%$ (Table C) by using partly acid resistant filtering instrument while keeping feed leaching solution's $\mathrm{pH}$ similar to $\mathrm{pH}$ in

\section{Table A.}

Table 3-26 SX results of leaching solution with different acid type and different filtering instrument. 


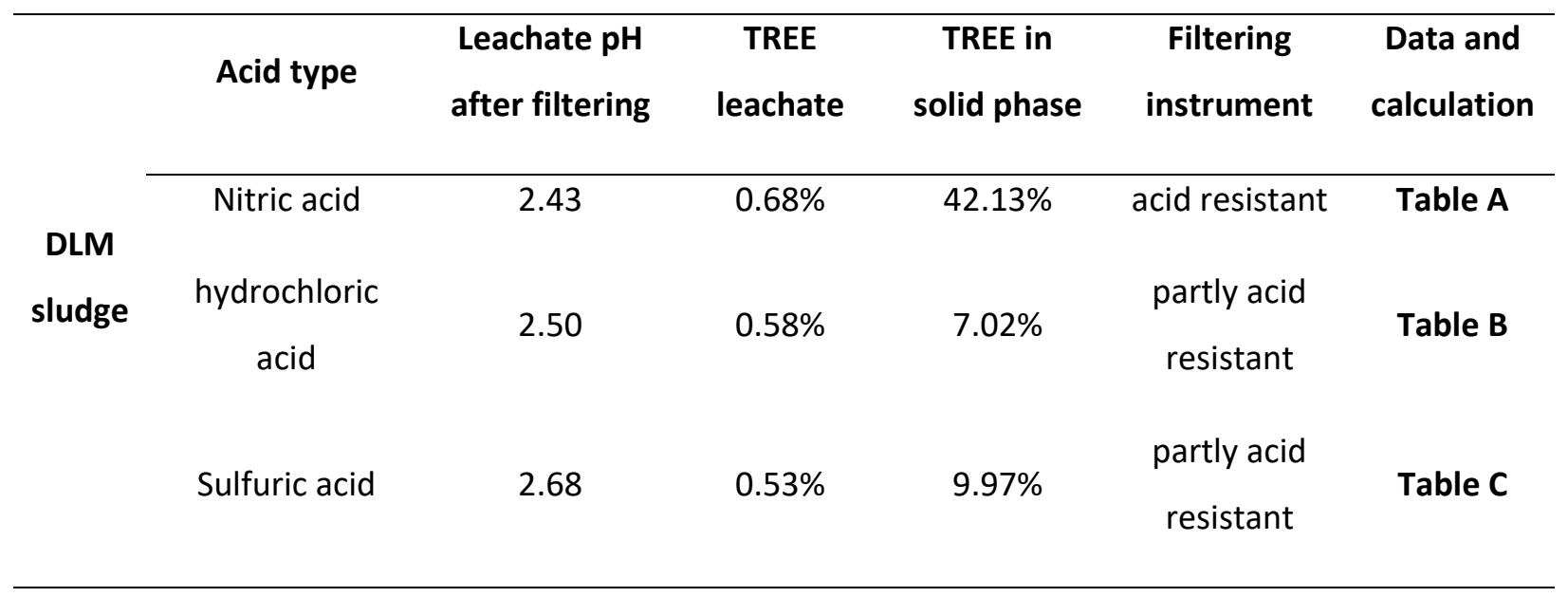
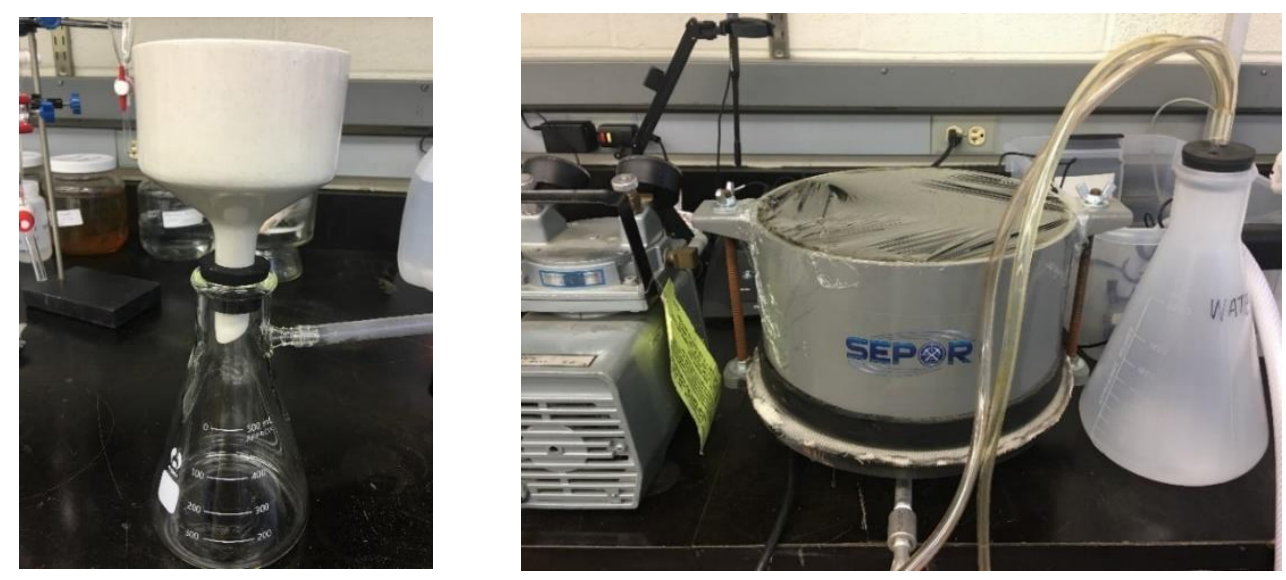

Figure 3.35 Acid resistant filtering instrument (left); partly acid resistant filtering instrument (right). 


\section{Sludge}

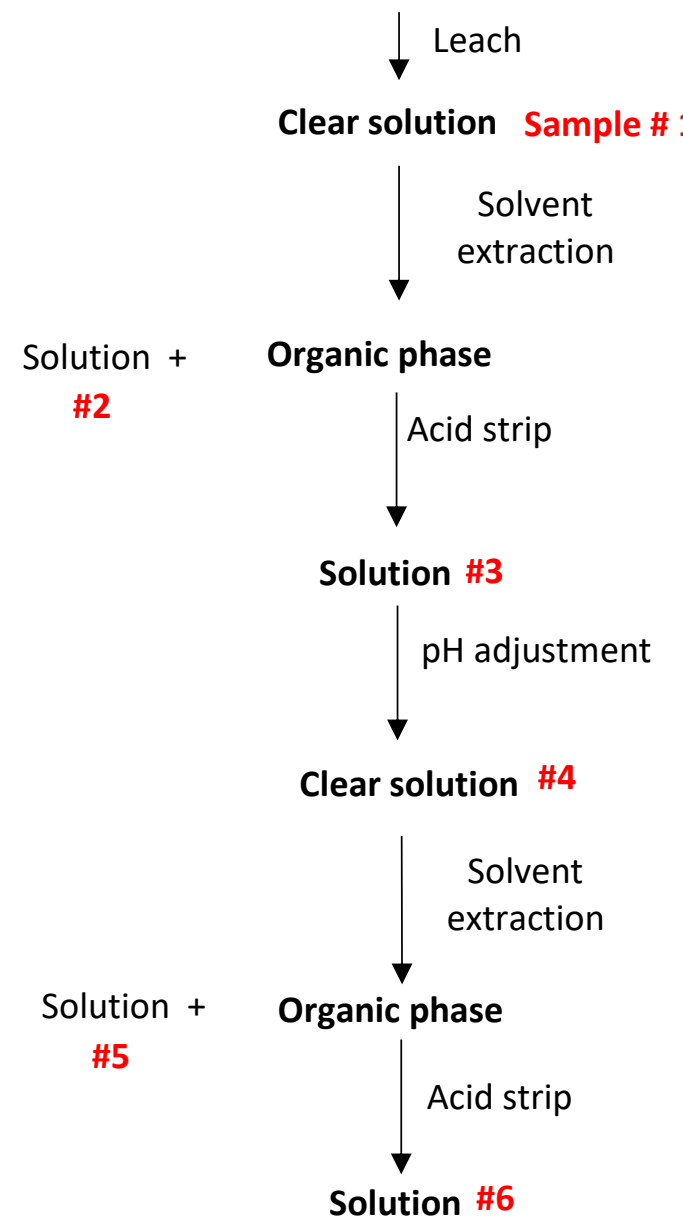

Figure 3.36 Flowsheet of six-step treatment for REE recovery.

Table A. SX results of nitric acid leaching solution using acid resistant filtering instrument.

\begin{tabular}{|c|c|c|c|c|c|c|c|c|c|c|}
\hline \multirow[b]{2}{*}{$\mathrm{pH}$} & \multirow[b]{2}{*}{ Treatment } & \multirow[b]{2}{*}{$\begin{array}{c}\text { Sample ID } \\
\#\end{array}$} & \multicolumn{3}{|c|}{ TMM } & \multicolumn{3}{|c|}{ TREE } & \multirow{2}{*}{$\begin{array}{l}\text { ^TREE } \\
\text { solid \% }\end{array}$} & \multirow{2}{*}{$\begin{array}{l}\text { Enrich. } \\
\text { factor }\end{array}$} \\
\hline & & & $\mathrm{mg} / \mathrm{L}$ & $\mathrm{mg}$ & $\%$ extr. & $\mathrm{mg} / \mathrm{L}$ & $\mathrm{mg}$ & $\%$ extr. & & \\
\hline \multirow[t]{3}{*}{2.4} & $\mathrm{PLS}^{\mathrm{a}}$ & 1 & 4313.69 & 431.37 & & 29.4 & 2.94 & & $0.68 \%$ & \\
\hline & $\mathrm{RA}^{\mathrm{b}}$ & 2 & 4147 & 414.7 & $3.90 \%$ & 5.54 & 0.55 & $81.16 \%$ & $12.52 \%$ & 18.5 \\
\hline & $\mathrm{AST}^{\mathrm{c}}$ & 3 & 527.69 & 52.77 & - & 21.09 & 2.11 & $88.39 \%$ & $3.84 \%$ & \\
\hline \multirow[t]{3}{*}{2} & $\mathrm{pH} \operatorname{adj}^{\mathrm{d}}$ & 4 & 259.56 & 25.96 & $50.80 \%$ & 13.87 & 1.39 & $34.23 \%$ & $5.07 \%$ & \\
\hline & $\mathrm{RA}^{\mathrm{b}}$ & 5 & 241.57 & 24.16 & $6.90 \%$ & 0.89 & 0.09 & $93.58 \%$ & $41.91 \%$ & 61.91 \\
\hline & $\mathrm{AST}^{\mathrm{c}}$ & 6 & 15.33 & 1.53 & $85.20 \%$ & 11.16 & 1.12 & $85.98 \%$ & $42.13 \%$ & 62.23 \\
\hline
\end{tabular}

${ }^{a}$ leaching solution, DLM, pH 2.4, $100 \mathrm{~mL}$

${ }^{b}$ after SX (100 mL solution:150 mL n-heptane:1.68 g HDEHP) 
c after acid stripping $\left(150 \mathrm{~mL}\right.$ organic phase: $100 \mathrm{~mL} \mathrm{HCl}$ solution $\left(9 \%, 60^{\circ} \mathrm{C}\right)$ )

${ }^{\mathrm{d}}$ after $\mathrm{pH}$ adjustment on stripping solution and then filtering

Table B. SX results of hydrochloric acid leaching solution using partly acid resistant filtering instrument.

\begin{tabular}{|c|c|c|c|c|c|c|c|c|c|c|}
\hline \multirow[b]{2}{*}{$\mathrm{pH}$} & \multirow[b]{2}{*}{ Treatment } & \multirow[b]{2}{*}{$\begin{array}{c}\text { Sample } \\
\text { ID \# }\end{array}$} & \multicolumn{3}{|c|}{ TMM } & \multicolumn{3}{|c|}{ TREE } & \multirow{2}{*}{$\begin{array}{l}\text { ^TREE } \\
\text { solid \% }\end{array}$} & \multirow{2}{*}{$\begin{array}{l}\text { Enrich } \\
\text { factor }\end{array}$} \\
\hline & & & $\mathrm{mg} / \mathrm{L}$ & $\mathrm{mg}$ & $\%$ extr. & $\mathrm{mg} / \mathrm{L}$ & $\mathrm{mg}$ & $\%$ extr. & & \\
\hline \multirow[t]{3}{*}{2.5} & PLS ${ }^{a}$ & 1 & 5014.66 & 501.47 & & 29.48 & 2.95 & & $0.58 \%$ & \\
\hline & $\mathrm{RA}^{\mathrm{b}}$ & 2 & 4823.65 & 482.37 & $3.80 \%$ & 8.35 & 0.84 & $71.68 \%$ & $9.96 \%$ & 17.04 \\
\hline & $\mathrm{AST}^{\mathrm{c}}$ & 3 & 709.16 & 70.92 & - & 16.33 & 1.63 & $77.28 \%$ & $2.25 \%$ & \\
\hline \multirow[t]{7}{*}{2.1} & $\mathrm{pH}$ adj ${ }^{\mathrm{d}}$ & 4 & 610.32 & 61.03 & $13.90 \%$ & 15.33 & 1.53 & $6.12 \%$ & $2.45 \%$ & \\
\hline & $\mathrm{RA}^{\mathrm{b}}$ & 5 & 433.91 & 43.39 & $28.90 \%$ & 2.63 & 0.26 & $82.83 \%$ & $6.71 \%$ & 11.49 \\
\hline & $\mathrm{AST}^{\mathrm{c}}$ & 6 & 185.29 & 18.53 & $105.00 \%$ & 14 & 1.4 & $110.25 \%$ & $7.02 \%$ & 12.02 \\
\hline & \multicolumn{10}{|c|}{ a leaching solution, DLM, pH 2.5, $100 \mathrm{~mL}$} \\
\hline & \multicolumn{10}{|c|}{ b after SX (100 mL solution:150 mL n-heptane:1.68 g HDEHP) } \\
\hline & \multicolumn{10}{|c|}{${ }^{\mathrm{C}}$ after acid stripping $\left(150 \mathrm{~mL}\right.$ organic phase: $100 \mathrm{~mL} \mathrm{HCl}$ solution $\left(9 \%, 60^{\circ} \mathrm{C}\right)$ ) } \\
\hline & \multicolumn{10}{|c|}{ d after $\mathrm{pH}$ adjustment on stripping solution and then filtering } \\
\hline
\end{tabular}

Table C. SX results of sulfuric acid leaching solution using partly acid resistant filtering instrument.

\begin{tabular}{|c|c|c|c|c|c|c|c|c|c|c|}
\hline \multirow[b]{2}{*}{$\mathrm{pH}$} & \multirow[b]{2}{*}{ Treatment } & \multirow[b]{2}{*}{$\begin{array}{c}\text { Sample } \\
\text { ID \# }\end{array}$} & \multicolumn{3}{|c|}{ TMM } & \multicolumn{3}{|c|}{ TREE } & \multirow{2}{*}{$\begin{array}{l}\text { ^TREE } \\
\text { solid \% }\end{array}$} & \multirow{2}{*}{$\begin{array}{l}\text { Enrich. } \\
\text { factor }\end{array}$} \\
\hline & & & $\mathrm{mg} / \mathrm{L}$ & $\mathrm{mg}$ & $\%$ extr. & $\mathrm{mg} / \mathrm{L}$ & $\mathrm{mg}$ & $\%$ extr. & & \\
\hline \multirow[t]{3}{*}{2.7} & PLS ${ }^{a}$ & 1 & 4357.22 & 435.72 & & 23.3 & 2.33 & & $0.53 \%$ & \\
\hline & $\mathrm{RA}^{\mathrm{b}}$ & 2 & 4158.57 & 415.86 & $4.60 \%$ & 7.64 & 0.76 & $67.21 \%$ & 7.31\% & 13.74 \\
\hline & $\mathrm{AST}^{\mathrm{c}}$ & 3 & 363.2 & 36.32 & $182.80 \%$ & 14.39 & 1.44 & $91.88 \%$ & $3.81 \%$ & \\
\hline \multirow[t]{7}{*}{2.1} & $\mathrm{pH}$ adj ${ }^{\mathrm{d}}$ & 4 & 225.9 & 22.59 & $37.80 \%$ & 11.79 & 1.18 & $18.07 \%$ & $4.96 \%$ & \\
\hline & $\mathrm{RA}^{\mathrm{b}}$ & 5 & 113.67 & 11.37 & $49.70 \%$ & 0.81 & 0.08 & $93.16 \%$ & $8.91 \%$ & 16.76 \\
\hline & $\mathrm{AST}^{\mathrm{c}}$ & 6 & 123.13 & 12.31 & $109.70 \%$ & 13.63 & 1.36 & $124.10 \%$ & $9.97 \%$ & 18.74 \\
\hline & \multicolumn{10}{|c|}{ a leaching solution, DLM, pH 2.68, $100 \mathrm{~mL}$} \\
\hline & \multicolumn{10}{|c|}{ b after SX (100 mL solution:150 mL n-heptane:1.68 g HDEHP) } \\
\hline & \multicolumn{10}{|c|}{${ }^{\circ}$ after acid stripping $\left(150 \mathrm{~mL}\right.$ organic phase: $100 \mathrm{~mL} \mathrm{HCl}$ solution $\left(9 \%, 60^{\circ} \mathrm{C}\right)$ ) } \\
\hline & \multicolumn{10}{|c|}{ d after $\mathrm{pH}$ adjustment on stripping solution and then filtering } \\
\hline
\end{tabular}


Critical REE, heavy REE and light REE distribution in whole process (Table A, B and C) are shown in Figure 3.37. Critical REEs: Nd, Eu, Y, Tb and Dy. Light REEs: La, Ce, Pr and Sm. Heavy REEs: Sc, Gd, Ho, Er, Tm, Yb and Lu. For sample 1, 3, 4 and 6, the more total percentage of critical and heavy REEs, the better. The percentages of critical REEs increase slightly in whole process, except for final acid stripping step. The losses of TREE in step 2 were high in these processes, especially for Table $\mathbf{B}$ and $\mathbf{C}$ due to iron competitive extraction. From data of sample 3 and 4, we can see that the losses of TREE in pH adjustment step are acceptable.
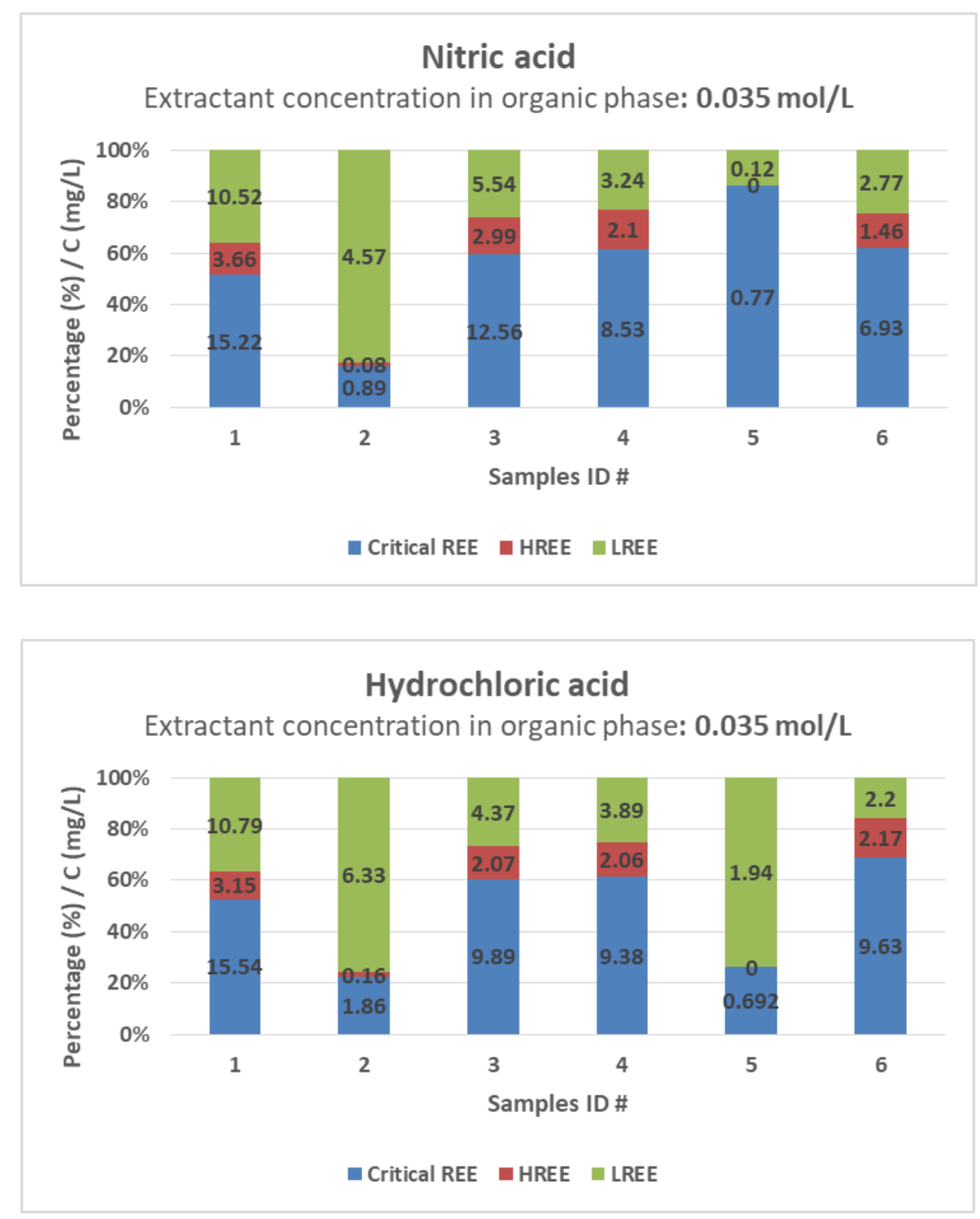


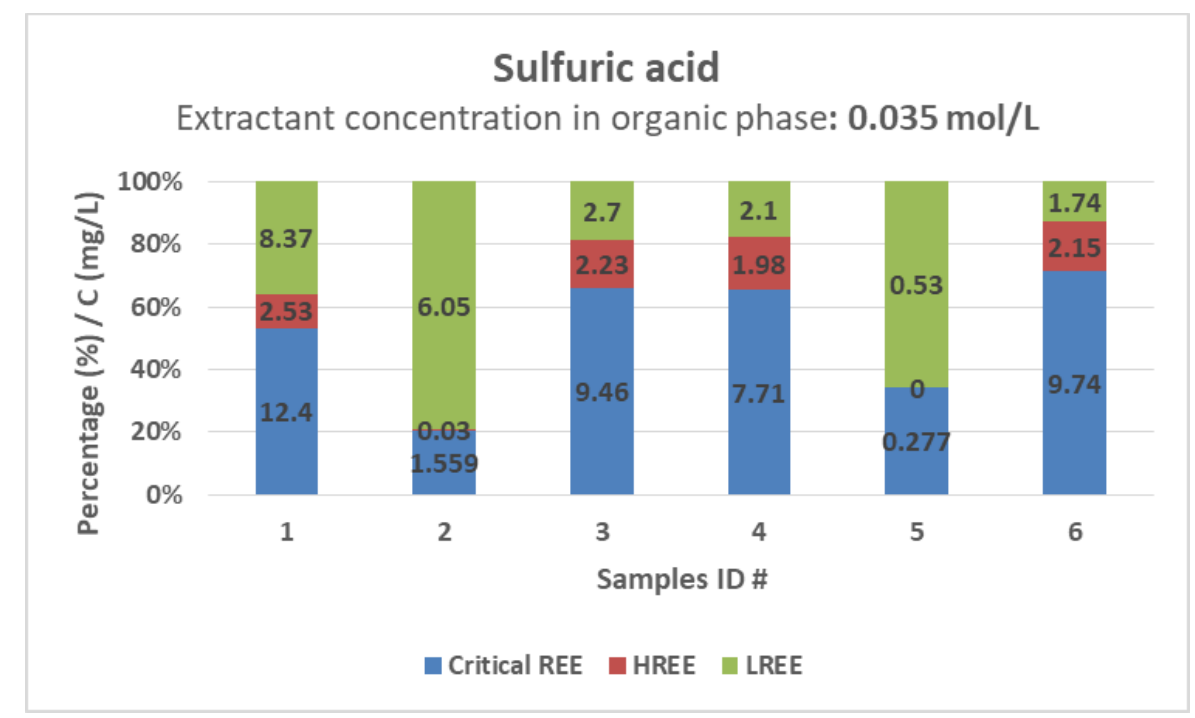

Figure 3.37 Critical REE, heavy REE and light REE distribution in whole process (Table A, B and C).

b) Filtering should be effective. Feed solution for SX should be as clear as possible.

Leaching experiments on sludge from DLM sites to recover REEs have also been conducted under a pH of about 3. Solvent extraction experiments were done on leaching solutions with two different filtration effect. Table 3-27 concludes SX results of Table $\mathbf{D}$ and $\mathbf{E}$, which followed the flowsheet in Figure 3.36. For these leaching solutions, the initial TREE percentage under different filtration effect is $0.66 \%$ and $0.65 \%$. After two-step SX runs, the estimated TREE in solid phase were about $49 \%$ for solution with good filtration effect. But the estimated TREE in solid phase after every single step (poor filtration effect) were all lower than those in Table D. It indicates that good filtration effect was necessary for SX runs.

Table 3-27 SX results of leaching solution with different filtration effect.

\begin{tabular}{|c|c|c|c|c|c|c|}
\hline \multirow{3}{*}{$\begin{array}{l}\text { DLM } \\
\text { sludge }\end{array}$} & $\begin{array}{l}\text { Acid } \\
\text { type }\end{array}$ & \multicolumn{2}{|c|}{$\begin{array}{l}\text { Leachate } \mathrm{pH} \text { after } \\
\text { filtering }\end{array}$} & \multirow{2}{*}{$\begin{array}{c}\text { TREE in } \\
\text { leachate }\end{array}$} & \multirow{2}{*}{$\begin{array}{c}\begin{array}{c}\text { TREE in solid phase } \\
\text { after multi-step } \\
\text { treatment }\end{array} \\
48.71 \%\end{array}$} & \multirow{2}{*}{$\begin{array}{c}\begin{array}{c}\text { Data and } \\
\text { calculation }\end{array} \\
\text { Table D }\end{array}$} \\
\hline & Nitric & $\begin{array}{l}\text { good filtration } \\
\text { effect }\end{array}$ & 2.90 & & & \\
\hline & acid & $\begin{array}{l}\text { poor filtration } \\
\text { effect }\end{array}$ & 2.76 & $0.65 \%$ & $28.62 \%$ & Table E \\
\hline
\end{tabular}

Table D. Results of SX experiment for DLM sludge under same SX conditions (good filtration effect). 


\begin{tabular}{|c|c|c|c|c|c|c|c|c|c|c|}
\hline \multirow[b]{2}{*}{$\mathrm{pH}$} & \multirow[b]{2}{*}{ Treatment } & \multirow[b]{2}{*}{$\begin{array}{c}\text { Sample } \\
\text { ID \# }\end{array}$} & \multicolumn{3}{|c|}{ TMM } & \multicolumn{3}{|c|}{ TREE } & \multirow{2}{*}{$\begin{array}{l}\wedge \text { TREE } \\
\text { solid \% }\end{array}$} & \multirow{2}{*}{$\begin{array}{l}\text { Enrich. } \\
\text { factor }\end{array}$} \\
\hline & & & $\mathrm{mg} / \mathrm{L}$ & $\mathrm{mg}$ & $\%$ extr. & $\mathrm{mg} / \mathrm{L}$ & $\mathrm{mg}$ & $\%$ extr. & & \\
\hline \multirow[t]{3}{*}{2.9} & PLS ${ }^{a}$ & 1 & 2267 & 226.7 & & 15.03 & 1.5 & & $0.66 \%$ & \\
\hline & $\mathrm{RA}^{\mathrm{b}}$ & 2 & 2260.56 & 226.06 & $0.30 \%$ & 0.32 & 0.03 & $97.87 \%$ & $69.54 \%$ & 105.59 \\
\hline & $\mathrm{AST}^{\mathrm{c}}$ & 3 & 119 & 11.9 & -- & 13.35 & 1.34 & $90.75 \%$ & $10.09 \%$ & \\
\hline \multirow[t]{7}{*}{2} & $\mathrm{pH}$ adj ${ }^{\mathrm{d}}$ & 4 & 88.67 & 8.87 & $25.50 \%$ & 10.83 & 1.08 & $18.88 \%$ & $10.88 \%$ & \\
\hline & $\mathrm{RA}^{\mathrm{b}}$ & 5 & 84.13 & 8.41 & $5.10 \%$ & 0.25 & 0.03 & $97.69 \%$ & $70.01 \%$ & 106.29 \\
\hline & $\mathrm{AST}^{\mathrm{c}}$ & 6 & 10.75 & 1.08 & $237.20 \%$ & 10.21 & 1.02 & $96.50 \%$ & $48.71 \%$ & 73.95 \\
\hline & a leaching & וס חת & $\mathrm{pH} 2.9,1$ & $00 \mathrm{~mL}$ & & & & & & \\
\hline & ${ }^{\mathrm{b}}$ after SX (1 & $\mathrm{mL}$ solu & $\mathrm{n}: 150 \mathrm{~mL}$ & n-hepta & $1.68 \mathrm{~g} \mathrm{H}$ & DEHP) & & & & \\
\hline & ${ }^{\mathrm{c}}$ after acid s & ripping (1 & $0 \mathrm{~mL}$ orgar & nic phase: & $100 \mathrm{~mL} \mathrm{H}$ & I soluti & n $(9 \%$, & $\left.\left.60^{\circ} \mathrm{C}\right)\right)$ & & \\
\hline & ${ }^{\mathrm{d}}$ after $\mathrm{pH}$ ac & justment & n stripping & solution & and then $f$ & tering & & & & \\
\hline
\end{tabular}

Table E. Results of SX experiment for DLM sludge under same SX conditions (poor filtration effect).

\begin{tabular}{|c|c|c|c|c|c|c|c|c|c|c|}
\hline \multirow[b]{2}{*}{$\mathrm{pH}$} & \multirow[b]{2}{*}{ Treatment } & \multicolumn{2}{|l|}{ Sample } & \multicolumn{2}{|l|}{ TMM } & \multicolumn{3}{|c|}{ TREE } & \multirow{2}{*}{$\begin{array}{l}\text { ^TREE } \\
\text { solid \% }\end{array}$} & \multirow{2}{*}{$\begin{array}{l}\text { Enrich } \\
\text { factor }\end{array}$} \\
\hline & & ID \# & $\mathrm{mg} / \mathrm{L}$ & $\mathrm{mg}$ & $\%$ extr. & $\mathrm{mg} / \mathrm{L}$ & $\mathrm{mg}$ & $\%$ extr. & & \\
\hline \multirow[t]{3}{*}{2.8} & PLS ${ }^{a}$ & 1 & 2269.03 & 226.9 & & 14.78 & 1.48 & & $0.65 \%$ & \\
\hline & $\mathrm{RA}^{\mathrm{b}}$ & 2 & 2289.21 & 228.92 & $-0.90 \%$ & 0.46 & 0.05 & $96.89 \%$ & -- & \\
\hline & $\mathrm{AST}^{\mathrm{c}}$ & 3 & 205.73 & 20.57 & -- & 12.53 & 1.25 & $87.50 \%$ & $5.74 \%$ & \\
\hline \multirow[t]{7}{*}{2} & $\mathrm{pH}$ adj ${ }^{d}$ & 4 & 105.88 & 10.59 & $48.50 \%$ & 9.84 & 0.98 & $21.47 \%$ & $8.50 \%$ & \\
\hline & $\mathrm{RA}^{\mathrm{b}}$ & 5 & 83.61 & 8.36 & $21.00 \%$ & 0 & 0 & $100.00 \%$ & $30.64 \%$ & 47.34 \\
\hline & $\mathrm{AST}^{\mathrm{c}}$ & 6 & 25.51 & 2.55 & $114.50 \%$ & 10.23 & 1.02 & $104.00 \%$ & $28.62 \%$ & 44.23 \\
\hline & ${ }^{a}$ leaching $s$ & ution, D & , $\mathrm{pH} 2.7$ & $5,100 \mathrm{~mL}$ & & & & & & \\
\hline & ${ }^{b}$ after SX (1 & $0 \mathrm{~mL}$ sol & tion:150 r & $n L$ n-hept & ane:1.68 g & HDEHP) & & & & \\
\hline & ${ }^{\mathrm{c}}$ after acid & tripping ( & $150 \mathrm{~mL}$ org & sanic pha & e: $100 \mathrm{~mL}$ & $\mathrm{ACl}$ sol & ion $(99$ & $\left.\left.\%, 60^{\circ} \mathrm{C}\right)\right)$ & & \\
\hline & ${ }^{\mathrm{d}}$ after $\mathrm{pH}$ a & justment & on strippi & g solutio & and then & filtering & & & & \\
\hline
\end{tabular}

Critical REE, heavy REE and light REE distribution in whole process (Table $\mathbf{D}$ and $\mathbf{E}$ ) are shown in Figure 3.38. Critical REEs: Nd, Eu, Y, Tb and Dy. Light REEs: La, Ce, Pr and Sm. Heavy REEs: Sc, Gd, Ho, Er, Tm, Yb and Lu. For sample 1, 3, 4 and 6, the more total percentage of critical and heavy REEs, the better. Besides, the percentages of critical REEs increase slightly in whole process, except for two acid stripping steps. It's because that the easier extraction of critical REEs, the harder stripping of them. The losses of TREE in step 
2 were low in these processes. From data of sample 3 and 4, we can see that the losses of TREE in pH adjustment step are acceptable.

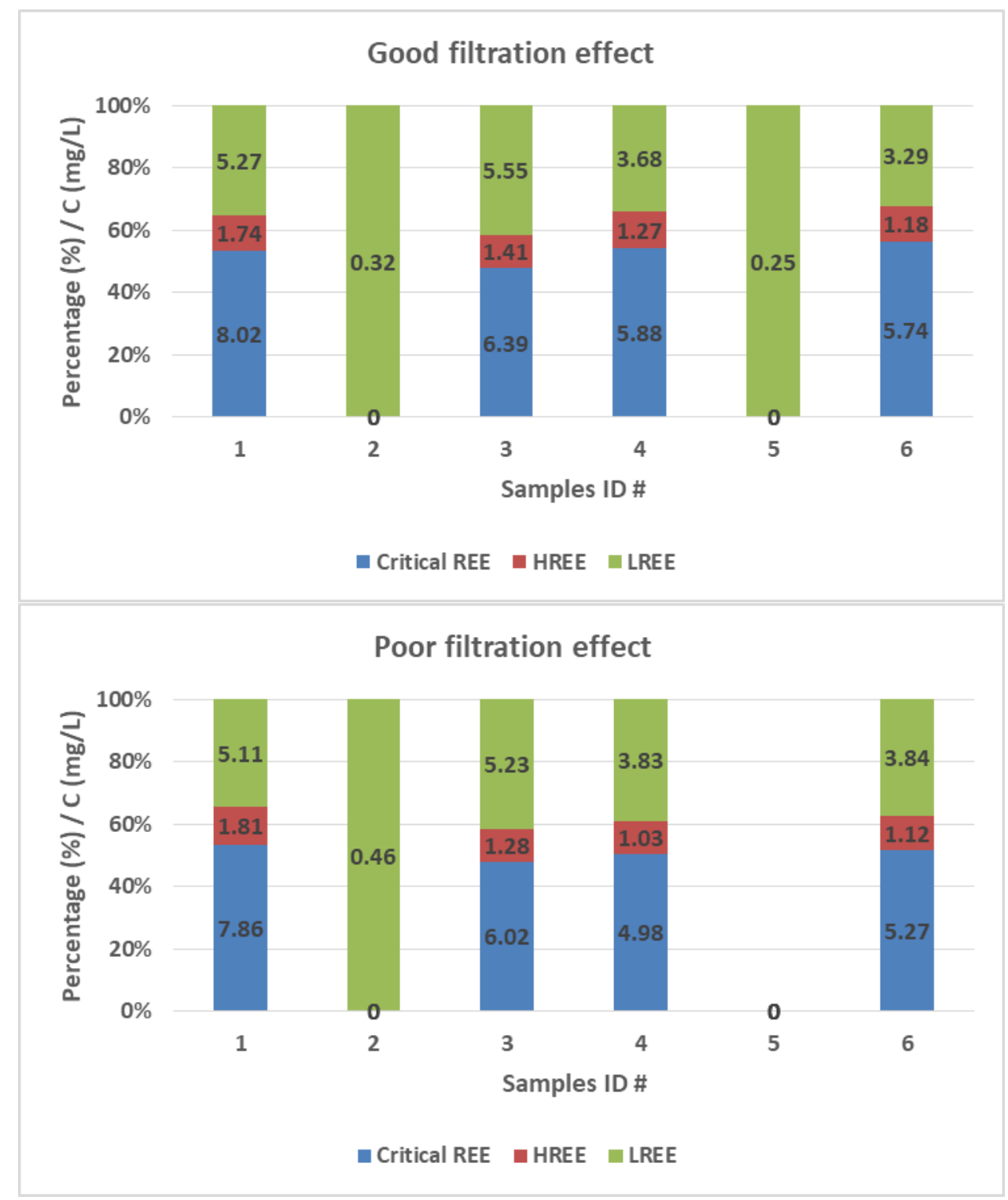

Figure 3.38 Critical REE, heavy REE and light REE distribution in whole process (Table D and E).

\section{2) Add water scrub step}

Leaching experiments on sludge from DLM sites to recover REEs have also been conducted under a pH of 2.4. Solvent extraction experiments were done on leaching solutions with and without water scrub step. Table 3-28 concludes SX results of Table $\mathbf{A}$ and $\mathbf{F}$. Table $\mathbf{F}$ followed the flowsheet in Figure 3.39. For the leaching solutions, the initial TREE percentage is $0.68 \%$. After two-step SX runs, the estimated TREE in 
solid phase were about $58 \%$ and $42 \%$ for solution with and without water scrub step. Though there is TREE loss (3.50\%) in water scrub step, the final purity of TREE increased a lot.

Table 3-28 SX results of leaching solution with and without water scrub step.

\begin{tabular}{|c|c|c|c|c|c|c|}
\hline \multirow{3}{*}{$\begin{array}{l}\text { DLM } \\
\text { sludge }\end{array}$} & \multirow{3}{*}{$\begin{array}{l}\text { Acid type } \\
\text { Nitric acid }\end{array}$} & \multirow{2}{*}{$\begin{array}{c}\begin{array}{c}\text { Leachate pH after } \\
\text { filtering }\end{array} \\
2.43\end{array}$} & \multirow{2}{*}{$\begin{array}{c}\text { TREE in } \\
\text { leachate } \\
0.68 \%\end{array}$} & \multicolumn{2}{|c|}{$\begin{array}{l}\text { TREE in solid phase } \\
\text { after multi-step } \\
\text { treatment }\end{array}$} & \multirow{2}{*}{$\begin{array}{c}\begin{array}{c}\text { Data and } \\
\text { calculation }\end{array} \\
\text { Table A }\end{array}$} \\
\hline & & & & $\begin{array}{l}\text { No water } \\
\text { scrub step }\end{array}$ & $42.13 \%$ & \\
\hline & & 2.43 & $0.68 \%$ & $\begin{array}{l}\text { Add water } \\
\text { scrub step }\end{array}$ & $57.73 \%$ & Table F \\
\hline
\end{tabular}




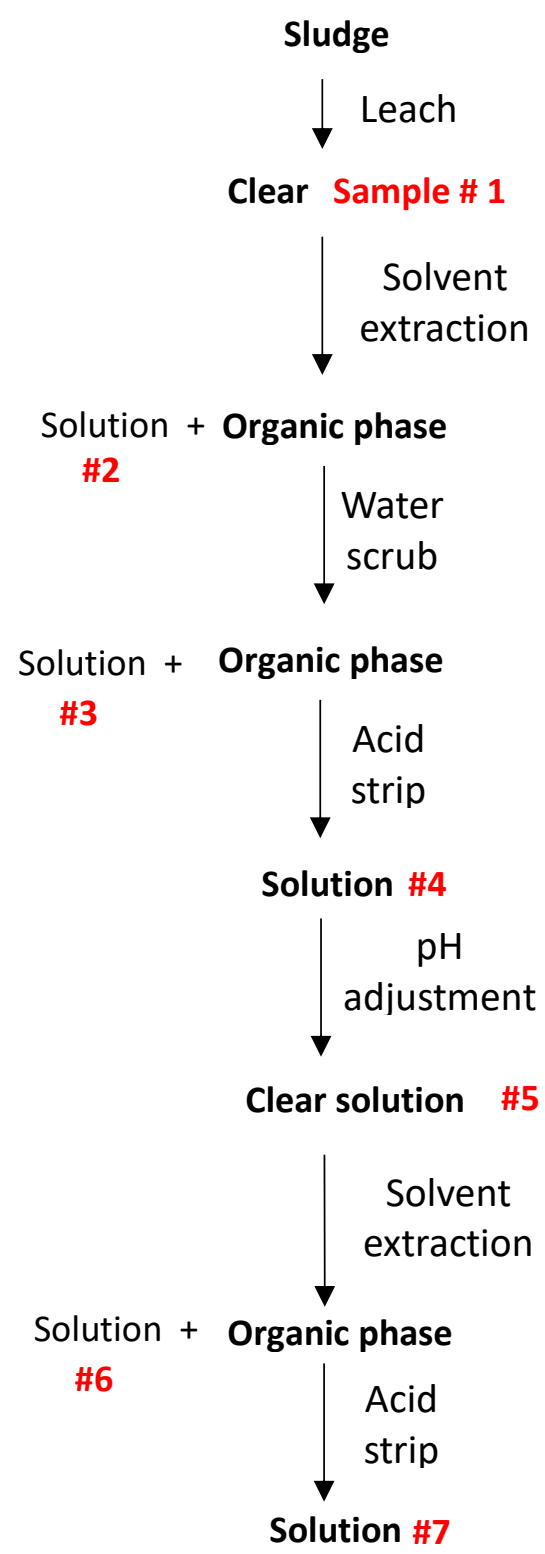

Figure 3.39 Flowsheet of seven-step treatment for REE recovery.

Table F. Results of SX experiment with water scrub step for DLM sludge.

\begin{tabular}{ccccccccccc}
\hline & & Sample & \multicolumn{3}{c}{ TMM } & \multicolumn{3}{c}{ TREE } & ^TREE & Enrich. \\
\cline { 4 - 9 } $\mathrm{pH}$ & Treatment $^{2.4}$ & ID \# & $\mathrm{mg} / \mathrm{L}$ & $\mathrm{mg}$ & $\%$ extr. & $\mathrm{mg} / \mathrm{L}$ & $\mathrm{mg}$ & $\%$ extr. & solid \% & factor \\
\hline & PLS $^{\mathrm{a}}$ & 1 & 4313.69 & 431.37 & & 29.4 & 2.94 & & $0.68 \%$ & \\
& RA $^{\mathrm{b}}$ & 2 & 4241.38 & 424.14 & $1.70 \%$ & 6.83 & 0.68 & $76.77 \%$ & $23.79 \%$ & 35.14 \\
& WST $^{\mathrm{e}}$ & 3 & 182.48 & 18.25 & - & 0.79 & 0.08 & $3.50 \%$ & $0.43 \%$ & \\
& AST $^{\mathrm{c}}$ & 4 & 281.97 & 28.2 & - & 21.78 & 2.18 & $100.00 \%$ & $7.17 \%$ & \\
\hline
\end{tabular}




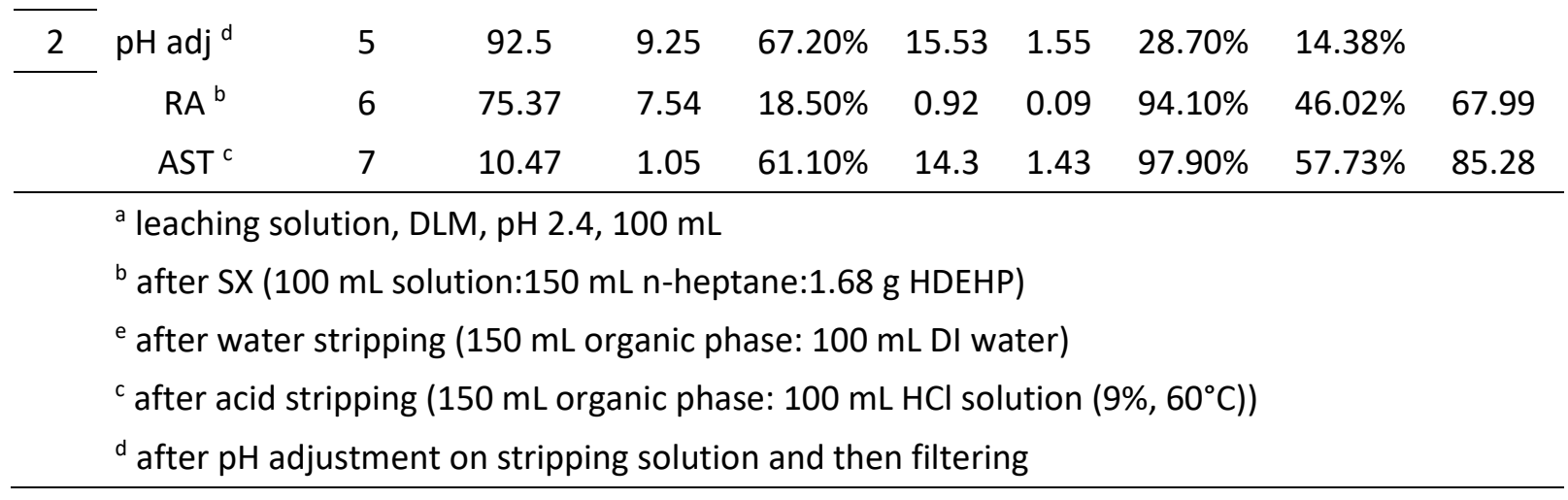

Critical REE, heavy REE and light REE distribution in whole process (Table F) are shown in Figure 3.40. Critical REEs: Nd, Eu, Y, Tb and Dy. Light REEs: La, Ce, Pr and Sm. Heavy REEs: Sc, Gd, Ho, Er, Tm, Yb and Lu. For sample 1, 4, 5 and 7, the more total percentage of critical and heavy REEs, the better. Besides, the percentage of critical REEs increase slightly in whole process. The loss of TREE in step 2 was high in the process. From data of sample 4 and 5, we can see that the loss of TREE in pH adjustment step was high. The $\mathrm{pH}$ should be adjusted to lower value to decrease TREE loss in this step.

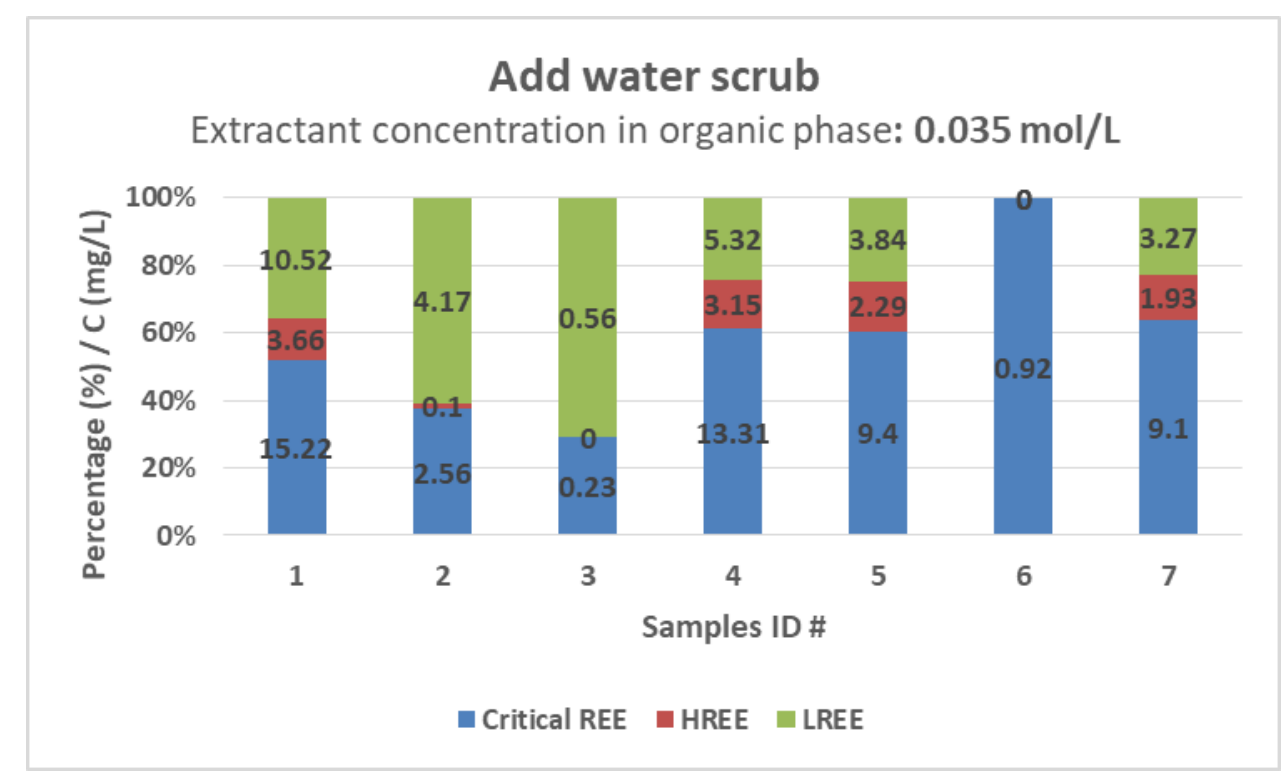

Figure 3.40 Critical REE, heavy REE and light REE distribution in whole process (Table F).

\section{3) Extractant concentration change in organic phase combining with new flowsheet.}

Leaching experiments on sludge from DLM sites to recover REEs have been conducted under a pH of 2.4. Solvent extraction experiments were done on leaching solution with different extractant concentration in organic phase. Table 3-29 concludes SX results of Table $\mathbf{I}, \mathbf{J}$ and $\mathbf{K}$, which followed the flowsheet in Figure 
3.41. Table $\mathbf{F}$ is also included to compare. For the leaching solution, the initial TREE percentage is $0.68 \%$. In Table I, J and K, major metal elements removal after whole process were all more than $99 \%$. Total rare earth elements (TREE) loss was $42.18 \%$ in Table I and the amount decreased from $2.94 \mathrm{mg}$ to $1.70 \mathrm{mg}$. The estimated TREE in solid phase based on cation measurement increased from $0.68 \%$ to $29.76 \%$. Total rare earth elements (TREE) loss was $46.60 \%$ in Table $\mathrm{J}$ and the amount decreased to $1.57 \mathrm{mg}$. The estimated TREE in solid phase increased to $26.13 \%$. However, total rare earth elements (TREE) loss was 81.29\% in Table $\mathrm{K}$ and the amount decreased to $0.55 \mathrm{mg}$. It was due to high TREE loss in $1_{\text {st }}$ and $3_{\text {rd }}$ acid stripping step. The estimated TREE in solid phase increased to only $13.34 \%$. The estimated TREE in solid phase was highest (57.73\%) in Table F. But the TREE loss was too high and extractant concentration of $0.035 \mathrm{~mol} / \mathrm{L}$ is not good for TREE recovery.

Table 3-29 SX results of leaching solution with different extractant concentration in organic phase by using new flowsheet.

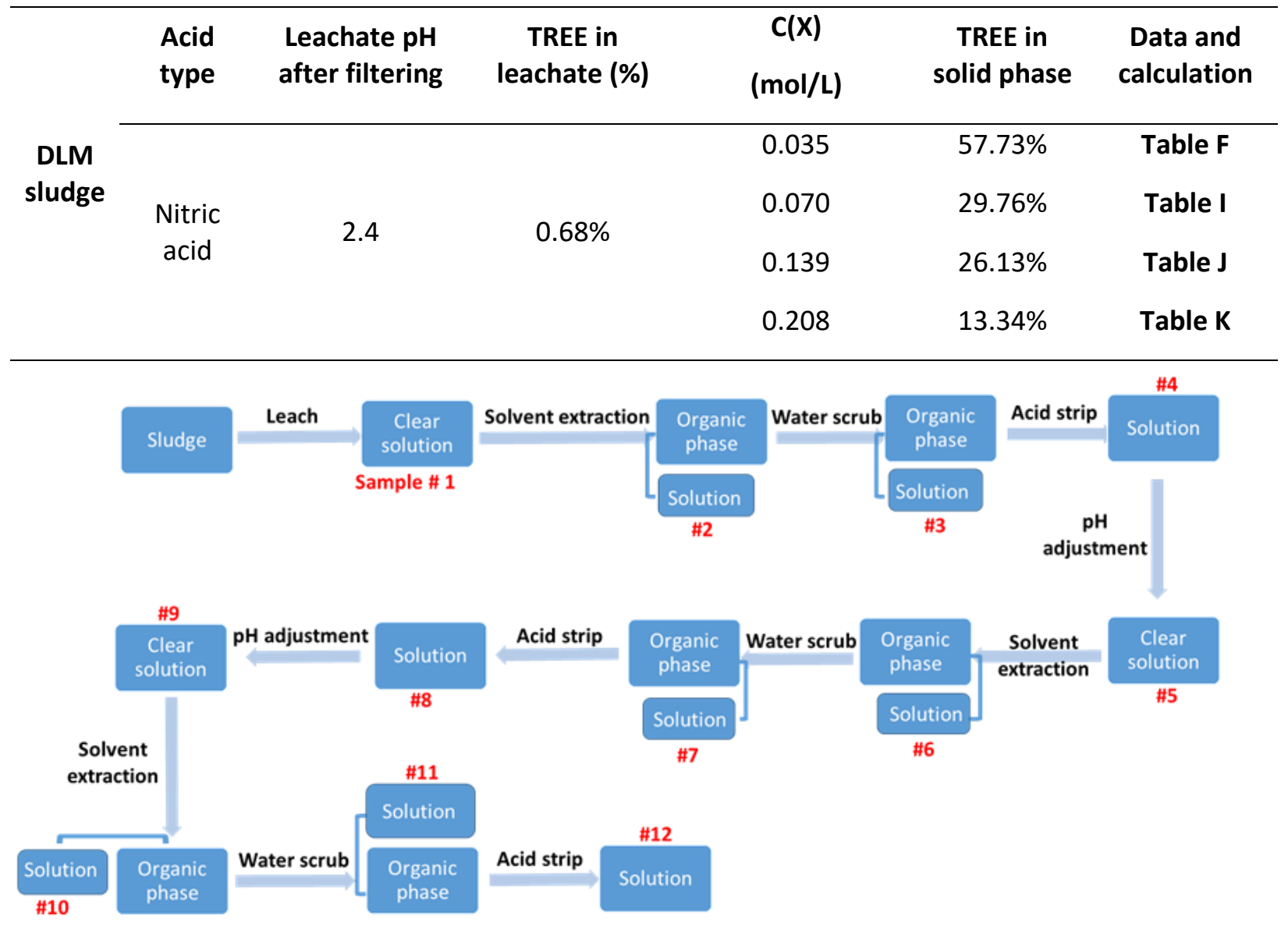

Figure 3.41 Flowsheet of twelve-step treatment for REE recovery. 
Table I. Results of solvent extraction experiment under different SX conditions (extractant: $0.070 \mathrm{~mol} / \mathrm{L}$ ).

\begin{tabular}{|c|c|c|c|c|c|c|c|c|c|c|}
\hline \multirow[b]{2}{*}{$\mathrm{pH}$} & \multirow[b]{2}{*}{ Treatment } & \multirow{2}{*}{$\begin{array}{c}\text { Sample } \\
\text { ID \# }\end{array}$} & \multicolumn{3}{|c|}{ TMM } & \multicolumn{3}{|c|}{ TREE } & \multirow{2}{*}{$\begin{array}{c}\text { ^TREE } \\
\text { solid \% }\end{array}$} & \multirow{2}{*}{$\begin{array}{l}\text { Enrich. } \\
\text { factor }\end{array}$} \\
\hline & & & $\mathrm{mg} / \mathrm{L}$ & $\mathrm{mg}$ & $\%$ extr. & $\mathrm{mg} / \mathrm{L}$ & $\mathrm{mg}$ & $\%$ extr. & & \\
\hline \multirow[t]{4}{*}{2.4} & $\mathrm{PLS}^{\mathrm{a}}$ & 1 & 4313.69 & 431.37 & & 29.4 & 2.94 & & $0.68 \%$ & \\
\hline & $\mathrm{RA}^{\mathrm{b}}$ & 2 & 4071.92 & 407.19 & $5.60 \%$ & 1.47 & 0.15 & $95.00 \%$ & $10.36 \%$ & 15.3 \\
\hline & WST $^{\mathrm{e}}$ & 3 & 188.37 & 18.84 & $77.90 \%$ & 0.15 & 0.02 & $0.50 \%$ & $0.08 \%$ & \\
\hline & $\mathrm{AST}^{\mathrm{c}}$ & 4 & 341.37 & 34.14 & - & 23.66 & 2.37 & $85.20 \%$ & $6.48 \%$ & \\
\hline \multirow[t]{4}{*}{2} & $\mathrm{pH}_{\mathrm{adj}}{ }^{\mathrm{d}}$ & 5 & 241.16 & 24.12 & $29.40 \%$ & 23.43 & 2.34 & $1.00 \%$ & $8.86 \%$ & \\
\hline & $\mathrm{RA}^{\mathrm{b}}$ & 6 & 154.74 & 15.47 & $35.80 \%$ & 0.19 & 0.02 & $99.20 \%$ & $21.19 \%$ & 31.31 \\
\hline & WST $^{\mathrm{e}}$ & 7 & 0.08 & 0.01 & $0.10 \%$ & 0 & 0 & $0.00 \%$ & $0.00 \%$ & \\
\hline & $\mathrm{AST}^{\mathrm{c}}$ & 8 & 93.99 & 9.4 & $108.90 \%$ & 22.78 & 2.28 & $98.00 \%$ & $19.51 \%$ & 28.82 \\
\hline \multirow[t]{4}{*}{2} & $\mathrm{pH} \operatorname{adj}^{\mathrm{d}}$ & 9 & 68.47 & 6.85 & $27.20 \%$ & 21.69 & 2.17 & $4.80 \%$ & $24.06 \%$ & \\
\hline & $\mathrm{RA}^{\mathrm{b}}$ & 10 & 16.52 & 1.65 & $75.90 \%$ & 0 & 0 & $100.00 \%$ & $29.45 \%$ & 43.51 \\
\hline & WST $^{\mathrm{e}}$ & 11 & 0.01 & 0 & $0.00 \%$ & 0 & 0 & $0.00 \%$ & $0.00 \%$ & \\
\hline & $\mathrm{AST}^{\mathrm{c}}$ & 12 & 40.1 & 4.01 & $77.20 \%$ & 16.99 & 1.7 & $78.30 \%$ & $29.76 \%$ & 43.96 \\
\hline \multicolumn{9}{|c|}{${ }^{a}$ leaching solution, DLM, pH 2.4, $100 \mathrm{~mL}$} & \multicolumn{2}{|c|}{ Code: } \\
\hline \multicolumn{9}{|c|}{ b after SX (100 mL solution:150 mL n-heptane:3.36 g HDEHP) } & \multicolumn{2}{|c|}{$\begin{array}{l}\text { PLS=pregnant } \\
\text { leach solution }\end{array}$} \\
\hline \multicolumn{9}{|c|}{${ }^{\mathrm{e}}$ after water stripping (150 mL organic phase: $100 \mathrm{~mL} \mathrm{DI}$ water $60^{\circ} \mathrm{C}$ ) } & \multicolumn{2}{|c|}{ RA=raffinate } \\
\hline \multicolumn{9}{|c|}{${ }^{\mathrm{C}}$ after acid stripping $\left(150 \mathrm{~mL}\right.$ organic phase: $100 \mathrm{~mL} \mathrm{HCl}$ solution $\left(9 \%, 60^{\circ} \mathrm{C}\right)$ ) } & \multicolumn{2}{|c|}{ WST=water strip } \\
\hline \multicolumn{9}{|c|}{$\mathrm{d}$ after $\mathrm{pH}$ adjustment on stripping solution and then filtering } & \multicolumn{2}{|c|}{ AST=acid strip } \\
\hline
\end{tabular}

Table J. Results of solvent extraction experiment under different SX conditions (extractant: $0.139 \mathrm{~mol} / \mathrm{L}$ ).

\begin{tabular}{ccccccccccc}
\hline & & Sample & \multicolumn{3}{c}{ TMM } & \multicolumn{3}{c}{ TREE } & ^TREE & Enrich. \\
$\mathrm{pH}$ & Treatment $^{2.4}$ & ID \# & $\mathrm{mg} / \mathrm{L}$ & $\mathrm{mg}$ & \% extr. & $\mathrm{mg} / \mathrm{L}$ & $\mathrm{mg}$ & $\%$ extr. & solid \% & factor \\
\hline & PLS $^{\mathrm{a}}$ & $\mathbf{1}$ & 4313.69 & 431.37 & & 29.4 & 2.94 & & $0.68 \%$ & \\
& RA $^{\mathrm{b}}$ & $\mathbf{2}$ & 3979.23 & 397.92 & $7.80 \%$ & 0.63 & 0.06 & $97.90 \%$ & $7.92 \%$ & 11.7 \\
& WST $^{\mathrm{e}}$ & $\mathbf{3}$ & 214.58 & 21.46 & $64.20 \%$ & 0.04 & 0 & $0.10 \%$ & $0.02 \%$ & \\
& AST $^{\mathrm{c}}$ & $\mathbf{4}$ & 446.55 & 44.66 & - & 22.85 & 2.29 & $79.50 \%$ & $4.87 \%$ & \\
\hline 2 & pH adj $^{\mathrm{d}}$ & $\mathbf{5}$ & 305.15 & 30.52 & $31.70 \%$ & 20.08 & 2.01 & $12.10 \%$ & $6.17 \%$ & \\
& RA $^{\mathrm{b}}$ & $\mathbf{6}$ & 238.68 & 23.87 & $21.80 \%$ & 0.33 & 0.03 & $98.40 \%$ & $22.91 \%$ & 33.84 \\
& WST $^{\mathrm{e}}$ & $\mathbf{7}$ & 0.08 & 0.01 & $0.10 \%$ & 0 & 0 & $0.00 \%$ & $0.00 \%$ & \\
& AST $^{\mathrm{c}}$ & $\mathbf{8}$ & 92.54 & 9.25 & $139.40 \%$ & 18.8 & 1.88 & $95.20 \%$ & $16.89 \%$ & 24.94 \\
\hline 2 & pH adj $^{\mathrm{d}}$ & $\mathbf{9}$ & 54.25 & 5.42 & $41.40 \%$ & 17.41 & 1.74 & $7.40 \%$ & $24.30 \%$ & \\
& RA $^{\mathrm{b}}$ & $\mathbf{1 0}$ & 17.07 & 1.71 & $68.50 \%$ & 0.02 & 0 & $99.90 \%$ & $31.87 \%$ & 47.08
\end{tabular}




\begin{tabular}{|c|c|c|c|c|c|c|c|c|c|}
\hline WST ${ }^{\text {e }}$ & 11 & 0 & 0 & $0.00 \%$ & 0 & 0 & $0.00 \%$ & $0.00 \%$ & \\
\hline $\mathrm{AST}^{\mathrm{c}}$ & 12 & 44.49 & 4.45 & $119.70 \%$ & 15.74 & 1.57 & $90.50 \%$ & $26.13 \%$ & 38.6 \\
\hline \multicolumn{7}{|c|}{ a leaching solution, DLM, pH 2.4, $100 \mathrm{~mL}$} & \multicolumn{2}{|c|}{ Code: } & \\
\hline \multicolumn{7}{|c|}{${ }^{\mathrm{b}}$ after SX (100 mL solution:150 mL n-heptane:6.72 g HDEHP) } & \multicolumn{3}{|c|}{ PLS=pregnant leach solution } \\
\hline \multicolumn{7}{|c|}{ e after water stripping ( $150 \mathrm{~mL}$ organic phase: $100 \mathrm{~mL}$ DI water $60^{\circ} \mathrm{C}$ ) } & \multicolumn{3}{|c|}{$R A=$ raffinate } \\
\hline \multicolumn{7}{|c|}{ ' after acid stripping (150 mL organic phase: $100 \mathrm{~mL} \mathrm{HCl}$ solution $\left(9 \%, 60^{\circ} \mathrm{C}\right)$ ) } & \multicolumn{3}{|c|}{ WST=water strip } \\
\hline \multicolumn{7}{|c|}{$\mathrm{d}$ after $\mathrm{pH}$ adjustment on stripping solution and then filtering } & \multicolumn{3}{|c|}{ AST=acid strip } \\
\hline
\end{tabular}

Table K. Results of solvent extraction experiment under different SX conditions (extractant: $0.208 \mathrm{~mol} / \mathrm{L}$ ).

\begin{tabular}{|c|c|c|c|c|c|c|c|c|c|c|}
\hline \multirow[b]{2}{*}{$\mathrm{pH}$} & \multirow[b]{2}{*}{ Treatment } & \multirow{2}{*}{$\begin{array}{c}\text { Sample } \\
\text { ID \# }\end{array}$} & \multicolumn{3}{|c|}{ TMM } & \multicolumn{3}{|c|}{ TREE } & \multirow{2}{*}{$\begin{array}{c}\text { ^TREE } \\
\text { solid \% }\end{array}$} & \multirow{2}{*}{$\begin{array}{l}\text { Enrich. } \\
\text { factor }\end{array}$} \\
\hline & & & $\mathrm{mg} / \mathrm{L}$ & $\mathrm{mg}$ & $\%$ extr. & $\mathrm{mg} / \mathrm{L}$ & $\mathrm{mg}$ & $\%$ extr. & & \\
\hline \multirow[t]{4}{*}{2.4} & PLS ${ }^{a}$ & 1 & 4313.69 & 431.37 & & 29.4 & 2.94 & & $0.68 \%$ & \\
\hline & $\mathrm{RA}^{\mathrm{b}}$ & 2 & 3794.9 & 379.49 & $12.00 \%$ & 1.21 & 0.12 & $95.90 \%$ & $5.15 \%$ & 7.61 \\
\hline & WST $^{\mathrm{e}}$ & 3 & 816.59 & 81.66 & $157.40 \%$ & 0.34 & 0.03 & $1.20 \%$ & $0.04 \%$ & \\
\hline & $\mathrm{AST}^{\mathrm{c}}$ & 4 & 649.93 & 64.99 & - & 14.5 & 1.45 & $52.10 \%$ & $2.18 \%$ & \\
\hline \multirow[t]{4}{*}{2} & $\mathrm{pH} \operatorname{adj}^{\mathrm{d}}$ & 5 & 480.78 & 48.08 & $26.00 \%$ & 12.31 & 1.23 & $15.10 \%$ & $2.50 \%$ & \\
\hline & $\mathrm{RA}^{\mathrm{b}}$ & 6 & 389.34 & 38.93 & $19.00 \%$ & 0 & 0 & $100.00 \%$ & $11.87 \%$ & 17.53 \\
\hline & WST $^{\mathrm{e}}$ & 7 & 1.86 & 0.19 & $2.00 \%$ & 0 & 0 & $0.00 \%$ & $0.00 \%$ & \\
\hline & $\mathrm{AST}^{\mathrm{c}}$ & 8 & 106.83 & 10.68 & $119.30 \%$ & 10.51 & 1.05 & $85.40 \%$ & $8.96 \%$ & 13.23 \\
\hline \multirow[t]{4}{*}{2} & $\mathrm{pH}$ adj ${ }^{d}$ & 9 & 89.35 & 8.94 & $16.40 \%$ & 8.96 & 0.9 & $14.70 \%$ & $9.11 \%$ & \\
\hline & $\mathrm{RA}^{\mathrm{b}}$ & 10 & 36.38 & 3.64 & $59.30 \%$ & 0 & 0 & $100.00 \%$ & $14.47 \%$ & 21.37 \\
\hline & WST $^{\mathrm{e}}$ & 11 & 0.1 & 0.01 & $0.20 \%$ & 0 & 0 & $0.00 \%$ & $0.00 \%$ & \\
\hline & $\mathrm{AST}^{\mathrm{c}}$ & 12 & 35.8 & 3.58 & $67.70 \%$ & 5.51 & 0.55 & $61.50 \%$ & $13.34 \%$ & 19.7 \\
\hline \multicolumn{8}{|c|}{ a leaching solution, DLM, pH 2.4, $100 \mathrm{~mL}$} & \multicolumn{3}{|l|}{ Code: } \\
\hline \multicolumn{8}{|c|}{${ }^{b}$ after SX (100 mL solution:150 mL n-heptane: 10.08 g HDEHP) } & PLS=pregn & ant leach sc & lution \\
\hline \multicolumn{8}{|c|}{${ }^{\mathrm{e}}$ after water stripping $\left(150 \mathrm{~mL}\right.$ organic phase: $100 \mathrm{~mL} \mathrm{DI}$ water $\left.60^{\circ} \mathrm{C}\right)$} & \multicolumn{3}{|c|}{ RA=raffinate } \\
\hline \multicolumn{8}{|c|}{${ }^{\circ}$ after acid stripping (150 mL organic phase: $100 \mathrm{~mL} \mathrm{HCl}$ solution $\left(9 \%, 60^{\circ} \mathrm{C}\right)$ ) } & \multicolumn{3}{|c|}{ WST=water strip } \\
\hline \multicolumn{8}{|c|}{${ }^{\mathrm{d}}$ after $\mathrm{pH}$ adjustment on stripping solution and then filtering } & \multicolumn{3}{|c|}{ AST=acid strip } \\
\hline
\end{tabular}

Critical REE, heavy REE and light REE distribution in whole process (Table I, $\mathbf{J}$ and $\mathbf{K}$ ) are shown in Figure 3.42. Critical REEs: Nd, Eu, Y, Tb and Dy. Light REEs: La, Ce, Pr and Sm. Heavy REEs: Sc, Gd, Ho, Er, Tm, Yb and Lu. For sample IDs marked as pink, the more total percentage of critical and heavy REEs, the better. The percentage of critical REEs increase slightly in whole process except for the final acid stripping step. In final step, total percentage of critical and heavy REE was about $72 \%, 67 \%$ and $58 \%$. There is no big difference in SX step with different extractant concentration. The TRRE losses in solvent extraction steps 
were all low. The losses of critical and heavy REE in step 2 were much lower than that in Table F. From data of sample $4 \& 5$ and $8 \& 9$, we can see that the loss of TREE in pH adjustment step is acceptable in all three graphs.
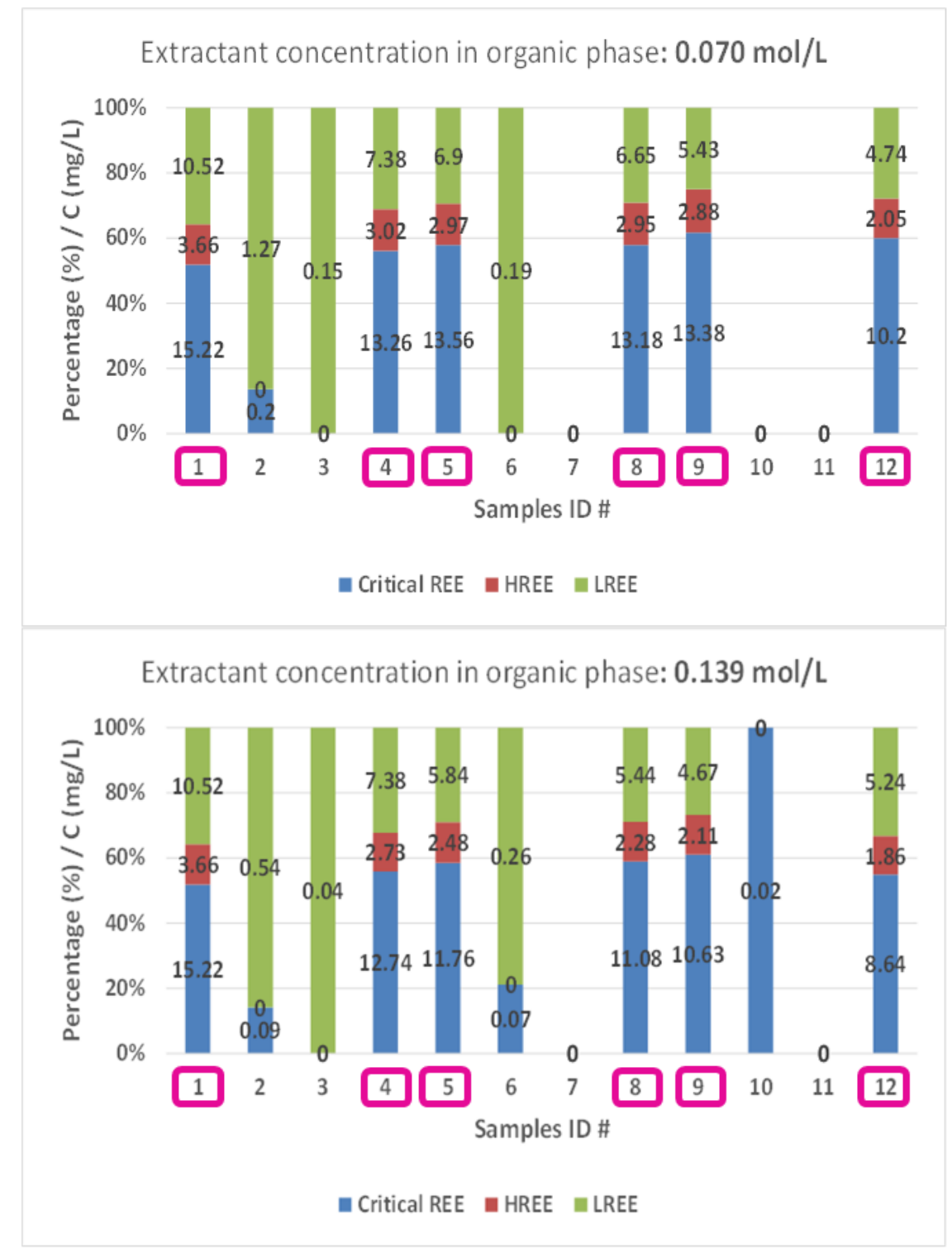


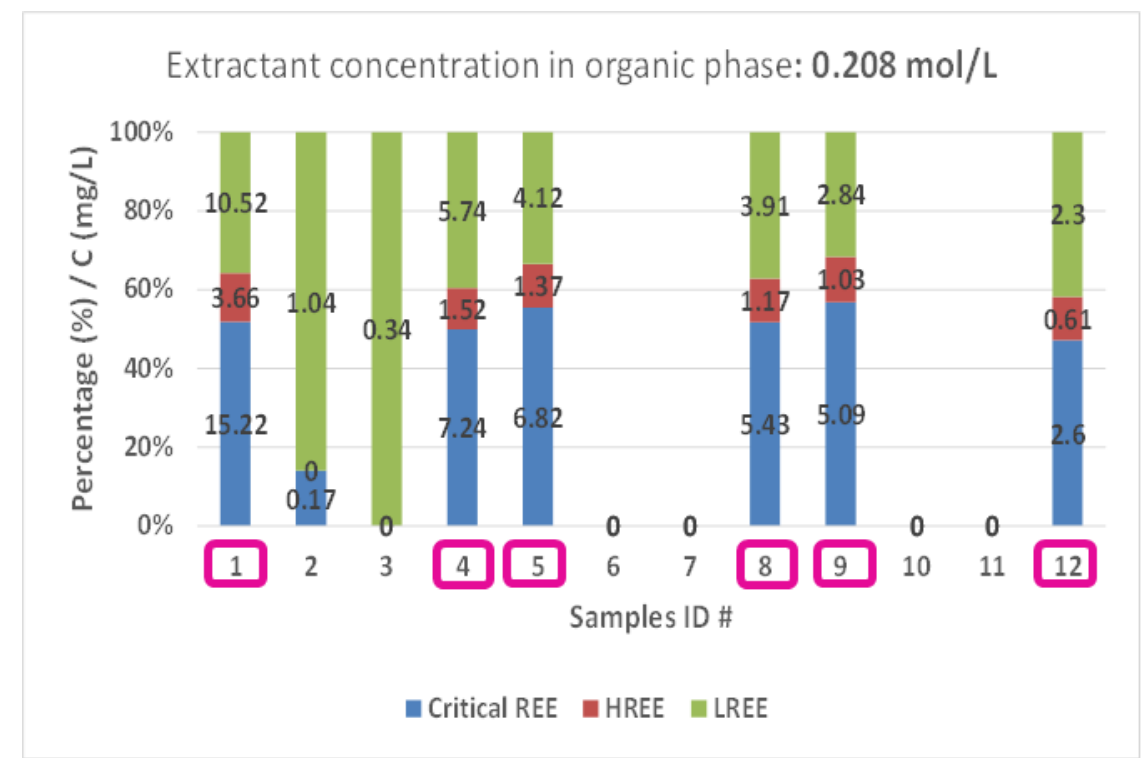

Figure 3.42 Critical REE, heavy REE and light REE distribution in whole process (Table I, J and K).

The extractant concentration effect on TREE recovery was also analyzed by separating process in flowsheet (Figure 3.41) to three parts. By comparing the $1_{\text {st }}$ SX part of four different extractant concentration, we can see that the lowest extractant concentration will lead to highest TREE purity (Figure 3.43). Since the TREE extraction rate was low for concentration of $0.035 \mathrm{~mol} / \mathrm{L}$, we should pay attention to the other three concentrations. Their TREE extraction rates were all more than $95 \%$. Because the results of SX step were calculated, there will be significant error even if the measurement error of raw data is very low. We focused on results of acid strip step. The TREE purity was highest (6.48\%) for extractant concentration of $0.07 \mathrm{~mol} / \mathrm{L}$.

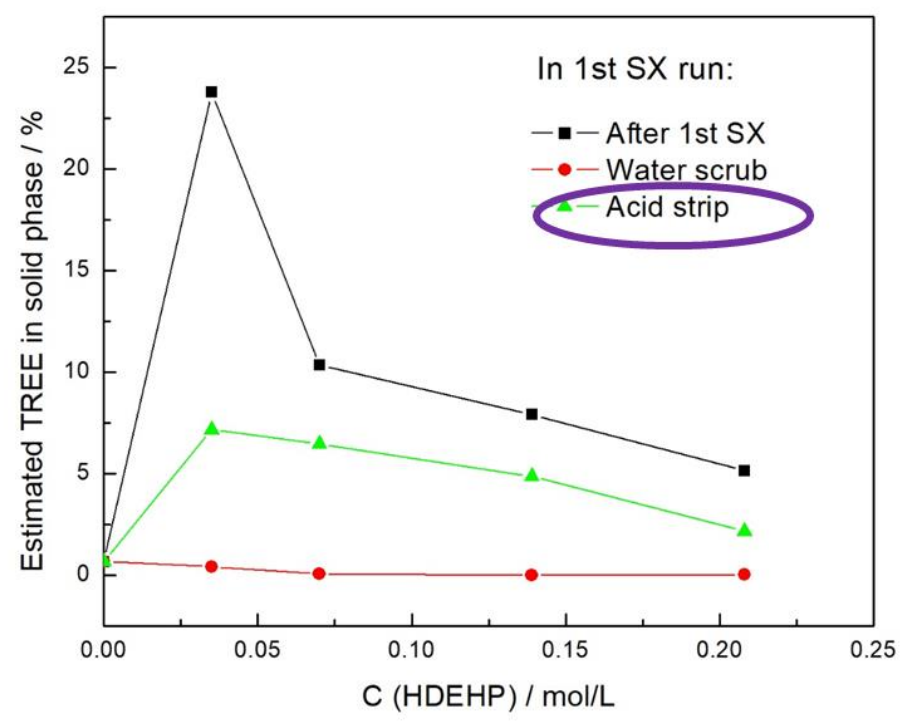


Figure 3.43 TREE purity for 1 st SX run with different extractant concentration (Table F, I, J and K).

By comparing the 2nd SX part of four different extractant concentration, we can see that the lowest extractant concentration still will lead to highest TREE purity. With the precondition of high TREE recovery rate, we focused on acid strip steps' results of three high extractant concentrations. The TREE purity was still highest for extractant concentration of $0.07 \mathrm{~mol} / \mathrm{L}$ (Figure 3.44 ) and increased from $6.48 \%$ to $19.51 \%$.

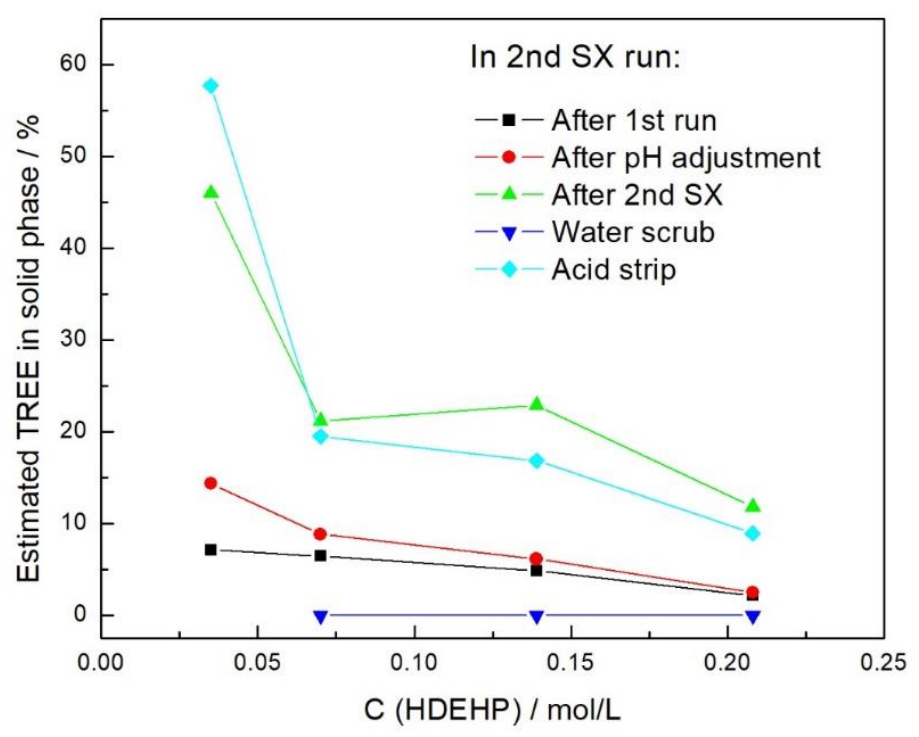

Figure 3.44 TREE purity for 2nd SX run with different extractant concentration (Table F, I, J and K).

By comparing the $3 r d S X$ parts' acid strip results of three different extractant concentration, the TREE purity was still highest for extractant concentration of $0.07 \mathrm{~mol} / \mathrm{L}$ (Figure 3.45) and increased from $19.51 \%$ to $29.76 \%$. 


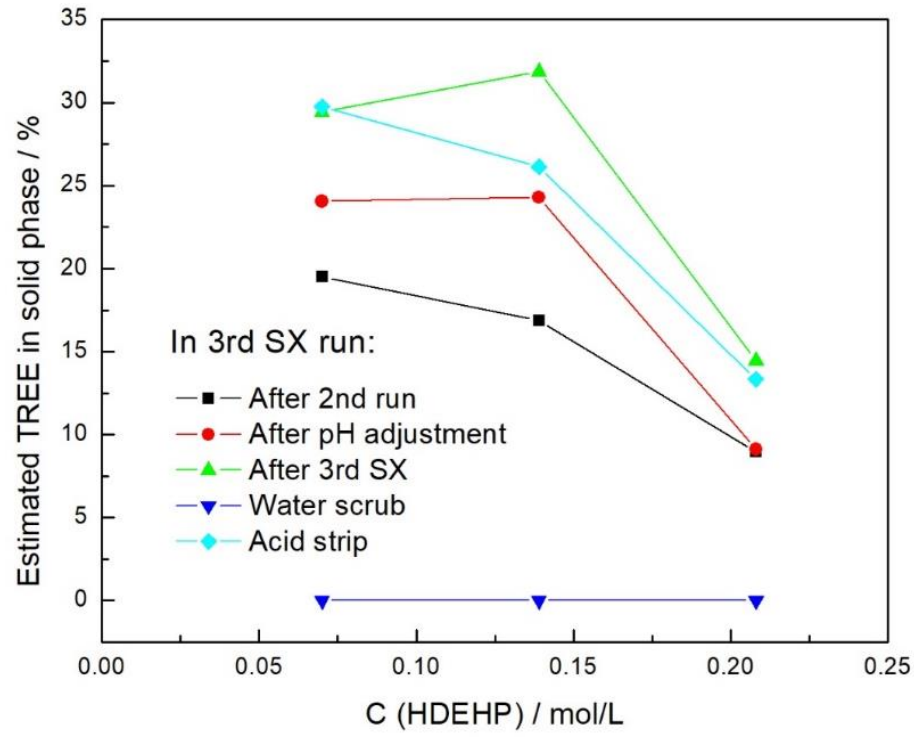

Figure 3.45 TREE purity for 3rd SX run with different extractant concentration (Table F, I, J and K).

\subsection{Conclusion}

Since chloride ions will facilitate Fe extraction and sulfuric acid will leach more major metal ions, nitric acid was selected as leaching acid for AMD sludge. Clear feed solution (leachate) was necessary for SX runs. Addition of a water scrub circuit was helpful to increase TREE purity. Optimum processing flow sheet for whole process is configured in Figure 3.41. The detailed different parameters are different for different specific solution. The appropriate parameters range for both high extraction efficiency and high purity of TREE on different leachates are summarized in Table 3-30.

Table 3-30 Appropriate parameters range for TREE recovery from different leachates.

\begin{tabular}{|c|c|c|c|c|}
\hline \multirow{2}{*}{ AMD sludge } & \multirow{2}{*}{ Parameters } & \multirow{2}{*}{ Experimental range } & $\%$ extr. TREE & Est. TREE \\
\hline & & & \multicolumn{2}{|c|}{ Appropriate parameters range } \\
\hline \multirow{2}{*}{$\mathrm{McV}$} & Initial pH & $1.1-4.0$ & higher, better & $2.5-3.5$ \\
\hline & $\mathrm{O}: \mathrm{A}$ ratio & $1.0-2.0$ & higher, better & $\sim 1.0$ \\
\hline \multirow{4}{*}{ DLM } & Initial pH & $0.5-4.2$ & higher, better & 2.4-3.0 \\
\hline & Solvent & n-heptane, kerosene & similar & similar \\
\hline & $\mathrm{C}(\mathrm{HDEHP})$ & $0.01 \mathrm{M}-0.21 \mathrm{M}$ & higher, better & $0.02 \mathrm{M}-0.07 \mathrm{M}$ \\
\hline & $\mathrm{O}: \mathrm{A}$ ratio & $1.5-3.0$ & higher, better & $\sim 1.5$ \\
\hline
\end{tabular}


The estimated TREE percentage in solid phase obtained in one mid-scale experiment (1.25 kg wet sludge from DLM site; solvent extraction: 20 L filtered leachate $(\mathrm{pH} 3.2)$ with $30 \mathrm{~L}$ organic solution; obtained 2.5 g concentrate solid sample) increased from initial $0.77 \%$ in leachate to final $4.63 \%$ in the solid.

In summary, clear feed solution with range of $\mathrm{pH}$ values from 2 to 3.5 was necessary for SX runs. High O:A ratio and extractant concentration will lead high extraction efficiencies of TREE, but purity of TREE in final product will decrease due to TMM competitive extraction. For DLM PLS 2.4, $0.07 \mathrm{~mol} / \mathrm{L}$ extractant was good for both high purity and recovery of TREE (Figure 3.46).

Results after 12 steps process

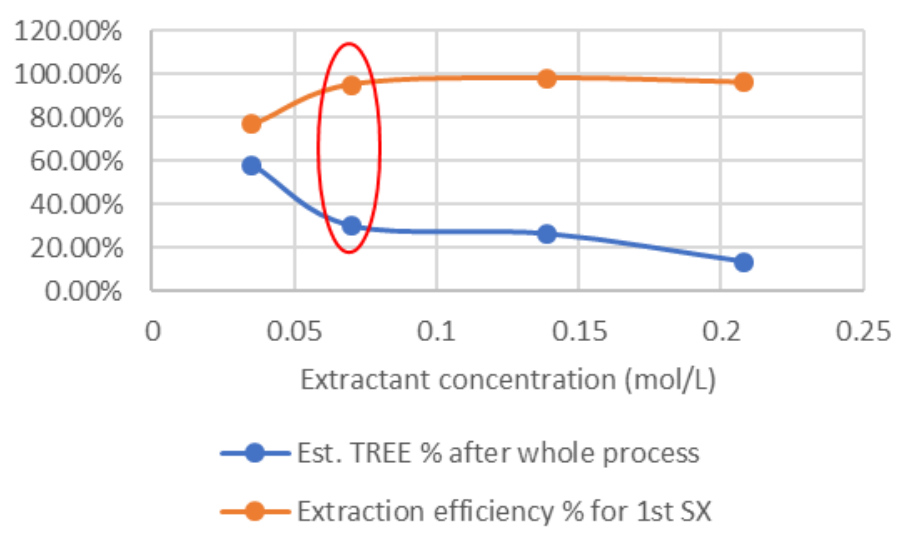

Remark: Est. TREE of $0.035 \mathrm{M} \mathrm{C(X)}$ is result of 7 steps treatment.

Figure 3.46 Extractant concentration effect on SX for TREE recovery from DLM PLS 2.4. 


\section{REEs recovery exploratory tests from coal mine drainage to support scale-up system}

In scale-up the lab experiments, acid leaching will be conducted in a semi-batch fashion with sufficient storage capacity to feed an aqueous, enriched REE liquor to a bench scale SX system with 100 mixersettlers operating in continuous fashion. To determine how many steps required for sufficient recovery of REEs and high selectivity of REEs over major metal ions, bench-scale solvent extraction was conducted to provide a purposeful starting point for the SX system parametric testing. Results of this program were provided as McCabe Thiele charts. (McCabe \& W, 1925)

The chart is constructed by determining the equilibrium distribution isotherm (DI) for extraction, scrub or stripping via experiments. The equilibrium isotherm can be obtained by mixing an aqueous solution and organic solution at different phase ratios $(\mathrm{A} / \mathrm{O})$ until equilibrium is reached. The obtained $\mathrm{DI}$ is specific for a particular system - any alteration would make it different. For extraction, the DI consists the concentration of metal ions in organic phase against the concentration of them in aqueous phase. After the DI has been plotted, the operating line (OP) can be drawn, and its gradient is equal to the $A / O$ ratio in the intended extraction process. (Cheng, Zhang, \& Pranolo, 2010; Yu \& Liu, 2010) It should go from a point on the DI corresponding to the metal ions concentration in the initial organic phase (zero for SX process in this project) to the value of intended metal ions concentration in loaded organic phase (LO) on the $x$ axis corresponding to the initial metal ions concentration in the aqueous phase (Feed solution). Then a horizontal line is drawn from the point where the OP line intersects with the feed line to the DI. A vertical line is then drawn from the DI curve down to the OP line from which point a horizontal line can be drawn again to the $\mathrm{DI}$, and so on. This procedure is repeated until a satisfactory degree of extraction from the aqueous phase has been obtained (zero loss for most plots in this project). Each horizontal line in the McCabe-Thiele chart corresponds to one step in the mixer-settler. A McCabe-Thiele chart for scrub and stripping is constructed in a similar way. For scrub and stripping, the plot consists the concentration of metal ions in aqueous phase against the concentration of them in organic phase. The gradient of operating line is equal to the O/A ratio in the intended scrub and stripping process.(Sadanandam, Singh, \& Sharma) 


\subsection{Bench-Scale Solvent Extraction Support}

Results of solvent extraction exploratory tests were provided as McCabe Thiele diagrams. Parameters to be evaluated in this test include the advance O:A ratio, $\mathrm{pH}$ of the pregnant leech solution (PLS), and concentration of extractant (D2EHPA) in the organic phase.

\subsubsection{SX McCabe-Thiele Exploratory Test-OM-PLS 1.1}

Bench-scale solvent extraction was conducted on the leaching solution of $\mathrm{pH} 1.1$ from the Omega (OM) site sludge (Table 4-1). Extraction efficiencies of the total major metal ions (TMM), total rare earth ions (TREE), critical rare earth ions (CREE: Nd, Eu, Y, Tb and Dy), heavy rare earth ions (HREE: Sc, Gd, Ho, Er, $\mathrm{Tm}, \mathrm{Yb}$ and $\mathrm{Lu}$ ) and light rare earth ions (LREE: $\mathrm{La}, \mathrm{Ce}, \mathrm{Pr}$ and $\mathrm{Sm}$ ) are shown in Figure 4.1 and Figure 4.2. TREE extraction efficiencies were low under these conditions, even in the highest extractant concentration of $1.0 \mathrm{M}(50 \%)$. HREE extraction efficiencies were higher than those of LREE and CREE. The extraction efficiency difference of HREE (82.44\%) and LREE (6.02\%) was high at D2EHPA of $1.0 \mathrm{M}$. Extraction efficiencies of LREE and CREE were very low at an extractant concentration of $0.05 \mathrm{M}$. Thus, HREE can be separately extracted from other metal ions at an extractant concentration of $0.05 \mathrm{M}$. An A:O ratio of 2 was appropriate for TREE selective extraction from TMM due to the high difference in their extraction efficiencies at all three extractant concentrations.

Table 4-1 Parameters and pH results of solvent extraction exploratory test of OM PLS 1.1.

\begin{tabular}{|c|c|c|c|c|c|c|c|c|}
\hline \multirow[b]{2}{*}{ Sample Name } & $\mathbf{F}$ & $\mathrm{C}$ & \multirow{2}{*}{$\begin{array}{c}\text { A:O } \\
\text { Ratio }\end{array}$} & 0 & $\mathbf{A}$ & TV & D & $\mathbf{E}$ \\
\hline & $\begin{array}{l}\text { PLS } \\
\mathrm{pH}\end{array}$ & $\mathrm{mol} / \mathrm{L}$ & & $\mathrm{ml}$ & $\mathrm{ml}$ & $\mathrm{ml}$ & $\begin{array}{c}\mathrm{pH}, \\
\text { before }\end{array}$ & $\begin{array}{l}\mathrm{pH}, \\
\text { after }\end{array}$ \\
\hline OM-SX-pH0.5-0.05M-1:10 & 0.5 & 0.05 & $10: 1$ & 20.00 & 200.00 & $\begin{array}{c}220.0 \\
0\end{array}$ & $\underline{1.08}$ & $\underline{1.07}$ \\
\hline OM-SX-pH0.5-0.05M-1:5 & 0.5 & 0.05 & $5: 1$ & 36.67 & 183.33 & $\begin{array}{c}220.0 \\
0\end{array}$ & $\underline{1.08}$ & $\underline{1.03}$ \\
\hline OM-SX-pH0.5-0.05M-1:2 & 0.5 & 0.05 & $2: 1$ & 73.33 & 146.67 & $\begin{array}{c}220.0 \\
0\end{array}$ & $\underline{1.08}$ & $\underline{0.96}$ \\
\hline OM-SX-pH0.5-0.05M-1:1 & 0.5 & 0.05 & $1: 1$ & 110.00 & 110.00 & $\begin{array}{c}220.0 \\
0\end{array}$ & $\underline{1.08}$ & $\underline{0.86}$ \\
\hline OM-SX-pH0.5-0.05M-1:1.5 & 0.5 & 0.05 & $1: 1.5$ & 132.00 & 88.00 & $\begin{array}{c}220.0 \\
0\end{array}$ & $\underline{1.08}$ & $\underline{0.73}$ \\
\hline OM-SX-pH0.5-0.05M-1:2 & 0.5 & 0.05 & $1: 2$ & 146.67 & 73.33 & $\begin{array}{c}220.0 \\
0\end{array}$ & $\underline{1.08}$ & $\underline{0.62}$ \\
\hline OM-SX-pH0.5-0.3M-1:10 & 0.5 & 0.30 & $10: 1$ & 20.00 & 200.00 & $\begin{array}{c}220.0 \\
0\end{array}$ & $\underline{1.08}$ & $\underline{0.97}$ \\
\hline OM-SX-pH0.5-0.3M-1:5 & 0.5 & 0.30 & $5: 1$ & 36.67 & 183.33 & $\begin{array}{c}220.0 \\
0\end{array}$ & $\underline{1.08}$ & $\underline{0.85}$ \\
\hline
\end{tabular}




\begin{tabular}{ccccccccc}
\hline OM-SX-pH0.5-0.3M-1:2 & 0.5 & 0.30 & $2: 1$ & 73.33 & 146.67 & $\begin{array}{c}220.0 \\
0\end{array}$ & $\underline{1.08}$ & $\underline{0.54}$ \\
OM-SX-pH0.5-0.3M-1:1 & 0.5 & 0.30 & $1: 1$ & 110.00 & 110.00 & $\begin{array}{c}220.0 \\
0\end{array}$ & $\underline{1.08}$ & $\underline{0.27}$ \\
OM-SX-pH0.5-0.3M-1:1.5 & 0.5 & 0.30 & $1: 1.5$ & 132.00 & 88.00 & $\begin{array}{c}220.0 \\
0\end{array}$ & $\underline{1.08}$ & $\underline{0.15}$ \\
OM-SX-pH0.5-0.3M-1:2 & 0.5 & 0.30 & $1: 2$ & 146.67 & 73.33 & $\begin{array}{c}220.0 \\
0\end{array}$ & $\underline{1.08}$ & $\underline{0.21}$ \\
\hline OM-SX-pH0.5-1.0M-1:10 & 0.5 & 1.00 & $10: 1$ & 20.00 & 200.00 & $\begin{array}{c}220.0 \\
0\end{array}$ & $\underline{1.08}$ & $\underline{0.7}$ \\
OM-SX-pH0.5-1.0M-1:5 & 0.5 & 1.00 & $5: 1$ & 36.67 & 183.33 & $\begin{array}{c}220.0 \\
0\end{array}$ & $\underline{1.08}$ & $\underline{0.46}$ \\
OM-SX-pH0.5-1.0M-1:2 & 0.5 & 1.00 & $2: 1$ & 73.33 & 146.67 & $\begin{array}{c}220.0 \\
0\end{array}$ & $\underline{1.08}$ & $\underline{0.19}$ \\
OM-SX-pH0.5-1.0M-1:1 & 0.5 & 1.00 & $1: 1$ & 110.00 & 110.00 & $\begin{array}{c}220.0 \\
0\end{array}$ & $\underline{1.08}$ & $\underline{0.01}$ \\
OM-SX-pH0.5-1.0M-1:1.5 & 0.5 & 1.00 & $1: 1.5$ & 132.00 & 88.00 & $\begin{array}{c}220.0 \\
0\end{array}$ & $\underline{1.08}$ & $\underline{\underline{-0.07}}$ \\
OM-SX-pH0.5-1.0M-1:2 & 0.5 & 1.00 & $1: 2$ & 146.67 & 73.33 & $\begin{array}{c}220.0 \\
0\end{array}$ & $\underline{1.08}$ & $\underline{\underline{-0.11}}$ \\
\hline
\end{tabular}

Remarks: A: aqueous phase; O: organic phase; TV: total volume; C: D2EPHA concentration.

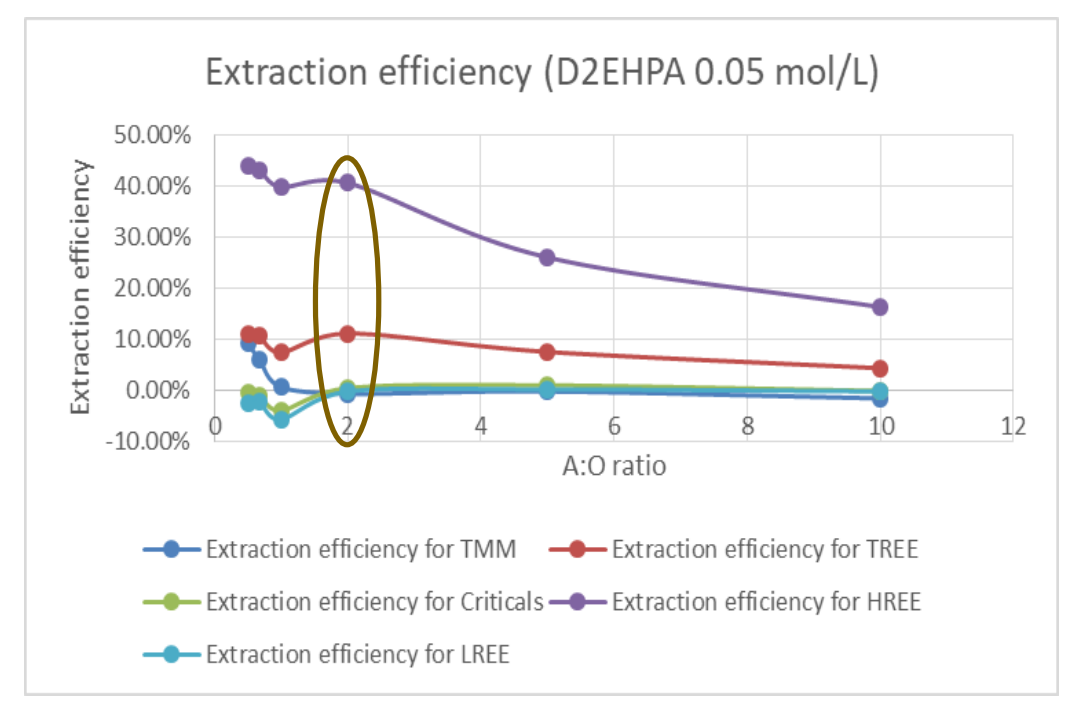



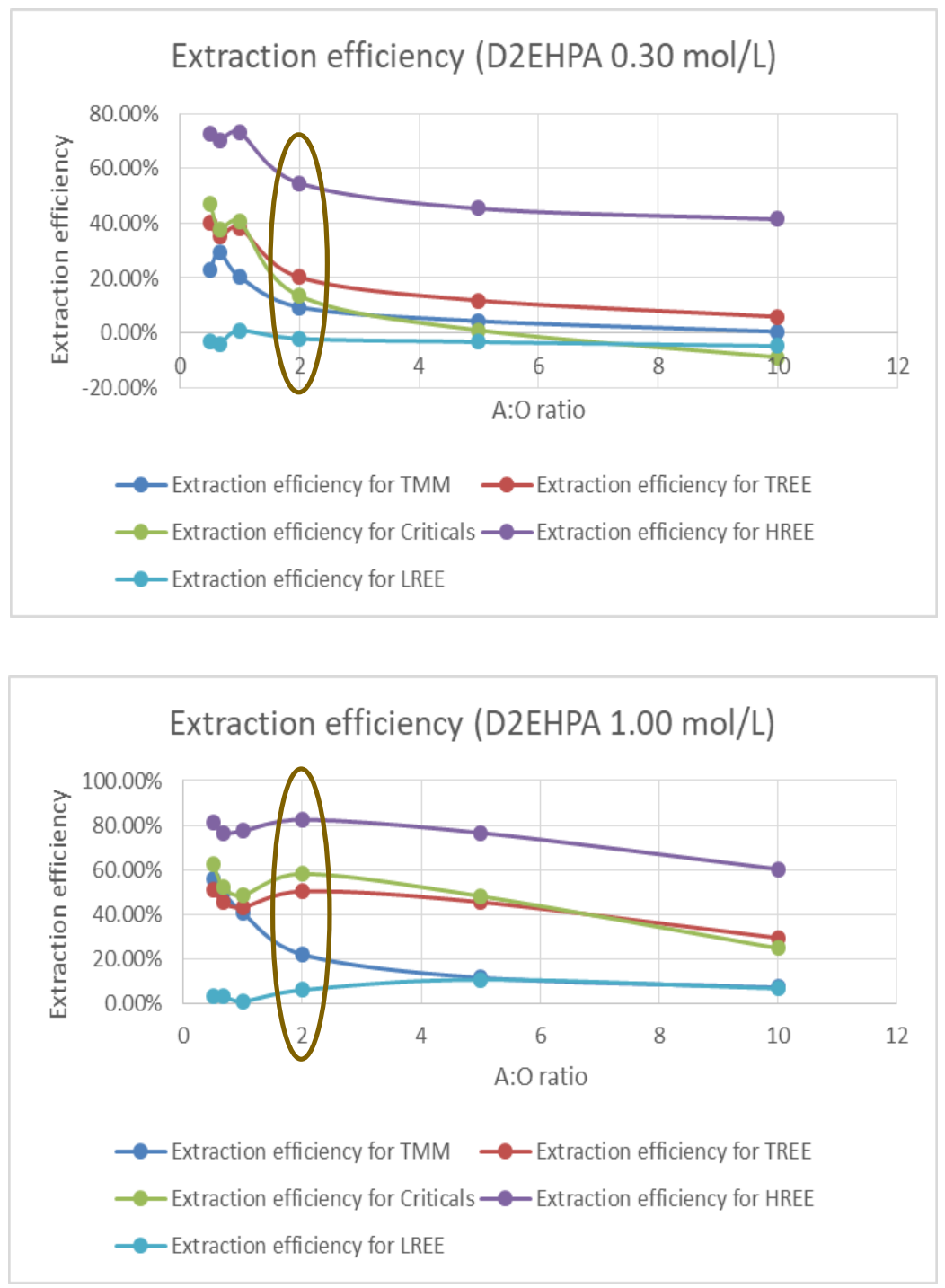

Figure 4.1 Extraction efficiency of TMM, TREE, CREE, HREE and LREE- OM PLS 1.1.

If the A:O ratio larger than 2 was chosen for REE extraction, TREE selective extraction from TMM was optimal at a D2EHPA concentration of $1.0 \mathrm{M}$. For an A:O ratio less than 1, TREE selective extraction from TMM was optimal at a D2EHPA concentration of $0.3 \mathrm{M}$ (Figure 4.2). 

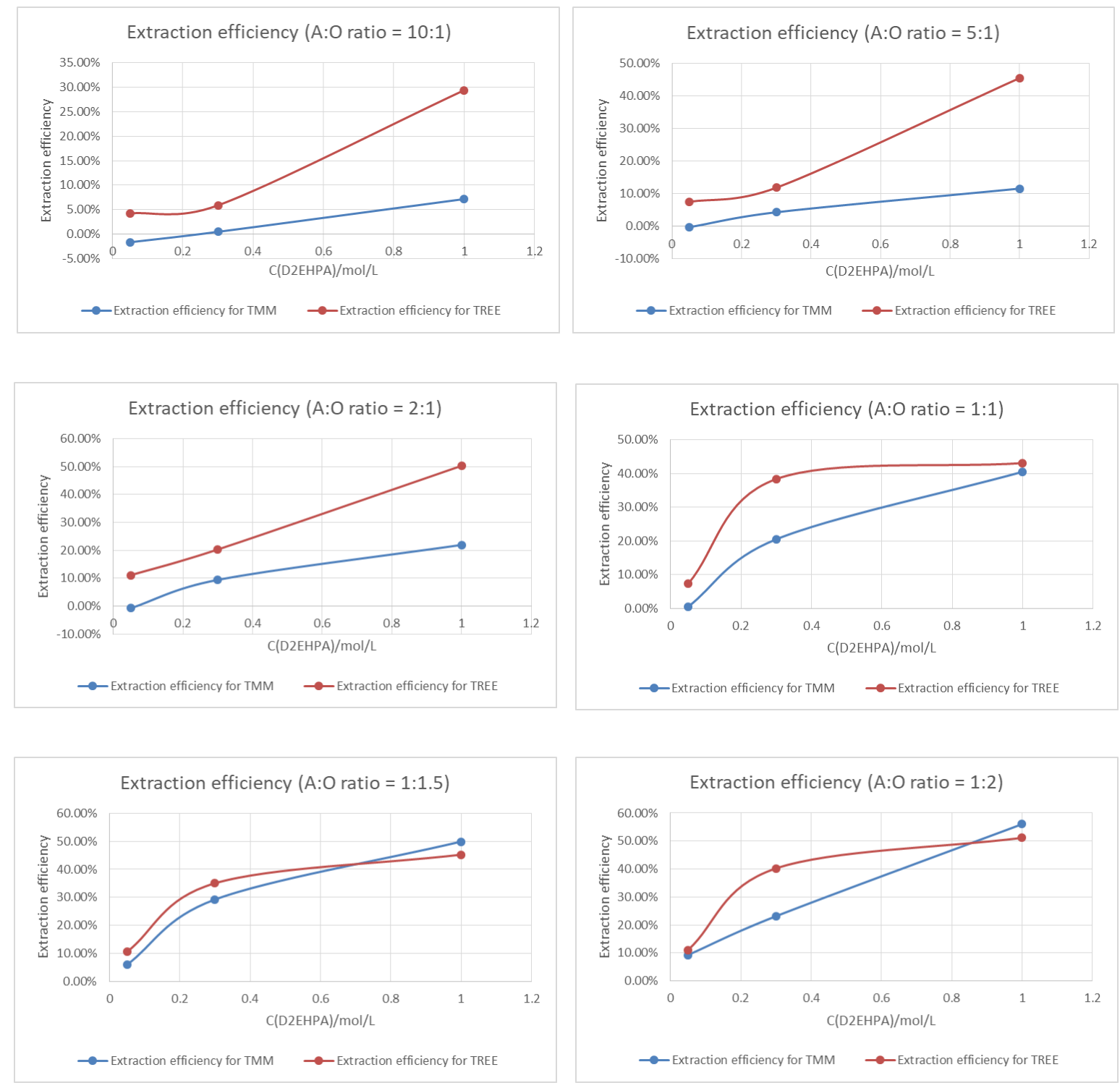

Figure 4.2 Extraction efficiency of TMM, TREE- OM PLS 1.1.

CREE, HREE, and LREE distribution in these processes are shown in Figure 4.3. HREE percentages in raffinate decreased when the extractant concentration increased. Total percentages of HREE and CREE in the organic phase increased when the extractant concentration increased. HREE can be separately extracted first at a low extractant concentration (0.05 M). The total of HREE and CREE can be separately extracted at a high extractant concentration (1.0 M). 

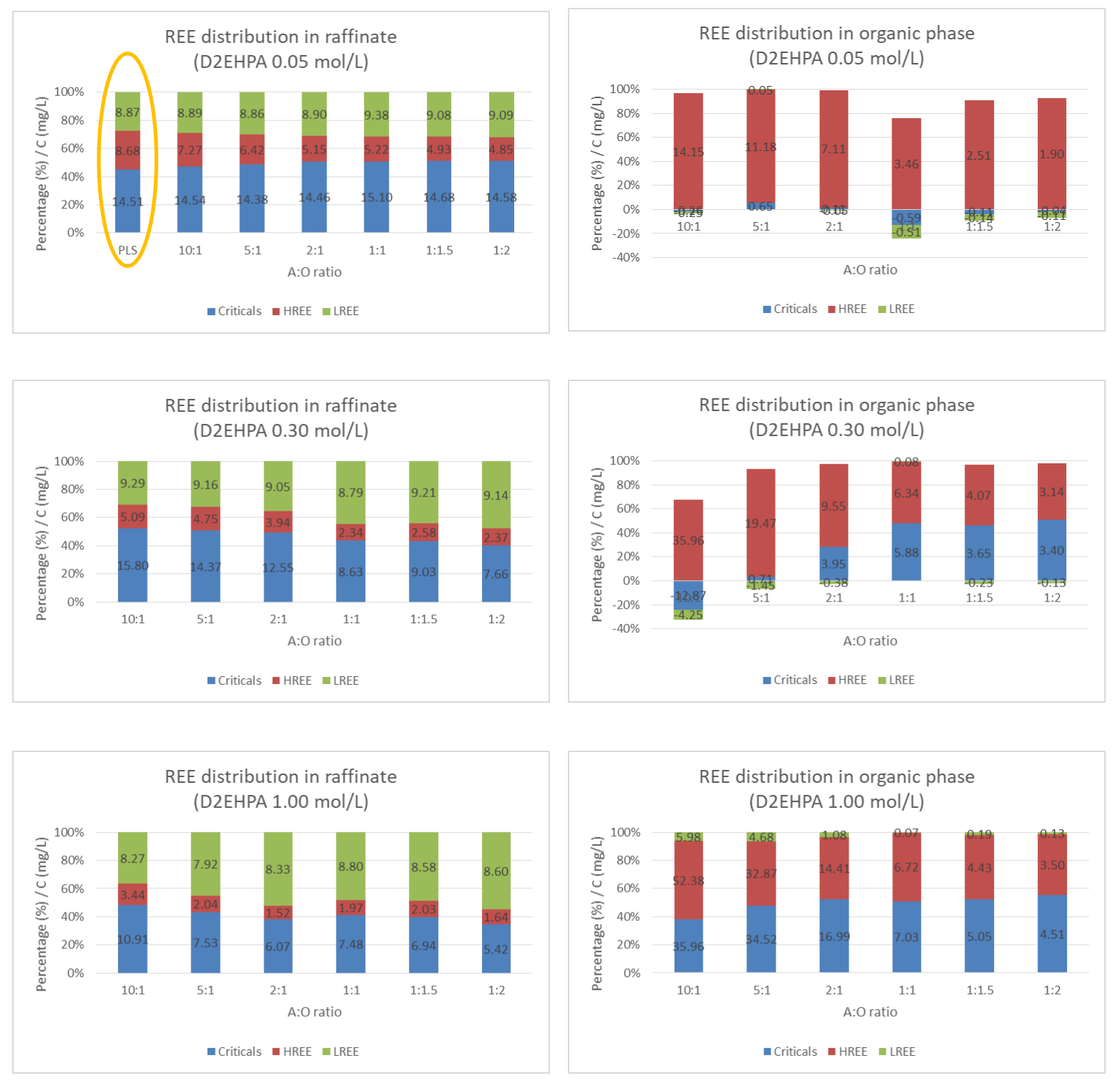

Figure 4.3 Critical REE, heavy REE and light REE distribution- OM PLS 1.1.

The McCabe Thiele diagrams of TREE in these processes were plotted in Figure 4.4. TREE extraction efficiencies were low (high $C(T R E E)$ in raffinate). For the following process, we need to decrease the A:O ratio to extract more TREE. One single step can extract half of the TREE if the intended A:O ratio is 2 and extractant concentration is $1.0 \mathrm{M}$. 

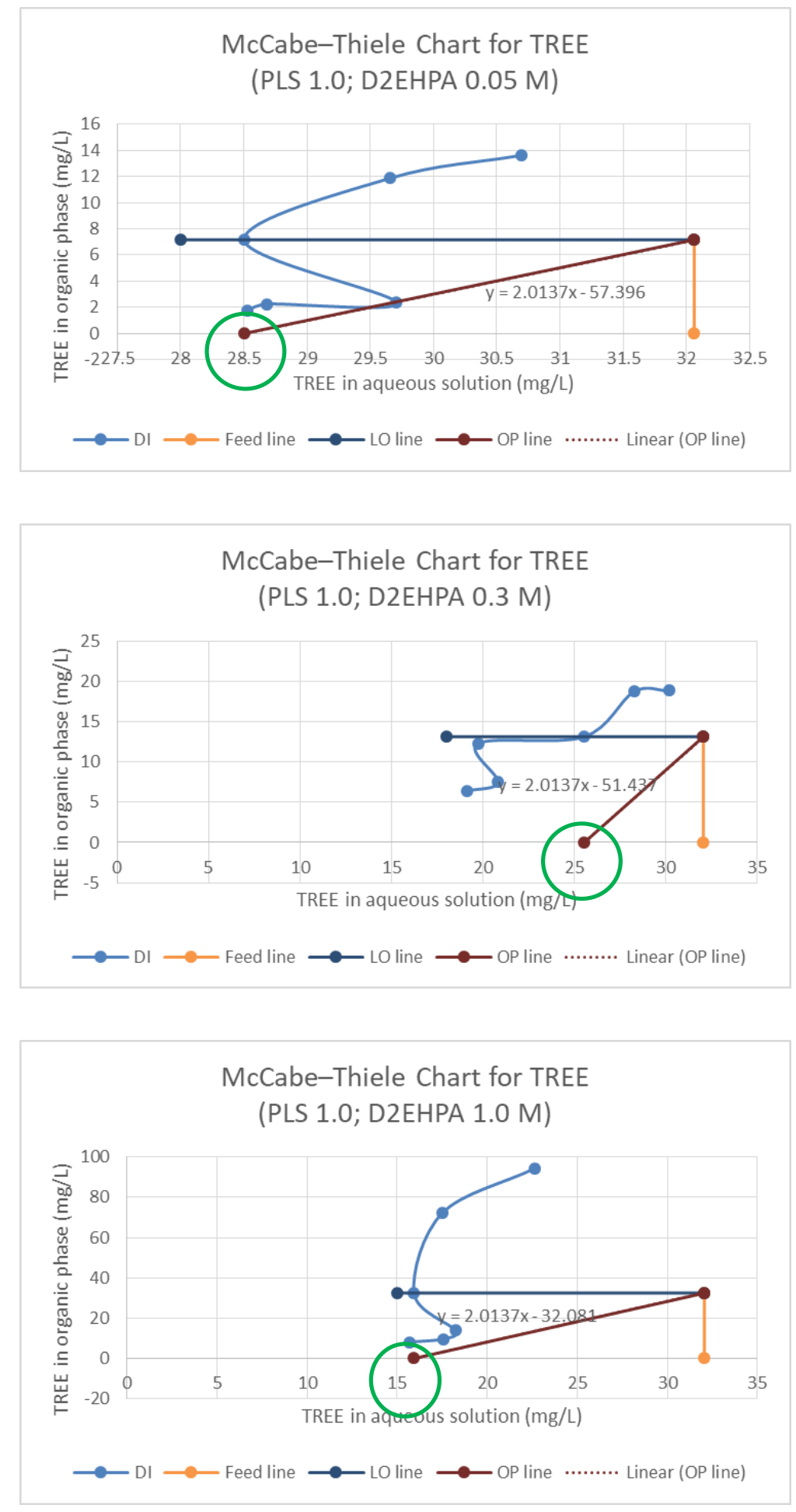

Figure 4.4 McCabe Thiele diagram of TREE- OM PLS 1.1. 
Since most HREE were extracted in these processes, the McCabe Thiele diagrams of HREE were also plotted (Figure 4.5). One single step can extract most HREE if the intended A:O ratio is 2 and extractant concentration is $1.0 \mathrm{M}$.
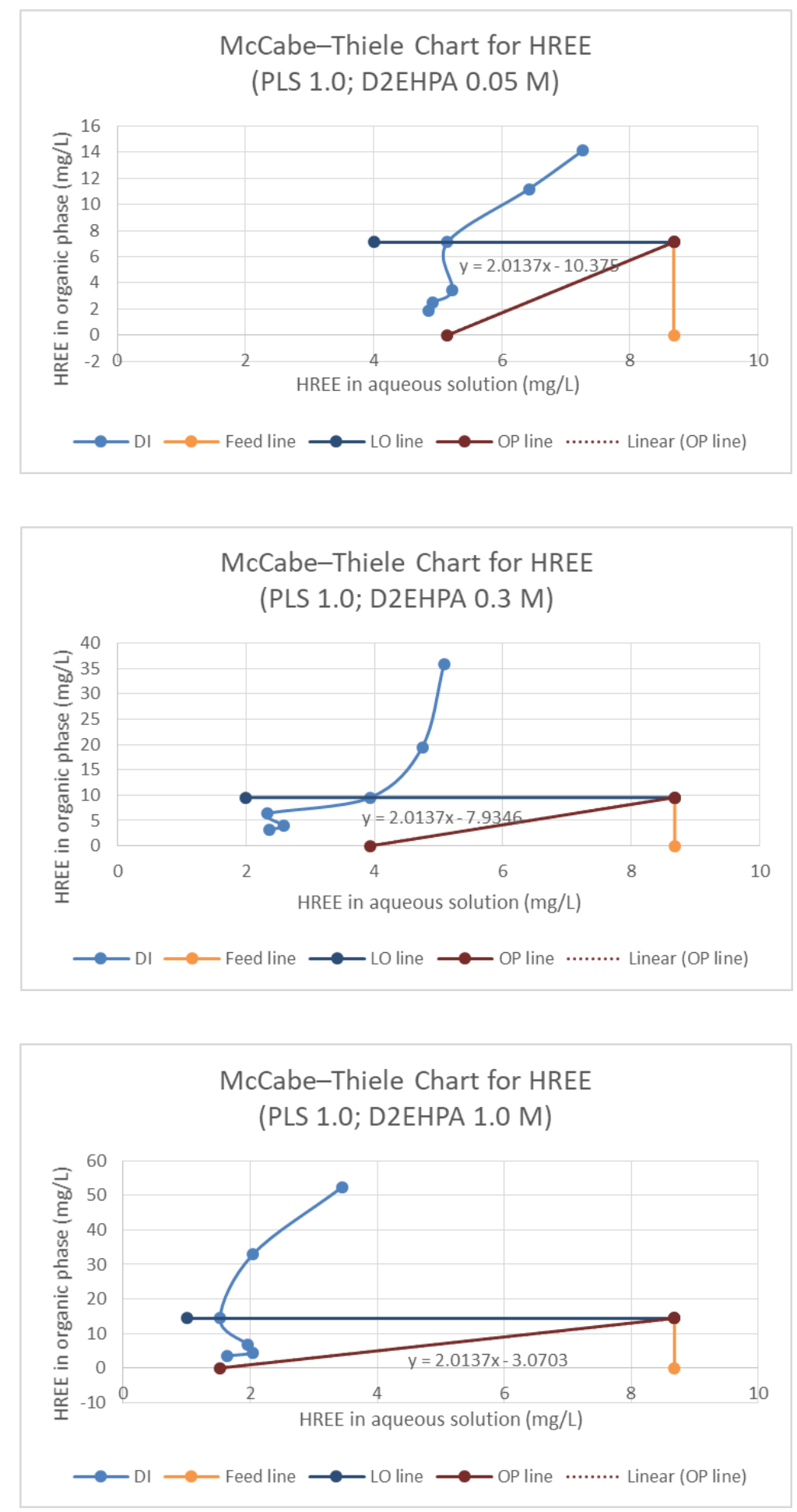


\section{Figure 4.5 McCabe Thiele diagram of HREE- OM PLS 1.1.}

Since extraction efficiencies of the element Sc were very high, the McCabe Thiele diagrams of Sc were also plotted (Figure 4.6). One single step can extract most Sc if the intended A:O ratio is 2, even at a low extractant concentration of $0.05 \mathrm{M}$. When using a high extractant concentration, the extraction of Fe will be significant, which should be avoided.
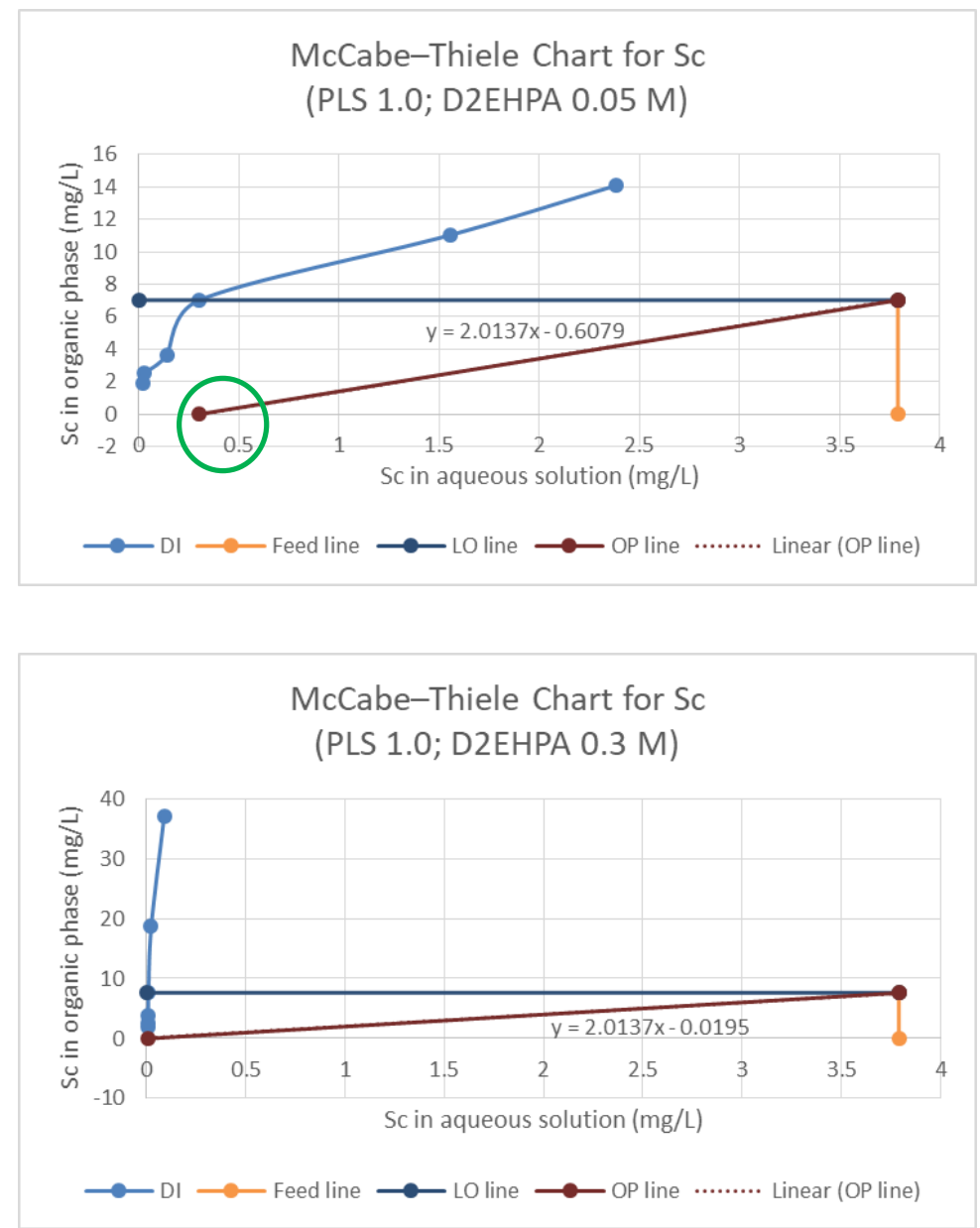


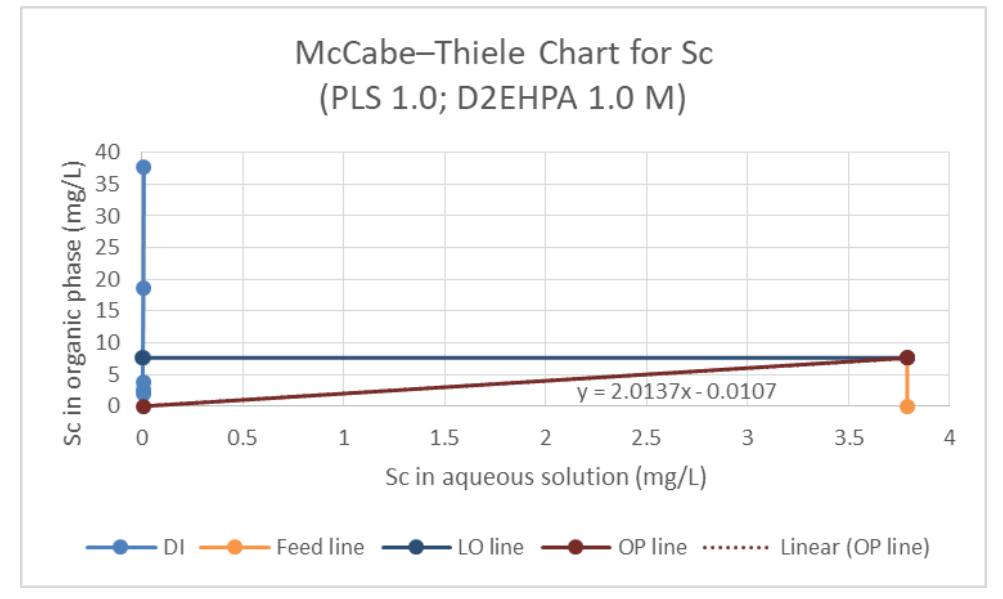

Figure 4.6 McCabe Thiele diagram of Sc- OM PLS 1.1.

In section 2, we have discussed the extraction mechanism; the extraction reaction equation is shown as Equation 2.1. Each time the extractant binds to a metal ion, a corresponding $\mathrm{H}_{+}$ion is released. The valence of the metal is equal to the moles of $\mathrm{H}_{+}$released. The total moles of $\mathrm{H}_{+}$ions released for each test can be calculated from the product of total moles of each metal (major metal and REE) extracted into the organic (ICP test) and the valence of each metal. The differences in $\mathrm{H}_{+}$concentration change determined between ICP and PH change are shown in Figure 4.7. Total moles of $\mathrm{H}+$ ions released from extracted metal ions were much higher than total moles of $\mathrm{H}_{+}$ions from $\mathrm{pH}$ change. By using the theoretical model, $\mathrm{pH}$ change can only be predicted qualitatively.

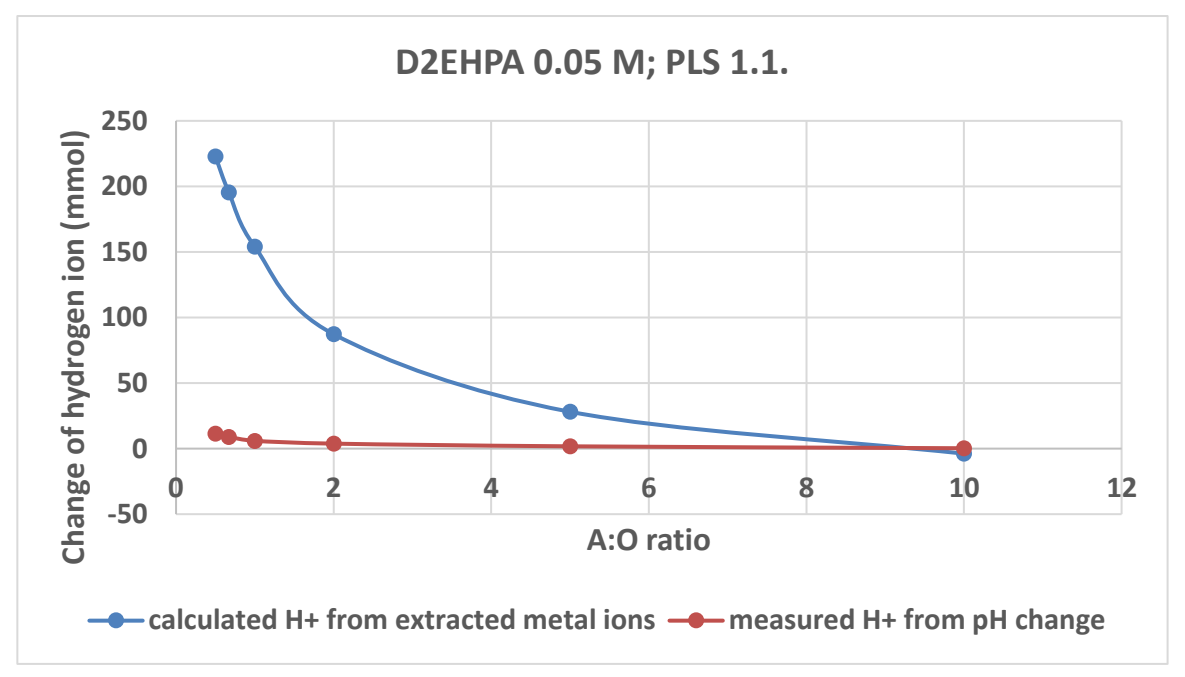



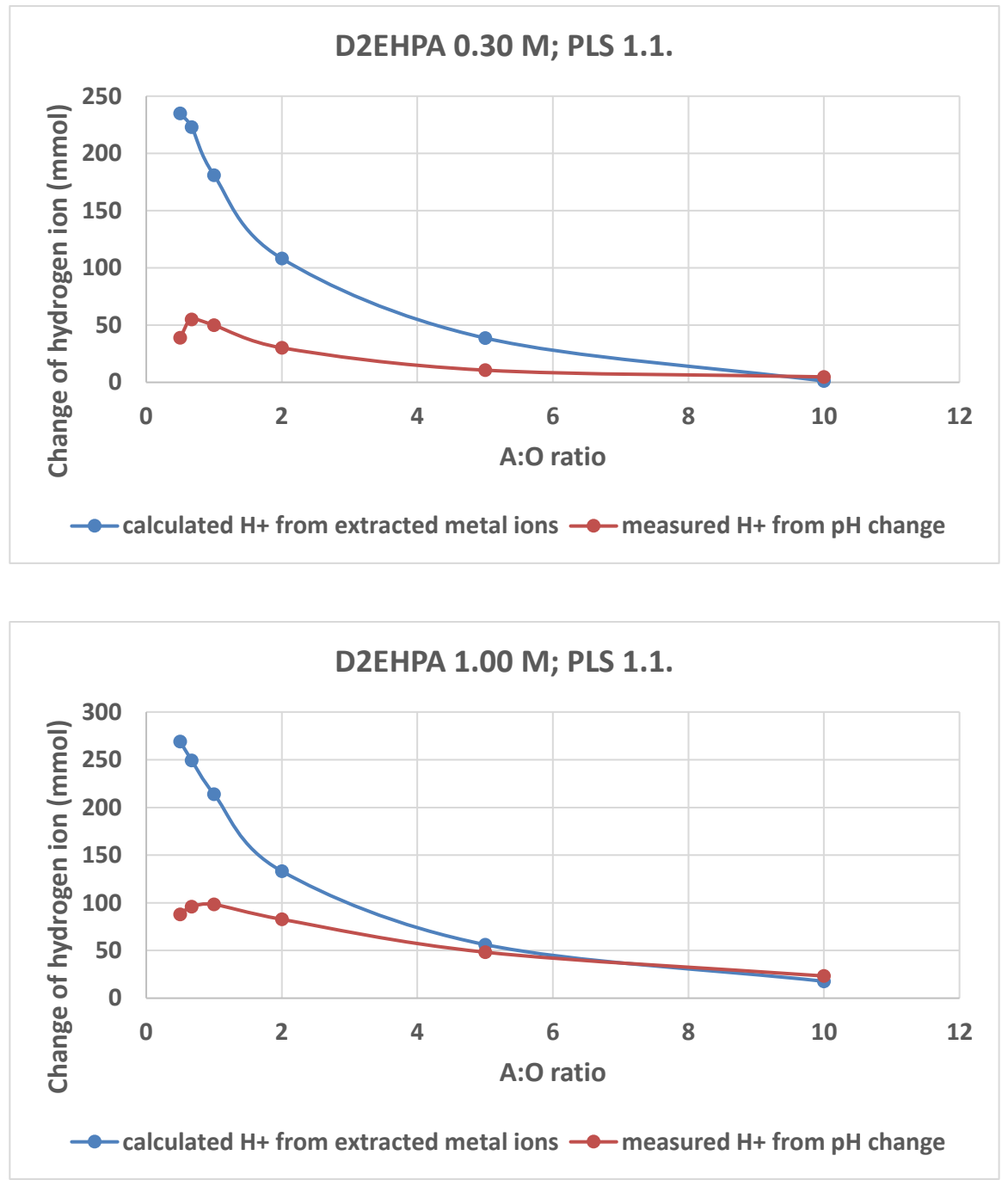

Figure 4.7 H+ concentration change determined by ICP and PH- OM PLS 1.1.

\subsubsection{SX McCabe-Thiele Exploratory Test-OM-PLS 2.7}

Bench-scale solvent extraction was conducted on a leaching solution of $\mathrm{pH} 2.7$ from the Omega site sludge (Table 4-2). Figure 4.8 shows the solution after different filtering processes. Most TREEs were lost after filtering and $\mathrm{pH}$ values increased. Since REE concentration after effective filtering was too low (Figure 4.9), PLS 2.7 was used for McCabe-Thiele exploratory test. Due to ineffective filtering, the feed solution (PLS 2.7) for SX was viscous and contained a lot of solids.

Table 4-2 Parameters and pH results of solvent extraction exploratory test of OM PLS 2.7.

\begin{tabular}{|c|c|c|c|c|c|c|c|c|}
\hline \multirow[t]{2}{*}{ Sample Name } & $\mathbf{F}$ & C & \multirow[t]{2}{*}{ A:O Ratio } & 0 & A & TV & D & $\mathbf{E}$ \\
\hline & PLS pH & $\mathrm{mol} / \mathrm{L}$ & & $\mathrm{ml}$ & $\mathrm{ml}$ & $\mathrm{ml}$ & $\mathrm{pH}$, before & $\mathrm{pH}$, after \\
\hline
\end{tabular}




\begin{tabular}{lcccccccc}
\hline OM-SX-pH2-0.3M-1:5 & 2.0 & 0.30 & $5: 1$ & 36.67 & 183.33 & 220.00 & $\underline{2.7}$ & $\underline{2.06}$ \\
OM-SX-pH2-0.3M-1:2 & 2.0 & 0.30 & $2: 1$ & 73.33 & 146.67 & 220.00 & $\underline{2.7}$ & $\underline{2.38}$ \\
OM-SX-pH2-0.3M-1:1 & 2.0 & 0.30 & $1: 1$ & 110.00 & 110.00 & 220.00 & $\underline{2.7}$ & $\underline{2.04}$ \\
OM-SX-pH2-0.3M-2:1 & 2.0 & 0.30 & $1: 2$ & 146.67 & 73.33 & 220.00 & $\underline{2.7}$ & $\underline{1.98}$ \\
OM-SX-pH2-0.3M-5:1 & 2.0 & 0.30 & $1: 5$ & 183.33 & 36.67 & 220.00 & $\underline{2.7}$ & $\underline{1.68}$ \\
OM-SX-pH2-0.3M-10:1 & 2.0 & 0.30 & $1: 10$ & 200.00 & 20.00 & 220.00 & $\underline{2.7}$ & $\underline{1.44}$ \\
\hline
\end{tabular}

Remarks: A: aqueous phase; O: organic phase; TV: total volume; C: D2EPHA concentration.
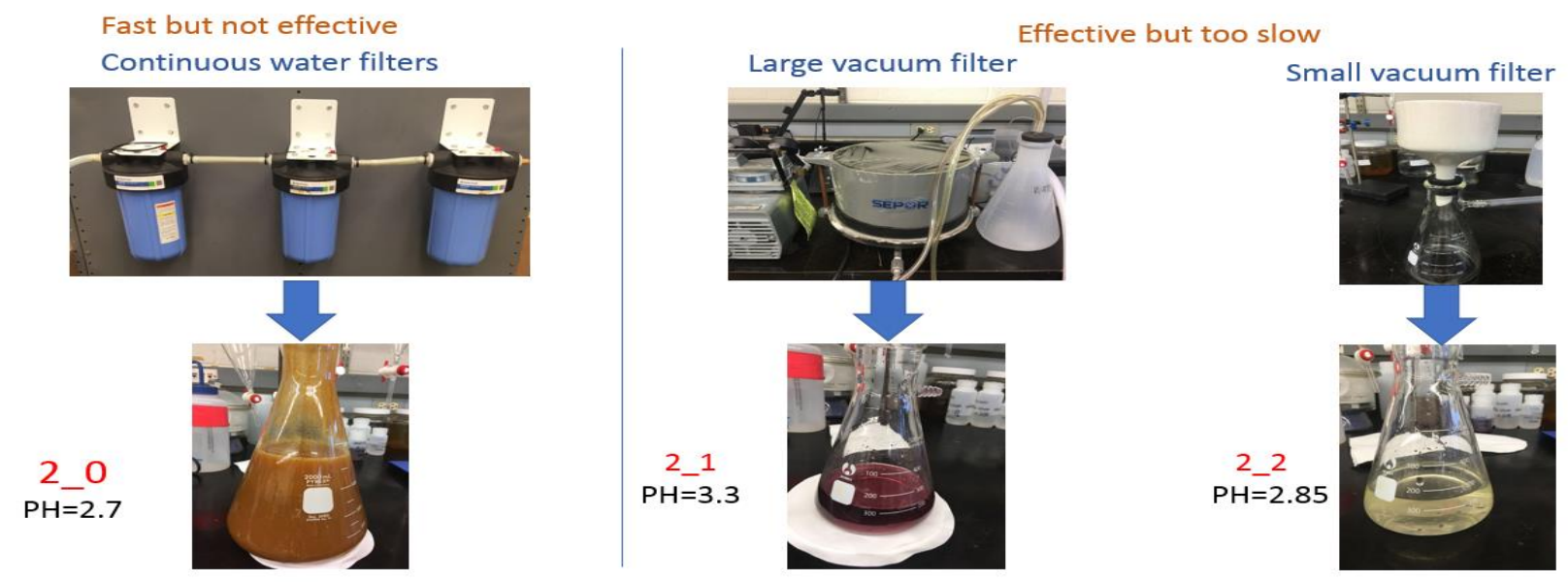

Figure 4.8 Filtering equipment and effect on OM PLS.
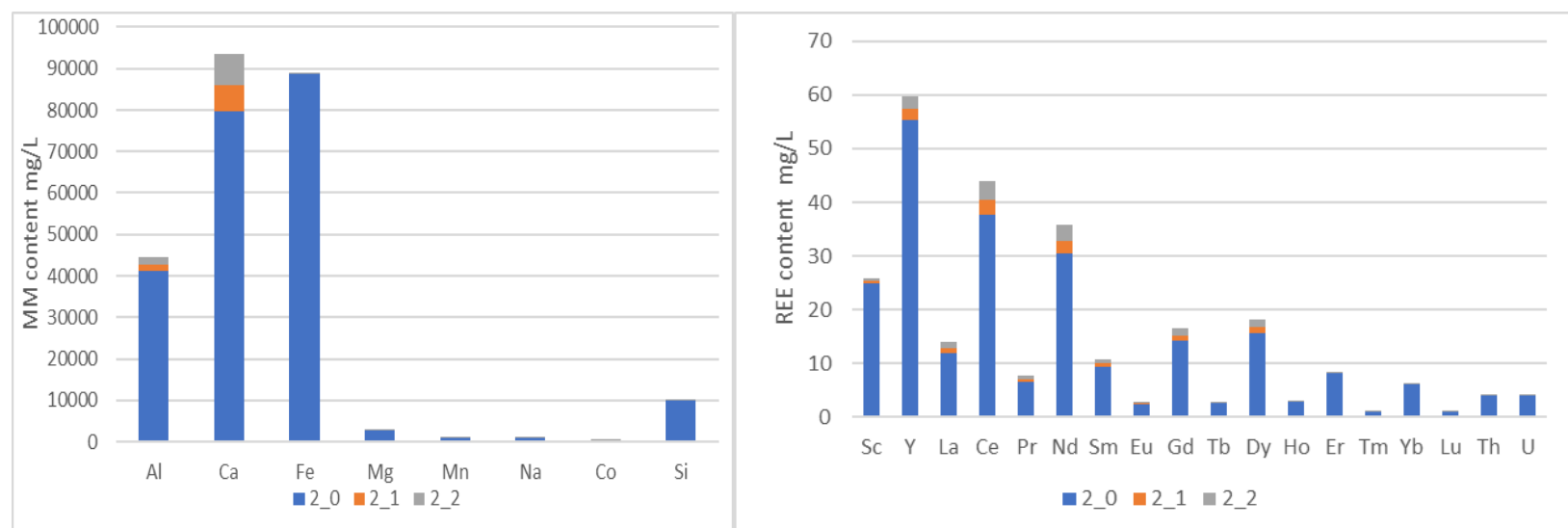

Figure 4.9 Filtering effect on OM PLS content.

The SX results of the original solution and the ineffective filtered solution were compared. Due to the influence of solids in the feed solution, the three phases were formed after SX. The concentrations of MM 
and REE in the clear phase and the mixed intermediate phase were measured by ICP. The results of an A:O ratio 1:1 are shown in Figure 4.10. Extraction efficiencies were improved after filtering (84\% > 77\%).

Original solution

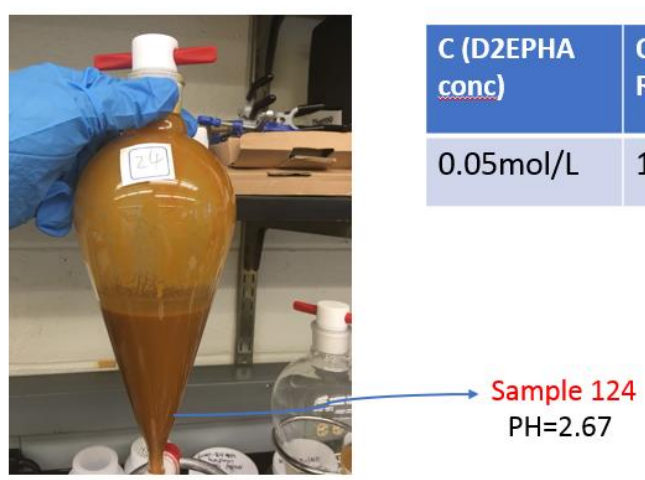

filtered solution

The solids in sludge will reduce the immiscibility between $O$ and $A$ phase
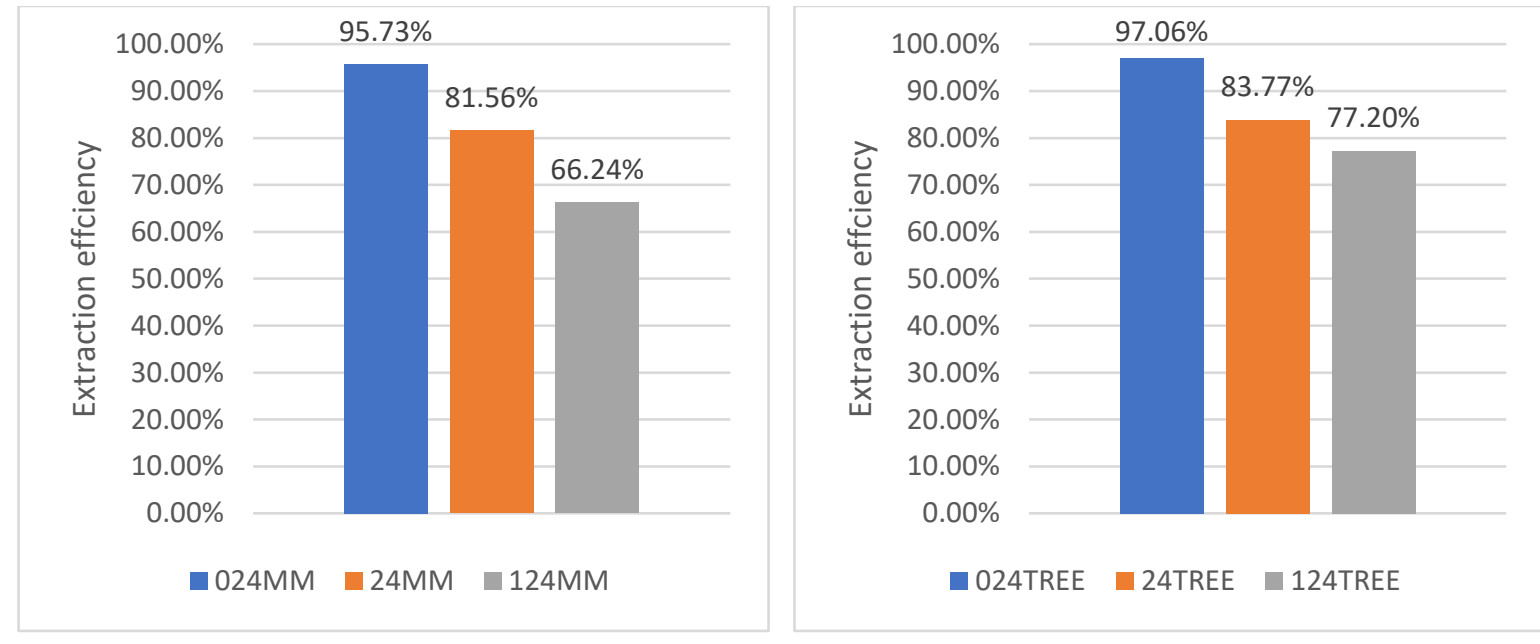

Figure 4.10 SX results on original leaching solution of OM sludge and filtered OM PLS 2.7.

When using a filtered viscosity solution for SX, a high A:O ratio should be used for REE extraction. The concentrations of MM and REE in clear phase and mixed intermediate phase were measured by ICP. The results of an A:O ratio of 5 are shown in Figure 4.11. Most TMM and TREE existed in intermediate mixed phase. Future SX on this intermediate phase may be useful for more TREE extraction. 

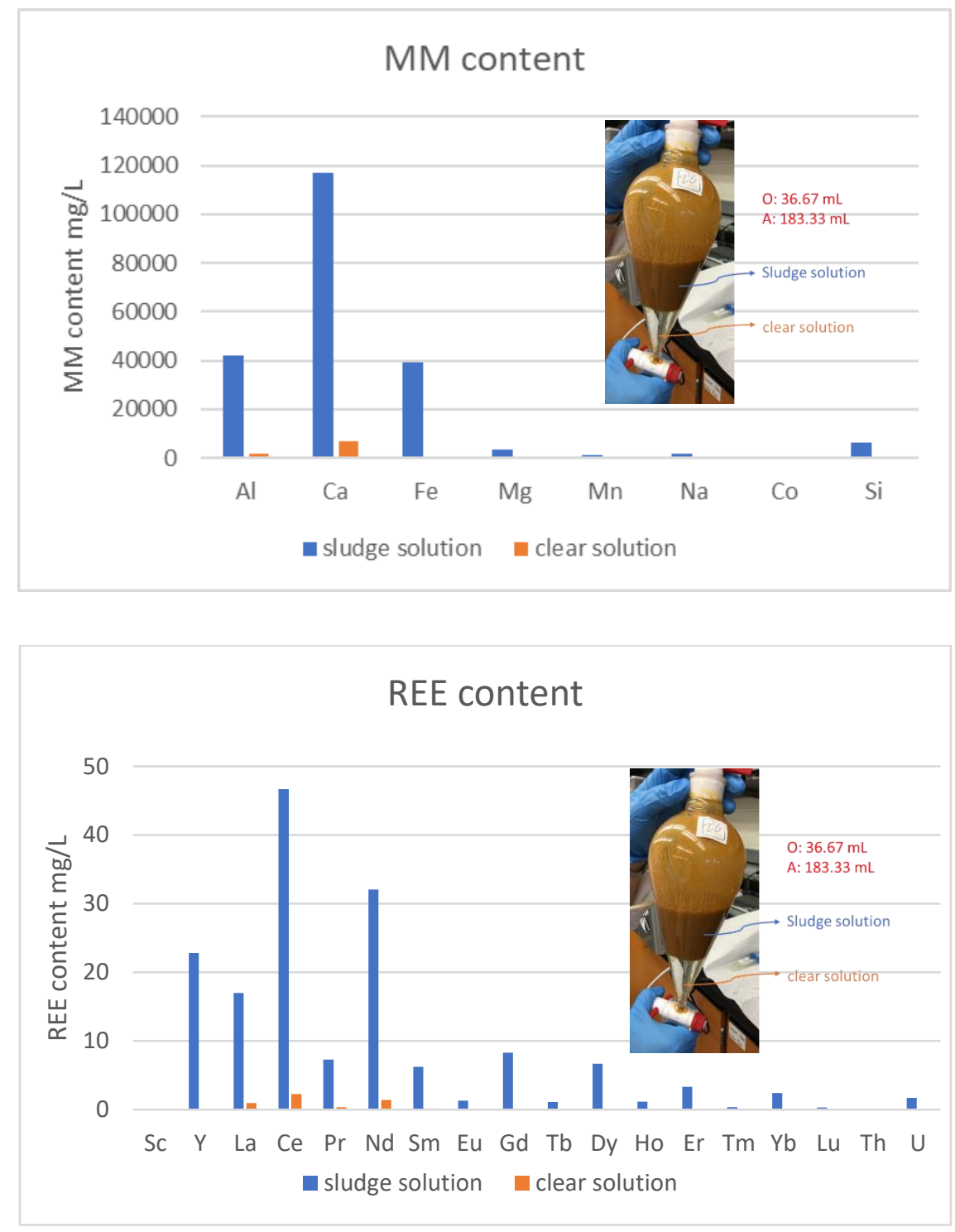

Figure 4.11 Metal concentration change after SX on OM PLS 2.7 (A:O=5).

Extraction efficiencies of total major metal ions (TMM), total rare earth ions (TREE), critical rare earth ions (CREE: Nd, Eu, Y, Tb and Dy), heavy rare earth ions (HREE: Sc, Gd, Ho, Er, Tm, Yb and Lu) and light rare earth ions (LREE: La, Ce, Pr and Sm) of different A:O ratios (Table 4-2) are shown in Figure 4.12. Extraction efficiencies of both TMM and TREE were low at a high A:O ratio. HREE and CREE extraction efficiencies were higher than LREE. An A:O ratio of lower than 0.5 is appropriate for TREE selective extraction from TMM. 

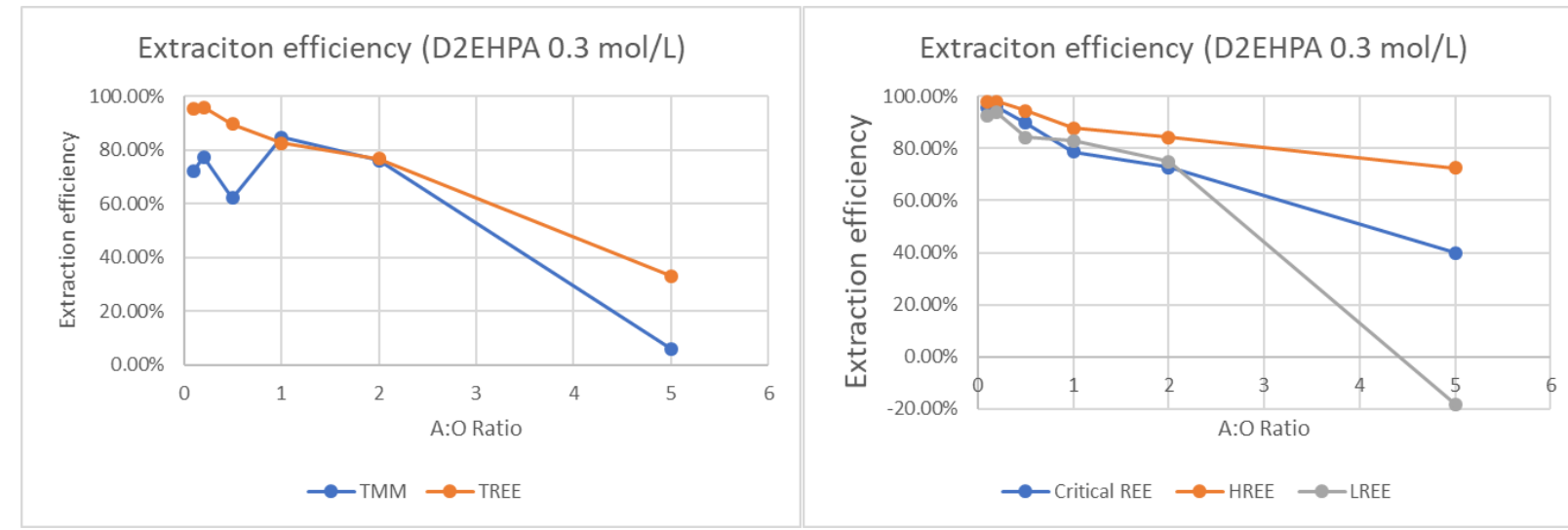

Figure 4.12 Extraction efficiency of TMM, TREE, CREE, HREE and LREE- OM PLS 2.7.

The A:O Ratio Effect on REE Distribution after SX is shown in Figure 4.13. The HREE percentages in organic phase were much higher than those in raffinate. The total of HREE and CREE may be separately extracted at extractant concentration of $0.3 \mathrm{M}$.
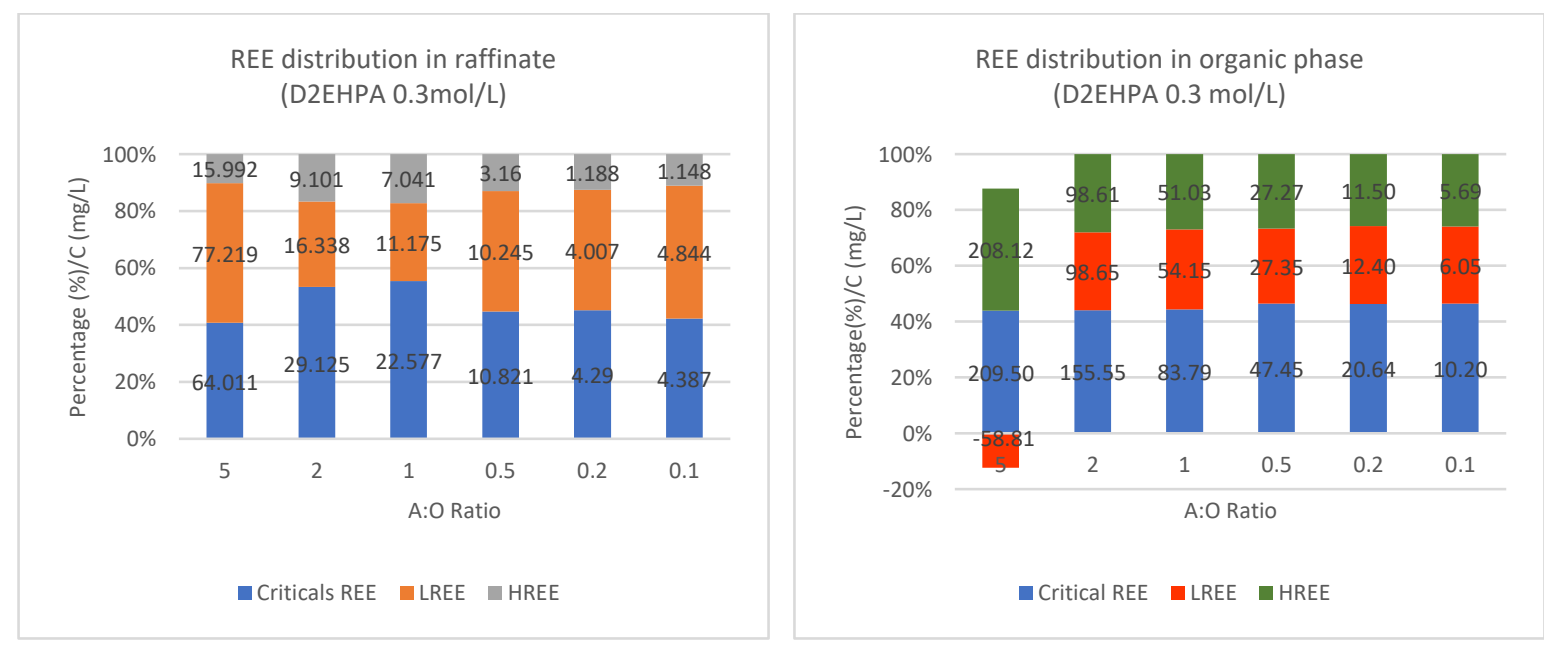

Figure 4.13 Critical REE, heavy REE and light REE distribution- OM PLS 2.7.

The McCabe Thiele diagram of TREE for Omega PLS 2.7 in these processes is plotted in Figure 4.14. Since TREE separation from TMM was difficult at an A:O ratio of 2, an intended A:O ratio of 0.5 was plotted. One single step can extract most TREE if using an A:O ratio of 0.5 . 


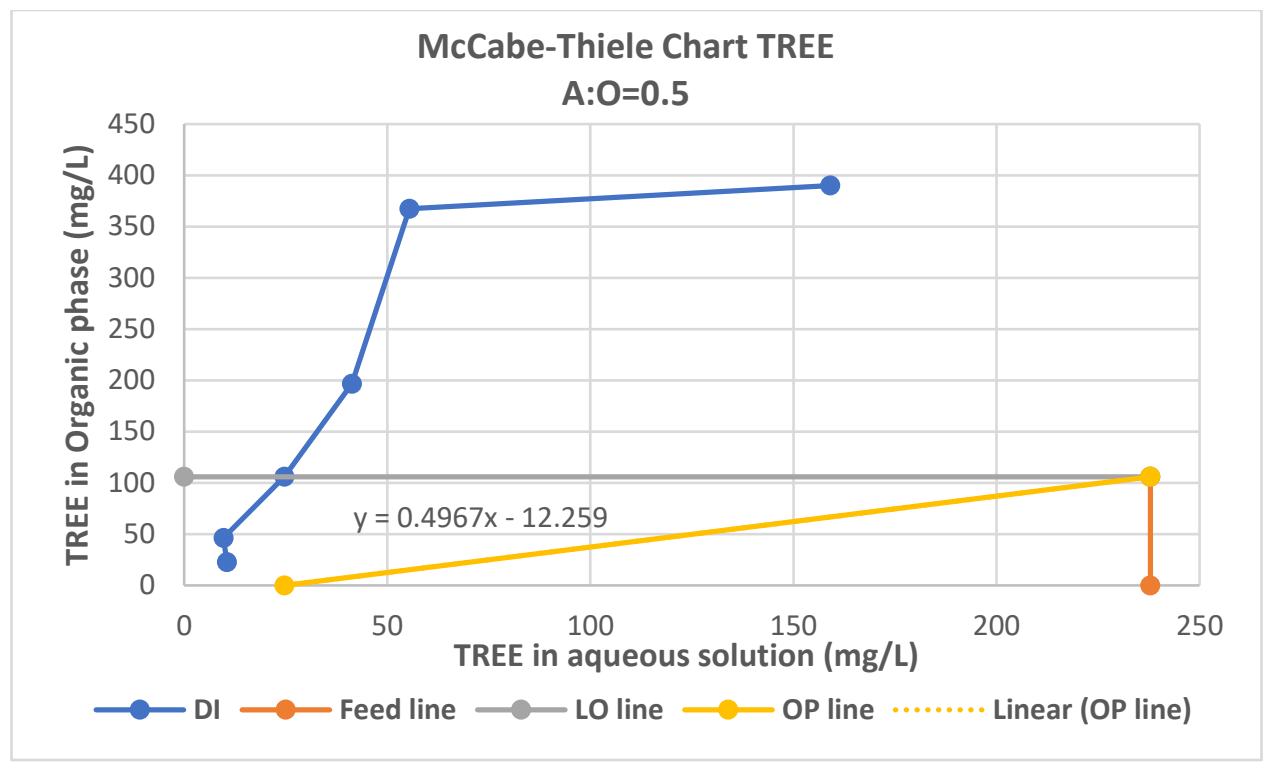

Figure 4.14 McCabe Thiele diagram of TREE- OM PLS 2.7.

\subsubsection{SX McCabe-Thiele Exploratory Test-OM-PLS 3}

To obtain optimized OM PLS 3 for SX, the sludge from Omega site were first leached by nitric acid to $\mathrm{pH}$ about 0 . After filtering, sodium hydroxide solution was added to the filtrate $(1.8 \mathrm{~L})$ to adjust $\mathrm{pH}$ value to about 3.5 to remove major metal ions. The PLS $(1.3 \mathrm{~L})$ was then obtained after second filtering and the final $\mathrm{pH}$ value was 3.2. The solution was difficult to filter than that of DLM and RS. After filtering, the concentration of REE decreased a little bit. The concentration of Fe and Al decreased significantly. Due to both concentration loss and significant volume loss, mass loss of TREE was $38.44 \%$ and mass loss of TMM was $86.13 \%$, as shown in Figure 4.15 .

Concentration change of MM

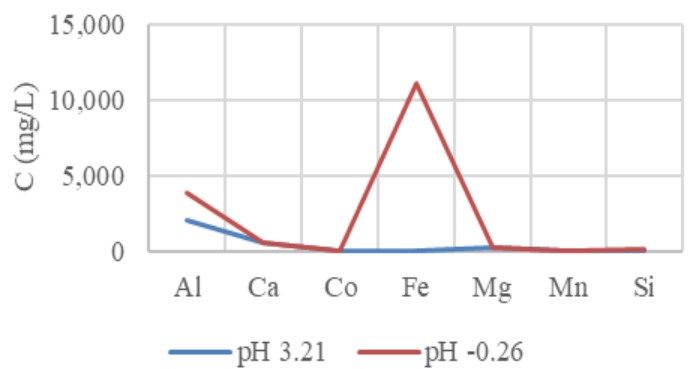

Concentration change of REE

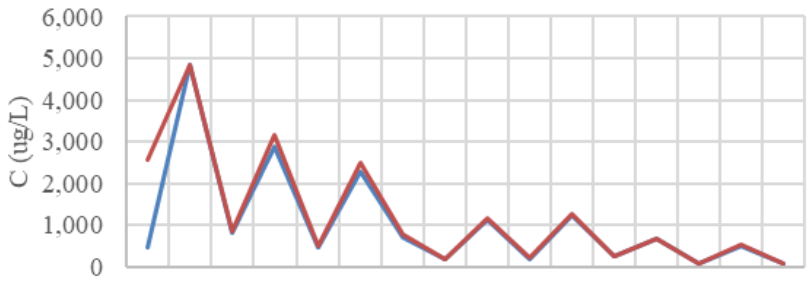

Sc Y La Ce Pr Nd Sm Eu Gd Tb Dy Ho Er Tm Yb Lu

$\longrightarrow \mathrm{pH} 3.21-\mathrm{pH}-0.26$ 
Mass change of MM

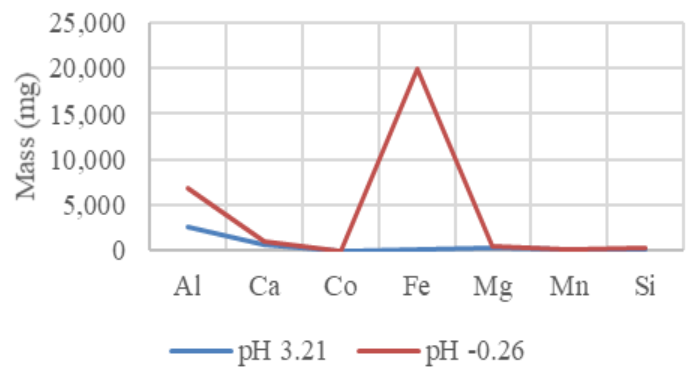

Mass change of REE

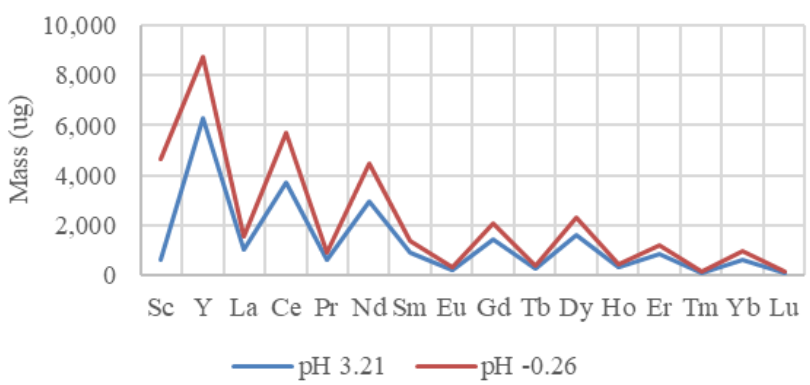

Figure 4.15 Concentration and mass change in OM PLS making process.

Laboratory-scale solvent extraction was conducted on an optimized leaching solution of $\mathrm{pH} 3$ from Omega site sludge (Table 4-3). Extraction efficiencies of total major metal ions, total rare earth ions, heavy rare earth ions (HREE: Sc, Y, Gd, Tb, Dy, Ho, Er, Tm, Yb and Lu) and light rare earth ions (LREE: La, Ce, Pr, Nd, $\mathrm{Sm}$ and $\mathrm{Eu})$ are shown in Figure 4.16. Extraction efficiencies increase with increase of O:A ratio. The extraction efficiencies difference between TREE and TMM were significant at different extractant concentration. Extraction efficiencies for TREE were almost $100 \%$ at extractant concentration of $0.3 \mathrm{~mol} / \mathrm{L}$. Thus, this extractant concentration was enough for TREE extraction. Competitive extraction occurred at extractant concentration of 1.0 M. Extraction efficiencies of HREE were higher than those of LREE at all extractant concentrations and O:A ratios. HREE selective extraction from LREE was appropriate at an O:A ratio between 0.5 and 1 for C(D2EHPA) $0.05 \mathrm{M}$.

Table 4-3 Parameters of solvent extraction exploratory test of OM PLS 3.

\begin{tabular}{|c|c|c|c|c|c|c|c|c|}
\hline \multirow[t]{2}{*}{ Sample Name } & $F$ & C & \multirow[t]{2}{*}{ A:O Ratio } & 0 & A & \multirow[t]{2}{*}{ TV } & \multirow{2}{*}{$\frac{\text { D }}{\mathrm{pH}, \text { before }}$} & \multirow{2}{*}{$\frac{\text { E }}{\mathrm{pH}, \text { after }}$} \\
\hline & PLS pH & $\mathrm{mol} / \mathrm{L}$ & & $\mathrm{ml}$ & $\mathrm{ml}$ & & & \\
\hline OM-SX-pH3-0.05M-1:5 & 3.0 & 0.05 & $1: 5$ & 18.33 & 91.67 & 110.00 & $\underline{3.21}$ & 2.62 \\
\hline OM-SX-pH3-0.05M-1:2 & 3.0 & 0.05 & $1: 2$ & 36.67 & 73.33 & 110.00 & $\overline{3.21}$ & $\overline{1.98}$ \\
\hline OM-SX-pH3-0.05M-1:1 & 3.0 & 0.05 & $1: 1$ & 55.00 & 55.00 & 110.00 & $\overline{3.21}$ & $\overline{1.71}$ \\
\hline OM-SX-pH3-0.05M-2:1 & 3.0 & 0.05 & $2: 1$ & 146.67 & 73.33 & 220.00 & $\overline{3.21}$ & 1.50 \\
\hline OM-SX-pH3-0.05M-5:1 & 3.0 & 0.05 & $5: 1$ & 183.33 & 36.67 & 220.00 & $\overline{3.21}$ & $\overline{1.20}$ \\
\hline OM-SX-pH3-0.05M-10:1 & 3.0 & 0.05 & $10: 1$ & 200.00 & 20.00 & 220.00 & $\underline{3.21}$ & $\overline{1.04}$ \\
\hline OM-SX-pH3-0.3M-1:5 & 3.0 & 0.30 & $1: 5$ & 18.33 & 91.67 & 110.00 & 3.21 & 1.61 \\
\hline OM-SX-pH3-0.3M-1:2 & 3.0 & 0.30 & $1: 2$ & 36.67 & 73.33 & 110.00 & $\overline{3.21}$ & 1.32 \\
\hline OM-SX-pH3-0.3M-1:1 & 3.0 & 0.30 & $1: 1$ & 55.00 & 55.00 & 110.00 & $\overline{3.21}$ & 1.15 \\
\hline OM-SX-pH3-0.3M-2:1 & 3.0 & 0.30 & $2: 1$ & 146.67 & 73.33 & 220.00 & $\overline{3.21}$ & 1.01 \\
\hline OM-SX-pH3-0.3M-5:1 & 3.0 & 0.30 & $5: 1$ & 183.33 & 36.67 & 220.00 & 3.21 & $\underline{0.87}$ \\
\hline OM-SX-pH3-0.3M-10:1 & 3.0 & 0.30 & $10: 1$ & 200.00 & 20.00 & 220.00 & $\overline{3.21}$ & $\underline{0.81}$ \\
\hline OM-SX-pH3-1.0M-1:5 & 3.0 & 1.00 & $1: 5$ & 18.33 & 91.67 & 110.00 & $\overline{3.21}$ & 1.14 \\
\hline OM-SX-pH3-1.0M-1:2 & 3.0 & 1.00 & $1: 2$ & 36.67 & 73.33 & 110.00 & 3.21 & 0.89 \\
\hline
\end{tabular}




\begin{tabular}{lllllllll}
\hline OM-SX-pH3-1.0M-1:1 & 3.0 & 1.00 & $1: 1$ & 55.00 & 55.00 & 110.00 & $\underline{3.21}$ & $\underline{0.79}$ \\
OM-SX-pH3-1.0M-2:1 & 3.0 & 1.00 & $2: 1$ & 146.67 & 73.33 & 220.00 & $\underline{3.21}$ & $\underline{0.71}$ \\
OM-SX-pH3-1.0M-5:1 & 3.0 & 1.00 & $5: 1$ & 183.33 & 36.67 & 220.00 & $\underline{3.21}$ & $\underline{0.56}$ \\
OM-SX-pH3-1.0M-10:1 & 3.0 & 1.00 & $10: 1$ & 200.00 & 20.00 & 220.00 & $\underline{3.21}$ & $\underline{0.51}$ \\
\hline
\end{tabular}

Remarks: A: aqueous phase; O: organic phase; TV: total volume; C: D2EPHA concentration.
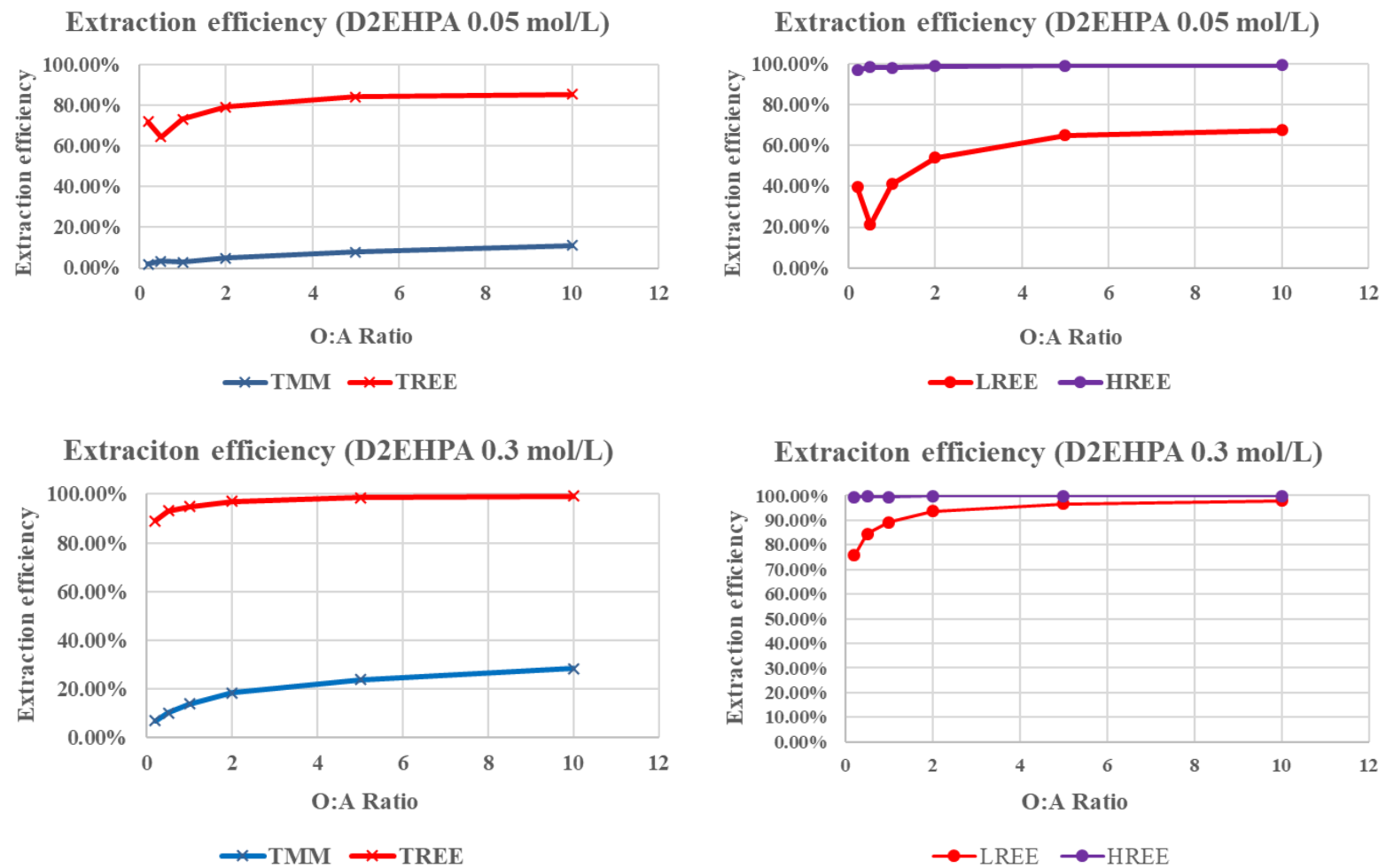

Extraction efficiency (D2EHPA $1.0 \mathrm{~mol} / \mathrm{L})$

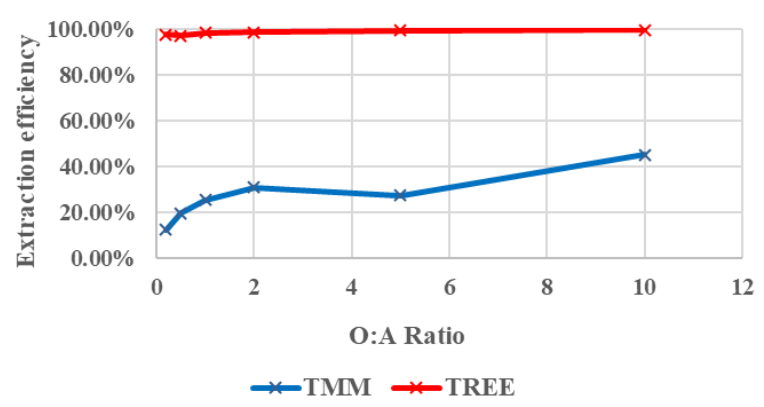

Extraciton efficiency (D2EHPA $1.0 \mathrm{~mol} / \mathrm{L})$

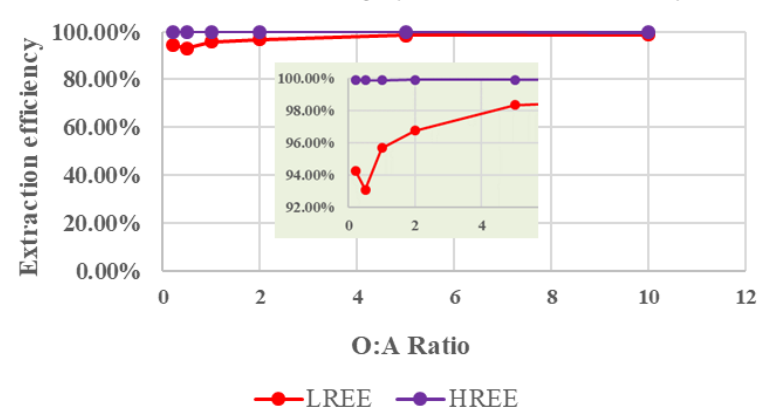

Figure 4.16 Extraction efficiency of TMM, TREE, HREE and LREE- OM PLS 3.

Extraction efficiencies of individual elements were also analyzed, as shown in Figure 4.17. For major metal ions, extraction efficiencies of iron element were very high at different extractant concentrations. For light rare earth elements, extraction efficiencies of lanthanum element were lowest at different conditions. All heavy rare earth elements were easily extracted even at lowest extractant concentration. 


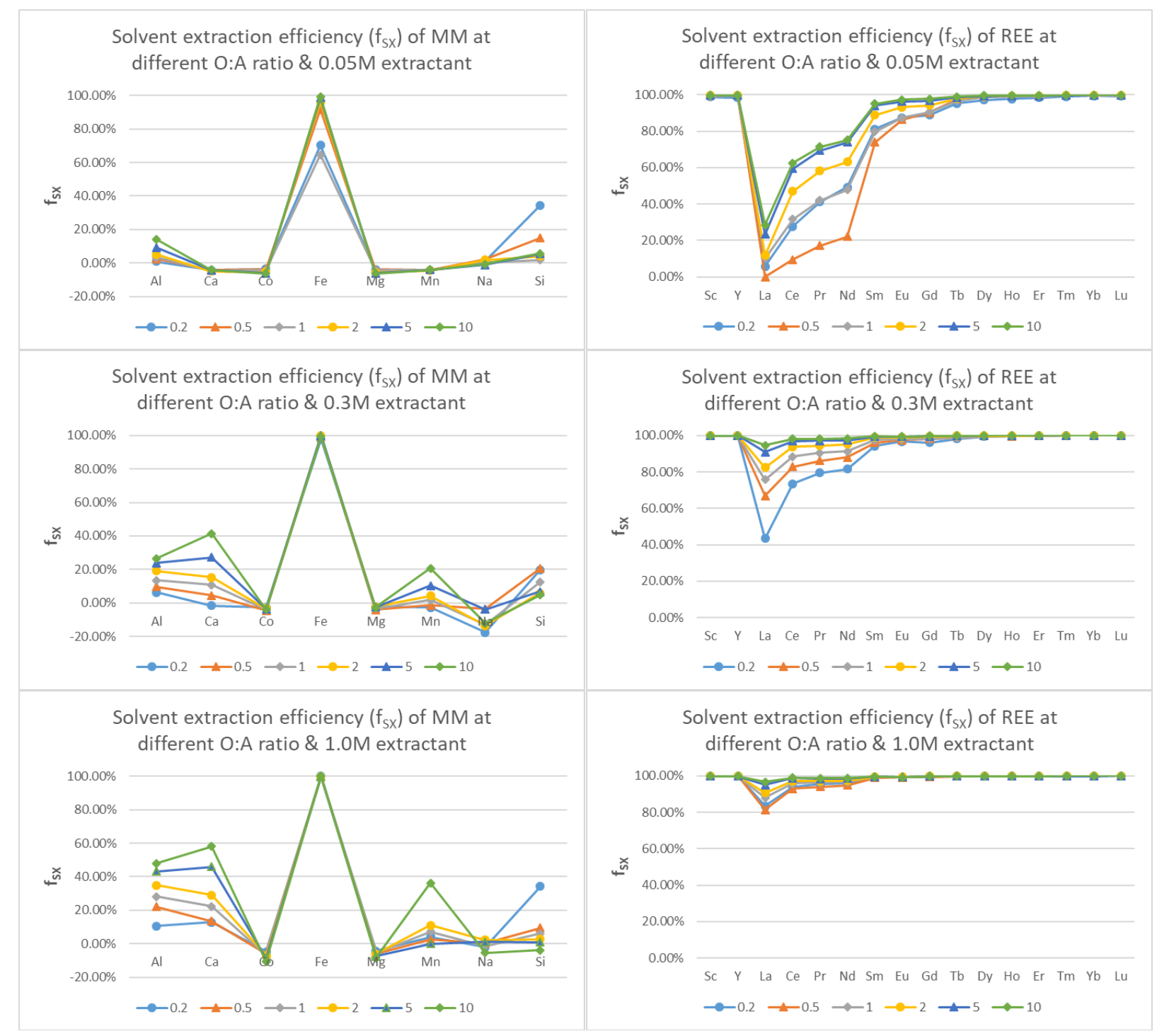

Figure 4.17 Extraction efficiency of individual elements- OM PLS 3.

HREE and LREE distribution in these processes is shown in Figure 4.18. HREE percentages in raffinate were almost 0 . HREE may be separately extracted from LREE at an O:A ratio less than 1 at an extractant concentration of $0.05 \mathrm{M}$. TREE extraction was high enough at an extractant concentration of less than 0.3 M. 

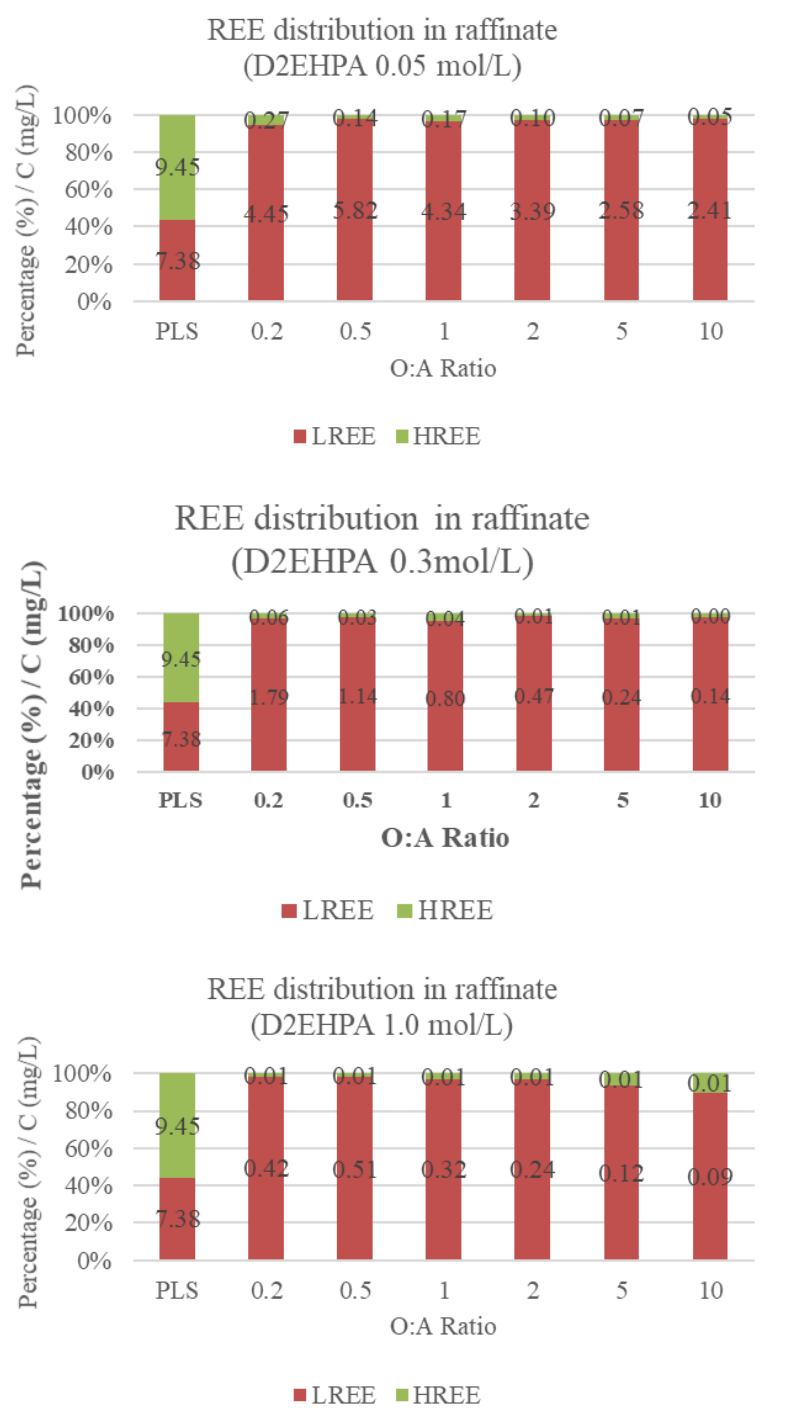
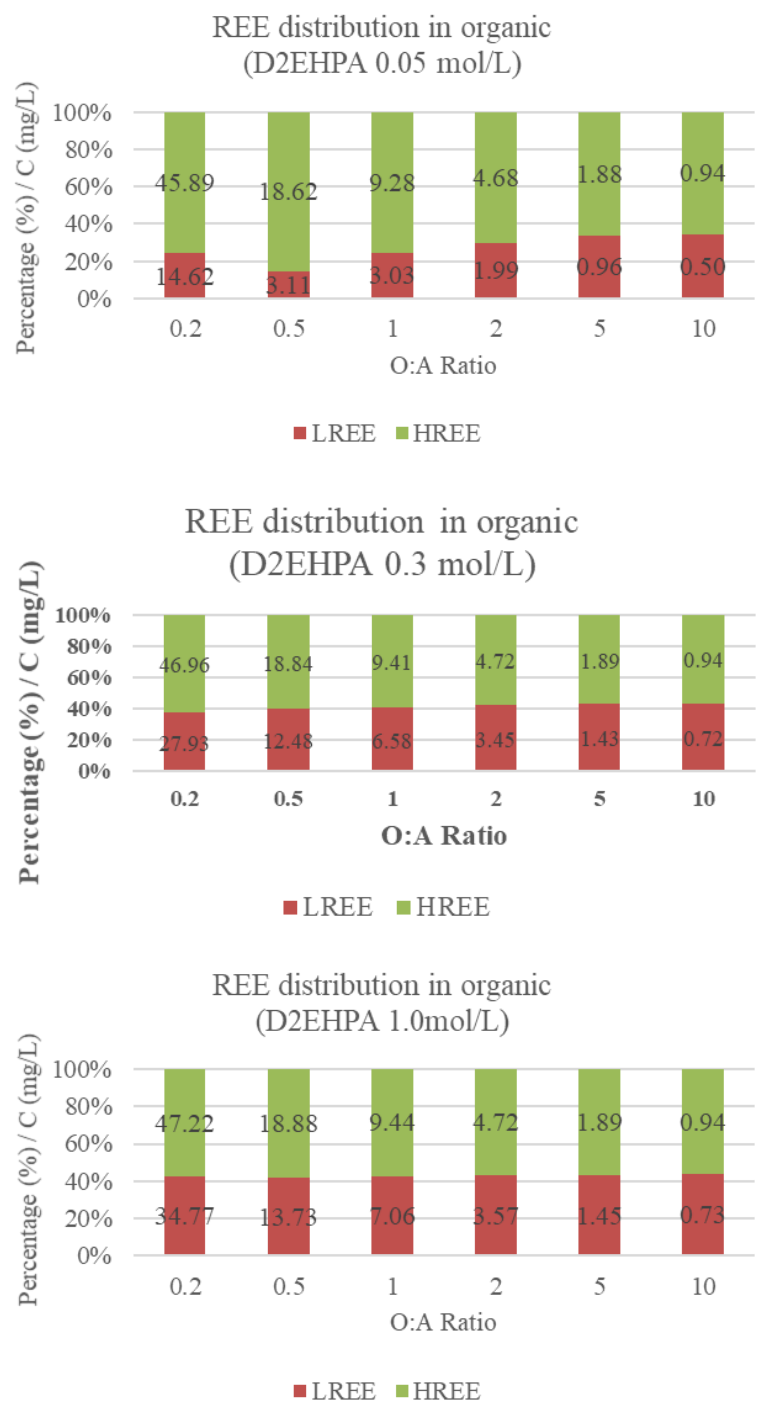

Figure 4.18 Heavy REE and light REE distribution- OM PLS 3.

McCabe Thiele diagrams of TREE, HREE and LREE in these processes are plotted in Figure 4.19 for extractant concentration of $0.05 \mathrm{M}$. TREE extraction efficiencies were relatively low (high C[TREE] in raffinate) at an extractant concentration of $0.05 \mathrm{M}$. Three steps can extract most TREE at intended O:A ratio of 1/4.2. Two steps can extract most HREE at intended O:A ratio of 1/4.7. LREE extraction was low and it can't be analyzed by McCabe Thiele diagram. 


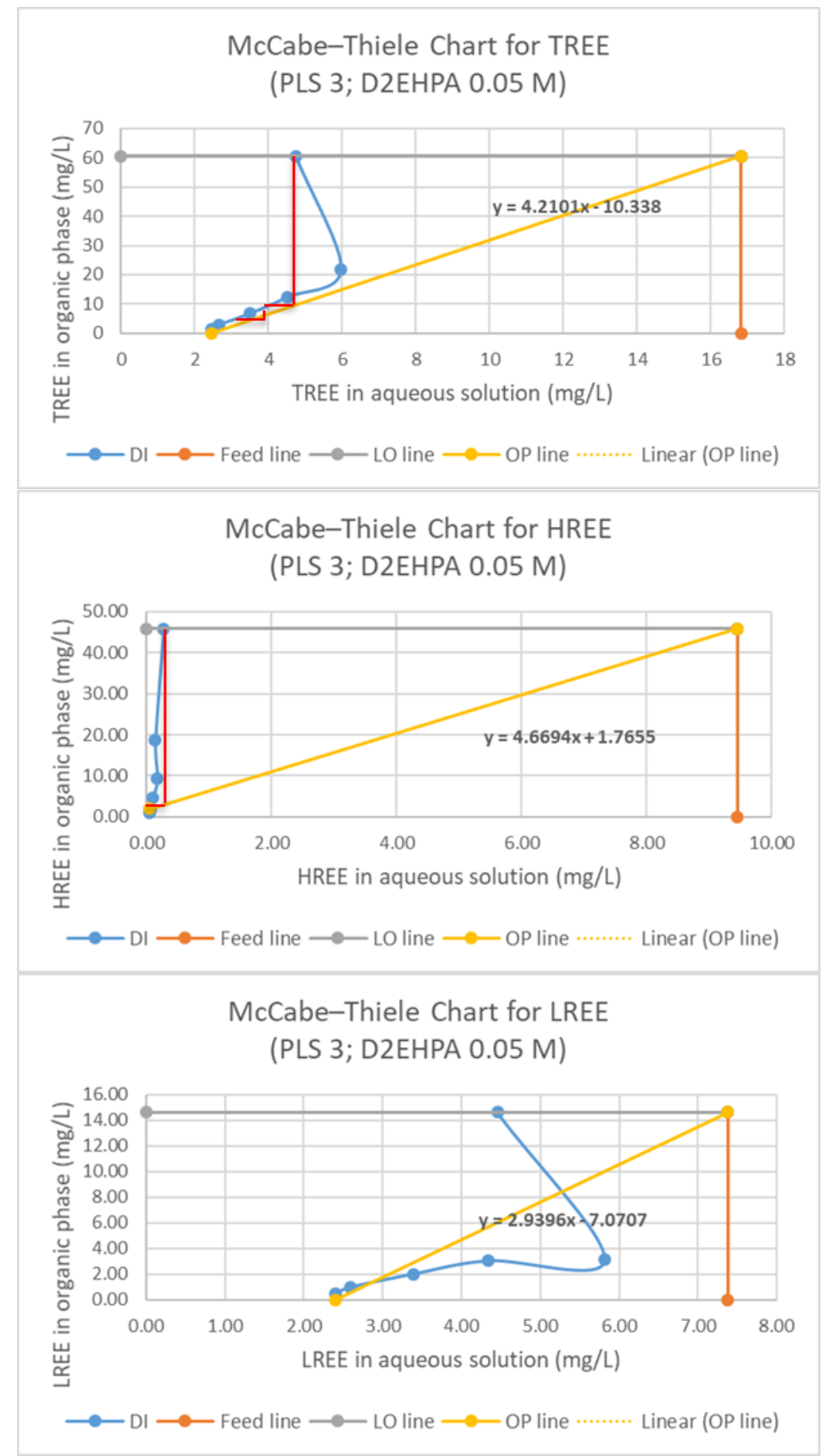

Figure 4.19 McCabe Thiele diagrams of TREE, HREE and LREE- OM PLS 3- 0.05 M.

McCabe Thiele diagrams of TREE, HREE and LREE in these processes are plotted in Figure 4.20 at extractant concentration of $0.3 \mathrm{M}$. TREE extraction efficiencies were high (very low C[TREE] in raffinate) at an 
extractant concentration of $0.3 \mathrm{M}$. Three steps can extract most TREE and LREE at intended O:A ratio of 1/4. One step can extract most HREE at intended O:A ratio of 1/5.

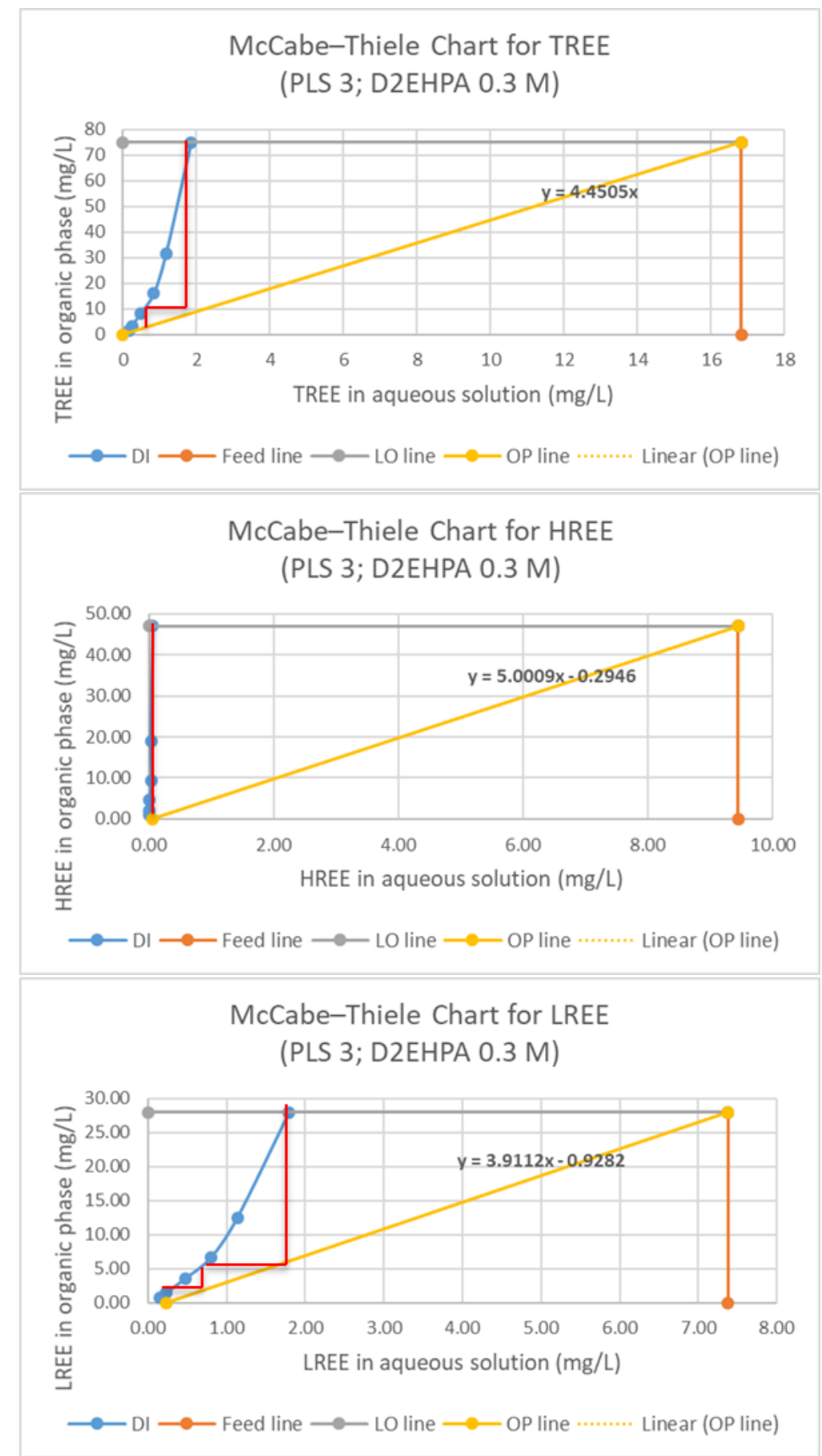

Figure 4.20 McCabe Thiele diagrams of TREE, HREE and LREE- OM PLS 3- 0.3 M. 
McCabe Thiele diagrams of TREE, HREE and LREE in these processes for extractant concentration of $1.0 \mathrm{M}$ are plotted in Figure 4.21. TREE extraction efficiencies were very high (very low C[TREE] in raffinate) at an extractant concentration of 1.0 M. One step can extract almost all HREE at intended O:A ratio of 1/4.8. Two steps can extract most TREE and LREE at intended O:A ratio about 1/5 and 1/4.8.

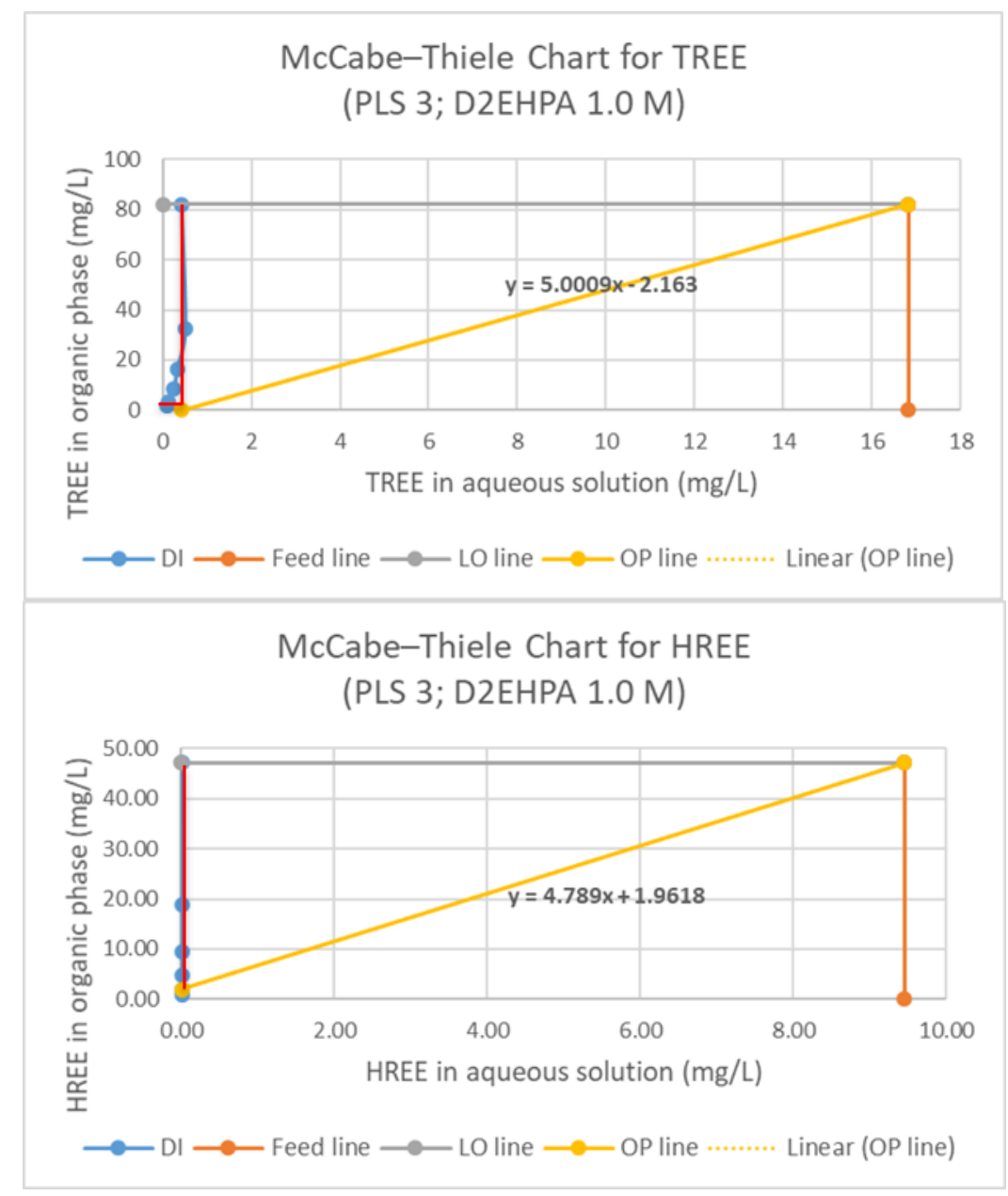




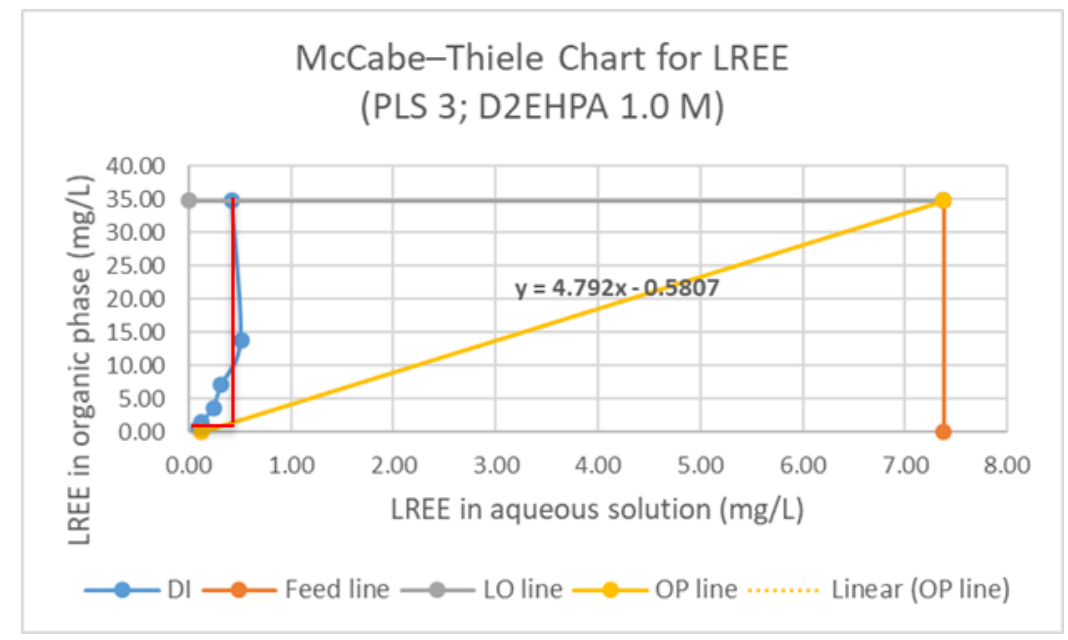

Figure 4.21 McCabe Thiele diagrams of TREE, HREE and LREE- OM PLS 3- 1.0 M.

\subsubsection{SX McCabe-Thiele Exploratory Test-DLM-PLS 2.5}

Bench-scale solvent extraction was also conducted on a leaching solution of $\mathrm{pH} 2.5$ from DLM site sludge (Table 4-4). Since TMM after SX were higher than TMM before SX, the extraction efficiency of total major metal ions (TMM) can be estimated as very low. Extraction efficiencies of critical rare earth ions (CREE: $\mathrm{Nd}, \mathrm{Eu}, \mathrm{Y}, \mathrm{Tb}$ and $\mathrm{Dy}$ ), heavy rare earth ions (HREE: Sc, Gd, Ho, Er, Tm, Yb and Lu), and light rare earth ions (LREE: La, Ce, Pr and Sm) are shown in Figure 4.22. Extraction efficiencies of HREE were higher than those of CREE and much higher than those of LREE. HREE and CREE selective extraction from LREE was appropriate at an A:O ratio 2 for C(D2EHPA) less than $0.3 \mathrm{M}$, but there was no selectivity between them at C(D2EHPA) $1.0 \mathrm{M}$.

Table 4-4 Parameters and pH results of solvent extraction exploratory test of DLM PLS 2.5

\begin{tabular}{|c|c|c|c|c|c|c|c|c|}
\hline \multirow[t]{2}{*}{ Sample Name } & $\mathbf{F}$ & C & \multirow[t]{2}{*}{ A:O Ratio } & \multirow{2}{*}{$\frac{\mathrm{O}}{\mathrm{ml}}$} & \multirow{2}{*}{$\begin{array}{l}\text { A } \\
\mathrm{ml}\end{array}$} & \multirow{2}{*}{$\begin{array}{l}\text { TV } \\
\mathrm{ml}\end{array}$} & \multirow{2}{*}{$\begin{array}{c}\text { D } \\
\mathrm{pH}, \\
\text { before }\end{array}$} & \multirow{2}{*}{$\begin{array}{c}\mathbf{E} \\
\mathrm{pH}, \\
\text { after }\end{array}$} \\
\hline & $\begin{array}{l}\mathrm{PLS} \\
\mathrm{pH}\end{array}$ & $\mathrm{mol} / \mathrm{L}$ & & & & & & \\
\hline DLM-SX-pH2-0.05M-1:5 & 2.0 & 0.05 & $5: 1$ & 36.67 & 183.33 & 220.00 & $\underline{2.5}$ & $\underline{1.97}$ \\
\hline DLM-SX-pH2-0.05M-1:2 & 2.0 & 0.05 & $2: 1$ & 73.33 & 146.67 & 220.00 & $\underline{2.5}$ & $\underline{1.56}$ \\
\hline DLM-SX-pH2-0.05M-1:1 & 2.0 & 0.05 & $1: 1$ & 110.00 & 110.00 & 220.00 & $\underline{2.5}$ & $\underline{1.36}$ \\
\hline DLM-SX-pH2-0.05M-2:1 & 2.0 & 0.05 & $1: 2$ & 146.67 & 73.33 & 220.00 & $\underline{2.5}$ & $\underline{1.21}$ \\
\hline DLM-SX-pH2-0.05M-5:1 & 2.0 & 0.05 & 1:5 & 183.33 & 36.67 & 220.00 & $\underline{2.5}$ & $\underline{1.01}$ \\
\hline $\begin{array}{c}\text { DLM-SX-pH2-0.05M- } \\
10: 1\end{array}$ & 2.0 & 0.05 & 1:10 & 200.00 & 20.00 & 220.00 & $\underline{2.5}$ & $\underline{0.83}$ \\
\hline
\end{tabular}




\begin{tabular}{lllllllll}
\hline DLM-SX-pH2-0.3M-1:5 & 2.0 & 0.30 & $5: 1$ & 36.67 & 183.33 & 220.00 & $\underline{2.5}$ & $\underline{1.25}$ \\
DLM-SX-pH2-0.3M-1:2 & 2.0 & 0.30 & $2: 1$ & 73.33 & 146.67 & 220.00 & $\underline{2.5}$ & $\underline{0.96}$ \\
DLM-SX-pH2-0.3M-1:1 & 2.0 & 0.30 & $1: 1$ & 110.00 & 110.00 & 220.00 & $\underline{2.5}$ & $\underline{0.84}$ \\
DLM-SX-pH2-0.3M-2:1 & 2.0 & 0.30 & $1: 2$ & 146.67 & 73.33 & 220.00 & $\underline{2.5}$ & $\underline{0.73}$ \\
DLM-SX-pH2-0.3M-5:1 & 2.0 & 0.30 & $1: 5$ & 183.33 & 36.67 & 220.00 & $\underline{2.5}$ & $\underline{0.58}$ \\
DLM-SX-pH2-0.3M-10:1 & 2.0 & 0.30 & $1: 10$ & 200.00 & 20.00 & 220.00 & $\underline{2.5}$ & $\underline{0.43}$ \\
\hline DLM-SX-pH2-1.0M-1:5 & 2.0 & 1.00 & $5: 1$ & 36.67 & 183.33 & 220.00 & $\underline{2.5}$ & $\underline{0.84}$ \\
DLM-SX-pH2-1.0M-1:2 & 2.0 & 1.00 & $2: 1$ & 73.33 & 146.67 & 220.00 & $\underline{2.5}$ & $\underline{0.63}$ \\
DLM-SX-pH2-1.0M-1:1 & 2.0 & 1.00 & $1: 1$ & 110.00 & 110.00 & 220.00 & $\underline{2.5}$ & $\underline{0.54}$ \\
DLM-SX-pH2-1.0M-2:1 & 2.0 & 1.00 & $1: 2$ & 146.67 & 73.33 & 220.00 & $\underline{2.5}$ & $\underline{0.46}$ \\
DLM-SX-pH2-1.0M-5:1 & 2.0 & 1.00 & $1: 5$ & 183.33 & 36.67 & 220.00 & $\underline{2.5}$ & $\underline{0.39}$ \\
DLM-SX-pH2-1.0M-10:1 & 2.0 & 1.00 & $1: 10$ & 200.00 & 20.00 & 220.00 & $\underline{2.5}$ & $\underline{0.30}$ \\
\hline
\end{tabular}

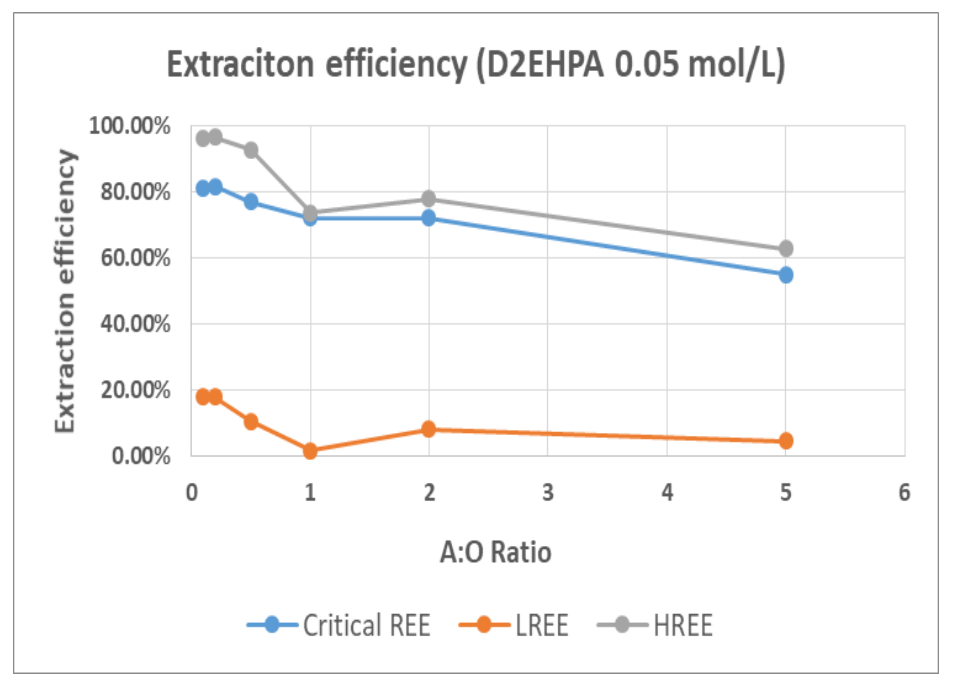



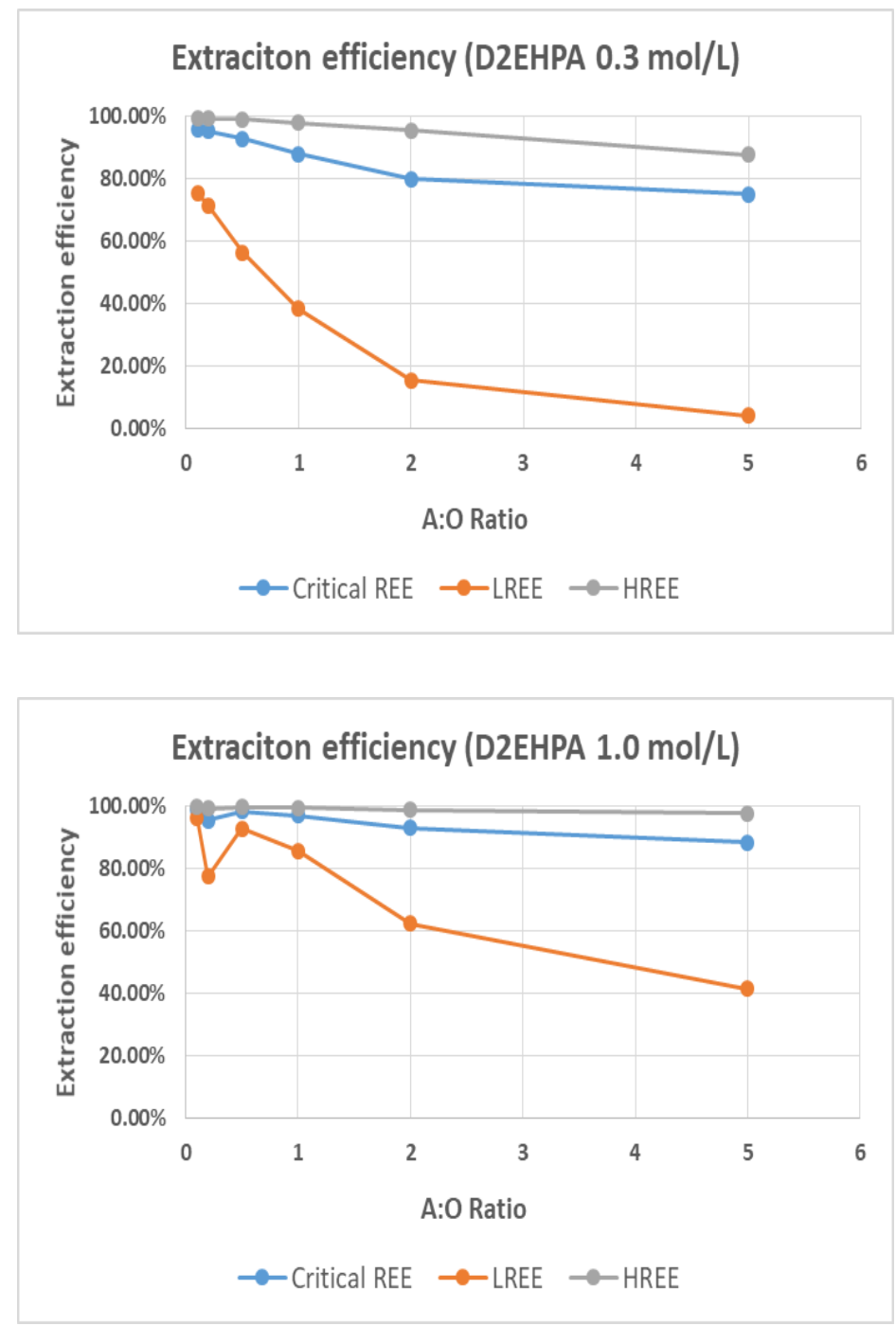

Figure 4.22 Extraction efficiency of CREE, HREE and LREE- DLM PLS 2.5.

CREE, HREE, and LREE distribution in these processes are shown in Figure 4.23. The HREE percentages in the organic phase were much higher than those in raffinate. The total of HREE and CREE may be separately extracted from LREE at an extractant concentration of less than $0.3 \mathrm{M}$ by using a high A:O ratio. When the extractant concentration was too high (1.0 M), the LREE percentages in organic phase were also high and could not be separately extracted. 

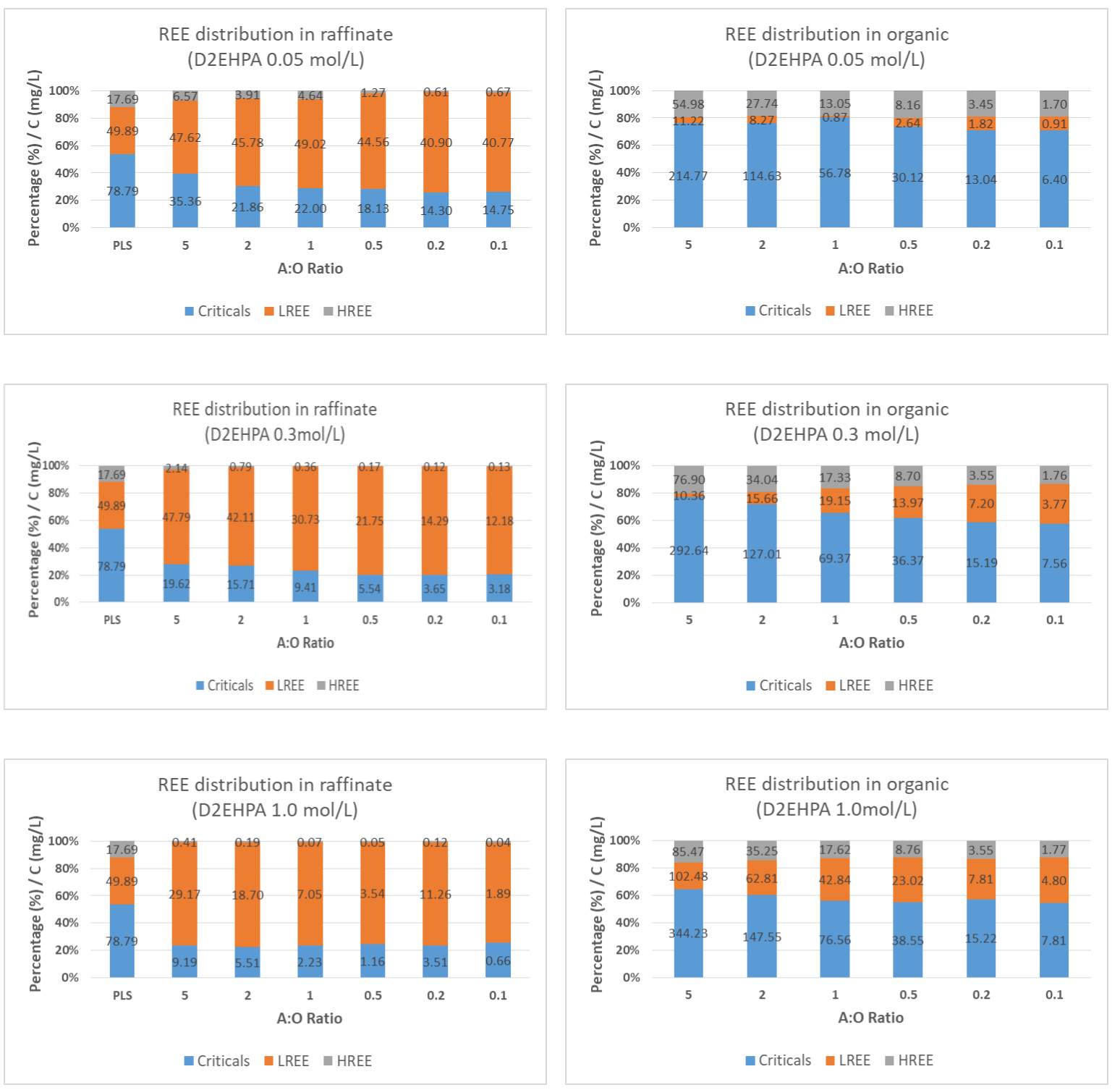

Figure 4.23 Critical REE, heavy REE and light REE distribution- DLM PLS 2.5.

McCabe Thiele diagrams of TREE in these processes were plotted (see Figure 4.24). The concentration of TREE in raffinate was high at an extractant concentration of $0.05 \mathrm{M}$. Two steps can extract $65 \%$ TREE at an intended A:O ratio of 3 . The concentration of TREE in raffinate was relatively lower at an extractant concentration of $0.3 \mathrm{M}$. Four steps can extract $85 \%$ TREE at an intended A:O ratio of 3 . The concentration of TREE in raffinate was low at an extractant concentration of $1.0 \mathrm{M}$. Two steps can extract 95\% TREE at an intended A:O ratio of 3.6. 


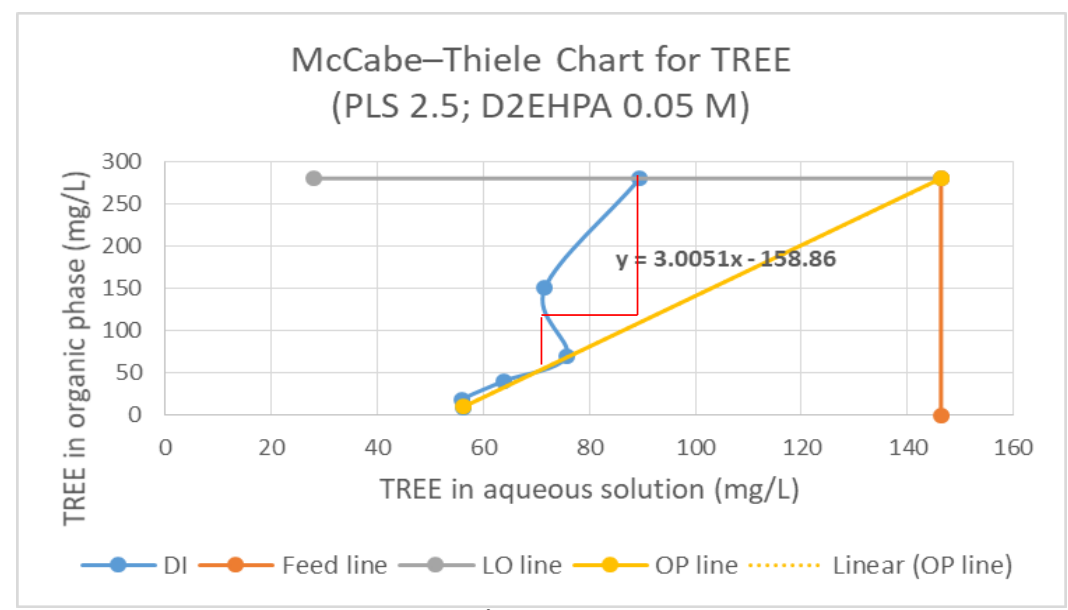

$\mathrm{A}: \mathrm{O}=3, \mathrm{C}(\mathrm{HREE}) \sim 50 \mathrm{mg} / \mathrm{L}$, two steps.

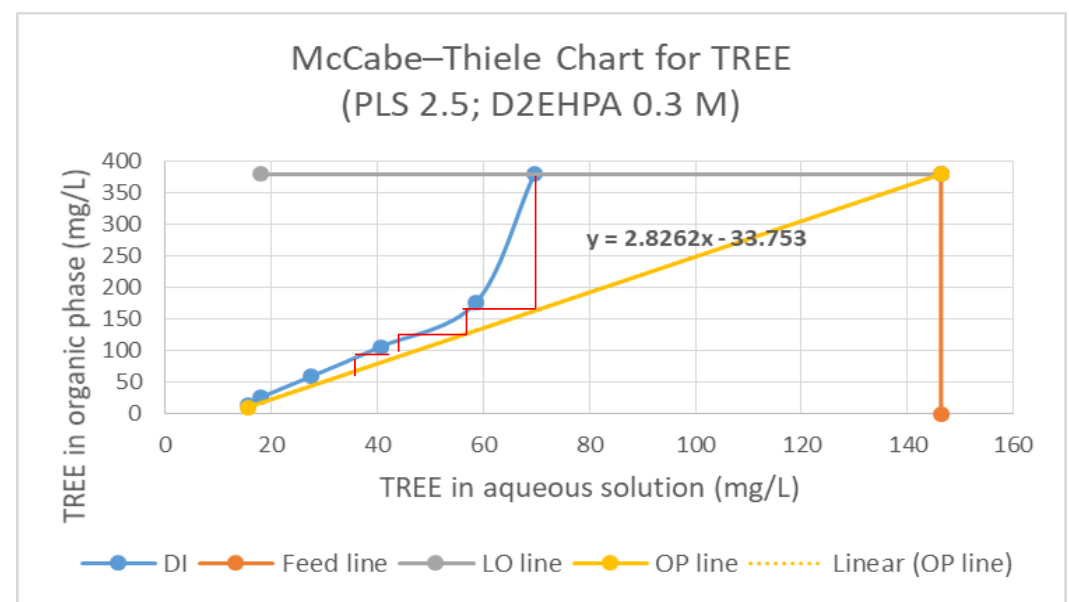

$\mathrm{A}: \mathrm{O}=3, \mathrm{C}(\mathrm{HREE}) \sim 20 \mathrm{mg} / \mathrm{L}$, four steps.

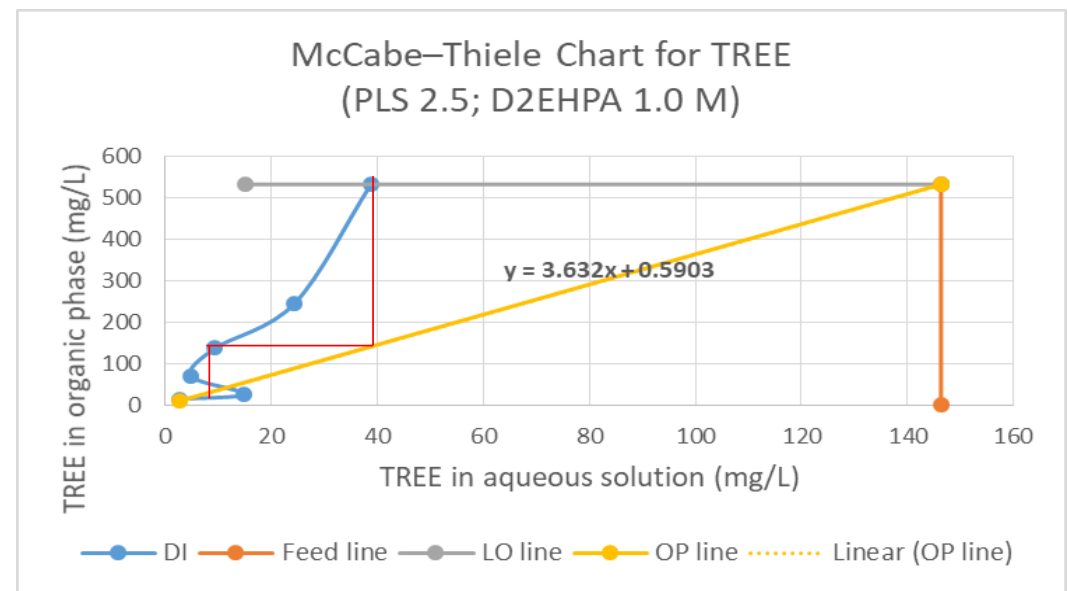

$\mathrm{A}: \mathrm{O}=3.6, \mathrm{C}(\mathrm{HREE}) \sim 0 \mathrm{mg} / \mathrm{L}$, two steps.

Figure 4.24 McCabe Thiele diagram of TREE- DLM PLS 2.5. 
Since most HREE were extracted in these processes, McCabe Thiele diagrams of HREE were also plotted (Figure 4.25). Concentration of HREE in raffinate was low at an extractant concentration of $0.05 \mathrm{M}$. Three steps can extract $95 \%$ HREE at an intended A:O ratio of 3. Concentration of HREE in raffinate was very low at an extractant concentration of $0.3 \mathrm{M}$. Two steps can extract 99\% HREE at an intended A:O ratio of 4.3. Concentration of HREE in raffinate was extremely low at an extractant concentration of $1.0 \mathrm{M}$. One step can extract $99 \%$ HREE at an intended A:O ratio of 4.7 .

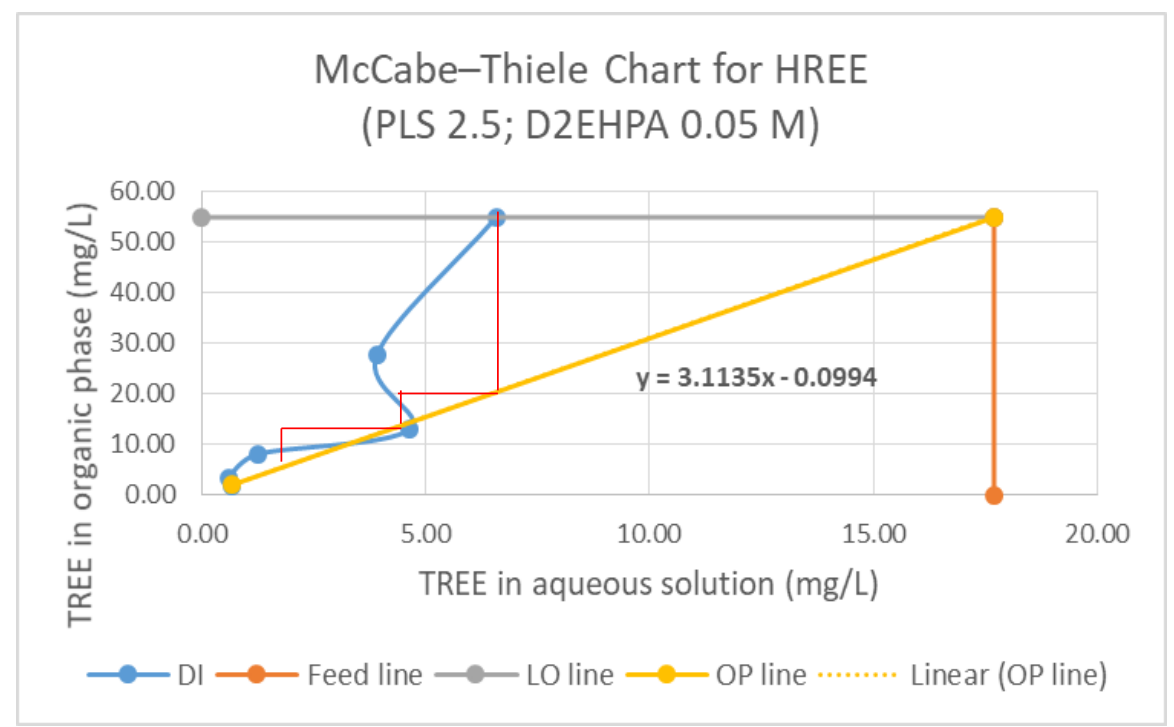

$\mathrm{A}: \mathrm{O}=3, \mathrm{C}(\mathrm{HREE}) \sim 0 \mathrm{mg} / \mathrm{L}$, three steps.

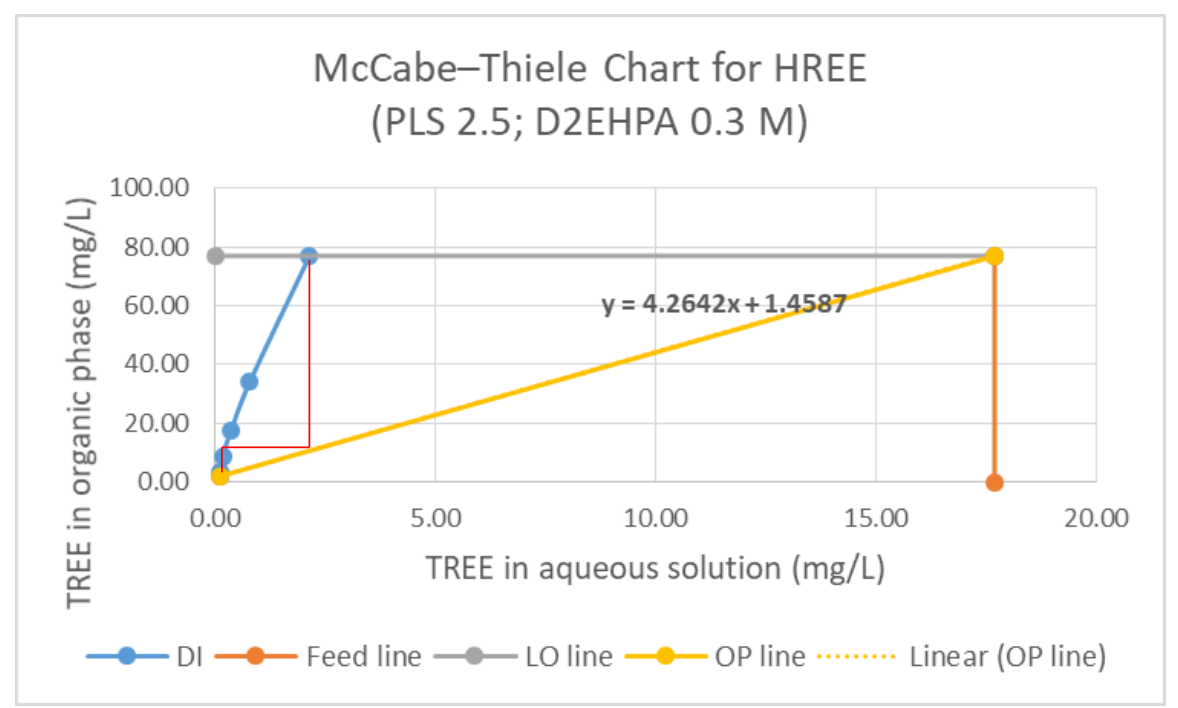

$\mathrm{A}: \mathrm{O}=4.3, \mathrm{C}(\mathrm{HREE}) \sim 0 \mathrm{mg} / \mathrm{L}$, two steps. 


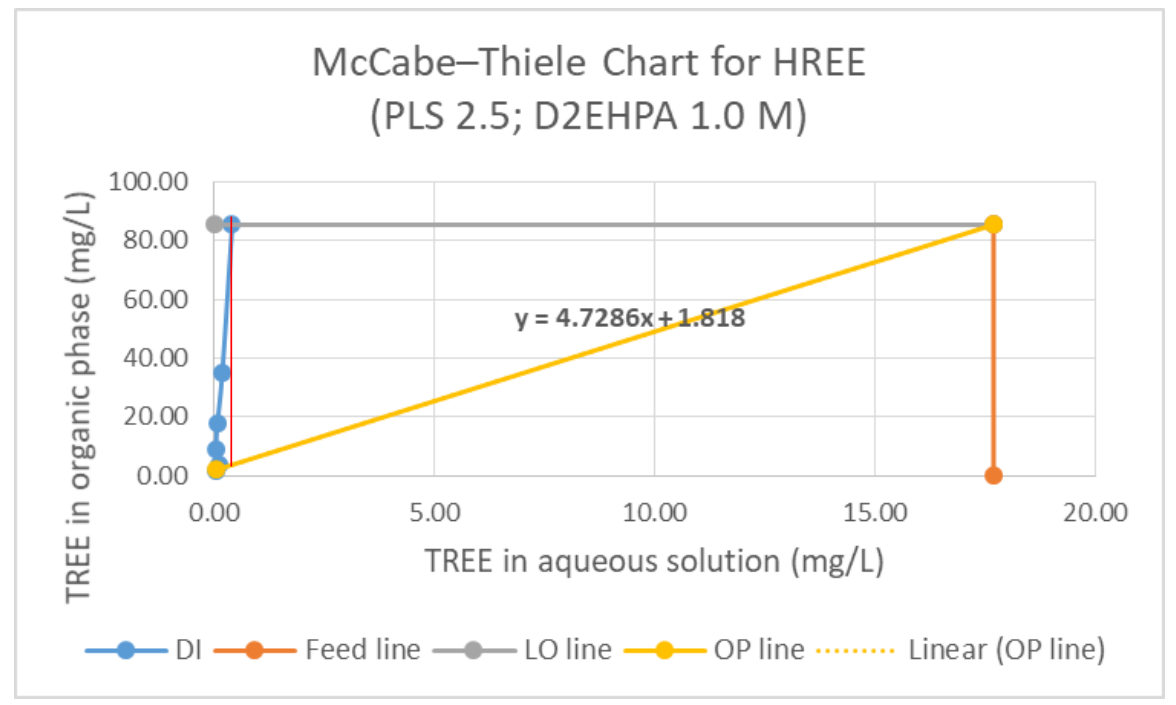

$\mathrm{A}: \mathrm{O}=4.7, \mathrm{C}(\mathrm{HREE}) \sim 0 \mathrm{mg} / \mathrm{L}$, one step.

Figure 4.25 McCabe Thiele diagram of HREE- DLM PLS 2.5

\subsubsection{SX McCabe-Thiele Exploratory Test-DLM-PLS 3.1}

In the last step of PLS optimization, add sodium hydroxide to produce PLS of higher $\mathrm{pH}$ in order to extract REE easily. After filtering, concentration of REE remained similar. Mass loss of TMM was $45.41 \%$ and mass loss of TREE was only $15.55 \%$.

After leaching AMD sludge to low $\mathrm{pH}(<1)$, sodium hydroxide was added to produce a PLS of higher $\mathrm{pH}$ in order to extract REE easily. After filtering, both concentration and mass of MM decreased. Mass loss of TMM was $45.41 \%$, but concentration of REE remained similar (Figure 4.26). Due to volume loss, mass loss of TREE was $15.55 \%$.
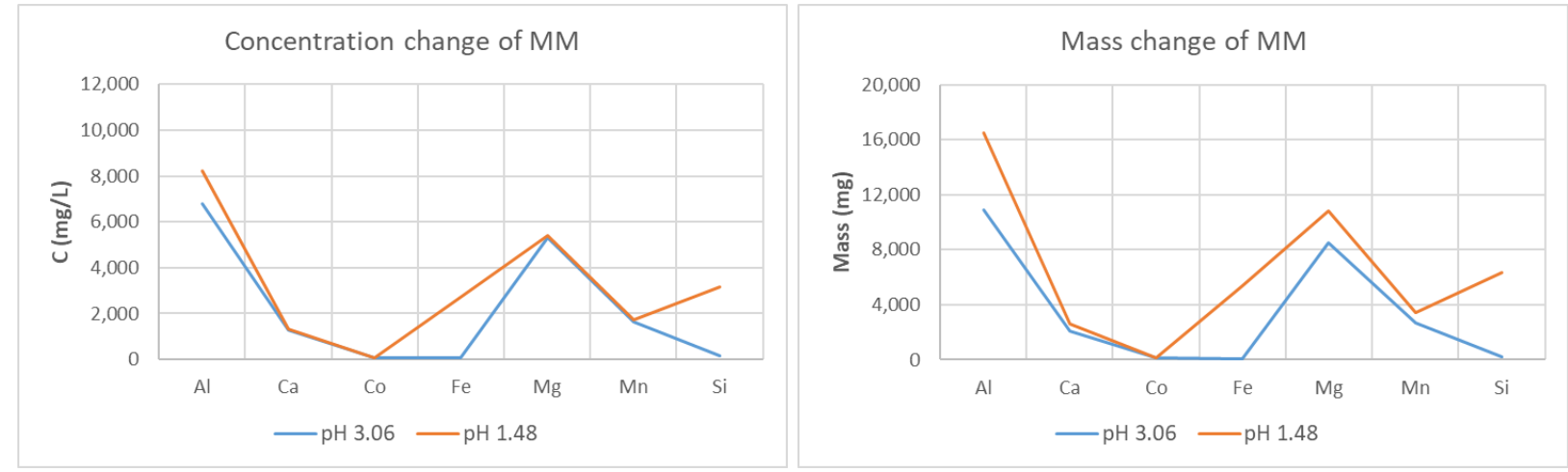

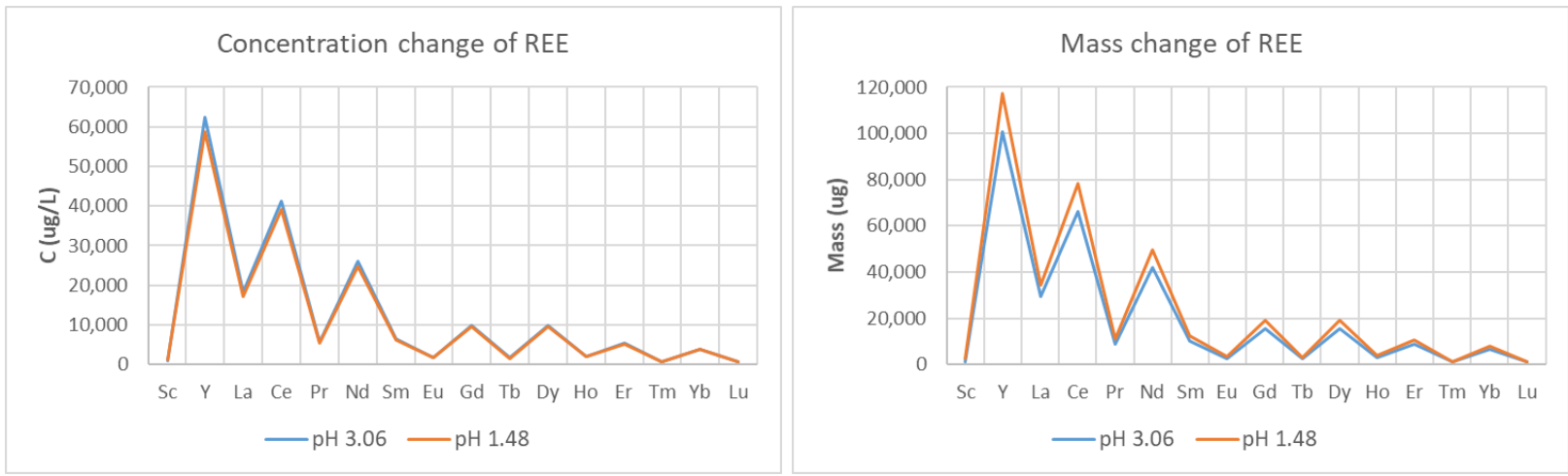

Figure 4.26 Concentration and mass change after pH adjustment to optimize DLM PLS.

Bench-scale solvent extraction was also conducted on optimized leaching solution of pH 3.1 from DLM site sludge (Table 4-5). Extraction efficiencies of total major metal ions, total rare earth ions, critical rare earth ions (CREE: Nd, Eu, Y, Tb and Dy), heavy rare earth ions (HREE: Sc, Gd, Ho, Er, Tm, Yb and Lu) and light rare earth ions (LREE: La, $\mathrm{Ce}, \mathrm{Pr}$ and $\mathrm{Sm}$ ) are shown in Figure 4.27. Extraction efficiency difference between TREE and TMM was significant for low A:O ratios. Extraction efficiencies of HREE were higher than those of CREE and much higher than those of LREE. HREE and CREE selective extraction from LREE was appropriate at an A:O ratio of 0.5 for extractant concentration of $0.05 \mathrm{M}$.

Table 4-5 Parameters and pH results of solvent extraction exploratory test of DLM PLS 3.1.

\begin{tabular}{|c|c|c|c|c|c|c|c|c|}
\hline \multirow[t]{2}{*}{ Sample Name } & $\mathbf{F}$ & C & \multirow[t]{2}{*}{ A:O Ratio } & 0 & A & TV & D & $\bar{E}$ \\
\hline & PLS pH & $\mathrm{mol} / \mathrm{L}$ & & $\mathrm{ml}$ & $\mathrm{ml}$ & $\mathrm{ml}$ & $\begin{array}{c}\mathrm{pH}, \\
\text { before }\end{array}$ & $\begin{array}{l}\mathrm{pH}, \\
\text { after }\end{array}$ \\
\hline DLM-SX-pH3-0.05M-1:5 & 3.3 & 0.05 & $5: 1$ & 18.33 & 91.67 & 110.00 & $\underline{3.06}$ & $\underline{3.05}$ \\
\hline DLM-SX-pH3-0.05M-1:2 & 3.3 & 0.05 & $2: 1$ & 36.67 & 73.33 & 110.00 & $\underline{3.06}$ & $\underline{3.01}$ \\
\hline DLM-SX-pH3-0.05M-1:1 & 3.3 & 0.05 & $1: 1$ & 110.00 & 110.00 & 220.00 & $\underline{3.06}$ & $\underline{2.94}$ \\
\hline DLM-SX-pH3-0.05M-2:1 & 3.3 & 0.05 & $1: 2$ & 146.67 & 73.33 & 220.00 & $\underline{3.06}$ & $\underline{2.96}$ \\
\hline DLM-SX-pH3-0.05M-5:1 & 3.3 & 0.05 & $1: 5$ & 183.33 & 36.67 & 220.00 & $\underline{3.06}$ & $\underline{2.54}$ \\
\hline DLM-SX-pH3-0.05M-10:1 & 3.3 & 0.05 & $1: 10$ & 200.00 & 20.00 & 220.00 & $\underline{3.06}$ & $\underline{1.62}$ \\
\hline
\end{tabular}



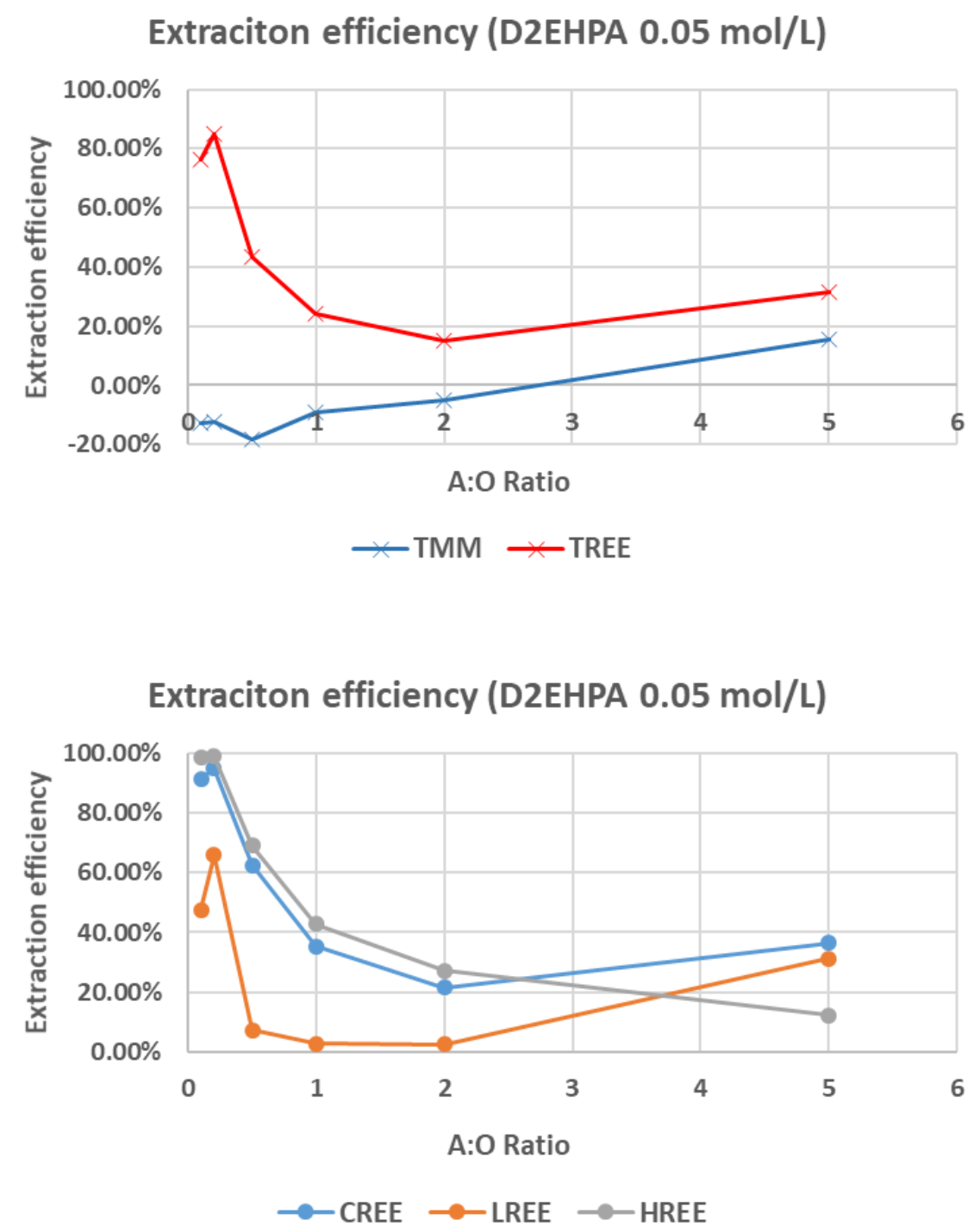

Figure 4.27 Extraction efficiency of TMM, TREE, CREE, HREE and LREE- DLM PLS 3.1.

CREE, HREE, and LREE distribution in these processes are shown in Figure 4.28. HREE percentages in organic phase are much higher than those in raffinate. Total of HREE and CREE may be separately extracted from LREE at an A:O ratio between 0.5 and 2.0 and at an extractant concentration of $0.05 \mathrm{M}$. 


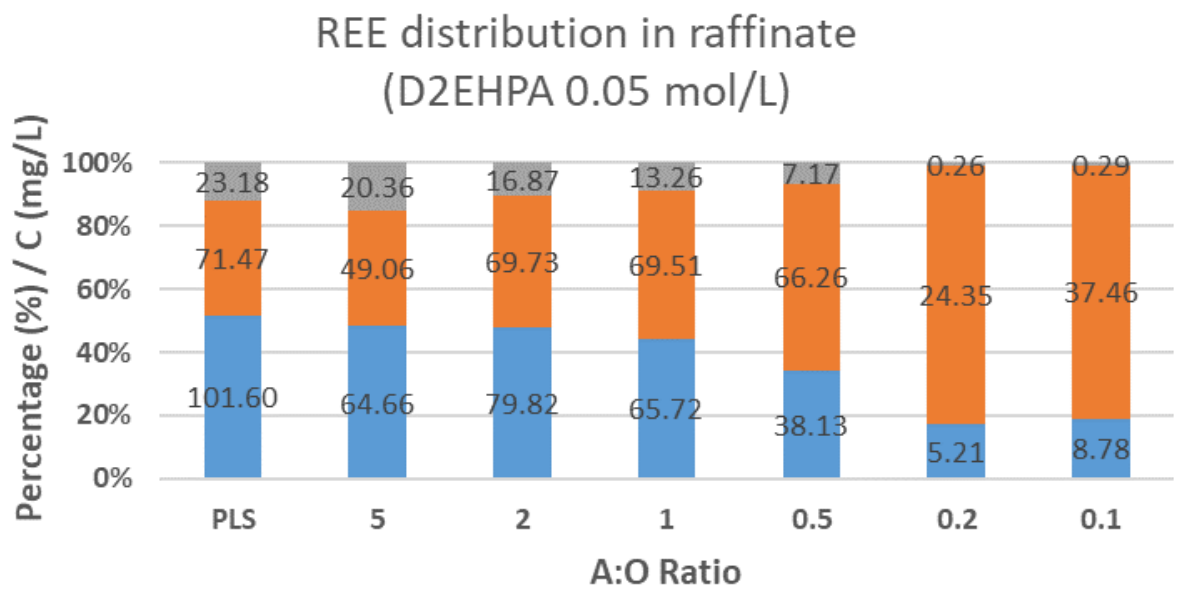

- Criticals a LREE $\quad$ HREE

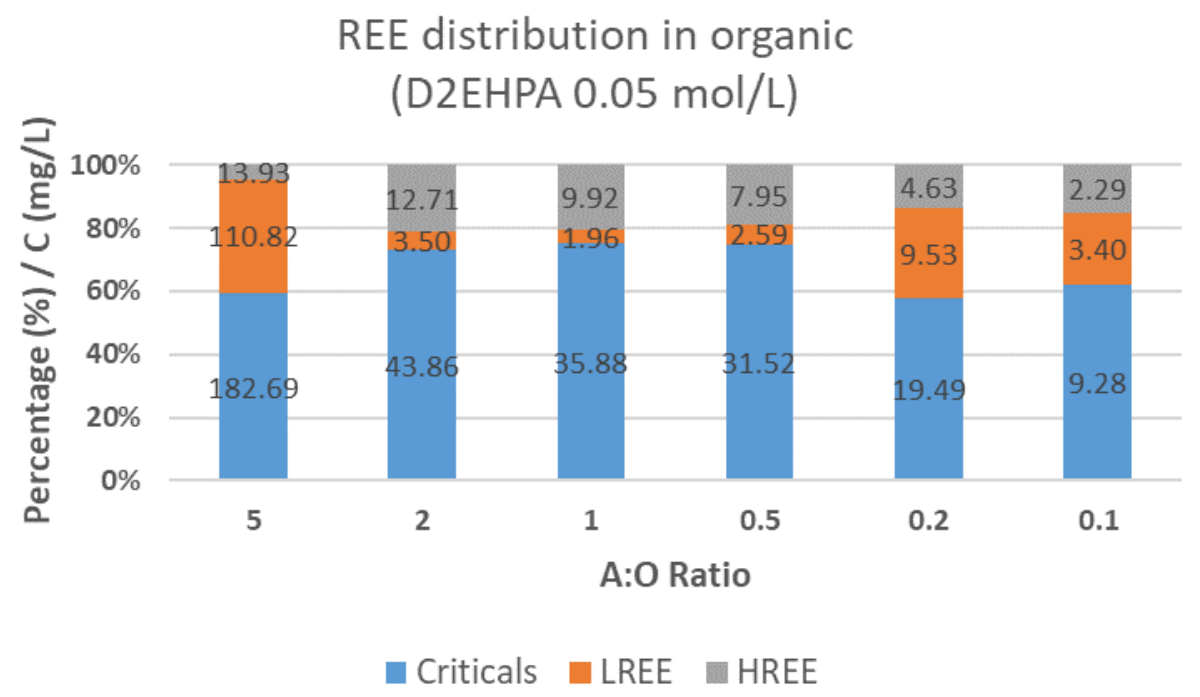

Figure 4.28 Critical REE, heavy REE and light REE distribution- DLM PLS 3.1.

McCabe Thiele diagram of TREE in these processes was plotted as Figure 4.29. Concentration of TREE in raffinate was high at extractant concentration of $0.05 \mathrm{M}$. The distribution curve of TREE was difficult to analyze by using McCabe Thiele method. 


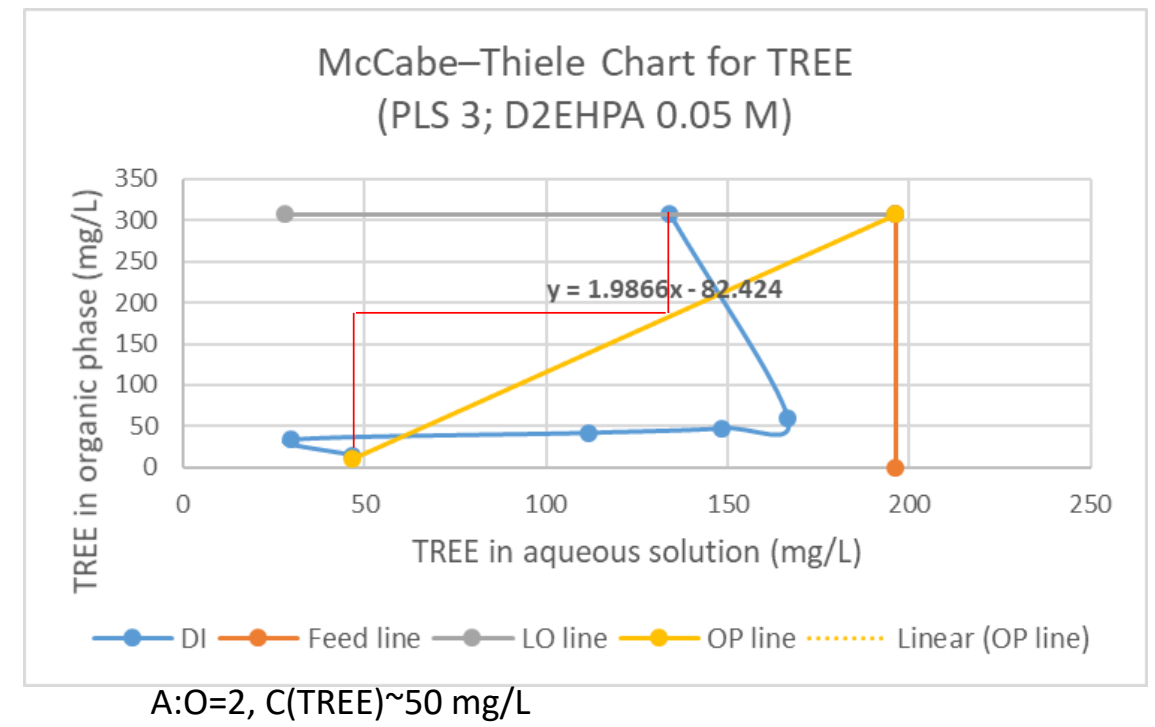

Figure 4.29 McCabe Thiele diagram of TREE- DLM PLS 3.1.

Since most HREE were extracted in these processes, McCabe Thiele diagram of HREE was also plotted (Figure 4.30). Six steps can extract 99\% HREE at intended A:O ratio of 0.5. If concentration of HREE in raffinate was acceptable at several milligrams per liter (less than $5 \mathrm{mg} / \mathrm{L}$ ), less steps will be required to extract HREE.

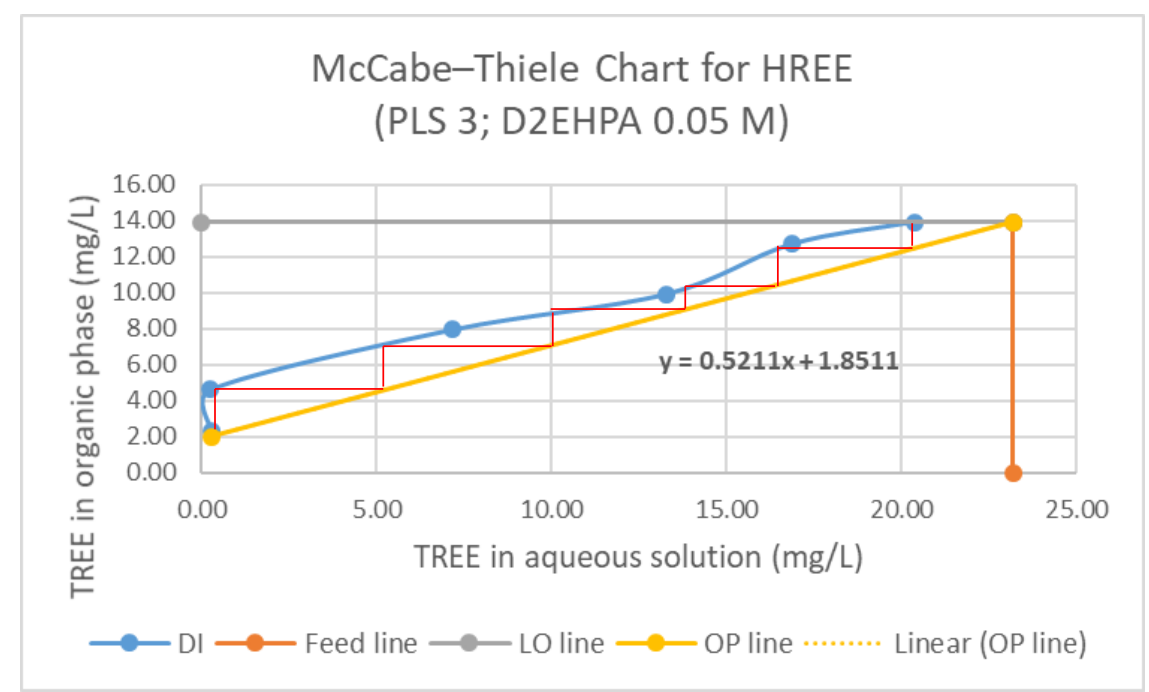

$\mathrm{A}: \mathrm{O}=0.52, \mathrm{C}(\mathrm{HREE}) \sim 0 \mathrm{mg} / \mathrm{L}$, six steps.

Figure 4.30 McCabe Thiele diagram of HREE- DLM PLS 3.1. 
In last report, solvent extraction was conducted at extractant concentration of $0.05 \mathrm{~mol} / \mathrm{L}$ on optimized leaching solution of $\mathrm{pH} 3$ from DLM site sludge. During this period, SX exploratory tests were performed on same solution at extractant concentration of $0.3 \mathrm{~mol} / \mathrm{L}$ and $1.0 \mathrm{~mol} / \mathrm{L}$.

Laboratory-scale solvent extraction was conducted on optimized leaching solution of $\mathrm{pH} 3$ from DLM site sludge. (Table 4-6) Extraction efficiencies of total major metal ions, total rare earth ions, critical rare earth ions (CREE: Nd, Eu, Y, Tb and Dy), heavy rare earth ions (HREE: Sc, Gd, Ho, Er, Tm, Yb and Lu) and light rare earth ions (LREE: La, Ce, Pr and Sm) were shown in Figure 4.31. Extraction efficiencies increase with decrease of A:O ratio. Extraction efficiency difference between TREE and TMM was significant. Some extraction efficiencies for TMM were negative due to measurement error on high concentrations of TMM. Extraction efficiencies of HREE were higher than those of CREE and much higher than those of LREE. HREE and CREE selective extraction from LREE was appropriate at A:O ratio 0.5 for C(D2EHPA) $0.3 \mathrm{~mol} / \mathrm{L}$. Extraction efficiencies for TREE were almost $100 \%$ at high extractant concentration of $1.0 \mathrm{~mol} / \mathrm{L}$.

Table 4-6 Parameters of solvent extraction exploratory test of DLM PLS 3.

\begin{tabular}{|c|c|c|c|c|c|c|c|c|}
\hline \multirow[t]{2}{*}{ Sample Name } & $F$ & C & \multirow{2}{*}{$\begin{array}{l}\text { O: A } \\
\text { Ratio }\end{array}$} & \multirow{2}{*}{$\begin{array}{c}\mathrm{O} \\
\mathrm{ml}\end{array}$} & \multirow{2}{*}{$\begin{array}{c}\text { A } \\
\mathrm{ml}\end{array}$} & \multirow{2}{*}{$\begin{array}{l}\text { TV } \\
\mathrm{ml}\end{array}$} & \multirow{2}{*}{$\begin{array}{c}\text { D } \\
\mathrm{pH}, \\
\text { before }\end{array}$} & \multirow{2}{*}{$\begin{array}{c}\mathbf{E} \\
\mathrm{pH}, \\
\text { after }\end{array}$} \\
\hline & $\begin{array}{l}\text { PLS } \\
\mathrm{pH}\end{array}$ & $\mathrm{mol} / \mathrm{L}$ & & & & & & \\
\hline DLM-SX-pH3-0.3M-5:1 & 3.3 & 0.30 & $5: 1$ & 18.33 & 91.67 & 110.00 & $\underline{3.06}$ & $\underline{2.99}$ \\
\hline DLM-SX-pH3-0.3M-2:1 & 3.3 & 0.30 & $2: 1$ & 36.67 & 73.33 & 110.00 & $\underline{3.06}$ & $\underline{2.85}$ \\
\hline DLM-SX-pH3-0.3M-1:1 & 3.3 & 0.30 & $1: 1$ & 110.00 & 110.00 & 220.00 & $\underline{3.06}$ & $\underline{2.06}$ \\
\hline DLM-SX-pH3-0.3M-1:2 & 3.3 & 0.30 & $1: 2$ & 146.67 & 73.33 & 220.00 & $\underline{3.06}$ & $\underline{1.4}$ \\
\hline DLM-SX-pH3-0.3M-1:5 & 3.3 & 0.30 & $1: 5$ & 183.33 & 36.67 & 220.00 & $\underline{3.06}$ & $\underline{0.84}$ \\
\hline DLM-SX-pH3-0.3M-1:10 & 3.3 & 0.30 & $1: 10$ & 200.00 & 20.00 & 220.00 & $\underline{3.06}$ & $\underline{0.64}$ \\
\hline DLM-SX-pH3-1.0M-5:1 & 3.3 & 1.00 & $5: 1$ & 18.33 & 91.67 & 110.00 & $\underline{3.06}$ & $\underline{2.85}$ \\
\hline DLM-SX-pH3-1.0M-2:1 & 3.3 & 1.00 & $2: 1$ & 36.67 & 73.33 & 110.00 & $\underline{3.06}$ & $\underline{1.65}$ \\
\hline DLM-SX-pH3-1.0M-1:1 & 3.3 & 1.00 & $1: 1$ & 110.00 & 110.00 & 220.00 & $\underline{3.06}$ & $\underline{0.92}$ \\
\hline DLM-SX-pH3-1.0M-1:2 & 3.3 & 1.00 & $1: 2$ & 146.67 & 73.33 & 220.00 & $\underline{3.06}$ & $\underline{0.62}$ \\
\hline DLM-SX-pH3-1.0M-1:5 & 3.3 & 1.00 & $1: 5$ & 183.33 & 36.67 & 220.00 & $\underline{3.06}$ & $\underline{0.47}$ \\
\hline DLM-SX-pH3-1.0M-1:10 & 3.3 & 1.00 & $1: 10$ & 200.00 & 20.00 & 220.00 & $\underline{3.06}$ & $\underline{0.43}$ \\
\hline
\end{tabular}


Extraciton efficiency (D2EHPA $0.3 \mathrm{~mol} / \mathrm{L}$ )

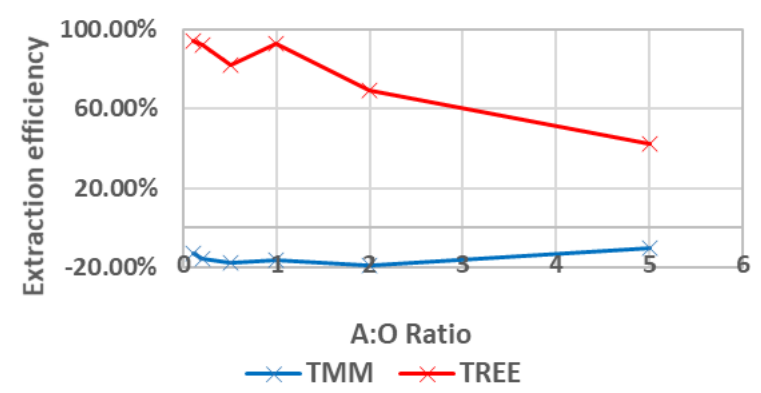

Extraction efficiency (D2EHPA $1.0 \mathrm{~mol} / \mathrm{L}$ )

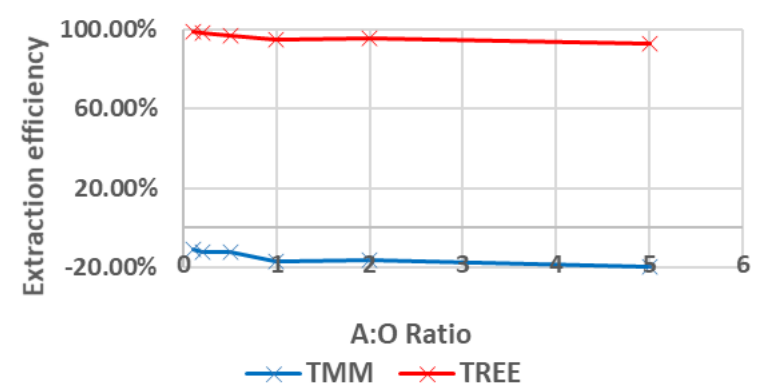

Extraciton efficiency (D2EHPA $0.3 \mathrm{~mol} / \mathrm{L}$ )

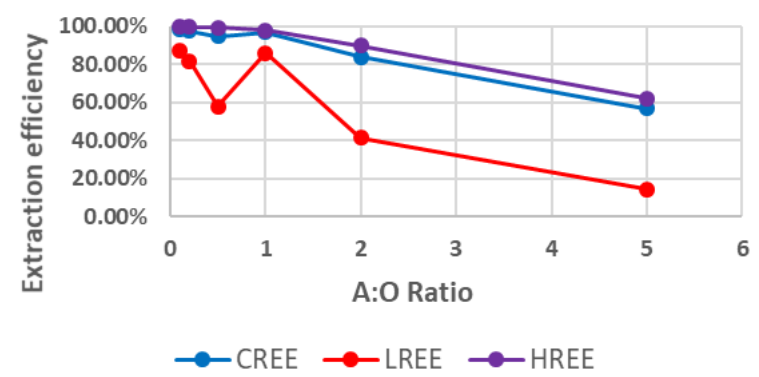

Extraciton efficiency (D2EHPA $1.0 \mathrm{~mol} / \mathrm{L}$ )

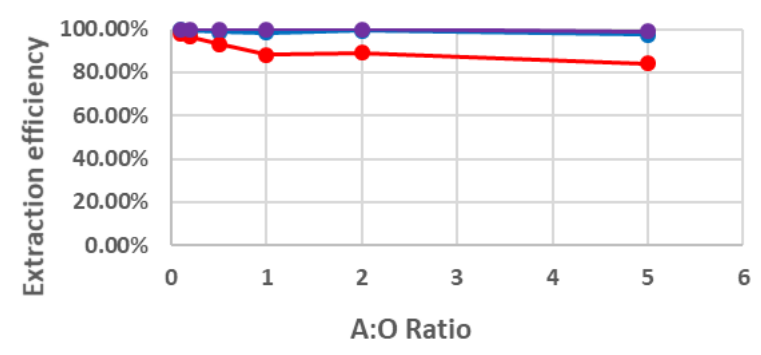

$\multimap$ CREE $\rightarrow$ LREE $\rightarrow$ HREE

Figure 4.31 Extraction efficiency of TMM, TREE, CREE, HREE and LREE- DLM PLS 3.

CREE, HREE and LREE distribution in these processes were shown in Figure 4.32. HREE percentages in raffinate were almost 0 . Percentages of HREE and CREE in organic phase were much higher than those in aqueous phase. REE concentration in organic phase was higher at higher A:O ratio. REE residue in raffinate was lower at lower A:O ratio. Total of HREE and CREE may be separately extracted from LREE at these two extractant concentrations.

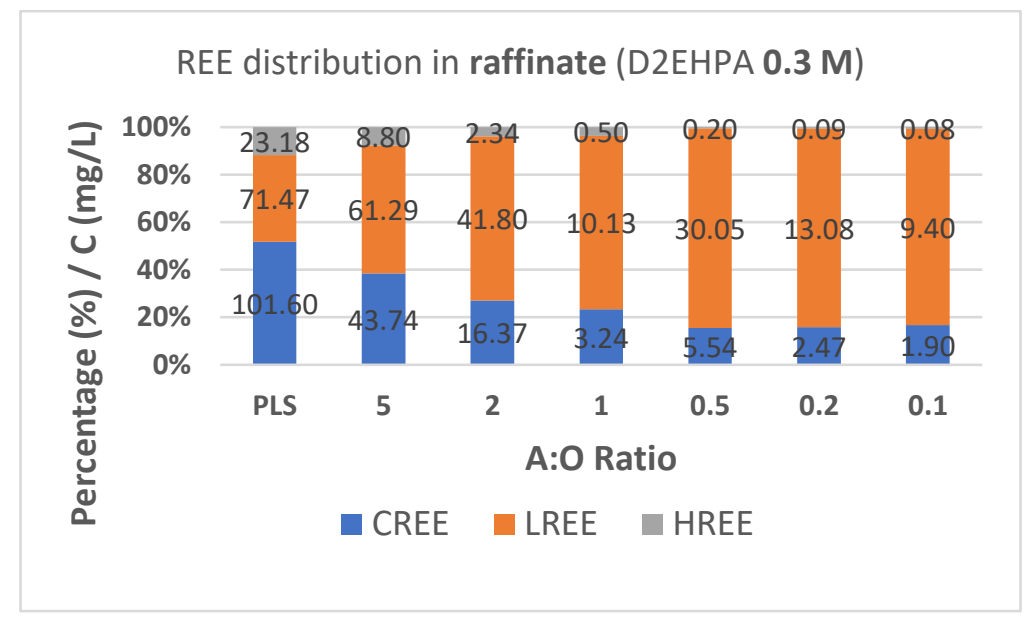



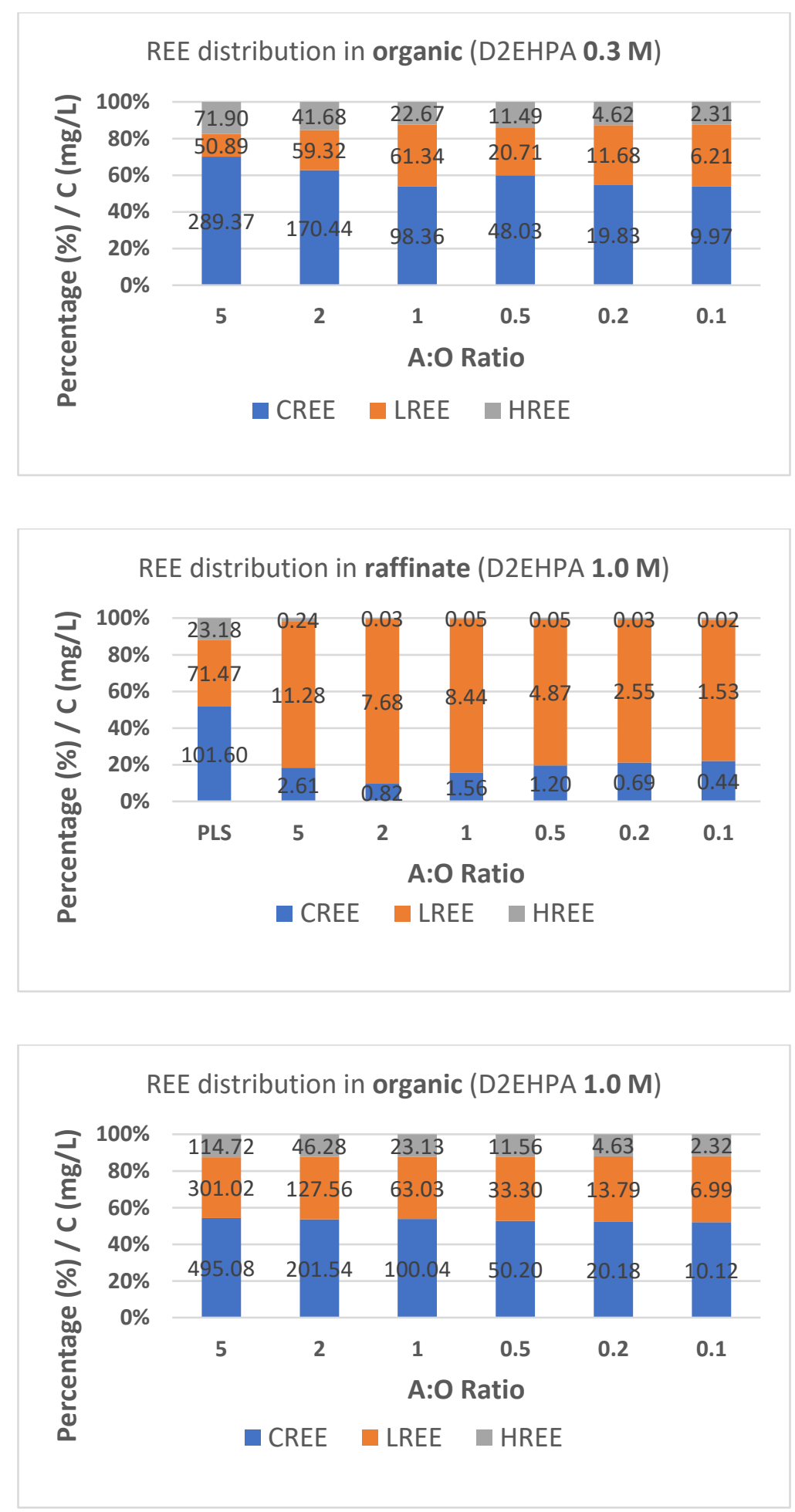

Figure 4.32 Critical REE, heavy REE and light REE distribution- DLM PLS 3.

McCabe Thiele diagrams of TREE, HREE and CREE in these processes were plotted as Figure 4.33 at extractant concentration of $0.3 \mathrm{M}$. Concentration of TREE in raffinate was low. Three steps can extract 
most TREE at intended A:O ratio of 2. Two steps can extract most HREE and CREE at intended A:O ratio of 3.

McCabe-Thiele Chart for TREE

(PLS 3; D2EHPA $0.3 \mathrm{M}$ )

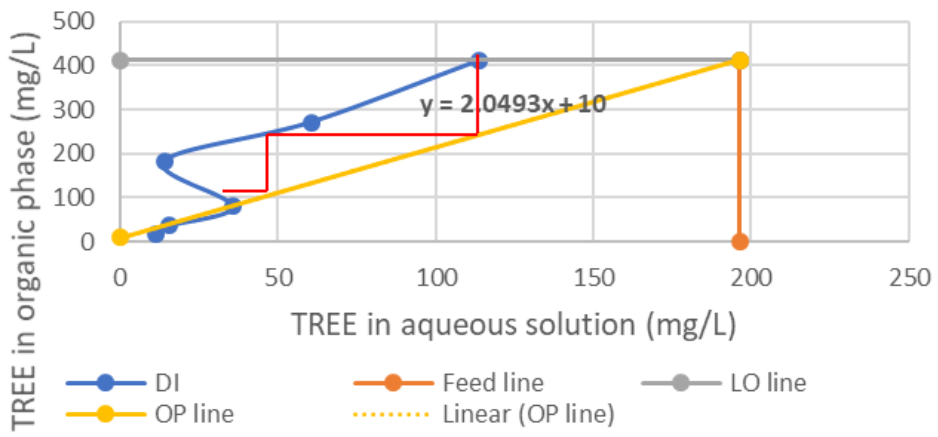

McCabe-Thiele Chart for HREE

(PLS 3; D2EHPA 0.3 M)

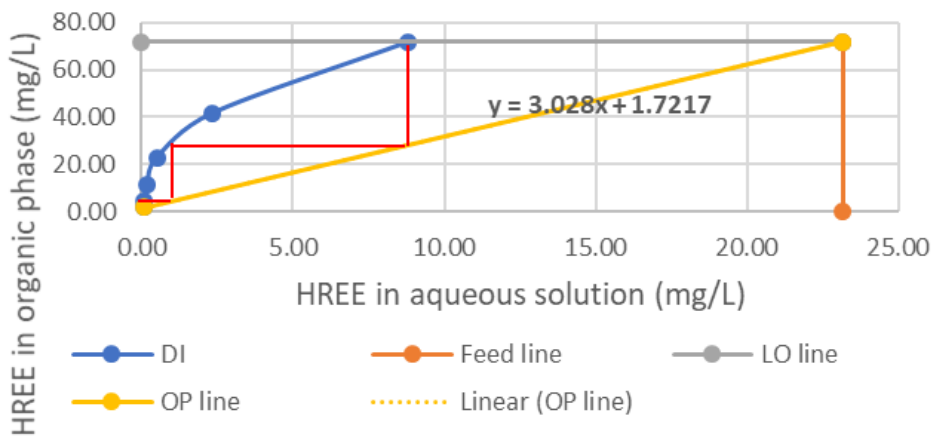

McCabe-Thiele Chart for CREE

(PLS 3; D2EHPA 0.3 M)

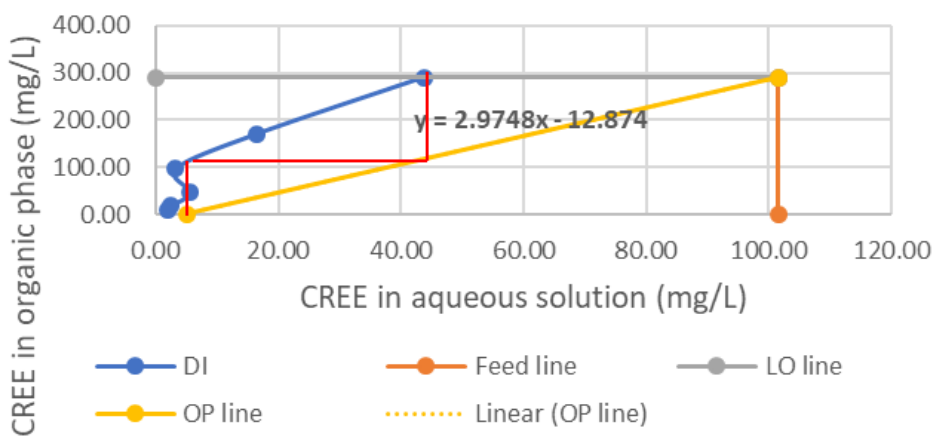

Figure 4.33 McCabe Thiele diagrams of TREE, HREE and CREE- DLM PLS 3- 0.3 M. 
McCabe Thiele diagrams of TREE, HREE and CREE in these processes were plotted as Figure 4.34 at extractant concentration of $1.0 \mathrm{M}$. Concentration of TREE in raffinate was almost 0 . Two steps can extract most TREE at intended A:O ratio of 4.7. One step can extract most HREE and CREE at intended A:O ratio of 5 .

McCabe-Thiele Chart for TREE

(PLS 3; D2EHPA $1.0 \mathrm{M}$ )

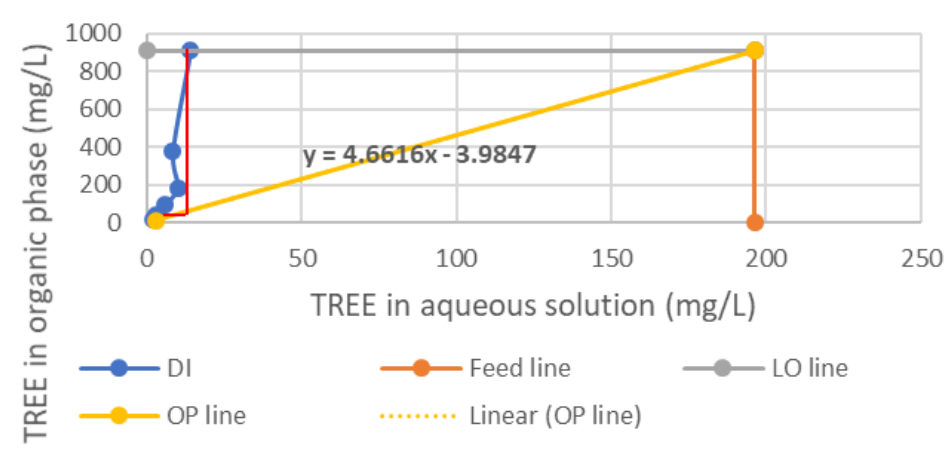

McCabe-Thiele Chart for HREE

(PLS 3; D2EHPA 1.0 M)

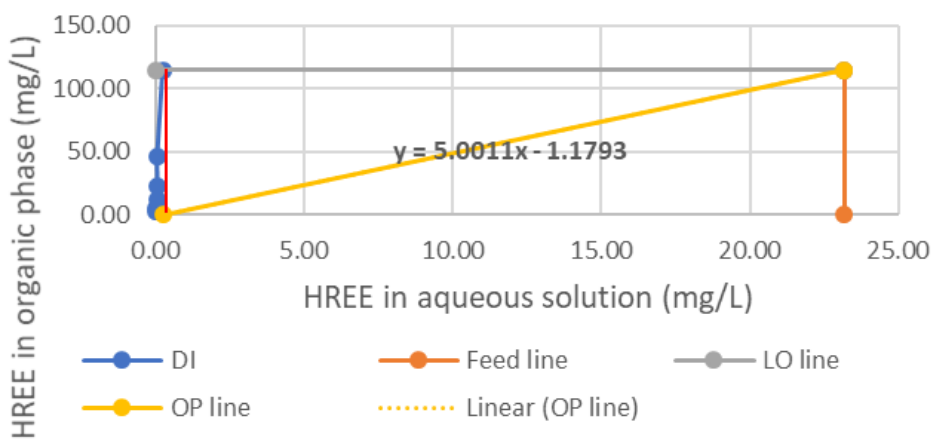




\section{McCabe-Thiele Chart for CREE}

(PLS 3; D2EHPA 1.0 M)

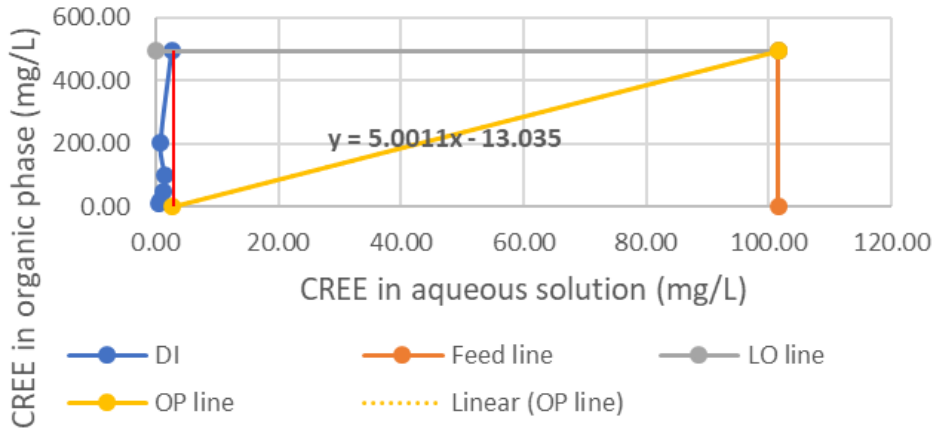

Figure 4.34 McCabe Thiele diagrams of TREE, HREE and CREE- DLM PLS 3- 1.0 M.

\subsubsection{SX McCabe-Thiele Exploratory Test-RS-PLS 3}

In the last step, add sodium hydroxide to produce PLS of higher $\mathrm{pH}$ in order to extract REE easily. The solution was much easier to filter than that of DLM. Pictures of the process were shown in Figure 4.35. After filtering, concentration of REE decreased a little bit. Concentration of Fe decreased significantly. Due to both concentration loss and volume loss, mass loss of TREE was $15.35 \%$ and mass loss of TMM was 59.39\%, Figure 4.36 .

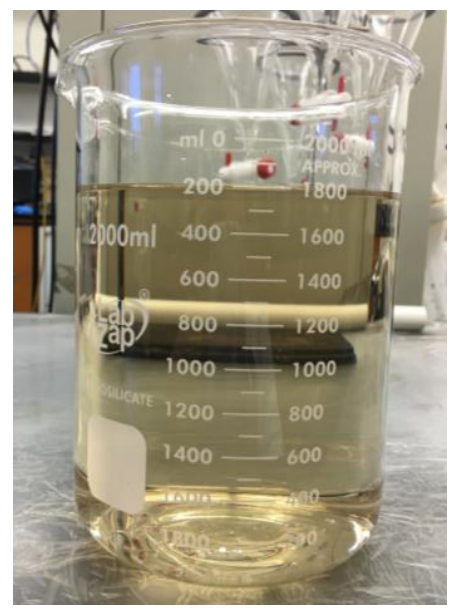

Initial:

$>\mathrm{pH}:-0.21$

$>$ Volume: $1.80 \mathrm{~L}$

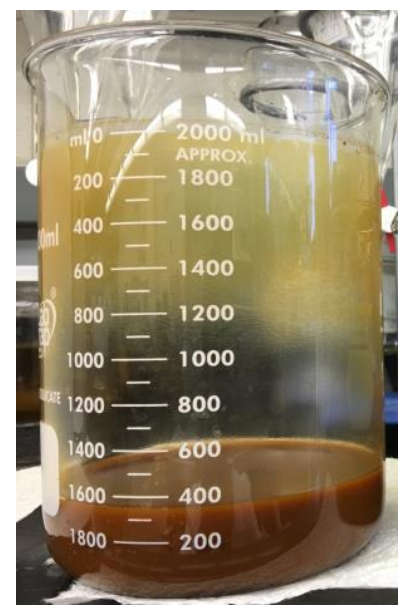

After adding $\mathrm{NaOH}$ :

$>\mathrm{pH}: 3.00$

$>$ Volume: $2.05 \mathrm{~L}$

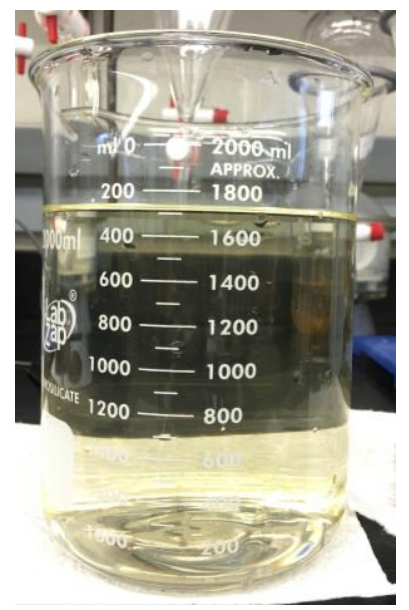

After filtering:

$>\mathrm{pH}: 2.98$

$>$ Volume: $1.72 \mathrm{~L}$

Figure 4.35 Pictures of solution in the RS PLS optimized process. 

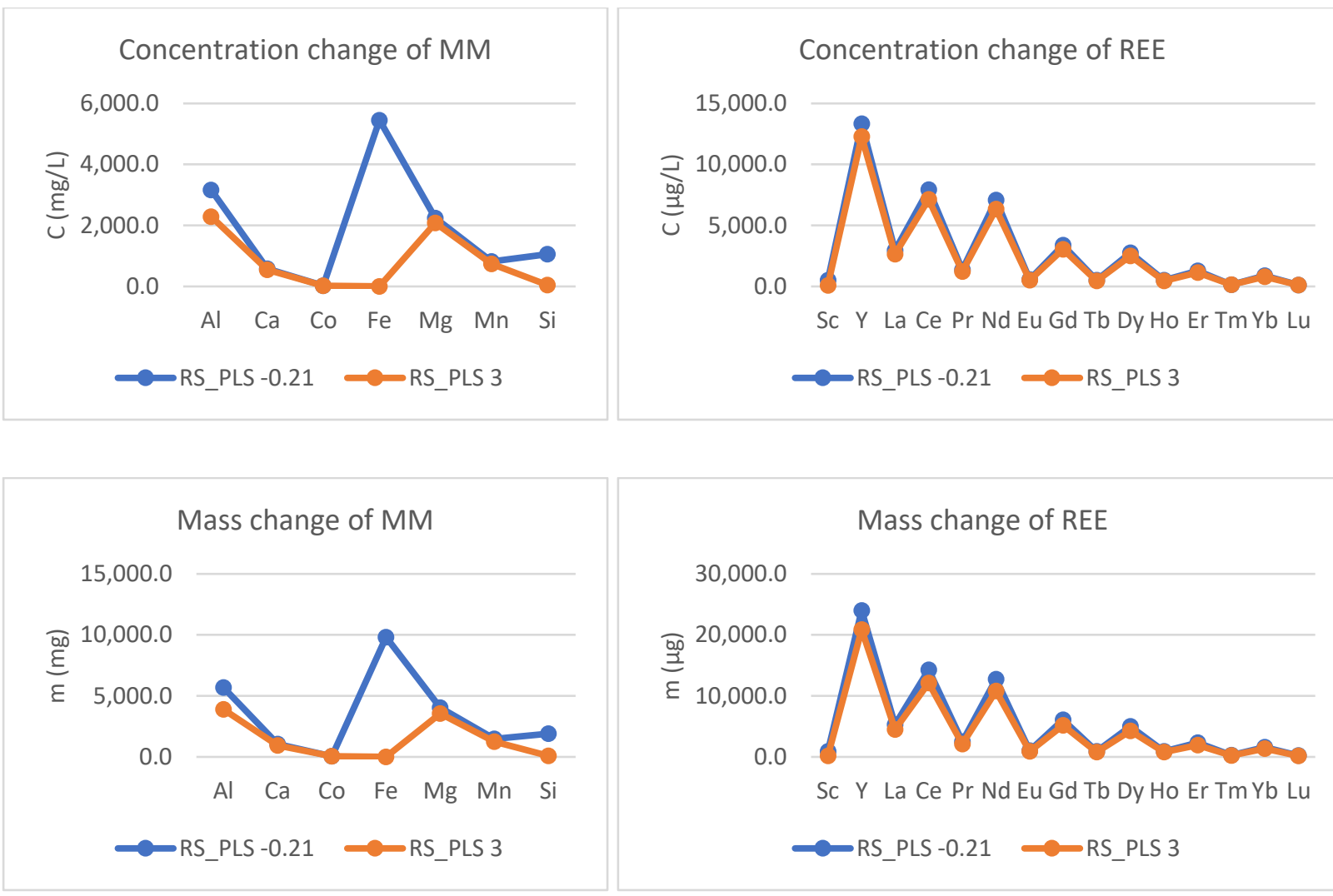

Figure 4.36 Concentration and mass change in RS PLS making process.

Laboratory-scale solvent extraction was conducted on optimized leaching solution of $\mathrm{pH} 3$ from Royal Scot (RS) site sludge. (Table 4-7) Extraction efficiencies of total major metal ions, total rare earth ions, heavy rare earth ions (HREE: Sc, Y, Gd, Tb, Dy, Ho, Er, Tm, Yb and Lu) and light rare earth ions (LREE: La, Ce, Pr, $\mathrm{Nd}, \mathrm{Sm}$ and $\mathrm{Eu}$ ) were shown in Figure 4.37. Extraction efficiencies increase with decrease of $\mathrm{A}: \mathrm{O}$ ratio. Extraction efficiency difference between TREE and TMM was significant. Some extraction efficiencies for TMM were negative due to measurement error on high concentrations of TMM. Extraction efficiencies of HREE were higher than those of LREE. HREE selective extraction from LREE was appropriate at A:O ratio between 1 and 2 for C(D2EHPA) 0.05 M. Extraction efficiencies for TREE were almost 100\% at high extractant concentration of $1.0 \mathrm{~mol} / \mathrm{L}$.

Table 4-7 Parameters and pH results of solvent extraction exploratory test of RS PLS 3.

\begin{tabular}{|c|c|c|c|c|c|c|c|c|}
\hline \multirow[t]{2}{*}{ Sample Name } & $\mathbf{F}$ & C & \multirow{2}{*}{$\begin{array}{l}\text { O: A } \\
\text { Ratio }\end{array}$} & 0 & A & TV & D & $E$ \\
\hline & $\begin{array}{c}\text { PLS } \\
\mathrm{pH}\end{array}$ & $\mathrm{mol} / \mathrm{L}$ & & $\mathrm{ml}$ & $\mathrm{ml}$ & $\mathrm{ml}$ & $\begin{array}{c}\mathrm{pH}, \\
\text { before }\end{array}$ & $\begin{array}{l}\mathrm{pH}, \\
\text { after }\end{array}$ \\
\hline RS-SX-pH3-0.05M-5:1 & 3.0 & 0.05 & $5: 1$ & 18.33 & 91.67 & 110.00 & 2.98 & 2.01 \\
\hline
\end{tabular}




\begin{tabular}{ccccccccc} 
RS-SX-pH3-0.05M-2:1 & 3.0 & 0.05 & $2: 1$ & 36.67 & 73.33 & 110.00 & $\underline{2.98}$ & $\underline{1.66}$ \\
RS-SX-pH3-0.05M-1:1 & 3.0 & 0.05 & $1: 1$ & 110.00 & 110.00 & 220.00 & $\underline{2.98}$ & $\underline{1.42}$ \\
RS-SX-pH3-0.05M-1:2 & 3.0 & 0.05 & $1: 2$ & 146.67 & 73.33 & 220.00 & $\underline{2.98}$ & $\underline{1.31}$ \\
RS-SX-pH3-0.05M-1:5 & 3.0 & 0.05 & $1: 5$ & 183.33 & 36.67 & 220.00 & $\underline{2.98}$ & $\underline{1.15}$ \\
RS-SX-pH3-0.05M-1:10 & 3.0 & 0.05 & $1: 10$ & 200.00 & 20.00 & 220.00 & $\underline{2.98}$ & $\underline{0.97}$ \\
\hline RS-SX-pH3-0.3M-5:1 & 3.0 & 0.30 & $5: 1$ & 18.33 & 91.67 & 110.00 & $\underline{2.98}$ & $\underline{1.45}$ \\
RS-SX-pH3-0.3M-2:1 & 3.0 & 0.30 & $2: 1$ & 36.67 & 73.33 & 110.00 & $\underline{2.98}$ & $\underline{1.24}$ \\
RS-SX-pH3-0.3M-1:1 & 3.0 & 0.30 & $1: 1$ & 110.00 & 110.00 & 220.00 & $\underline{2.98}$ & $\underline{1.06}$ \\
RS-SX-pH3-0.3M-1:2 & 3.0 & 0.30 & $1: 2$ & 146.67 & 73.33 & 220.00 & $\underline{2.98}$ & $\underline{1.00}$ \\
RS-SX-pH3-0.3M-1:5 & 3.0 & 0.30 & $1: 5$ & 183.33 & 36.67 & 220.00 & $\underline{2.98}$ & $\underline{0.88}$ \\
RS-SX-pH3-0.3M-1:10 & 3.0 & 0.30 & $1: 10$ & 200.00 & 20.00 & 220.00 & $\underline{2.98}$ & $\underline{0.79}$ \\
\hline RS-SX-pH3-1.0M-5:1 & 3.0 & 1.00 & $5: 1$ & 18.33 & 91.67 & 110.00 & $\underline{2.98}$ & $\underline{1.05}$ \\
RS-SX-pH3-1.0M-2:1 & 3.0 & 1.00 & $2: 1$ & 36.67 & 73.33 & 110.00 & $\underline{2.98}$ & $\underline{0.87}$ \\
RS-SX-pH3-1.0M-1:1 & 3.0 & 1.00 & $1: 1$ & 110.00 & 110.00 & 220.00 & $\underline{2.98}$ & $\underline{0.70}$ \\
RS-SX-pH3-1.0M-1:2 & 3.0 & 1.00 & $1: 2$ & 146.67 & 73.33 & 220.00 & $\underline{2.98}$ & $\underline{0.63}$ \\
RS-SX-pH3-1.0M-1:5 & 3.0 & 1.00 & $1: 5$ & 183.33 & 36.67 & 220.00 & $\underline{2.98}$ & $\underline{0.57}$ \\
RS-SX-pH3-1.0M-1:10 & 3.0 & 1.00 & $1: 10$ & 200.00 & 20.00 & 220.00 & $\underline{2.98}$ & $\underline{0.53}$ \\
\hline
\end{tabular}
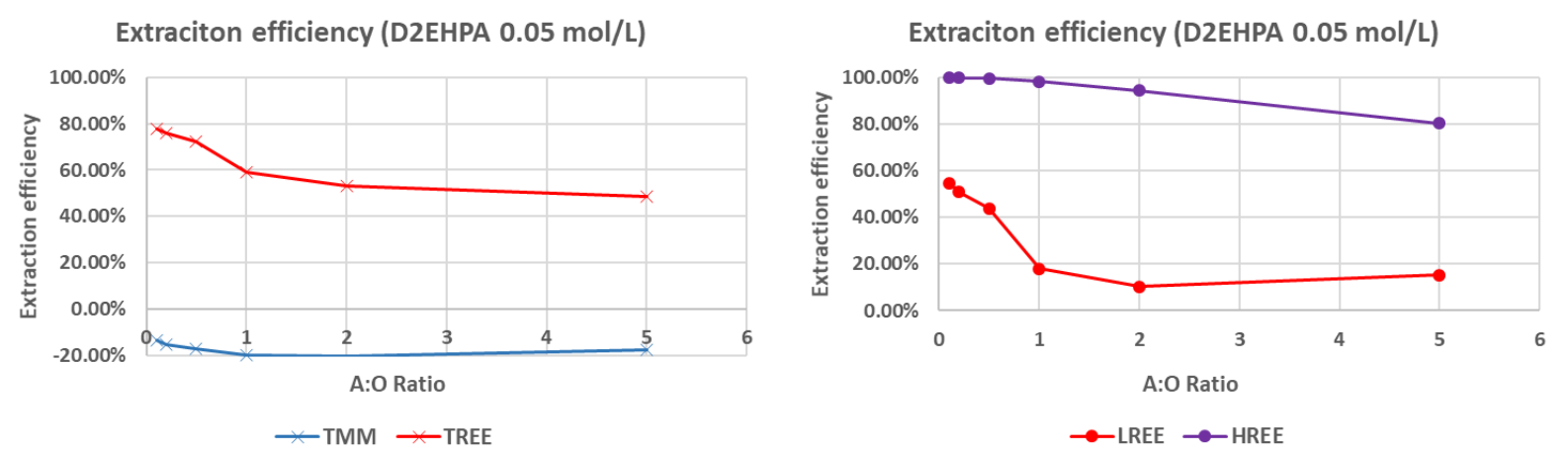
Extraciton efficiency (D2EHPA $0.3 \mathrm{~mol} / \mathrm{L}$ )

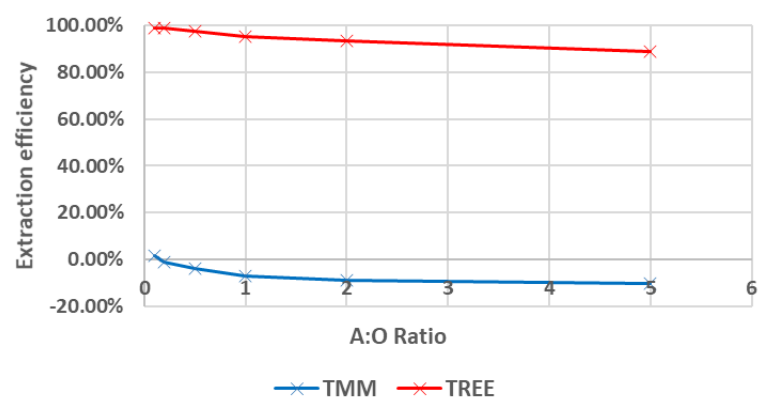

Extraction efficiency (D2EHPA $1.0 \mathrm{~mol} / \mathrm{L}$ )

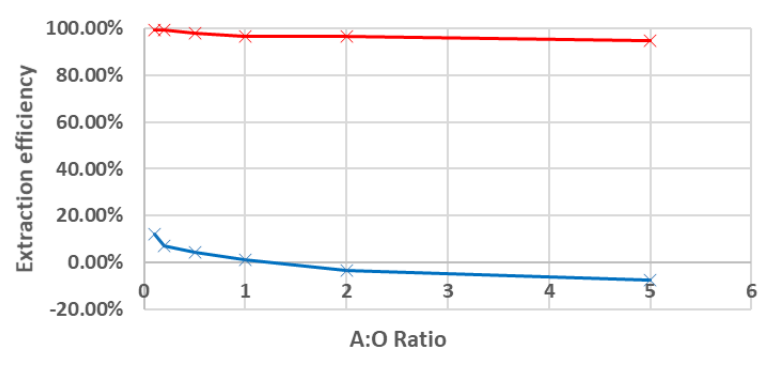

$\multimap$ TMM $\multimap$ TREE
Extraciton efficiency (D2EHPA $0.3 \mathrm{~mol} / \mathrm{L}$ )

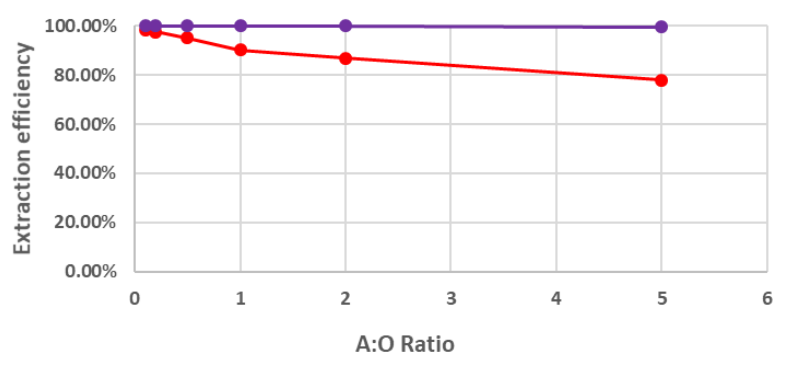

$\rightarrow$ LREE $\rightarrow$ HREE

Extraciton efficiency (D2EHPA $1.0 \mathrm{~mol} / \mathrm{L}$ )

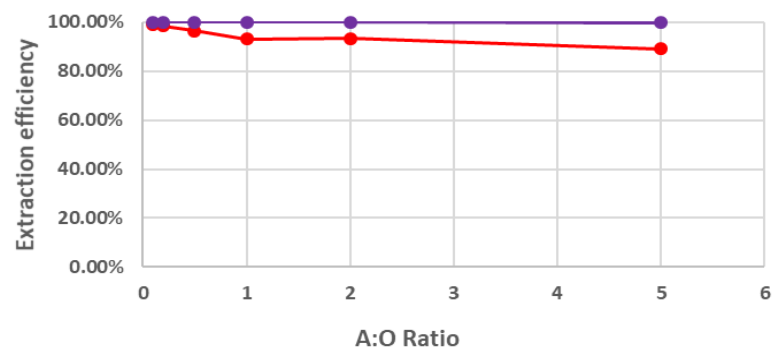

$\rightarrow$ LREE $\rightarrow$ HREE

Figure 4.37 Extraction efficiency of TMM, TREE, HREE and LREE- RS PLS 3.

HREE and LREE distribution in these processes were shown in Figure 4.38. HREE percentages in raffinate were almost 0 . HREE may be separately extracted from LREE at A:O ratio larger than 2 at extractant concentration of $0.05 \mathrm{M}$. TREE extraction was high enough at extractant concentration less than $0.3 \mathrm{M}$.
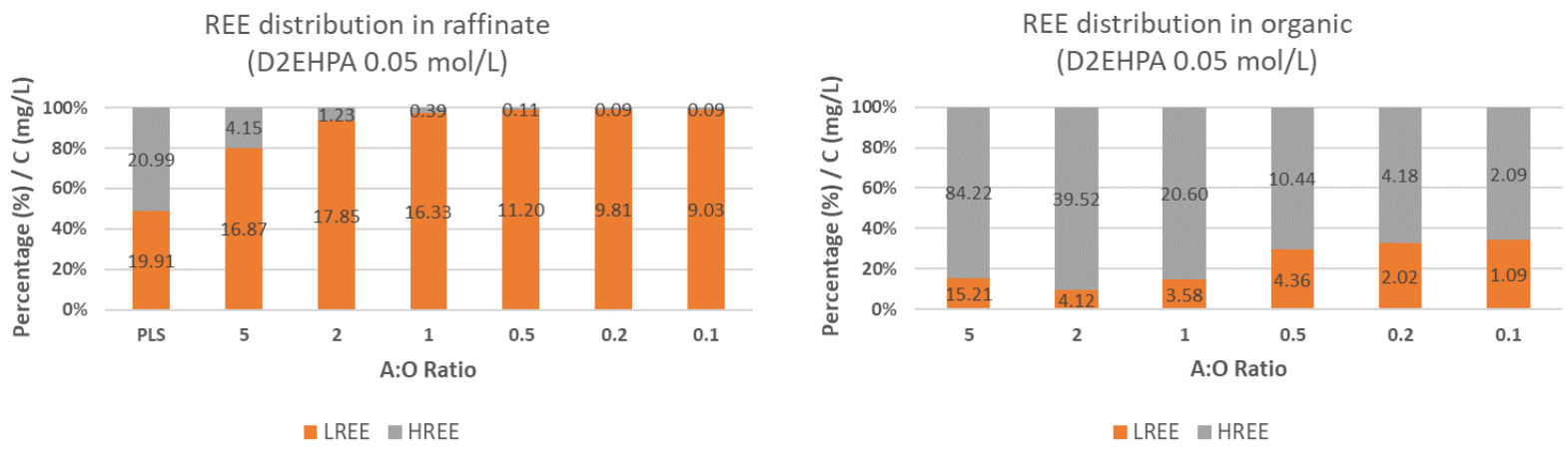

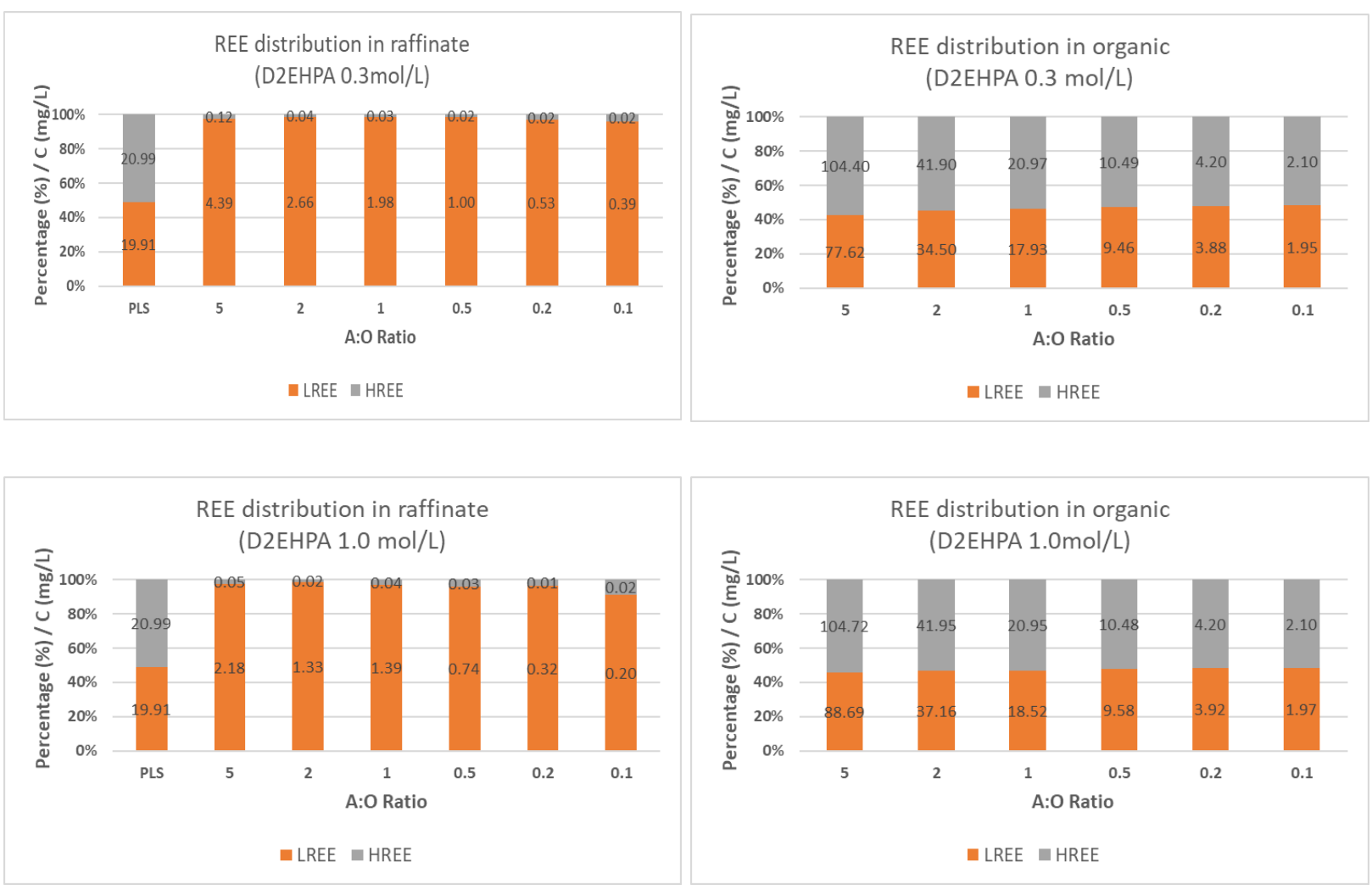

Figure 4.38 Heavy REE and light REE distribution- RS PLS 3.

McCabe Thiele diagrams of TREE, HREE and LREE in these processes were plotted as Figure 4.39. TREE extraction efficiencies were low (high C(TREE) in raffinate) at extractant concentration of $0.05 \mathrm{M}$. Two steps can extract most TREE at intended A:O ratio of 2.8. Two steps can extract most HREE at intended A:O ratio of 3.9. LREE extraction was low.

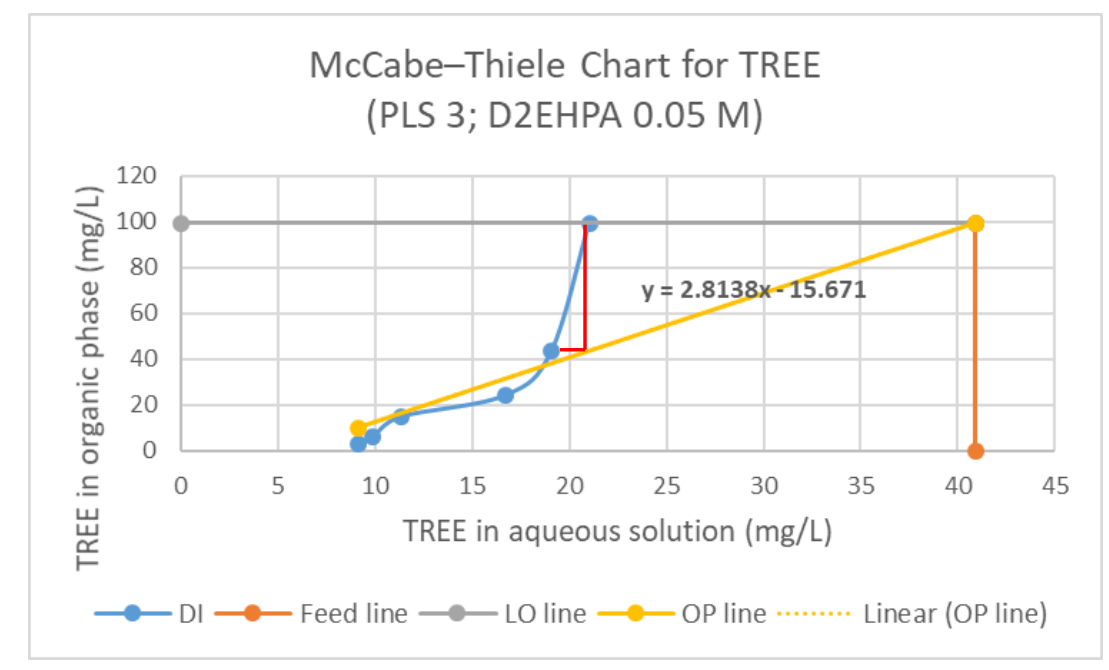



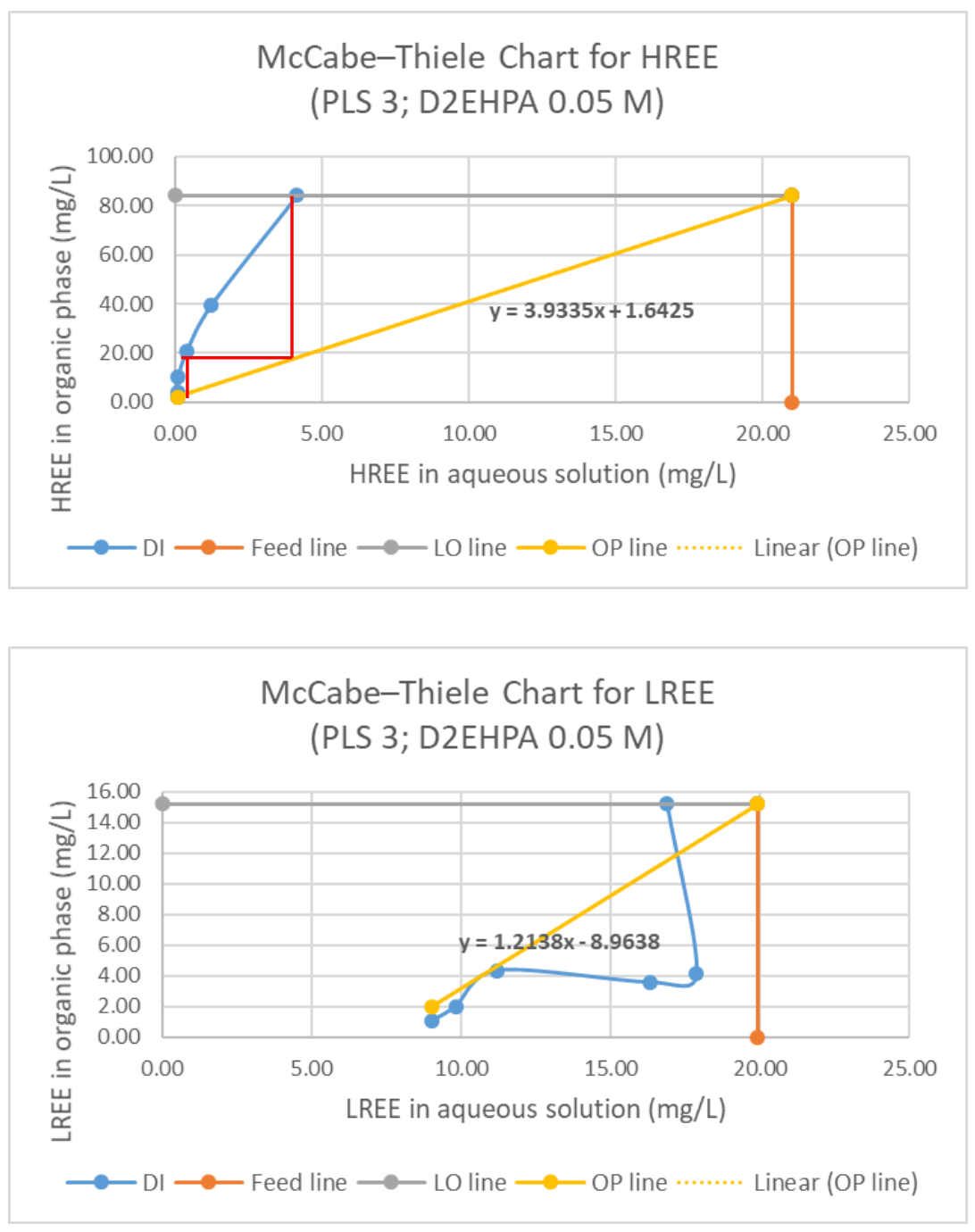

Figure 4.39 McCabe Thiele diagrams of TREE, HREE and LREE- RS PLS 3- 0.05 M.

McCabe Thiele diagrams of TREE, HREE and LREE in these processes were plotted as Figure 4.40. TREE extraction efficiencies were high (very low C(TREE) in raffinate) at extractant concentration of $0.3 \mathrm{M}$. One step can extract almost all HREE at intended A:O ratio of 4.9. Three steps can extract most TREE and LREE at intended A:O ratio about 4. 

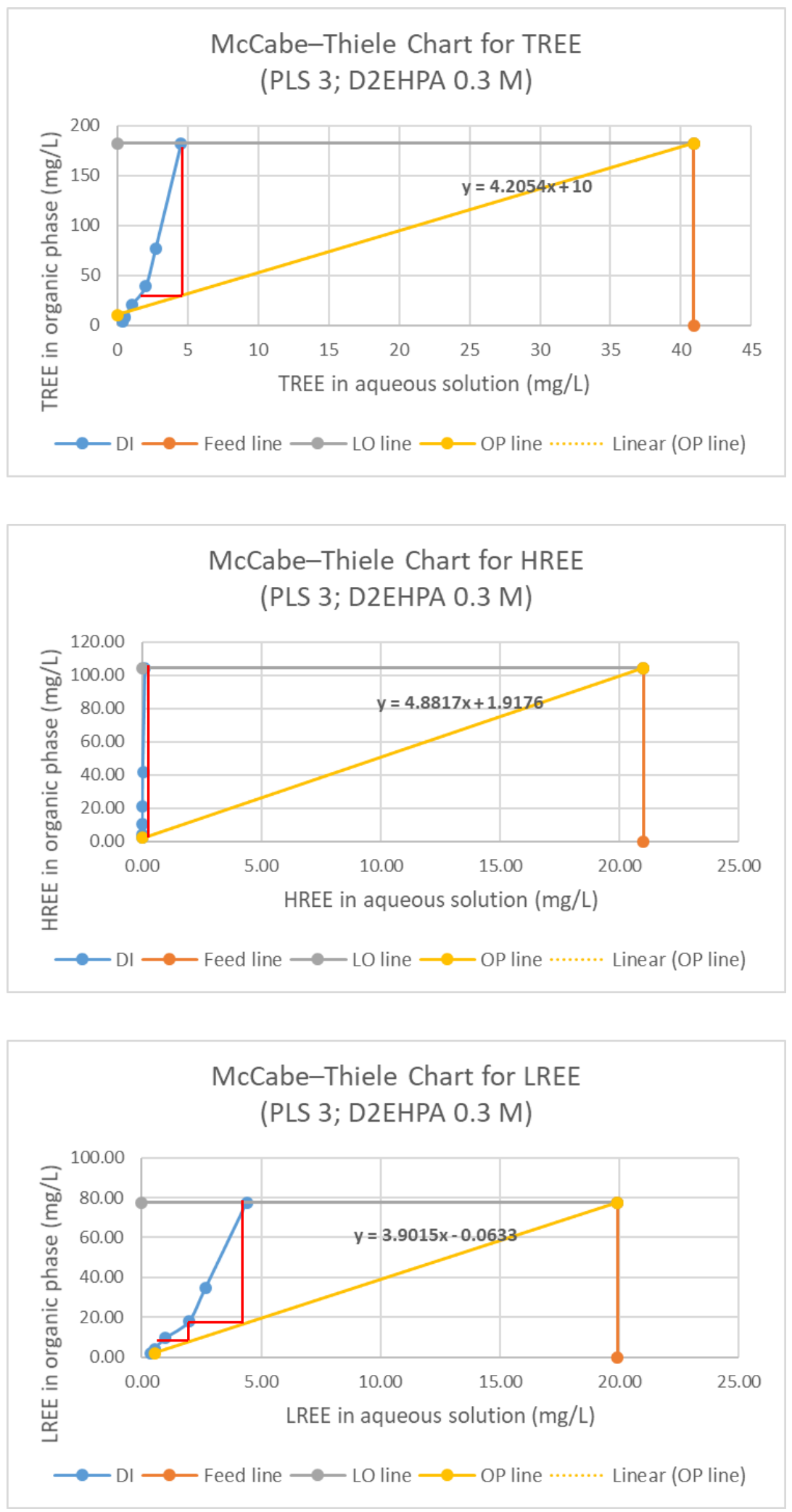

Figure 4.40 McCabe Thiele diagrams of TREE, HREE and LREE- RS PLS 3- 0.3 M. 
McCabe Thiele diagrams of TREE, HREE and LREE in these processes were plotted as Figure 4.41. TREE extraction efficiencies were very high (very low C(TREE) in raffinate) at extractant concentration of 1.0 M. One step can extract almost all HREE at intended A:O ratio of 4.9. Two steps can extract most TREE and LREE at intended A:O ratio about 4.5.
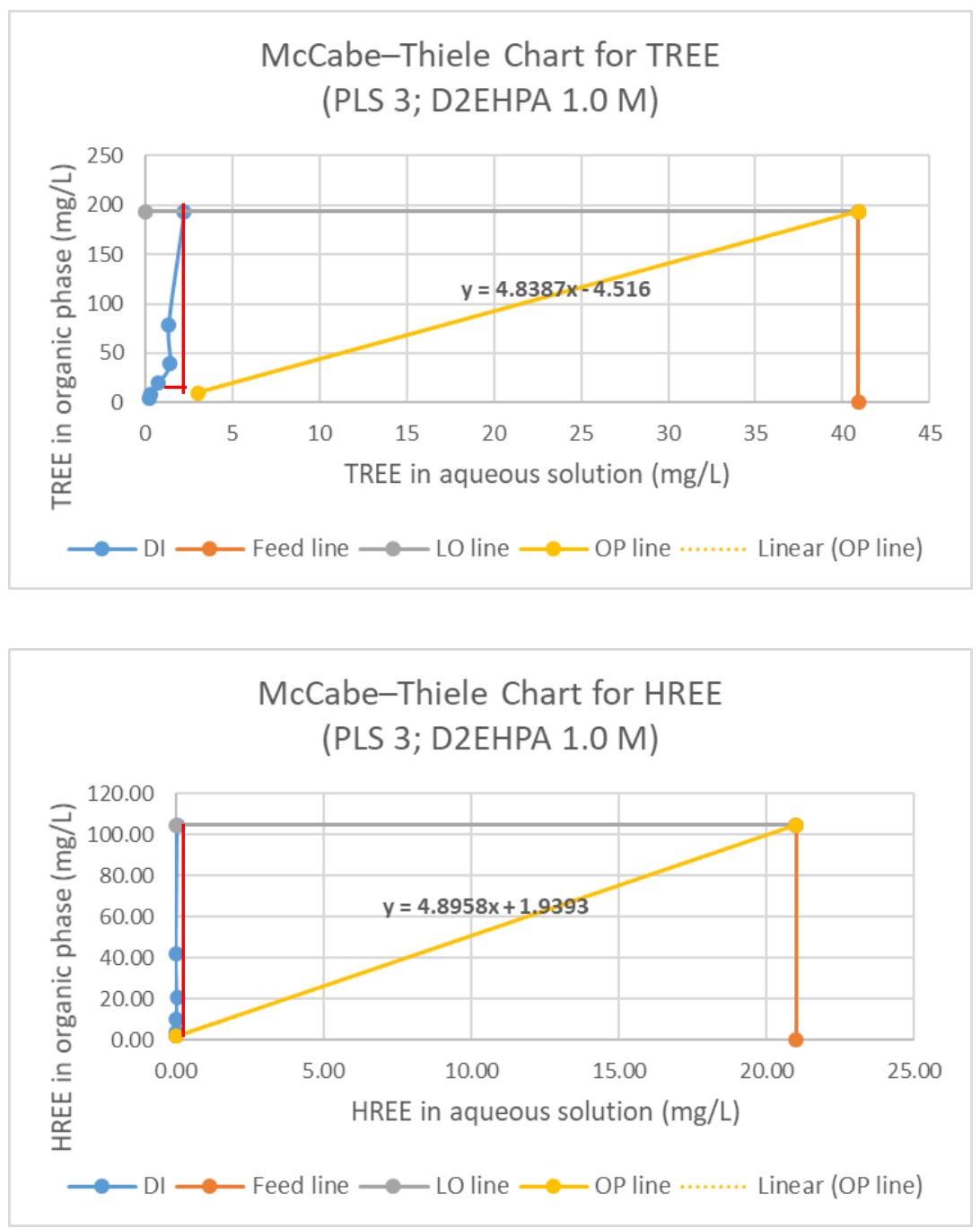


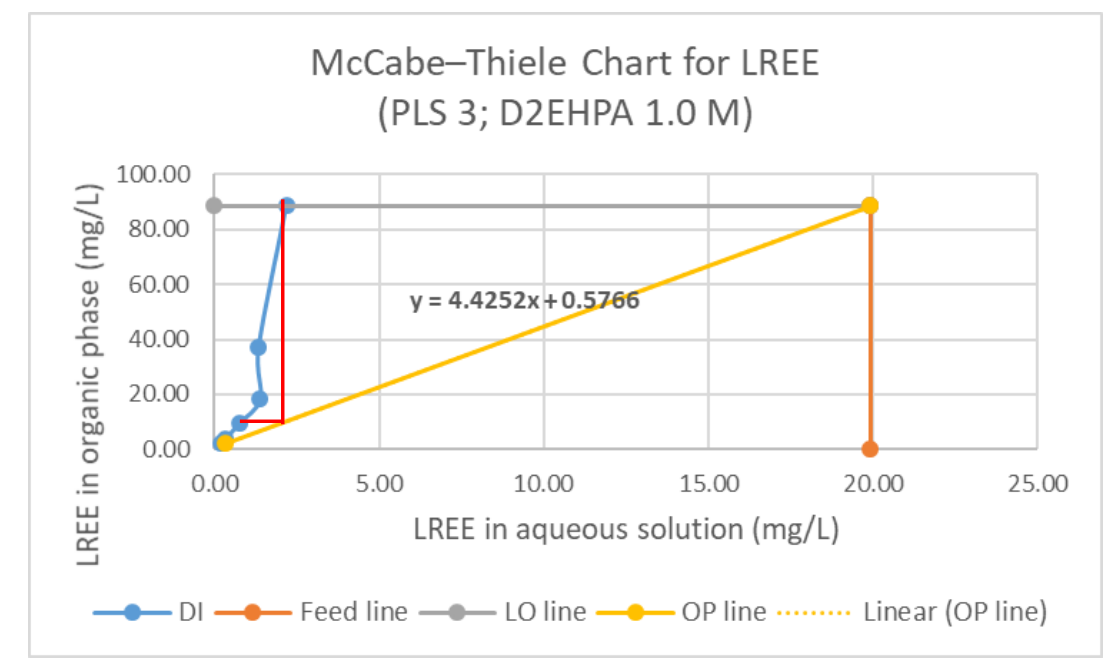

Figure 4.41 McCabe Thiele diagrams of TREE, HREE and LREE- RS PLS 3- 1.0 M.

\subsubsection{Bench-Scale Solvent Extraction Support Summary}

SX was conducted to obtain McCabe Thiele (McT) diagrams for different PLS from DLM, OM and RS sites. The optimal running conditions for SX at a laboratory scale were achieved (Figure 4.42) and can provide a purposeful starting point for the SX system parametric testing. For DLM PLS 3, 0.3 M extractant concentration was best for HREE separation from LREE. Total LREE can be recovered at $1.0 \mathrm{M}$ extractant concentration. The optimum O:A ratio was about 1. For OM and RS PLS 3, $0.05 \mathrm{M}$ extractant concentration was appropriate for HREE separation from LREE. Total LREE can be recovered at $0.3 \mathrm{M}$ extractant concentration. The optimum O:A ratio was about 2 for OM PLS 3 and 5 for RS PLS 3.

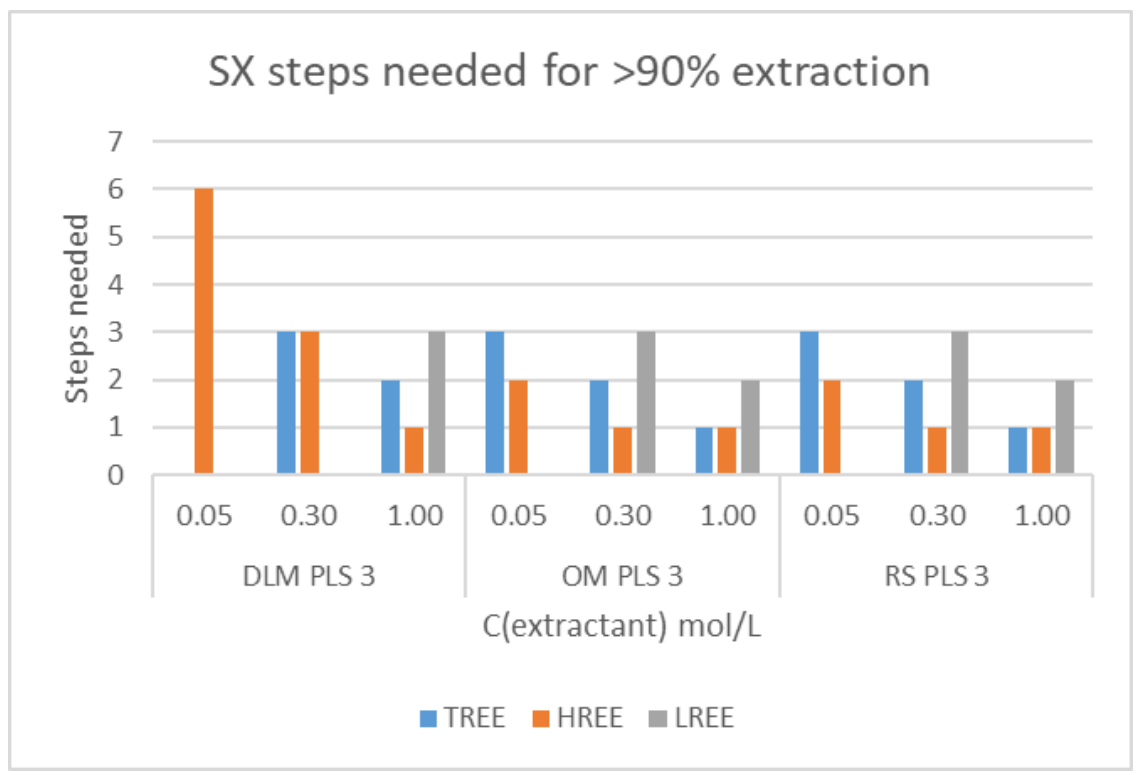




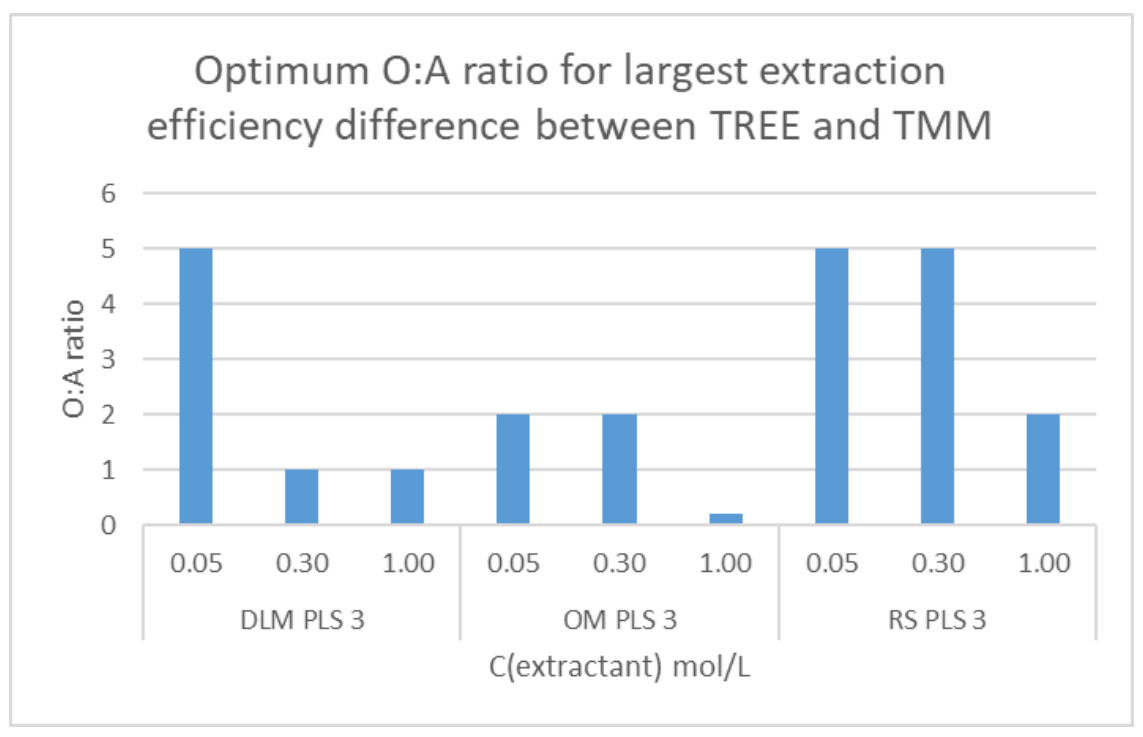

Figure 4.42 Optimum parameters of SX for different PLS.

\subsection{Bench-Scale Scrub Support}

Through SX exploratory tests, optimized parameters were applied to bench-scale solvent extraction, and the loaded organic phase was collected and used for scrubbing exploratory tests. Results of scrub exploratory tests were provided as McCabe Thiele diagrams. Parameters to be evaluated in this test include the O:A ratio and concentration of acid $(\mathrm{HCl}, \mathrm{HNO})$ in the aqueous phase. Objective of scrub exploratory tests is to find optimal parameters for maximized scrub efficiency for major metal ions (MM) and minimized scrub efficiency for rare earth elements (REEs) and the number of steps needed in a mixersettler to reach desired separation.

\subsubsection{Scrub McCabe-Thiele Exploratory Test-OM}

Scrub exploratory tests were conducted using DI water on OM loaded organic phase (Table 4-8). Figure 4.43 shows pictures of the scrub process after equilibrium. Aqueous samples results were received. The data can't be analyzed due to pending organic head sample results. The data analysis will be included in next report.

Table 4-8 Parameters of DI water scrub exploratory test on OM loaded organic.

\begin{tabular}{|c|c|c|c|c|c|c|}
\hline \multirow{2}{*}{ Sample \# } & \multirow{2}{*}{$\begin{array}{l}\text { Sample } \\
\text { Name }\end{array}$} & \multirow{2}{*}{$\begin{array}{c}\text { C } \\
\mathrm{mol} / \mathrm{L}\end{array}$} & \multirow{2}{*}{$\begin{array}{l}\text { O: A } \\
\text { Ratio }\end{array}$} & \multirow{2}{*}{$\begin{array}{c}0 \\
\mathrm{ml}\end{array}$} & \multirow{2}{*}{$\begin{array}{c}\text { A } \\
\mathrm{ml}\end{array}$} & \multirow{2}{*}{$\begin{array}{l}\text { TV } \\
\mathrm{ml}\end{array}$} \\
\hline & & & & & & \\
\hline \multicolumn{2}{|c|}{ OM-Scrub-0-1:5 } & 0.00 & $1: 5$ & 18.33 & 91.67 & 110.00 \\
\hline \multicolumn{2}{|c|}{ OM-Scrub-0-1:2 } & 0.00 & $1: 2$ & 36.67 & 73.33 & 110.00 \\
\hline \multicolumn{2}{|c|}{ OM-Scrub-0-1:1 } & 0.00 & $1: 1$ & 55.00 & 55.00 & 110.00 \\
\hline \multicolumn{2}{|c|}{ OM-Scrub-0-2:1 } & 0.00 & $2: 1$ & 73.33 & 36.67 & 110.00 \\
\hline
\end{tabular}




\begin{tabular}{lllllll}
\hline 5 & OM-Scrub-0-5:1 & 0.00 & $5: 1$ & 183.33 & 36.67 & 220.00 \\
6 & OM-Scrub-0-10:1 & 0.00 & $10: 1$ & 200.00 & 20.00 & 220.00 \\
\hline
\end{tabular}

Remarks: A: aqueous phase; 0 : organic phase; TV: total volume; C: acid concentration.
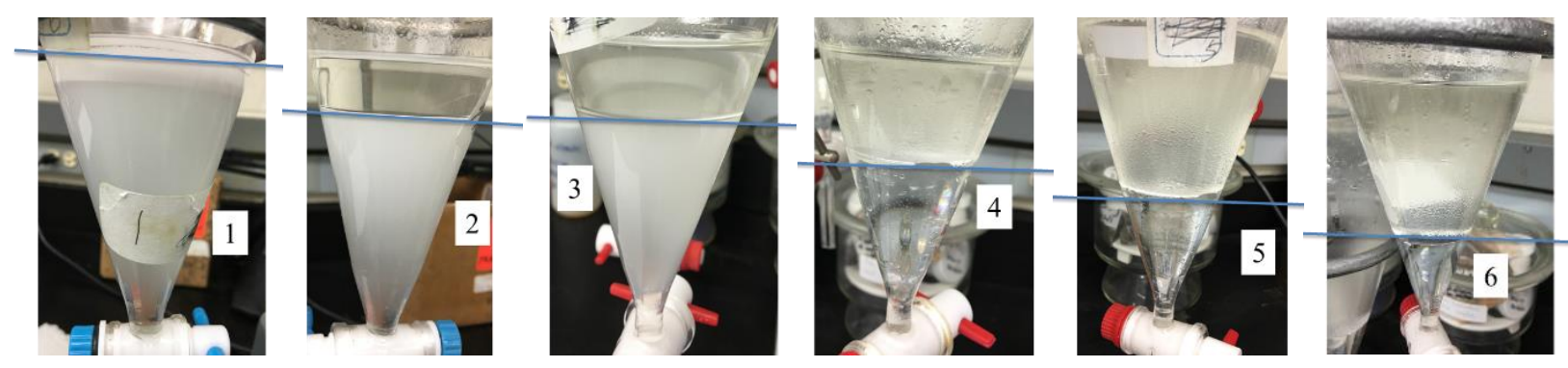

Figure 4.43 Pictures of water scrub process after equilibrium.

Figure 4.44 shows scrub efficiency results of the scrub tests. Scrub efficiency equation is shown as Equation 5. Scrub efficiency of Mn element was high, while the scrub efficiencies of Al and Fe were very low. For rare earth elements, the lower O:A ratio, the higher scrub efficiency. However, the O:A ratio effect on scrub efficiency of major metal ions was not obvious. Scrub efficiencies of total major metal ions (TMM) and total rare earth elements (TREE) were also summarized. The biggest difference of them was at low O:A ratio. The scrub efficiencies of light rare earth elements (LREE) and heavy rare earth elements (HREE) were almost same at highest O:A ratio of 10.

\section{Equation 5:}

$f_{S C}:$ Scrub efficiency of $M=\frac{\text { Mass of scrubbed metal ions } M \text { into aqueous samples }}{\text { Initial mass of metal ions } M \text { in loaded organic head sample }}$

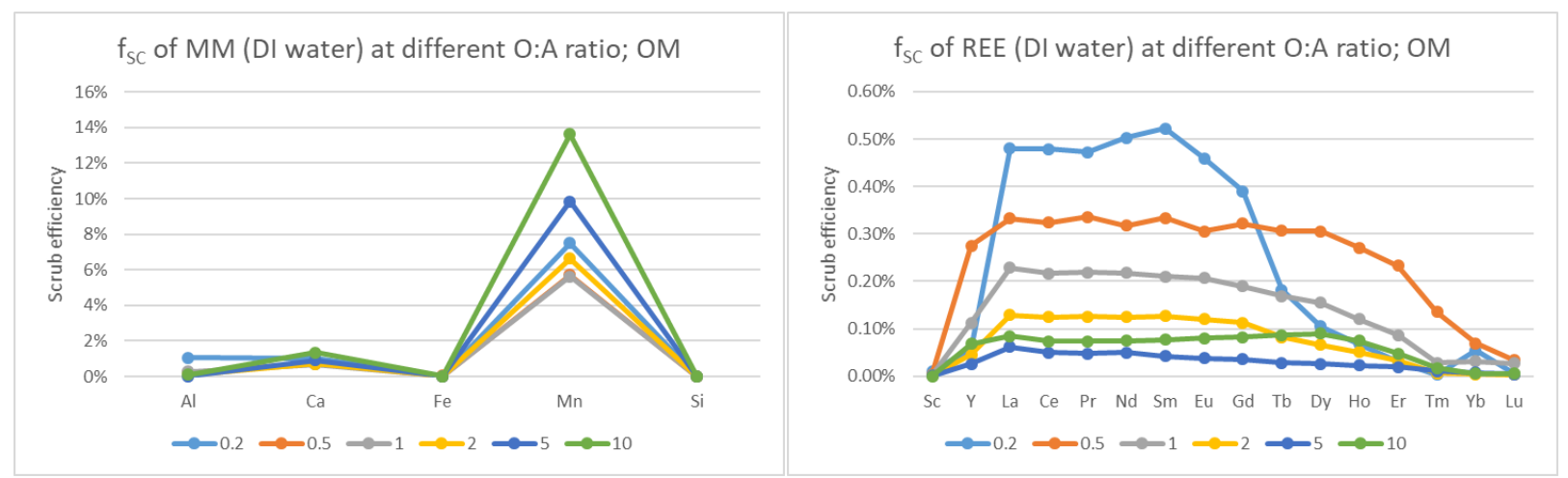


Scrub efficiency (DI water); OM

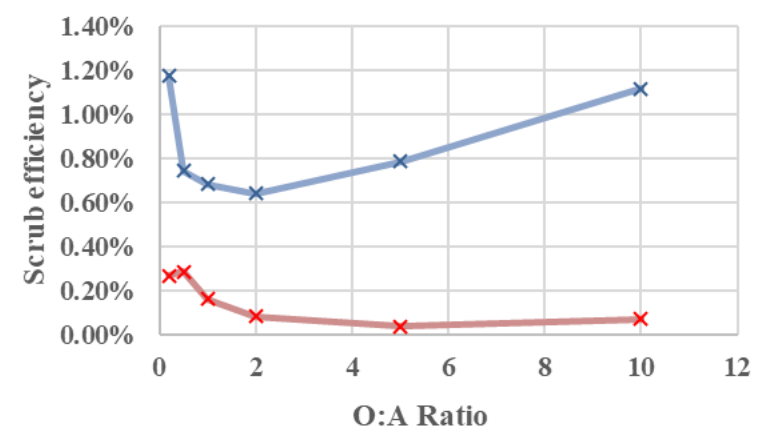

$\times$ TMM $\times$ TREE
Scrub efficiency (DI water); OM

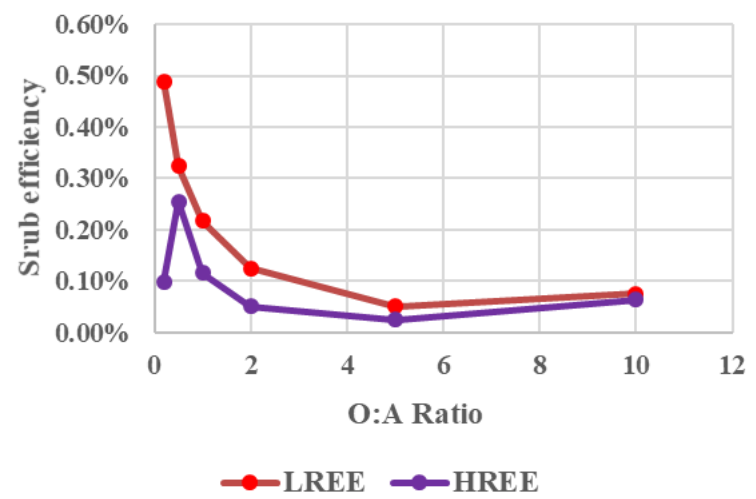

Figure 4.44 Water scrub efficiency of individual and total elements for OM loaded organic.

Since scrub efficiency of MM was very low by using DI water, exploratory tests were conducted using diluted hydrochloric acid on OM loaded organic phase (Table 4-9). Scrub efficiency results of the scrub tests are shown in Figure 4.45. At high O:A ratio, REE loss was not obvious at $0.1 \mathrm{M} \mathrm{HCl}$. To remove more $\mathrm{MM}$, especially $\mathrm{Al}$ and $\mathrm{Ca}$, scrub tests were conducted at $0.5 \mathrm{M} \mathrm{HCl}$. LREEs were easier to remove than $\mathrm{Al}$ and Fe under these conditions. Even at high O:A ratio, LREE loss was obvious at $0.5 \mathrm{M} \mathrm{HCl}$.

Table 4-9 Parameters of scrub exploratory test of OM loaded organic.

\begin{tabular}{llllll}
\hline \multirow{2}{*}{ Sample Name } & $\mathbf{C}(\mathbf{H C l})$ & $\mathbf{O}: \mathbf{A}$ & $\mathbf{0}$ & $\mathbf{A}$ & $\mathbf{T V}$ \\
\cline { 2 - 6 } & $\mathrm{mol} / \mathrm{L}$ & Ratio & $\mathrm{ml}$ & $\mathrm{ml}$ & $\mathrm{ml}$ \\
\hline OM-Scrub-0.1-1:5 & 0.10 & $1: 5$ & 18.33 & 91.67 & 110.00 \\
OM-Scrub-0.1-1:2 & 0.10 & $1: 2$ & 36.67 & 73.33 & 110.00 \\
OM-Scrub-0.1-1:1 & 0.10 & $1: 1$ & 55.00 & 55.00 & 110.00 \\
OM-Scrub-0.1-2:1 & 0.10 & $2: 1$ & 73.33 & 36.67 & 110.00 \\
OM-Scrub-0.1-5:1 & 0.10 & $5: 1$ & 183.33 & 36.67 & 220.00 \\
OM-Scrub-0.1-10:1 & 0.10 & $10: 1$ & 200.00 & 20.00 & 220.00 \\
\hline OM-Scrub-0.5-1:5 & 0.50 & $1: 5$ & 18.33 & 91.67 & 110.00 \\
OM-Scrub-0.5-1:2 & 0.50 & $1: 2$ & 36.67 & 73.33 & 110.00 \\
OM-Scrub-0.5-1:1 & 0.50 & $1: 1$ & 55.00 & 55.00 & 110.00 \\
OM-Scrub-0.5-2:1 & 0.50 & $2: 1$ & 73.33 & 36.67 & 110.00 \\
OM-Scrub-0.5-5:1 & 0.50 & $5: 1$ & 183.33 & 36.67 & 220.00 \\
OM-Scrub-0.5-10:1 & 0.50 & $10: 1$ & 200.00 & 20.00 & 220.00 \\
\hline
\end{tabular}



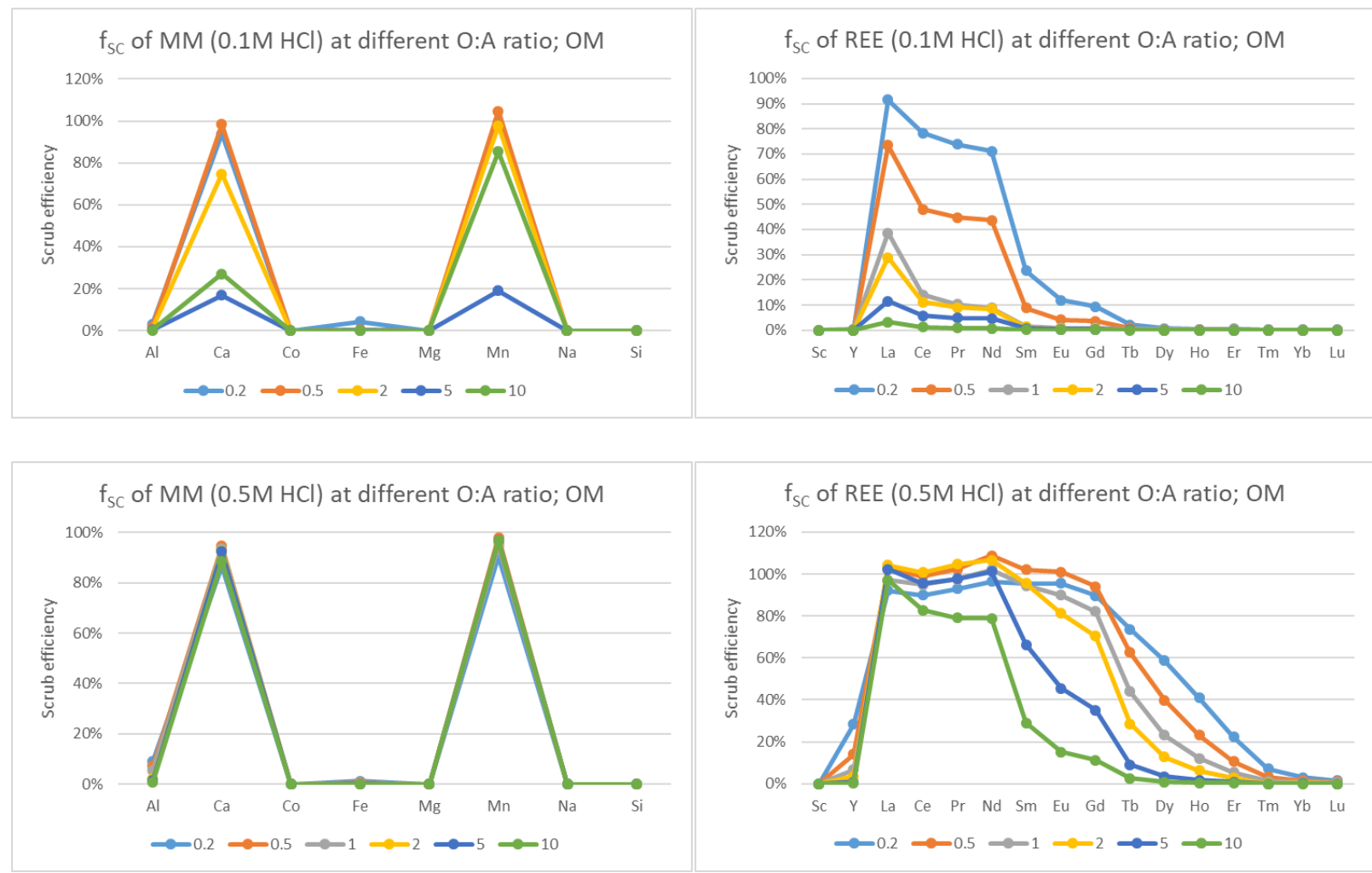

Figure 4.45 Scrub efficiency of individual MM and REE- OM.

Since scrub of HREE was not obvious, McCabe Thiele (McT) diagrams of TREE and LREE in these processes are plotted in Figure 4.46. Preferred conditions of scrub tests are to save acid, use less steps and choose high O:A ratio. The McT charts analysis results are summarized for OM scrub tests in Table 4-10. TREE residue after scrub by $0.1 \mathrm{M} \mathrm{HCl}$ was very high and about $70 \%$ of LREE can be scrubbed at intended O:A ratio of 0.4 after three steps scrub. By using $0.5 \mathrm{M} \mathrm{HCl}$, about $60 \%$ of TREE will be loss at O:A ratio of 5.4 after three steps scrub. Almost all LREE can be scrubbed at O:A ratio of 7.7 after three steps scrub. Since REE loss was obvious at $0.5 \mathrm{M} \mathrm{HCl}$, scrub process can't be conducted at this condition.
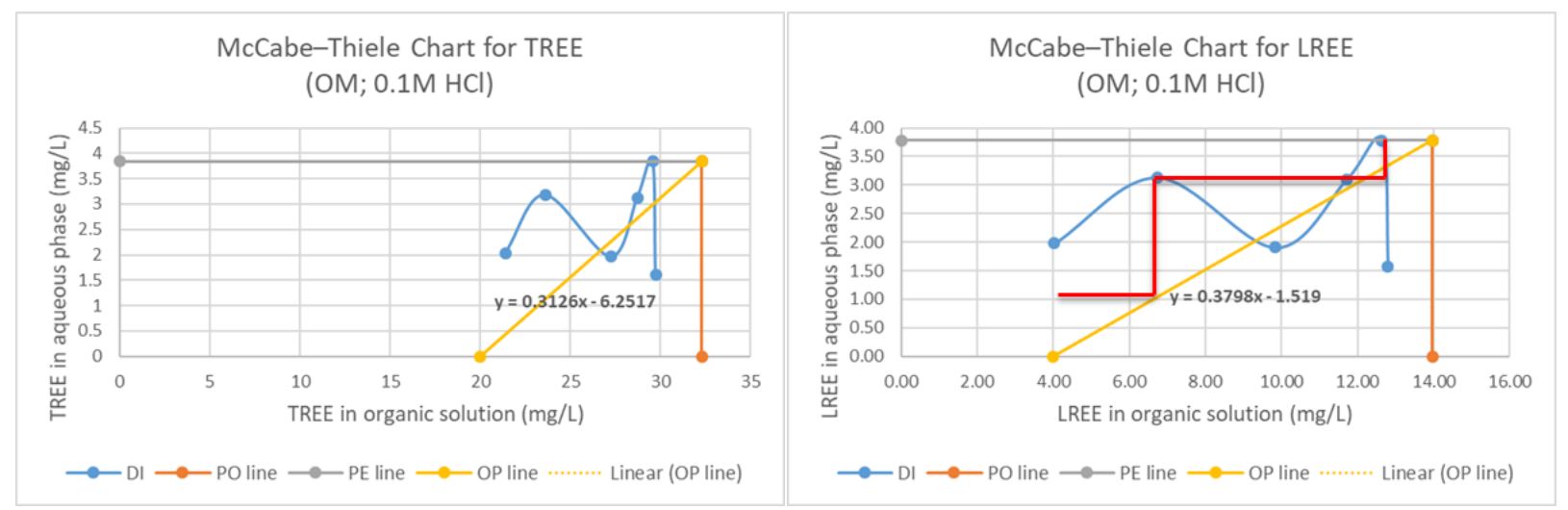


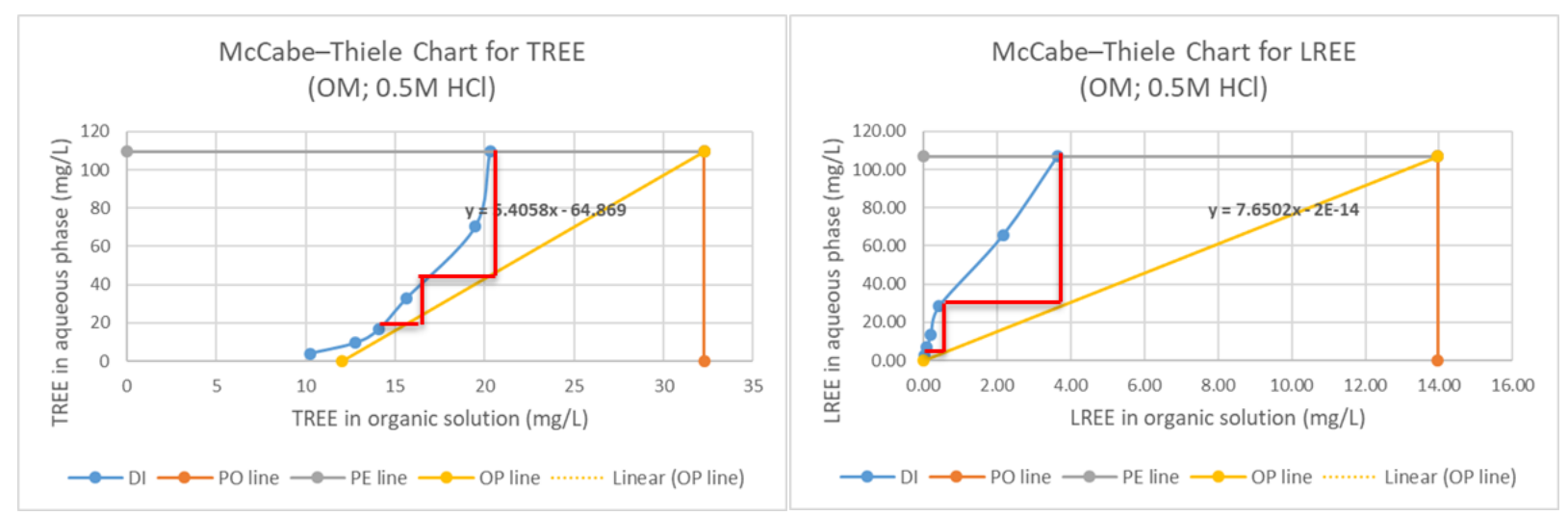

Figure 4.46 McCabe Thiele diagrams of TREE and LREE- OM.

Table 4-10 McT charts results summary of REE for OM scrub tests.

\begin{tabular}{ccccc}
\hline Acid solution & REE & Intended O:A ratio & Steps number & Residue \\
\hline & TREE & - & - & high \\
$0.1 \mathrm{M} \mathrm{HCl}$ & & 0.4 & 3 & $29 \%$ \\
& LREE & 5.4 & 3 & $39 \%$ \\
$0.5 \mathrm{M} \mathrm{HCl}$ & TREE & & 3 & low \\
& LREE & 7.7 & & \\
\hline
\end{tabular}

McCabe Thiele (McT) diagrams of TMM and $\mathrm{Ca}$ in these processes are plotted in Figure 4.47. The McT charts analysis results are summarized for the scrub tests in Table 4-11. TMM residue after scrub by 0.1M $\mathrm{HCl}$ was very high and almost all of Ca can be scrubbed at intended O:A ratio of 2.7 after three steps scrub. By using $0.5 \mathrm{M} \mathrm{HCl}$, only $27 \%$ of TMM will be left in the organic phase at O:A ratio of 8.1 after two steps scrub. Almost all of Ca can be scrubbed at O:A ratio of 8.9 after two steps scrub. However, to avoid REE loss, $0.1 \mathrm{M} \mathrm{HCl}$ was enough for efficient Ca scrub. 


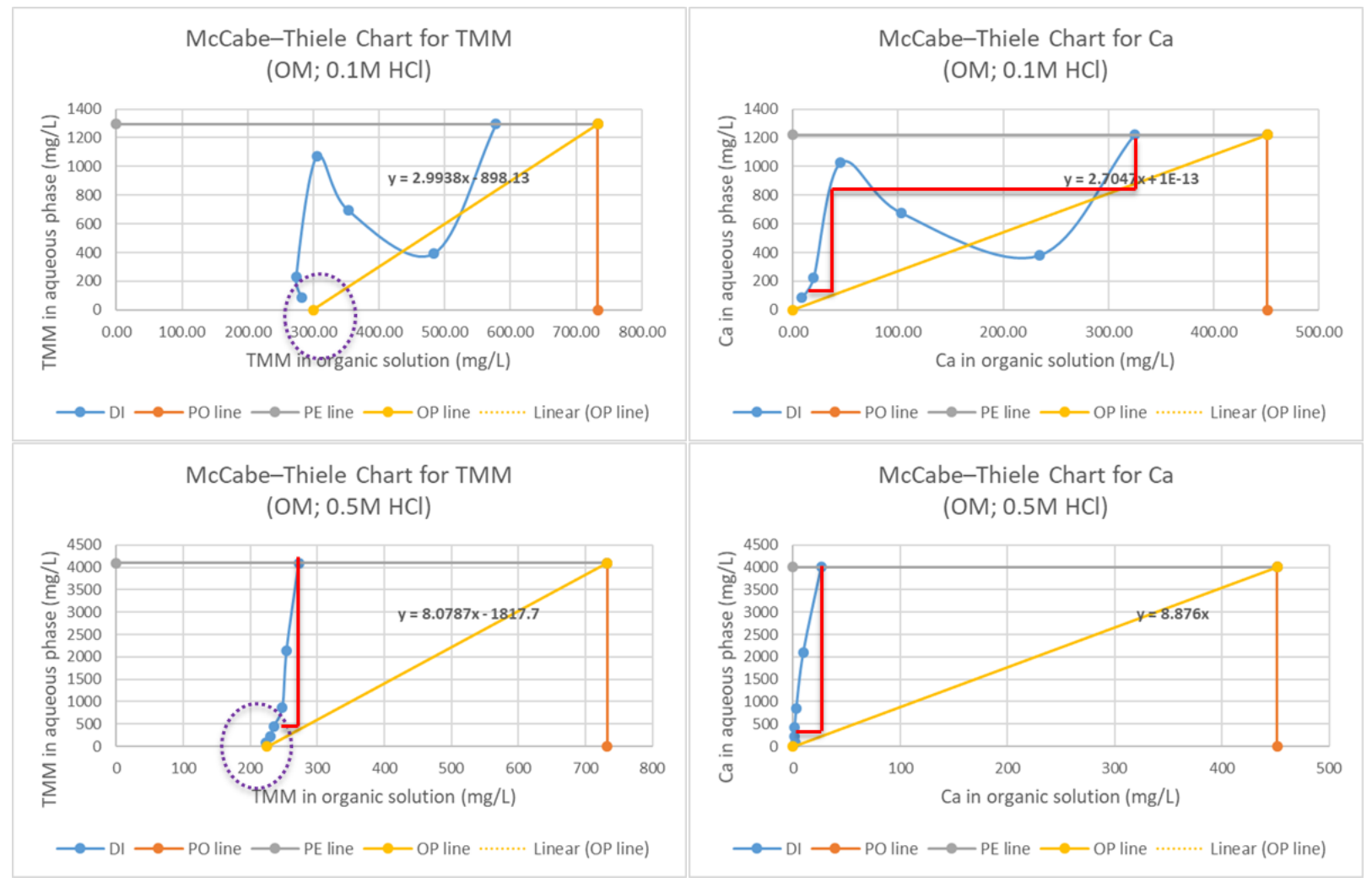

Figure 4.47 McCabe Thiele diagrams of TMM and Ca- OM.

Table 4-11 McT charts results summary of MM for OM scrub tests.

\begin{tabular}{ccccc}
\hline Acid solution & REE & Intended O:A ratio & Steps number & Residue \\
\hline & TMM & - & - & high \\
$0.1 \mathrm{M} \mathrm{HCl}$ & $\mathrm{Ca}$ & 2.7 & 3 & low \\
& $\mathrm{TMM}$ & 8.1 & 2 & $27 \%$ \\
$0.5 \mathrm{M} \mathrm{HCl}$ & $\mathrm{Ca}$ & 8.9 & 2 & low \\
& & & & \\
\hline
\end{tabular}

\subsubsection{Scrub McCabe-Thiele Exploratory Test-DLM}

Through SX exploratory tests, optimized parameters were applied for bench-scale DLM solvent extraction and loaded organic phase were collected and used for DLM scrub exploratory tests. Scrub exploratory tests was conducted using diluted $\mathrm{HCl}$ on DLM loaded organic phase (Table 4-12). Figure 4.48 shows 
pictures of these scrub process after equilibrium. When equilibrium $\mathrm{pH}$ values were larger than 3 , crud formed, and the aqueous solution were viscous.

Table 4-12 Parameters and pH results of diluted HCl scrub exploratory test of DLM.

\begin{tabular}{ccccccccc}
\hline \multirow{2}{*}{ Sample \# } & \multirow{2}{*}{ Sample Name } & $\mathbf{C}(\mathbf{H C l})$ & $\mathbf{O}: \mathbf{A}$ & $\mathbf{O}$ & $\mathbf{A}$ & $\mathbf{T V}$ & $\mathbf{D}$ & $\mathbf{E}$ \\
\cline { 3 - 9 } & & $\mathrm{mol} / \mathrm{L}$ & Ratio & $\mathrm{ml}$ & $\mathrm{ml}$ & $\mathrm{ml}$ & $\mathrm{pH}$, before & $\mathrm{pH}$, after \\
\hline 1 & DLM-Scrub--0.1M-1:5 & $\mathbf{0 . 1}$ & $1: 05$ & 18.33 & 91.67 & 110 & $\underline{1.07}$ & $\underline{\underline{1.09}}$ \\
2 & DLM-Scrub--0.1M-1:2 & $\mathbf{0 . 1}$ & $1: 02$ & 36.67 & 73.33 & 110 & $\underline{1.07}$ & $\underline{\underline{1.25}}$ \\
3 & DLM-Scrub--0.1M-1:1 & $\mathbf{0 . 1}$ & $1: 01$ & 55 & 55 & 110 & $\underline{1.07}$ & $\underline{\underline{1.5}}$ \\
4 & DLM-Scrub--0.1M-2:1 & $\mathbf{0 . 1}$ & $2: 01$ & 73.33 & 36.67 & 110 & $\underline{1.07}$ & $\underline{2.72}$ \\
5 & DLM-Scrub--0.1M-5:1 & $\mathbf{0 . 1}$ & $5: 01$ & 183.33 & 36.67 & 220 & $\underline{1.07}$ & $\underline{\underline{3.53}}$ \\
6 & DLM-Scrub--0.1M-10:1 & $\mathbf{0 . 1}$ & $10: 01$ & 200 & 20 & 220 & $\underline{1.07}$ & $\underline{\underline{3.54}}$ \\
\hline 7 & DLM-Scrub--0.5M-1:5 & $\mathbf{0 . 5}$ & $1: 05$ & 18.33 & 91.67 & 110 & $\underline{0.32}$ & $\underline{0.37}$ \\
8 & DLM-Scrub--0.5M-1:2 & $\mathbf{0 . 5}$ & $1: 02$ & 36.67 & 73.33 & 110 & $\underline{0.32}$ & $\underline{\underline{0.4}}$ \\
9 & DLM-Scrub--0.5M-1:1 & $\mathbf{0 . 5}$ & $1: 01$ & 55 & 55 & 110 & $\underline{0.32}$ & $\underline{0.39}$ \\
10 & DLM-Scrub--0.5M-2:1 & $\mathbf{0 . 5}$ & $2: 01$ & 73.33 & 36.67 & 110 & $\underline{0.32}$ & $\underline{0.48}$ \\
11 & DLM-Scrub--0.5M-5:1 & $\mathbf{0 . 5}$ & $5: 01$ & 183.33 & 36.67 & 220 & $\underline{0.32}$ & $\underline{1.05}$ \\
12 & DLM-Scrub--0.5M-10:1 & $\mathbf{0 . 5}$ & $10: 01$ & 200 & 20 & 220 & $\underline{0.32}$ & $\underline{3.01}$ \\
\hline 13 & DLM-Scrub--1.0M-1:5 & $\mathbf{1}$ & $1: 05$ & 18.33 & 91.67 & 110 & $\underline{-0.02}$ & $\underline{-0.06}$ \\
14 & DLM-Scrub--1.0M-1:2 & $\mathbf{1}$ & $1: 02$ & 36.67 & 73.33 & 110 & $\underline{-0.02}$ & $\underline{0.02}$ \\
15 & DLM-Scrub--1.0M-1:1 & $\mathbf{1}$ & $1: 01$ & 55 & 55 & 110 & $\underline{-0.02}$ & $\underline{0.05}$ \\
16 & DLM-Scrub--1.0M-2:1 & $\mathbf{1}$ & $2: 01$ & 73.33 & 36.67 & 110 & $\underline{-0.02}$ & $\underline{0.1}$ \\
17 & DLM-Scrub--1.0M-5:1 & $\mathbf{1}$ & $5: 01$ & 183.33 & 36.67 & 220 & $\underline{-0.02}$ & $\underline{\underline{0.35}}$ \\
18 & DLM-Scrub--1.0M-10:1 & $\mathbf{1}$ & $10: 01$ & 200 & 20 & 220 & $\underline{-0.02}$ & $\underline{1.12}$ \\
\hline
\end{tabular}
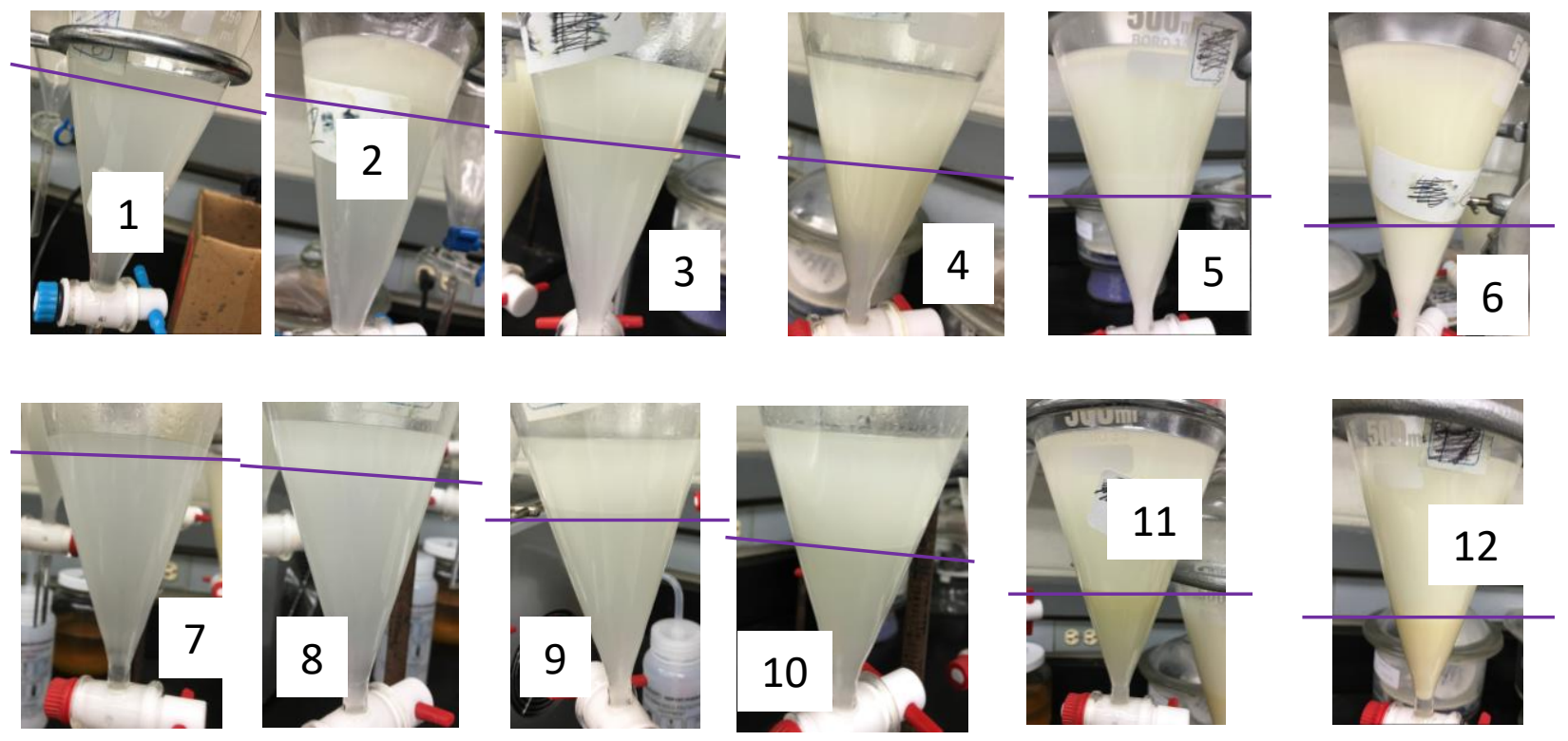

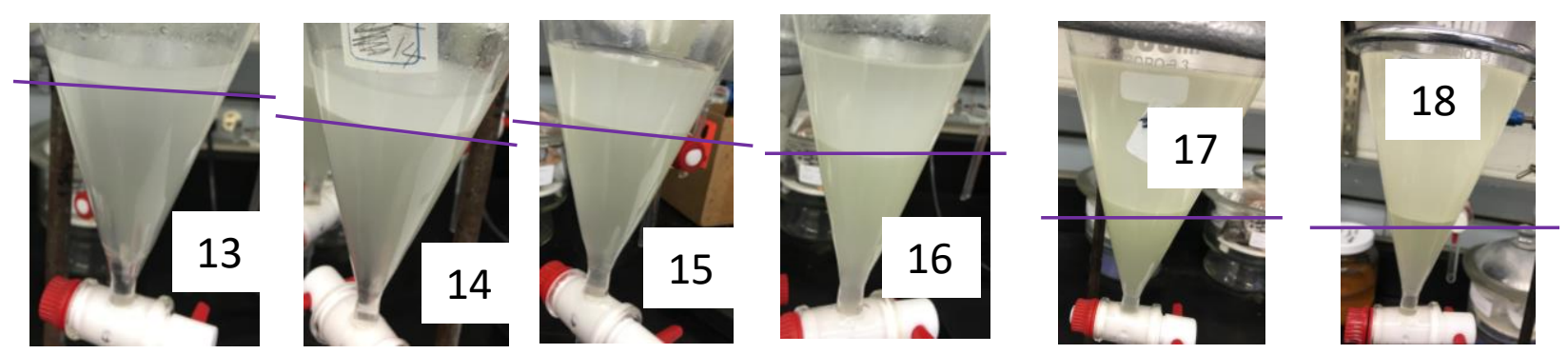

Figure 4.48 Pictures of HCl scrub process after equilibrium-DLM.

Scrub exploratory tests was also conducted using DI water on DLM loaded organic phase (Table 4-13).

Figure 4.49 shows pictures of these scrub process after equilibrium. All equilibrium pH values were larger than 3, but aqueous samples were still clear due to low O:A ratio (samples 1-3).

Table 4-13 Parameters and pH results of water scrub exploratory test of DLM.

\begin{tabular}{|c|c|c|c|c|c|c|c|c|}
\hline & & $\mathrm{C}(\mathrm{HCl})$ & O: A & 0 & A & TV & D & E \\
\hline ample \# & fample IName & $\mathrm{mol} / \mathrm{L}$ & Ratio & $\mathrm{ml}$ & $\mathrm{ml}$ & $\mathrm{ml}$ & $\mathrm{pH}$, before $\mathrm{p}$ & $\mathrm{H}$, after \\
\hline 1 & DLM-Scrub-0-1:5 & 0.00 & $1: 5$ & 18.33 & 91.671 & 110.00 & $\underline{5.21}$ & $\underline{3.74}$ \\
\hline 2 & DLM-Scrub-0-1:2 & 0.00 & $1: 2$ & 36.67 & 73.331 & 110.00 & $\underline{5.21}$ & $\underline{3.58}$ \\
\hline 3 & DLM-Scrub-0-1:1 & 0.00 & 1:1 & 55.00 & 55.001 & 110.00 & $\underline{5.21}$ & $\underline{3.75}$ \\
\hline 4 & DLM-Scrub-0-2:1 & 0.00 & $2: 1$ & 73.33 & 36.671 & 110.00 & $\underline{5.21}$ & $\underline{3.82}$ \\
\hline 5 & DLM-Scrub-0-5:1 & 0.00 & $5: 1$ & 183.33 & 36.672 & 220.00 & $\underline{5.21}$ & $\underline{3.69}$ \\
\hline 6 & DLM-Scrub-0-10:1 & $1 \quad 0.00$ & $10: 1$ & 200.00 & 20.002 & 220.00 & $\underline{5.21}$ & $\underline{3.75}$ \\
\hline
\end{tabular}
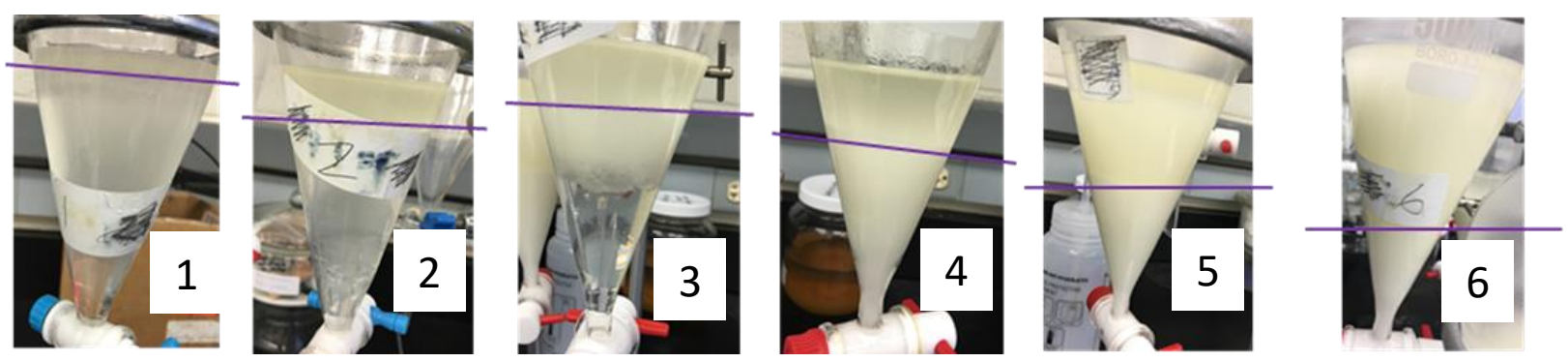

Figure 4.49 Pictures of water scrub process after equilibrium.

Exploratory tests were also conducted diluted hydrochloric acid of $0.01 \mathrm{M}$ on DLM loaded organic phase (Table 4-14). Scrub efficiency results of the whole scrub tests are shown in Figure 4.50. Scrub efficiencies of $\mathrm{MM}$ and REE were already larger than $100 \%$ even with DI water. This is unexpected and there may be 
significant measurement error. The lower O:A ratio, the higher scrub efficiency. The O:A ratio effect was obvious at higher acid concentrations. Major elements that are easy to scrub are $\mathrm{Ca}, \mathrm{Mg}$ and $\mathrm{Na}$. LREEs were easier to scrub than HREEs. The higher acid concentration to use, the smaller difference between scrub efficiencies of LREE and HREE. Due to measurements error, metal ions concentrations left in the organic phase after some scrub tests were higher than the initial concentrations in the organic. Thus, these data can't be analyzed by McT methods.

Table 4-14 Parameters of 0.01 M HCl scrub exploratory test of DLM loaded organic.

\begin{tabular}{llllll}
\hline \multirow{2}{*}{ Sample Name } & $\mathbf{C}(\mathbf{H C l})$ & $\mathbf{0 :} \mathbf{A}$ & $\mathbf{0}$ & $\mathbf{A}$ & TV \\
\cline { 2 - 6 } & $\mathrm{mol} / \mathrm{L}$ & Ratio & $\mathrm{ml}$ & $\mathrm{ml}$ & $\mathrm{ml}$ \\
\hline DLM-Scrub--0.01M-1:5 & 0.01 & $1: 5$ & 18.33 & 91.67 & 110.00 \\
DLM-Scrub--0.01M-1:2 & 0.01 & $1: 2$ & 36.67 & 73.33 & 110.00 \\
DLM-Scrub--0.01M-1:1 & 0.01 & $1: 1$ & 55.00 & 55.00 & 110.00 \\
DLM-Scrub--0.01M-2:1 & 0.01 & $2: 1$ & 73.33 & 36.67 & 110.00 \\
DLM-Scrub--0.01M-5:1 & 0.01 & $5: 1$ & 183.33 & 36.67 & 220.00 \\
DLM-Scrub--0.01M-10:1 & 0.01 & $10: 1$ & 200.00 & 20.00 & 220.00 \\
\hline
\end{tabular}

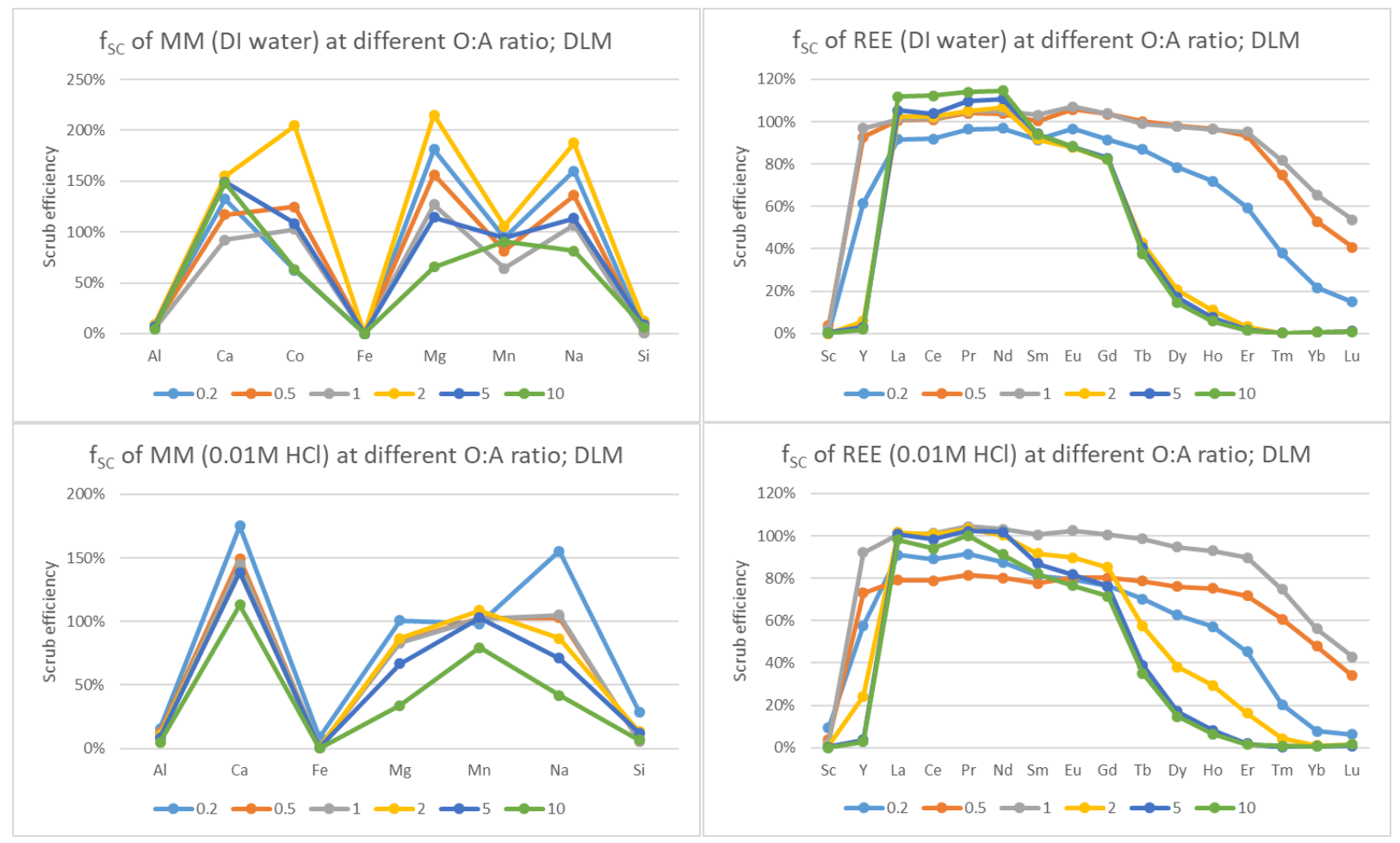




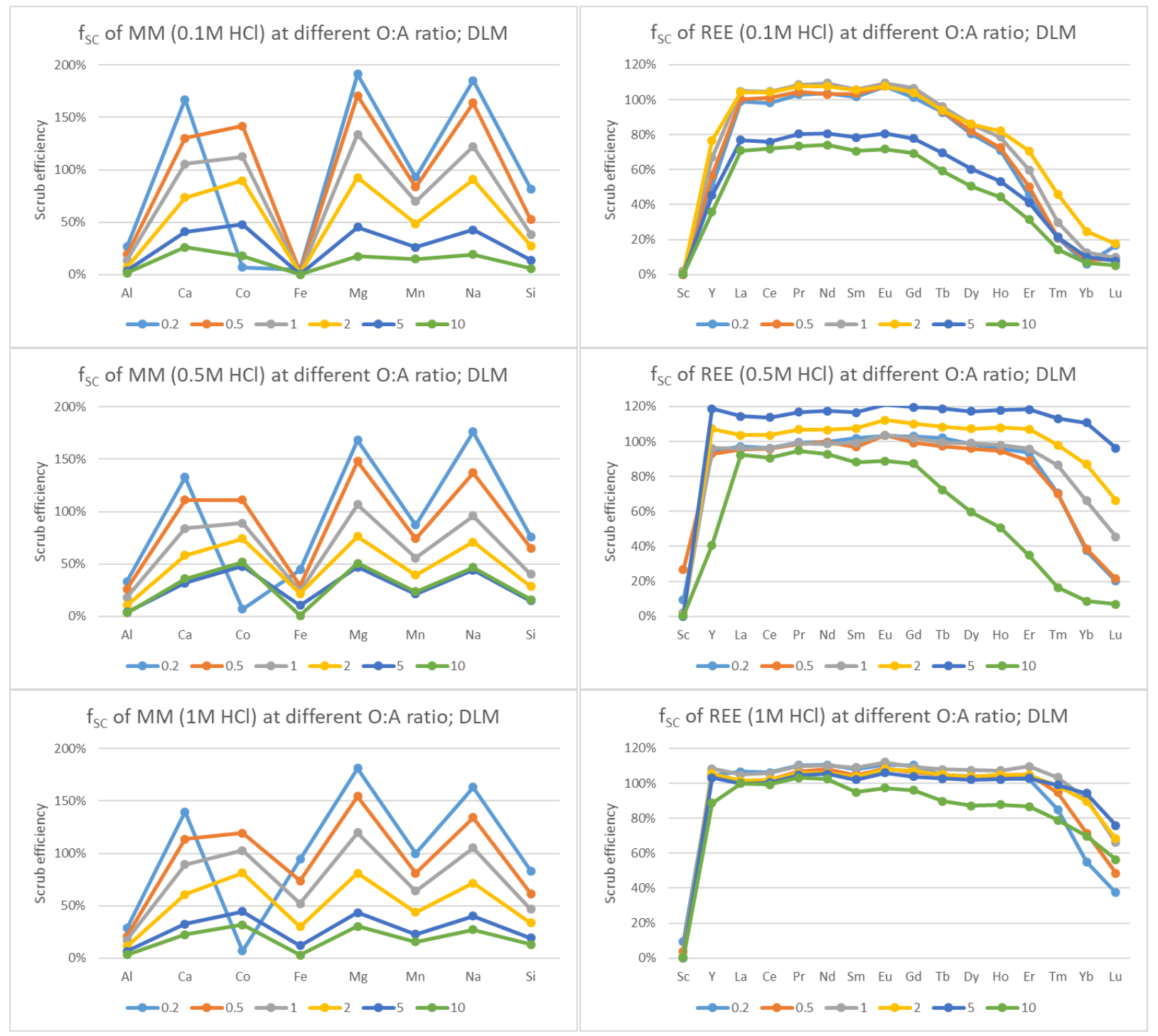

Figure 4.50 Scrub efficiency of individual MM and REE- DLM.

\subsubsection{Scrub McCabe-Thiele Exploratory Test-RS}

Through SX exploratory tests, optimized parameters were applied for bench-scale RS solvent extraction and loaded organic phase were collected and used for RS scrub exploratory tests. Scrub exploratory tests was conducted using DI water on RS loaded organic phase (Table 4-15). Scrub efficiency results of the scrub tests are shown in Figure 4.51. Scrub for MM was obvious and about $20-30 \%$ major metal ions were scrubbed by water. Scrub efficiencies of REE increased when using low O:A ratio. The loss of REE was acceptable. The distribution curves of TMM and TREE are also plotted (Figure 4.52). But the irregular curves can't be analyzed by McT method due to experiment error.

Table 4-15 Parameters of water scrub exploratory test of RS loaded organic. 


\begin{tabular}{llllll}
\hline \multirow{2}{*}{ Sample Name } & $\mathbf{C}(\mathbf{H C l})$ & O: $\mathbf{A}$ & $\mathbf{0}$ & $\mathbf{A}$ & TV \\
\cline { 2 - 6 } & $\mathrm{mol} / \mathrm{L}$ & Ratio & $\mathrm{ml}$ & $\mathrm{ml}$ & $\mathrm{ml}$ \\
\hline RS-Scrub-0-1:5 & 0.00 & $1: 5$ & 18.33 & 91.67 & 110.00 \\
RS-Scrub-0-1:2 & 0.00 & $1: 2$ & 36.67 & 73.33 & 110.00 \\
RS-Scrub-0-1:1 & 0.00 & $1: 1$ & 55.00 & 55.00 & 110.00 \\
RS-Scrub-0-2:1 & 0.00 & $2: 1$ & 73.33 & 36.67 & 110.00 \\
RS-Scrub-0-5:1 & 0.00 & $5: 1$ & 183.33 & 36.67 & 220.00 \\
RS-Scrub-0-10:1 & 0.00 & $10: 1$ & 200.00 & 20.00 & 220.00 \\
\hline
\end{tabular}

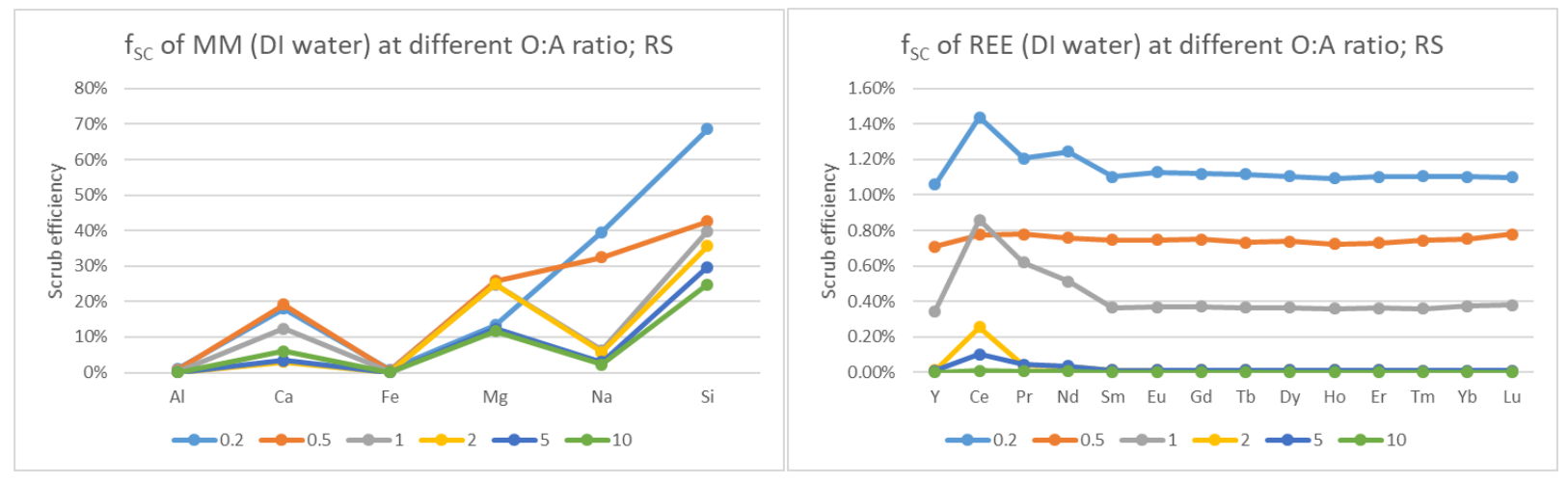

Figure 4.51 Scrub efficiency of individual MM and REE- RS.

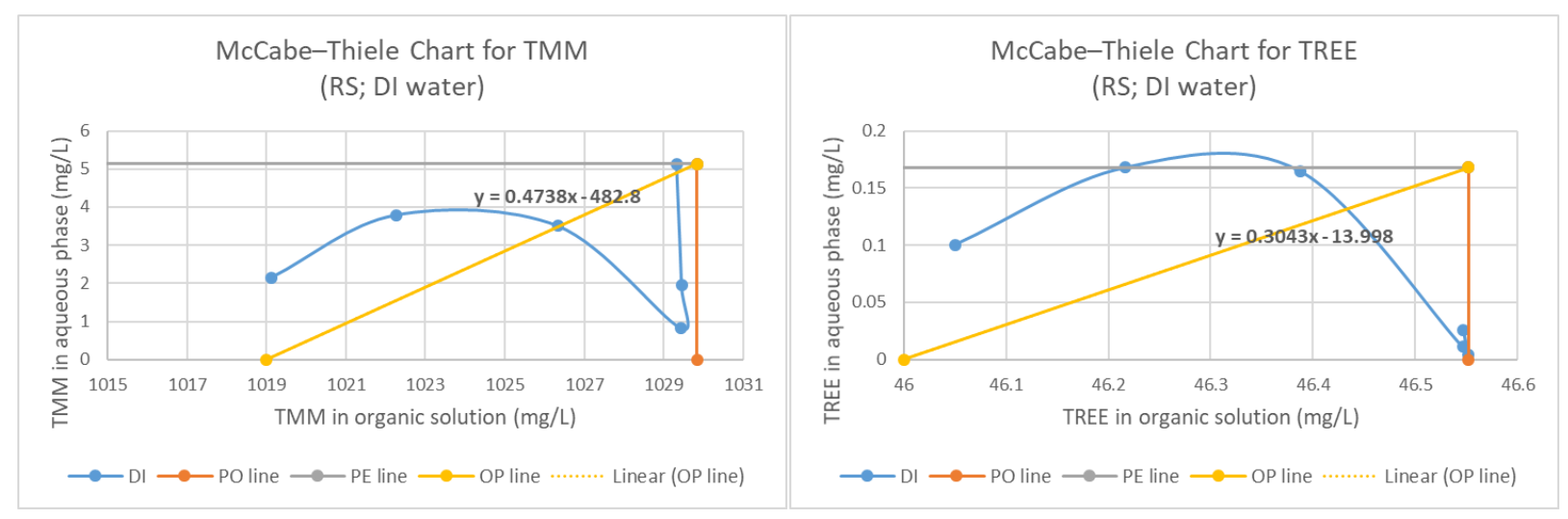

Figure 4.52 McCabe Thiele diagrams of TREE and TMM scrub process- RS.

\subsection{Bench-Scale Stripping Support - McCabe-Thiele Exploratory Test-RS}

Through SX and scrub exploratory tests, appropriate parameters were applied to bench-scale solvent extraction and scrub, and the scrubbed loaded organic phase was collected and used for stripping exploratory tests. Objective of strip exploratory tests was to find optimal parameters (O:A ratio, acid concentration) for maximized $f_{S T}$ for REEs and the number of steps needed in a mixer-settler to reach desired separation. Preferred conditions: Save acid; Use less steps; Choose high O:A ratio. 
Stripping exploratory tests were conducted using diluted nitric acid and hydrochloric acid on RS scrubbed loaded organic phase (Table 4-16 and Table 4-17). Figure 4.53 and Figure 4.54 show pictures of the stripping process after equilibrium.

Table 4-16 Parameters of $\mathrm{HNO}_{3}$ stripping exploratory tests of RS scrubbed loaded organic.

\begin{tabular}{lllllll}
\hline \multirow{2}{*}{ Sample \# } & \multirow{2}{*}{ Sample Name } & $\mathbf{C}$ (HNO3) & O: $\mathbf{A}$ & $\mathbf{0}$ & $\mathbf{A}$ & TV \\
\cline { 3 - 7 } & & $\mathrm{mol} / \mathrm{L}$ & Ratio & $\mathrm{ml}$ & $\mathrm{ml}$ & $\mathrm{ml}$ \\
\hline 1 & RS-ST-HNO3-3M-1:5 & 3.00 & $1: 5$ & 18.33 & 91.67 & 110.00 \\
2 & RS-ST-HNO3-3M-1:2 & 3.00 & $1: 2$ & 36.67 & 73.33 & 110.00 \\
3 & RS-ST-HNO3-3M-1:1 & 3.00 & $1: 1$ & 55.00 & 55.00 & 110.00 \\
4 & RS-ST-HNO3-3M-2:1 & 3.00 & $2: 1$ & 73.33 & 36.67 & 110.00 \\
5 & RS-ST-HNO3-3M-5:1 & 3.00 & $5: 1$ & 183.33 & 36.67 & 220.00 \\
6 & RS-ST-HNO3-3M-10:1 & 3.00 & $10: 1$ & 200.00 & 20.00 & 220.00 \\
\hline 7 & RS-ST-HNO3-6M-1:5 & 6.00 & $1: 5$ & 18.33 & 91.67 & 110.00 \\
8 & RS-ST-HNO3-6M-1:2 & 6.00 & $1: 2$ & 36.67 & 73.33 & 110.00 \\
9 & RS-ST-HNO3-6M-1:1 & 6.00 & $1: 1$ & 55.00 & 55.00 & 110.00 \\
10 & RS-ST-HNO3-6M-2:1 & 6.00 & $2: 1$ & 73.33 & 36.67 & 110.00 \\
11 & RS-ST-HNO3-6M-5:1 & 6.00 & $5: 1$ & 183.33 & 36.67 & 220.00 \\
12 & RS-ST-HNO3-6M-10:1 & 6.00 & $10: 1$ & 200.00 & 20.00 & 220.00 \\
\hline
\end{tabular}
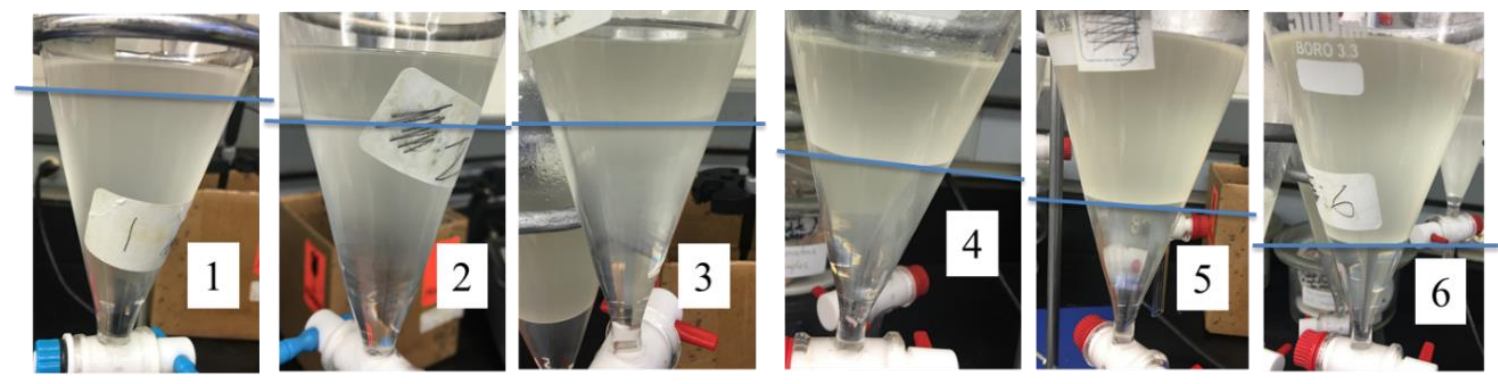

No crud formation because of low initial concentration.
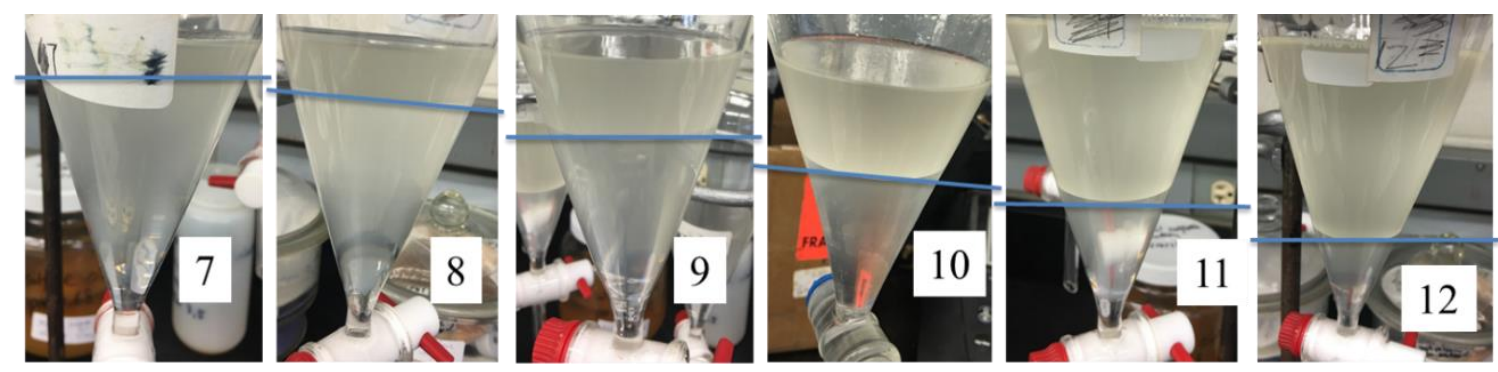

No crud formation because of low initial concentration.

Figure 4.53 Pictures of the $\mathrm{HNO}_{3}$ stripping process after equilibrium - RS.

Table 4-17 Parameters of HCl stripping exploratory tests of RS scrubbed loaded organic. 


\begin{tabular}{llllll}
\hline \multirow{2}{*}{ Sample \# } & Sample Name & C (HCl) O: A & O & A & TV \\
\cline { 3 - 6 } & & & & & \\
\hline
\end{tabular}

$1 \quad$ RS-ST-HCl-3M-1:5 $3.00 \quad 1: 5 \quad 18.3391 .67110 .00$

2 RS-ST-HCl-3M-1:2 $3.00 \quad 1: 2 \quad 36.67 \quad 73.33110 .00$

3 RS-ST-HCl-3M-1:1 $3.00 \quad 1: 1 \quad 55.00 \quad 55.00110 .00$

$4 \quad$ RS-ST-HCl-3M-2:1 $3.00 \quad 2: 1 \quad 73.33 \quad 36.67110 .00$

$5 \quad$ RS-ST-HCl-3M-5:1 $3.00 \quad 5: 1 \quad 183.3336 .67220 .00$

6 RS-ST-HCl-3M-10:1 $3.00 \quad$ 10:1 200.00 20.00220.00

$7 \quad \overline{R S-S T-H C l-6 M-1: 5} \overline{6.00} \overline{1: 5} \overline{18.33} \overline{91.67} \overline{110.00}$

$8 \quad$ RS-ST-HCl-6M-1:2 $\quad 6.00 \quad 1: 2 \quad 36.67 \quad 73.33110 .00$

$9 \quad$ RS-ST-HCl-6M-1:1 $6.00 \quad 1: 1 \quad 55.00 \quad 55.00110 .00$

10 RS-ST-HCl-6M-2:1 $\quad 6.00 \quad 2: 1 \quad 73.33 \quad 36.67110 .00$

11 RS-ST-HCl-6M-5:1 $6.00 \quad 5: 1 \quad 183.3336 .67220 .00$

12 RS-ST-HCl-6M-10:1 6.00 10:1 200.0020.00220.00

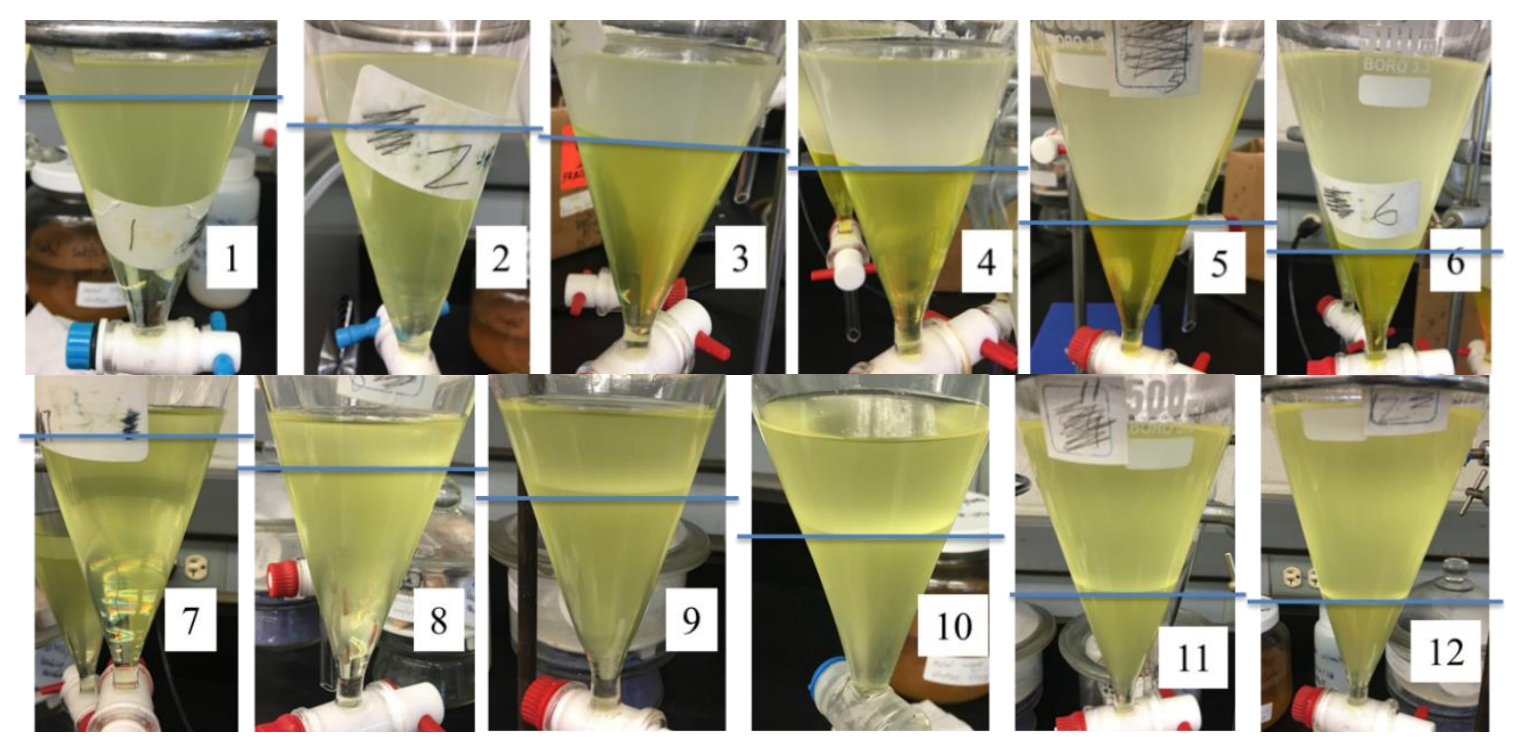

Figure 4.54 Pictures of the HCl stripping process after equilibrium - RS. 
Stripping efficiency equation is shown as Equation 6. Stripping efficiencies of individual MM and REE for RS are shown in Figure 4.55. For rare earth elements, the lower O:A ratio, the higher stripping efficiency. However, the O:A ratio effect on stripping efficiency of major metal ions was not obvious. Stripping efficiencies of $\mathrm{Mg}, \mathrm{Na}$ and $\mathrm{Mn}$ element were high, especially with $\mathrm{HNO}_{3}$, while the stripping efficiencies of Al and Fe were low. Stripping efficiencies of $\mathrm{Ca}$, as easy to strip element, were relatively lower. This is due to much higher initial concentration of $\mathrm{Ca}$ in the organic phase. For element $\mathrm{Fe}$, it is easier to strip by using hydrochloric acid than nitric acid. This is caused by the formation of $\mathrm{Fe}^{3+}$ and $\mathrm{Cl}^{-}$complex. LREE stripping efficiencies were similar by using $\mathrm{HCl}$ and $\mathrm{HNO}_{3}$ at same concentration. For $\mathrm{HREE}$ stripping, $\mathrm{HCl}$ was better than $\mathrm{HNO}_{3}$. $3 \mathrm{M} \mathrm{HNO}_{3}$ can be used for HREE separation. $6 \mathrm{M} \mathrm{HCl}$ would be better for TREE stripping even at highest $\mathrm{O}: \mathrm{A}$ ratio of 10 .

\section{Equation 6:}

$f_{S T}:$ Strip efficiency of $M=\frac{\text { Mass of stripped metal ions } M \text { into aqueous samples }}{\text { Initial mass of metal ions } M \text { in scrubbed loaded organic head sample }}$
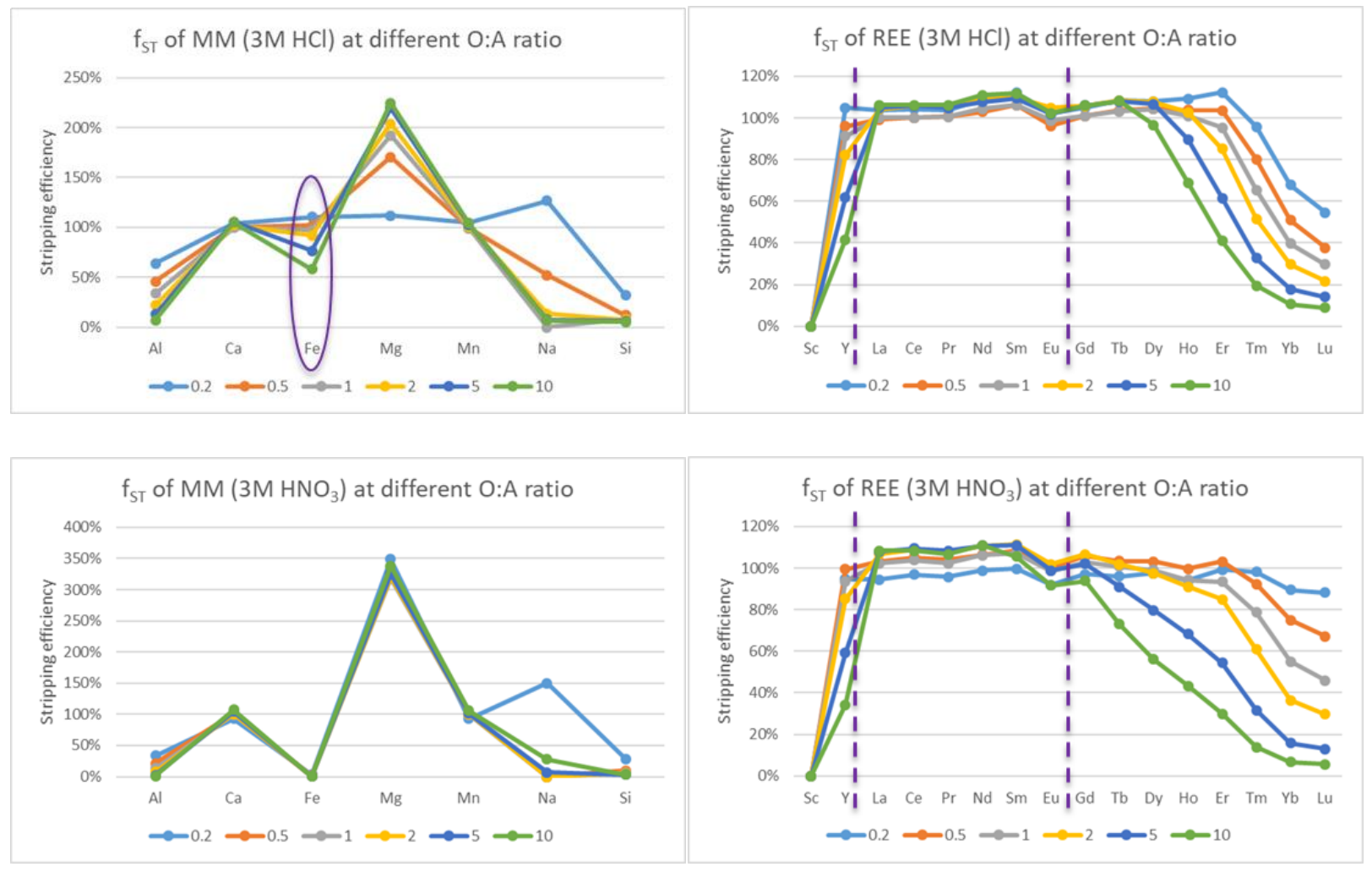

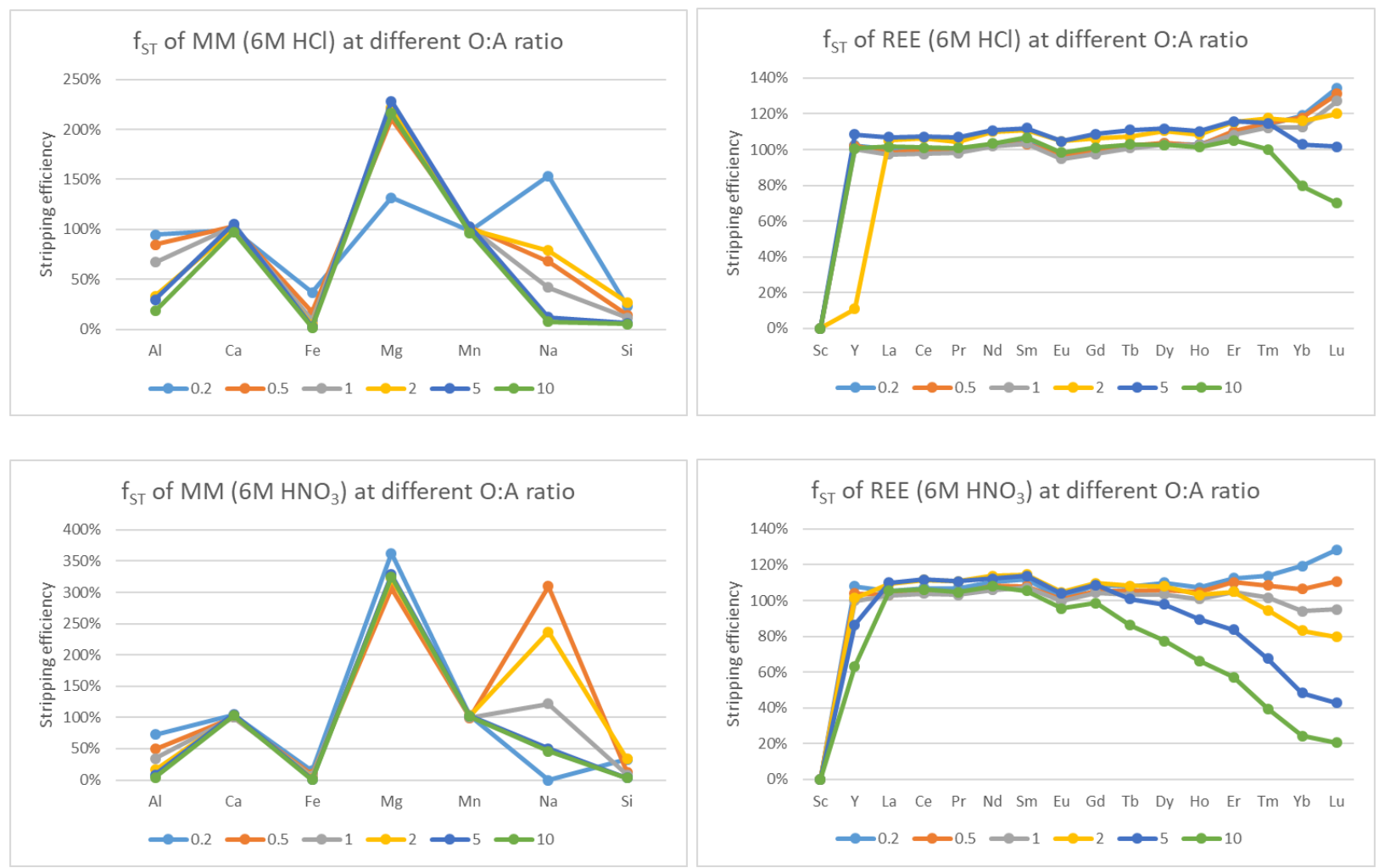

Figure 4.55 Stripping efficiency of individual MM and REE- RS.

McCabe Thiele (McT) diagrams of TREE in these processes are plotted in Figure 4.56. The McT charts analysis results are summarized for RS stripping tests in Table 4-18. Most TREE can be stripped into the aqueous phase at intended O:A ratio of about 8 after three steps stripping by $\mathrm{HNO}_{3}$ and $3 \mathrm{M} \mathrm{HCl}$. Almost all of TREE can be stripped by $6 \mathrm{M} \mathrm{HCl}$ at highest O:A ratio of 10 after only one step stripping. Thus, TREE stripping can be achieved by using $6 \mathrm{M} \mathrm{HCl}$.
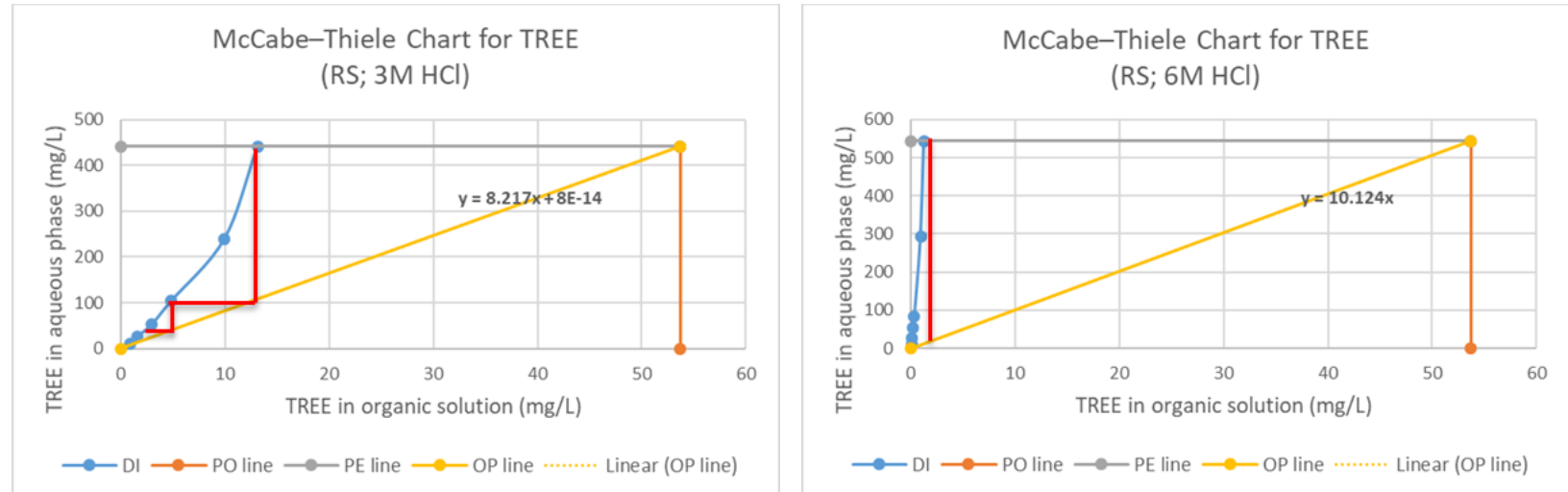

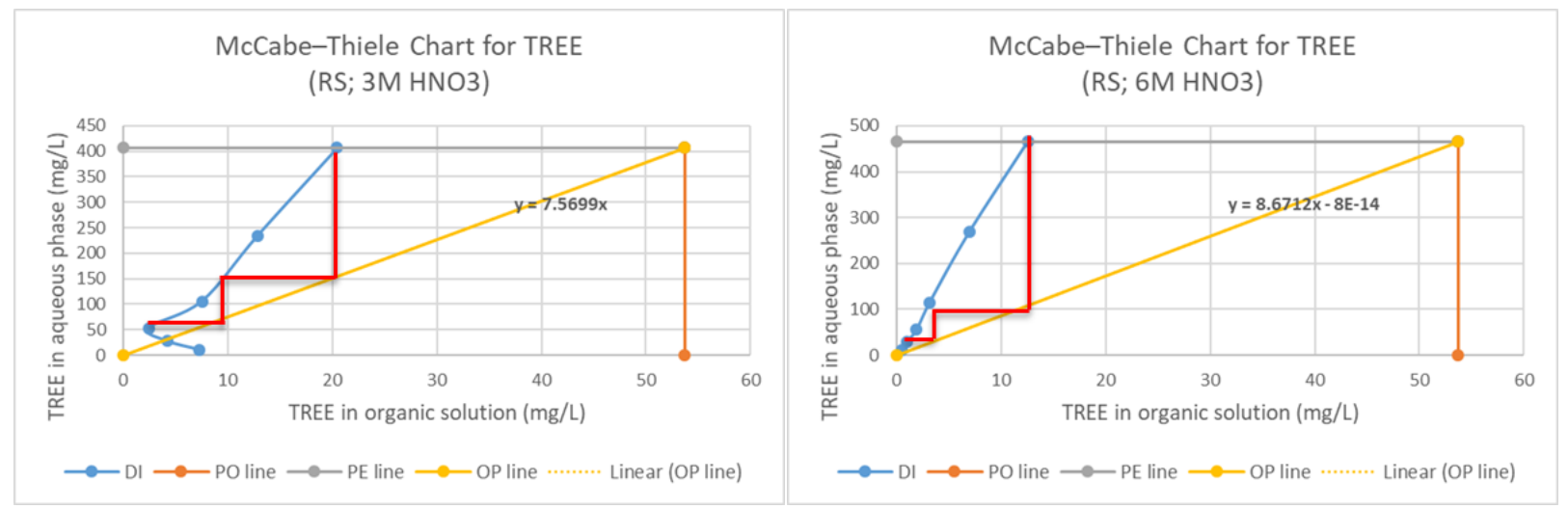

Figure 4.56 McCabe Thiele diagrams of TREE stripping process- RS.

Table 4-18 McT charts results summary of TREE for RS stripping tests.

\begin{tabular}{ccc}
\hline Acid solution & Intended O:A ratio & Steps number \\
\hline $3 \mathrm{M} \mathrm{HCl}$ & 8.2 & 3 \\
$6 \mathrm{M} \mathrm{HCl}$ & 10 & 1 \\
$3 \mathrm{M} \mathrm{HNO3}$ & 7.6 & 3 \\
$6 \mathrm{M} \mathrm{HNO3}$ & 8.7 & 3 \\
\hline
\end{tabular}

McCabe Thiele (McT) diagrams of LREE in these processes are plotted in Figure 4.57. The McT charts analysis results are summarized for these RS stripping tests in Table 4-19. Most LREE can be stripped into the aqueous phase at O:A ratio of 11 after two steps stripping by $\mathrm{HNO}_{3}$, while it only needs one step at same O:A ratio by using $\mathrm{HCl}$. Since TREE stripping is significant by using $6 \mathrm{M} \mathrm{HCl}, 3 \mathrm{M} \mathrm{HNO}_{3}$ can be used first for LREE strip. 


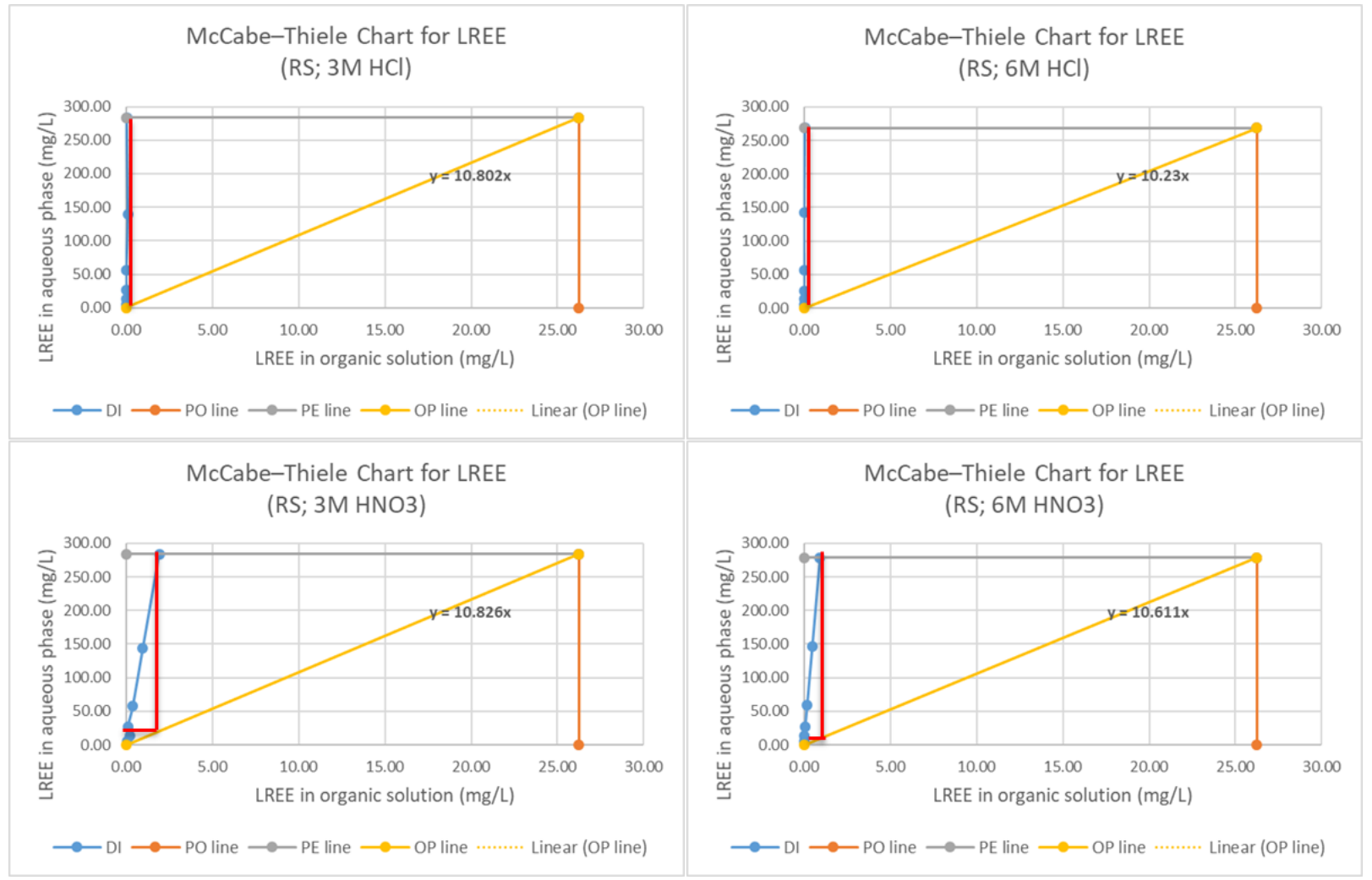

Figure 4.57 McCabe Thiele diagrams of LREE stripping process- RS.

Table 4-19 McT charts results summary of LREE for RS stripping tests.

\begin{tabular}{ccc}
\hline Acid solution & Intended O:A ratio & Steps number \\
\hline $3 \mathrm{M} \mathrm{HCl}$ & 11 & 1 \\
$6 \mathrm{M} \mathrm{HCl}$ & 10 & 1 \\
$3 \mathrm{M} \mathrm{HNO3}$ & 11 & 2 \\
$6 \mathrm{M} \mathrm{HNO3}$ & 11 & 2 \\
\hline
\end{tabular}

McCabe Thiele (McT) diagrams of HREE in these processes are plotted in Figure 4.58. The McT charts analysis results are summarized for these RS stripping tests in Table 4-20. Most HREE can be stripped into the aqueous phase at O:A ratio of 10 after one step stripping by $6 \mathrm{M} \mathrm{HCl}$, while about 4 steps are required at lower O:A ratio by using $\mathrm{HNO}_{3}$ and $3 \mathrm{M} \mathrm{HCl}$. After LREEs are stripped by using $3 \mathrm{M} \mathrm{HNO}_{3}, 6 \mathrm{M} \mathrm{HCl}$ can be used then for HREE strip. 


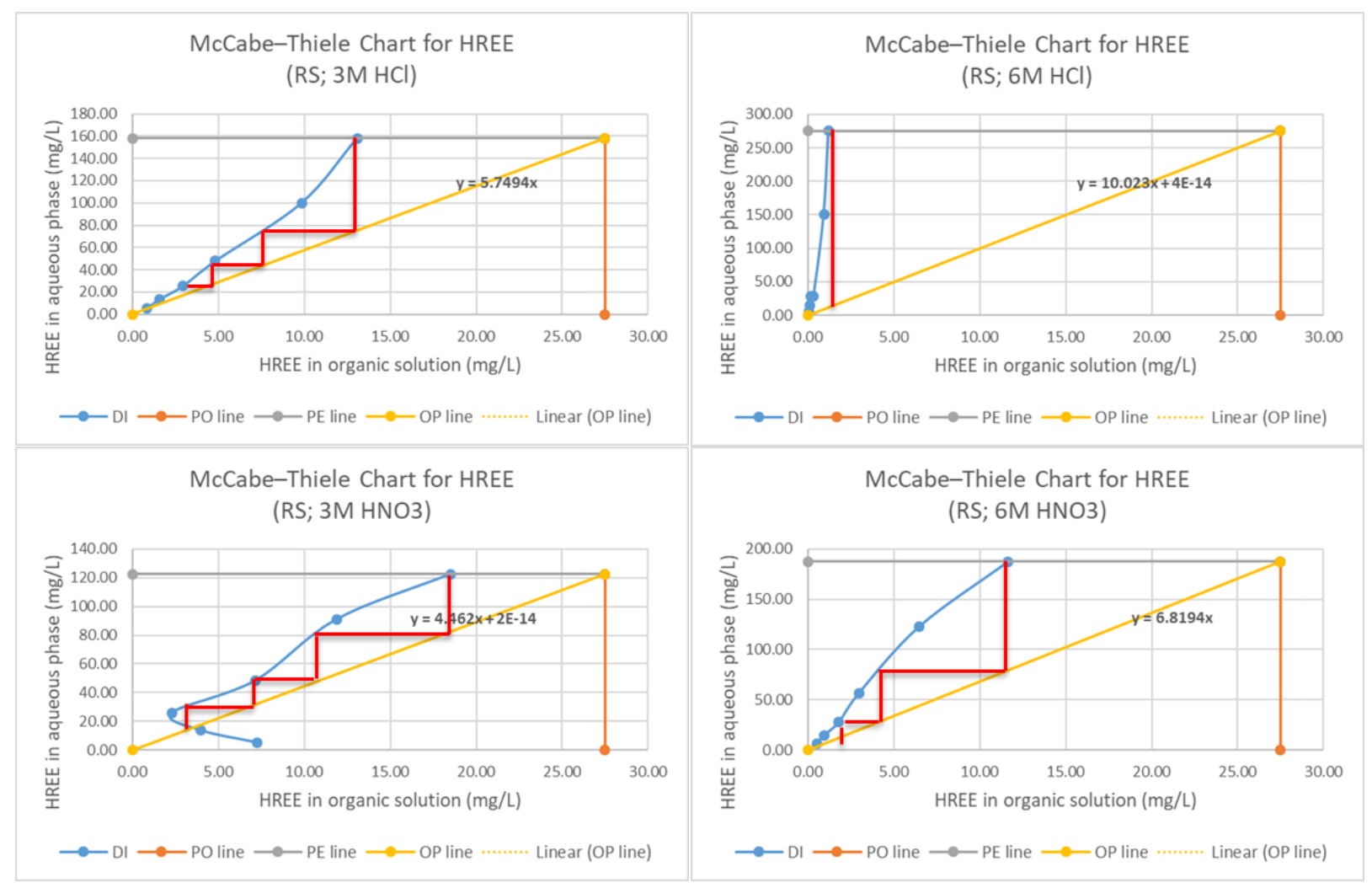

Figure 4.58 McCabe Thiele diagrams of HREE stripping process- RS.

Table 4-20 McT charts results summary of HREE for RS stripping tests.

\begin{tabular}{ccc}
\hline Acid solution & Intended O:A ratio & Steps number \\
\hline $3 \mathrm{M} \mathrm{HCl}$ & 5.7 & 4 \\
$6 \mathrm{M} \mathrm{HCl}$ & 10 & 1 \\
$3 \mathrm{M} \mathrm{HNO3}$ & 4.5 & 4 \\
$6 \mathrm{M} \mathrm{HNO3}$ & 6.8 & 3 \\
\hline
\end{tabular}

McCabe Thiele (McT) diagrams of TMM in these processes are plotted in Figure 4.59. The TMM residue left in the organic phase after stripping was high at these conditions. For organic solvent reuse, exploratory tests at much lower O:A ratio required to determine steps number needed. 


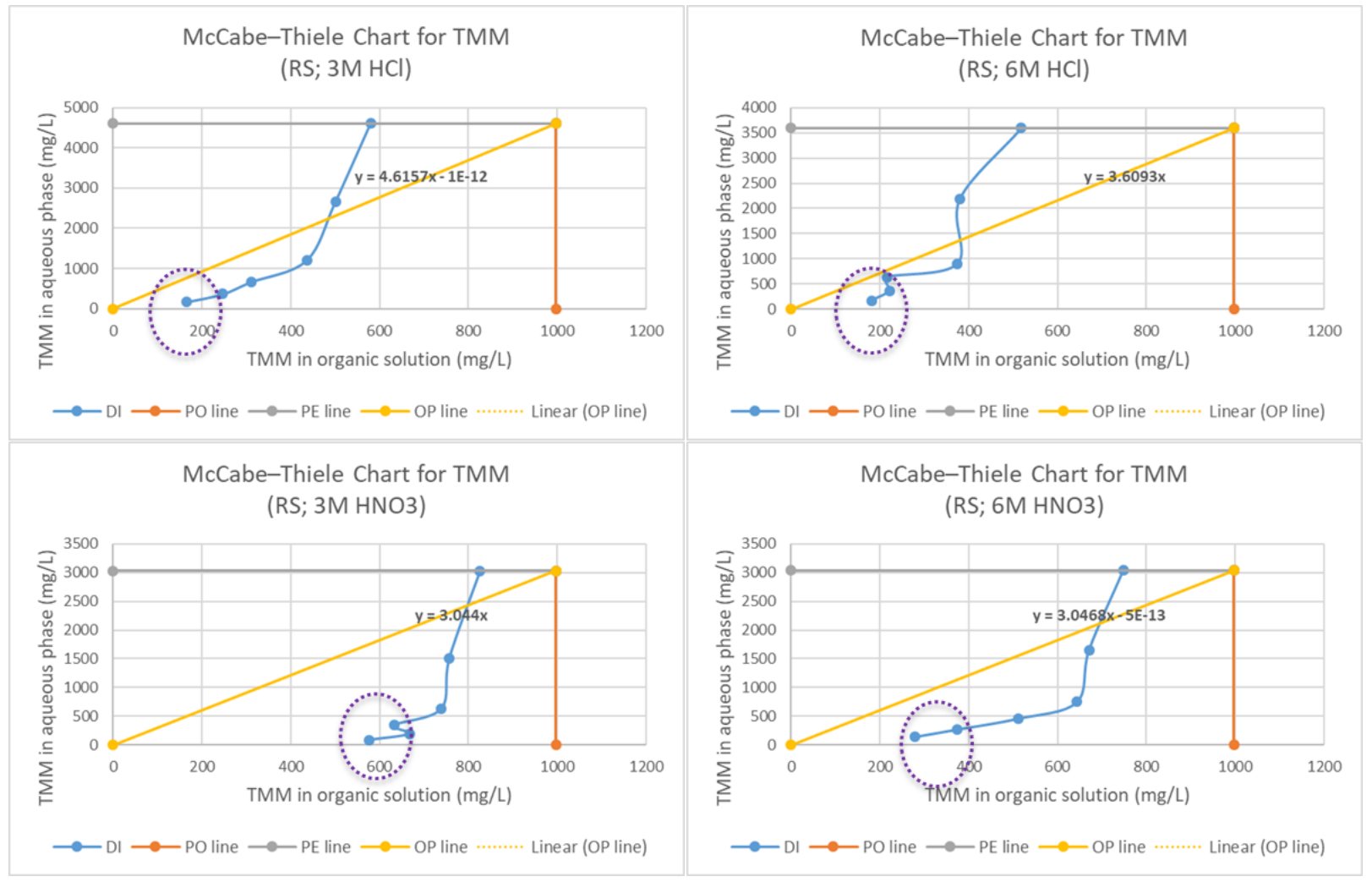

Figure 4.59 McCabe Thiele diagrams of TMM stripping process- RS.

Exploratory tests milestone status is summarized in Table 4-21. Stripping tests are non-applicable for OM and DLM due to significant crud formation.

Table 4-21 Exploratory tests milestone status.

\section{Exploratory tests SX Scrub Stripping}

\begin{tabular}{llll}
\hline DLM & $v$ & $v$ & NA \\
OM & $v$ & $v$ & NA \\
RS & $v$ & $v$ & $v$ \\
\hline
\end{tabular}

4.4 Summary of exploratory tests on RS leachate and bench-scale REE recovery on it Exploratory tests were conducted at different O:A ratios and extractant concentrations to obtain optimum parameters for RS REE extraction. Scrub exploratory tests were conducted by using RS loaded organic obtained after optimum extraction from cooperator using scaled-up facility. Then scrubbed loaded 
organic obtained after optimum scrub from cooperator using scaled-up facility was used for RS stripping exploratory tests. Optimum parameters and steps needed for every process were achieved. A whole flowsheet was then schemed to recover TREE and separate HREE.

For each experiment, aqueous solution was mixed with organic solution at room temperature and mixed for $10 \mathrm{~min}$ at agitation Speed of $240 \mathrm{rpm}$. After standing still for 3 hours for equilibration, the phases could separate.

Based on exploratory test results and analysis, a whole series tests following the flowsheet (Figure 4.60) were conducted on RS leachate to recover and separate heavy and light REE (HREE, LREE). The optimum parameters to be used are summarized in Table 4-22.

\section{Optimum parameters}

LO: Loaded organic
A: Aqueous
R: Raffinate
O: Organic

?\% REE

Leachate 0: $100 \mathrm{~mL}$

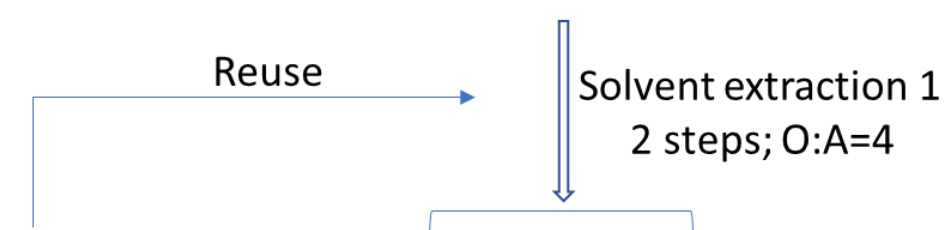

R 7: $400 \mathrm{~mL} \quad$ O 7: $2000 \mathrm{~mL}$

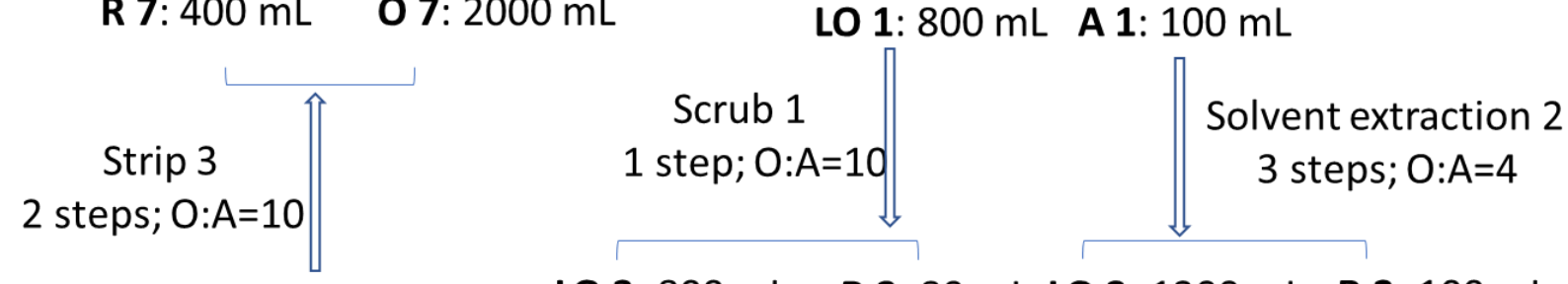

LO 1: $800 \mathrm{~mL}$ A 1: $100 \mathrm{~mL}$

LO 6: $2000 \mathrm{~mL}$

LO 3: $800 \mathrm{~mL} \quad$ R 3: $80 \mathrm{~mL}$ LO 2: $1200 \mathrm{~mL}$ R 2: $100 \mathrm{~mL}$

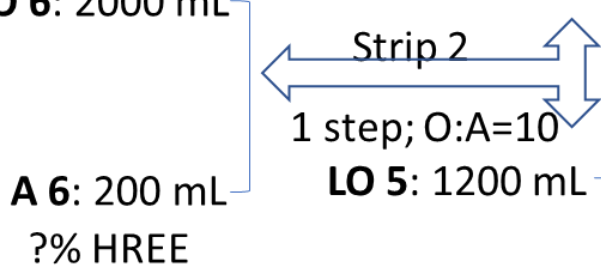

A 5: $240 \mathrm{~mL}$

Strip 1

LO 4: $1200 \mathrm{~mL} \quad$ R 4: $120 \mathrm{~mL}$

2 steps; $O: A=10$
Scrub 2

1 step; $O: A=10$ ?\% LREE

Figure 4.60 Whole flowsheet with optimum parameters from exploratory tests for RS REE recovery.

Table 4-22 Parameters used for REE recovery from RS leachate. 


\begin{tabular}{|c|c|c|c|c|c|c|c|}
\hline $\begin{array}{l}\text { Optimum } \\
\text { parameters }\end{array}$ & $C(X)$ & $\begin{array}{l}\text { Acid type and } \\
\text { concentration }\end{array}$ & $\begin{array}{l}\mathrm{O}: \mathrm{A} \\
\text { ratio }\end{array}$ & Steps & Objective & 0 & A \\
\hline Leachate & & & & & & & A 0 \\
\hline SX 1 & $0.05 \mathrm{M}$ & & 4.0 & 2 & Extract HREE & LO 1 & A 1 \\
\hline SX 2 & $0.3 \mathrm{M}$ & & 4.0 & 3 & Extract TREE & LO 2 & R 2 \\
\hline Scrub 1 & & DI water & 10.0 & 1 & Remove MM & LO from 1 to 3 & R 3 \\
\hline Scrub 2 & & DI water & 10.0 & 1 & Remove MM & LO from 2 to 4 & R 4 \\
\hline Strip 1 & & $3 \mathrm{M} \mathrm{HNO3}$ & 10.8 & 2 & Strip LREE & LO from 4 to 5 & A 5 \\
\hline Strip 2 & & $6 \mathrm{M} \mathrm{HCl}$ & 10.0 & 1 & Strip HREE & LO from 3 and 5 to 6 & A 6 \\
\hline Strip 3 & & $12 \mathrm{M} \mathrm{HCl}$ & 10.0 & 2 & Strip MM & O 7 for reuse & R 7 \\
\hline
\end{tabular}

Results of REE recovery from RS leachate following whole flowsheet are summarized in Table 4-23. The initial TREE was $0.09 \%$ in the RS leachate. The first step solvent extraction was to extract HREE first, but the HREE/TREE percentage was similar to the initial ratio. This may be due to parameters choice from exploratory tests with error. Lower O:A ratio should be used for HREE extraction exploratory test. The TREE was increased to $1.53 \%$ after second SX and TREE loss in raffinate was very low. The TREE percentages in raffinate after two scrub process were almost zero and can be ignored. After first stripping, the LREE/TREE ratio was more than $99 \%$ and our objective was achieved to separate LREE first. For second stripping, only very small amount of TREE was stripped into A6 and HREE percentage increased a little bit. The TREE percentage increased to $2.22 \%$ after third stripping with concentrated $\mathrm{HCl}$ and most TREE remained in the organic solution. This result means that concentrated $\mathrm{HCl}$ need to be used with more steps for stripping of TREE.

Table 4-23 Results of REE recovery from RS leachate following whole flowsheet.

\begin{tabular}{cccccccc}
\hline Sample name & TMM & TREE & LREE & HREE & $\begin{array}{c}\text { TREE/ } \\
\text { (TMM+TREE) }\end{array}$ & LREE/TREE & HREE/TREE \\
& mg & ug & ug & ug & $\%$ & $\%$ & $\%$ \\
\hline A-0 & 4635.63 & 4135.53 & 1982.02 & 2153.51 & $0.09 \%$ & $47.93 \%$ & $52.07 \%$ \\
LO-1 & 199.73 & 1872.09 & 1100.24 & 771.85 & $0.93 \%$ & $58.77 \%$ & $41.23 \%$ \\
A-1 & 4435.91 & 2263.44 & 881.79 & 1381.66 & $0.05 \%$ & $38.96 \%$ & $61.04 \%$ \\
\hline
\end{tabular}




\begin{tabular}{cccccccc}
\hline LO-2 & 145.06 & 2257.12 & 875.52 & 1381.60 & $1.53 \%$ & $38.79 \%$ & $61.21 \%$ \\
R-2 & 4290.85 & 6.32 & 6.26 & 0.06 & $0.00 \%$ & $99.05 \%$ & $0.95 \%$ \\
LO-3 & 178.37 & 1867.44 & 1098.47 & 768.97 & $1.04 \%$ & $58.82 \%$ & $41.18 \%$ \\
R-3 & 21.35 & 4.65 & 1.77 & 2.88 & $0.02 \%$ & $38.11 \%$ & $61.89 \%$ \\
LO-4 & 123.44 & 2255.39 & 873.86 & 1381.54 & $1.79 \%$ & $38.75 \%$ & $61.25 \%$ \\
R-4 & 21.62 & 1.73 & 1.67 & 0.06 & $0.01 \%$ & $96.52 \%$ & $3.48 \%$ \\
LO-5 & 66.38 & 1511.80 & 137.21 & 1374.59 & $2.23 \%$ & $9.08 \%$ & $90.92 \%$ \\
A-5 & 57.06 & 743.59 & 736.65 & 6.94 & $1.29 \%$ & $99.07 \%$ & $0.93 \%$ \\
LO-3 + LO-5 & 244.75 & 3379.24 & 1235.67 & 2143.57 & $1.36 \%$ & $36.57 \%$ & $63.43 \%$ \\
LO-6 & 189.28 & 3376.71 & 1234.64 & 2142.07 & $1.75 \%$ & $36.56 \%$ & $63.44 \%$ \\
A-6 & 55.47 & 2.53 & 1.03 & 1.50 & $0.00 \%$ & $40.78 \%$ & $59.22 \%$ \\
O-7 & 177.45 & 3107.54 & 1150.51 & 1957.03 & $1.72 \%$ & $37.02 \%$ & $62.98 \%$ \\
R-7 & 11.83 & 269.18 & 84.13 & 185.04 & $2.22 \%$ & $31.26 \%$ & $68.74 \%$ \\
\hline
\end{tabular}




\section{CONCLUSION}

Acid mine drainage (AMD) is the primary cause of aquatic habitat loss in the Appalachian Coal Basin and many other mining districts across the U.S. and the world. Rare earth elements (REES) have wide applications due to their special physical and chemical properties. Trace amounts of REEs were detected in some specific AMD sites. The objective of this work is to develop a cost-effective and environmentally benign process to treat and recover REEs from AMD. Solvent extraction (SX) is one effective way to turn AMD into a commercially viable feedstock for rare earth production.

In this work, solvent extraction experiments were conducted on Y-Ca-Mg-Al-HDEHP-n-heptane- $\mathrm{HNO}_{3}-\mathrm{H}_{2} \mathrm{O}$ system by changing different parameters. Three different low ratios of REEs over major metal ions were used for SX feed solution to simulate treated acid mine drainage (AMD). The higher the O:A ratio, the easier to recover $Y$ from aqueous solution. The higher the extractant concentration, the more extracted $Y$ in the organic phase. But to concentrate REEs from wastewater with very low REE content, lower extractant concentration should be used to reduce competitive extraction. In the experiment parameters range for this solvent extraction system, the lower the concentration ratio of $Y$ to major metal ions, the easier to separate $\mathrm{Y}$ from them. $\mathrm{pH} 2.4$ is best for $\mathrm{Y}$ separation in these solutions. The appropriate condition to separate and recover REE in similar system and parameters range is using extractant concentration $15 \mathrm{~g} / \mathrm{L}$ at O:A ratio of 1.5 . This work provides a basis for rare earth production from wastewater.

Bench-scale REEs recovery from different kinds of sludge leachate with different $\mathrm{pH}$ values by multi-step SX experiments were performed. The whole process mainly includes solvent extraction, scrub and stripping steps. Several steps process with appropriate parameters will concentrate REEs by dozens of times. Mid-scale work was also performed. The estimated REEs percentage in obtained solid phase increased from initial $0.77 \%$ in leachate to final $4.63 \%$ in the solid.

SX McCabe-Thiele Exploratory Testing on optimized PLS from the Omega, Royal Scot and DLM sites were performed, as well as scrub and stripping McCabe-Thiele Exploratory Test, following ALSX Testing Regime Flowsheet to provide a purposeful starting point for the scale-up SX system parametric testing. Results of this program were provided as McCabe Thiele diagrams. Optimum parameters and steps required for sufficient recovery of REEs and high selectivity of REEs over major metal ions were obtained for different kinds of leachate in this work. Continuous work following whole flowsheet with optimum parameters was 
conducted on RS leachate for REEs recovery. The REEs percentage increased from initial $0.09 \%$ to $2.22 \%$ and most light REEs can be easily separated from heavy REEs.

Overall, a cost-effective and environmentally benign process is developed to treat and recover REEs from AMD sludge. Solvent extraction (SX) is one effective way to turn AMD into a commercially viable feedstock for rare earth production. Detailed parameters and treatment flowsheet are obtained for different AMD sludge leachates. This work provides a basis of potential industrial REE production from waste AMD. 


\section{FUTURE WORK}

In this work, limited work was conducted for REE recovery from AMD sludge leachates. To produce valuable REE product for commercial use, there is still a long way to go:

1) To increase TREE purity: treatment of more steps and choice of detailed parameters in following scale-up mixer-settler system;

2) Stripping of TREE:

a. In this work, stripping of light rare earth elements was easier than that of heavy rare earth elements and they can both be stripped by acid solution. But more research is required to reach higher stripping efficiency of TREE;

b. Based on stripping results of all experiments in this work, it should be noted that it's difficult to strip element Sc in extracted organic phase in this solvent extraction system by acid solution. An alternative way is the direct stripping of Sc (III) by alkaline solutions or fluoride salts with the formation of insoluble precipitates. (Ditze \& Kongolo, 1997; Haslam, 1999; Singh \& Dhadke, 2003) For example, 80\% Sc (III) was stripped with $0.5 \mathrm{M}$ $\mathrm{NaOH}$ directly from the loaded HDEHP organic. (W. Wang \& Cheng, 2011)

3) Separation of individual REE elements: individual REE elements oxides are valuable final product for commercial use;

4) Infinite scientific research. 


\section{REFERENCE}

‡ Design-Expert ${ }^{\circledR}$ Software, v11, Stat-Ease, Inc., Minneapolis, MN, 55413 USA, www.statease.com.

Arnold, D. C. (2015). Composition-driven structural phase transitions in rare-earth-doped bifeo3 ceramics: a review. IEEE Transactions on Ultrasonics, Ferroelectrics, and Frequency Control, 62(1), 21.

B., S. M. (1990). Determination of trace lanthanides and yttrium in seawater by inductively coupled plasma mass spectrometry after preconcentration with solvent extraction and back-extraction. Anal. Chem.

Bard, A. J., Parsons, R., \& Jordan, J. (1985). Standard potentials in aqueous solutions.

Bau, M. (1999). Scavenging of dissolved yttrium and rare earths by precipitating iron oxyhydroxide: experimental evidence for $\mathrm{Ce}$ oxidation, $\mathrm{Y}-\mathrm{Ho}$ fractionation, and lanthanide tetrad effect. Geochimica et Cosmochimica Acta, 63(1), 11.

Chen, X., Ren, P., Li, T., Trembly, J. P., \& Liu, X. (2018). Zinc removal from model wastewater by electrocoagulation: Processing, kinetics and mechanism. Chemical Engineering Journal, 349, 358367. doi:https://doi.org/10.1016/j.cej.2018.05.099

Cheng, C. Y., Zhang, W., \& Pranolo, Y. (2010). Separation of Cobalt and Zinc from Manganese, Magnesium, and Calcium using a Synergistic Solvent Extraction System Consisting of Versatic 10 and LIX 63. Solvent Extraction and Ion Exchange, 28(5), 17. doi:Solvent Extraction and Ion Exchange, Vol. 28, No. 5, September-October 2010: pp. 608-624

Ditze, A., \& Kongolo, K. (1997). Recovery of scandium from magnesium, aluminium and iron scrap. Hydrometallurgy, 44(1-2), 179-184.

Dupont, D., \& Binnemans, K. (2015). Recycling of rare earths from NdFeB magnets using a combined leaching/extraction system based on the acidity and thermomorphism of the ionic liquid [Hbet][Tf2N]. doi:10.1039/C5GC00155B

Feng, Y., Yang, L., Liu, J., \& Logan, B. E. (2016). Electrochemical technologies for wastewater treatment and resource reclamation. doi:10.1039/C5EW00289C

Gergoric, M., Ekberg, C., Foreman, M. R. S. J., Steenari, B.-M., \& Retegan, T. (2017). Characterization and Leaching of Neodymium Magnet Waste and Solvent Extraction of the Rare-Earth Elements Using TODGA. Journal of Sustainable Metallurgy, 3(3), 638-645. doi:10.1007/s40831-017-0122-8

Goto, T., Kimura, T., Lawes, G., Ramirez, A. P., \& Tokura, Y. (2004). Ferroelectricity and Giant Magnetocapacitance in Perovskite Rare-Earth Manganites. Physical Review Letters, 92(25), 257201. doi:10.1103/PhysRevLett.92.257201

Haslam, M. (1999). An investigation into the feasibility of extracting scandium from nickel laterite ores. Paper presented at the In Proceeding of ALTA 1999 Nickel/Cobalt Pressure Leaching \& Hydrometallurgy Forum.

Hoogerstraete, T. V., Blanpain, B., Gerven, T. V., \& Binnemans, K. (2014). From NdFeB magnets towards the rare-earth oxides: a recycling process consuming only oxalic acid. doi:10.1039/C4RA13787F

Hoogerstraete, T. V., Wellens, S., Verachtert, K., \& Binnemans, K. (2013). Removal of transition metals from rare earths by solvent extraction with an undiluted phosphonium ionic liquid: separations relevant to rare-earth magnet recycling. doi:10.1039/C3GC40198G

Jordens, A., Cheng, Y. P., \& Waters, K. E. (2013). A review of the beneficiation of rare earth element bearing minerals. Minerals Engineering, 41, 97-114. doi:https://doi.org/10.1016/j.mineng.2012.10.017

Kim, D., Powell, L. E., Delmau, L. H., Peterson, E. S., Herchenroeder, J., \& Bhave, R. R. (2015). Selective Extraction of Rare Earth Elements from Permanent Magnet Scraps with Membrane Solvent Extraction. doi:10.1021/acs.est.5b01306 
Kim, E., \& Osseo-Asare, K. (2012). Aqueous stability of thorium and rare earth metals in monazite hydrometallurgy: Eh-pH diagrams for the systems Th-, Ce-, $\mathrm{La}-, \mathrm{Nd}-(\mathrm{PO} 4)-(\mathrm{SO} 4)-\mathrm{H} 2 \mathrm{O}$ at $25^{\circ} \mathrm{C}$. Hydrometallurgy, 113-114, 67-78. doi:https://doi.org/10.1016/j.hydromet.2011.12.007

Larsson, K., \& Binnemans, K. (2014). Selective extraction of metals using ionic liquids for nickel metal hydride battery recycling. doi:10.1039/C3GC41930D

Li, H., Guo, F., Zhang, Z., Li, D., \& Wang, Z. (2006). A new hydrometallurgical process for extracting rare earths from apatite using solvent extraction with P350. Journal of Alloys and Compounds, 408412, 995-998. doi:https://doi.org/10.1016/j.jallcom.2004.12.119

Li, W., Guan, B., Yan, J., Zhang, N., Zhang, X., \& Liu, X. (2016). Enhanced surface exchange activity and electrode performance of $(\mathrm{La} 2-2 \mathrm{xSr} 2 \mathrm{x})(\mathrm{Ni} 1-\mathrm{xMnx}) \mathrm{O} 4+\delta$ cathode for intermediate temperature solid oxide fuel cells. Journal of Power Sources, 318, 178-183. doi:https://doi.org/10.1016/j.jpowsour.2016.04.022

Marie, C., Hiscox, B., \& Nash, K. L. (2011). Characterization of HDEHP-lanthanide complexes formed in a non-polar organic phase using 31P NMR and ESI-MS. doi:10.1039/C1DT11534K

McCabe, W. L., \& W, T. E. (1925). Graphical Design of Fractionating Columns -McCabe and Thiele. Industrial and engineering chemistry, 7.

Mollah, M. Y. A. (2001). Electrocoagulation (EC) - science and applications. Journal of Hazardous Materials, 84(1), 13.

Nepo, H. J. (2016). Electrocoagulation process in water treatment: A review of electrocoagulation modeling approaches. Desalination, 404, 21.

PRAKASH, V. (2014). ELECTROCHEMICAL RECOVERY OF RARE EARTH ELEMENTS FROM MAGNET SCRAPS - A THEORETICAL ANALYS. Paper presented at the 1st European Rare Earth Resources Conference.

Preston, J. S. (1996). Recovery of REO from phosphoric acid byproduct_Part 1_Preston et aThe-recoveryof-rare-earth-oxides-from-a-phosphoric-acid-by-product-Part-1-Leaching-of-rare-earth-valuesand-recovery-of-a-mixed-rare-earth-oxide-by-solvent-extraction. Hydrometallurgy.

R. Chi, Z. X. (1999). A solution chemistry approach to the study of rare earth element precipitation by oxalic acid | SpringerLink. Metallurgical and Materials Transactions B. doi:10.1007/s11663-9990047-0

REE - Rare Earth Elements - Metals, Minerals, Mining, Uses. (2018). Retrieved from https://geology.com/articles/rare-earth-elements/

Reporter. (2019). Lynas and Blue Line MoU for rare earths separation. Retrieved from https://www.miningmagazine.com/chemicals-reagents/news/1364528/lynas-and-blue-linemou-for-rare-earths-separation

Riaño, S., \& Binnemans, K. (2015). Extraction and separation of neodymium and dysprosium from used NdFeB magnets: an application of ionic liquids in solvent extraction towards the recycling of magnets. doi:10.1039/C5GC00230C

Rout, A., \& Binnemans, K. (2013). Liquid-liquid extraction of europium(III) and other trivalent rare-earth ions using a non-fluorinated functionalized ionic liquid. doi:10.1039/C3DT52285G

Rout, A., \& Binnemans, K. (2014). Separation of rare earths from transition metals by liquid-liquid extraction from a molten salt hydrate to an ionic liquid phase. Dalton Trans, 43(8), 3186-3195. doi:10.1039/c3dt52541d

Rout, A., Kotlarska, J., Dehaen, W., \& Binnemans, K. (2013). Liquid-liquid extraction of neodymium(III) by dialkylphosphate ionic liquids from acidic medium: the importance of the ionic liquid cation. doi:10.1039/C3CP52218K

Rout, A., Wellens, S., \& Binnemans, K. (2013). Separation of rare earths and nickel by solvent extraction with two mutually immiscible ionic liquids. doi:10.1039/C3RA46261G 
Sadanandam, R., Singh, D. K., \& Sharma, A. K. Use of operating line equations and operating parameters in solvent extraction system for the separation and purification of metal ions. In: Bhabha Atomic Research Centre, Mumbai, India.

Separation Hydrometallurgy of Rare Earth Elements / Jack Zhang / Springer. (2016).

Singh, R. K., \& Dhadke, P. M. (2003). Extraction and separation of scandium (III) from perchlorate media, by D2EHPA and PC-88A. Bull Chem Technol Macedonia, 22, 1-11.

Skousen, J., Zipper, C., Rose, A., Ziemkiewicz, P., Nairn, R., McDonald, L., \& Kleinmann, R. (2017). Review of Passive Systems for Acid Mine Drainage Treatment. Mine Water and the Environment, 36(1), 133-153. doi:10.1007/s10230-016-0417-1

Survey, U. S. G. (2018). U.S. Mines Produced an Estimated \$75.2 Billion in Minerals During 2017. Retrieved from https://www.usgs.gov/news/us-mines-produced-estimated-752-billion-minerals-during$\underline{2017}$

Tay, P. K. R., Manjula-Basavanna, A., \& Joshi, N. S. (2018). Repurposing bacterial extracellular matrix for selective and differential abstraction of rare earth elements. doi:10.1039/C8GC01355A

Vass, C. R., Noble, A., \& Ziemkiewicz, P. F. (2019a). The Occurrence and Concentration of Rare Earth Elements in Acid Mine Drainage and Treatment By-products: Part 1-Initial Survey of the Northern Appalachian Coal Basin. Mining, Metallurgy \& Exploration, 36(5), 903-916.

Vass, C. R., Noble, A., \& Ziemkiewicz, P. F. (2019b). The Occurrence and Concentration of Rare Earth Elements in Acid Mine Drainage and Treatment Byproducts. Part 2: Regional Survey of Northern and Central Appalachian Coal Basins. Mining, Metallurgy \& Exploration, 36(5), 917-929.

Wang, K., Adidharma, H., Radosz, M., Wan, P., Xu, X., Russell, C. K., .. Yu, J. (2017). Recovery of rare earth elements with ionic liquids. doi:10.1039/C7GC02141K

Wang, L., Huang, X., Yu, Y., Xiao, Y., Long, Z., \& Cui, D. (2013). Eliminating ammonia emissions during rare earth separation through control of equilibrium acidity in a $\mathrm{HEH}(\mathrm{EHP})-\mathrm{Cl}$ system. Green Chemistry, 15(7), 6. doi:10.1039/C3GC40470F

Wang, W., \& Cheng, C. Y. (2011). Separation and purification of scandium by solvent extraction and related technologies: a review. Journal of Chemical Technology \& Biotechnology, 86(10), 1237-1246.

Wikipedia. (2018a). Inductively coupled plasma atomic emission spectroscopy. Retrieved from https://en.wikipedia.org/wiki/Inductively_coupled_plasma_atomic_emission_spectroscopy

Wikipedia. (2018b). Inductively coupled plasma mass spectrometry. Retrieved from https://en.wikipedia.org/wiki/Inductively_coupled_plasma_mass_spectrometry

Xie, R.-J., Hirosaki, N., Li, Y., \& Takeda, T. (2010). Rare-Earth Activated Nitride Phosphors: Synthesis, Luminescence and Applications. Materials, 3(6), 3777-3793. doi:10.3390/ma3063777

Yan, H., Wang, L., Xiong, W., Li, B., Li, J., Earths, B. R. I. o. R., . . Ltd, T. B. R. I. O. R. E. C. (2017). Rare Earth Based Hydrogen Storage Alloy and Application Thereof.

Yasuda, K. (2016). Selective Formation of Rare-Earth-Nickel Alloys via Electrochemical Reactions in NaCl$\mathrm{KCl}$ Molten Salt. Journal of The Electrochemical Society.

Yu, J., \& Liu, D. (2010). Extraction of magnesium from phosphoric acid using dinonylnaphthalene sulfonic acid. Chemical Engineering Research and Design, 88(5-6), 6. 